UNIVERSIDAD POLITÉCNICA DE MADRID ESCUELA TÉCNICA SUPERIOR DE EDIFICACIÓN

\title{
ANÁLISIS DEL DISEÑO CONCEPTUAL DE CENTROS DE EXPERIMENTACIÓN ANIMAL EN EL ÁMBITO DE LOS INSTITUTOS DE INVESTIGACIÓN SANITARIA
}

TESIS DOCTORAL

Aitziber Goikoetxea Ibarrondo

Ingeniera de Edificación

Máster en Arquitectura, Organización y

Gestión de Infraestructuras Hospitalarias 

DEPARTAMENTO DE CONSTRUCCIONES

ARQUITECTÓNICAS Y SU CONTROL

ESCUELA TÉCNICA SUPERIOR DE EDIFICACIÓN

\section{ANÁLISIS DEL DISEÑO CONCEPTUAL \\ DE CENTROS DE EXPERIMENTACIÓN ANIMAL \\ EN EL ÁMBITO DE LOS \\ INSTITUTOS DE INVESTIGACIÓN SANITARIA}

Autora

Aitziber Goikoetxea Ibarrondo

Mercedes Valiente López

Directores

Dra. Arquitecta

Francisco Domouso de Alba

Dr. por la Universidad Politécnica de Madrid

Arquitecto 

Tribunal nombrado por el Mgco. y Excmo. Sr. Rector de la Universidad Politécnica de Madrid, el día de de 2020.

Presidente:

Secretario:

Vocal:

Vocal:

Vocal:

Suplente:

Suplente:

Realizado el acto de defensa y lectura de la Tesis el día de de 2020 en

la Escuela Técnica Superior de Edificación de la UPM.

Calificación: 

A mi familia, por su apoyo incondicional.

A Pedro, mi polaris particular.

Y a Garazi, mi mejor tesis doctoral. 



\section{ÍNDICE}

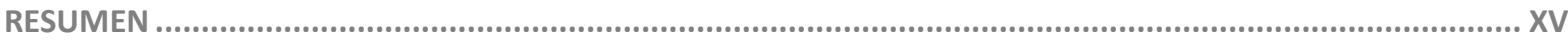

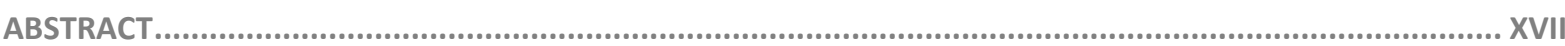

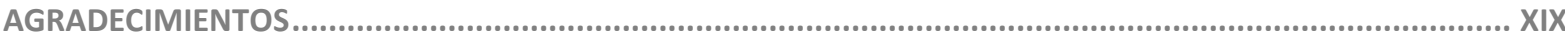

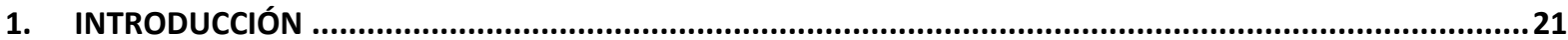

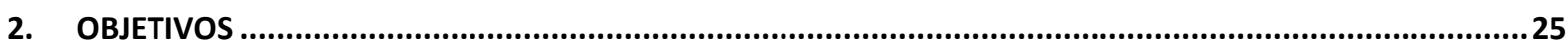

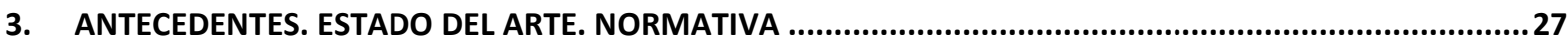

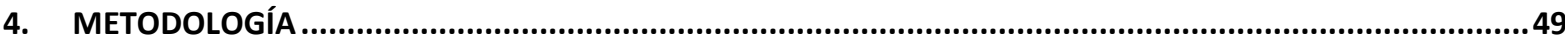

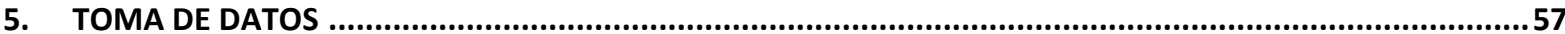

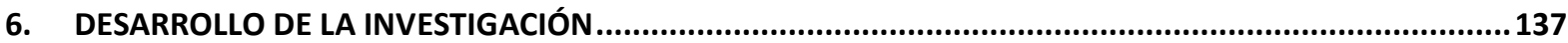

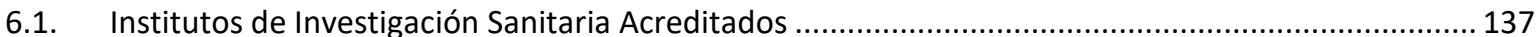

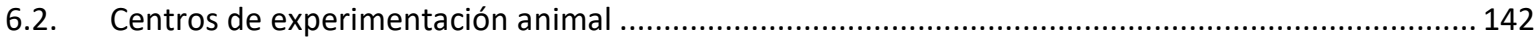

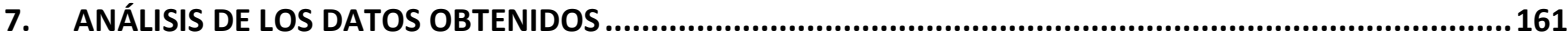

7.1. Organización y diseño del centro de experimentación animal ....................................................... 165

7.2. Organización y diseño del área de experimentación animal grande ............................................... 199

7.3. Organización y diseño del área de experimentación animal pequeño ........................................295

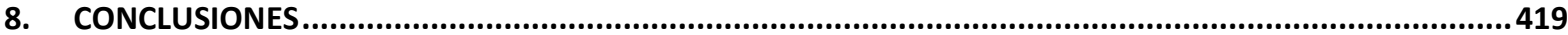

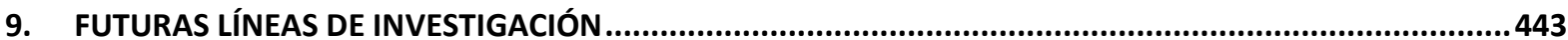

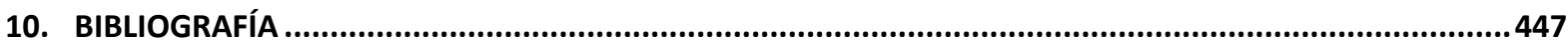

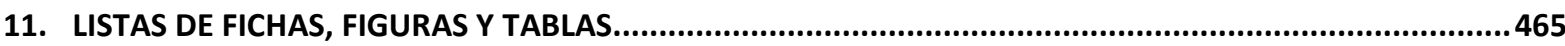

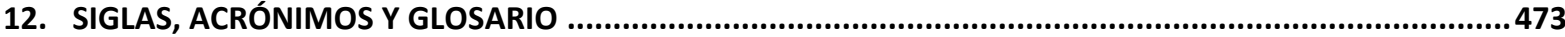




\section{ÍNDICE EXTENDIDO}

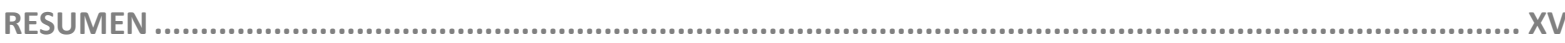

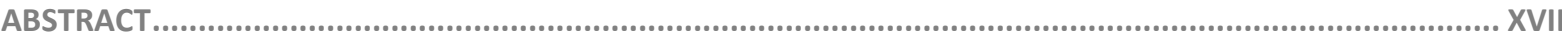

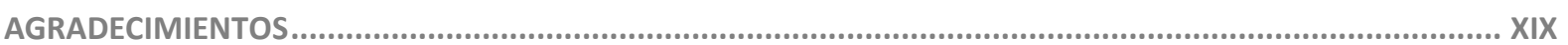

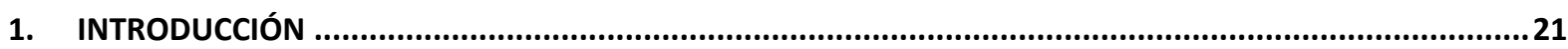

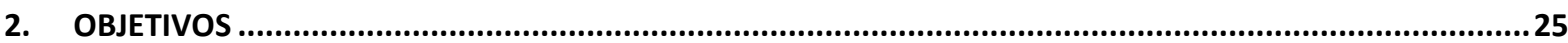

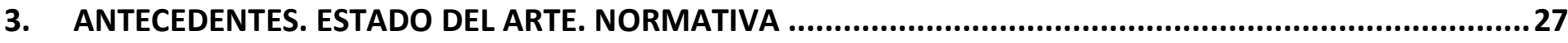

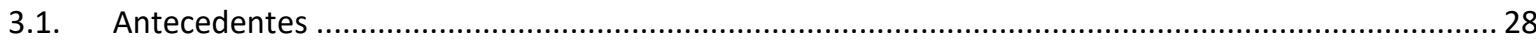

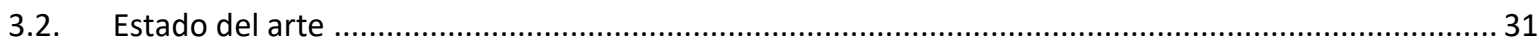

3.2.1. Publicaciones, guías, recomendaciones, libros blancos, publicaciones periódicas ..................... 31

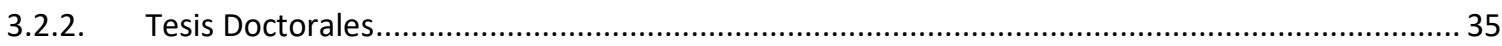

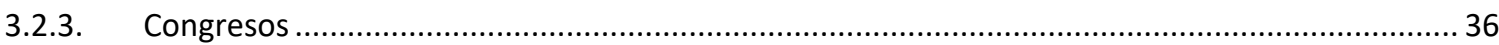

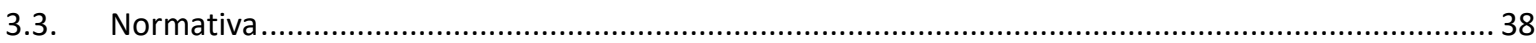

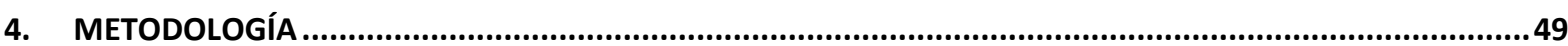

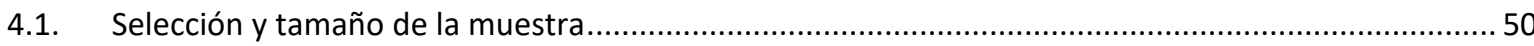

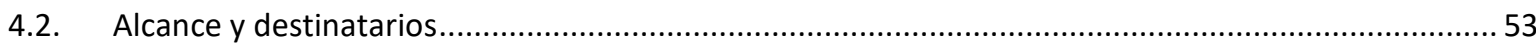

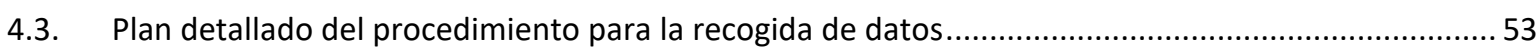

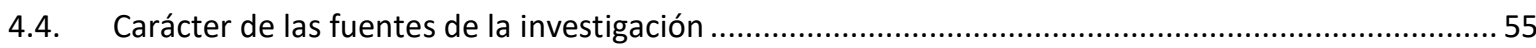

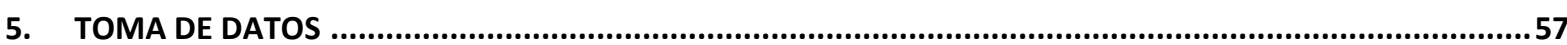

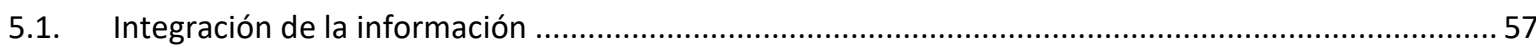

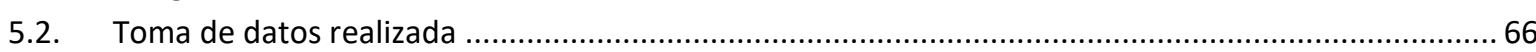

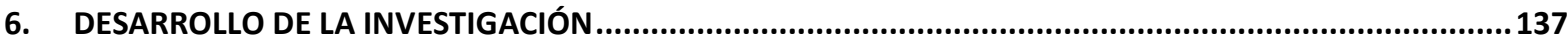

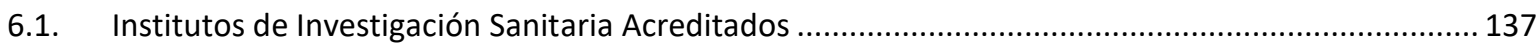

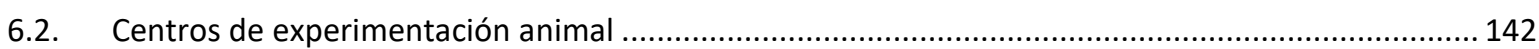

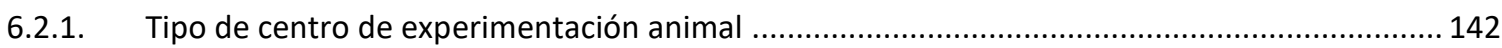

6.2.2. Sistemas de gestión de calidad en los animalarios............................................................. 143

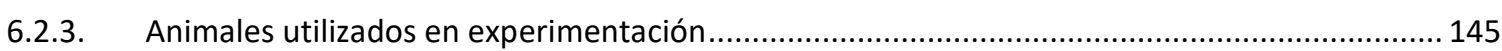

6.2.3.1. Especies animales utilizados en experimentación ....................................................................146

6.2.3.2. Tipos de animales utilizados en experimentación................................................................................150

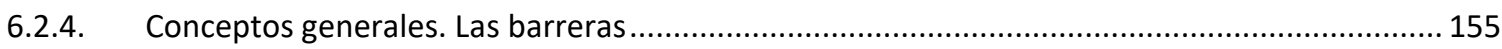

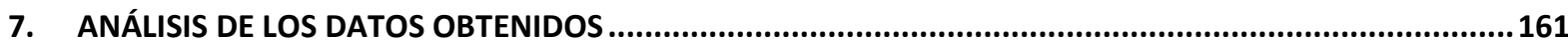

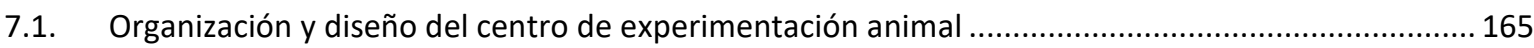

7.1.1. Representaciones gráficas de la distribución en planta ....................................................... 165

7.1.2. Características generales del centro de experimentación animal .........................................178

7.1.3. Criterio organizativo del centro de experimentación animal ................................................... 185

7.1.4. Síntesis de la organización y diseño del centro de experimentación animal ............................. 195

7.2. Organización y diseño del área de experimentación animal grande .............................................. 199

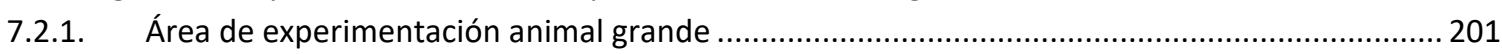

7.2.1.1. Unidades que componen el área de experimentación de animal grande ..............................201

7.2.1.2. Condicionantes de organización del área de experimentación animal grande.......................203

7.2.1.3. Representaciones gráficas de la distribución del área de experimentación animal grande ............208

7.2.1.4. Criterio organizativo del área de experimentación animal grande ..........................................219

7.2.1.5. Síntesis del área de experimentación animal grande ............................................................223 


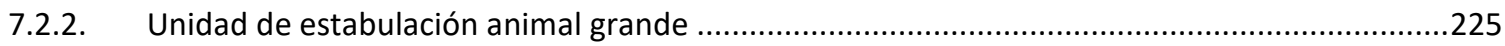

7.2.2.1. Locales que componen la unidad de estabulación animal grande....................................................225

7.2.2.2. Representaciones gráficas de la distribución de la unidad de estabulación animal grande ...........228

7.2.2.3. Características generales de la unidad de estabulación animal grande ...........................................2239

7.2.2.4. Criterio organizativo de la unidad de estabulación animal grande ................................................2 244

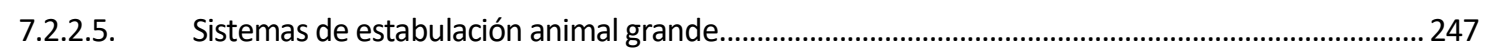

7.2.2.6. Síntesis de la unidad de estabulación animal grande ..................................................................... 256

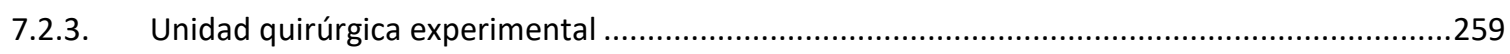

7.2.3.1. Locales que componen la unidad quirúrgica experimental.............................................................260

7.2.3.2. Representaciones gráficas de la distribución de la unidad quirúrgica experimental .......................262

7.2.3.3. Características generales de la unidad quirúrgica experimental ......................................................2273

7.2.3.4. Criterio organizativo de la unidad quirúrgica experimental ............................................................... 282

7.2.3.5. Síntesis de la unidad quirúrgica experimental ................................................................................290

7.3. Organización y diseño del área de experimentación animal pequeño......................................295

7.3.1. Área de experimentación animal pequeño........................................................................297

7.3.1.1. Unidades que componen el área de experimentación animal pequeño .......................................... 298

7.3.1.2. Condicionantes de organización del área de experimentación animal pequeño..............................301

7.3.1.3. Representaciones gráficas de la distribución del área de experimentación animal pequeño........ 309

7.3.1.4. Características generales y criterio organizativo del área de experimentación animal pequeño....... 320

7.3.1.5. Diseño constructivo del área de experimentación animal pequeño ..................................................324

7.3.1.6. Síntesis del área de experimentación animal pequeño .........................................................................334

7.3.2. Unidad de experimentación convencional animal pequeño ....................................................341

7.3.2.1. Locales que componen la unidad de experimentación convencional animal pequeño................... 342

7.3.2.2. Representaciones gráficas distribución de unidad de experimentación convencional animal pequeño.. 345

7.3.2.3. Características generales de la unidad de experimentación convencional animal pequeño .......... 356

7.3.2.4. Criterio organizativo de la unidad de experimentación convencional animal pequeño ..................364

7.3.2.5. Síntesis de la unidad de experimentación convencional animal pequeño.........................................378

7.3.3. Unidad de experimentación en barrera animal pequeño.......................................................385

7.3.3.1. Locales que componen la unidad de experimentación en barrera ................................................... 387

7.3.3.2. Representaciones gráficas de la distribución de la unidad de experimentación en barrera........... 389

7.3.3.3. Características generales de la unidad de experimentación en barrera............................................ 397

7.3.3.4. Criterio organizativo de la unidad de experimentación en barrera.....................................................406

7.3.3.5. Síntesis de la unidad de experimentación en barrera animal pequeño ............................................ 416

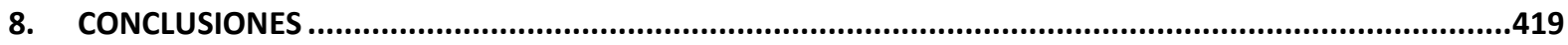

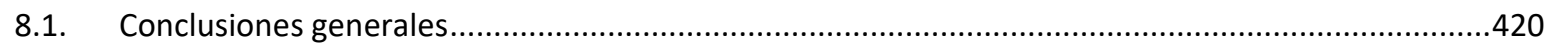

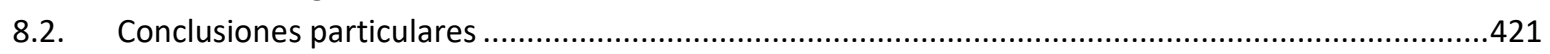

8.2.1. Conclusiones de la organización y diseño del centro de experimentación animal......................421

8.2.2. Conclusiones del área de experimentación animal grande ......................................................423

8.2.2.1. Conclusiones de la unidad de estabulación animal grande................................................................ 424

8.2.2.2. Conclusiones de la unidad quirúrgica experimental.............................................................................. 425

8.2.3. Conclusiones del área de experimentación animal pequeño ....................................................428

8.2.3.1. Conclusiones de la unidad de experimentación convencional animal pequeño.............................. 432

8.2.3.2. Conclusiones de la unidad de experimentación en barrera animal pequeño ....................................437

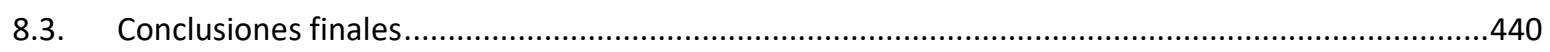

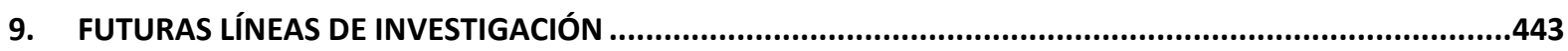




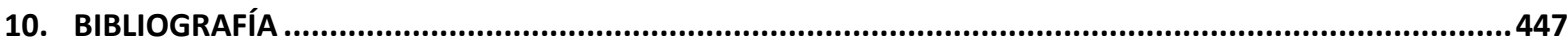

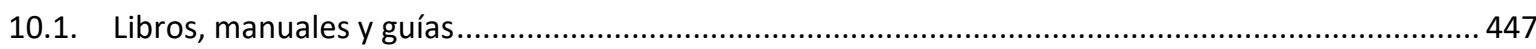

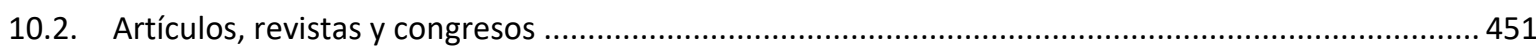

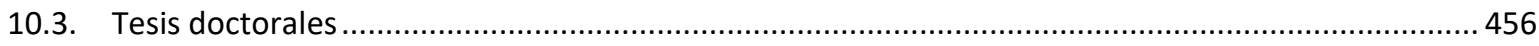

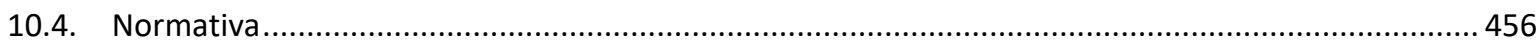

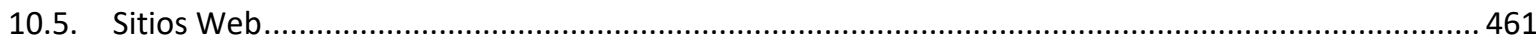

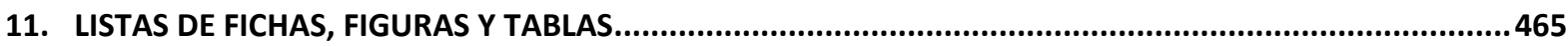

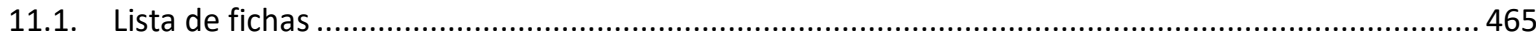

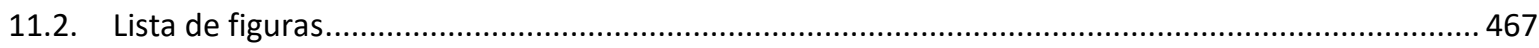

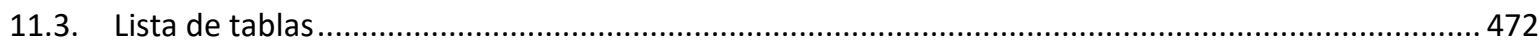

12. SIGLAS, ACRÓNIMOS Y GLOSARIO

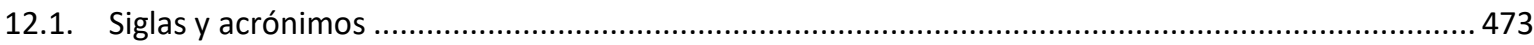

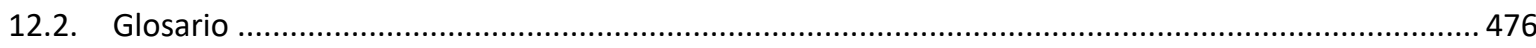




\section{RESUMEN}

La investigación sanitaria es necesaria para el éxito de cualquier estrategia que se proponga mejorar la calidad y la expectativa de vida de los ciudadanos, así como para aumentar su bienestar. Uno de los instrumentos para llevar a cabo esa investigación son los Institutos de Investigación Sanitaria, siendo su misión principal realizar investigación traslacional, de manera que todo el conocimiento generado a partir de la investigación biomédica se traduzca en el tratamiento y prevención de enfermedades, y, en definitiva, en la mejora de la calidad de vida de la población. Para poder llevar a cabo esa investigación, a pesar de contar con modelos alternativos, hoy en día, siguen existiendo pruebas para las cuales los modelos animales continúan siendo insustituibles.

La tesis se enmarca en las instalaciones diseñadas y organizadas para poder experimentar con animales. Con el fin de analizar los centros de experimentación animal de vanguardia en el ámbito de la investigación biomédica, el presente trabajo se ha centrado en el estudio de los centros de experimentación animal de los Institutos de Investigación Sanitaria Acreditados.

A la hora de planificar y diseñar un centro de experimentación animal es recomendable visitar y recopilar la información disponible sobre unidades similares ya construidas, con el fin de analizar los diferentes conceptos y flujos de trabajo establecidos que puedan servir de referencia para su diseño. El objetivo principal de esta investigación es realizar un estudio pormenorizado sobre la organización y diseño de estos centros de experimentación animal. Con ello se pretende tener el conocimiento suficiente sobre las diferentes soluciones adoptadas en instalaciones diseñadas y construidas que puedan servir de complemento para afrontar futuros proyectos.

El estudio parte de la base de conocer los centros de experimentación, es decir, ver las diferentes instalaciones y hablar con los responsables y usuarios de las mismas, para poder saber su opinión sobre sus propias instalaciones en funcionamiento. Fruto de la investigación y considerando la toma de datos realizada de cada centro, a partir de la puesta en común de los resultados obtenidos y reflejados tanto en representaciones gráficas estandarizadas como en tablas específicas, en este trabajo se analizan el diseño conceptual, así como el modelo organizativo y funcional de diez centros de experimentación animal correspondientes a Institutos de Investigación Sanitaria Acreditados, así como de las principales áreas funcionales y unidades que los componen.

Lo que este trabajo de investigación aporta es una amplia visión de la variedad de soluciones adoptadas en el diseño de los centros de experimentación animal. Se considera una herramienta complementaria a las guías existentes y fundamental para afrontar el diseño y construcción de nuevos centros de investigación de este tipo. Su estudio y análisis probablemente permita a los diseñadores 
en el ámbito de la arquitectura e ingeniería enfocar el proyecto de una nueva instalación con una visión más amplia y a su vez más selectiva, una vez conocidas las fortalezas y debilidades de cada solución analizada en este trabajo, teniendo presente que el objetivo final de este tipo de instalaciones será planificar, diseñar y construir lo mejor posible en aras a conseguir un funcionamiento eficiente, económico y seguro. 


\section{ABSTRACT}

Health research is necessary for the success of any strategy that aims to improve the quality and life expectancy of citizens, as well as to increase their well-being. One of the instruments available to carry out this research are the Health Research Institutes. Their main mission is to carry out translational research, so that all the knowledge generated from biomedical research is translated into the treatment and prevention of diseases, in short, in the improvement of the quality of life of the population. In order to achieve this research, despite having alternative models, there is still evidence which shows that animal models continue to be irreplaceable.

The thesis is framed in the facilities designed and organized to be able to experiment with animals. In order to analyze cutting-edge animal experimentation centers in the field of biomedicine, this paper has focused on the study of animal research facilities of Accredited Health Research Institutes.

When planning and designing an animal experimentation unit, it is advisable to visit and collect the data available on similar units already constructed or in operation, in order to analyze the different concepts and workflows established that can serve as reference for its design. The main objective of this research is to carry out a detailed study of the organization and design of these animal research centers. With this it is intended to have sufficient knowledge about the different solutions adopted in the designed and constructed facilities, which can serve as a complement to face future projects.

The study starts from the base of knowing the animal research centers, that is, visiting the different facilities and talking with the managers and users, in order to know their opinion. Taking as a basis the data compiled from each center, and after sharing the results obtained in standardized graphic representations and specific tables, in this work the organizational and functional model of ten animal research centers corresponding to Accredited Health Research Institutes is analyzed.

This research work offers a full range of solutions that can be adopted in the design of animal experimentation centers. It is considered a complementary tool to the existing guides and essential to face the design and construction of new research centers of this type. Their study and analysis will probably allow designers in the field of architecture and engineering to focus the project of a new installation with a broader and at the same time more selective vision, once known the strengths and weaknesses of each solution analyzed in this work, always bearing in mind that the final objective of this type of facilities will be to plan, design and build the best possible in order to achieve an efficient, economical and safe operation facility. 


\section{AGRADECIMIENTOS}

Deseo expresar mi más sincero agradecimiento a todas las personas que me han brindado su apoyo en el desarrollo de este trabajo de investigación, ya que sin su ayuda y sabiduría la presente tesis doctoral no se habría podido llevar a término.

En primer lugar, quiero dar las gracias a mis Directores de Tesis por haber confiado en mí desde el primer momento, por guiarme en este recorrido, así como por su apoyo y sus ánimos a seguir.

También quiero agradecer a todas las personas que con su intermediación han propiciado el acceso a cada uno de los Institutos de Investigación Sanitaria, así como a los responsables del área de experimentación animal de los institutos visitados, por su confianza y dedicación. No puedo olvidar la inestimable ayuda prestada por parte de Alex Rojo, Antonio Roldán, Carlos Correa, Carlos San José, Carlota Largo, Fernando Asensio, Garikoitz Azkona, Hugo Salgado, Isabel Blanco, Joan Pere Cardona, Juan Martín Caballero, Juan Rodríguez, María Carmen Rey, Montse Grau, Rosa Bonavia, Sara Capdevila, Sergio Salazar y Victoria Eugenia Mielgo.

Un agradecimiento especial a mi familia, ya que, sin pensarlo, todos se han visto involucrados de una manera u otra en esta aventura, y muy ilusionados, cada uno ha aportado su granito de arena. También a Garazi, por recordarme lo más importante.

De forma muy especial, mi más profundo agradecimiento a mi compañero de vida Pedro por haber estado a mi lado durante esta larga e intensa experiencia, ya que, sin su complicidad, comprensión y apoyo esta tesis seguiría siendo una ilusión por alcanzar.

Gracias a todos por haberlo hecho posible. 


\section{INTRODUCCIÓN}

La investigación sanitaria es un elemento necesario para el éxito de cualquier estrategia que se proponga mejorar la calidad y la expectativa de vida de los ciudadanos, así como para aumentar su bienestar. En estos días inéditos de alarma sanitaria y confinamiento obligatorio que vivimos a causa del coronavirus Covid19, quizás seamos más conscientes de la importancia de la investigación biomédica, y por tanto, del esfuerzo que es necesario que realice un país en este ámbito para poder cumplir con lo que se ha convertido en el primer y único objetivo por encima de todos los demás: preservar ante todo la salud de los ciudadanos.

La búsqueda de dianas terapéuticas comienza con la investigación básica y suele implicar el uso de modelos compuestos por células animales o humanas en cultivo. Cuando se llega a descubrir algún mecanismo de trascendencia terapéutica, es cuando se continúa la investigación con modelos animales, iniciando entonces lo que se conoce como la fase preclínica. Para desarrollar esta fase, es necesario disponer de modelos animales que reproduzcan el estado sanitario que se pretende estudiar a semejanza del ser humano. En el caso concreto de los coronavirus SARS-MERS-CoV, un estudio publicado en la revista Cell demostraba que estos accedían al interior de nuestras células a través de una proteína llamada ACE2. Además, se detectó que la proteína ACE2 de los ratones es distinta a la proteína ACE2 humana, por lo que estos virus no eran capaces de infectar a los ratones. Esta circunstancia impediría usar estos roedores como modelos animales para el estudio de estas infecciones; es por ello que resulta necesario previamente transformar el ratón, para alterar ese gen y poder convertirlo en uno susceptible de ser infectable por estos virus. El uso de estos ratones modificados genéticamente en los centros de investigación, para experimentar con ellos bajo condiciones ambientales específicas, podrá permitir el desarrollo de los trabajos de investigación que lleven a la consecución de una vacuna contra el coronavirus Covid 19 aplicable en seres humanos.

En España, la investigación biomédica vivió cambios importantes organizativos y de funcionamiento a partir de la acreditación de los Institutos de Investigación Sanitaria. Los Institutos de Investigación Sanitaria Acreditados son el resultado de la asociación a los hospitales docentes e investigadores del Sistema Nacional de Salud, de Universidades y otros centros públicos y privados de investigación. Se trata de instituciones con entidad jurídica propia, independiente al Hospital, pero cuyas instalaciones habitualmente están dentro del ámbito hospitalario, siendo los investigadores trabajadores del propio hospital.

Su objetivo principal es realizar investigación traslacional, de manera que todo el conocimiento generado a partir de la investigación biomédica de excelencia se traduzca, finalmente, en el 
tratamiento y prevención de enfermedades; en definitiva, en la mejora de la salud y calidad de vida de la población. Dentro de estos institutos se encuentran las unidades de apoyo a la investigación, que permiten proporcionar a los investigadores apoyo en diversos ámbitos tales como: el metodológico y de servicios comunes, de procedimientos y plataformas tecnológicas o incluso en las tecnologías de la información.

La tesis se enmarca en el estudio de una de las plataformas de apoyo a la investigación y que se denomina Centro de Experimentación Animal. Con el fin de investigar los citados centros de vanguardia en el ámbito de la investigación biomédica, el presente trabajo se ha centrado en el estudio de los Centros de Experimentación Animal de los Institutos de Investigación Sanitaria Acreditados.

En ciencias biomédicas, la experimentación animal se basa, entre otros, en el uso de modelos animales para investigar y comprender las causas, diagnóstico y tratamiento de enfermedades que afectan al humano y a los animales. El diseño de los experimentos que utilizan animales exige la definición detallada de las características genético-sanitarias y ambientales, así como una actitud ética y moral frente al uso de seres vivos, ya que solo de esa manera se podrán obtener en las investigaciones resultados válidos, confiables, reproducibles y comparables, para la elaboración de nuevos dispositivos, fármacos y procedimientos con carácter terapéutico y de diagnóstico ( Rodriguez Yunta 2007).

De esta manera, a la hora de establecer directrices y criterios específicos para el diseño y construcción de los centros de experimentación animal, aparte del tipo de investigación a llevar a cabo y el modelo animal con el que se va a experimentar, hay que tener en cuenta la evolución de las técnicas de experimentación, el concepto de la ética, el establecimiento de los requisitos para validar la experimentación, así como la preocupación por el bienestar animal.

La tesis se enmarca precisamente en las infraestructuras necesarias para el desarrollo de esta actividad investigadora, y más concretamente, en la organización y diseño de los centros de experimentación animal alojados en los Institutos de Investigación Sanitaria Acreditados. Teniendo presentes los manuales y guías existentes para el planteamiento de este tipo de instalaciones, se analizan las características principales, la organización y distribución planteada, los flujos de trabajo implantados, así como el diseño constructivo adoptados en los centros de experimentación animal de diez Institutos de Investigación Sanitaria Acreditados, así como en las áreas y unidades principales que lo componen. 


\section{Motivación}

En el año 2002, el Gobierno Vasco realiza una apuesta de desarrollo a través del Plan bioBASK 2010, con el objetivo de impulsar la actividad investigadora y empresarial en biociencias y llegar de esta manera a consolidar en el País Vasco una actividad empresarial reconocible en el ámbito de las biociencias a escala internacional, generadora de empleo y riqueza y promotora de una mejor calidad de vida. Con el objetivo de crear nuevas empresas, empleos y formación de alto nivel se plantean varios ejes estratégicos:

- Generar conocimiento a través de la creación de centros de investigación en cooperación.

- Impulsar el desarrollo empresarial a través de la creación de bioincubadoras.

- Dinamizar el sector a través de la agencia coordinadora del plan bioBASK.

Siendo en esa época profesional integrante del grupo de consultoría y asistencia técnica para el diseño y construcción de equipamientos del Parque Científico y Tecnológico de Bizkaia, se nos plantea la oportunidad de trabajar en el desarrollo e implementación de las infraestructuras para acometer el plan descrito, participando en equipos multidisciplinares para el diseño y ejecución de centros de investigación en ciencias de la vida y de laboratorios de investigación en el ámbito de la biología, biomateriales, biofísica y bioquímica, entre otros.

En el año 2014 y continuando con la misma filosofía de trabajo, participamos en el desarrollo del proyecto de ejecución e implementación del Instituto de Investigación Sanitaria Biocruces en el Hospital de Cruces en Bizkaia. Es a raíz de esta intervención cuando centro mis inquietudes investigadoras en los institutos del ámbito sanitario, y específicamente, en los centros de experimentación animal. 


\section{OBJETIVOS}

En general, a la hora de afrontar el proyecto de una nueva unidad, resulta recomendable visitar o recopilar la información que se encuentra disponible sobre unidades similares ya construidas, con el fin de analizar los diferentes conceptos de diseño, organización y flujos de trabajo establecidos que puedan servir de aplicación en la elaboración de esos nuevos proyectos.

\section{Objetivo principal}

El objetivo principal de esta tesis es realizar un estudio pormenorizado sobre la organización y diseño de los centros de experimentación animal de los Institutos de Investigación Sanitaria Acreditados. Con ello se pretende adquirir el conocimiento suficiente sobre las diferentes soluciones adoptadas en este tipo de instalaciones para que permita facilitar la toma de decisiones en el diseño de futuros centros a los profesionales responsables de la elaboración de los planes funcionales, a los técnicos responsables del diseño, construcción y puesta en funcionamiento de las instalaciones, así como al personal investigador y responsable del bienestar animal.

\section{Objetivos específicos}

Para conseguir ese objetivo principal se han establecido unos objetivos específicos que se han desarrollado a través de los diferentes apartados que componen la tesis, y que a continuación se describen, de tal forma que se pueda apreciar con exactitud las pretensiones del estudio:

1. Analizar las características generales que definen estos centros de experimentación animal, así como el de las áreas, unidades y locales que los componen.

2. Analizar su implantación en relación al entorno hospitalario, así como en el conjunto edificatorio del Instituto de Investigación Sanitaria.

3. Analizar el criterio organizativo a través del estudio de los tipos de accesos diseñados, la distribución en plantas, así como la relación y comunicación entre las diferentes áreas que componen el centro de experimentación animal.

4. Estudio de los flujos de trabajo establecidos para el personal, animales, suministro de materiales y retirada de residuos en cada una de las distribuciones planteadas, ya que una correcta organización de los flujos de trabajo será fundamental para garantizar la asepsia necesaria en cada una de las zonas. 
5. Analizar someramente el diseño de la arquitectura interior, así como los sistemas constructivos y materiales elegidos, y su conveniencia en base a las prestaciones, funcionalidad, durabilidad, garantía de conservación y mantenimiento. En estos centros existe un tránsito continuo de diversos materiales, ya que se trata de mover jaulas, comida, productos farmacéuticos, sustancias biológicas, así como el manejo y la manipulación de animales; y, además, se requiere la desinfección y esterilización de las superficies para garantizar el éxito de la experimentación.

6. Analizar el equipamiento que es necesario tener en cuenta desde la fase inicial del diseño de la unidad. En general, es el relacionado con las numerosas tareas y cuidados a llevar a cabo en los propios animales estabulados, así como por el tipo de alojamiento o por los requerimientos propios de la investigación.

Una instalación bien planeada, diseñada y construida, así como adecuadamente mantenida y gestionada es fundamental para el cuidado y uso de animales de experimentación, ya que facilita el funcionamiento eficiente, económico y seguro ( National Research Council 2011, p. 133). Es por ello que se considera interesante el presente trabajo, ya que el objetivo principal es que los resultados obtenidos del análisis de diferentes casos puedan servir de guía o referencia; en primer lugar, a los profesionales responsables de los centros de experimentación animal, por ser habitualmente los encargados de elaborar el plan funcional de partida; en segundo lugar, a los profesionales de la arquitectura, edificación e ingeniería, como responsables del diseño, construcción y puesta en funcionamiento de las infraestructuras; y en tercer lugar, a los investigadores y responsables del bienestar animal, por ser los usuarios finales de las instalaciones diseñadas. 


\section{ANTECEDENTES. ESTADO DEL ARTE. NORMATIVA}

El diseño de los centros de experimentación animal de los Institutos de Investigación Sanitaria Acreditados está directamente relacionado con el modelo animal con el que se va a experimentar y con el tipo de la investigación a llevar a cabo. Es por este motivo que la evolución de las técnicas de experimentación, el concepto de la ética, el establecimiento de los requisitos para validar la experimentación, así como la preocupación por el bienestar animal, con el paso de los años, han ido estableciendo diferentes directrices y criterios específicos para el diseño y construcción de este tipo de instalaciones.

Como punto de partida de la investigación, se ha tratado de recopilar la documentación de referencia en cuanto a normativa, guías, recomendaciones, libros blancos, publicaciones periódicas, tesis doctorales y actas de congresos que están relacionados con los centros de experimentación animal de los Institutos de Investigación Sanitaria Acreditados.

La búsqueda se ha centrado específicamente en temas relacionados con los Institutos de Investigación Sanitaria, la investigación biomédica, la experimentación animal, el bienestar animal, el cuidado de animales de laboratorio, la bioética de la experimentación animal y la bioseguridad y biocontención, y que, a su vez, tienen relación directa con criterios, parámetros o directrices a tener en cuenta en el diseño de este tipo de centros. Esta información se considera básica para comprender la complejidad de los centros, los condicionantes relacionados con la organización y el funcionamiento, así como las necesidades de cada una de las áreas y unidades de experimentación, y para poder establecer los criterios que se deben o se recomiendan utilizar a día de hoy. 


\subsection{Antecedentes}

La organización básica de la investigación en España comienza a mediados de los años 80 con la publicación de la Ley de la Ciencia ${ }^{1}$ que sienta las bases para el desarrollo de las políticas científicas y tecnológicas a través de los Planes Nacionales de Investigación, Ciencia y Desarrollo Tecnológico. De esta manera, se empiezan a incrementar los recursos destinados a la investigación y empieza a surgir una comunidad investigadora sólida.

La investigación sanitaria o biomédica es la investigación científica destinada a obtener conocimientos y proponer soluciones a los problemas de salud de las personas y la población. Este tipo de investigación incluye la investigación en ciencias biológicas, orientada a la fisiología humana (investigación biomédica básica); en medicina clínica, para prevenir, diagnosticar, tratar, determinar la severidad o la prevalencia de una enfermedad; en salud pública, enfocada a problemas poblacionales; en administración en salud, para mejorar la gestión y eficiencia de la acción médica; y en ciencias sociales, para reconocer comportamientos individuales y colectivos que puedan influir sobre la salud.

Uno de los escenarios en los que tiene cabida la investigación sanitaria o biomédica es en el ámbito hospitalario. La investigación biomédica realizada en los hospitales ha ido evolucionando con el paso del tiempo, de manera que si en un principio cualquier médico de hospital era reconocido para llevar a cabo un proyecto de investigación al margen de su grado de calidad, con la creación de las unidades mixtas de investigación se delimitó el número de investigadores seleccionados entre el personal médico del propio hospital, de la universidad y de otros entes de investigación como el CSIC, y se realizó una selección competitiva externa basada en la existencia de líneas de investigación financiadas tanto por fondos públicos como privados y por el impacto del trabajo de investigación tanto sobre el mundo académico como sobre el mercado. También se formaron las Fundaciones Biomédicas Hospitalarias ${ }^{2}$ como entidades jurídicas independientes al hospital con capacidad para impulsar y fomentar la investigación y asumir su gestión. Estas fundaciones han sido un apoyo de gran valor para alcanzar las tres finalidades que se asignan a los hospitales universitarios: curar, enseñar e investigar.

\footnotetext{
${ }^{1}$ Ley 13/1986, de 14 de abril, de Fomento y Coordinación general de la Investigación Científica y Técnica.

2 La estructura organizativa de las Fundaciones Biomédicas es similar a la del resto de Fundaciones, se rigen por un Patronato y su correspondiente Presidente, un Director, que puede tener diferente perfil (gestor, científico u otras formas intermedias o combinadas), y dos órganos asesores: la Comisión Científica (que deberá asumir la elaboración de propuestas sobre la política científica de la Fundación) y el Consejo Asesor (que tendrá su cometido en el asesoramiento al Patronato en todos aquellos temas dirigidos a la política económica y social de la entidad). A su vez, las Fundaciones tienen un órgano rector, que vela por su correcto funcionamiento, que es el Protectorado de Fundaciones de cada Comunidad Autónoma.
} 
La investigación biomédica vivió a nivel nacional importantes cambios organizativos y de funcionamiento, a partir de la publicación en el año 2004 del Real Decreto 339 sobre Acreditación de Institutos de Investigación Sanitaria. Posteriormente, se promulga la Ley de Investigación Biomédica ${ }^{3}$ para dar respuesta al agigantado avance de la investigación y a los nuevos métodos y técnicas aplicados en la evolución de la biomedicina, que reivindicaban un necesario avance también en el ámbito legislativo para aclarar y definir situaciones en el ámbito científico que, hasta ese momento, estaban prohibidas o eran éticamente discutibles.

El primer modelo de este tipo de institutos creado en España fue el Instituto de Investigaciones Biomédicas August Pi i Sunyer (IDIBAPS), fundado en 1996 en Barcelona, surgido al amparo de una iniciativa conjunta del Hospital Clínic y la Universidad de Barcelona, a la que se incorporaron la Generalitat de Catalunya y el CSIC. Años después, el 25 de febrero de 2009, se convirtió en uno de los primeros institutos acreditados por el Instituto de Salud Carlos III junto con los siguientes cuatro institutos de investigación: Vall d'Hebrón, Bellvitge, Germans Trias i Pujol y el Instituto de Biomedicina de Sevilla.

Los Institutos de Investigación Sanitaria son entidades dedicadas a la investigación básica y aplicada, creadas mediante la asociación entre un hospital docente e investigador del Sistema Nacional de Salud (su núcleo básico) con universidades y otros centros de investigación públicos o privados. La finalidad de dichos institutos es potenciar el hospital como centro de investigación en un entorno docente, asistencial e investigador privilegiado que aproxime la investigación básica, clínica y de servicios sanitarios, para que el conocimiento generado a partir de la investigación biomédica se traduzca en el tratamiento y prevención de enfermedades, en definitiva, en la mejora de la salud y calidad de vida de la población.

La acreditación como Instituto de Investigación Sanitaria es un reconocimiento a la excelencia en los resultados científicos y en los retornos beneficiosos (sanitarios, sociales y económicos) producto de la labor investigadora en el ámbito hospitalario. Dicha acreditación es, por tanto, una apuesta estratégica que se configura como el entorno idóneo para el desarrollo de una investigación traslacional de excelencia.

La creación de estos institutos ha servido para dar cohesión, convergencia y sentido a la investigación sanitaria que se realiza en los complejos hospitalarios más importantes de nuestro Sistema Nacional

\footnotetext{
${ }^{3}$ Ley 14/2007, de 3 de julio de Investigación Biomédica.
} 
de Salud, y que frente a la investigación dispersa y heterogénea fruto del ingenio y del esfuerzo individual, buscan:

- La confluencia convergente de dicho ingenio en líneas de investigación estratégicas.

- La incorporación de los grupos de investigación básica en salud existentes en las Universidades, el Consejo Superior u otros centros públicos o privados, para que conjuntamente converjan con los grupos que desarrollan la investigación clínica.

- Programas de inversión compartidos y orientados hacia las líneas estratégicas definidas previamente en los institutos, frente a inversiones diseminadas fruto de proyectos individuales en cada una de las instituciones.

La investigación biomédica realizada en ellos debe ser evaluada para asegurar su calidad y poder recibir una financiación adecuada y sostenible, ya que es fundamental que los organismos públicos y privados que financian la investigación sanitaria en España den apoyo preferente a instituciones con programas de investigación clínica bien establecidos y de calidad contrastada (Font 2008) , que son fundamentalmente aquellas que aseguran dos condiciones básicas: la calidad e integridad de los investigadores y la calidad e integridad del sistema institucional que da soporte a dicha investigación. En este sentido, en el contexto de planificación y coordinación nacional, el Instituto de Salud Carlos III juega un papel fundamental como organismo gestor de las actividades de la Acción Estratégica en Salud AES englobada en el Plan Estatal de Investigación Científica, Técnica y de Innovación 2017-2020.

Dentro de los institutos se encuentran las unidades de apoyo a la investigación, que permiten proporcionar a los investigadores distintos tipos de apoyo:

- Apoyo en aspectos metodológicos o instrumentales y de servicios comunes de interés para varios equipos o líneas de investigación.

- Apoyo en procedimientos y plataformas tecnológicas comunes como son (estabulario, banco de tejidos, criopreservación, análisis de imágenes y otros laboratorios de apoyo a la investigación)

- Apoyo relacionado con las tecnologías de la información (bibliotecas, bases de datos bibliográficas y comunicaciones en red).

La tesis se centra específicamente en uno de los servicios de apoyo que habitualmente ofrecen los institutos de investigación sanitaria: el centro de experimentación animal. 


\subsection{Estado del arte}

\subsubsection{Publicaciones, guías, recomendaciones, libros blancos, publicaciones periódicas}

La Organización Mundial de la Salud, constituida en 1948, a día de hoy mantiene su firme compromiso con los principios establecidos en el preámbulo de la constitución, y para cumplir sus objetivos, entre las funciones básicas que desarrolla, están el determinar las líneas de investigación y estimular la producción, difusión y aplicación de conocimientos valiosos, así como establecer y promover normas, y seguir de cerca su aplicación en la práctica. Las Ediciones de la OMS se convierte en el editor más idóneo para la difusión de los importantes consejos científicos, técnicos y médicos que la Organización Mundial de la Salud desea transmitir al mundo, y constituye, por tanto, un componente esencial de la nueva cultura de gestión de conocimientos y de comunicaciones de la organización.

Entre sus múltiples publicaciones, cabe señalar el Manual de Bioseguridad en el laboratorio ${ }^{4}$ y el Manual de bioseguridad en el laboratorio de tuberculosis ${ }^{5}$. En el primer manual, fija conceptos básicos en materia de bioseguridad y bioprotección, para alentar a elaborar códigos nacionales de prácticas para la manipulación sin riesgo de microorganismos patógenos en los laboratorios que se encuentran dentro de sus fronteras nacionales. Entre los muchos temas que aborda, establece directrices en materia de seguridad para la realización de trabajos en laboratorios y animalarios, así como criterios de diseño e instalaciones para cada uno de los casos. Establece que las designaciones del nivel de bioseguridad se basan en una combinación de las características de diseño, construcción, medios de contención, equipo, prácticas y procedimientos de operación necesarios para trabajar con agentes patógenos de los distintos grupos de riesgo. En cuanto al equipamiento diseñado para proteger a los trabajadores, las cabinas de seguridad biológica, analiza la clasificación, características de cada una y criterios de elección. Así mismo, establece los criterios de desinfección y esterilización que se deben llevar a cabo para cada caso; material, equipamiento y salas, así como la manera de eliminar los desechos. El segundo manual, Manual de bioseguridad en el laboratorio de tuberculosis, se elaboró sobre la base de las conclusiones de la reunión del grupo de expertos, de manera que las recomendaciones se apoyan en evaluaciones de los riesgos asociados a las distintas técnicas utilizadas en diferentes tipos de laboratorios de tuberculosis. Además, el manual describe los requisitos básicos para las instalaciones y las prácticas, que pueden adaptarse de modo que sigan la reglamentación local o nacional o a consecuencia de una evaluación de riesgos.

Entre las publicaciones que tienen relación y establecen directrices sobre las características constructivas y de diseño de la instalación se distinguen entre otros las siguientes: Guide for the care

\footnotetext{
4 Organización Mundial de la Salud. 2005. Manual de bioseguridad en el laboratorio, 3th ed, Ginebra: Ediciones de la OMS. ${ }^{5}$ Organización Mundial de la Salud. 2013. Manual de bioseguridad en el laboratorio de tuberculosis, Ginebra: Ediciones de la OMS.
} 
and use of laboratory animals, Guidelines on: laboratory animal facilities - characteristics, design and development NIH Design Policy and Guidelines, Planning and designing research animal facilities, Design standards for small animals (rodents) vivarium, Manual sobre el cuidado y uso de animales de experimentación, Cage processing in animal facilities y Design standards for small animals vivarium.

La publicación Guide for the care and use of laboratory animals ${ }^{6}$, también conocida como The Guide o The ILAR Guide, se publicó por primera vez en 1963 y es el resultado del trabajo realizado por miembros procedentes de los consejos de la Academia Nacional de Ciencias, la Academia Nacional de Ingeniería y el Instituto de Medicina de los Estados Unidos de América, y es de aplicación en sus políticas de servicios de salud pública; además, los estándares sobre el cuidado y uso de animales en ella establecidos son una referencia aceptados a nivel internacional. Bajo la premisa de que una instalación bien planificada, bien diseñada, bien construida, bien mantenida y administrada es fundamental para el cuidado y uso los animales, entre los diferentes propósitos de esta guía está establecer las directrices y recomendaciones para el diseño y construcción de los centros de experimentación animal, con la intención de ayudar a los investigadores en el cumplimiento de su obligación de planificar y realizar experimentos con animales de acuerdo con los más altos principios científicos, humanos y éticos.

Siendo el Consejo Canadiense de Protección Animal el responsable de supervisar el uso de animales destinados a la investigación, docencia y experimentación, en la publicación Guidelines on: laboratory animal facilities - characteristics, design and development ${ }^{7}$ pretende establecer directrices sobre cuestiones de actualidad y preocupaciones emergentes en el cuidado y uso de los animales, de manera que se centra en establecer directrices sobre las características que deben tener las áreas de experimentación animal, sin llegar a abarcar todos los conceptos establecidos en The Guide.

\section{El Design Requirements Manual for Biomedical Laboratories and Animal Research Facilities DRM ${ }^{8}$} anteriormente denominada National Institute ol Health Design Policy and Guidelines establece los requisitos de diseño y manual de orientación para la construcción de los laboratorios de investigación biomédica e instalaciones de investigación animal en los EE.UU. Este documento promulga los estándares mínimos de diseño que deben cumplir las instalaciones nuevas y reformadas del NIH con

\footnotetext{
${ }^{6}$ National Research Council. 2011. Guide for the Care and Use of Laboratory Animals. 8th ed. Washington, DC: The National Academy Press.

7 Neil, D. y Mckay, D. 2003. Guidelines on: laboratory animal facilities - characteristics, design and development. Canada: CCAC Canadian Council on animal care

${ }^{8}$ Division of technical resources. 2019. NIH Design requirements manual. Rev 1.4. The national institutes of health.
} 
el fin de garantizar que las instalaciones sean de la más alta calidad para apoyar la investigación biomédica.

Siendo la investigación animal un tema oportuno, ya que estamos en medio de una revolución, las instituciones de investigación han construido, instalaciones de investigación animal renovadas, o están planeando hacerlo, para satisfacer las demandas de la investigación biomédica debido al crecimiento en el uso de roedores genéticamente alterados y al aumento de la investigación en enfermedades infecciosas. Hay múltiples soluciones para abordar la miríada de factores que influyen en el diseño y la construcción de las instalaciones de investigación animal. Partiendo del hecho de que no existe un "mejor" diseño aplicable a todas las instalaciones, y posiblemente ni siquiera un solo "mejor" diseño para una instalación concreta, el libro Planning and designing research animal

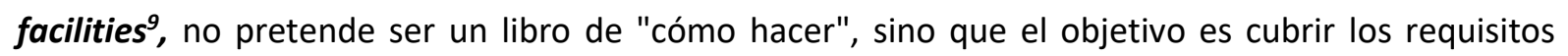
programáticos básicos de las Instalaciones de investigación animal, proporcionando ideas para conocer las necesidades y poder estimular el proceso creativo. Esto requiere un profundo conocimiento y comprensión de todos los aspectos relacionados con las instalaciones de investigación animal, arquitectura, ingeniería, construcción y requisitos programáticos. La información contenida en este libro pretende facilitar la comunicación entre las distintas disciplinas, proporcionar la información necesaria y estimular la creatividad que ayudará a la toma de decisiones prudentes y avanzar en la base de conocimientos para la planificación, diseño y construcción de instalaciones de investigación animal.

En cuanto a las publicaciones periódicas, existen numerosas revistas a nivel mundial sobre animales de experimentación e investigación biomédica: Actualidad médica, Animales de laboratorio, Laboratory animals, Bioética, Journal of the American Association for Laboratory Animal Science JAALAS, Journal of Civil Engineering and Architecture o ILAR Journal, que en ocasiones publican artículos con temas que pueden tener relación con la construcción de las instalaciones, en este sentido resulta especialmente interesante la publicación periódica News to use, The National Institute of Health, Design requeriments manual.

En cuanto a la investigación en los hospitales del Sistema Nacional de Salud, cabe señalar, que la investigación sanitaria es un elemento necesario para el éxito de cualquier estrategia que se proponga mejorar la salud de los ciudadanos. La integración de la investigación con la práctica clínica garantiza una mayor calidad de los servicios de salud y una mejor y más rápida implantación de los avances

\footnotetext{
${ }^{9}$ Hessler, J.R. y Lehner, N.D.M. 2009. Planning and designing research animal facilitie. 1st ed: San Diego: Elsevier.
} 
científicos en la prevención, diagnóstico y tratamiento de las enfermedades, y un cuidado más ético y eficiente de los pacientes (Carrasco 2007, p. 237).

El Libro blanco sobre el sistema sanitario españo/ ${ }^{10}$, analiza el desarrollo del Sistema Nacional de Salud a lo largo del pasado siglo, haciendo hincapié en aquellos hitos importantes que lo han conducido al aseguramiento universal y público actual, referencia mundial por su universalización y eficiencia. Por otra parte, muestra la preocupación sobre la percepción de una serie de problemas que pueden poner en cuestión su sostenibilidad debido al incremento progresivo de los gastos sanitarios. Entre los muchos temas que aborda, también enumera una serie de problemas que habría que resolver, apuntando a que la protección sanitaria es uno de los principales instrumentos de cohesión de la sociedad y núcleo fundamental del estado de bienestar. Además, incluye una serie de recomendaciones del grupo de trabajo, entre las que se establece que la investigación biosanitaria ha de ser impulsada, no sólo como un aspecto clave en la formación integral de médicos y cirujanos, sino como pieza sustancial de la calidad y desarrollo del SNS. Los resultados de la innovación deberán representar una fuente de ingresos para el Sistema que, en el momento actual, es un mero comprador de tecnología externa.

El libro Gestión sanitaria integral: pública y privada ${ }^{11}$ surge de la necesidad de disponer de un texto asequible, actual y riguroso que sirva de referencia y orientación a todos aquellos que quieren aproximarse al mundo de la gestión sanitaria. Entre los diferentes temas que aborda se encuentra la gestión de la investigación biomédica en los hospitales, de manera que; por una parte, se revisan los conceptos básicos, el marco regulador, los criterios y prioridades de la investigación en salud en España; y, por la otra, se revisa la evolución y desarrollo en España de las Unidades de Investigación de los hospitales desde su creación, y su coexistencia con la nueva figura de las fundaciones de investigación. En lo relacionado a las Fundaciones de Investigación, nos explica cómo están dotadas de autonomía de gestión, que nacen con el objeto de gestionar programas y proyectos de investigación clínica y otras actividades en el ámbito de la biomedicina, para contribuir a la promoción y protección de la salud de la población y al progreso y mejora del SNS. Con ellas se pretende, además, estimular, impulsar, promover y facilitar, la investigación científica y la gestión del conocimiento, así como fomentar la formación del personal investigador y definir y recomendar la política de investigación del respectivo centro sanitario.

\footnotetext{
${ }^{10}$ España. Academia europea de ciencias y arte. 2011. Libro Blanco sobre el Sistema Sanitario Español. Madrid: Academia Europea de ciencias y arte.

${ }^{11}$ Cabo, J. 2010. Gestión sanitaria integral: pública y privada. Madrid: Centro de Estudios Financieros.
} 
También hay que tener en cuenta, que otra de las áreas de investigación de los centros de experimentación animal asociados a los hospitales es la docencia. En docencia, las prácticas con animales tienen como objetivo aprender ciertos procesos fisiológicos, características anatómicas o adquirir habilidades clínicas y quirúrgicas, así como adquirir destreza en el manejo de los nuevos equipos o técnicas, como forma de entrenamiento. Para ello, es necesario que los centros dispongan de unas infraestructuras adecuadas y lo más similares a las condiciones reales en las que van a tener que ejercer la práctica quirúrgica ya con pacientes. En este sentido, tienen especial interés las siguientes publicaciones: Bloque quirúrgico estándares y recomendaciones ${ }^{12}$, Guía de buenas prácticas para la circulación en el bloque quirúrgico ${ }^{13}$ y el Libro blanco de la actividad y gestión del bloque quirúrgico en España. ${ }^{14}$

\subsubsection{Tesis Doctorales}

Si bien no se han encontrado tesis doctorales relacionadas con el diseño y construcción de los centros de experimentación animal, se han encontrado varias tesis relacionadas con los animalarios entre las que, por la afinifad con la investigación, se encuentra la siguiente.

La Tesis Revisión del convenio Europeo ETS 123 del consejo de Europa: Impacto de su aplicación sobre los animalarios Españoles, analiza la necesidad de adaptación de los animalarios españoles a las nuevas circunstancias, con el consiguiente impacto organizativo y económico que ello supone. Los objetivos alcanzados por la Tesis pueden dividirse en tres partes:

a) Impacto económico y organizativo de la aplicación de la revisión del Convenio Europeo ETS 123 en los animalarios españoles desde su entrada en vigor.

b) Opinión de los responsables de los animalarios sobre las propuestas ofrecidas por el Convenio para la mejora del bienestar animal, especialmente acerca del aumento del tamaño de las jaulas y la aplicación del enriquecimiento ambiental en las mismas.

c) Obtención y comparación de los datos españoles y los de la Unión Europea sobre la utilización de animales de experimentación, que incluye a su vez:

- Investigar el tipo, número y distribución de las especies animales en los animalarios españoles registrados.

\footnotetext{
12 España. Ministerio de Sanidad y Política Social. 2009. Bloque quirúrgico estándares y recomendaciones. Madrid: Ministerio de Sanidad y Política Social Centro de publicaciones.

${ }^{13}$ Martínez, M. L. 2014. Guía de buenas prácticas para la circulación en el bloque quirúrgico, Madrid: Instituto Nacional de Gestión Sanitaria.

${ }^{14}$ Albarracín, A. y otros.2015. Libro blanco de la actividad y gestión del bloque quirúrgico en España. Madrid: Antares consulting.
} 
- Conocer la tendencia de utilización de animales para investigación en España, comparándola con el resto de países de la Unión Europea.

- Averiguar si en España se ha reducido el número de animales utilizados en experimentación, para cumplir los objetivos trazados por la Unión Europea.

- Deducir si en España se está produciendo una modificación en los hábitos de utilización de las especies animales.

\subsubsection{Congresos}

La investigación planteada está relacionada y tiene implicación en mayor o menor medida con el ámbito de la investigación sanitaria, la experimentación animal, los hospitales, la bioseguridad y biocontención, la arquitectura y la ingeniería, por tanto, para el inicio de la investigación, se han consultado las actas y ponencias de los congresos relacionados con estas áreas, entre los que cabe señalar los siguientes:

El congreso nacional de bioseguridad y biocontención, organizado por la Asociación Española de Bioseguridad (AEBIOS), nace con el objetivo general de reforzar y brindar conocimientos actualizados y avanzados en bioseguridad y biocontención, para su posible aplicación en instalaciones, centros y laboratorios relacionados con la sanidad humana, animal y vegetal, sobre la base de una concepción técnica y científica.

El seminario de ingeniería hospitalaria, Congreso Nacional, organizado por la Asociación Española de Ingeniería Hospitalaria, se ha convertido en una cita ineludible para los profesionales responsables de la redacción de proyectos del ámbito hospitalario. Su objetivo fundamental es que el seminario sea un foro de participación donde poder compartir nuevos conocimientos, ideas y experiencias, que sirva para afrontar los cambios que se producen día a día en el sector. Para ello se cuenta con la implicación de profesionales y empresas, como parte activa del programa científico.

La Sociedad Secal, que es la sociedad más destacada en el ámbito del animal de laboratorio de nuestro país, celebra bianualmente El Congreso Nacional de la Sociedad Española para las Ciencias del Animal de Laboratorio. Este congreso está orientado a profesionales relacionados con el animal de laboratorio, desde cuidadores hasta investigadores, pasando por responsables y técnicos de animalario, que en su mayoría pertenecen a centros de investigación, tanto del sector público como privado, universidades y centros de producción de animales. El objetivo general del congreso es, entre otros, presentar las perspectivas y oportunidades que brindan las diferentes especies animales, las técnicas de experimentación animal, los avances realizados en la investigación con animales en diferentes enfermedades, el equipamiento y la gestión del personal del animalario. Además, 
puntualmente, se tratan temas relacionados con las infraestructuras necesarias para poder realizar la actividad investigadora.

El Congreso nacional de hospitales y gestión sanitaria, organizado por la Asociación Nacional de Directivos de Enfermería (ANDE) y la Sociedad Española de Directivos de la Salud (SEDISA), de carácter bianual, nace con el fin de tratar temas de candente actualidad relativos a los hospitales y su gestión. Hay que tener en cuenta que una parte fundamental de cualquier sistema de salud son sus servicios sanitarios. En este sentido es necesario poner énfasis en la importancia que tiene la docencia, la formación y la investigación, no sólo para los profesionales sanitarios en relación con la calidad de su trabajo diario en la prestación de atención a los ciudadanos, sino también para las organizaciones sanitarias como proveedoras de servicios de salud a la sociedad. Por otra parte, las infraestructuras forman una parte fundamental para ofrecer un óptimo servicio. Analizar las propuestas vanguardistas, examinar modelos que han fracasado y descubrir el porqué y desarrollar nuevos enfoques para optimizar las condiciones de gestión es, entre otros, uno de los objetivos del congreso.

A nivel europeo e internacional caben mencionar El congreso de la federación europea de sociedades para las ciencias del animal de laboratorio, El congreso internacional sobre comportamiento y bienestar animal, El congreso internacional de la federación internacional de ingeniería hospitalaria y El congreso europeo de ingeniería hospitalaria que abordan temas y estudios de interés en relación a la investigación planteada. 


\subsection{Normativa}

La investigación biomédica requiere el uso de modelos animales de experimentación. Es por ello, que para afrontar la organización y diseño de los centros de experimentación animal de los Institutos de Investigación Sanitaria es necesario considerar la normativa de aplicación relacionada con el ámbito de la experimentación animal.

Los modelos animales han sido utilizados desde hace muchos años en distintas áreas de investigación, constituyendo uno de los pasos fundamentales en la biomedicina, y, hoy en día, a pesar de contar con modelos alternativos para la investigación, siguen existiendo pruebas para las cuales, el modelo animal continúa siendo insustituible.

\section{Legislación Internacional}

El Código de Nüremberg ${ }^{15}$ es muy probablemente el documento más importante en relación con la historia de la investigación biomédica, ya que es considerado el primer antecedente de relevancia internacional sobre ética de la investigación. Este código, que consta de diez puntos sobre la ética de la experimentación en humanos, se desarrolló después de la II Guerra Mundial y fue producto de uno de los juicios en el que siete médicos fueron condenados a la pena de muerte por horca por crímenes de guerra y crímenes contra la humanidad; fueron acusados de haber realizado acciones peligrosas y que incluso llegaron a provocar la muerte de personas durante los experimentos humanos efectuados con presos de los campos de concentración, sin su consentimiento. Este código sirvió para fijar unas reglas o principios que buscaban defender los derechos de los sujetos que participan en la investigación médica, de tal manera que aparte de incluir la necesidad absoluta del consentimiento informado y el derecho del sujeto a retirarse de la participación en la experimentación, estableció que "el experimento deberá diseñarse y basarse sobre los datos de la experimentación animal previa y sobre el conocimiento de la historia natural de la enfermedad y de otros problemas en estudio que puedan prometer resultados que justifiquen la realización del experimento". Aunque el Código de Nüremberg no fue oficialmente adoptado por las leyes de muchas naciones o por códigos éticos de muchas asociaciones médicas, su influencia ha sido muy profunda en relación con aspectos éticos de la investigación.

Prácticamente en la misma época, en el año 1946, se constituyó la Asociación médica mundial, que en 1964, daría lugar a la Declaración de Helsinki ${ }^{16}$. Esta declaración, que recogió el espíritu del Código de Nüremberg y lo perfeccionó desde un punto de vista procedimental y sustantivo, estableció que la

\footnotetext{
15 Tribunal internacional de Nüremberg. 1947. Código de Nüremberg. Nüremberg.

${ }^{16}$ Declaración de Helsinki de la Asociación Médica Mundial. 1964. Principios éticos para las investigaciones médicas en seres humanos. Helsinki.
} 
investigación médica en sujetos humanos "debe apoyarse en un profundo conocimiento de la bibliografía científica [...], así como en experimentos de laboratorio correctamente realizados y en animales, cuando sea oportuno. Se debe cuidar también del bienestar de los animales utilizados en los experimentos.", de manera que pasó a ser la norma internacional sobre ética de la investigación biomédica. A través de sus sucesivas revisiones, la declaración se constituyó como referente internacional en ética de la investigación, con amplio impacto en las normativas de distintos países, así como en otras normas internacionales.

Por otra parte, a partir de 1940 se inició la creación de una nueva especialidad dentro de la medicina veterinaria: La ciencia del animal de laboratorio. Esta ciencia, que engloba a diversos profesionales entre veterinarios, investigadores de diversas disciplinas, farmacéuticos o médicos, fue creada para ayudar a la comunidad científica a mejorar todos los aspectos concernientes a la experimentación animal. Basada en investigaciones, normas, principios y legislaciones, se ocupa simultáneamente de mejorar la investigación biomédica y asegurar el bienestar animal, abordando el estudio del animal de experimentación en sí mismo, de sus características fisiológicas, genéticas, reproductivas, y sanitarias, así como de los métodos de producción, manejo o mantenimiento, entre otros. Las sociedades creadas en relación a esta ciencia son muchas, destacando las siguientes: American Association for Laboratory Animal Science AALAS, International Council for Laboratory Animal Science ICLAS, Canadian Council of Animal Care CCAC y Federation of European Laboratory Animal Science FELASA. Esta última engloba las principales sociedades para las ciencias del animal de laboratorio de los países de la Unión Europea, y entre ellas se encuentra la Sociedad Española para las Ciencias del Animal de Laboratorio SECAL. Estas instituciones han publicado guías con reconocimiento internacional donde se detallan las normas y recomendaciones generales para el cuidado y uso de los animales en forma científica, técnica y humanitariamente apropiada, así como sobre la planificación y conducción de los experimentos con animales (Hernández 2006).

El eje central de estas regulaciones está basado en el principio establecido en el libro The principles of humane animal experimental techniques ${ }^{17}$. En él se expone por primera vez que la excelencia científica está fuertemente ligada al uso humanitario de los animales de laboratorio, y define claramente las normas en las que se basan los principios éticos de la investigación con animales, "el principio de las 3Rs: reducir, reemplazar y refinar", siendo estos los fundamentos para una racional e inteligente estrategia para minimizar el uso de animales, así como las causas de dolor y estrés.

\footnotetext{
${ }^{17}$ Russel, W.M.S. y Burch, R.L. 1959. The principles of humane animal experimental techniques, London: Methuen.
} 
En primer lugar, establecen que los proyectos de investigación que requieren el uso de animales de laboratorio deben ser realizados con el número mínimo necesario de animales que permitan obtener resultados científicamente válidos. El perfeccionamiento del diseño de los experimentos y la selección del modelo más adecuado contribuyen al cumplimiento de este principio.

En segundo lugar, los procedimientos in vivo deben ser reemplazados siempre que sea posible por métodos alternativos que no usen animales vivos, como modelos matemáticos, simulación por computador, test serológicos, cultivos celulares y sistemas biológicos in vitro.

En tercer y último lugar, el refinamiento involucra fundamentalmente la estandarización según parámetros internacionales: definición genético-sanitaria y la calidad del ambiente donde son criados y mantenidos los animales antes y durante la experimentación. Incluye todos los procedimientos para minimizar y eliminar el dolor, así como todos los métodos de enriquecimiento para asegurar el bienestar animal.

Estados Unidos estableció, en un periodo relativamente corto, un sistema normativo que refrendó el Código Nüremberg y la Declaración de Helsinki, de manera que en 1966 promulgó The Animal Welfare $A c t^{18}$. Esta es la única ley federal en los Estados Unidos que regula el tratamiento de animales en investigación, exhibición y transporte. Otras leyes, políticas y pautas pueden incluir cobertura adicional de especies o especificaciones para el cuidado y uso de animales, pero todas se refieren a la Ley de The Animal Welfare Act como el estándar mínimo aceptable.

La mayor parte de las leyes de aplicación internacional tienen su origen en las leyes estadounidenses, ya que han sido pioneras en materia de protección animal. De esta manera, la mayoría de los países del mundo que quieren legislar sobre esta materia lo hacen tomando como referencia The Animal Welfare Act (Míguez 2016).

\section{Legislación Europea}

A nivel europeo, la voluntad política y la demanda social por una mayor protección de los animales fueron determinantes para que a partir de los años setenta el Consejo de Europa, al que España entró a formar parte en 1977, contribuyera a la creación de un espacio legal común europeo mediante la elaboración de convenios, acuerdos y recomendaciones. En muchos casos, estos instrumentos sirven de referente en todo el continente y constituyen la base para la modificación y armonización de las

\footnotetext{
18 United States Department of Agriculture. 2017. Animal Welfare Act and Animal Welfare Regulations. Washington, D.C.: The Animal and Plant Health Inspection Service.
} 
legislaciones de los diferentes países en las diferentes áreas de trabajo. Actualmente, los cinco convenios básicos del Consejo de Europa referentes al bienestar animal son los siguientes:

- Convenio para la Protección de los animales en el Transporte Internacional. Realizado en París el 13 de diciembre de 1968. Firmado y ratificado por España. Entró en vigor el 3 de febrero de 1975. - Convenio para la Protección de los animales en Explotaciones Ganaderas. Realizado en Estrasburgo el 10 de marzo de 1976. Firmado y ratificado por España. Entró en vigor el 6 de noviembre de 1988.

- Convenio para la Protección de los Animales al Sacrificio. Hecho en Estrasburgo el 10 de mayo de 1979. No ha sido firmado ni ratificado por España.

- Convenio para la Protección de los Animales de Compañía. Elaborado en Estrasburgo en octubre de 1987. No ha sido firmado ni ratificado por España.

- Convenio para la Protección de los Animales de Experimentación y otros fines científicos. Realizado en Estrasburgo el 18 de marzo de 1986. Firmado y ratificado por España. Entró en vigor el 1 de enero de 1991.

En lo que se refiere al Convenio para la Protección de los Animales de Experimentación y otros fines científicos, denominado Convenio 123, entre muchos de los aspectos que trata, reconoce que el hombre tiene la obligación de respetar a todos los animales, aceptando, sin embargo, que en su búsqueda del conocimiento, la salud y la seguridad, tiene necesidad de utilizar animales. Expone todos los casos en los que será permitida la experimentación animal, y detalla el alojamiento al que tiene derecho el animal destinado a ser utilizado. Algunas cuestiones concretas, contempladas de forma no suficientemente profunda en este texto, o que podrían considerarse confusas, se han desarrollado mediante diferentes instrumentos:

- Resolución sobre la interpretación de ciertas disposiciones y expresiones del Convenio para la protección de los animales vertebrados utilizados con fines experimentales y otros fines científicos, adoptada en Consulta Multilateral el 27 de noviembre de 1992.

- Resolución sobre la formación y educación de las personas que trabajan con animales de laboratorio, adoptada en Consulta Multilateral el 3 de diciembre de 1993.

- Resolución sobre instalaciones y cuidados a los animales de laboratorio, adoptada en Consulta Multilateral el 30 de mayo de 1997.

- Resolución sobre adquisición y transporte de los animales de laboratorio, adoptada en Consulta Multilateral el 30 de mayo de 1997.

- Declaración de intenciones sobre animales usados con propósitos científicos (4/12/1997). Firmada por España. 
- Recomendación Rec (2003) 10 del Comité de Ministros de los estados miembros sobre xenotrasplante, adoptada por el Comité de Ministros del 19 de junio de 2003, en la reunión 844.

La evolución de la experimentación y, sobre todo, la profundización en los conocimientos acerca de las necesidades de los animales utilizados en experimentación, pusieron de manifiesto la necesidad de modificar diferentes aspectos, sobre todo los que se refieren al alojamiento y manejo de estos animales. Para poder adaptar el Convenio 123 a los sucesivos cambios que en estos aspectos se han manifestado necesarios, se elaboró y aprobó el Protocolo de Enmienda al Convenio 123 y se abrió a la firma el 22 de junio de 1998 en Estrasburgo. España lo firmó el 1 de julio de 2003 y lo ratificó el 17 de noviembre; sin embargo, aún no ha entrado en vigor, ya que para ello es necesario que lo firmen y ratifiquen todos los países que ya lo hicieron con el Convenio 123. Este Protocolo de Enmienda permite que las modificaciones respecto a las características de alojamiento y manejo detalladas en los apéndices puedan modificarse por un procedimiento mucho más sencillo y dinámico. ${ }^{19}$

La primera legislación global a nivel europeo es la Directiva 86/609/CEE del Consejo de Europa. En esta normativa se recogen, entre otros, los siguientes aspectos: que los experimentos deben tener como objetivo el bien del hombre o de la naturaleza; que los animales deben estabularse de manera adecuada, e intentar evitarles todo sufrimiento o ansiedad, o paliar el que obligadamente se pueda producir; que los experimentadores deben estar adecuadamente capacitados para la investigación; que no deben existir alternativas al empleo de los animales, se prohíbe el empleo de animales silvestres, y se establece la obligación de métodos indoloros de eutanasia o la liberación del animal y sus condiciones. Además, introduce requisitos de tipo administrativo para la realización de experimentación con animales, así como para su cría y estabulación, y establece que debe fomentarse la búsqueda de técnicas alternativas al empleo de animales de experimentación. Se recogen aspectos muy generales, basado en el Principio de las $3 R s$, con el que se dejaba abierta la posibilidad a los estados miembros de aprobar leyes más exigentes, tal y como ocurrió en Reino Unido y otros países europeos.

El 22 de septiembre de 2010, el Parlamento Europeo y el Consejo adoptaron la Directiva 2010/63/UE, relativa a la protección de los animales utilizados para fines científicos, cuya finalidad era la aportación de una mayor protección de los animales de laboratorio y una mejora de sus condiciones de vida, estableciendo los estándares de bienestar más altos, siendo esta la normativa vigente a nivel europeo.

19 Ministerio de agricultura, pesca y alimentación. Gobierno de España. https://www.mapa.gob.es/va/ganaderia/temas/produccion-y-mercados-ganaderos/bienestanimal/animales-delaboratorio/ 


\section{Legislación Española}

La normativa de aplicación para comprender y diseñar los centros de experimentación animal de los Institutos de Investigación Sanitaria se basa fundamentalmente en la normativa estatal y autonómica relacionada con la experimentación animal. Así mismo, para el desarrollo de cualquier proyecto constructivo, además, se deberá considerar todo el marco normativo de aplicación a nivel estatal, autonómico y local que aborde desde las exigencias que deben cumplir los edificios en relación con los requisitos básicos de seguridad y habitabilidad establecidos en el Código Técnico de la Edificación, hasta cada una de las normas de aplicación necesarias para garantizar la puesta en servicio y uso de las instalaciones, normativa que no se refleja en este trabajo.

A nivel estatal la normativa vigente de aplicación en el campo de la experimentación animal es la siguiente:

- Real Decreto 53/2013, de 1 de febrero, por el que se establecen las normas básicas aplicables para la protección de los animales utilizados en experimentación y otros fines científicos, incluyendo la docencia.

- Real Decreto 1386/2018, de 19 de noviembre, por el que se modifica el Real Decreto 53/2013, de 1 de febrero, por el que se establecen las normas básicas aplicables para la protección de los animales utilizados en experimentación y otros fines científicos, incluyendo la docencia.

- Orden ECC/566/2015, de 20 de marzo, por la que se establecen los requisitos de capacitación que debe cumplir el personal que maneje animales utilizados, criados o suministrados con fines de experimentación y otros fines científicos, incluyendo la docencia

La Directiva 86/609/CEE fue incorporada a nuestro ordenamiento, a través del RD 223/1988 ${ }^{20}$, que básicamente, se limitó a trasladar la legislación europea a la normativa nacional, sin añadir exigencias más estrictas. Posteriormente, en el año 2005 vio la luz el RD 1201/2005²1. Este Real Decreto reguló, entre otros aspectos, las condiciones en que se podían utilizar animales de experimentación; el registro de establecimientos de cría, suministradores y usuarios de animales de experimentación; así como los requisitos de las instalaciones y equipos de los mismos. Así mismo, introdujo dos aspectos novedosos: por un lado, se establecieron las categorías profesionales del personal que trabaja con animales de laboratorio, definiéndose el tipo de formación que debía tener cada una de estas; y por

\footnotetext{
${ }^{20}$ Real Decreto 223/1988, de 14 de marzo, sobre protección de los animales utilizados para experimentación y otros fines científicos

${ }^{21}$ Real Decreto 1201/2005, de 10 de octubre, sobre protección de los animales utilizados para experimentación y otros fines científicos. Esta normativa se basa en la ley catalana Ley 5/1995, de 21 de junio, de protección de los animales utilizados para experimentación animal y para otras finalidades científicas, que fue pionera entre las comunidades autónomas ya que proporcionó un tratamiento pormenorizado y propio, introduciendo diferencias notables con relación a la normativa estatal.
} 
otro lado, se introdujo el concepto del Comité ético de bienestar animal, sus funciones y composición, así como su obligatoriedad en los centros de titularidad estatal.

El marco legislativo en torno a la experimentación animal se completó con la entrada en vigor de la Ley $32 / 2007^{22}$. Este instrumento legislativo estableció un conjunto de principios sobre el cuidado de los animales y la regulación del correspondiente régimen sancionador en caso de incumplimiento de la normativa de bienestar animal, en materias específicas como la protección de los animales de producción en las propias explotaciones ganaderas, durante aquellas operaciones relacionadas con el transporte y el sacrificio o matanza, así como la protección de determinados animales utilizados para experimentación y otros fines científicos y educativos.

El RD53/2013 ${ }^{23}$ se elaboró en desarrollo de la Ley 32/2007 debido al carácter marcadamente técnico de la disposición. Entre otros aspectos, regula detalladamente las condiciones mínimas en las que han de alojarse los animales y los cuidados que éstos han de recibir, así como los requisitos mínimos exigidos a los criadores, suministradores y usuarios de animales de experimentación, todo ello con el objetivo principal de garantizar su bienestar en la mayor medida posible. Se establecen, así mismo, las normas a las que deben atenerse los proyectos y procedimientos desde que se inician hasta que finalizan. Entre otros, marca como objetivo último el total reemplazo de los animales en los procedimientos y se fijan normas específicas para la utilización de determinados tipos de las especies amenazadas y los animales de compañía. En este sentido, se fijan unos requisitos especialmente estrictos en el caso de los primates no humanos. Además, estipula la obligatoriedad de publicar anualmente información estadística sobre los animales utilizados en España. Respondiendo a dicha obligación, el Ministerio de Agricultura, Alimentación y Medio Ambiente publica el informe sobre usos de animales en experimentación y otros fines científicos incluyendo la docencia.

Con el fin de incorporar los avances realizados en este tema y contemplados en la Directiva 2010/63/UE, y con la finalidad de solucionar la distorsión detectada con respecto a la normativa vigente, a través de la Ley $6 / 2013^{24}$,se procede a modificar cuatro artículos afectados de la Ley $32 / 2007$. Por lo tanto, se adapta a la evolución de los conocimientos en materia de bienestar de los animales, tanto en lo referente a su ámbito de aplicación como en la supresión de ciertas definiciones, elevando con ello los niveles mínimos de protección de los animales, que se encuentran ya o puedan establecerse en los términos de la normativa comunitaria e internacional, y encauzando el progreso

\footnotetext{
22 Ley 32/2007, de 7 de noviembre, para el cuidado de los animales, en su explotación, transporte, experimentación y sacrificio.

${ }^{23}$ Real Decreto 53/2013, de 1 de febrero, por el que se establecen las normas básicas aplicables para la protección de los animales utilizados en experimentación y otros fines científicos, incluyendo la docencia.

${ }^{24}$ Ley 6/2013, de 11 de junio, de modificación de la Ley 32/2007, de 7 de noviembre, para el cuidado de los animales, en su explotación, transporte, experimentación y sacrificio.
} 
de dichos conocimientos de la manera más racional. Se incluye además una mención expresa a la aplicación de la normativa de la Unión Europea a los procedimientos y proyectos que deben ser regulados, evaluados y autorizados en los términos establecidos en la misma. Asimismo, y a fin de proporcionar un claro cumplimiento de la normativa comunitaria, que exige resolución expresa, a través de esta ley, se establece el sentido desestimatorio del silencio administrativo en la autorización de los proyectos.

Posteriormente, con fecha 20 de marzo de 2015 entra en vigor la Orden ECC/566/2015, por la que se establecen los requisitos de capacitación que debe cumplir el personal que maneje animales utilizados, criados o suministrados con fines de experimentación y otros fines científicos, incluyendo la docencia. El objeto de esta orden ministerial es desarrollar los requisitos de capacitación del personal regulados con carácter general en el artículo 15 del RD 53/2013.

\section{Normas UNE}

Debido al progreso en campos como la biomedicina o la biotecnología, el uso de material biológico en los laboratorios está cada vez más extendido; por este motivo, las instalaciones de contención biológica han proliferado en los últimos años por todo el mundo, siendo su diseño y gestión bastante heterogéneos. A raíz de esta situación, en 2007, dos de las organizaciones internacionales más importantes en el ámbito de la bioseguridad, la Asociación Americana de Seguridad Biológica (ABSA) y Asociación Europea de seguridad Biológica (EBSA) promovieron la elaboración de un documento sobre gestión de la bioseguridad y la bioprotección en los laboratorios. El documento obtenido, el CWA 15793:2008 Laboratory biorisk management, aunque se desarrolló en el seno del Comité Europeo de Normalización (CEN) en la forma de un CEN Workshop Agreement (CWA), fue elaborado por la comunidad internacional con carácter globalizador para que tuviera un enfoque común en el ámbito internacional. Debido a su complejidad, en 2010 se decidió elaborar una guía de aplicación para facilitar su implantación. Así, se desarrolló el CWA 16335:2011 Biosafety Profesional Competence y el CWA 16393:2012 Laboratory biorisk management - Guidelines for the implementation of CWA 15793:2008. ${ }^{25}$

A nivel nacional, AENOR crea un grupo de expertos en bioseguridad cuya actividad se ha centrado en la elaboración de las normas UNE que aplican los CWA referenciados para el ámbito nacional:

- UNE-CWA 15793:2013. Gestión del riesgo biológico en el laboratorio,

- UNE-CWA 16393:2014. Gestión del riesgo biológico en el laboratorio. Guía para la aplicación del CWA 15793:2008.

- UNE-CWA 16335:2014. Competencia del profesional en bioseguridad.

\footnotetext{
${ }^{25}$ Usera, F. y Perez, J. 2014. Nuevas normas para la gestión del riesgo en laboratorios. AENOR Bioseguridad, 296: 42-45.
} 
Consciente de las dificultades actuales en la materia, la proliferación de Instalaciones de Nivel 3 de Contención Biológica en España y la diferencia de criterios existentes en las mismas, ese grupo ha liderado la generación de la norma UNE 171400-1:2019 de Diseño de instalaciones de nivel 3 de contención biológica (NCB3). Pormenoriza todos los aspectos de diseño que deben cumplir estas instalaciones fijándose en estándares internacionales, siendo una norma que afecta a las nuevas instalaciones.

A nivel autonómico, para asegurar el cumplimiento de todos los aspectos éticos y legales, así como para mejorar la transparencia y la trazabilidad de los resultados experimentales, se establecieron a través de la normativa autonómica, las siguientes directrices adicionales: en primer lugar, se creó la Comisión de Experimentación Animal, encargada de supervisar desde el gobierno autonómico todas las cuestiones relativas a la experimentación animal; y en segundo lugar, tipificó los delitos contra la ley dividiéndolos por su gravedad en leves, graves y muy graves; así mismo, estableció las sanciones correspondientes a cada grado de delito.

Las comunidades autónomas que han desarrollado legislación propia sobre bienestar animal son: Andalucía, Aragón, Cantabria, Cataluña, Galicia, Comunidad de Madrid, Comunidad Foral de Navarra, Comunidad Valenciana y País Vasco.

\section{Andalucía}

- Ley 11/2003, de 24 de noviembre, de protección de los animales.

- Decreto 142/2002, de 7 de mayo, por el que se crea y regula el registro de establecimientos de cría, suministradores y usuarios de animales de experimentación y otros fines científicos.

- Decreto 199/2005, de 20 de septiembre, por el que se modifica el Decreto 142/2002.

Aragón

- Ley 11/2003, de 19 de marzo, de protección animal, de la Comunidad Autónoma de Aragón.

- Orden de 20 de abril de 2006, del Departamento de Agricultura y Alimentación, por la que se convoca el proceso de homologación para el ejercicio profesional en los centros de experimentación animal y otros fines científicos.

- Decreto 239/2008, de 16 de diciembre, del Gobierno de Aragón, por el que se establecen las normas de homologación de los cursos de formación y las de acreditación de las entidades de formación, de los cuidadores y manipuladores de animales, de los adiestradores de los animales de compañía y de los animales potencialmente peligrosos.

\section{Cantabria}

- Orden de 2 de febrero de 1989, de la Consejería de Ganadería, Agricultura y Pesca, sobre protección de los animales utilizados para experimentación y otros fines científicos. 


\section{Cataluña}

- Ley 5/1995, de 21 de junio, sobre protección de los animales utilizados para experimentación y otras finalidades científicas.

- Decreto 214/1997, de 30 de julio, por el que se regula la utilización de animales para experimentación y para otras finalidades científicas.

- Decreto 286/1997, de 31 de octubre, de modificación del Decreto 214/1997, de 30 de julio, por el que se regula la utilización de animales para experimentación y para otras finalidades científicas.

- Decreto 164/98, de 8 de julio, que modifica el Decreto de 30 de julio de 1997.

- Ley 22/2003, de 4 de julio, de protección de los animales.

\section{Galicia}

- Orden de 15 de septiembre de 2006 por la que se crea el Comité de Bioética de la Consellería del Medio Rural.

- Decreto 296/2008, de 30 de diciembre, de protección de los animales utilizados para experimentación y otros fines científicos, incluida la docencia, y por el que se crea el registro de los centros de cría, de suministradores y usuarios y la Comisión Gallega de Bienestar de los Animales de Experimentación.

\section{Comunidad de Madrid}

- Orden de 4 de agosto de 1989 del Consejero de Agricultura y cooperación por la que se dan normas sobre protección de los animales utilizados para experimentación y otros fines científicos.

\section{Comunidad Foral de Navarra}

- Orden Foral de 5 de agosto de 1991, del Consejero de Agricultura, Ganadería y Montes, sobre protección de los animales utilizados en experimentación y fines científicos en la C.F de Navarra.

\section{Comunidad Valenciana}

- Decreto 13/2007, de 26 de enero, del Consell, sobre protección de los animales utilizados para experimentación y otros fines científicos.

\section{País Vasco}

- Orden de 25 de junio de 1991, del Consejero de Agricultura y Pesca, por la que se dictan normas sobre protección de los animales utilizados para la experimentación y otros fines científicos. 


\section{METODOLOGÍA}

La elaboración de este trabajo de investigación ha requerido la definición de un procedimiento metodológico específico para establecer la estrategia necesaria para cumplir los objetivos del estudio. La investigación es un conjunto de procesos sistémicos, críticos y empíricos que se aplican en el estudio de fenómenos o problemas planteados. Sin embargo, se pueden realizar a través de dos aproximaciones o enfoques diferentes: el enfoque cuantitativo y el enfoque cualitativo. En el enfoque cualitativo hay una realidad subjetiva por descubrir e interpretar que va a variar en su forma y contenido entre los diferentes individuos y grupos, por lo que se parte de la premisa de que todo es relativo y solo puede ser entendido desde el punto de vista de los actores estudiados. La estrategia general de este tipo de investigación es la siguiente (Hernández 2014):

1. Observación y evaluación de fenómenos.

2. Definición de criterios como consecuencia de la observación y evaluación.

3. Fundamento de los criterios o suposiciones.

4. Revisión y análisis.

5. Proposición de nuevas suposiciones o ideas.

La investigación cualitativa parte de un objetivo que es la idea fundamental de la investigación, para a través de la revisión de la literatura realizar una inmersión que se apoya en procesos inductivos basados en explorar y describir para luego generar perspectivas teóricas. No se inicia con una teoría particular que luego se somete al mundo empírico para confirmar que está apoyada por hechos, por tanto, se considera también interpretativo, pues intenta encontrar sentido a los fenómenos en términos de los significados que los individuos otorguen.

El objetivo principal de esta tesis es realizar un estudio pormenorizado sobre la organización y diseño de los centros de experimentación animal, por tanto, la investigación se aborda desde un enfoque cualitativo. Se trata de crear conocimiento sobre la realidad de los centros construidos, y para ello, se describen, comprenden e interpretan las diferentes soluciones adoptadas a través de las percepciones producidas por la experiencia de uso de las instalaciones. La toma de datos de los centros de experimentación animal, y el posterior análisis y puesta en común de los mismos se ha utilizado para establecer unos patrones de comportamiento, de manera que los resultados obtenidos de la investigación sirvan como complemento de la documentación existente a este tema concreto. El propósito de la toma de datos no es medir variables o hacer un análisis estadístico sobre los resultados, sino que los datos se recolectan para analizarlos, comprenderlos y generar conocimiento.

Por otra parte, el alcance de la investigación de tipo descriptivo trata de describir fenómenos, situaciones y contextos, ya que se busca especificar las propiedades y características del elemento 
sometido a análisis; se pretende recoger información de manera independiente sobre los conceptos o las variables. Por lo tanto, el alcance de esta investigación es de tipo descriptivo, ya que se trata de especificar las propiedades, características y resultados del funcionamiento de los centros sometidos a análisis, es decir, se han recogido y evaluado datos sobre diversos conceptos para describirlos, sin relacionarlos unos con otros; $y$, a partir de la puesta en común de los resultados, se han analizado las soluciones mayoritarias y específicas adoptadas.

Con el propósito de responder a las preguntas de investigación planteadas y cumplir con los objetivos del estudio, se ha diseñado una investigación de tipo no experimental, por tratarse de observar los casos construidos para después analizarlos, y transversal puesto que el propósito ha sido realizar la recopilación de datos de los centros de investigación construidos y que estaban en funcionamiento a fecha enero 2016, siendo este el periodo concreto en el que se ha abordado la investigación.

\subsection{Selección y tamaño de la muestra}

La unidad sometida a análisis es el diseño de los centros de experimentación animal. Para poder centrar la investigación, desde el origen se han fijado una serie de características que han permitido acotar la muestra en un ámbito concreto, además de garantizar una homogeneidad de la misma. Estamos hablando, pues, de una selección no probabilística en la que la elección de la muestra no depende de la probabilidad, sino que está dirigida y determinada por los condicionantes que se han fijado para la elección de la muestra.

Para afrontar la investigación, las variables del estudio que se han acotado han sido desde el ámbito geográfico, por el tipo de investigación realizada en el centro, así como por la calidad de sus investigaciones. En cuanto al marco geográfico, el estudio ha considerado los centros de experimentación animal de ámbito nacional, si bien los datos obtenidos se han contrastado con un centro de referencia a nivel europeo. En lo referente al tipo de investigación, los experimentos con animales tienen su fundamento en el hecho de considerar a otras especies animales como modelos en miniatura de los problemas humanos. Esta experimentación animal se realiza básicamente en tres campos: la investigación, la docencia y la industria. El presente estudio se ha acotado a los centros cuya finalidad es la combinación de la investigación sanitaria y la docencia, y específicamente, a los institutos que están asociados a los hospitales del Sistema Nacional de Salud, y cuya misión principal es promover la docencia y la investigación de calidad, así como potenciar la innovación en tecnologías médicas y sanitarias que reviertan en una mejora en la asistencia sanitaria.

De esta manera, con la intención de investigar los centros de vanguardia en el ámbito de la investigación sanitaria, el estudio se centra únicamente en los Institutos de Investigación Sanitaria 
Acreditados por el Instituto de Salud Carlos III, que son centros asociados a los hospitales docentes e investigadores del Sistema Nacional de Salud. El hospital universitario es una piedra angular en la enseñanza de la medicina, en el cual confluyen tres facetas inseparables: la asistencial, la investigadora y la docente. De esta manera, estamos garantizando que el tipo de investigación en ellos realizada es homogénea, de calidad y se acota al ámbito biomédico y a la docencia.

Aunque las primeras acreditaciones de los institutos de investigación se realizan en el año 2009, como consecuencia del RD 339/2004, en muchos casos, son centros con una larga trayectoria y fruto de proyectos iniciados años atrás. De esta manera, en base a los datos aportados por el propio Instituto de Salud Carlos $1 \mathrm{II}^{26}$, son veintinueve los Institutos de Investigación Sanitaria Acreditados hasta enero de 2016; de esos veintinueve institutos se han estudiado trece, y como resultado de la investigación, en la tesis se analizan diez de ellos. Se estima que se trata de un número suficientemente representativo de datos para considerar que la información que se deduce de ellos permita facilitar la toma de decisiones en el diseño de futuros centros.

\section{Institutos de Investigación Sanitaria estudiados}

\begin{tabular}{|c|c|c|c|}
\hline 1. & IdiPAZ & Instituto de Investigación Sanitaria Hospital La Paz & Madrid \\
\hline 2. & $\mathrm{i}+12$ & _Instituto de Investigación Hospital 12 de Octubre & Madrid \\
\hline & liSGM & _Instituto de Investigación Sanitaria Gregorio Marañón & Madrid \\
\hline 4. & IRICYS & Instituto Ramón y Cajal de Investigación Sanitaria & Madrid \\
\hline 5. & IIS Biodonostia & _Instituto de Investigación Sanitaria Biodonostia & Gipuzkoa \\
\hline 0. & IIS Biocruces & Instituto de Investigación Sanitaria Biocruces & Bizkaia \\
\hline 7. & IISA & _IIS Aragón Instituto de Investigación Sanitaria Aragón & Zaragoza \\
\hline 0 & VHIR & _IR-HUVH Institut de Recerca Hospital Universitari Vall D’hebron & Barcelona \\
\hline 9 & IGTP & _Institut d'investigació en Ciéncies de la Salut Germans Trias I Pujol & Barcelona \\
\hline 10 & IIS La Fe & _Fundación para la Investigación del Hospital Universitario La Fe & Valencia \\
\hline 11 & IDIBELL_ & _Institut d'investigació Biomédica de Bellvitge & Brcelona \\
\hline 12 & IDIBAPS & _Institut d'investigaciones Biomédicas August Pi Y Sunyer & Barcelona \\
\hline & IMIM & Instituto Hospital del Mar de Investigaciones Biomédicas & Barcelona \\
\hline
\end{tabular}

\section{Institutos de Investigación Sanitaria analizados en la tesis}

\begin{tabular}{|c|c|c|c|}
\hline 1. & IdiPAZ & _Instituto de Investigación Sanitaria Hospital La Paz. & Madrid \\
\hline 2. & $\mathrm{i}+12$ & Instituto de Investigación Hospital 12 De Octubre & Madrid \\
\hline & liSGM & Instituto de Investigación Sanitaria Gregorio Marañón & Madrid \\
\hline & IRICYS & Instituto Ramón y Cajal de Investigación Sanitaria & Madrid \\
\hline 5 & IIS Biodonostia & _Instituto de Investigación Sanitaria Biodonostia & Gipuzkoa \\
\hline & IIS Biocruces & Instituto de Investigación Sanitaria Biocruces & Bizka \\
\hline & IISA & _IIS Aragón Instituto de Investigación Sanitaria Aragón & Zaragoza \\
\hline & VHIR & IR-HUVH Institut de Recerca Hospital Universitari Vall D’hebron & Barcelona \\
\hline & IGTP & _Institut d'investigació en Ciéncies de la Salut Germans Trias I Pujol & \\
\hline & IIS La Fe & Fundación para la Investigación del Hospital Universitario La Fe & - Val \\
\hline
\end{tabular}

${ }^{26}$ http://www.isciii.es/ISCIII/es/contenidos/fd-investigacion/fd-institutos-investigacion-sanitaria/listado-de-iisacreditados.shtml. Consultado enero 2016. 
La realidad es que existe un recelo generalizado en mostrar este tipo de instalaciones, fundamentalmente por temas de confidencialidad, por la posible contaminación de la instalación y porque la experimentación animal es un tema controvertido que genera opiniones y posicionamientos extremos y variados; y, por lo tanto, el acceso a ellos no ha sido tarea sencilla.

En la determinación del número de centros visitados sobre los que se ha realizado la investigación han tenido gran importancia; por una parte, los contactos personales que han hecho posible una presentación previa para a continuación poder establecer el contacto directamente con los responsables de los centros; y, por la otra, la voluntad de los responsables de los mismos a mostrar y a someter a análisis sus instalaciones. A pesar de las dificultadas encontradas, y aunque no se han podido visitar todos los centros deseados, mediante una gestión adecuada, se han conseguido visitar un número notable para el desarrollo de la investigación.

Por otra parte, la falta de datos suficientes para poder incorporarlos a la muestra, incluso el dimensionamiento y los servicios que ofrece el propio centro en relación al resto de institutos, han propiciado que de los trece centros estudiados únicamente se incorporen a la muestra diez de ellos.

Con el fin de tener una visión global de este tipo de instalaciones y poder compararlas con instalaciones de mayor entidad, se han realizado también visitas; a nivel nacional, a las instalaciones del Centro Nacional de Investigaciones Oncológicas CNIO en Madrid; y, a nivel europeo, a las instalaciones del animalario de la Facultad de Anatomía Patológica del University College London UCL en Londres. Además, la investigación se ha complementado con el estudio de otros centros de experimentación animal como son, el CICbiomaGUNE y el CICbioGUNE, que junto con el Parque de Investigación Biomédica de Barcelona PRBB (que es el centro en el que realiza la experimentación animal el Instituto Hospital del Mar de Investigaciones Biomédicas IMIM), el CNIO y el IDIBELL, como ya analizaremos más adelante, son cinco de los nueve centros de experimentación animal acreditados por AAALAC ${ }^{27}$ a nivel nacional a fecha febrero 2020.

Siendo el objetivo del estudio analizar intensivamente estos casos para proveer mayor entendimiento sobre el diseño de este tipo de instalaciones, y considerando la acotación de variables descritas anteriormente, la investigación se ha delimitado a los centros de experimentación animal de ámbito nacional integrados en los Institutos de Investigación Sanitaria que están acreditados por el Instituto de Salud Carlos III.

${ }^{27}$ AAALAC International es una organización privada, no gubernamental, que promueve el trato humanitario de los animales en las actividades científicas mediante programas voluntarios de evaluación y acreditación. 


\subsection{Alcance y destinatarios}

El alcance y aplicación del análisis realizado se sitúan en los sectores tanto de la arquitectura e ingeniería como en el médico, veterinario e investigador. Por tanto, sus principales destinatarios son; por una parte, los profesionales de la arquitectura, edificación e ingeniería, empresas constructoras incluso suministradores de productos que pueden participar en el diseño, construcción, puesta en servicio, mantenimiento o uso de este tipo de instalaciones; por otra parte, los responsables del cuidado y bienestar animal; y, por último, los profesionales de los campos de la medicina e investigación, incluso los responsables de los centros de experimentación animal.

\subsection{Plan detallado del procedimiento para la recogida de datos}

Una vez diseñada la investigación y seleccionada la muestra adecuada en base al objetivo establecido, el siguiente paso ha consistido en recolectar los datos necesarios para el estudio. Para ello, previamente, se ha elaborado un plan detallado sobre el procedimiento a llevar a cabo, para a continuación identificar y localizar los diferentes tipos de fuentes, establecer el método para la recolecta de los datos, y, por último, estudiar la forma de prepararlos para analizarlos y poder representarlos, y así, dar respuesta al objetivo planteado.

El estudio parte de la base de conocer los centros de experimentación, es decir, ver las instalaciones y hablar con los responsables o usuarios de las mismas para poder saber su opinión sobre sus propias instalaciones en funcionamiento. Para lograr ese objetivo en este estudio se ha seguido el siguiente esquema metodológico:

1. La investigación parte de la base de datos proporcionada por el Instituto de Salud Carlos III, en la que se especifica cuáles son y en qué fecha se acreditaron los institutos de investigación sanitaria de nuestro país a fecha enero de 2016. Esta búsqueda se ha materializado a través de la consulta en la página web del Instituto de Salud Carlos III que ha permitido identificar los Institutos de Investigación Sanitaria Acreditados.

2. Otra fuente inicial para la obtención de datos ha sido la información existente en la página web de cada instituto de investigación, que ha servido para obtener los contactos, además de otros datos de partida básicos sobre los centros de experimentación, los modelos animales utilizados y el tipo de instalaciones.

3. Se acudió a contactos personales y a través de ellos se lograron los contactos de las personas responsables de los animalarios de los institutos, así como una recomendación previa. Hay que tener en cuenta que la investigación animal es un tema que socialmente no siempre está bien vista, y que, en general, los responsables de los centros son reticentes a mostrar las 
instalaciones y la investigación realizada a cualquier persona desconocida, incluso por motivos de confidencialidad y posible contaminación de la instalación. El primer contacto, por tanto, ha sido mediante recomendación previa. A pesar de ello, no todos los centros de los que se disponía recomendación previa se han conseguido visitar.

4. A continuación, con la recomendación previa, se optó por entablar un primer contacto telefónico con los responsables del centro para exponer el objeto del estudio y conocer su voluntad para colaborar en él. Tras una breve presentación, se realizó una somera exposición del objetivo principal de la investigación que se estaba llevando a cabo y se les solicitó la documentación relativa a las instalaciones del centro.

5. Tras una respuesta afirmativa para colaborar en la investigación y una vez analizada la documentación aportada por cada uno de ellos, el siguiente paso fue realizar la visita de inspección. Para establecer cada visita, se envió un email explicativo del objetivo de la investigación y se concretaron las fechas de las visitas.

6. Para conocer de primera mano los centros, en cada visita se realizó un recorrido y toma de datos de las instalaciones, se solicitó la documentación gráfica de las plantas del centro de experimentación animal y se mantuvo una entrevista con los responsables de la misma.

Las visitas realizadas han permitido conocer el diseño constructivo, así como analizar las características particulares en cuanto a implantación, organización de espacios, interrelación entre ellos, así como los procedimientos de trabajo establecidos, y, por lo tanto, la definición de flujos de trabajo de cada uno de los elementos que transitan por la unidad.

La documentación gráfica ha sido fundamental para poder reflejar, analizar y compartir las diferentes propuestas realizadas en cada centro. En numerosos casos, los propios responsables de los centros han sido los que han proporcionado la documentación gráfica de las plantas de distribución de las instalaciones visitadas; en otros casos, la documentación se ha obtenido por medio de los responsables del diseño, las empresas contratistas o por búsquedas realizadas en internet, ya que al ser obras promovidas por instituciones públicas, estos proyectos han sido adjudicados mediante concursos públicos, y, por lo tanto, dicha documentación ha sido publicada y accesible durante un periodo de tiempo determinado.

En diversos casos, la información correspondiente de cada centro de experimentación se ha complementado con las presentaciones realizadas por los usuarios en diferentes congresos, seminarios o curso de especialización. 
Las entrevistas con los agentes involucrados en el uso diario de las instalaciones han permitido conocer sus opiniones sobre las bondades y deficiencias detectadas en la organización y construcción de la unidad, y saber si las instalaciones han requerido alguna modificación o reorganización del funcionamiento del centro. Disponer de dicho testimonio ha resultado una aportación realmente interesante para el estudio.

7. Para el desarrollo de la investigación han sido muy enriquecedoras también la información obtenida; por una parte, por los diferentes agentes que han tomado parte en el proceso constructivo de este tipo de centros como son los responsables de la administración, técnicos responsables de la elaboración y dirección de los proyectos, constructores y suministradores de equipos; $y$, por otra parte, por los profesionales que sin haber intervenido directamente en los centros investigados, debido a su trayectoria profesional y sabiduría sobre los temas tratados, se ha considerado interesante la aportación que pudieran hacer a la investigación.

8. Con el fin de contextualizar la investigación, se ha realizado una búsqueda de la bibliografía relacionada con el diseño y construcción de este tipo de instalaciones.

\subsection{Carácter de las fuentes de la investigación}

Toda la documentación que ha sido necesaria recopilar para llevar a efecto la investigación, y que a continuación procedemos a detallar, la podemos clasificar en fuentes primarias y secundarias.

\section{Fuentes documentales primarias}

En esta tesis se ha sometido a estudio el diseño de los centros de experimentación animal; por tanto, las fuentes primarias las constituyen todas aquellas que aportan conocimiento e información detallada sobre el diseño y construcción de las edificaciones de los diferentes centros de experimentación analizados. Las fuentes primarias son fundamentalmente las siguientes:

- Las páginas web del ISCIII y de los diferentes Institutos de Investigación Sanitaria analizados.

- Los planes funcionales, pliegos de condiciones y proyectos de ejecución de los centros de experimentación animal de los institutos.

- Ponencias en congresos, seminarios y cursos de especialización en los que se han expuesto el diseño y organización de los centros analizados.

- Las visitas de inspección visual y reportaje fotográfico de las instalaciones analizadas.

- Las entrevistas realizadas a los agentes que han intervenido en el proceso de diseño y construcción, así como a los usuarios de los mismos. 


\section{Fuentes documentales secundarias}

En este caso, las fuentes secundarias las constituyen todas aquellas que aportan la información necesaria a tener en cuenta a la hora de diseñar y construir un centro de experimentación animal. Nos referimos; por un lado, a todas aquellas fuentes que nos aportan el conocimiento necesario para poder comprender la complejidad y funcionamiento de este tipo de centros, y en consecuencia, nos permiten tener una visión generalizada de cómo deben estar organizados y diseñados; y, por la otra, la relativa a los materiales, sistemas constructivos, instalaciones y equipamiento que está relacionada con la construcción de centros de experimentación animal.

Nos referimos a los libros, guías, manuales, publicaciones periódicas, tesis doctorales, actas de congresos, catálogos de materiales, etc. de las dos áreas de conocimiento descritas, y que se detallan en el estado del arte de la presente tesis.

Además, para la la investigación ha sido muy valiosa la información que se me ha facilitado sobre las presentaciones realizadas en el Master Course in Laboratory Animal Science and Welfare de la Universidad Autónoma de Barcelona 2015 y que tienen relación con la construcción de este tipo de instalaciones. 


\section{TOMA DE DATOS}

Una vez realizado el estudio de campo, el siguiente paso ha consistido en analizar la forma de documentar los datos obtenidos para representarlos, analizarlos, poder compararlos, y así, dar respuesta al objetivo planteado.

\subsection{Integración de la información}

La toma de datos se ha materializado a través de la elaboración de cuatro fichas tipo prediseñadas y una encuesta de opinión anónima. Las fichas tipo estandarizadas lo componen: la presentación del instituto, las características principales del centro de experimentación animal, la documentación gráfica I estandarizada y la documentación gráfica II estandarizada.

El objetivo de estas fichas ha sido sistematizar el estudio de cada centro seleccionado para su análisis y que han permitido identificar y extraer la información más relevante necesaria para llevar a cabo el estudio. Así mismo, registrar los datos de cada uno de los centros de experimentación animal sometidos a estudio de una manera homogénea, ha proporcionado un método adecuado para relacionarlos entre sí y hacer una puesta en común de los resultados obtenidos, para su posterior análisis.

Para facilitar la identificación de la toma de datos y el posterior análisis, cada instituto queda referenciado por la siguiente codificación de siglas:

\begin{tabular}{|c|c|c|}
\hline iPAZ & _Instituto de Investigación Sanitaria Hospital La Paz & Madrid \\
\hline+12 & Instituto de Investigación Hospital 12 De Octubre & Madrid \\
\hline SGM & _Instituto de Investigación Sanitaria Gregorio Marañón & Madrid \\
\hline IRICYS & _Instituto Ramón y Cajal de Investigación Sanitaria & Madrid \\
\hline IIS Biodonostia _ & _Instituto de Investigación Sanitaria Biodonostia & Gipuzkoa \\
\hline IIS Biocruces & _Instituto de Investigación Sanitaria Biocruces & _Bizkaia \\
\hline IISA & _IIS Aragón Instituto de Investigación Sanitaria Aragón & Zaragoza \\
\hline VHIR & _IR-HUVH Institut de Recerca Hospital Universitari Vall D’hebron & Barcelona \\
\hline IGTP & _Institut d'investigació en Ciéncies de la Salut Germans Trias I Pujol & Barcelona \\
\hline & _Fundación para la Investigación del Hospital Universitario La Fe & - Valencia \\
\hline
\end{tabular}


Cada una de las fichas que componen la toma de datos de cada instituto está compuesta por cuatro campos (Figura 01):

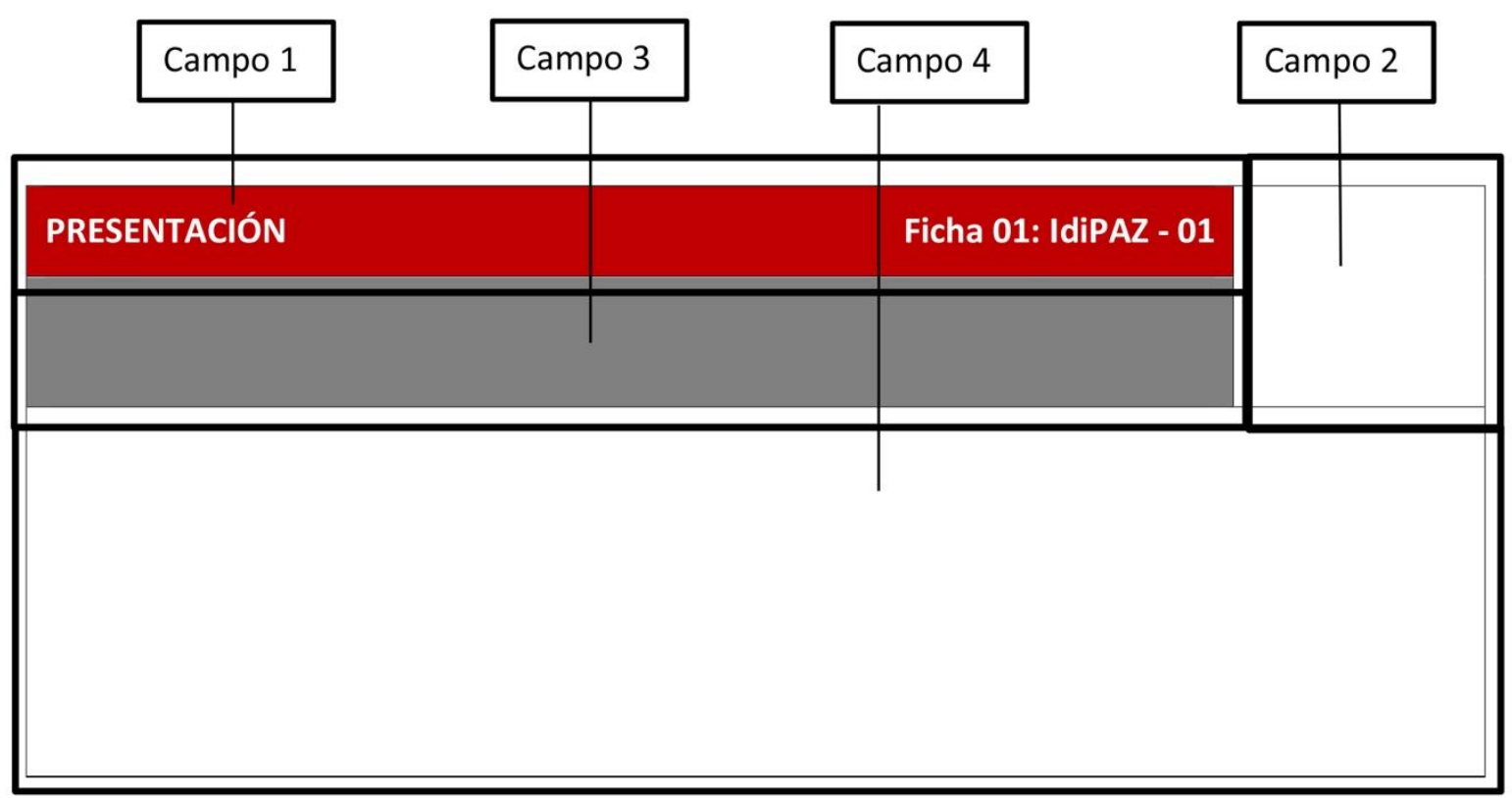

Figura 01. Campos ficha tipo toma de datos.

Fuente. Elaboración propia.

Campo 1: Representada en trama granate recoge los siguientes datos generales sobre el centro de experimentación:

- El tipo de ficha que es: presentación, características principales, documentación gráfica I o documentación gráfica II.

- El número de ficha: cada ficha tiene una codificación numérica en la que queda también identificado el instituto con sus siglas al que le sigue un código numérico que identifica el tipo de ficha que es (01: presentación del instituto, 02: características principales, 03: documentación gráfica I, 04: documentación gráfica II).

De esta manera, la Ficha 01: IdiPAZ - 01 identifica la ficha №1 que corresponde al instituto Idipaz y recoge la información relacionada con la presentación del instituto.

Campo 2: corresponde al cajetín de la parte derecha en la que se representa el logotipo del instituto de investigación sanitaria, lo cual permite una localización sencilla del centro.

Campo 3: representada en trama gris recoge la identificación completa del instituto al que pertenece el centro de experimentación animal, así como el resumen de la información general que aporta la ficha.

Campo 4: recoge el contenido específico de la ficha correspondiente a cada centro de experimentación animal. 
De esta manera, las cuatro fichas tipo de cada instituto y la encuesta de opinión anónima que comprenden la toma de datos son las siguientes:

1. Ficha 01: presentación del instituto. En ella se hace una breve presentación del instituto de investigación sanitaria y recoge los siguientes conceptos: la acreditación del instituto, su composición, su misión y las principales áreas de investigación (Figura 02).

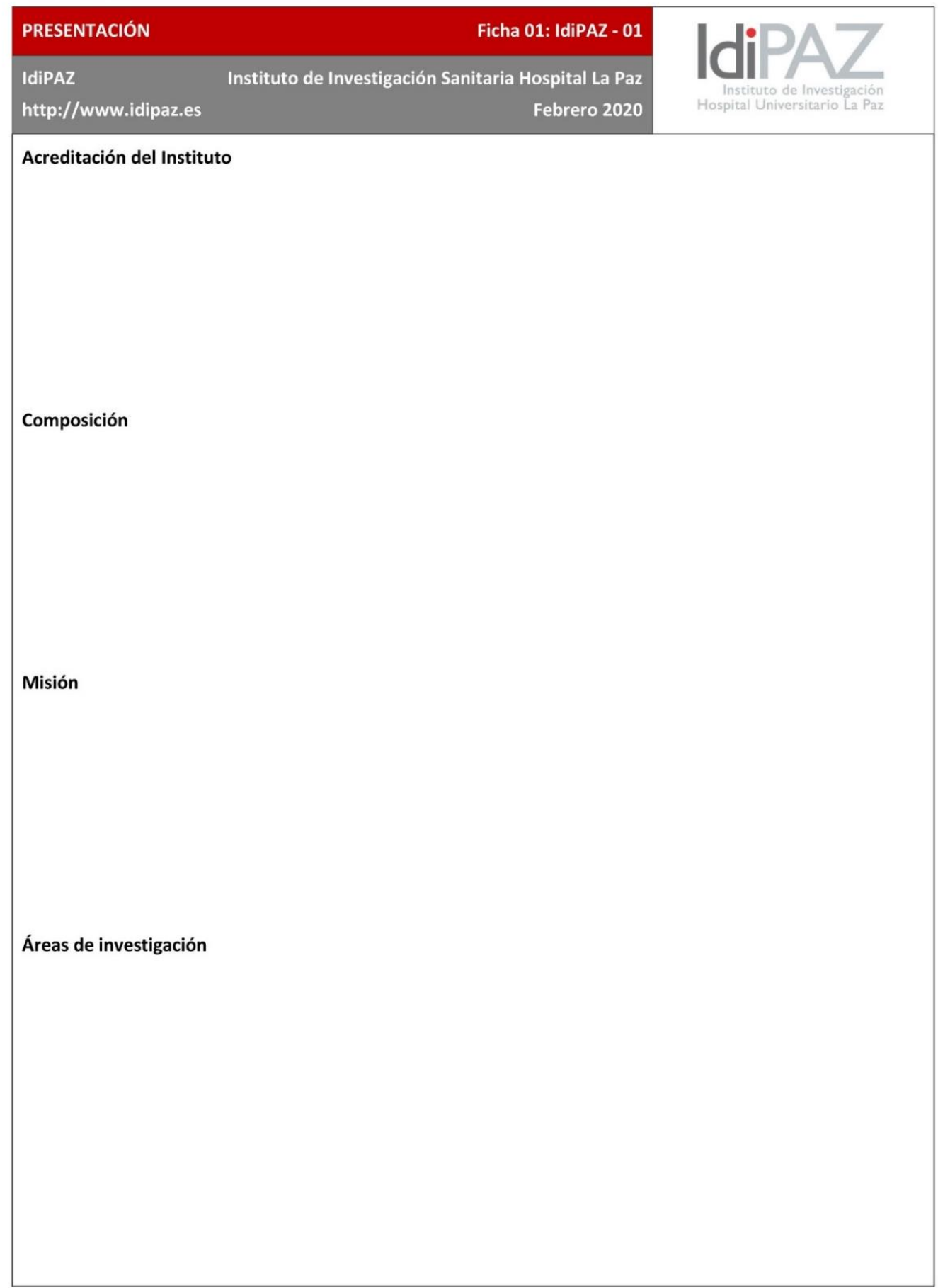

Figura 02. Ficha presentación tipo.

Fuente. Elaboración propia. 
2. Ficha 02: características principales. Para la toma de datos de las características principales del centro de experimentación animal de cada instituto se ha elaborado una ficha tipo en la que han quedado identificadas: los datos de identificación del instituto de investigación sanitaria, así como las características generales, constructivas y de organización del instituto, del centro de experimentación animal, del área de experimentación animal grande y pequeño, así como de las unidades principales que la componen (Figura 03).

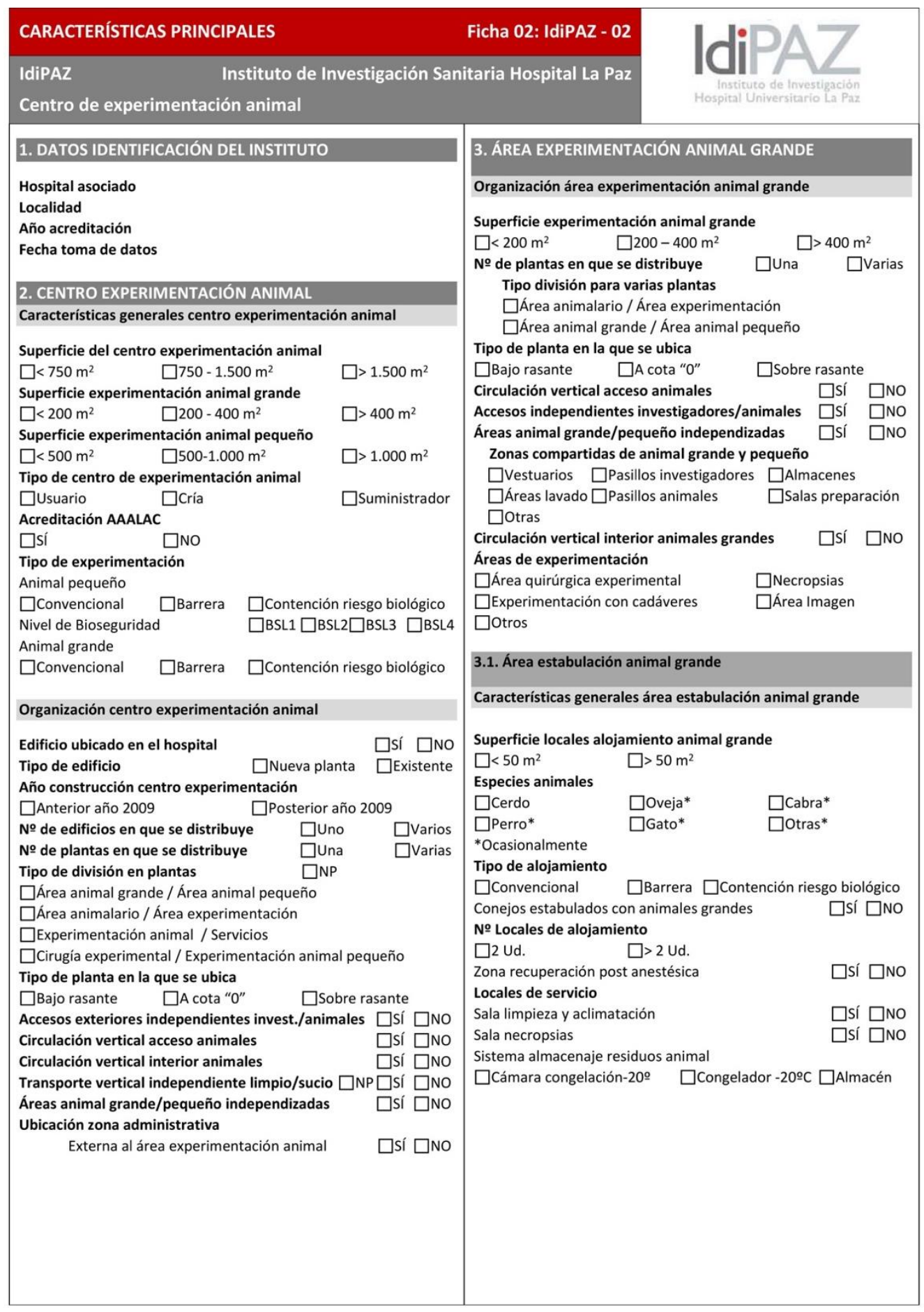

Ficha características principales tipo $1 / 3$

Figura 03. Ficha características principales tipo.

Fuente. Elaboración propia. 


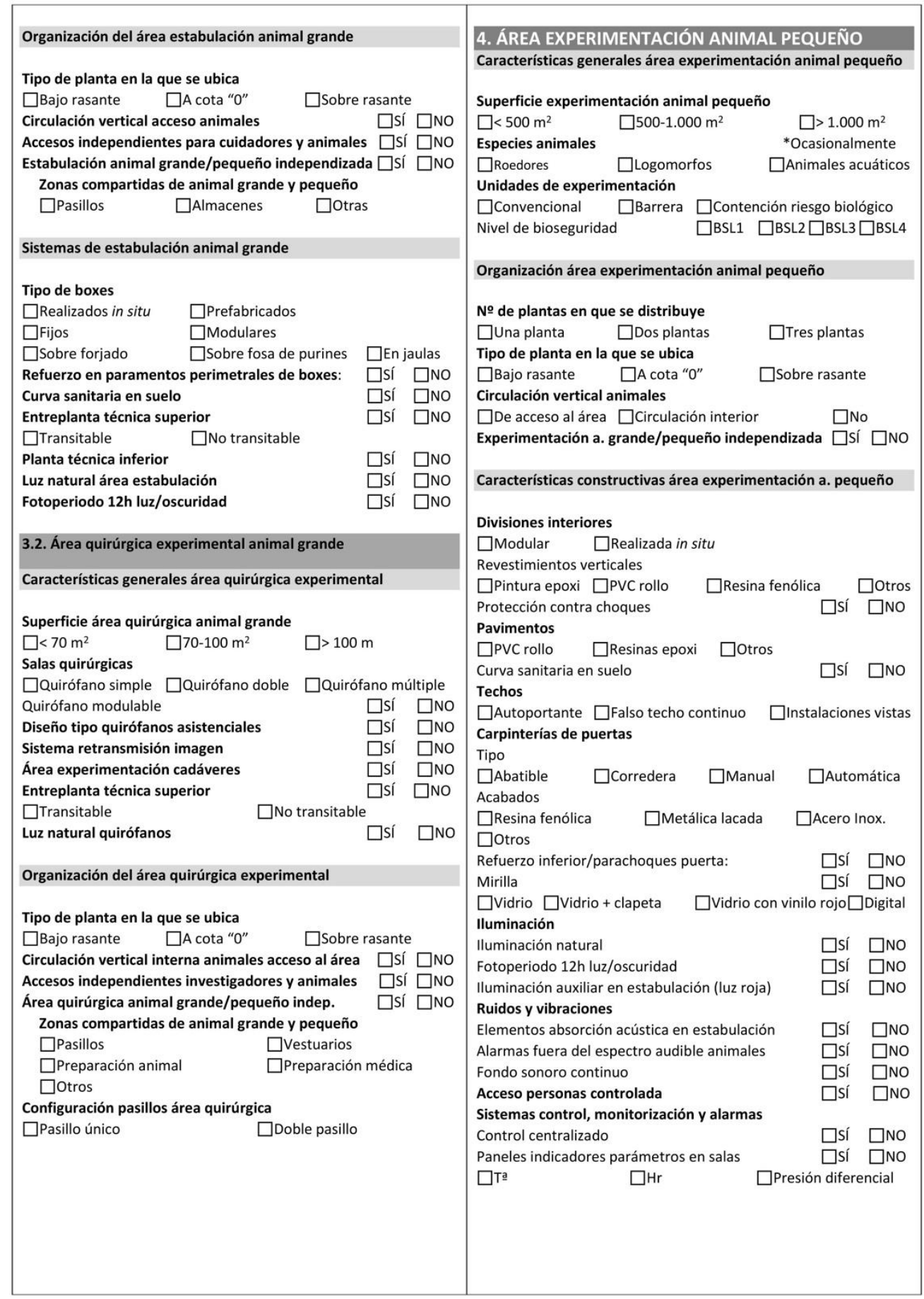

Ficha características principales tipo 2/3 


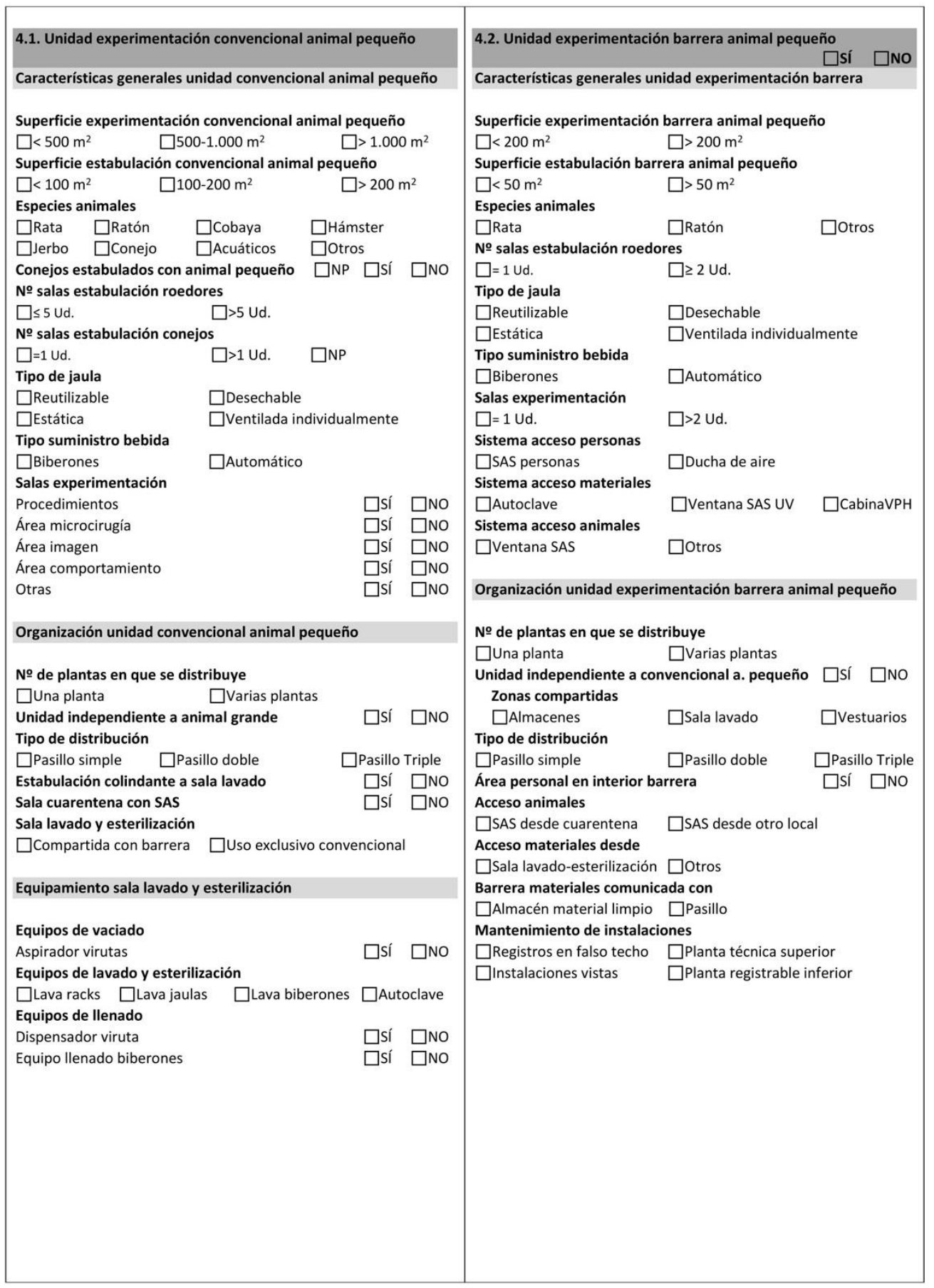

Ficha características principales tipo $3 / 3$ 
3. Ficha 03: documentación gráfica I. A partir de la documentación gráfica de las plantas de distribución obtenidas de cada uno de los centros, con el fin de facilitar su interpretación, se han elaborado unos planos estandarizados, de manera que en la denominada Documentación gráfical se identifica mediante código de colores el área funcional al que pertenece cada zona (Figura 04).

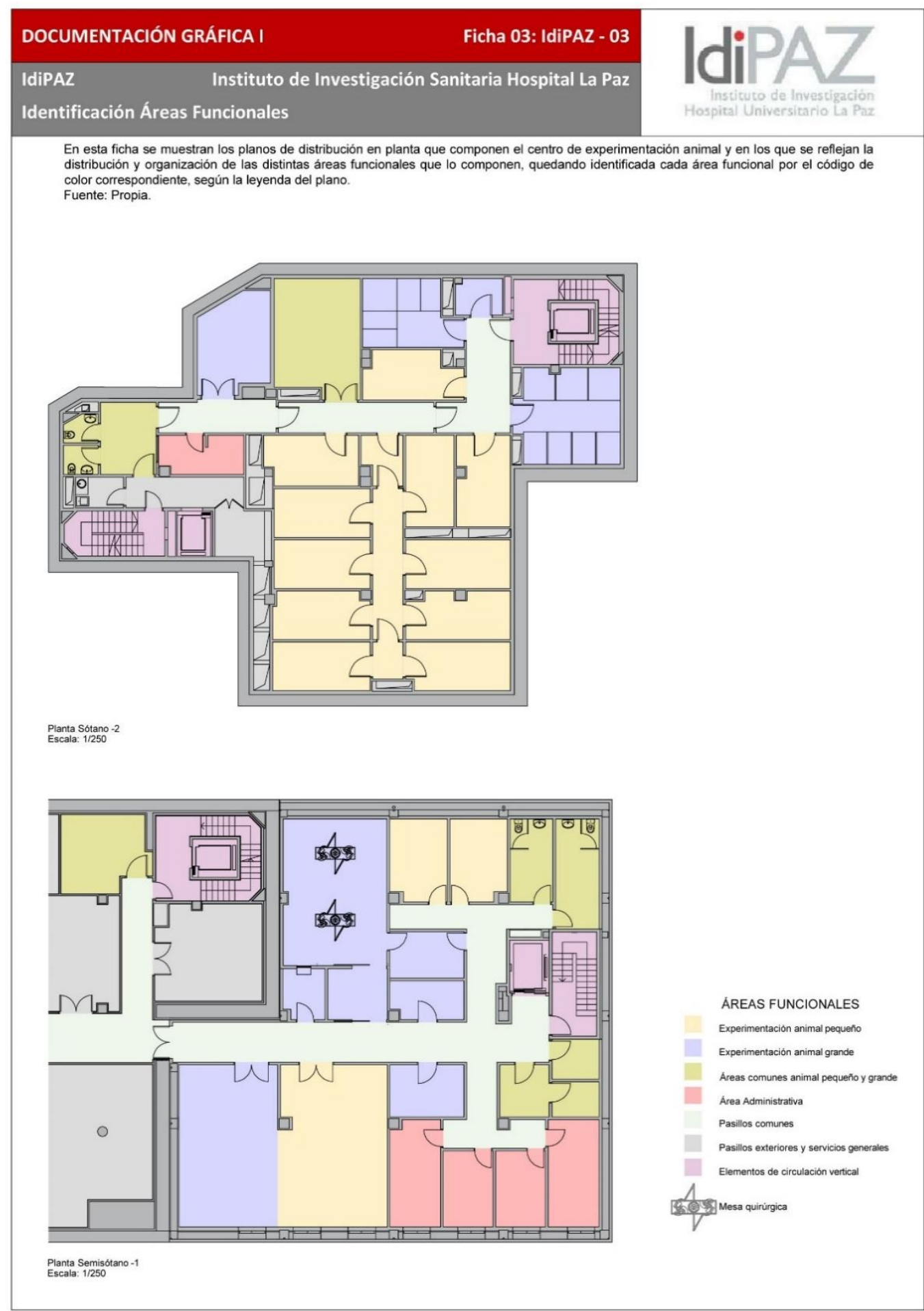

Figura 04. Ficha documentación gráfica I tipo.

Fuente. Elaboración propia. 
4. Ficha 04: documentación gráfica II. A partir de la documentación gráfica de las plantas de distribución obtenidas de cada uno de los centros, con el fin de facilitar su interpretación, se han elaborado unos planos estandarizados, de manera que en la denominada Documentación gráficall se ha identificado por código de colores y tramas el tipo de local que es y por código numérico el uso del local (Figura 05).

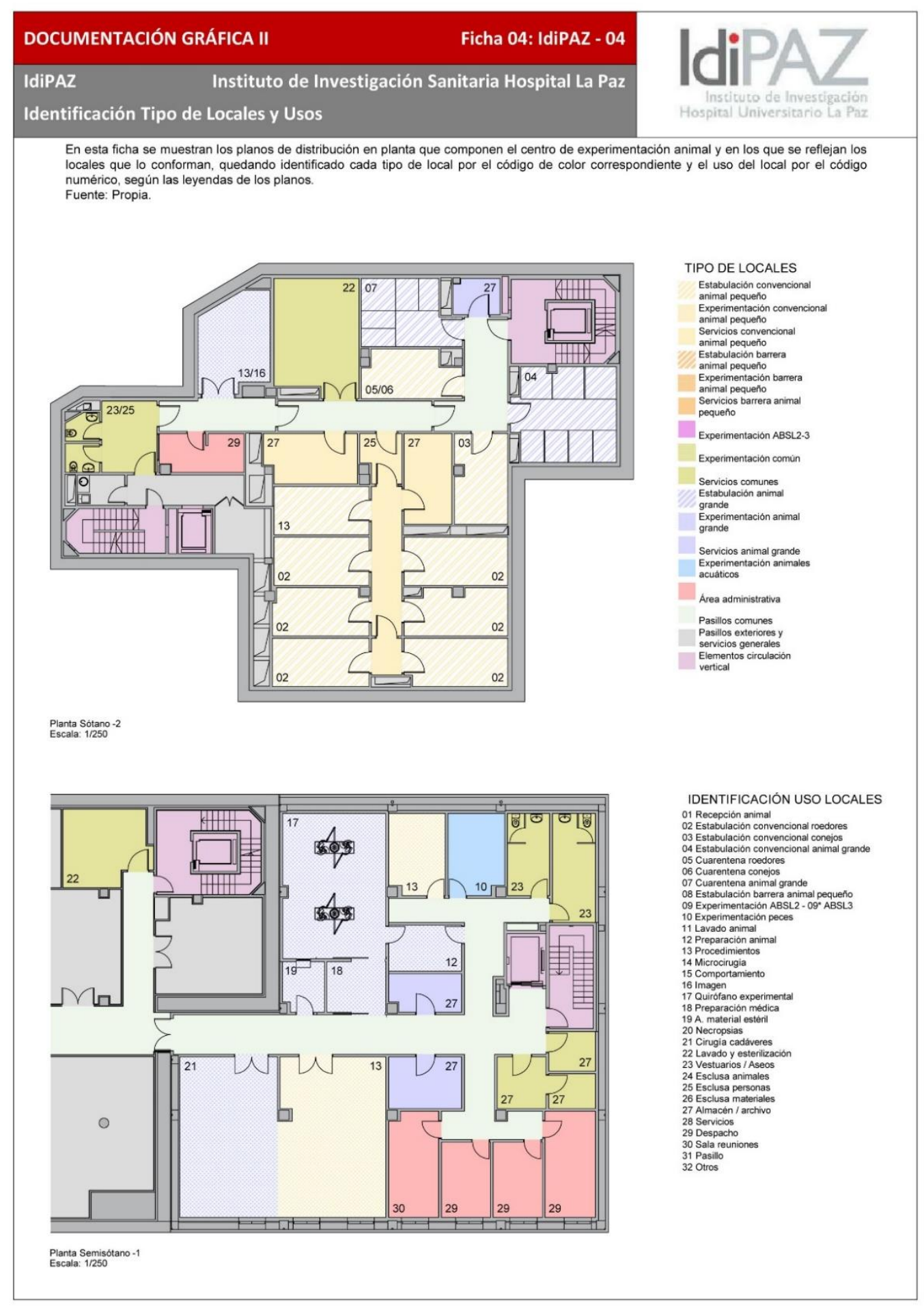

Figura 05. Ficha documentación gráfica II tipo.

Fuente. Elaboración propia. 
5. Encuesta de opinión anónima. El trabajo de campo se ha completado con las entrevistas realizadas a los usuarios o personas conocedoras de las instalaciones. Para recoger su parecer se ha elaborado una encuesta de opinión tipo con preguntas mixtas, ya que existe una combinación de cerradas y abiertas que nos ha permitido conocer la visión de los responsables o usuarios sobre la organización, diseño, características constructivas y equipamiento de sus propios centros de experimentación animal. Con el fin de mantener el anonimato de las personas encuestadas, estas fichas se recopilan todas juntas al final de la toma de datos, de manera que la numeración de la encuesta no mantiene una correspondencia con el orden asignado al instituto de investigación (Figura 06).

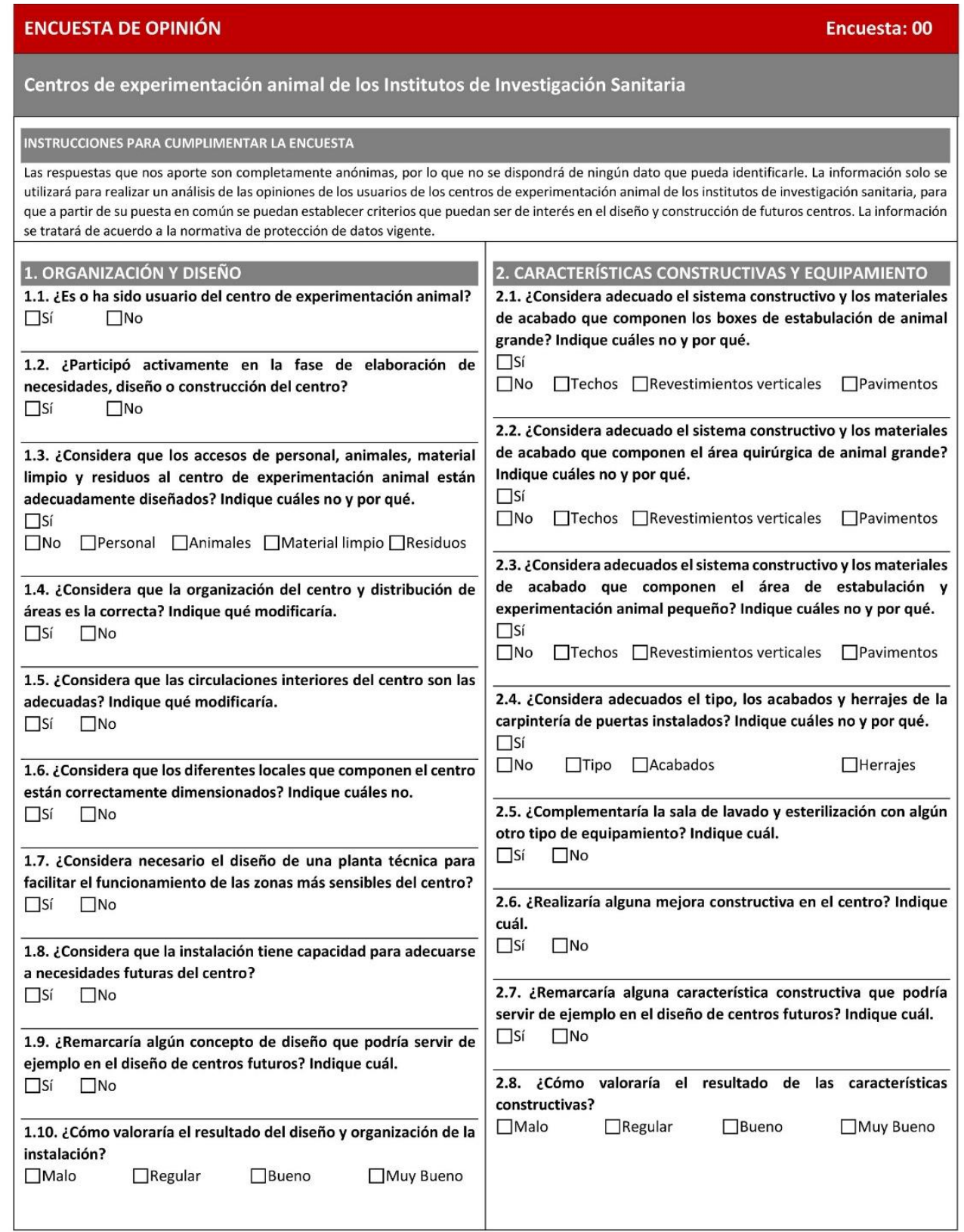

Figura 06. Ficha encuesta de opinión anónima tipo.

Fuente. Elaboración propia. 


\subsection{Toma de datos realizada}

A continuación, se presenta la toma de datos realizada en los diez centros de experimentación animal de los Institutos de Investigación Sanitaria Acreditados analizados en la tesis. 


\section{PRESENTACIÓN}

IdiPAZ

http://www.idipaz.es

\section{Ficha 01: IdiPAZ - 01}

Instituto de Investigación Sanitaria Hospital La Paz

Febrero 2020

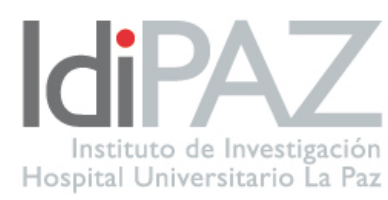

\section{Acreditación del Instituto}

El Instituto de Investigación Sanitaria del Hospital Universitario La Paz (IdiPAZ) se constituyó formalmente el 15 de diciembre de 2009, y un año después en abril de 2010 pasaría a ser el primer instituto acreditado por el Instituto de Salud Carlos III de la Comunidad de Madrid y el octavo de España, siendo reacreditado en mayo de 2015, durante un periodo de cinco años.

\section{Composición}

El IdiPAZ se concibe como un espacio de investigación biomédica fruto de la relación entre el Hospital Universitario La Paz, el Hospital Universitario de Fuenlabrada, la Universidad Autónoma de Madrid y la Fundación para la Investigación Biomédica del Hospital Universitario La Paz.

\section{Misión}

IdiPAZ trabaja para constituirse como un referente en la investigación biomédica traslacional, nacional e internacional, fomentando la investigación de calidad a nivel básico, clínico, epidemiológico y de servicios para la salud. Además, está encaminado a favorecer y desarrollar programas y proyectos de investigación o formación de investigadores, con especial atención de la formación científica de profesionales en metodología de la investigación y de las necesidades del ámbito de Atención Primaria.

\section{Áreas de investigación}

La actividad de los grupos de investigación del instituto se centran en seis áreas estratégicas: Área de Neurociencias; Área de Cardiovascular; Área de Enfermedades Infecciosas e Inmunidad; Área de Patologías de Grandes Sistemas; Área de Cáncer y Genética Molecular Humana; y Área de Cirugía, Transplantes y Tecnologías para la Salud. 


\section{CARACTERÍSTICAS PRINCIPALES}

Instituto de Investigación Sanitaria Hospital La Paz

IdiPAZ

ción animal

Ficha 02: IdiPAZ - 02

Centro de experimentación animal

\section{DATOS IDENTIFICACIÓN DEL INSTITUTO}

\section{Hospital asociado}

Localidad

Año acreditación

Fecha toma de datos

Hospital Universitario La Paz

Madrid

2010

2016

\section{CENTRO EXPERIMENTACIÓN ANIMAL}

Características generales centro experimentación animal

Superficie del centro experimentación animal

$\square<750 \mathrm{~m}^{2} \quad \bigotimes 750-1.500 \mathrm{~m}^{2}$
Superficie experimentación animal grande

$\square<200 \mathrm{~m}^{2} \quad$ Q200-400 $\mathrm{m}^{2}$

$\square>1.500 \mathrm{~m}^{2}$

Superficie experimentación animal pequeño

$\bigotimes<500 \mathrm{~m}^{2} \quad \square 500-1.000 \mathrm{~m}^{2}$

Tipo de centro de experimentación animal

\Usuario $\quad$ \Cría

Acreditación AAALAC

$\square$ Sí $\quad$ \NO

Tipo de experimentación

Animal pequeño

\Convencional $\square$ Barrera $\square$ Contención riesgo biológico

Nivel de Bioseguridad $\square$ BSL1 $\square$ BSL2 $\square$ BSL3 $\square$ BSL4

Animal grande

凶Convencional $\square$ Barrera $\square$ Contención riesgo biológico

\section{Organización centro experimentación animal}

Edificio ubicado en el hospital

Tipo de edificio

Año construcción centro experimentación

$\square$ Anterior año 2.009

\Posterior año 2009

№ de edificios en que se distribuye $\quad$ Uno $\square$ Varios

№ de plantas en que se distribuye $\square$ Una $\quad$ Varias

Tipo de división en plantas $\quad \square \mathrm{NP}$

$\square$ Área animal grande / Área animal pequeño

囚Área animalario / Área experimentación

$\square$ Experimentación animal /Servicios

$\square$ Cirugía experimental / Experimentación animal pequeño

Tipo de planta en la que se ubica

$\triangle$ Bajo rasante $\square$ A cota "0" $\square$ Sobre rasante

Accesos exteriores independientes invest./animales $\bigotimes$ Sí $\square$ NO

Circulación vertical acceso animales

Circulación vertical interior animales

冈sí $\square$ NO

凶sí $\square$ NO

Transporte vertical independiente limpio/sucio $\square$ NP $\square$ Sí $\bigotimes N O$

Áreas animal grande/pequeño independizadas

Ubicación Zona administrativa

$\square$ sí $\bigotimes$ NO

Externa al área experimentación animal

\section{3. ÁREA EXPERIMENTACIÓN ANIMAL GRANDE}

Organización área experimentación animal grande

Superficie experimentación animal grande
$\square<200 \mathrm{~m}^{2}$
\200 - $400 \mathrm{~m}^{2}$
$\square$ Una
$\square>400 \mathrm{~m}^{2}$
№ de plantas en que se distribuye
\Varias

Tipo división para varias plantas

\Área animalario / Área experimentación

$\square$ Área animal grande / Área animal pequeño

Tipo de plantas en la que se ubica

Bajo rasante $\square$ A cota “0" $\square$ Sobre rasante

Circulación vertical acceso animales $\quad$ SI $\square$ NO

Accesos independientes investigadores/animales $\bigotimes \mathrm{SI} \quad \square \mathrm{NO}$

Áreas animal grande/pequeño independizadas $\square S I \quad$ \NO

Zonas compartidas de animal grande y pequeño

\Vestuarios $\bigotimes$ Pasillos investigadores $\bigotimes$ Almacenes

\Áreas lavado $\triangle$ Pasillos animales $\square$ Salas preparación

$\square$ otras

Circulación vertical interior animales grandes

\SI $\square$ NO

Áreas de experimentación

\Área quirúrgica experimental

囚Experimentación con cadáveres

$\square$ otros

\section{$\square$ Necropsias \\ $\square$ Área Imagen}

\section{1. Área estabulación animal grande}

Características generales área estabulación animal grande

Superficie locales alojamiento animal grande

$\bigotimes<50 \mathrm{~m}^{2} \quad \square>50 \mathrm{~m}^{2}$

Especies animales

$\triangle$ Cerdo $\quad$ Doveja* $\quad$ Cabra*

\Perro* $\quad$ Gato* $\quad \square$ Otras*

*Ocasionalmente

Tipo de alojamiento

冈Convencional $\square$ Barrera $\square$ Contención riesgo biológico Conejos estabulados con animales grandes $\quad \square \mathrm{SI}$ № Locales de alojamiento

\2 Ud $\square>2$ Ud

Zona recuperación post anestésica

Locales de servicio

Sala limpieza y aclimatación

$\triangle \mathrm{SI} \square \mathrm{NO}$

Sala necropsias

Sistema almacenaje residuos animal

$\square \mathrm{SI} \bigotimes \mathrm{NO}$

$\square \mathrm{SI} \bigotimes \mathrm{NO}$

\Cámara congelación-20ㅇ $\square$ Congelador -20ㄷ $\square$ Almacén 


\section{Organización del área estabulación animal grande}

Tipo de planta en la que se ubica

$\triangle$ Bajo rasante $\square$ A cota " 0 "

$\square$ Sobre rasante

Circulación vertical acceso animales

凶sí $\square$ No

Accesos independientes para cuidadores y animales $\bigotimes \mathrm{Sí} \square \mathrm{NO}$ Estabulación animal grande/pequeño independizada $\square$ sí $\bigotimes N O$ Zonas compartidas de animal grande y pequeño

\Pasillos $\quad$ Xilmacenes $\quad$ Otras

\section{Sistemas de estabulación animal grande}

\section{Tipo de boxes}

$\bigotimes$ Realizados in situ

\section{$\square$ Prefabricados}

$\square$ Fijos

\section{冈Modulares}

冈Sobre forjado $\square$ Sobre fosa de purines $\square$ En jaulas Refuerzo en paramentos perimetrales de boxes: $\square$ sí $\bigotimes N O$ Curva sanitaria en suelo Entreplanta técnica superior
$\square$ Transitable
\No transitable

Planta técnica inferior

\sí $\square \mathrm{NO}$

凶sí $\square$ No

Luz natural área estabulación

Fotoperiodo $12 \mathrm{~h}$ luz/oscuridad

凶sí $\square$ NO

$\square$ sí $\quad \mathrm{NO}$

\sí $\square$ NO

\section{2. Área quirúrgica experimental animal grande}

\section{Características generales área quirúrgica experimental}

Superficie área quirúrgica animal grande

\begin{tabular}{|c|c|}
\hline$\square 70-100 \mathrm{~m}^{2}$ & $\square>100 \mathrm{~m}$ \\
\hline \multicolumn{2}{|l|}{ Salas quirúrgicas } \\
\hline$\square$ Quirófano simple QQuirófano doble & $\square$ Quirófano múltiple \\
\hline Quirófano modulable & $\square$ sí $\quad$ NNO \\
\hline Diseño tipo quirófanos asistenciales & $\square$ NO \\
\hline Sistema retransmisión imagen & 凶NO \\
\hline Área experimentación cadáveres & $\square$ NO \\
\hline Entreplanta técnica superior & 凶sí $\square$ No \\
\hline
\end{tabular}

$\square$ Transitable $\quad$ No transitable

Luz natural quirófanos

$\square \mathrm{SI} \quad$ NNO

\section{Organización del área quirúrgica experimental}

Tipo de planta en la que se ubica

\Bajo rasante $\square$ A cota “0" $\square$ Sobre rasante

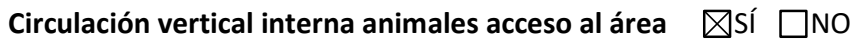

Accesos independientes investigadores y animales $\bigotimes \mathrm{Sí} \square$ NO

Área quirúrgica animal grande/pequeño indep.

$\square$ sí $\bigotimes$ NO

Zonas compartidas de animal grande y pequeño
$\triangle$ Pasillos
QVestuarios
$\square$ Preparación animal
$\square$ Preparación médica

\Otros

Configuración pasillos área quirúrgica

邓Pasillo único $\square$ Doble pasillo
4. ÁREA EXPERIMENTACIÓN ANIMAL PEQUEÑO

Características generales área experimentación animal pequeño

Superficie experimentación animal pequeño

$\bigotimes<500 \mathrm{~m}^{2} \quad \square 500-1.000 \mathrm{~m}^{2}$

$\square>1.000 \mathrm{~m}^{2}$

Especies animales

\Roedores $\quad$ LLogomorfos

*Ocasionalmente

Unidades de experimentación

\Convencional $\square$ Barrera $\square$ Contención riesgo biológico

Nivel de bioseguridad

$\square$ BSL1 $\square$ BSL2 $\square$ BSL3 $\square$ BSL4

\section{Organización área experimentación animal pequeño}

№ de plantas en que se distribuye

$\square$ Una planta $\quad$ Dos plantas $\square$ Tres plantas

Tipo de planta en la que se ubica

\Bajo rasante $\square$ A cota " 0 " $\square$ Sobre rasante

Circulación vertical animales

\De acceso al área $\bigotimes$ Circulación interior $\square$ No

Experimentación a. grande/pequeño independizada $\square$ sí $\bigotimes N O$

Características constructivas área experimentación a. pequeño

Divisiones interiores

$\square$ Modular $\quad$ Realizada in situ

Revestimientos verticales

$\square$ Pintura epoxi $\triangle$ PVC rollo $\square$ Resina fenólica $\square$ otros

Protección contra choques

Pavimentos

\PVC rollo $\square$ Resinas epoxi $\square$ Otros

Curva sanitaria en suelo

\sí $\square$ NO

Techos

$\square$ Autoportante $\bigotimes$ Falso techo continuo $\square$ Instalaciones vistas Carpinterías de puertas

Tipo

\Abatible $\square$ Corredera $\quad$ Manual $\square$ Automática

Acabados

$\square$ Resina fenólica $\quad$ Metálica lacada $\square$ Acero Inox

Refuerzo inferior/parachoques puerta:

$\triangle \mathrm{SI} \square \mathrm{NO}$ Mirilla

\SI $\square$ NO

$\square$ Vidrio $\square$ Vidrio + clapeta $\square$ Vidrio con vinilo rojo $\bigotimes$ Digital lluminación

lluminación natural

Fotoperiodo $12 \mathrm{~h}$ luz/oscuridad

$\square$ sí $\quad \mathrm{NO}$

Ruidos y vibraciones

Elementos absorción acústica en estabulación $\square$ sí $\quad$ \NO

Alarmas fuera del espectro audible animales $\square$ sí $\quad$ \NO

Fondo sonoro continuo

Acceso personas controlada

$\square$ sí $\quad$ NO

Sistemas control, monitorización y alarmas

Control centralizado

\sí $\square$ NO

Paneles indicadores parámetros en salas

$\square$ Ta

$\square \mathrm{Hr}$

邓sí $\square$ No

$\square$ sí $\bigotimes N O$

$\square$ Presión diferencial 


\subsection{Unidad experimentación convencional animal pequeño \\ Características generales unidad convencional animal pequeño}

Superficie experimentación convencional animal pequeño
$\bigotimes<500 \mathrm{~m}^{2}$
$\square 500-1.000 \mathrm{~m}^{2}$
$\square>1.000 \mathrm{~m}^{2}$

Superficie estabulación convencional animal pequeño

$\square<100 \mathrm{~m}^{2} \quad$ \100-200 $\mathrm{m}^{2} \quad \square>200 \mathrm{~m}^{2}$

Especies animales

\Rata $\bigotimes$ Ratón $\bigotimes$ Cobaya $\square$ Hámster

\Jerbo $\quad$ Conejo $\quad$ Acuáticos $\square$ Otros

Conejos estabulados con animal pequeño $\square$ NP $\square$ sí $\quad$ NO

№ salas estabulación roedores

$\square \leq 5$ Ud $\quad \square>5$ Ud

№ salas estabulación conejos

$\bigotimes=1$ Ud $\square>1$ Ud $\square$ NP

Tipo de jaula

\Reutilizable

$\square$ Desechable

囚stática

Tipo suministro bebida

冈Biberones

\Ventilada individualmente

Salas experimentación

Procedimientos

Área microcirugía

Área imagen

Área comportamiento

Otras

$\square$ Automático

\section{Organización unidad convencional animal pequeño}

№ de planta en que se distribuye

$\square$ Una planta $\quad$ VVarias plantas

Unidad independiente a animal grande

Tipo de distribución

\Pasillo simple $\square$ Pasillo doble

Estabulación colindante a sala lavado

Sala cuarentena con SAS

Sala lavado y esterilización

$\square$ Compartida con barrera $\quad$ Uso exclusivo convencional

\section{Equipamiento sala lavado y esterilización}

Equipos de vaciado

Aspirador virutas

Equipos de lavado y esterilización

$\square$ Lava racks $\bigotimes$ Lava jaulas $\square$ Lava biberones $\bigotimes$ Autoclave

Equipos de llenado

Dispensador viruta

Equipo llenado biberones
.2. Unidad experimentación barrera animal pequeño

$\square$ sí $\quad$ NO

Características generales unidad experimentación barrera

Superficie experimentación barrera animal pequeño
$\square<200 \mathrm{~m}^{2}$
$\square>200 \mathrm{~m}^{2}$

Superficie estabulación barrera animal pequeño

$\square<50 \mathrm{~m}^{2}$

$\square>50 \mathrm{~m}^{2}$

Especies animales

$\square$ Rata $\square$ Ratón $\square$ otros

№ salas estabulación roedores

$\square=1$ Ud

$\square \geq 2$ Ud

Tipo de jaula

$\square$ Reutilizable

$\square$ Estática

Tipo suministro bebida

$\square$ Biberones

$\square$ Desechable

$\square$ Ventilada individualmente

Salas experimentación

$\square=1$ Ud

Automático

Sistema acceso personas

$\square$ SAS personas $\square$ Ducha de aire

Sistema acceso materiales

$\square$ Autoclave

$\square$ Ventana SAS UV

$\square$ CabinaVPH

Sistema acceso animales

$\square$ Ventana SAS

$\square$ otros

Organización unidad experimentación barrera animal pequeño

№ de plantas en que se distribuye
$\square$ Una planta
$\square$ Varias plantas

Unidad independiente a convencional a. pequeño $\square$ sí $\square$ NO

Zonas compartidas

$\square$ Almacenes $\square$ sala lavado $\square$ Vestuarios

Tipo de distribución

$\square$ Pasillo simple $\square$ Pasillo doble $\square$ Pasillo Triple

Área personal en interior barrera $\square$ sí $\square$ NO

Acceso animales

$\square$ SAS desde cuarentena $\square$ SAS desde otro local

Acceso materiales desde

$\square$ Sala lavado-esterilización $\square$ Otros

Barrera materiales comunicada con

$\square$ Almacén material limpio $\square$ Pasillo

Mantenimiento de instalaciones

$\square$ Registros en falso techo $\square$ Planta técnica superior

$\square$ Instalaciones vistas $\square$ Planta registrable inferior 


\section{DOCUMENTACIÓN GRÁFICA I}

\section{Ficha 03: IdiPAZ - 03}

IdiPAZ

Instituto de Investigación Sanitaria Hospital La Paz

Identificación Áreas Funcionales

IdiPAZ

Instituto de Investigación
Hospital Universitario La Paz

En esta ficha se muestran los planos de distribución en planta que componen el centro de experimentación animal y en los que se reflejan la distribución y organización de las distintas áreas funcionales que lo componen, quedando identificada cada área funcional por el código de color correspondiente, según la leyenda del plano.

Fuente: Elaboración propia.

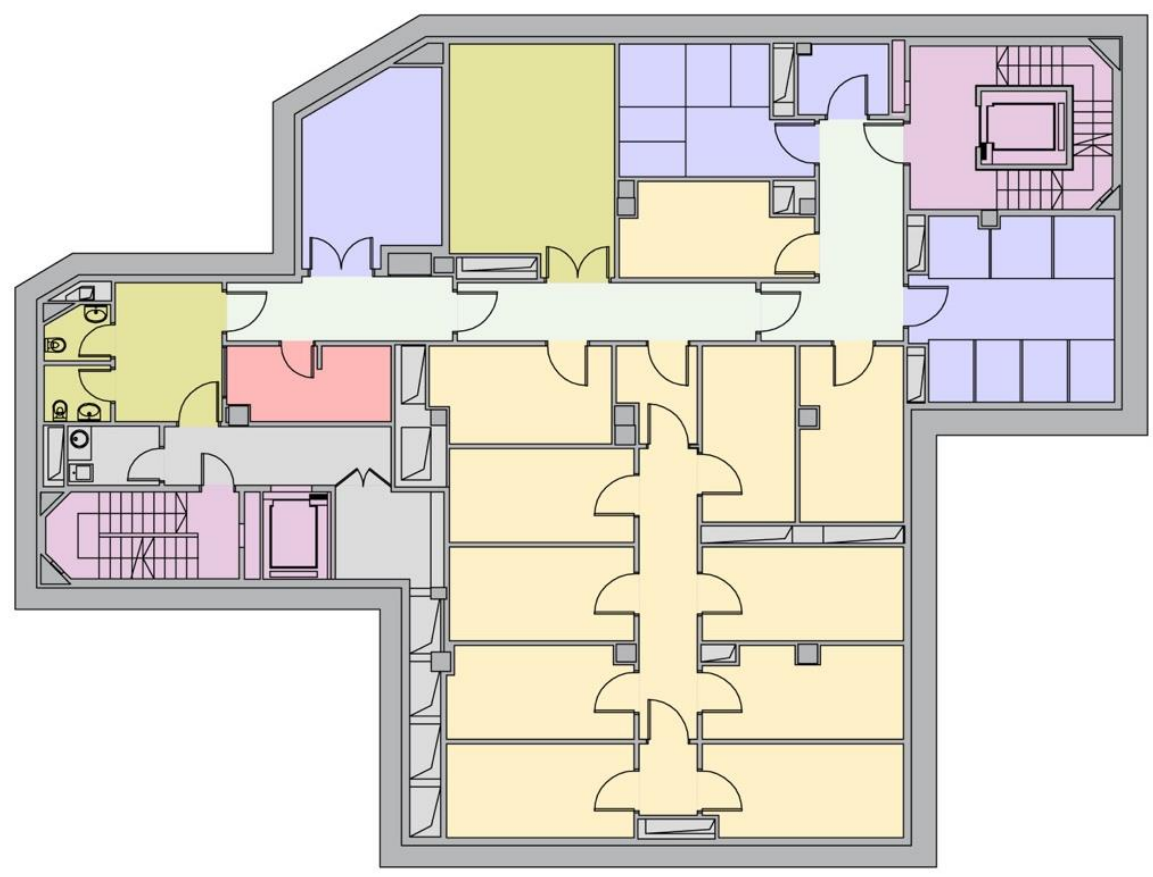

Planta Sótano -2

Escala: $1 / 250$

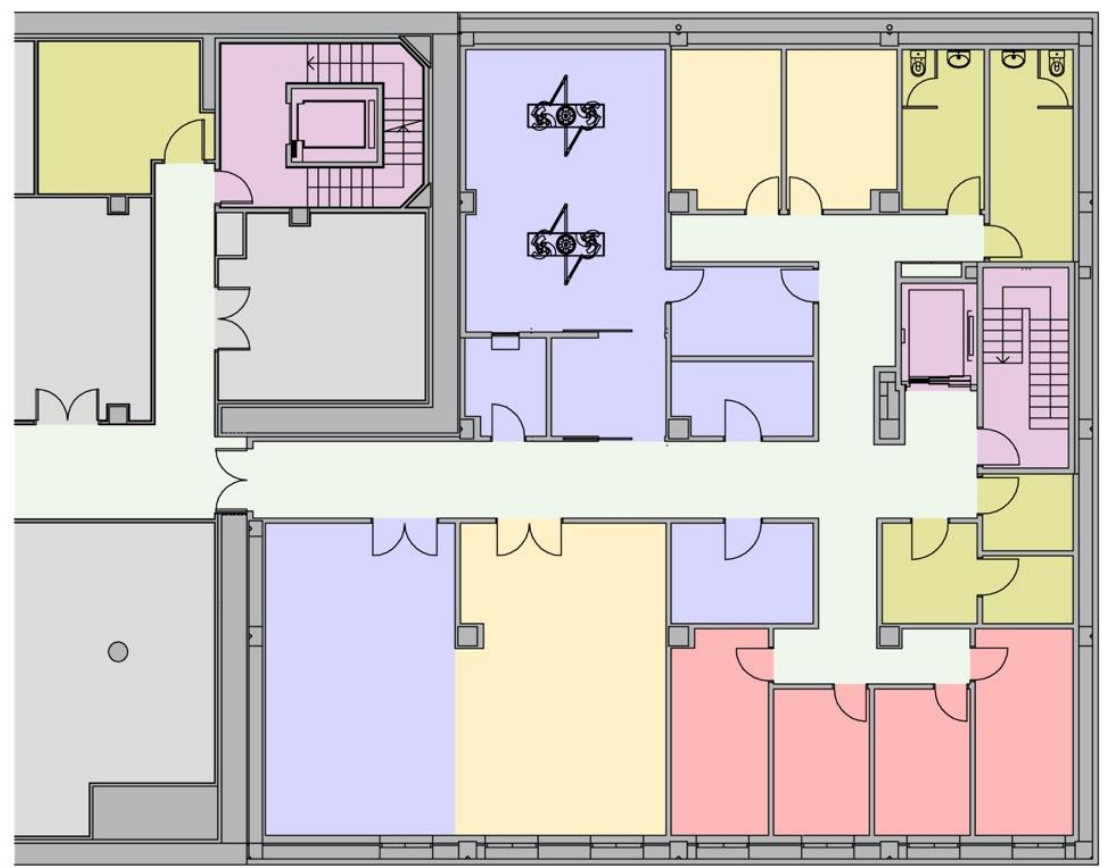

ÁREAS FUNCIONALES

Experimentación animal pequeño

Experimentación animal grande

Áreas comunes animal pequeño y grande

Area Administrativa

Pasillos comunes

Pasillos exteriores y servicios generales

Elementos de circulación vertical

Planta Semisótano -1

Escala: 1/250 


\section{DOCUMENTACIÓN GRÁFICA II}

\section{Ficha 04: IdiPAZ - 04}

IdiPAZ

\section{Instituto de Investigación Sanitaria Hospital La Paz}

\section{Identificación Tipo de Locales y Usos}

En esta ficha se muestran los planos de distribución en planta que componen el centro de experimentación animal y en los que se reflejan los locales que lo conforman, quedando identificado cada tipo de local por el código de color correspondiente y el uso del local por el código numérico, según las leyendas de los planos.

Fuente: Elaboración propia.

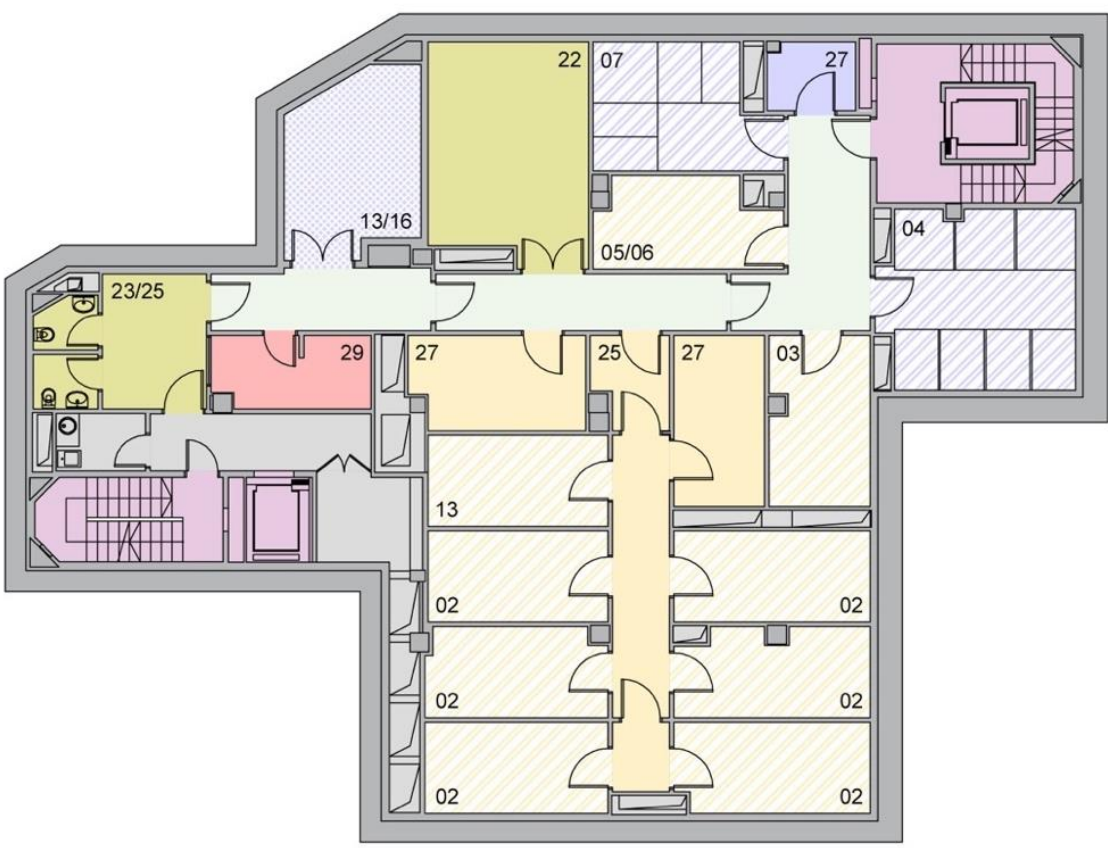

Planta Sótano -2

Escala: $1 / 250$

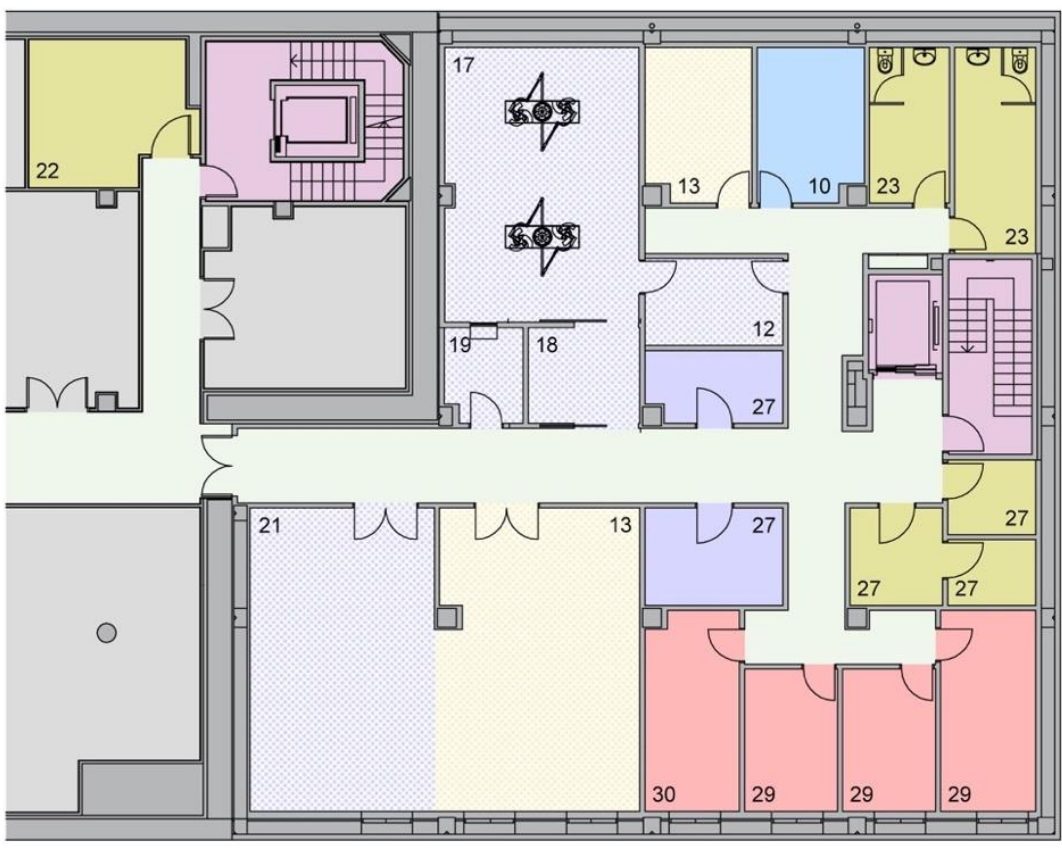

IDENTIFICACIÓN USO LOCALES

01 Recepción animal

02 Estabulación convencional roedores

03 Estabulación convencional conejos

04 Estabulacion convencional animal grande

05 Cuarentena roedores

07 Cuarentena animal grand

08 Estabulación barrera animal pequeño

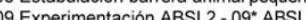

10 Experimentación peces

11 Lavado animal

12 Preparación animal

13 Procedimientos

15 Comportamien

16 Imagen

17 Quirófano experimenta

18 Preparación médica

19 A. material estén

20 Necropsias

21 Cirugia cadáveres

22 Lavado y esterilización

23 Vestuarios/Aseos

25 Esclusa personas

25 Esclusa personas

27 Almacén / archivo

28 Servicios

29 Despacho

30 Sala reuniones

31 Pasillo

32 Otros

Planta Semisótano -1

Escala: 1/250 


\section{PRESENTACIÓN}

$\mathrm{i}+12$

https://imas12.es/

\section{Ficha 05: i+12 - 01}

Instituto de Investigación Hospital 12 de Octubre

Febrero 2020

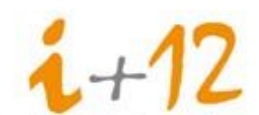

Instituto de Investigación Hospital 12 de Octubre

\section{Acreditación del Instituto}

El Instituto de Investigación Sanitaria Hospital 12 de Octubre (i+12) se creó el 15 de diciembre de 2009 por convenio firmado entre el Servicio Madrileño de Salud, la Universidad Complutense de Madrid, la Universidad Autónoma de Madrid, la Fundación para la Investigación Biomédica del Hospital 12 de Octubre y la Agencia de Formación, Investigación y Estudios Sanitarios de la Comunidad de Madrid "Pedro Laín Entralgo". Posteriormente, en 2015 se incorporaron el Centro de Investigaciones Energéticas, Medioambientales y Tecnológicas (CIEMAT) y la Universidad Europea, obteniendo la acreditación por parte del Instituto de Salud Carlos III con fecha 14 de marzo de 2011 y siendo reacreditado en el año 2016 por un periodo de cinco años.

\section{Composición}

El Hospital Universitario 12 de Octubre es el núcleo básico del Instituto, al que se asocia personal docente e investigador de la Universidad Complutense de Madrid, de la Universidad Autónoma de Madrid, del Centro de Investigaciones Energéticas, Medioambientales y Tecnológicas y de la Universidad Europea, así como de grupos de investigación de Atención Primaria de la Comunidad de Madrid, siendo la Fundación para la Investigación Biomédica de este hospital la entidad gestora del Instituto. El Instituto se concibe como una estructura dinámica e integradora, orientada a la colaboración y asociación con otros agentes y entidades afines de su entorno. En este contexto, el Instituto se encuentra actualmente en proceso de incorporación de nuevos socios que fortalecerán y complementarán la actividad desarrollada por sus profesionales.

\section{Misión}

El Instituto i+12 se concibe como una estructura funcional de investigación biomédica multidisciplinar y traslacional orientada a la investigación básica, clínica, epidemiológica y en servicios de salud.

\section{Áreas de investigación}

El Instituto i+12 ha elaborado y desarrollado una metodología de priorización de la investigación, tras cuya aplicación le ha permitido definir y organizar las líneas de trabajo de sus profesionales en nueve grandes áreas científicas: Cáncer; Enfermedades crónicas y trasplante; Enfermedades raras y de base genética; Epidemiología y evaluación de las tecnologías, servicios sanitarios y sistemas de información; Cardiovascular; Enfermedades

inflamatorias y trastornos inmunitarios; Enfermedades infecciosas y SIDA; Neurociencias y salud mental; y Área transversal. 


\section{CARACTERÍSTICAS PRINCIPALES}

Instituto de Investigación Hospital 12 de octubre

Ficha 06: i+12 - 02

$1+12$

Centro de experimentación animal

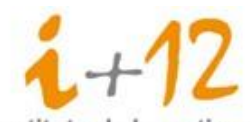

Instituto de Investigación Hospital 12 de Octubre

\section{DATOS IDENTIFICACIÓN DEL INSTITUTO}

Hospital asociado

Localidad

Año acreditación

Fecha toma de datos

Hospital Universitario 12 de octubre

Madrid

2011

2016

\section{CENTRO EXPERIMENTACIÓN ANIMAL}

Características generales centro experimentación animal

Superficie del centro experimentación animal
$\bigotimes<750 \mathrm{~m}^{2}$
$\square 750-1.500 \mathrm{~m}^{2}$

$\square>1.500 \mathrm{~m}^{2}$

Superficie experimentación animal grande

$\bigotimes<200 \mathrm{~m}^{2} \quad \square 200-400 \mathrm{~m}^{2}$

$\square>400 \mathrm{~m}^{2}$

Superficie experimentación animal pequeño

$\bigotimes<500 \mathrm{~m}^{2} \quad \square 500-1.000 \mathrm{~m}^{2}$

Tipo de centro de experimentación animal

\Usuario $\quad$ \Cría

Acreditación AAALAC

$\square$ Sí $\quad$ \NO

Tipo de experimentación

Animal pequeño

\Convencional $\square$ Barrera $\square$ Contención riesgo biológico

Nivel de Bioseguridad $\square$ BSL1 $\square$ BSL2 $\square$ BSL3 $\square$ BSL4

Animal grande

凶Convencional $\square$ Barrera $\square$ Contención riesgo biológico

\section{Organización centro experimentación animal}

Edificio ubicado en el hospital

Tipo de edificio $\square$ Nueva planta $\square$ Existente

Año construcción centro experimentación

\Anterior año $2.009 \square$ Posterior año 2009

№ de edificios en que se distribuye $\quad$ Uno $\square$ Varios

№ de plantas en que se distribuye $\quad$ Una $\square$ Varias

Tipo de división en plantas $\quad$ QNP

$\square$ Área animal grande / Área animal pequeño

$\square$ Área animalario / Área experimentación

$\square$ Experimentación animal /Servicios

$\square$ Cirugía experimental / Experimentación animal pequeño

Tipo de planta en la que se ubica

$\square$ Bajo rasante $\square$ A cota "0" $\square$ Sobre rasante

Accesos exteriores independientes invest./animales $\bigotimes \mathrm{SÍ} \square \mathrm{NO}$

Circulación vertical acceso animales $\square$ Sí $\square N O$

Circulación vertical interior animales $\square$ sí $\bigotimes N O$

Transporte vertical independiente limpio/sucio $\triangle N P \square$ Sí $\square$ NO

Áreas animal grande/pequeño independizadas $\square$ sí $\square$ NO

Ubicación zona administrativa

Externa al área experimentación animal

\section{3. ÁREA EXPERIMENTACIÓN ANIMAL GRANDE}

Organización área experimentación animal grande

Superficie experimentación animal grande
$\bigotimes<200 \mathrm{~m}^{2}$
$\square 200-400 \mathrm{~m}^{2}$
$\square>400 \mathrm{~m}^{2}$

№ de plantas en que se distribuye

\Una

$\square$ Varias

Tipo división para varias plantas

$\square$ Área animalario / Área experimentación

$\square$ Área animal grande / Área animal pequeño

Tipo de planta en la que se ubica

$\square$ Bajo rasante $\square$ A cota “0” $\square$ Sobre rasante

Circulación vertical acceso animales $\square$ sí $\quad$ NO

Accesos independientes investigadores/animales $\square s i ́ \quad \square$ NO

Áreas animal grande/pequeño independizadas $\square$ sí $\quad N \mathrm{NO}$

Zonas compartidas de animal grande y pequeño

\Vestuarios $\bigotimes$ Pasillos investigadores $\bigotimes$ Almacenes

\Áreas lavado $\triangle$ Pasillos animales $\bigotimes$ Salas preparación

$\square$ otras

Circulación vertical interior animales grandes

$\square$ sí $\quad \mathrm{NO}$

Áreas de experimentación

\Área quirúrgica experimental

$\square$ Experimentación con cadáveres

$\square$ otros

\section{1. Área estabulación animal grande}

Características generales área estabulación animal grande

Superficie locales alojamiento animal grande

$\bigotimes<50 \mathrm{~m}^{2} \quad \square>50 \mathrm{~m}^{2}$

Especies animales

$\triangle$ Cerdo

$\square$ Perro*

囚oveja*

$\square$ Gato*

\Cabra*

*Ocasionalmente

Tipo de alojamiento

\Convencional $\square$ Barrera $\square$ Contención riesgo biológico Conejos estabulados con animales grandes $\square$ sí $\square$ No № Locales de alojamiento

\2 Ud $\square>2$ Ud

Zona recuperación post anestésica

$\square$ Necropsias

$\square$ Área Imagen

Locales de servicio

Sala limpieza y aclimatación

Sala necropsias

Sistema almacenaje residuos animal

$\square$ Cámara congelación-20 $\quad$ Congelador -20C $\square$ Almacén 


\begin{tabular}{|c|c|c|c|}
\hline \multicolumn{4}{|c|}{ Sistemas de estabulación animal grande } \\
\hline \multicolumn{4}{|l|}{ Tipo de boxes } \\
\hline$\bigotimes$ Realizados in situ & $\square$ Prefabricados & & \\
\hline$\overline{\nabla F i j o s}$ & $\square$ Modulares & & \\
\hline 凶Sobre forjado & $\square$ Sobre fosa de purines & \multicolumn{2}{|c|}{$\square$ En jaulas } \\
\hline \multicolumn{2}{|c|}{ Refuerzo en paramentos perimetrales de boxes: } & $\square$ sí & \NO \\
\hline \multicolumn{2}{|c|}{ Curva sanitaria en suelo } & 凶sí & $\square$ NO \\
\hline \multicolumn{2}{|c|}{ Entreplanta técnica superior } & $\square$ sí & 区NO \\
\hline$\square$ Transitable & $\square$ No transitable & & \\
\hline \multicolumn{2}{|l|}{ Planta técnica inferior } & $\square$ sí & \NO \\
\hline \multicolumn{2}{|c|}{ Luz natural área estabulación } & 凶sí & $\square \mathrm{NO}$ \\
\hline \multicolumn{2}{|c|}{ Fotoperiodo $12 \mathrm{~h}$ luz/oscuridad } & $\square$ sí & 区NO \\
\hline
\end{tabular}

3.2. Área quirúrgica experimental animal grande

Características generales área quirúrgica experimental

Superficie área quirúrgica animal grande
$\bigotimes<70 \mathrm{~m}^{2}$
$\square 70-100 \mathrm{~m}^{2}$
$\square>100 \mathrm{~m}$

Salas quirúrgicas

$\square$ Quirófano simple Quirófano doble $\square$ Quirófano múltiple Quirófano modulable $\square$ sí \No Diseño tipo quirófanos asistenciales

Sistema retransmisión imagen

Área experimentación cadáveres

Entreplanta técnica superior

$\square$ Transitable

Luz natural quirófanos

冈No transitable

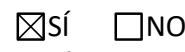

$\square$ sí $\quad$ NNO

$\square$ sí $\quad$ NO

\sí $\square$ NO

$\square$ sí $\quad$ NO

\section{Organización del área quirúrgica experimental}

Tipo de planta en la que se ubica
$\square$ Bajo rasante
$\triangle \mathrm{A}$ cota " 0 "
$\square$ Sobre rasante

Circulación vertical interna animales acceso al área $\square$ sí $\bigotimes N O$

Accesos independientes investigadores y animales $\square$ sí $\bigotimes N \mathrm{NO}$

Área quirúrgica animal grande/pequeño indep.

$\square$ sí $\bigotimes$ NO

Zonas compartidas de animal grande y pequeño
\Pasillos
\Vestuarios
冈Preparación animal
囚preparación médica

$\square$ Otros

Configuración pasillos área quirúrgica

$\square$ Pasillo único

\Doble pasillo
4. ÁREA EXPERIMENTACIÓN ANIMAL PEQUEÑO

Características generales área experimentación animal pequeño

Superficie experimentación animal pequeño

$\bigotimes<500 \mathrm{~m}^{2} \quad \square 500-1.000 \mathrm{~m}^{2} \quad \square>1.000 \mathrm{~m}^{2}$

Especies animales

\Roedores $\quad$ QLogomorfos $\square$ Animales acuáticos

Unidades de experimentación

\Convencional $\square$ Barrera $\square$ Contención Riesgo Biológico

Nivel de bioseguridad

$\square \mathrm{BSL} 1 \quad \square \mathrm{BSL} 2 \square \mathrm{BSL} 3 \square \mathrm{BSL} 4$

Organización área experimentación animal pequeño

№ de plantas en que se distribuye

\Una planta $\square$ Dos plantas $\square$ Tres plantas

Tipo de planta en la que se ubica

$\square$ Bajo rasante $\square$ A cota “0" $\square$ Sobre rasante

Circulación vertical animales

$\square$ De acceso al área $\square$ Circulación interior $\quad$ No

Experimentación a. grande/pequeño independizada $\square$ sí $\bigotimes N O$

Características constructivas área experimentación a. pequeño

Divisiones interiores

$\square$ Modular $\quad$ Realizada in situ

Revestimientos verticales

$\square$ Pintura epoxi $\triangle$ PVC rollo $\square$ Resina fenólica $\square$ Otros

Protección contra choques \sí $\square$ NO

Pavimentos

\PVC rollo $\square$ Resinas epoxi $\square$ otros

Curva sanitaria en suelo

\sí $\square$ No

Techos

$\square$ Autoportante $\bigotimes$ Falso techo continuo $\square$ Instalaciones vistas Carpinterías de puertas

Tipo

\Abatible $\square$ Corredera $\quad$ Manual $\square$ Automática

Acabados

$\square$ Resina fenólica $\square$ Metálica lacada $\quad$ Acero Inox

$\square$ Otros

Refuerzo inferior/parachoques puerta: $\square$ sí $\quad$ NO

Mirilla

\Sí $\square$ NO

$\square$ Vidrio $\quad$ Vidrio + clapeta $\quad \square$ Vidrio con vinilo rojo $\square$ Digital

lluminación

Iluminación natural

Fotoperiodo $12 \mathrm{~h}$ luz/oscuridad

$\square$ sí $\bigotimes N O$

\sí $\square$ No

Iluminación auxiliar en estabulación (luz roja) $\quad$ Sí $\square$ NO

Ruidos y vibraciones

Elementos absorción acústica en estabulación $\square$ sí $\quad$ NO

Alarmas fuera del espectro audible animales $\square$ sí $\quad$ NO

Fondo sonoro continuo $\square$ \í \NO

Acceso personas controlada

Sistemas control, monitorización y alarmas

Control centralizado

\sí $\square$ NO

Paneles indicadores parámetros en salas

$\square$ Ta

$\square \mathrm{Hr}$

\sí $\square$ No

$\square$ sí $\quad$ NNO

$\square$ Presión diferencial 


\subsection{Unidad experimentación convencional animal pequeño \\ Características generales unidad convencional animal pequeño}

Superficie experimentación convencional animal pequeño
$\bigotimes<500 \mathrm{~m}^{2}$
$\square 500-1.000 \mathrm{~m}^{2}$
$\square>1.000 \mathrm{~m}^{2}$

Superficie estabulación convencional animal pequeño
$\bigotimes<100 \mathrm{~m}^{2}$
$\square 100-200 \mathrm{~m}^{2}$
$\square>200 \mathrm{~m}^{2}$

Especies animales
囚Rata $\bigotimes$ Ratón
$\square$ Cobaya
$\square$ Hámster
$\square$ Jerbo $\bigotimes$ Conejo
$\square$ Acuáticos
$\square$ Otros

Conejos estabulados con animal pequeño $\square \mathrm{NP} \quad$ Sí $\square$ NO

№ salas estabulación roedores

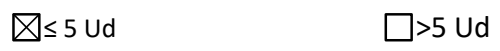

№ salas estabulación conejos
$\bigotimes=1$ Ud
$\square>1$ Ud
$\square$ NP
Tipo de jaula
$\bigotimes$ Reutilizable
Đstática
$\square$ Desechable
$\square$ Ventilada individualmente

Tipo suministro bebida

冈Biberones

Salas experimentación

Procedimientos

Área microcirugía

Área imagen

Área comportamiento

Otros

$\square$ Automático

\section{Organización unidad convencional animal pequeño}

№ de plantas en que se distribuye

囚Una planta $\square$ Varias plantas

Unidad independiente a animal grande

Tipo de distribución

$\square$ Pasillo simple $\quad$ Pasillo doble

Estabulación colindante a sala lavado

Sala cuarentena con SAS

Sala lavado y esterilización

$\square$ Compartida con barrera

\Uso exclusivo convencional

\section{Equipamiento sala lavado y esterilización}

Equipos de vaciado

Aspirador virutas

Equipos de lavado y esterilización

$\square$ Lava racks $\bigotimes$ Lava jaulas $\square$ Lava biberones $\bigotimes$ Autoclave

Equipos de llenado

Dispensador viruta

Equipo llenado biberones

$\square$ sí $\quad$ No

$\square$ sí \NO

$\square$ sí $\quad \mathrm{NO}$

\subsection{Unidad experimentación barrera animal pequeño}

$\square$ sí $\quad$ NO

Características generales unidad experimentación barrera

Superficie experimentación barrera animal pequeño
$\square<200 \mathrm{~m}^{2}$
$\square>200 \mathrm{~m}^{2}$

Superficie estabulación barrera animal pequeño

$\square<50 \mathrm{~m}^{2} \quad \square>50 \mathrm{~m}^{2}$

Especies animales

$\square$ Rata $\square$ Ratón $\square$ otros

№ salas estabulación roedores

$\square=1$ Ud

$\square \geq 2 \mathrm{Ud}$

Tipo de jaula

$\square$ Reutilizable

$\square$ Estática

Tipo suministro bebida

$\square$ Biberones

$\square$ Desechable

$\square$ Ventilada individualmente

Salas experimentación

$\square=1 \mathrm{Ud}$

$\square$ Automático

Sistema acceso personas

$\square$ SAS personas

Sistema acceso materiales

$\square$ Autoclave

$>2$ Ud

Sistema acceso animales

$\square$ Ventana SAS

\section{Organización unidad experimentación barrera animal pequeño}

№ de plantas en que se distribuye
$\square$ Una planta
$\square$ Varias plantas

Unidad independiente a convencional a. pequeño $\square$ sí $\square$ NO Zonas compartidas

$\square$ Almacenes $\square$ sala lavado $\square$ Vestuarios

Tipo de distribución

$\square$ Pasillo simple $\square$ Pasillo doble $\square$ Pasillo Triple

Área personal en interior barrera $\square$ sí $\square$ NO

Acceso animales

$\square$ SAS desde cuarentena $\square$ SAS desde otro local

Acceso materiales desde

$\square$ Sala lavado-esterilización $\square$ Otros

Barrera materiales comunicada con

$\square$ Almacén material limpio $\square$ Pasillo

Mantenimiento de instalaciones

$\square$ Registros en falso techo $\square$ Planta técnica superior

$\square$ Instalaciones vistas $\quad \square$ Planta registrable inferior 


\section{DOCUMENTACIÓN GRÁFICA I}

\section{Ficha 07: i+12 - 03}

$i+12$

Instituto de Investigación Hospital 12 de Octubre

Identificación Áreas Funcionales

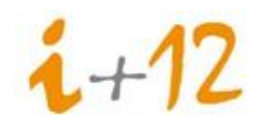

Instituto de Investigación Hospital 12 de Octubre

En esta ficha se muestran los planos de distribución en planta que componen el centro de experimentación animal y en los que se reflejan la distribución y organización de las distintas áreas funcionales que lo componen, quedando identificada cada área funcional por el código de color correspondiente, según la leyenda del plano.

Fuente: Elaboración propia.

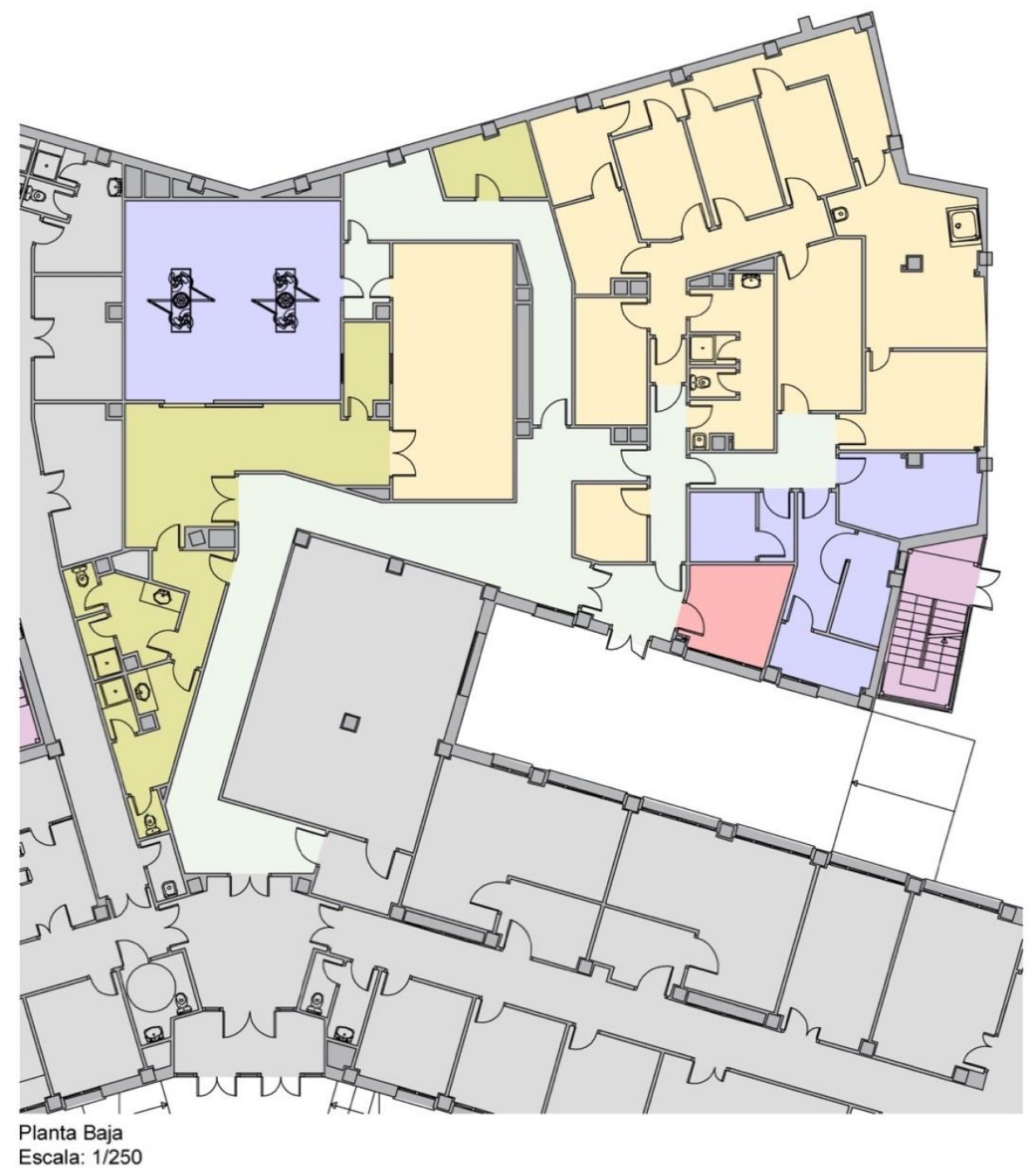

ÁREAS FUNCIONALES

Experimentación animal pequeño

Experimentación animal grande

Areas comunes animal pequeño y grande

Area Administrativa

Pasillos comunes

Pasillos exteriores y servicios generales

Elementos de circulación vertical

Kos Mesa quirúrgica 


\section{DOCUMENTACIÓN GRÁFICA II}

Instituto de Investigación Hospital 12 de Octubre

Identificación Tipo de Locales y Usos

En esta ficha se muestran los planos de distribución en planta que componen el centro de experimentación animal y en los que se reflejan los locales que lo conforman, quedando identificado cada tipo de local por el código de color correspondiente y el uso del local por el código numérico, según las leyendas de los planos.

Fuente: Elaboración propia.

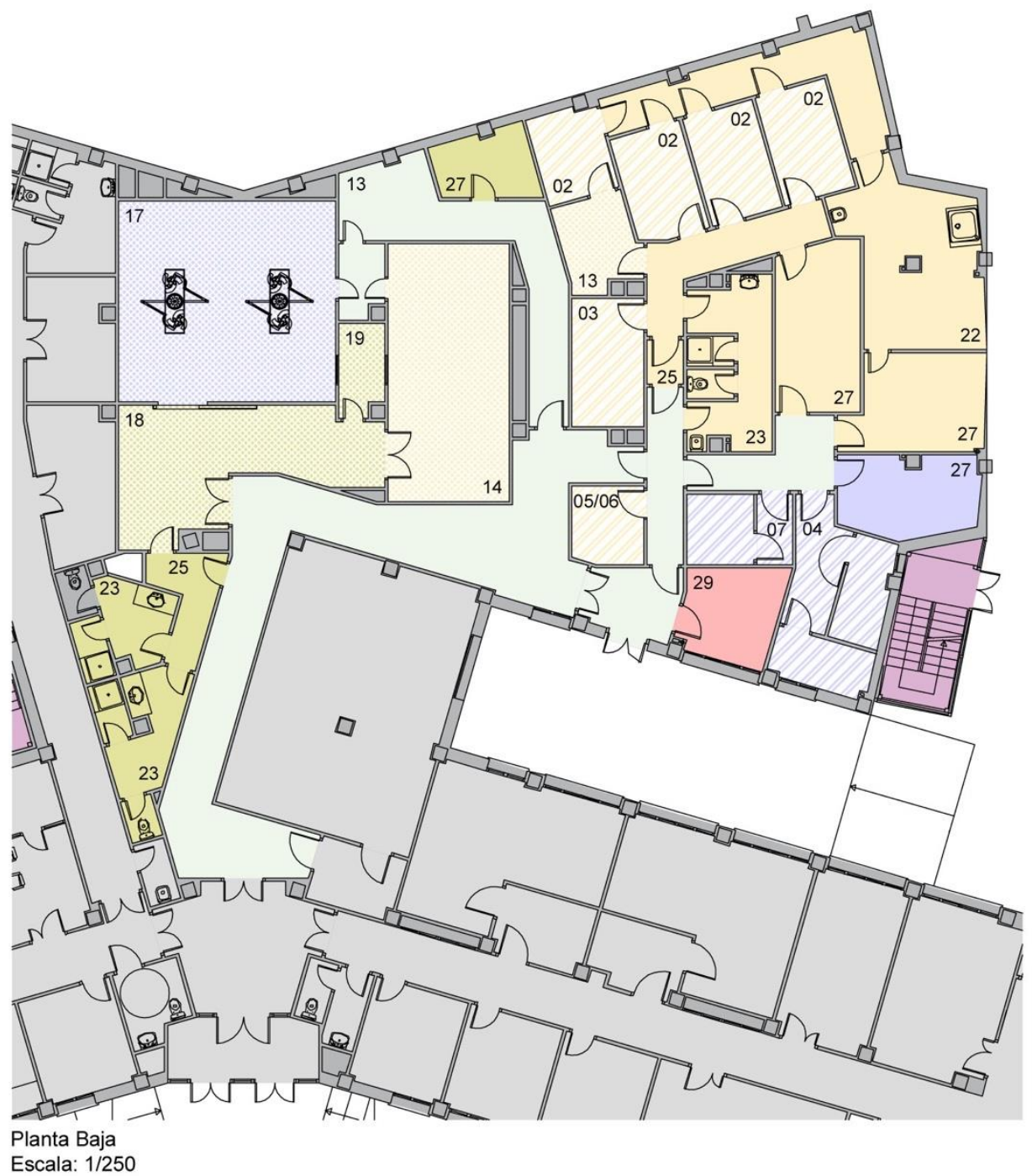

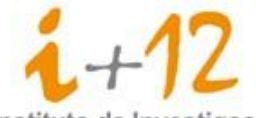

Instituto de Investigación Hospital 12 de Octubre
IDENTIFICACIÓN USO LOCALES

2 Estabulación convencional roedores

03 Estabulación convencional conejos

04 Estabulación convencional animal grande

05 Cuarentena roedores

06 Cuarentena conejos

07 Cuarentena animal grande

08 Estabulación barrera animal pequeño

09 Experimentación ABSL2 - 09* ABSL3

10 Experimentación peces

11 Lavado animal

12 Preparación anima

13 Procedimientos

14 Microcirugia

15 Comportamiento

16 Imagen 
PRESENTACIÓN

IISGM
Ficha 09: liSGM - 01

Instituto de Investigación Sanitaria Gregorio Marañón

http://www.iisgm.com

Febrero 2020

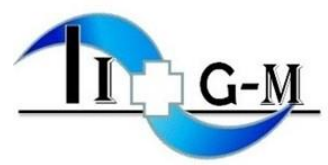

\section{Acreditación del Instituto}

El instituto de Investigación Sanitaria Gregorio Marañón (IISGM) se constituyó a través del convenio de colaboración entre el Servicio Madrileño de Salud, la Universidad Complutense, la Universidad Carlos III, la Fundación y la Agencia Laín Entralgo en el año 2011. Tras haber cumplido todos los requisitos, el Instituto fue acreditado por el Instituto de Salud Carlos III como Instituto de Investigación Sanitaria el 21 de mayo de 2012.

\section{Composición}

El liSGM está constituido por el Servicio Madrileño de Salud, a través del Hospital Universitario Gregorio Marañón, que representa el núcleo básico del Instituto, y grupos del ámbito de Atención Primaria del área de influencia del Hospital, por la Universidad Complutense de Madrid, la Universidad Carlos III de Madrid, la Fundación para la investigación biomédica del Hospital Gregorio Marañón y la Dirección General de Investigación, Formación e Infraestructuras Sanitarias de la Consejería de Sanidad de la Comunidad de Madrid.

\section{Misión}

Es una institución encaminada a la investigación traslacional cooperativa de excelencia, orientada a la generación de conocimiento y a la rápida aplicación de los avances producidos en la práctica asistencial y que contribuye a la capacitación de los investigadores, todo ello con el fin de favorecer la eficiencia del Sistema Nacional de Salud, aportando valor añadido.

\section{Áreas de investigación}

Dentro de la evaluación estratégica del Instituto se han definido áreas priorizadas de investigación de acuerdo a la pertinencia social y potencial repercusión en la salud de la población, a la entidad científica de la propia área, a la existencia de líneas de investigación adecuadamente definidas y complementarias con las de otras áreas, así como a la capacidad de ejercer una tutela efectiva de los grupos menos avanzados en el desarrollo investigador. De acuerdo a estos criterios y tras el correspondiente análisis y debate interno y la asesoría del Comité Científico Externo se han definido las siguientes siete áreas de investigación prioritarias: Ingeniería biomédica; Enfermedades cardiovasculares; Neurociencias y salud mental; Microbiología clínica, Enfermedades infecciosas y sida; Patología del sistema inmune; Oncología traslacional; y Patología de grandes sistemas y trasplantes de órganos. 


\section{CARACTERÍSTICAS PRINCIPALES}

Instituto de Investigación Sanitaria Gregorio Marañón

Ficha 10: liSGM - 02

IISGM

Centro de experimentación animal

\section{DATOS IDENTIFICACIÓN DEL INSTITUTO}

\section{Hospital asociado}

Localidad

Año acreditación

Fecha toma de datos

Hospital G. Universitario Gregorio Marañón

Madrid

2012

2016

\section{CENTRO EXPERIMENTACIÓN ANIMAL}

Características generales centro experimentación animal

Superficie del centro experimentación animal
$\bigotimes<750 \mathrm{~m}^{2}$
$\square 750$ - $1.500 \mathrm{~m}^{2}$

$\square>1.500 \mathrm{~m}^{2}$

Superficie experimentación animal grande

$\bigotimes<200 \mathrm{~m}^{2} \quad \square 200-400 \mathrm{~m}^{2}$
Superficie experimentación animal pequeño

$\bigotimes<500 \mathrm{~m}^{2} \quad \square 500-1.000 \mathrm{~m}^{2}$
Tipo de centro de experimentación animal

$\square>400 \mathrm{~m}^{2}$

\Usuario $\quad$ \Cría

Acreditación AAALAC

$\square$ Sí $\quad$ \NO

Tipo de experimentación

Animal pequeño

$\triangle$ Convencional $\quad$ Barrera $\triangle$ Contención riesgo biológico

Nivel de Bioseguridad $\square$ BSL1 $\triangle \mathrm{BSL} \square \square \mathrm{BSL3} \square \mathrm{BSL4}$

Animal grande

冈Convencional $\square$ Barrera $\square$ Contención riesgo biológico

\section{Organización centro experimentación animal}

Edificio ubicado en el hospital

Tipo de edificio $\square$ Nueva planta $\triangle$ Existente

Año construcción centro experimentación

$\square$ Anterior año $2.009 \quad$ \Posterior año 2009

№ de edificios en que se distribuye $\quad$ Uno $\square$ Varios

№ de plantas en que se distribuye $\quad$ \Una $\square$ Varias

Tipo de división en plantas $\quad$ DNP

$\square$ Área animal grande / Área animal pequeño

$\square$ Área animalario / Área experimentación

$\square$ Experimentación animal /Servicios

$\square$ Cirugía experimental / Experimentación animal pequeño

Tipo de planta en la que se ubica

$\square$ Bajo rasante $\square$ A cota “0" $\square$ Sobre rasante

Accesos exteriores independientes invest./animales $\bigotimes$ sí $\square$ NO Circulación vertical acceso animales $\square$ sí $\bigotimes N O$

Circulación vertical interior animales $\square$ sí $\bigotimes N O$

Transporte vertical independiente limpio/sucio $\triangle N P \square$ sí $\square$ NO Áreas animal grande/pequeño independizadas $\square$ sí $\bigotimes N O$ Ubicación zona administrativa

Externa al área experimentación animal

\section{3. ÁREA EXPERIMENTACIÓN ANIMAL GRANDE}

Organización área experimentación animal grande

Superficie experimentación animal grande
$\bigotimes<200 \mathrm{~m}^{2}$
$\square 200-400 \mathrm{~m}^{2}$
$\square>400 \mathrm{~m}^{2}$

№ de plantas en que se distribuye

\Una

Tipo división para varias plantas

$\square$ Área animalario / Área experimentación

$\square$ Área animal grande / Área animal pequeño

Tipo de planta en la que se ubica

$\square$ Bajo rasante $\triangle$ A cota "0" $\square$ sobre rasante

Circulación vertical acceso animales $\square$ Sí $\bigotimes N O$

Accesos independientes investigadores/animales $\bigotimes \mathrm{sí} \quad \square \mathrm{NO}$

Áreas animal grande/pequeño independizadas $\square s i ́ \quad$ \NO

Zonas compartidas de animal grande y pequeño

$\triangle$ Vestuarios $\triangle$ Pasillos investigadores $\triangle$ Almacenes

$\square$ Áreas lavado $\triangle$ Pasillos animales $\square$ Salas preparación

$\square$ otras

Circulación vertical interior animales grandes

$\square$ sí $\quad \mathrm{NO}$

Áreas de experimentación

囚Área quirúrgica experimental

$\square$ Experimentación con cadáveres

$\square$ Necropsias

$\square$ otros

\section{1. Área estabulación animal grande}

Características generales área estabulación animal grande

Superficie locales alojamiento animal grande

$\bigotimes<50 \mathrm{~m}^{2} \quad \square>50 \mathrm{~m}^{2}$

Especies animales

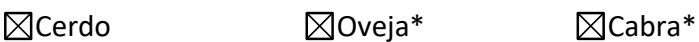

$\square$ Perro* $\square$ Gato* $\quad \square$ Otras*

*Ocasionalmente

Tipo de alojamiento

冈Convencional $\square$ Barrera $\square$ Contención riesgo biológico Conejos estabulados con animales grandes $\square$ sí \NO № Locales de alojamiento

\2 Ud $\square>2$ Ud

Zona recuperación post anestésica

凶sí $\square$ NO

Locales de servicio

Sala limpieza y aclimatación

$\square$ sí $\bigotimes \mathrm{NO}$

Sala necropsias

$\square$ sí 冈NO

Sistema almacenaje residuos animal

$\square$ Cámara congelación-20 $\quad$ Congelador -20드 $\square$ Almacén 


\section{Organización del área estabulación animal grande}

Tipo de planta en la que se ubica

$\square$ Bajo rasante $\square$ A cota "0"

$\square$ Sobre rasante

Circulación vertical acceso animales

$\square$ sí $\triangle \mathrm{NO}$

Accesos independientes para cuidadores y animales $\square$ sí $\bigotimes N O$ Estabulación animal grande/pequeño independizada $\square$ sí $\bigotimes N O$ Zonas compartidas de animal grande y pequeño

\Pasillos $\quad$ DAlmacenes $\square$ Otras

\section{Sistemas de estabulación animal grande}

\section{Tipo de boxes}

$\square$ Realizados in situ $\quad$ Prefabricados

$\square$ Fijos $\quad$ MModulares

$\square$ Sobre forjado $\quad$ Sobre fosa de purines $\bigotimes$ En jaulas

Refuerzo en paramentos perimetrales de boxes: $\quad$ SÍ $\square$ NO

Curva sanitaria en suelo

Entreplanta técnica superior

$\square$ Transitable $\quad$ No transitable

Planta técnica inferior

\sí $\square$ NO

\sí $\square$ NO

Luz natural área estabulación

Fotoperiodo $12 \mathrm{~h}$ luz/oscuridad

凶sí $\square$ No

\sí $\square$ NO

$\square$ sí $\square$ NO

\section{2. Área quirúrgica experimental animal grande}

\section{Características generales área quirúrgica experimental}

Superficie área quirúrgica animal grande
$\bigotimes<70 \mathrm{~m}^{2}$
$\square 70-100 \mathrm{~m}^{2}$
$\square>100 \mathrm{~m}$

Salas quirúrgicas

$\square$ Quirófano simple Quirófano doble $\square$ Quirófano múltiple Quirófano modulable

Diseño tipo quirófanos asistenciales

Sistema retransmisión imagen

Área experimentación cadáveres

Entreplanta técnica superior

$\square$ Transitable

$\bigotimes$ No transitable

Luz natural quirófanos

$\square$ sí $\quad$ NO

\section{Organización del área quirúrgica experimental}

Tipo de planta en la que se ubica

\section{$\square$ Bajo rasante $\triangle$ A cota “0" $\square$ Sobre rasante}

Circulación vertical interna animales acceso al área $\square$ Sí $\bigotimes N O$

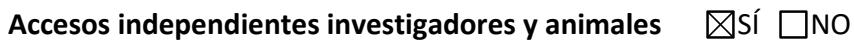

Área quirúrgica animal grande/pequeño indep.

Zonas compartidas de animal grande y pequeño
\Pasillos
冈vestuarios
$\square$ Preparación animal
$\square$ Preparación médica

$\square$ Otros

Configuración pasillos área quirúrgica

$\square$ Pasillo único $\quad$ Doble pasillo
4. ÁREA EXPERIMENTACIÓN ANIMAL PEQUEÑO

Características generales área experimentación animal pequeño

Superficie experimentación animal pequeño

$\bigotimes<500 \mathrm{~m}^{2} \quad \square 500-1.000 \mathrm{~m}^{2} \quad \square>1.000 \mathrm{~m}^{2}$

Especies animales *Ocasionalmente

冈Roedores $\square$ Logomorfos $\square$ Animales acuáticos

Unidades de experimentación

\Convencional $\bigotimes$ Barrera $\bigotimes$ Contención riesgo biológico

Nivel de bioseguridad $\square$ BSL1 $\quad$ BSL2 $\square$ BSL3 $\square$ BSL4

\section{Organización área experimentación animal pequeño}

№ de plantas en que se distribuye

囚Una planta $\square$ Dos plantas $\square$ Tres plantas

Tipo de planta en la que se ubica

$\square$ Bajo rasante $\square$ A cota “0" $\square$ Sobre rasante

Circulación vertical animales

$\square$ De acceso al área $\square$ Circulación interior $\quad$ No

Experimentación a. grande/pequeño independizada $\square$ sí $\bigotimes N O$

Características constructivas área experimentación a. pequeño

Divisiones interiores

\Modular $\square$ Realizada in situ

Revestimientos verticales

$\square$ Pintura epoxi $\square$ PVC rollo $\quad$ Resina fenólica $\square$ otros Protección contra choques $\quad$ \í $\square$ NO

Pavimentos

\PVC rollo $\square$ Resinas epoxi $\square$ Otros

Curva sanitaria en suelo

凶sí $\square$ NO

Techos

$\square$ Autoportante $\quad$ Falso techo continuo $\square$ Instalaciones vistas Carpinterías de puertas

Tipo

\Abatible $\square$ Corredera $\quad$ Manual $\square$ Automática

Acabados

\Resina fenólica $\square$ Metálica lacada $\square$ Acero Inox

$\square$ otros

Refuerzo inferior/parachoques puerta: $\square$ sí $\quad$ NO

Mirilla \Sí $\square$ NO

$\square$ Vidrio $\quad$ Vidrio + clapeta $\quad \square$ Vidrio con vinilo rojo $\square$ Digital lluminación

lluminación natural $\square$ sí \NO

Fotoperiodo 12h luz/oscuridad $\quad$ \sí $\square$ NO

lluminación auxiliar en estabulación (luz roja) $\quad$ Sí $\square$ NO

Ruidos y vibraciones

Elementos absorción acústica en estabulación $\square$ sí $\quad$ \NO

Alarmas fuera del espectro audible animales $\square$ sí $\quad$ NO

Fondo sonoro continuo $\square$ sí $\quad$ \NO

Acceso personas controlada

\Sí $\square$ NO

Sistemas control, monitorización y alarmas

Control centralizado \sí $\square$ NO

Paneles indicadores parámetros en salas $\square$ sí $\square$ NO
$\square$ Tạ
$\square \mathrm{Hr}$
$\square$ Presión diferencial 


\subsection{Unidad experimentación convencional animal pequeño \\ Características generales unidad convencional animal pequeño}

Superficie experimentación convencional animal pequeño
$\bigotimes<500 \mathrm{~m}^{2}$
$\square 500-1.000 \mathrm{~m}^{2}$
$\square>1.000 \mathrm{~m}^{2}$

Superficie estabulación convencional animal pequeño

$\bigotimes<100 \mathrm{~m}^{2} \quad \square 100-200 \mathrm{~m}^{2} \quad \square>200 \mathrm{~m}^{2}$

Especies animales

\Rata $\quad$ Ratón $\square$ Cobaya $\square$ Hámster

$\square$ Jerbo $\square$ Conejo $\square$ Acuáticos $\square$ Otros

Conejos estabulados con animal pequeño $\square$ NP $\square$ sí $\quad$ NO

№ salas estabulación roedores

$\bigotimes \leq 5$ Ud $\square>5$ Ud

№ salas estabulación conejos
$\square=1$ Ud
$\square>1 \cup d$
\NP

Tipo de jaula

囚eutilizable

$\square$ Estática

Tipo suministro bebida

冈Biberones

\section{$\square$ Desechable \\ \Ventilada individualmente}

Salas experimentación

Procedimientos

Área microcirugía

Área imagen

Área comportamiento

$\square$ Automático

Otros

Organización unidad convencional animal pequeño

№ de plantas en que se distribuye

\Una planta $\square$ Varias plantas

Unidad independiente a animal grande

Tipo de distribución

\Pasillo simple $\square$ Pasillo doble

Estabulación colindante a sala lavado

Sala cuarentena con SAS

Sala lavado y esterilización

囚Compartida con barrera

$\square$ Uso exclusivo convencional

Equipamiento sala lavado y esterilización

Equipos de vaciado

Aspirador virutas

Equipos de lavado y esterilización

$\square$ Lava racks $\bigotimes$ Lava jaulas $\bigotimes$ Lava biberones $\bigotimes$ Autoclave

Equipos de llenado

Dispensador viruta

凶sí $\square$ NO

凶sí $\square$ NO

\sí $\square$ NO

$\square$ sí $\bigotimes N \mathrm{NO}$

$\square$ sí $\quad \mathrm{NO}$

Equipo llenado biberones $\quad$ sí $\square$ NO
4.2. Unidad experimentación barrera animal pequeño

\sí $\square$ NO

Características generales unidad experimentación barrera

Superficie experimentación barrera animal pequeño
$\bigotimes<200 \mathrm{~m}^{2}$
$\square>200 \mathrm{~m}^{2}$

Superficie estabulación barrera animal pequeño

$\bigotimes<50 \mathrm{~m}^{2}$

$\square>50 \mathrm{~m}^{2}$

Especies animales

\Rata $\quad$ QRatón $\square$ Otros

№ salas estabulación roedores

$\square=1$ Ud

$\bigotimes \geq 2$ Ud

Tipo de jaula

$\bigotimes$ Reutilizable

$\square$ Estática

$\square$ Desechable

Tipo suministro bebida

\Biberones $\square$ Automático

Salas experimentación

$\square=1$ Ud

$\bigotimes>2$ Ud

Sistema acceso personas

\SAS personas $\square$ Ducha de aire

Sistema acceso materiales

\Autoclave

Sistema acceso animales

\Ventana SAS

\Ventana SAS UV $\triangle$ CabinaVPH

Organización unidad experimentación barrera animal pequeño

№ de plantas en que se distribuye

囚Una planta $\square$ Varias plantas

Unidad independiente a convencional a. pequeño $\square$ sí $\quad$ NO

Zonas compartidas

\Almacenes $\quad$ \sala lavado $\quad$ Vestuarios

Tipo de distribución

囚Pasillo simple $\square$ Pasillo doble $\square$ Pasillo Triple

Área personal en interior barrera $\square$ sí $\bigotimes N O$

Acceso animales

$\square$ SAS desde cuarentena $\quad$ SAS desde otro local

Acceso materiales desde

\Sala lavado-esterilización $\square$ Otros

Barrera materiales comunicada con

囚Almacén material limpio $\square$ Pasillo

Mantenimiento de instalaciones

$\bigotimes$ Registros en falso techo $\square$ Planta técnica superior

$\square$ Instalaciones vistas $\quad$ Planta registrable inferior 


\section{DOCUMENTACIÓN GRÁFICA I}

\section{Ficha 11: liSGM - 03}

IISGM

\section{Instituto de Investigación Sanitaria Gregorio Marañón}

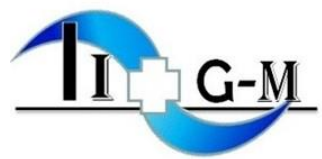

\section{Identificación Áreas Funcionales}

En esta ficha se muestran los planos de distribución en planta que componen el centro de experimentación animal y en los que se reflejan la distribución y organización de las distintas áreas funcionales que lo componen, quedando identificada cada área funcional por el código de color correspondiente, según la leyenda del plano.

Fuente: Elaboración propia.

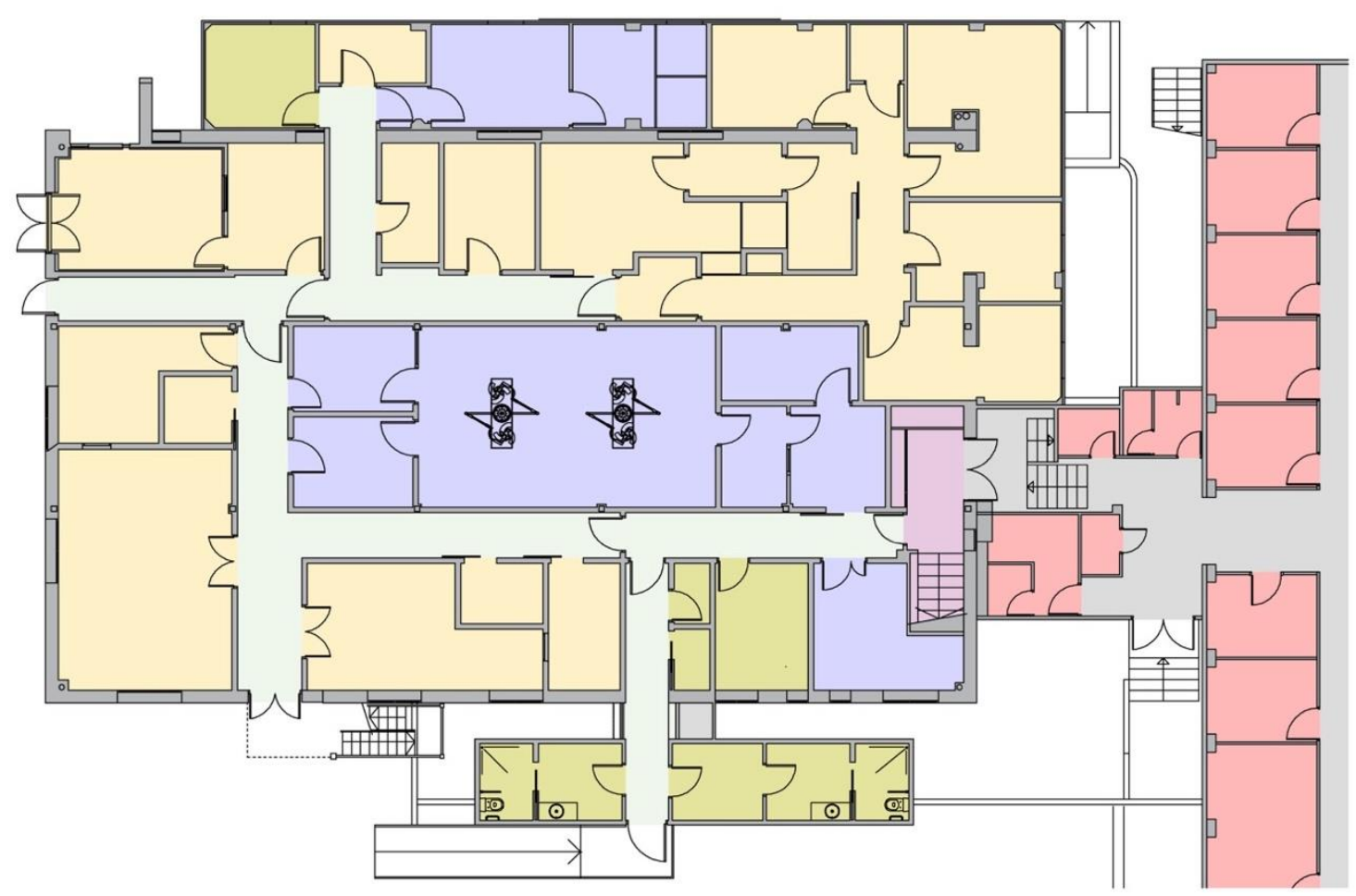

Planta Baja

Escala: 1/250

\section{ÁREAS FUNCIONALES}

Experimentación animal pequeño

Experimentación animal grande

Areas comunes animal pequeño y grande

Área Administrativa

Pasillos comunes

Pasillos exteriores y servicios generales

Elementos de circulación vertical 


\section{DOCUMENTACIÓN GRÁFICA II}

Ficha 12: liSGM - 04

IISGM

Instituto de Investigación Sanitaria Gregorio Marañón

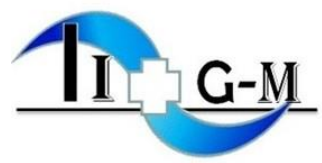

\section{Identificación Tipo de Locales y Usos}

En esta ficha se muestran los planos de distribución en planta que componen el centro de experimentación animal y en los que se reflejan los locales que lo conforman, quedando identificado cada tipo de local por el código de color correspondiente y el uso del local por el código numérico, según las leyendas de los planos.

Fuente: Elaboración propia.

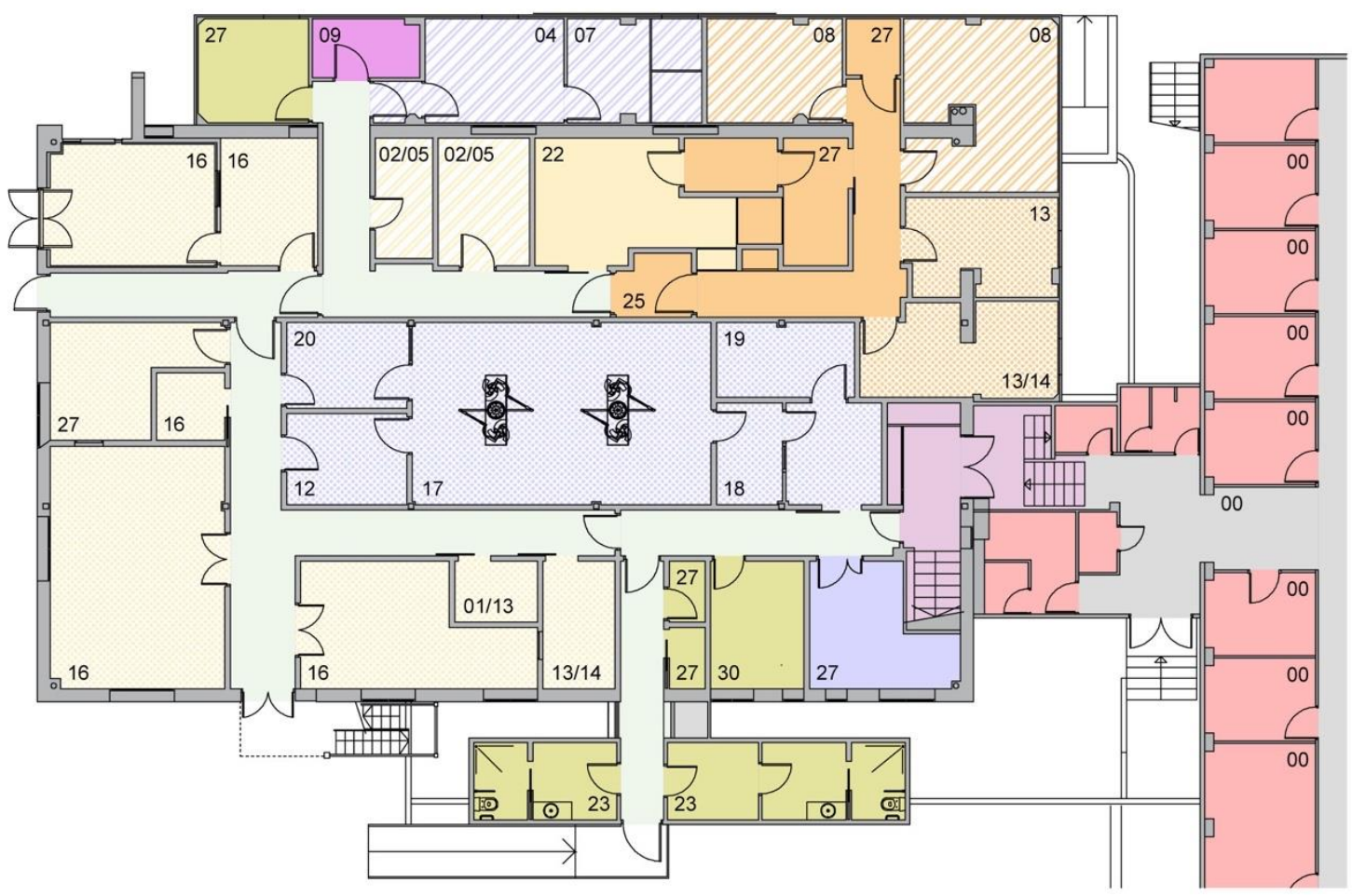

Planta Baja

Escala: $1 / 250$

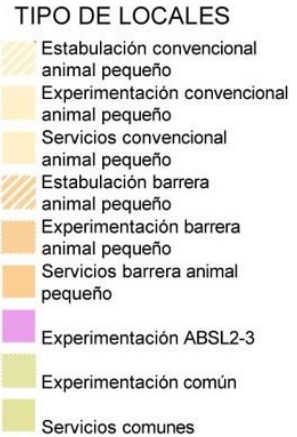

TIPO DE LOCALES

Experimentación convencion

nimal pequeño

Experimentación ABSL2-3

Servicios comunes
Estabulación animal

grande

Experimentación anima

grande

Servicios animal grande

Experimentación animales

Área administrativa

Pasillos comunes

Pasillos exteriores y

servicios generales

Elementos circulación

vertical
IDENTIFICACIÓN USO LOCALES

01 Recepción animal

02 Estabulación convencional roedore

03 Estabulación convencional conejos

04 Estabulación convencional animal grande

05 Cuarentena roedores

06 Cuarentena conejos

Trenarentena animal grande

08 Estabulacion barrera animal pequeño

09 Experimentación ABSL2 - 09* ABSL3

10 Experimentación peces

11 Lavado animal

12 Preparacion anim

13 Procedimientos

14 Microcirugia

16 Imagen
17 Quirófano experimental 18 Preparación médic 20 Necropsias 21 Cirugia cadáveres 22 Lavado y esterilización 23 Vestuarios/Aseos 24 Esclusa animales 25 Esclusa personas 27 Almacén / archivo 28 Servicios 29 Despacho 30 Sala reuniones 32 Otros 
PRESENTACIÓN

IRYCIS
Ficha 13: IRYCIS - 01

Instituto Ramón y Cajal de Investigación Sanitaria

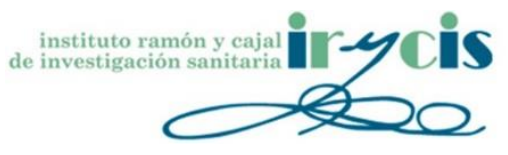

http://www.irycis.org/

Febrero 2020

\section{Acreditación del Instituto}

El instituto Ramón y Cajal de Investigación Sanitaria (IRYCIS) se constituyó en diciembre de 2009. Posteriormente, recibió su acreditación del Ministerio de Ciencia e Innovación en el año 2011 y la renovación de la misma en enero de 2017, a manos de la Secretaria de Estado de Investigación, Desarrollo e Innovación.

\section{Composición}

El IRYCIS es una alianza formada por el Hospital Universitario Ramón y Cajal, que constituye el núcleo básico del instituto, la Universidad de Alcalá de Henares que confiere el carácter universitario al Hospital, la Universidad Complutense de Madrid a través de la participación de grupos de la Facultad de Farmacia, Medicina, CC Biológicas y Químicas, la Universidad Autónoma de Madrid a través de la participación de grupos pertenecientes a la Facultad de Ciencias, la Fundación para la investigación biomédica del Hospital Universitario Ramón y Cajal, como órgano de gestión del IRYCYS y la Dirección general de investigación de la Consejería de Sanidad de la Comunidad de Madrid, como organismo en el ámbito de la política científica regional.

\section{Misión}

Su misión es ser un espacio dedicado a la investigación biomédica de excelencia, dirigida a generar conocimientos útiles para la identificación y tratamiento de enfermedades actuales o potenciales y por tanto con un marcado carácter traslacional y con vocación de convertirse en referencia de ámbito nacional e internacional aplicando en todas sus acciones una filosofía de calidad y mejora continua.

\section{Áreas de investigación}

Se establecen unas áreas prioritarias de investigación con la misión fundamental de velar por la consecución de los objetivos marcados para el conjunto de su área y garantizar la comunicación y colaboración entre los distintos grupos de investigación que la integran. Las cinco áreas prioritarias de investigación son: Neurociencias y órgano de los sentidos; Microbiología, inmunología e infección; Enfermedades crónicas y cáncer; Epidemiología y tecnología sanitaria; Cardiometabolismo y patología de sistemas. 


\section{CARACTERÍSTICAS PRINCIPALES}

Instituto Ramón y Cajal de Investigación Sanitaria

Ficha 14: IRYCIS - 02

IRYCIS

\section{DATOS IDENTIFICACIÓN DEL INSTITUTO}

$\begin{array}{lr}\text { Hospital asociado } & \text { Hospital Universitario Ramón y Cajal } \\ \text { Localidad } & \text { Madrid } \\ \text { Año acreditación } & 2011 \\ \text { Fecha toma de datos } & 2016\end{array}$

\section{CENTRO EXPERIMENTACIÓN ANIMAL}

Características generales centro experimentación animal

Superficie del centro experimentación animal

$\square<750 \mathrm{~m}^{2} \quad \square 750-1.500 \mathrm{~m}^{2}$
Superficie experimentación animal grande

$\square>1.500 \mathrm{~m}^{2}$

Superficie experimentación animal pequeño

$\square<500 \mathrm{~m}^{2} \quad \bigotimes 500-1.000 \mathrm{~m}^{2}$
Tipo de centro de experimentación animal

冈Usuario $\quad$ QCría

\Cría

$\square$ Sí $\quad$ QNO

Tipo de experimentación

Animal pequeño

\Convencional $\square$ Barrera $\square$ Contención riesgo biológico

Nivel de Bioseguridad $\square$ BSL1 $\square$ BSL2 $\square$ BSL3 $\square$ BSL4

Animal grande

冈Convencional $\square$ Barrera $\square$ Contención riesgo biológico

\section{Organización centro experimentación animal}

Edificio ubicado en el hospital

Tipo de edificio

Año construcción centro experimentación

\Anterior año 2.009

$\square$ Posterior año 2009

№ de edificios en que se distribuye $\quad$ Uno $\square$ Varios

№ de plantas en que se distribuye $\quad$ Una $\square$ Varias

Tipo de división en plantas $\quad$ \NP

$\square$ Área animal grande / Área animal pequeño

$\square$ Área animalario / Área experimentación

$\square$ Experimentación animal /Servicios

$\square$ Cirugía experimental / Experimentación animal pequeño

Tipo de planta en la que se ubica
$\square$ Bajo rasante
$\triangle \mathrm{A}$ cota "0"
$\square$ Sobre rasante

Accesos exteriores independientes invest./animales $\bigotimes \mathrm{SÍ} \square \mathrm{NO}$ Circulación vertical acceso animales $\square$ Sí $\square N O$ Circulación vertical interior animales $\square$ sí $\bigotimes N O$ Transporte vertical independiente limpio/sucio $\triangle N P \square$ sí $\square$ NO Áreas animal grande/pequeño independizadas $\square$ sí $\square$ NO Ubicación zona administrativa

Externa al área experimentación animal

\section{3. ÁREA EXPERIMENTACIÓN ANIMAL GRANDE}

Organización área experimentación animal grande

Superficie experimentación animal grande
$\square<200 \mathrm{~m}^{2}$
$\nabla 200$ - $400 \mathrm{~m}^{2}$
$>400 \mathrm{~m}^{2}$

\Una

№ de plantas en que se distribuye

$\square$ Varias

Tipo división para varias plantas

$\square$ Área animalario / Área experimentación

$\square$ Área animal grande / Área animal pequeño

Tipo de planta en la que se ubica

$\square$ Bajo rasante $\triangle$ A cota “0" $\square$ Sobre rasante Circulación vertical acceso animales $\square$ sí $\quad$ NO Accesos independientes investigadores/animales $\quad$ sí $\square$ NO Áreas animal grande/pequeño independizadas $\quad$ Sí $\square$ NO Zonas compartidas de animal grande y pequeño

$\triangle$ Vestuarios $\triangle$ Pasillos investigadores $\triangle$ Almacenes

\Áreas lavado $\triangle$ Pasillos animales $\square$ Salas preparación $\square$ Otras

Circulación vertical interior animales grandes

$\square$ sí $\quad \mathrm{NO}$

Áreas de experimentación

囚Área quirúrgica experimental $\square$ Necropsias

$\square$ Experimentación con cadáveres $\quad$ Área Imagen

$\square$ otros

\section{1. Área estabulación animal grande}

Características generales área estabulación animal grande

Superficie locales alojamiento animal grande

$\square<50 \mathrm{~m}^{2} \quad \quad \nabla>50 \mathrm{~m}^{2}$

Especies animales

\Cerdo $\quad$ Doveja* $\square$ Cabra*

$\triangle$ Perro* $\square$ Gato* $\quad \square$ Otras*

*Ocasionalmente

Tipo de alojamiento

\Convencional $\square$ Barrera $\square$ Contención riesgo biológico Conejos estabulados con animales grandes $\square$ sí $\square$ NO № Locales de alojamiento

\2 Ud $\square>2$ Ud

Zona recuperación post anestésica

凶sí $\square$ No

Locales de servicio

Sala limpieza y aclimatación

$\square$ sí $\bigotimes$ NO

Sala necropsias

$\square$ sí $\bigotimes N O$

Sistema almacenaje residuos animal

$\square$ Cámara congelación-20ㅇ $\quad$ Congelador -20ㄷ $\square$ Almacén 


\section{Organización del área estabulación animal grande}

Tipo de planta en la que se ubica

$\square$ Bajo rasante $\square$ A cota "0"

$\square$ Sobre rasante

Circulación vertical acceso animales

$\square \mathrm{sí} \otimes \mathrm{NO}$

Accesos independientes para cuidadores y animales $\square$ sí $\bigotimes N O$ Estabulación animal grande/pequeño independizada $\square$ sí $\bigotimes N O$ Zonas compartidas de animal grande y pequeño

\Pasillos $\quad$ Balmacenes $\square$ Otras

\section{Sistemas de estabulación animal grande}

\section{Tipo de boxes}

$\bigotimes$ Realizados in situ

囚Fijos

\Sobre forjado

\section{$\square$ Prefabricados}

\section{$\square$ Modulares}

Refuerzo en paramentos perimetrales de boxes: $\square$ sí $\bigotimes N O$

Curva sanitaria en suelo

Entreplanta técnica superior

$\square$ Transitable $\quad$ No transitable

Planta técnica inferior

Luz natural área estabulación

Fotoperiodo $12 \mathrm{~h}$ luz/oscuridad

$\square$ sí $\quad$ NO

\sí $\square$ NO

$\square$ sí $\quad$ No

\section{2. Área quirúrgica experimental animal grande}

\section{Características generales área quirúrgica experimental}

Superficie área quirúrgica animal grande
$\nabla<70 \mathrm{~m}^{2}$
$\square 70-100 \mathrm{~m}^{2}$
$\square>100 \mathrm{~m}$

Salas quirúrgicas

QQuirófano simple $\square$ Quirófano doble $\square$ Quirófano múltiple Quirófano modulable

Diseño tipo quirófanos asistenciales

Sistema retransmisión imagen

Área experimentación cadáveres

Entreplanta técnica superior

$\square$ Transitable

Luz natural quirófanos

$\bigotimes$ No transitable

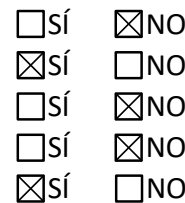

\section{Organización del área quirúrgica experimental}

Tipo de planta en la que se ubica

\section{$\square$ Bajo rasante $\quad$ A cota “0" $\square$ Sobre rasante}

Circulación vertical interna animales acceso al área $\square$ sí \NO

Accesos independientes investigadores y animales $\square$ sí $\bigotimes N O$

Área quirúrgica animal grande/pequeño indep.

Zonas compartidas de animal grande y pequeño
\pasillos
\Vestuarios
$\square$ Preparación animal
$\square$ Preparación médica
$\square$ otros

Configuración pasillos área quirúrgica

\Pasillo único

$\square$ Doble pasillo
4. ÁREA EXPERIMENTACIÓN ANIMAL PEQUEÑO

Características generales área experimentación animal pequeño

Superficie experimentación animal pequeño
$\square<500 \mathrm{~m}^{2}$
\500-1.000 m²
$\square>1.000 \mathrm{~m}^{2}$
Especies animales
* Ocasionalmente

\Roedores $\quad \square$ Logomorfos $\square$ Animales acuáticos

Unidades de experimentación

\Convencional $\square$ Barrera $\square$ Contención riesgo biológico

Nivel de bioseguridad

$\square$ BSL1 $\square$ BSL2 $\square$ BSL3 $\square$ BSL4

\section{Organización área experimentación animal pequeño}

№ de plantas en que se distribuye

\Una planta $\square$ Dos plantas $\square$ Tres plantas

Tipo de planta en la que se ubica

$\square$ Bajo rasante $\square$ A cota “0" $\square$ Sobre rasante

Circulación vertical animales

$\square$ De acceso al área $\square$ Circulación interior $\quad$ No

Experimentación a. grande/pequeño independizada $\square$ sí $\bigotimes N O$

Características constructivas área experimentación a. pequeño

Divisiones interiores

$\square$ Modular $\quad$ Realizada in situ

Revestimientos verticales

$\square$ Pintura epoxi $\quad$ PVC rollo $\square$ Resina fenólica $\square$ otros

Protección contra choques

Pavimentos

\PVC rollo $\square$ Resinas epoxi $\square$ Otros

Curva sanitaria en suelo

邓sí $\square$ No

Techos

$\square$ Autoportante $\quad$ Falso techo continuo $\square$ Instalaciones vistas Carpinterías de puertas

Tipo

\Abatible $\square$ Corredera $\quad$ Manual $\square$ Automática

Acabados

$\square$ Resina fenólica $\quad$ Metálica lacada $\square$ Acero Inox

$\square$ Otros

Refuerzo inferior/parachoques puerta: $\square$ sí $\quad$ NO

Mirilla \Sí $\square$ NO

$\square$ Vidrio $\quad$ Vidrio + clapeta $\quad \square$ Vidrio con vinilo rojo $\square$ Digital lluminación

lluminación natural $\square$ sí \NO

Fotoperiodo 12h luz/oscuridad $\quad$ \sí $\square$ NO

lluminación auxiliar en estabulación (luz roja) $\square$ sí $\quad$ \NO

Ruidos y vibraciones

Elementos absorción acústica en estabulación $\square$ sí $\quad$ \NO

Alarmas fuera del espectro audible animales $\square$ sí $\quad$ NO

Fondo sonoro continuo $\square$ sí $\quad$ \NO

Acceso personas controlada $\quad$ $\quad \square$ Ní

Sistemas control, monitorización y alarmas

Control centralizado \sí $\square$ NO

Paneles indicadores parámetros en salas $\square$ sí $\square$ NO

$\square$ Ta $\quad \square \mathrm{Hr} \quad \square$ Presión diferencial 


\subsection{Unidad experimentación convencional animal pequeño \\ Características generales unidad convencional animal pequeño}

Superficie experimentación convencional animal pequeño
$\square<500 \mathrm{~m}^{2}$
$\bigotimes 500-1.000 \mathrm{~m}^{2}$
$\square>1.000 \mathrm{~m}^{2}$

Superficie estabulación convencional animal pequeño

$\square<100 \mathrm{~m}^{2} \quad \square 100-200 \mathrm{~m}^{2} \quad \square>200 \mathrm{~m}^{2}$

Especies animales

\Rata $\quad$ Ratón $\square$ Cobaya $\square$ Hámster

$\square$ Jerbo $\quad$ Conejo $\square$ Acuáticos $\square$ Otros

Conejos estabulados con animal pequeño $\square$ NP $\square$ sí $\quad$ NO

№ salas estabulación roedores

$\square \leq 5$ Ud $\quad \square>5$ Ud

№ salas estabulación conejos

$\bigotimes=1$ Ud $\square>1$ Ud $\square$ NP

Tipo de jaula

\Reutilizable

$\square$ Desechable

囚stática

Tipo suministro bebida

冈Biberones

\Ventilada individualmente

Salas experimentación

Procedimientos

Área microcirugía

Área imagen

Área comportamiento

\Automático

Otras

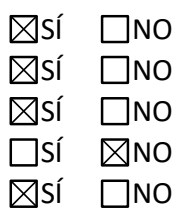

Organización unidad convencional animal pequeño

№ de plantas en que se distribuye

\Una planta $\square$ Varias plantas

Unidad independiente a animal grande

Tipo de distribución

$\square$ Pasillo simple $\quad$ Pasillo doble

Estabulación colindante a sala lavado

Sala cuarentena con SAS

Sala lavado y esterilización

$\square$ Compartida con barrera $\quad$ Uso exclusivo convencional

Equipamiento sala lavado y esterilización

Equipos de vaciado

Aspirador virutas

Equipos de lavado y esterilización

\Lava racks $\square$ Lava jaulas $\square$ Lava biberones $\bigotimes$ Autoclave

Equipos de llenado

Dispensador viruta

Equipo llenado biberones
4.2. Unidad experimentación barrera animal pequeño

$\square$ sí \NO

Características generales unidad experimentación barrera

Superficie experimentación barrera animal pequeño
$\square<200 \mathrm{~m}^{2}$
$\square>200 \mathrm{~m}^{2}$

Superficie estabulación barrera animal pequeño

$\square<50 \mathrm{~m}^{2}$

$\square>50 \mathrm{~m}^{2}$

Especies animales

$\square$ Rata $\square$ Ratón $\square$ otros

№ salas estabulación roedores

$\square=1$ Ud

$\square \geq 2$ Ud

Tipo de jaula

$\square$ Reutilizable

$\square$ Estática

Tipo suministro bebida

$\square$ Biberones

$\square$ Desechable

$\square$ Ventilada individualmente

Salas experimentación

$\square=1$ Ud

$\square$ Automático

Sistema acceso personas

$\square$ SAS personas

Sistema acceso materiales

$\square$ Autoclave

$\square>2$ Ud

Sistema acceso animales

$\square$ Ventana SAS

$\square$ Ducha de aire

$\square$ Ventana SAS UV $\square$ CabinaVPH

Organización unidad experimentación barrera animal pequeño

№ de plantas en que se distribuye

$\square$ Una planta $\square$ Varias plantas

Unidad independiente a convencional a. pequeño $\square$ Sí $\square$ NO Zonas compartidas

$\square$ Almacenes $\square$ sala lavado $\square$ Vestuarios

Tipo de distribución

$\square$ Pasillo simple $\square$ Pasillo doble $\square$ Pasillo Triple

Área personal en interior barrera $\square$ sí $\square$ NO

Acceso animales

$\square$ SAS desde cuarentena $\square$ SAS desde otro local

Acceso materiales desde

$\square$ Sala lavado-esterilización $\square$ Otros

Barrera materiales comunicada con

$\square$ Almacén material limpio $\square$ Pasillo

Mantenimiento de instalaciones

$\square$ Registros en falso techo $\square$ Planta técnica superior

$\square$ Instalaciones vistas $\square$ Planta registrable inferior 


\section{DOCUMENTACIÓN GRÁFICA I}

\section{Ficha 15: IRYCIS - 03}

IRYCIS

Instituto Ramón y Cajal de Investigación Sanitaria

Identificación Áreas Funcionales

En esta ficha se muestran los planos de distribución en planta que componen el centro de experimentación animal y en los que se reflejan la distribución y organización de las distintas áreas funcionales que lo componen, quedando identificada cada área funcional por el código de color correspondiente, según la leyenda del plano.

Fuente: Elaboración propia.

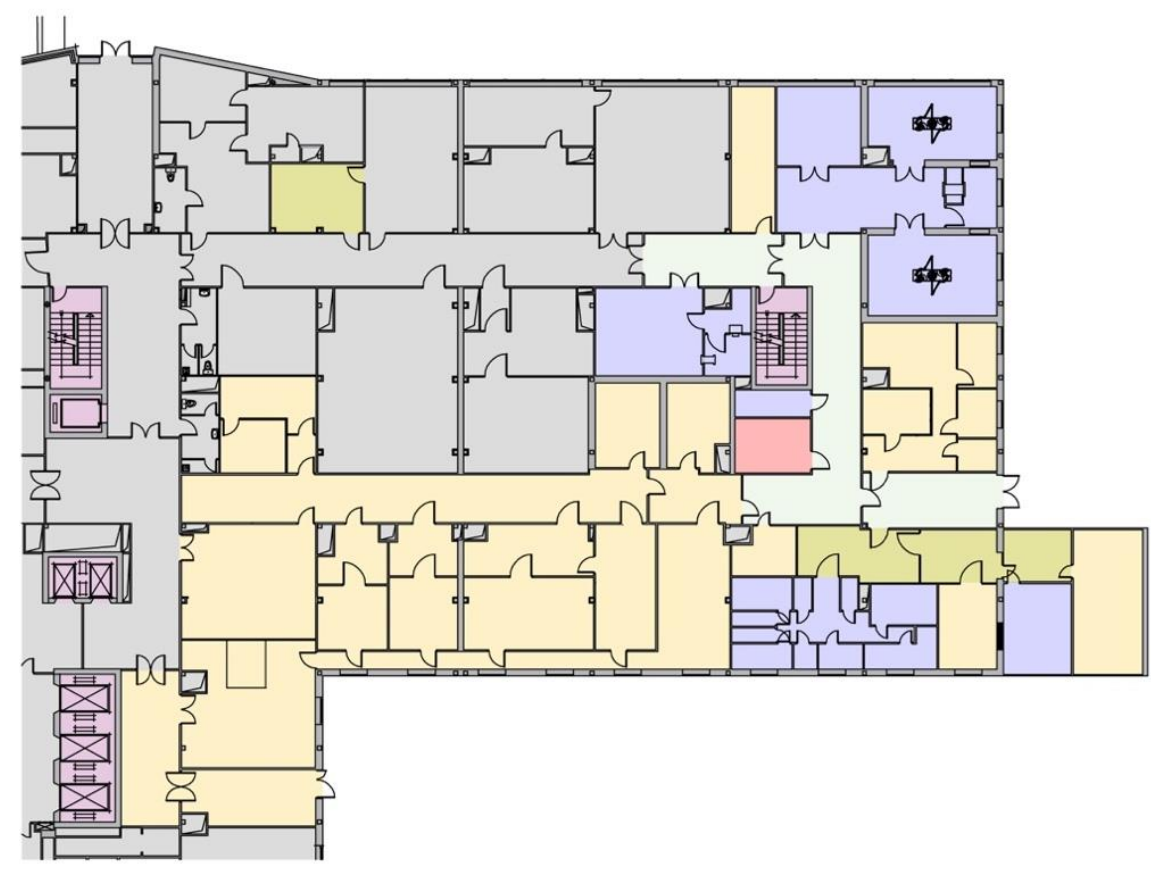

Planta Semisótano -3

Escala: 1/500

\section{ÁREAS FUNCIONALES}

Experimentación animal pequeño

Experimentación animal grande

Áreas comunes animal pequeño y grande

Area Administrativa

Pasillos comunes

Pasillos exteriores y servicios generales

Elementos de circulación vertical 
DOCUMENTACIÓN GRÁFICA ॥

Ficha 16: IRYCIS - 04

IRYCIS

Instituto Ramón y Cajal de Investigación Sanitaria

\section{Identificación Tipo de Locales y Usos}

En esta ficha se muestran los planos de distribución en planta que componen el centro de experimentación animal y en los que se reflejan los locales que lo conforman, quedando identificado cada tipo de local por el código de color correspondiente y el uso del local por el código numérico, según las leyendas de los planos.

Fuente: Elaboración propia.

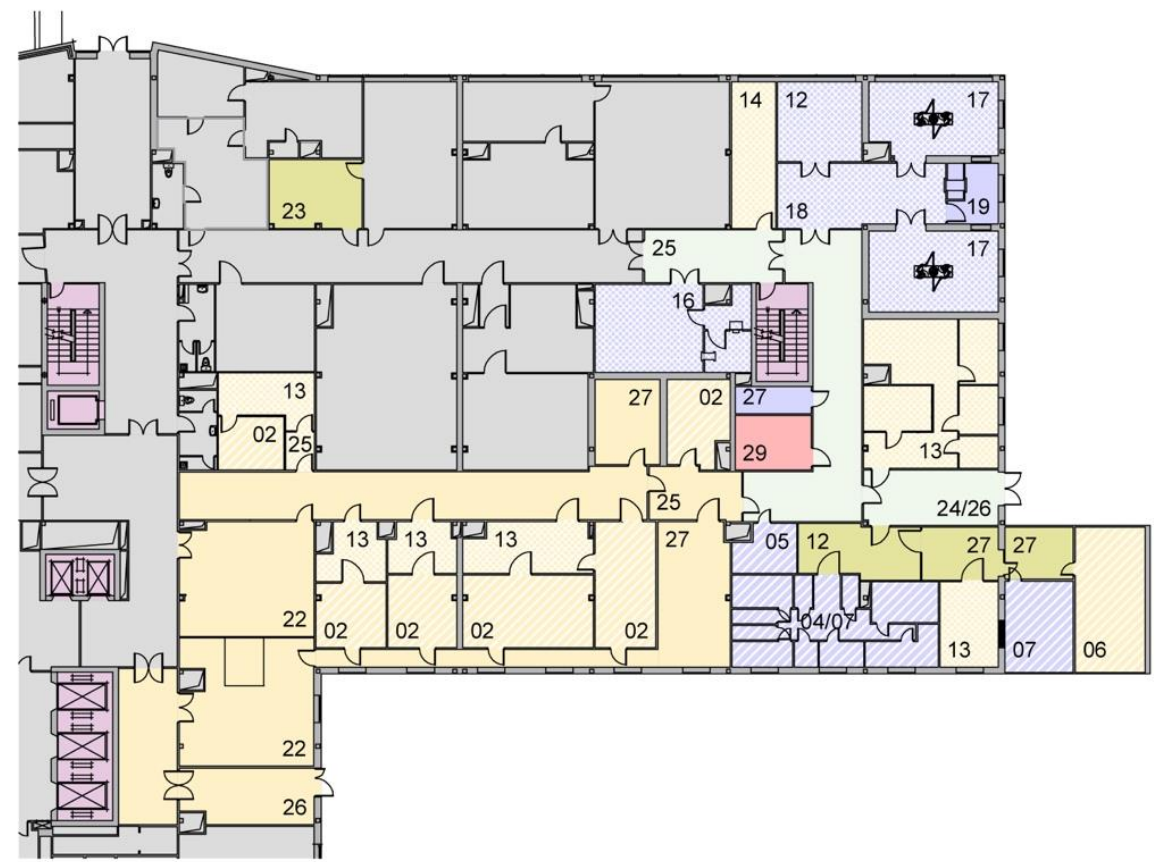

Planta Semisótano -3

Escala: $1 / 500$
TIPO DE LOCALES animal pequeño

Experimentación convencion

animal pequeño

animal pequeño

Estabulación barre

animal pequeño

Experimentación barrera

animal pequeño

Servicios barrera animal

pequeño

Experimentación ABSL2-3

Experimentación común

Servicios comunes
Estabulación convencional

Servicios convencional
Estabulación animal

grande

Experimentación animal

grande

Servicios animal grande Experimentación animales acuáticos

Área administrativa

Pasillos comunes

Pasillos exteriores y

Pasilios exteriores
servicios generales

Elementos circulación

vertical
IDENTIFICACIÓN USO LOCALES

01 Recepción animal

02 Estabulación convencional roedores

03 Estabulación convencional conejos

D4 Estabutión convenciona

05 Cuarentena roedores

06 Cuarentena conejos

07 Cuarentena animal grande

08 Estabulación barrera animal pequeño

09 Experimentación ABSL2 - $09^{\star} A B S L 3$

10 Experimentación peces

11 Lavado animal

12 Preparación anim

13 Procedimientos

14 Microcirugia

16 Imagen
17 Quirófano experimental 18 Preparación médica 19 A. material estéril 20 Necropsias

21 Cirugia cadáveres

22 Lavado y esterilización

23 Vestuarios/Aseos

24 Esclusa animales

25 Esclusa personas

26 Esclusa materiales

28 Servicios

28 Servicios

30 Sala reuniones

31 Pasillo 
PRESENTACIÓN

IIS biodonostia

http://www.biodonostia.org
Ficha 17: IIS biodonostia - 01

Instituto de Investigación Sanitaria biodonostia

Febrero 2020

\section{biodonostia}

osasun ikerketa institutua

instituto de investigación sanitaria

\section{Acreditación del Instituto}

El Instituto de Investigación Sanitaria biodonostia (IIS biodonostia) se creó en el año 2008 gracias al compromiso de los investigadores, las entidades públicas y otros entes financiadores, siendo acreditado en el año 2011 como Instituto de Investigación Sanitaria por parte del Instituto de Salud Carlos III y re-acreditándose en el año 2016 logrando de este modo mantenerse como uno de los Institutos de Salud referentes a nivel estatal.

\section{Composición}

Su núcleo de referencia es la OSI Donostialdea (Organización Sanitaria Integrada), y al igual que en la mayoría de Institutos de Investigación Sanitaria, también está integrada en este caso por la Universidad del País Vasco. A este núcleo se encuentran asimismo incorporadas la Diputación Foral de Gipuzkoa, la Fundación Euskampus y la Fundación Ikerbasque. La singularidad del Instituto radica en el resto de los miembros integrantes. Se encuentra incluida Atención Primaria, los Hospitales Comarcales y las OSIs del territorio de Gipuzkoa. También está integrado el Parque Científico y Tecnológico de Gipuzkoa, y un elevado número de centros de base tecnológica, entre los que se ubican los que forman el Instituto: Vicomtech, Cidetec, Osatek, Matía Instituto Gerontológico, BCBL y Onkologikoa, y centros convenidos asimismo con el Instituto que no están dentro de sus Órganos de Gobierno: CIC nanoGUNE, CIC biomaGUNE, Tecnalia, CITA Alzheimer y Fundación Dr. Carlos Elosegui de Policlínica Gipuzkoa.

\section{Misión}

La misión del IIS Biodonostia es ser el centro de I+D+i de referencia del Sistema Sanitario Público en Gipuzkoa, liderar el desarrollo de actividades científicas e innovadoras de excelencia de carácter traslacional y gran repercusión en Euskadi, generando sinergias con su entorno empresarial que permitan afrontar proyectos de valor añadido cuyos resultados reviertan en el paciente y la sociedad.

\section{Áreas de investigación}

El IIS Biodonostia se configura científicamente en torno a tres áreas de investigación transversales y siete áreas de investigación verticales. Las áreas verticales son: Neurociencias, Enfermedades hepáticas y gastrointestinales; Enfermedades infecciosas; Oncología; Enfermedades sistémicas; Epidemiología y salud pública; y Bioingeniería. Por otra parte, las áreas de investigación transversal tienen como objetivo impulsar la especialización en Envejecimiento y en Medicina de precisión, potenciar la excelencia en investigación e innovación, desarrollar Proyectos de Investigación e Innovación de ato impacto, e Innovación orientada al mercado y a resultados en salud. 


\section{CARACTERÍSTICAS PRINCIPALES}

Instituto de Investigación Sanitaria Biodonostia

IIS Biodonostia

Centro de experimentación animal

\section{DATOS IDENTIFICACIÓN DEL INSTITUTO}

Hospital asociado

Localidad

Año acreditación

Fecha toma de datos

Hospital Universitario Donostia

Donostia

2011

2016

\section{CENTRO EXPERIMENTACIÓN ANIMAL}

Características generales centro experimentación animal

Superficie del centro experimentación animal
$\bigotimes<750 \mathrm{~m}^{2}$
$\square 750$ - $1.500 \mathrm{~m}^{2}$

$\square>1.500 \mathrm{~m}^{2}$

Superficie experimentación animal grande

$\bigotimes<200 \mathrm{~m}^{2} \quad \square 200-400 \mathrm{~m}^{2}$
Superficie experimentación animal pequeño

$\square<500 \mathrm{~m}^{2} \quad \square 500-1.000 \mathrm{~m}^{2}$
Tipo de centro de experimentación animal

$\square>400 \mathrm{~m}^{2}$

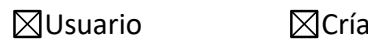

Acreditación AAALAC

$\square$ Sí $\quad$ \NO

Tipo de experimentación

Animal pequeño

\Convencional $\triangle$ Barrera $\square$ Contención riesgo biológico

Nivel de Bioseguridad $\square$ BSL1 $\square$ BSL2 $\square$ BSL3 $\square$ BSL4

Animal grande

凶Convencional $\square$ Barrera $\square$ Contención riesgo biológico

\section{Organización centro experimentación animal}

Edificio ubicado en el hospital

Tipo de edificio

Año construcción centro experimentación

$\square$ Anterior año 2.009

\Posterior año 2009

№ de edificios en que se distribuye $\quad$ Uno $\square$ Varios

№ de plantas en que se distribuye $\quad$ Una $\square$ Varias

Tipo de división en plantas $\quad$ \NP

$\square$ Área animal grande / Área animal pequeño

$\square$ Área animalario / Área experimentación

$\square$ Experimentación animal /Servicios

$\square$ Cirugía experimental / Experimentación animal pequeño

Tipo de planta en la que se ubica

$\square$ Bajo rasante $\square$ A cota “0" $\square$ Sobre rasante

Accesos exteriores independientes invest./animales $\bigotimes$ sí $\square$ NO Circulación vertical acceso animales $\square$ sí $\bigotimes N \mathrm{NO}$ Circulación vertical interior animales $\square$ sí $\bigotimes N \mathrm{NO}$ Transporte vertical independiente limpio/sucio $\triangle N P \square$ sí $\square$ NO Áreas animal grande/pequeño independizadas $\square$ sí $\square$ NO Ubicación zona administrativa

Externa al área experimentación animal

\section{3. ÁREA EXPERIMENTACIÓN ANIMAL GRANDE}

Organización área experimentación animal grande

Superficie experimentación animal grande
$\bigotimes<200 \mathrm{~m}^{2}$
$\square 200-400 \mathrm{~m}^{2}$
$\square>400 \mathrm{~m}^{2}$

№ de planta en que se distribuye

\Una

$\square$ Varias

Tipo división para varias plantas

$\square$ Área animalario / Área experimentación

$\square$ Área animal grande / Área animal pequeño

Tipo de planta en la que se ubica

$\square$ Bajo rasante $\triangle A$ cota “0" $\square$ Sobre rasante

Circulación vertical acceso animales $\square$ Sí $\quad$ NO

Accesos independientes investigadores/animales $\bigotimes \mathrm{sí} \quad \square \mathrm{NO}$

Áreas animal grande/pequeño independizadas $\square$ sí $\quad$ NO

Zonas compartidas de animal grande y pequeño

$\triangle$ Vestuarios $\triangle$ Pasillos investigadores $\triangle$ Almacenes

$\square$ Áreas lavado $\triangle$ Pasillos animales $\quad$ Salas preparación

$\square$ Otras

Circulación vertical interior animales grandes

$\square$ sí $\quad$ NO

Áreas de experimentación

\Área quirúrgica experimental

$\square$ Experimentación con cadáveres

$\square$ Necropsias

$\square$ otros

$\square$ Área Imagen

\section{1. Área estabulación animal grande}

Características generales área estabulación animal grande

Superficie locales alojamiento animal grande

$\bigotimes<50 \mathrm{~m}^{2} \quad \square>50 \mathrm{~m}^{2}$

Especies animales

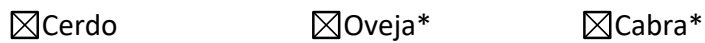

$\square$ Perro* $\square$ Gato* $\quad \square$ Otras*

*Ocasionalmente

Tipo de alojamiento

冈Convencional $\square$ Barrera $\square$ Contención riesgo biológico Conejos estabulados con animales grandes $\square$ sí $\square$ NO № Locales de alojamiento

\2 Ud $\square>2$ Ud

Zona recuperación post anestésica

凶sí $\square$ No

Locales de servicio

Sala limpieza y aclimatación

\sí $\square \mathrm{NO}$

Sala necropsias

$\square$ sí 凶NO

Sistema almacenaje residuos animal

$\square$ Cámara congelación-20 $\square$ Congelador -20ㅡ \Almacén 


\section{Organización del área estabulación animal grande}

Tipo de planta en la que se ubica

$\square$ Bajo rasante $\square$ A cota "0"

$\square$ Sobre rasante

Circulación vertical acceso animales

$\square$ sí $\triangle N \mathrm{NO}$

Accesos independientes para cuidadores y animales $\bigotimes$ sí $\square$ NO Estabulación animal grande/pequeño independizada $\square$ sí $\bigotimes N O$ Zonas compartidas de animal grande y pequeño

\Pasillos \Almacenes $\square$ Otras

\section{Sistemas de estabulación animal grande}

\section{Tipo de boxes}

$\square$ Realizados in situ $\quad$ Prefabricados

$\square$ Fijos $\quad$ MModulares

$\square$ Sobre forjado $\quad$ Sobre fosa de purines $\square$ En jaulas

Refuerzo en paramentos perimetrales de boxes: $\quad$ Sí $\square$ NO

Curva sanitaria en suelo

Entreplanta técnica superior

$\square$ Transitable $\quad$ No transitable

Planta técnica inferior

\sí $\square$ NO

凶sí $\square$ No

Luz natural área estabulación

Fotoperiodo $12 \mathrm{~h}$ luz/oscuridad

$\square$ sí $\bigotimes N O$

$\square$ sí $\bigotimes$ NO

凶sí $\square$ NO

\section{2. Área quirúrgica experimental animal grande}

\section{Características generales área quirúrgica experimental}

Superficie área quirúrgica animal grande

\begin{tabular}{|c|c|c|}
\hline$\triangle<70 \mathrm{~m}^{2}$ & \multicolumn{2}{|l|}{$\square>100 \mathrm{~m}$} \\
\hline Salas quirúrgicas & \multirow{2}{*}{\multicolumn{2}{|c|}{$\square$ Quirófano múltiple }} \\
\hline$\square$ Quirófano simple $\quad$ Quirófano doble & & \\
\hline Quirófano modulable & 口sí & $\triangle N O$ \\
\hline Diseño tipo quirófanos asistenciales & 凶sí & $\square \mathrm{NO}$ \\
\hline Sistema retransmisión imagen & $\square$ sí & \NO \\
\hline Área experimentación cadáveres & $\square$ sí & $\triangle N O$ \\
\hline Entreplanta técnica superior & 凶sí & $\square$ NO \\
\hline
\end{tabular}

$\square$ Transitable $\quad$ No transitable

Luz natural quirófanos

$\square$ sí $\quad \mathrm{NO}$

\section{Organización del área quirúrgica experimental}

Tipo de planta en la que se ubica

\section{$\square$ Bajo rasante $\square$ A cota “0" $\square$ Sobre rasante}

Circulación vertical interna animales acceso al área $\square$ sí $\bigotimes N O$

Accesos independientes investigadores y animales $\quad$ Sí $\square$ NO

Área quirúrgica animal grande/pequeño indep.

$\square$ sí $\bigotimes N O$

Zonas compartidas de animal grande y pequeño
$\triangle$ Pasillos
\Vestuarios
冈Preparación animal
$\square$ Preparación médica

$\square$ Otros

Configuración pasillos área quirúrgica

$\square$ Pasillo único $\quad$ Doble pasillo
4. ÁREA EXPERIMENTACIÓN ANIMAL PEQUEÑO

Características generales área experimentación animal pequeño

Superficie experimentación animal pequeño
$\square<500 \mathrm{~m}^{2}$
\500-1.000 m²
$\square>1.000 \mathrm{~m}^{2}$
Especies animales
* Ocasionalmente

\Roedores $\quad$ Llogomorfos $\square$ Animales acuáticos

Unidades de experimentación

\Convencional $\quad$ Barrera $\square$ Contención riesgo biológico

Nivel de bioseguridad

$\square$ BSL1 $\square$ BSL2 $\square$ BSL3 $\square$ BSL4

\section{Organización área experimentación animal pequeño}

№ de plantas en que se distribuye

\Una planta $\square$ Dos plantas $\square$ Tres plantas

Tipo de planta en la que se ubica

$\square$ Bajo rasante $\square$ A cota “ 0 " $\square$ Sobre rasante

Circulación vertical animales

$\square$ De acceso al área $\square$ Circulación interior $\quad \square$ No

Experimentación a. grande/pequeño independizada $\square$ sí $\bigotimes N O$

Características constructivas área experimentación a. pequeño

Divisiones interiores

$\square$ Modular $\quad$ Realizada in situ

Revestimientos verticales

\Pintura epoxi $\square$ PVC rollo $\square$ Resina fenólica $\square$ otros

Protección contra choques

Pavimentos

$\square$ PVC rollo $\quad$ Resinas epoxi $\square$ Otros

Curva sanitaria en suelo

$\square$ sí \NO

Techos

$\square$ Autoportante $\otimes$ Falso techo continuo $\square$ Instalaciones vistas Carpinterías de puertas

Tipo

\Abatible $\square$ Corredera $\quad$ Manual $\square$ Automática

Acabados

$\square$ Resina fenólica $\quad$ Metálica lacada $\square$ Acero Inox

$\square$ Otros

Refuerzo inferior/parachoques puerta: $\square$ sí $\quad$ NO

Mirilla \sí $\square$ NO

\Vidrio $\square$ Vidrio + clapeta $\square$ Vidrio con vinilo rojo $\square$ Digital lluminación

lluminación natural $\square$ sí \NO

Fotoperiodo 12h luz/oscuridad $\quad$ \sí $\square$ NO

lluminación auxiliar en estabulación (luz roja) \sí $\square$ NO

Ruidos y vibraciones

Elementos absorción acústica en estabulación $\square$ sí $\quad$ \NO

Alarmas fuera del espectro audible animales $\square$ sí $\quad$ NO

Fondo sonoro continuo $\square$ sí $\quad$ \NO

Acceso personas controlada $\quad$ \Sí $\square$ NO

Sistemas control, monitorización y alarmas

Control centralizado \sí $\square$ NO

Paneles indicadores parámetros en salas $\square$ sí $\quad$ NO
$\square$ Ta
$\square \mathrm{Hr}$
$\square$ Presión diferencial 


\subsection{Unidad experimentación convencional animal pequeño \\ Características generales unidad convencional animal pequeño}

Superficie experimentación convencional animal pequeño
$\square<500 \mathrm{~m}^{2}$
$\bigotimes 500-1.000 \mathrm{~m}^{2}$
$\square>1.000 \mathrm{~m}^{2}$

Superficie estabulación convencional animal pequeño

$\bigotimes<100 \mathrm{~m}^{2} \quad \square 100-200 \mathrm{~m}^{2} \quad \square>200 \mathrm{~m}^{2}$

Especies animales

\Rata $\quad$ Ratón $\quad$ Cobaya $\square$ Hámster

$\square$ Jerbo $\quad$ Conejo $\square$ Acuáticos $\square$ Otros

Conejos estabulados con animal pequeño $\square$ NP $\quad$ Sí $\square$ NO

№ salas estabulación roedores

$\bigotimes \leq 5$ Ud $\quad \square>5$ Ud

№ salas estabulación conejos
$\square=1$ Ud
$\bigotimes>1 \cup d$
$\square N P$

Tipo de jaula

囚eutilizable

冈stática

Tipo suministro bebida

冈Biberones

$\square$ Desechable

$\bigotimes$ Ventilada individualmente

Salas experimentación

Procedimientos

Área microcirugía

Área imagen

Área comportamiento

Otros

$\square$ Automático

\section{Organización unidad convencional animal pequeño}

№ de plantas en que se distribuye

\Una planta $\square$ Varias plantas

Unidad independiente a animal grande

Tipo de distribución

$\square$ Pasillo simple $\quad$ Pasillo doble

Estabulación colindante a sala lavado

Sala cuarentena con SAS

Sala lavado y esterilización

囚Compartida con barrera

$\square$ Uso exclusivo convencional

\section{Equipamiento sala lavado y esterilización}

Equipos de vaciado

Aspirador virutas

Equipos de lavado y esterilización

\Lava racks $\square$ Lava jaulas $\bigotimes$ Lava biberones $\bigotimes$ Autoclave

Equipos de llenado

Dispensador viruta

Equipo llenado biberones

$\square$ sí $\quad \mathrm{NO}$

\sí $\square$ NO

$\square$ sí $\quad \mathrm{NO}$
4.2. Unidad experimentación barrera animal pequeño

\sí $\square$ NO

Características generales unidad experimentación barrera

Superficie experimentación barrera animal pequeño
$\bigotimes<200 \mathrm{~m}^{2}$
$\square>200 \mathrm{~m}^{2}$

Superficie estabulación barrera animal pequeño

$\bigotimes<50 \mathrm{~m}^{2}$

$\square>50 \mathrm{~m}^{2}$

Especies animales

\Rata $\quad$ QRatón $\square$ Otros

№ salas estabulación roedores

$\square=1$ ud $\quad \bigotimes \geq 2$ Ud

Tipo de jaula

\Reutilizable $\square$ Desechable

$\square$ Estática $\quad$ VVentilada individualmente

Tipo suministro bebida

\Biberones $\square$ Automático

Salas experimentación

$\square=1$ Ud

$\bigotimes>2$ Ud

Sistema acceso personas

\SAS personas $\square$ Ducha de aire

Sistema acceso materiales

$\square$ Autoclave

$\square$ Ventana SAS UV $\quad$ CabinaVPH

Sistema acceso animales

$\square$ Ventana SAS \Otros

\section{Organización unidad experimentación barrera animal pequeño}

№ de plantas en que se distribuye
\Una planta
$\square$ Varias plantas

Unidad independiente a convencional a. pequeño $\square$ sí $\bigotimes N O$ Zonas compartidas

\Almacenes $\quad$ Ssala lavado $\quad$ Vestuarios

Tipo de distribución

\Pasillo simple $\square$ Pasillo doble $\square$ Pasillo Triple

Área personal en interior barrera $\square$ Sí $\quad$ NO

Acceso animales

$\square$ SAS desde cuarentena $\quad$ SAS desde otro local

Acceso materiales desde

$\square$ Sala lavado-esterilización 凶otros

Barrera materiales comunicada con

$\square$ Almacén material limpio $\bigotimes$ Pasillo

Mantenimiento de instalaciones

$\bigotimes$ Registros en falso techo $\square$ Planta técnica superior

$\square$ Instalaciones vistas $\square$ Planta registrable inferior 


\section{DOCUMENTACIÓN GRÁFICA I}

\section{Ficha 19: IIS biodonostia - 03}

IIS biodonostia

Instituto de Investigación Sanitaria biodonostia

Identificación Áreas Funcionales

En esta ficha se muestran los planos de distribución en planta que componen el centro de experimentación animal y en los que se reflejan la distribución y organización de las distintas áreas funcionales que lo componen, quedando identificada cada área funcional por el código de color correspondiente, según la leyenda del plano.

Fuente: Elaboración propia.

\section{biodonostia}

ososun ikerketo institutu

instituto de investigación sanitario

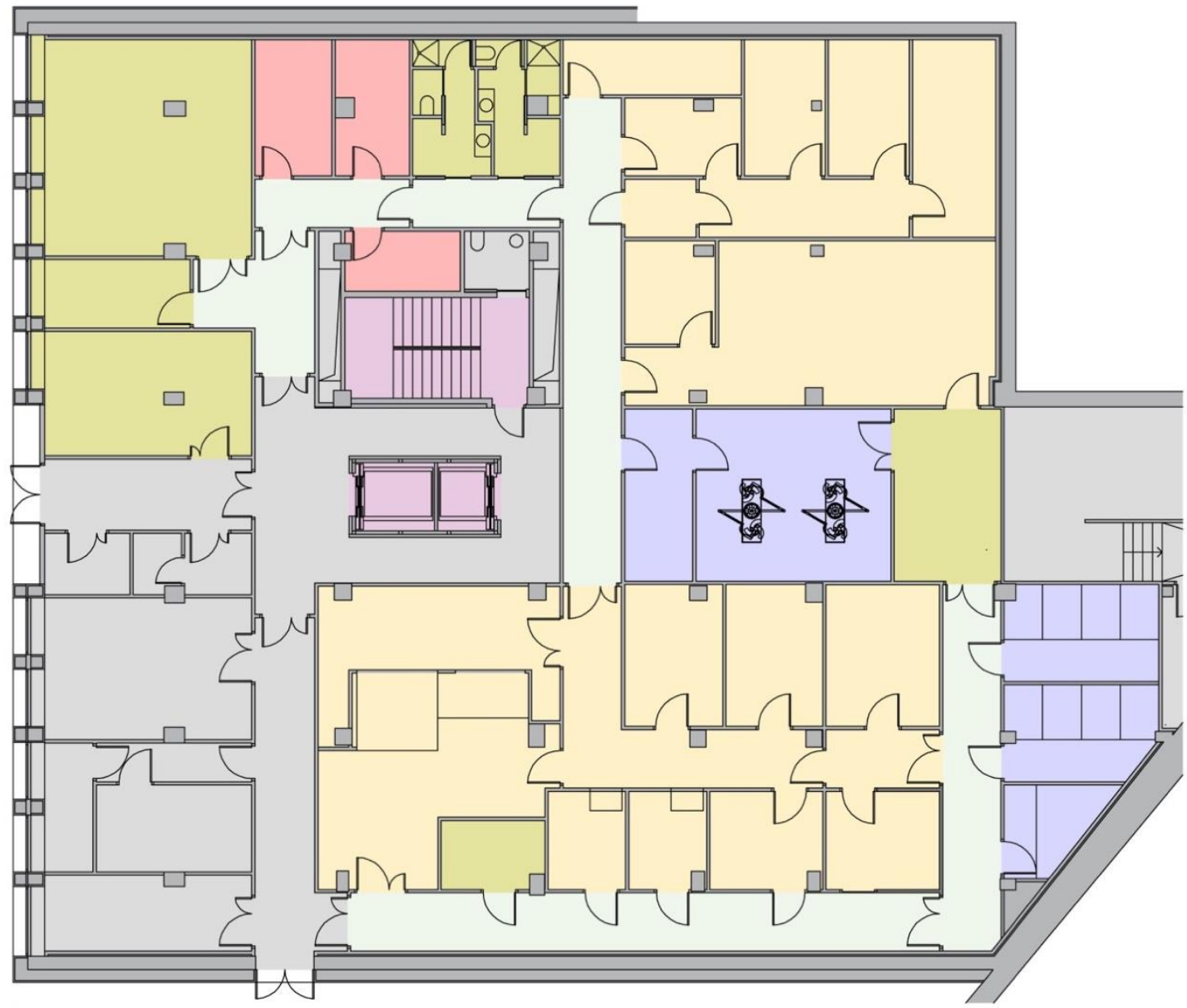

Planta Semisótano

Escala: $1 / 250$

ÁREAS FUNCIONALES

Experimentación animal pequeño

Experimentación animal grande

Áreas comunes animal pequeño y grande

Área Administrativa

Pasillos comunes

Pasillos exteriores y servicios generales

Elementos de circulación vertical 


\section{DOCUMENTACIÓN GRÁFICA II}

Instituto de Investigación Sanitaria biodonostia

IIS biodonostia

\section{les y Usos}

Ficha 20: IIS biodonostia - 04

\section{biodonostia}

osasun ikerketa institutua

instituto de investigación sanitario

En esta ficha se muestran los planos de distribución en planta que componen el centro de experimentación animal y en los que se reflejan los locales que lo conforman, quedando identificado cada tipo de local por el código de color correspondiente y el uso del local por el código numérico, según las leyendas de los planos.

Fuente: Elaboración propia.

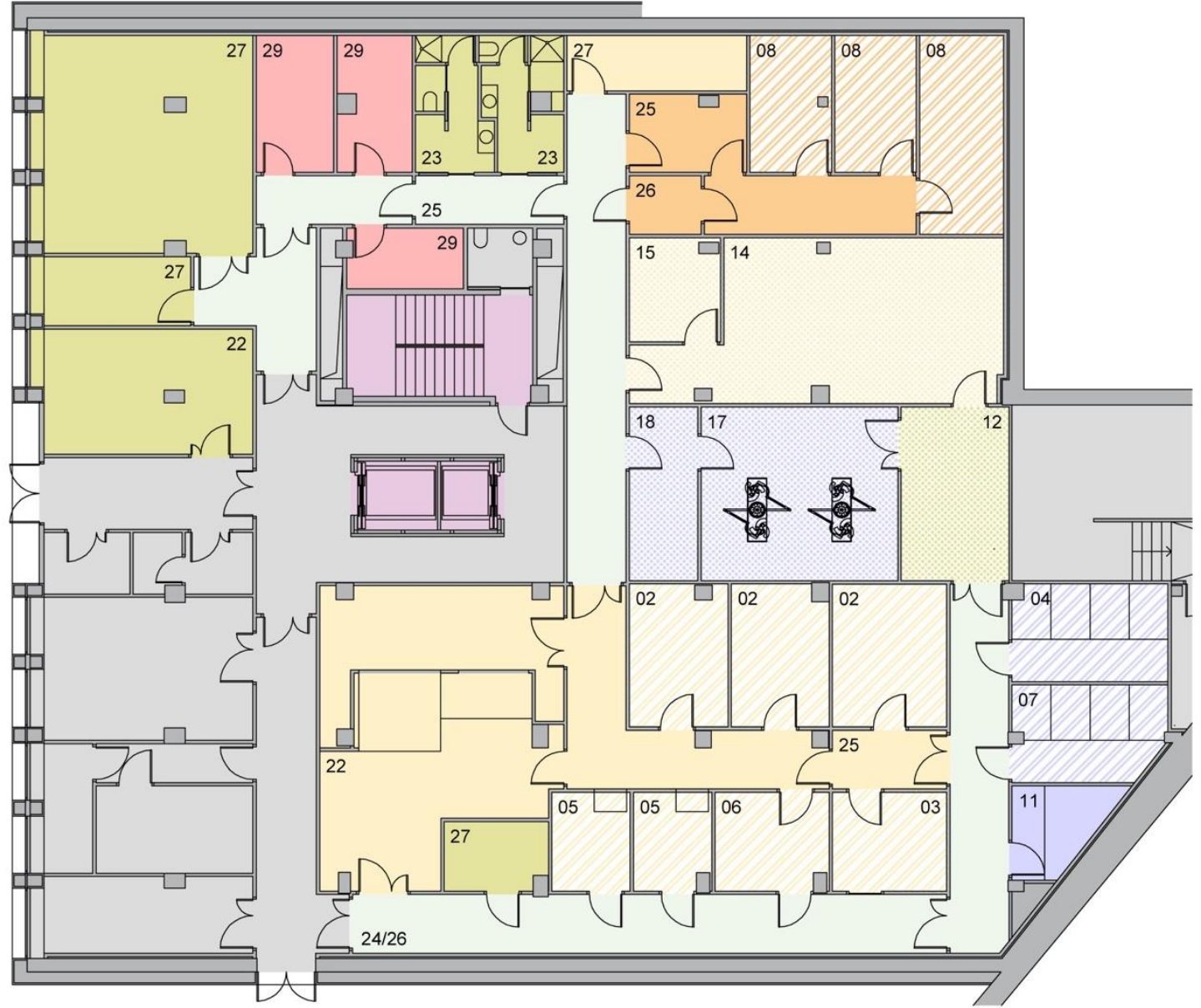

Planta Semisótano

Escala: $1 / 250$

TIPO DE LOCALES

Estabulación convencional animal pequeño

Experimentación convenciona

animal pequeño

Servicios convencion

animal pequeño

animal pequeño

Experimentación

animal pequeño

Servicios barrera anima

pequeño

Experimentación ABSL2-3

Experimentación común

Servicios comunes
Estabulación animal

grande

Experimentación animal

grande

Servicios animal grande

Experimentación animales

acuáticos

Área administrativa

Pasillos comunes

Pasillos exteriores $y$

servicios generales

Elementos circulación

vertical
IDENTIFICACIÓN USO LOCALES

01 Recepción animal

02 Estabulación convencional roedores

03 Estabulación convencional conejos

19 A materión médica

20 Necropsias

05 Cuarentena roedores 21 Cirugia cadáveres

06 Cuarentena conejos 22 Lavado y esterilización

07 Cuarentena animal grande 23 Vestuarios / Aseos

08 Estabulación barrera animal pequeño 24 Esclusa animales

09 Experimentación ABSL2 - 09*ABSL3 25 Esclusa person

10 Experimentación peces 09 ABSL3

10 Experimentacion peces 26 Esclusa materiales

11 Lavado animal

12 Preparación anim

14 Microcirugia

15 Comportamiento

16 Imagen
28 Servicios

28 Servicios

29 Despacho

31 Pasillo

31 Pasillo 
PRESENTACIÓN

IIS biocruces

https://www.biocrucesbizkaia.org/web/biocruces/inicio
Ficha 21: IIS biocruces - 01

Biocruces Bizkaia Instituto de Investigación Sanitaria

Febrero 2020

\section{biocruces}

osasun ikerketa institutua

instituto de investigación sanitaria

\section{Acreditación del Instituto}

Biocruces Bizkaia Instituto de Investigación Sanitaria (IIS biocruces) se crea en el año 2008, de acuerdo a la estrategia propuesta desde el Instituto de Salud Carlos III de desarrollo de los Institutos de Investigación Sanitaria como estructuras organizativas de promoción y desarrollo de la Investigación en los Hospitales. Su finalidad era promover la investigación biomédica, epidemiológica, de salud pública y en servicios sanitarios, fundamentar científicamente los programas y políticas del sistema sanitario y potenciar de forma preferente la investigación traslacional, de manera que en el año 2015 obtiene la acreditación como Instituto de investigación Sanitaria por parte del Instituto de Salud Carlos III.

\section{Composición}

El núcleo de IIS Biocruces Bizkaia es el Hospital Universitario Cruces que durante muchos años, ha sido un referente sanitario, en asistencia, docencia e investigación. A lo largo de los años, se ha ido configurando la estructura organizativa y científica, así como desarrollando acuerdos y convenios para la integración de grupos, unidades y organizaciones dentro del Instituto, siendo las entidades que lo conforman las siguientes: Departamento de Salud del Gobierno Vasco; Osakidetza; Universidad del País Vasco, La Fundación Vasca de Innovación e Investigación Sanitaria BIOEF y la BBK. Así mismo, Biocruces Bizkaia ha establecido una red de alianzas con los agentes biotecnológicos, destacándose los acuerdos con CIC bioGUNE, BCAM e Ikerbasque.

\section{Misión}

Tiene como misión promover, cohesionar y apoyar a los grupos de investigación que conforman el Instituto para desarrollar una investigación traslacional de calidad y potenciar la innovación efectiva y la colaboración con otras entidades. Todo ello con el fin de proporcionar nuevas herramientas, prácticas y conocimiento para contribuir a la mejora de la atención sanitaria, la salud de la población, la creación de riqueza y el desarrollo económico.

\section{Áreas de investigación}

Las siete principales áreas de investigación del instituto se centran en: Atención primaria en salud, prevención y enfermedades crónicas; Cáncer; Endocrinología, metabolismo, nutrición y enfermedades renales; Enfermedades autoinmunes, inflamatorias e infecciosas; Enfermedades del sistema nervioso; Innovación en cirugía, trasplante y técnicas para la salud; y Salud materno-infantil y reproducción asistida. 
CARACTERÍSTICAS PRINCIPALES

Ficha 22: IIS Biocruces - 02

IIS Biocruces

Biocruces Bizkaia Instituto de Investigación Sanitaria

Centro de experimentación animal

\section{biocruces}

osasun ikerketa institutua instituto de investigación sanitaria

\section{DATOS IDENTIFICACIÓN DEL INSTITUTO}

Hospital asociado

Localidad

Año acreditación

Fecha toma de datos

Hospital Universitario de Cruces Barakaldo

2015

2017

\section{CENTRO EXPERIMENTACIÓN ANIMAL}

Características generales centro experimentación animal

Superficie del centro experimentación animal

$$
\square<750 \mathrm{~m}^{2} \quad \text { } \square 750-1.500 \mathrm{~m}^{2}
$$

Superficie experimentación animal grande

$\square<200 \mathrm{~m}^{2} \quad \square 200-400 \mathrm{~m}^{2}$
Superficie experimentación animal pequeño

$\square<500 \mathrm{~m}^{2} \quad \square 500-1.000 \mathrm{~m}^{2}$
Tipo de centro de experimentación animal

\Usuario $\quad$ \Cría

Acreditación AAALAC

$\square$ sí $\quad$ \NO

Tipo de experimentación

Animal pequeño

\Convencional $\quad$ Barrera $\square$ Contención riesgo biológico

Nivel de Bioseguridad $\square$ BSL1 $\square$ BSL2 $\square$ BSL3 $\square$ BSL4

Animal grande

冈Convencional $\square$ Barrera $\square$ Contención riesgo biológico

\section{Organización centro experimentación animal}

Edificio ubicado en el hospital

Tipo de edificio

Año construcción centro experimentación

$\square$ Anterior año 2.009

\Posterior año 2009

№ de edificios en que se distribuye $\quad$ Uno $\square$ Varios

№ de plantas en que se distribuye $\square$ Una $\quad$ Varias

Tipo de división en plantas $\square$ NP

\Área animal grande / Área animal pequeño

$\square$ Área animalario / Área experimentación

$\square$ Experimentación animal /Servicios

$\square$ Cirugía experimental / Experimentación animal pequeño

Tipo de planta en la que se ubica
\Bajo rasante
$\triangle \mathrm{A}$ cota "O"
$\square$ Sobre rasante

Accesos exteriores independientes invest./animales $\bigotimes$ Sí $\square$ NO Circulación vertical acceso animales

Circulación vertical interior animales

凶sí $\square$ No

Transporte vertical independiente limpio/sucio

Áreas animal grande/pequeño independizadas

Ubicación zona administrativa

Externa al área experimentación animal

\section{3. ÁREA EXPERIMENTACIÓN ANIMAL GRANDE}

Organización área experimentación animal grande

Superficie experimentación animal grande
$\square<200 \mathrm{~m}^{2}$
$\bigotimes 200-400 \mathrm{~m}^{2}$
$\square>400 \mathrm{~m}^{2}$

№ de plantas en que se distribuye

\Una

$\square$ Varias

Tipo división para varias plantas

$\square$ Área animalario / Área experimentación

$\square$ Área animal grande / Área animal pequeño

Tipo de planta en la que se ubica

$\square$ Bajo rasante $\triangle$ A cota “0" $\square$ Sobre rasante

Circulación vertical acceso animales $\square$ Sí $\quad$ NO

Accesos independientes investigadores/animales $\quad \mathrm{sí} \quad \square \mathrm{NO}$

Áreas animal grande/pequeño independizadas $\quad$ sí $\square$ NO

Zonas compartidas de animal grande y pequeño

$\square$ Vestuarios $\square$ Pasillos investigadores $\square$ Almacenes

$\square$ Áreas lavado $\square$ Pasillos animales $\square$ Salas preparación

$\square$ Otras

Circulación vertical interior animales grandes

$\square$ sí $\quad$ No

Áreas de experimentación

\Área quirúrgica experimental $\quad$ Necropsias

$\square$ Experimentación con cadáveres $\quad \square$ Área Imagen

$\square$ Otros

\section{1. Área estabulación animal grande}

Características generales área estabulación animal grande

Superficie locales alojamiento animal grande

$\bigotimes<50 \mathrm{~m}^{2} \quad \square>50 \mathrm{~m}^{2}$

Especies animales

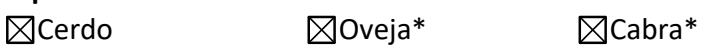

$\square$ Perro* $\square$ Gato* $\quad \square$ Otras*

*Ocasionalmente

Tipo de alojamiento

冈Convencional $\square$ Barrera $\square$ Contención riesgo biológico Conejos estabulados con animales grandes $\square$ sí $\bigotimes N O$ № Locales de alojamiento

\2 Ud $\square>2$ Ud

Zona recuperación post anestésica

Locales de servicio

Sala limpieza y aclimatación

凶sí $\square$ NO

Sala necropsias

\sí $\square$ NO

凶sí $\square$ NO

Sistema almacenaje residuos animal

凶Cámara congelación-20 $\square$ Congelador -20ㄷ $\square$ Almacén 


\section{Organización del área estabulación animal grande}

Tipo de planta en la que se ubica

$\square$ Bajo rasante $\square$ A cota "0"

$\square$ Sobre rasante

Circulación vertical acceso animales

$\square$ sí $\triangle N \mathrm{NO}$

Accesos independientes para cuidadores y animales $\bigotimes$ sí $\square$ NO

Estabulación animal grande/pequeño independizada $\bigotimes S i ́$ $\square$ NO

Zonas compartidas de animal grande y pequeño

$\square$ Pasillos $\square$ Almacenes $\square$ Otras

\section{Sistemas de estabulación animal grande}

Tipo de boxes

$\square$ Realizados in situ $\quad$ Prefabricados

$\square$ Fijos $\quad$ MModulares

$\square$ Sobre forjado $\quad$ Sobre fosa de purines $\square$ En jaulas

Refuerzo en paramentos perimetrales de boxes $\quad$ SÍ $\square$ NO

Curva sanitaria en suelo

Entreplanta técnica superior

$\square$ Transitable $\quad$ No transitable

Planta técnica inferior

\sí $\square \mathrm{NO}$

凶sí $\square$ No

Luz natural área estabulación

Fotoperiodo $12 \mathrm{~h}$ luz/oscuridad

凶sí $\square$ NO

$\square$ sí $\square \mathrm{NO}$

\sí $\square$ NO

\section{2. Área quirúrgica experimental animal grande}

\section{Características generales área quirúrgica experimental}

Superficie área quirúrgica animal grande

$\square<70 \mathrm{~m}^{2} \quad \square 70-100 \mathrm{~m}^{2} \quad \square>100 \mathrm{~m}$

Salas quirúrgicas

囚Quirófano simple Quirófano doble $\square$ Quirófano múltiple Quirófano modulable

Diseño tipo quirófanos asistenciales

Sistema retransmisión imagen

Área experimentación cadáveres

Entreplanta técnica superior

$\square$ Transitable

$\bigotimes$ No transitable

Luz natural quirófanos

$\square$ sí $\quad \mathrm{NO}$

\section{Organización del área quirúrgica experimental}

Tipo de planta en la que se ubica

\section{$\square$ Bajo rasante $\bigotimes$ A cota “0" $\square$ Sobre rasante}

Circulación vertical interna animales acceso al área $\square$ Sí $\bigotimes N O$

Accesos independientes investigadores y animales $\quad$ Sí $\square$ NO

Área quirúrgica animal grande/pequeño indep.

凶sí $\square$ No

Zonas compartidas de animal grande y pequeño
$\square$ Pasillos
$\square$ Vestuarios
$\square$ Preparación animal
$\square$ Preparación médica
$\square$ otros

Configuración pasillos área quirúrgica

$\square$ Pasillo único $\quad$ Doble pasillo
4. ÁREA EXPERIMENTACIÓN ANIMAL PEQUEÑO

Características generales área experimentación animal pequeño

Superficie experimentación animal pequeño
$\square<500 \mathrm{~m}^{2}$
冈500-1.000 m²
$\square>1.000 \mathrm{~m}^{2}$

Especies animales

\Roedores $\quad$ Logomorfos

*Ocasionalmente

Unidades de experimentación

\Convencional $\quad$ Barrera $\square$ Contención riesgo biológico

Nivel de bioseguridad

$\square$ BSL1 $\square$ BSL2 $\square$ BSL3 $\square$ BSL4

\section{Organización área experimentación animal pequeño}

№ de plantas en que se distribuye

\Una planta $\square$ Dos plantas $\square$ Tres plantas

Tipo de planta en la que se ubica

\Bajo rasante $\square$ A cota " 0 " $\square$ Sobre rasante

Circulación vertical animales

$\triangle$ De acceso al área $\square$ Circulación interior $\quad \square$ No

Experimentación a. grande/pequeño independizada $\bigotimes$ sí $\square$ NO

Características constructivas área experimentación a. pequeño

Divisiones interiores

\Modular $\square$ Realizada in situ

Revestimientos verticales

$\square$ Pintura epoxi $\square$ PVC rollo $\quad$ Resina fenólica $\square$ otros

Protección contra choques $\square$ sí $\square$ NO

Pavimentos

\PVC rollo $\square$ Resinas epoxi $\square$ Otros

Curva sanitaria en suelo

邓sí $\square$ No

Techos

\Autoportante $\square$ Falso techo continuo $\square$ Instalaciones vistas Carpinterías de puertas

Tipo

\Abatible $\square$ Corredera $\quad$ Manual $\square$ Automática

Acabados

\Resina fenólica $\square$ Metálica lacada $\square$ Acero Inox

$\square$ otros

Refuerzo inferior/parachoques puerta: $\square$ sí $\quad$ NO

Mirilla \sí $\square$ NO

$\square$ Vidrio $\square$ Vidrio + clapeta $\quad$ VVidrio con vinilo rojo $\square$ Digital lluminación

lluminación natural $\square$ sí \NO

Fotoperiodo 12h luz/oscuridad $\quad$ \sí $\square$ NO

lluminación auxiliar en estabulación (luz roja) $\quad$ Sí $\square$ NO

Ruidos y vibraciones

Elementos absorción acústica en estabulación $\quad$ \í $\square$ NO

Alarmas fuera del espectro audible animales $\square$ sí $\quad$ NO

Fondo sonoro continuo

$\square$ sí $\quad \mathrm{NO}$

Acceso personas controlada

\sí $\square$ NO

Sistemas control, monitorización y alarmas

Control centralizado \sí $\square$ NO

Paneles indicadores parámetros en salas $\quad$ \sí $\square$ NO

$\triangle \mathrm{T}^{\mathrm{a}} \quad$ Q $\quad$ Hr $\quad$ Presión diferencial 


\subsection{Unidad experimentación convencional animal pequeño \\ Características generales unidad convencional animal pequeño}

Superficie experimentación convencional animal pequeño
$\square<500 \mathrm{~m}^{2}$
$\bigotimes 500-1.000 \mathrm{~m}^{2}$
$\square>1.000 \mathrm{~m}^{2}$

Superficie estabulación convencional animal pequeño

$\bigotimes<100 \mathrm{~m}^{2} \quad \square 100-200 \mathrm{~m}^{2} \quad \square>200 \mathrm{~m}^{2}$

Especies animales

\Rata $\quad$ Ratón $\square$ Cobaya $\square$ Hámster

$\square$ Jerbo $\quad$ Conejo $\square$ Acuáticos $\square$ Otros

Conejos estabulados con animal pequeño $\square$ NP $\square$ sí $\square$ NO

№ salas estabulación roedores

$\bigotimes \leq 5$ Ud $\square>5$ Ud

№ salas estabulación conejos

$\bigotimes=1$ Ud $\square>1$ Ud $\square$ NP

Tipo de jaula

\Reutilizable

冈stática

Tipo suministro bebida

冈Biberones

$\square$ Desechable

$\bigotimes$ Ventilada individualmente

Salas experimentación

Procedimientos

Área microcirugía

Área imagen

Área comportamiento

$\square$ Automático

Otras

Organización unidad convencional animal pequeño

№ de plantas en que se distribuye

\Una planta $\square$ Varias plantas

Unidad independiente a animal grande

Tipo de distribución

\Pasillo simple $\square$ Pasillo doble

Estabulación colindante a sala lavado

Sala cuarentena con SAS

Sala lavado y esterilización

囚Compartida con barrera

$\square$ Uso exclusivo convencional

\section{Equipamiento sala lavado y esterilización}

Equipos de vaciado

Aspirador virutas

Equipos de lavado y esterilización

$\square$ Lava racks $\bigotimes$ Lava jaulas $\bigotimes$ Lava biberones $\bigotimes$ Autoclave

Equipos de llenado

Dispensador viruta

Equipo llenado biberones
4.2. Unidad experimentación barrera animal pequeño

\sí $\square$ NO

Características generales unidad experimentación barrera

Superficie experimentación barrera animal pequeño
$\bigotimes<200 \mathrm{~m}^{2}$
$\square>200 \mathrm{~m}^{2}$

Superficie estabulación barrera animal pequeño

$\bigotimes<50 \mathrm{~m}^{2}$

$\square>50 \mathrm{~m}^{2}$

Especies animales

\Rata $\quad$ QRatón $\square$ Otros

№ salas estabulación roedores

$\bigotimes=1$ ud $\square \geq 2$ Ud

Tipo de jaula

囚Reutilizable $\square$ Desechable

$\square$ Estática $\quad$ QVentilada individualmente

Tipo suministro bebida

\Biberones $\square$ Automático

Salas experimentación

$\bigotimes=1$ Ud $\square>2$ Ud

Sistema acceso personas
$\square$ SAS personas
冈Ducha de aire

Sistema acceso materiales

\Autoclave

\Ventana SAS UV $\quad$ CabinaVPH

Sistema acceso animales

$\triangle$ Ventana SAS

$\square$ otros

Organización unidad experimentación barrera animal pequeño

№ de plantas en que se distribuye

\Una planta $\square$ Varias plantas

Unidad independiente a convencional a. pequeño $\square$ sí $\quad$ NO Zonas compartidas

\Almacenes $\quad$ \sala lavado $\quad$ Vestuarios

Tipo de distribución

\Pasillo simple $\square$ Pasillo doble $\square$ Pasillo Triple

Área personal en interior barrera $\square$ Sí $\square N O$

Acceso animales

囚SAS desde cuarentena $\square$ SAS desde otro local

Acceso materiales desde

\Sala lavado-esterilización $\square$ Otros

Barrera materiales comunicada con

囚Almacén material limpio $\square$ Pasillo

Mantenimiento de instalaciones

$\square$ Registros en falso techo $\triangle$ Planta técnica superior

$\square$ Instalaciones vistas $\quad$ Planta registrable inferior 


\section{DOCUMENTACIÓN GRÁFICA I}

\section{Ficha 23: IIS biocruces - 03}

IIS biocruces

Biocruces Bizkaia Instituto de Investigación Sanitaria

Identificación Áreas Funcionales

b+ocruces

osasun ikerketa institutua instituto de investigación sanitaria

En esta ficha se muestran los planos de distribución en planta que componen el centro de experimentación animal y en los que se reflejan la distribución y organización de las distintas áreas funcionales que lo componen, quedando identificada cada área funcional por el código de color correspondiente, según la leyenda del plano.

Fuente: Elaboración propia.

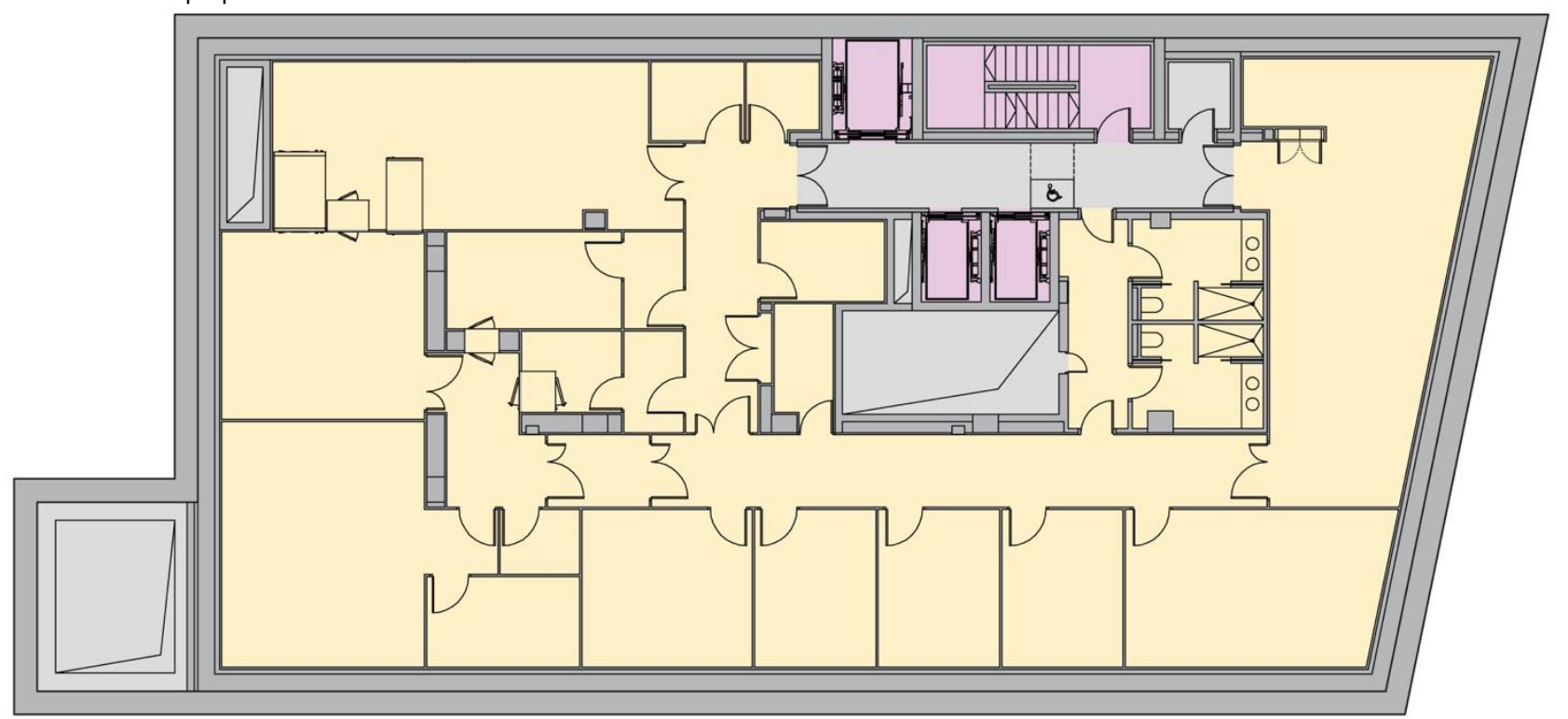

Planta Sótano -1

Escala: 1/250

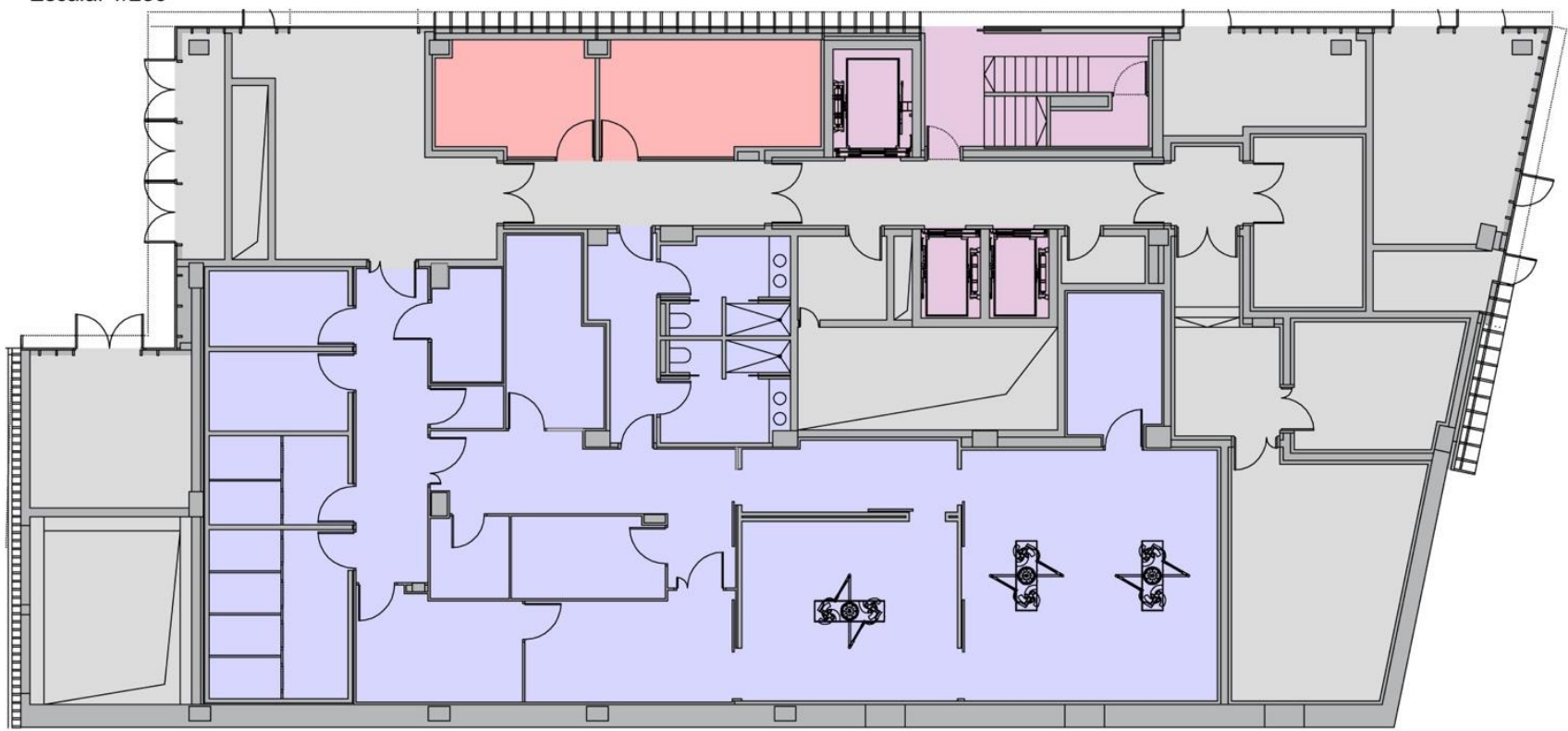

Planta Semisótano

Escala: 1/250

ÁREAS FUNCIONALES

Experimentación animal pequeño

Experimentación animal grande

Áreas comunes animal pequeño y grande

Área Administrativa

Pasillos comunes

Pasillos exteriores y servicios generales

Elementos de circulación vertical 


\section{DOCUMENTACIÓN GRÁFICA II}

Biocruces Bizkaia Instituto de Investigación Sanitaria

IIS biocruces

Locales y Usos

Ficha 24: IIS biocruces - 04

\section{Identificación Tipo de Locales y Usos}

\section{biocruces}

osasun ikerketa institutua

instituto de investigación sanitaria

En esta ficha se muestran los planos de distribución en planta que componen el centro de experimentación animal y en los que se reflejan los locales que lo conforman, quedando identificado cada tipo de local por el código de color correspondiente y el uso del local por el código numérico, según las leyendas de los planos.

Fuente: Elaboración propia.

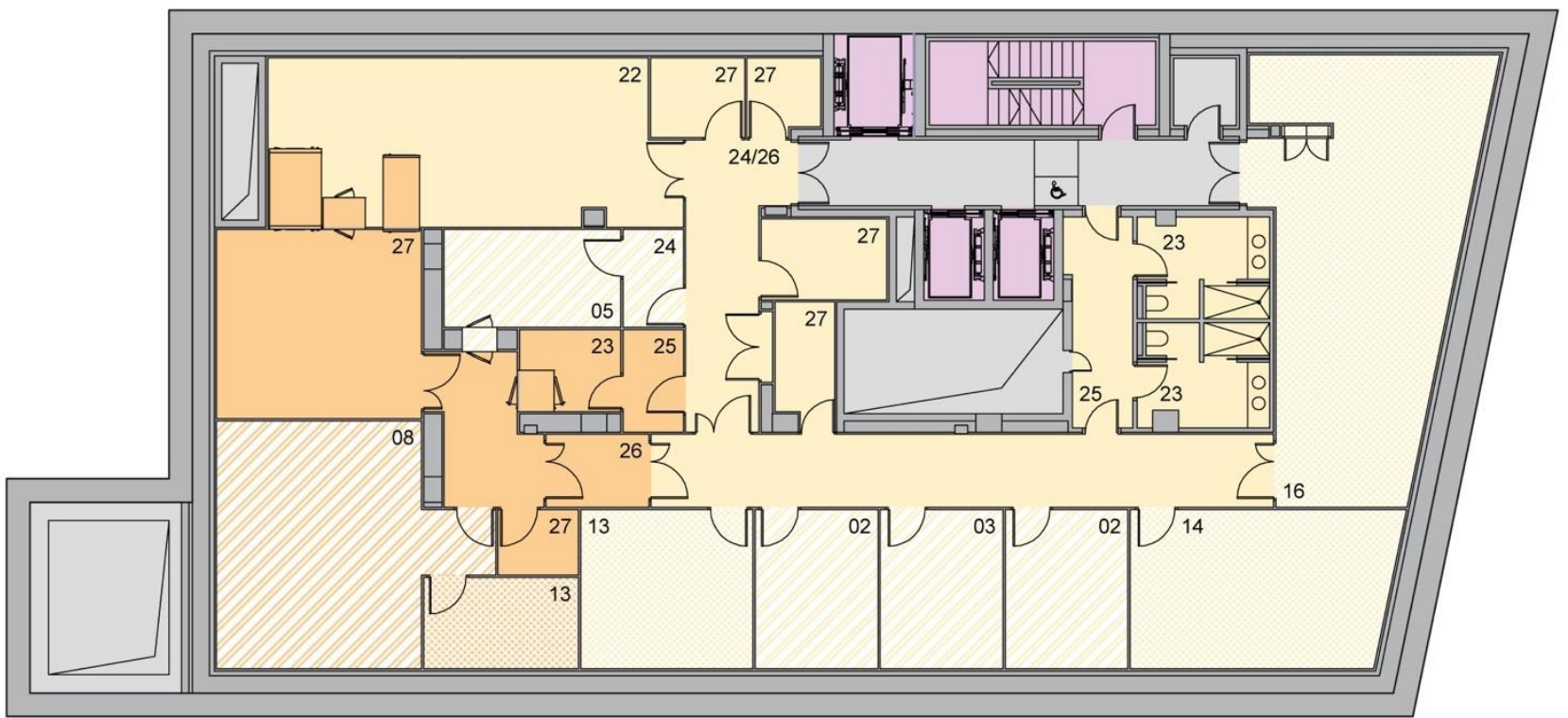

Planta Sótano -1

Escala: $1 / 250$

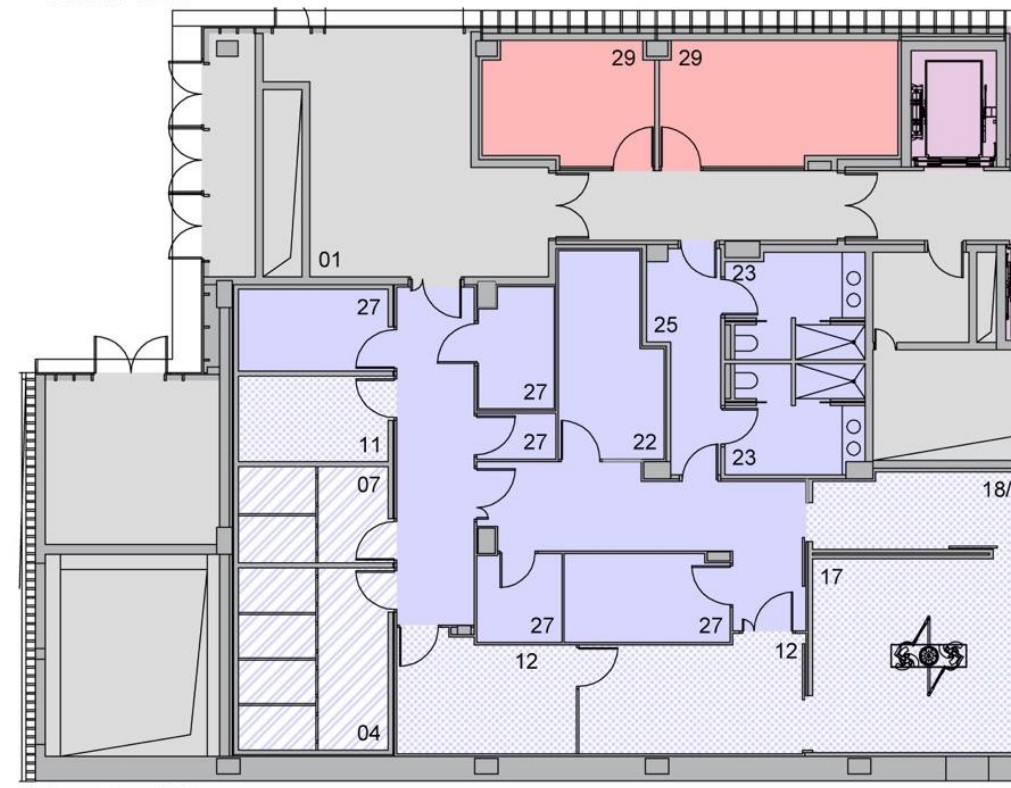

Planta Semisótano

Escala: $1 / 250$

\begin{tabular}{|l}
\hline TIPO DE LOCALES \\
Estabulación convencional \\
animal pequeño \\
Experimentación convencional \\
animal pequeño \\
Servicios convencional \\
animal pequeño \\
Estabulación barrera \\
animal pequeño \\
Experimentación barrera \\
animal pequeño \\
Servicios barrera animal \\
pequeño \\
\hline Experimentación ABSL2-3 \\
\\
Experimentación común \\
Servicios comunes
\end{tabular}

IDENTIFICACIÓN USO LOCALES

01 Recepción animal 17 Quirófano experimenta

02 Estabulación convencional roedores $\quad 18$ Preparación médica

03 Estabulación convencional conejos 19 A. material estéri

04 Estabulación convencional animal grande 20 Necropsias

05 Cuarentena roedores 21 Cirugia cadáveres

06 Cuarentena conejos 22 Lavado y esterilización

07 Cuarentena animal grande 23 Vestuarios / Aseos

O8 Estabulacion barrera animal pequeño 24 Esclusa animales

10 Experimentación peces $\quad 26$ Esclusa materiales

11 Experimentación peces 27 Almasén / archivo

12 Preparación animal 28 Servicios

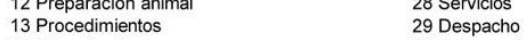

14 Microcirugia $\quad 30$ Sala reuniones

$\begin{array}{ll}15 \text { Comportamiento } & 31 \text { Pasillo } \\ 16 \text { Imagen } & 32 \text { Otros }\end{array}$ 


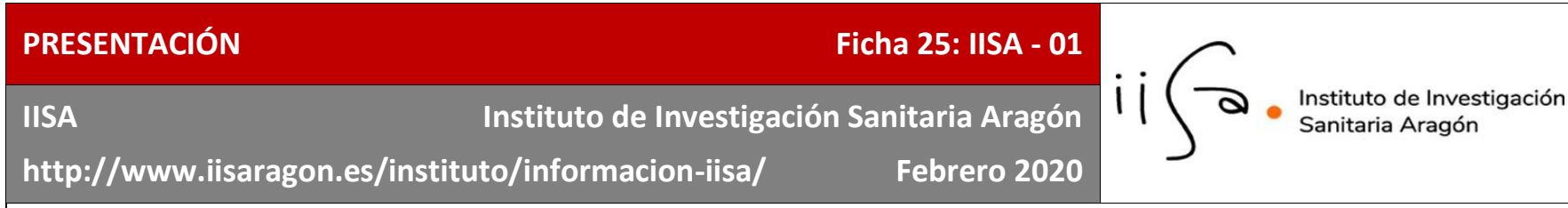

\section{Acreditación del Instituto}

El Instituto de Investigación Sanitaria Aragón (IISA) fue acreditado con fecha 18 de mayo de 2015, atendiendo a la propuesta del Instituto de Salud Carlos III y de la Consejería de Sanidad, Bienestar Social y Familia del Gobierno de Aragón, tras el informe previo favorable emitido por la Comisión de Evaluación de Acreditaciones del Instituto de Salud Carlos III.

\section{Composición}

El IISA es el Instituto de Investigación Sanitaria del Complejo Hospitalario formado por los Hospitales Docentes y Universitarios Hospital Clínico Universitario Lozano Blesa y Hospital Universitario Miguel Servet y Atención Primaria de Salud. A este Complejo Hospitalario se le asocian, a través de distintos instrumentos jurídicos, la Universidad de Zaragoza y el Instituto Aragonés de Ciencias de la Salud.

\section{Misión}

La misión del IIS Aragón es facilitar la investigación y la innovación efectiva en los Servicios de Salud mediante la generación de conocimiento y su traslación asistencial, siendo los fines: por una parte; aproximar la investigación básica y aplicada, clínica y de servicios sanitarios; por otra parte, crear un entorno investigador, asistencial y docente de calidad que integre a los profesionales sanitarios, los especialistas en formación, los alumnos de postgrado, y grado; y, por último, constituir el lugar idóneo para la captación de talento y la ubicación de las grandes instalaciones científico-tecnológicas.

\section{Áreas de investigación}

Las seis principales áreas de investigación del instituto se centran en: Neurociencias, salud mental y órganos de los sentidos; Tecnologías e innovación aplicada a la salud; Inmunidad, cáncer, enfermedades de origen infeccioso o base molecular; Cardiovascular, metabolismo y nutrición; Investigación e innovación en enfermería y cuidados de la salud; y Salud pública, cronicidad, servicios sanitarios y atención primaria. 
CARACTERÍSTICAS PRINCIPALES

IISA
Ficha 26: IISA - 02

Instituto de Investigación Sanitaria Aragón

Centro de experimentación animal

\section{DATOS IDENTIFICACIÓN DEL INSTITUTO}

Hospital asociado Hospital Clínico Universitario Lozano Blesa y Hospital Universitario Miguel Servet

\section{Localidad}

Año acreditación

Fecha toma de datos

Madrid

2015

2015

\section{CENTRO EXPERIMENTACIÓN ANIMAL}

Características generales centro experimentación animal

Superficie del centro experimentación animal
$\square<750 \mathrm{~m}^{2}$
$\square 750$ - $1.500 \mathrm{~m}^{2}$

$\bigotimes>1.500 \mathrm{~m}^{2}$

Superficie experimentación animal grande
$\square<200 \mathrm{~m}^{2}$
$\square 200-400 \mathrm{~m}^{2}$
$\bigotimes>400 \mathrm{~m}^{2}$

Superficie experimentación animal pequeño
$\square<500 \mathrm{~m}^{2}$
$\square 500-1.000 \mathrm{~m}^{2}$
$\bigotimes>1.000 \mathrm{~m}^{2}$

Tipo de centro de experimentación animal

凶Usuario \Cría

Acreditación AAALAC

口sí \NO

Tipo de experimentación

Animal pequeño

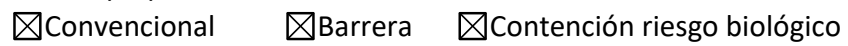

Nivel de Bioseguridad $\square$ BSL1 $\triangle B S L 2 \square B S L 3 \square B S L 4$

Animal grande

凶Convencional $\square$ Barrera $\square$ Contención riesgo biológico

\section{Organización centro experimentación animal}

Edificio ubicado en el hospital

Tipo de edificio $\quad$ \Nueva planta $\square$ Existente

Año construcción centro experimentación

$\square$ Anterior año 2.009 \Posterior año 2009

№ de edificios en que se distribuye $\quad \square$ Uno $\square$ Varios

№ de plantas en que se distribuye $\square$ Una $\quad$ VVarias

Tipo de división en plantas $\square$ NP

$\square$ Área animal grande / Área animal pequeño

$\square$ Área animalario / Área experimentación

$\square$ Experimentación animal /Servicios

\Cirugía experimental / Experimentación animal pequeño

Tipo de planta en la que se ubica

\Bajo rasante $\triangle A$ cota "0" $\square$ Sobre rasante

Accesos exteriores independientes invest./animales \sí $\square$ NO

Circulación vertical acceso animales 邓sí $\square$ NO

Circulación vertical interior animales

Transporte vertical independiente limpio/sucio $\square N P \square$ sí $\bigotimes N O$

Áreas animal grande/pequeño independizadas

Ubicación zona administrativa

Externa al área experimentación animal

\section{3. ÁREA EXPERIMENTACIÓN ANIMAL GRANDE}

Organización área experimentación animal grande

Superficie experimentación animal grande

$$
\square<200 \mathrm{~m}^{2} \quad \square 200-400 \mathrm{~m}^{2} \quad \square>400 \mathrm{~m}^{2}
$$

№ de plantas en que se distribuye $\quad$ Una $\square$ Varias

Tipo división para varias plantas

$\square$ Área animalario / Área experimentación

$\square$ Área animal grande / Área animal pequeño

Tipo de planta en la que se ubica
$\square$ Bajo rasante
\A cota " 0 "
$\square$ Sobre rasante

Circulación vertical acceso animales $\square$ sí \NO

Accesos independientes investigadores/animales \sí $\square$ NO

Áreas animal grande/pequeño independizadas $\square$ sí $\quad$ NO

Zonas compartidas de animal grande y pequeño

$\square$ Vestuarios $\triangle$ Pasillos investigadores $\triangle$ Almacenes

$\square$ Áreas lavado $\triangle$ Pasillos animales $\square$ Salas preparación

$\square$ Otras

Circulación vertical interior animales grandes $\quad \square$ sí $\quad$ NO

Áreas de experimentación

\Área quirúrgica experimental \Necropsias

$\square$ Experimentación con cadáveres $\square$ Área Imagen

$\square$ Otros

\section{1. Área estabulación animal grande}

Características generales área estabulación animal grande

Superficie locales alojamiento animal grande

$\square<50 \mathrm{~m}^{2} \quad \square>50 \mathrm{~m}^{2}$

Especies animales

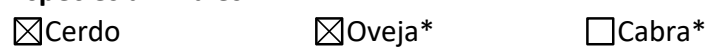

$\square$ Perro* $\square$ Gato* $\square$ Dtras*

*Ocasionalmente

Tipo de alojamiento

冈Convencional $\square$ Barrera $\square$ Contención riesgo biológico

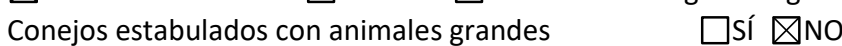
№ Locales de alojamiento

$$
\square 2 \text { Ud } \quad \square>2 \text { Ud }
$$

Zona recuperación post anestésica

凶sí $\square$ NO

Locales de servicio

Sala limpieza y aclimatación

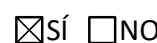

Sala necropsias

\sí $\square$ NO

Sistema almacenaje residuos animal

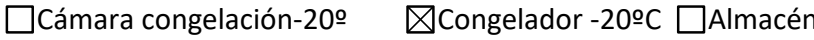




\section{Organización del área estabulación animal grande}

Tipo de planta en la que se ubica

$\square$ Bajo rasante $\square$ A cota "0"

$\square$ Sobre rasante

Circulación vertical acceso animales

$\square$ sí $\triangle N \mathrm{NO}$

Accesos independientes para cuidadores y animales $\bigotimes$ sí $\square$ NO Estabulación animal grande/pequeño independizada $\square$ sí $\bigotimes N O$ Zonas compartidas de animal grande y pequeño

\Pasillos $\square$ Almacenes $\square$ Otras

\section{Sistemas de estabulación animal grande}

\section{Tipo de boxes}

$\square$ Realizados in situ $\quad$ Prefabricados

$\square$ Fijos $\quad$ MModulares

$\square$ Sobre forjado $\quad$ Sobre fosa de purines $\square$ En jaulas

Refuerzo en paramentos perimetrales de boxes: $\quad$ sí $\square$ NO

Curva sanitaria en suelo

Entreplanta técnica superior

$\square$ Transitable $\quad$ No transitable

Planta técnica inferior

\sí $\square \mathrm{NO}$

凶sí $\square$ No

Luz natural área estabulación

Fotoperiodo $12 \mathrm{~h}$ luz/oscuridad

凶sí $\square$ No

$\square$ sí $\square \mathrm{NO}$

\sí $\square$ NO

\section{2. Área quirúrgica experimental animal grande}

\section{Característica generales área quirúrgica experimental}

Superficie área quirúrgica animal grande
$\square<70 \mathrm{~m}^{2}$
$\square 70-100 \mathrm{~m}^{2}$
$\bigotimes>100 m$

Salas quirúrgicas

QQuirófano simple Quirófano doble $\square$ Quirófano múltiple Quirófano modulable

Diseño tipo quirófanos asistenciales

Sistema retransmisión imagen

Área experimentación cadáveres

Entreplanta técnica superior

$\square$ Transitable

$\bigotimes$ No transitable

Luz natural quirófanos

$\square$ sí $\quad \mathrm{NO}$

\section{Organización del área quirúrgica experimental}

Tipo de planta en la que se ubica

\section{$\square$ Bajo rasante $\square$ A cota “0" $\square$ Sobre rasante}

Circulación vertical interna animales acceso al área $\square$ sí \NO

Accesos independientes investigadores y animales $\quad$ Sí $\square$ NO

Área quirúrgica animal grande/pequeño indep.

凶sí $\square$ No

Zonas compartidas de animal grande y pequeño
$\square$ Pasillos
$\square$ Vestuarios
$\square$ Preparación animal
$\square$ Preparación médica
$\square$ otros

Configuración pasillos área quirúrgica

$\square$ Pasillo único $\quad$ Doble pasillo
4. ÁREA EXPERIMENTACIÓN ANIMAL PEQUEÑO

Características generales área experimentación animal pequeño

Superficie experimentación animal pequeño

$\square<500 \mathrm{~m}^{2} \quad \square 500-1.000 \mathrm{~m}^{2} \quad \square>1.000 \mathrm{~m}^{2}$

Especies animales

*Ocasionalmente

\Roedores $\square$ Logomorfos $\square$ Animales acuáticos

Unidades de experimentación

\Convencional $\triangle$ Barrera $\bigotimes$ Contención riesgo biológico

Nivel de bioseguridad

$\triangle \mathrm{BSL1} \quad \triangle \mathrm{BSL2} \square \mathrm{BSL} 3 \square \mathrm{BSL4}$

\section{Organización área experimentación animal pequeño}

№ de plantas en que se distribuye

\Una planta $\square$ Dos plantas $\square$ Tres plantas

Tipo de planta en la que se ubica

\Bajo rasante $\square$ A cota "0" $\square$ Sobre rasante

Circulación vertical animales

$\triangle$ De acceso al área $\square$ Circulación interior $\quad \square$ No

Experimentación a. grande/pequeño independizada $\bigotimes$ sí $\square$ NO

Características constructivas área experimentación a. pequeño

Divisiones interiores

$\square$ Modular $\quad$ Realizada in situ

Revestimientos verticales

\Pintura epoxi $\square$ PVC rollo $\square$ Resina fenólica $\square$ otros

Protección contra choques

Pavimentos

\PVC rollo $\square$ Resinas epoxi $\square$ Otros

Curva sanitaria en suelo

\sí $\square$ NO

Techos

$\square$ Autoportante $\triangle$ Falso techo continuo $\square$ Instalaciones vistas Carpinterías de puertas

Tipo

\Abatible $\square$ Corredera $\quad$ Manual $\square$ Automática

Acabados

$\square$ Resina fenólica $\quad$ Metálica lacada $\square$ Acero Inox

$\square$ Otros

Refuerzo inferior/parachoques puerta: $\square$ sí $\quad$ NO

Mirilla \sí $\square$ NO

$\square$ Vidrio $\square$ Vidrio + clapeta $\quad$ VVidrio con vinilo rojo $\square$ Digital lluminación

lluminación natural $\square$ sí \NO

Fotoperiodo 12h luz/oscuridad $\quad$ \sí $\square$ NO

lluminación auxiliar en estabulación (luz roja) $\quad$ Sí $\square$ NO

Ruidos y vibraciones

Elementos absorción acústica en estabulación $\square$ sí $\quad$ \NO

Alarmas fuera del espectro audible animales $\square$ sí $\quad$ NO

Fondo sonoro continuo $\square$ sí $\quad$ \NO

Acceso personas controlada

\Sí $\square$ NO

Sistemas control, monitorización y alarmas

Control centralizado \sí $\square$ NO

Paneles indicadores parámetros en salas $\square$ sí $\quad$ \NO
$\square$ Ta
$\square \mathrm{Hr}$
$\square$ Presión diferencial 


\subsection{Unidad experimentación convencional animal pequeño \\ Características generales unidad convencional animal pequeño}

Superficie experimentación convencional animal pequeño
$\square<500 \mathrm{~m}^{2}$
$\square 500-1.000 \mathrm{~m}^{2}$
$\bigotimes>1.000 \mathrm{~m}^{2}$

Superficie estabulación convencional animal pequeño

$\square<100 \mathrm{~m}^{2} \quad \square 100-200 \mathrm{~m}^{2} \quad \quad \nabla>200 \mathrm{~m}^{2}$

Especies animales

\Rata $\quad$ Ratón $\square$ Cobaya $\square$ Hámster

\Jerbo $\square$ Conejo $\square$ Acuáticos $\square$ Otros

Conejos estabulados con animal pequeño $\square$ NP $\square$ sí $\quad$ NO

№ salas estabulación roedores

$\square \leq 5$ Ud $\quad \square>5$ Ud

№ salas estabulación conejos

$\square=1$ Ud
Tipo de jaula

囚Reutilizable

$\square>1 \cup d$

$\triangle N P$

\Estática

Tipo suministro bebida

冈Biberones

$\square$ Desechable

$\bigotimes$ Ventilada individualmente

Salas experimentación

Procedimientos

Área microcirugía

Área imagen

Área comportamiento

Otras

$\square$ Automático

\section{Organización unidad convencional animal pequeño}

№ de plantas en que se distribuye

\Una planta $\square$ Varias plantas

Unidad independiente a animal grande

Tipo de distribución

\Pasillo simple $\square$ Pasillo doble

Estabulación colindante a sala lavado

Sala cuarentena con SAS

Sala lavado y esterilización

\Compartida con barrera

$\square$ Uso exclusivo convencional

\section{Equipamiento sala lavado y esterilización}

Equipos de vaciado

Aspirador virutas

Equipos de lavado y esterilización

\Lava racks $\square$ Lava jaulas $\bigotimes$ Lava biberones $\bigotimes$ Autoclave

Equipos de llenado

Dispensador viruta

Equipo llenado biberones

凶sí $\square$ NO

\sí $\square$ NO

\sí $\square$ NO

凶sí $\square$ NO
4.2. Unidad experimentación barrera animal pequeño

\sí $\square$ NO

Características generales unidad experimentación barrera

Superficie experimentación barrera animal pequeño
$\square<200 \mathrm{~m}^{2}$
$\bigotimes>200 \mathrm{~m}^{2}$

Superficie estabulación barrera animal pequeño

$\square<50 \mathrm{~m}^{2}$

$\bigotimes>50 \mathrm{~m}^{2}$

Especies animales

囚Rata $\quad$ QRatón $\square$ Otros

№ salas estabulación roedores

$\square=1$ Ud

$\bigotimes \geq 2$ Ud

Tipo de jaula

囚eutilizable

$\square$ Estática

Tipo suministro bebida

\Biberones

$\square$ Desechable

$\triangle$ Ventilada individualmente

Salas experimentación

$\square=1$ Ud

$\square$ Automático

Sistema acceso personas
$\square$ SAS personas
冈Ducha de aire

$\bigotimes>2$ Ud

Sistema acceso materiales

\Autoclave

Sistema acceso animales

\Ventana SAS

\Ventana SAS UV $\triangle$ CabinaVPH

Organización unidad experimentación barrera animal pequeño

№ de plantas en que se distribuye

囚Una planta $\square$ Varias plantas

Unidad independiente a convencional a. pequeño $\square$ sí $\quad$ NO

Zonas compartidas

$\square$ Almacenes $\quad$ SSala lavado $\square$ Vestuarios

Tipo de distribución

\Pasillo simple $\square$ Pasillo doble $\square$ Pasillo Triple

Área personal en interior barrera $\square$ Sí $\quad$ NO

Acceso animales

囚SAS desde cuarentena $\square$ SAS desde otro local

Acceso materiales desde

\Sala lavado-esterilización $\bigotimes$ Otros

Barrera materiales comunicada con

囚Almacén material limpio $\square$ Pasillo

Mantenimiento de instalaciones

$\bigotimes$ Registros en falso techo $\square$ Planta técnica superior

$\square$ Instalaciones vistas $\quad$ Planta registrable inferior 


\section{DOCUMENTACIÓN GRÁFICA I}

\section{Ficha 27: IISA - 03}

IISA

Instituto de Investigación Sanitaria Aragón

Identificación Áreas Funcionales

$i i \int \begin{aligned} & \text { Instituto de Investigación } \\ & \text { Sanitaria Aragón }\end{aligned}$

En esta ficha se muestran los planos de distribución en planta que componen el centro de experimentación animal y en los que se reflejan la distribución y organización de las distintas áreas funcionales que lo componen, quedando identificada cada área funcional por el código de color correspondiente, según la leyenda del plano.

Fuente: Elaboración propia.

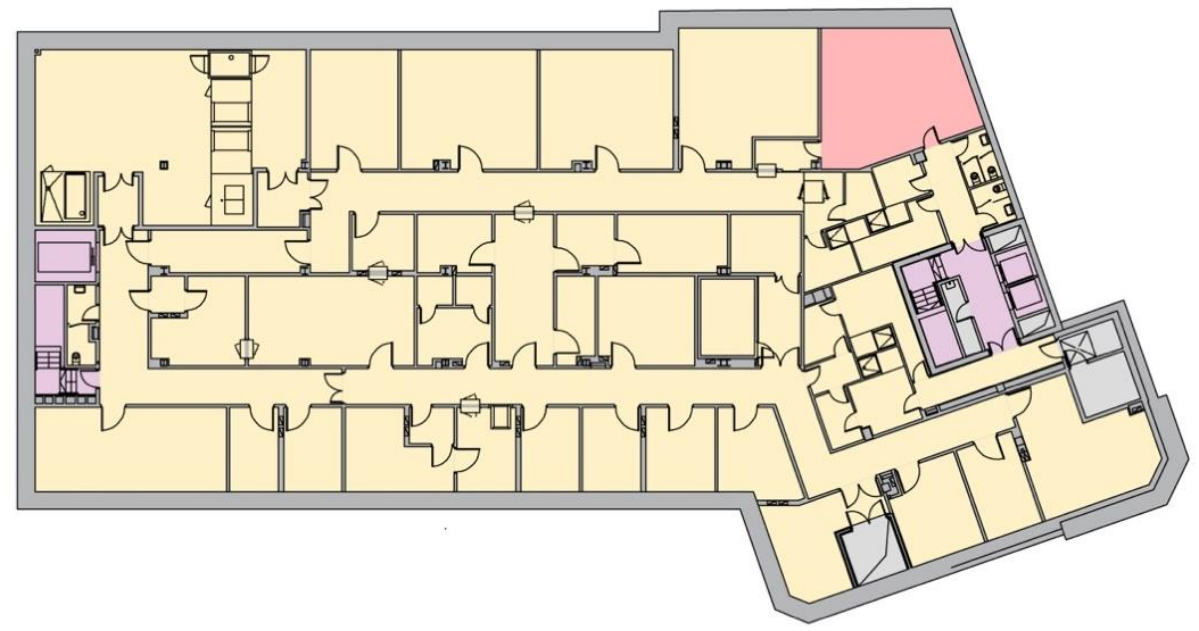

Planta Sótano -1

Escala: $1 / 500$

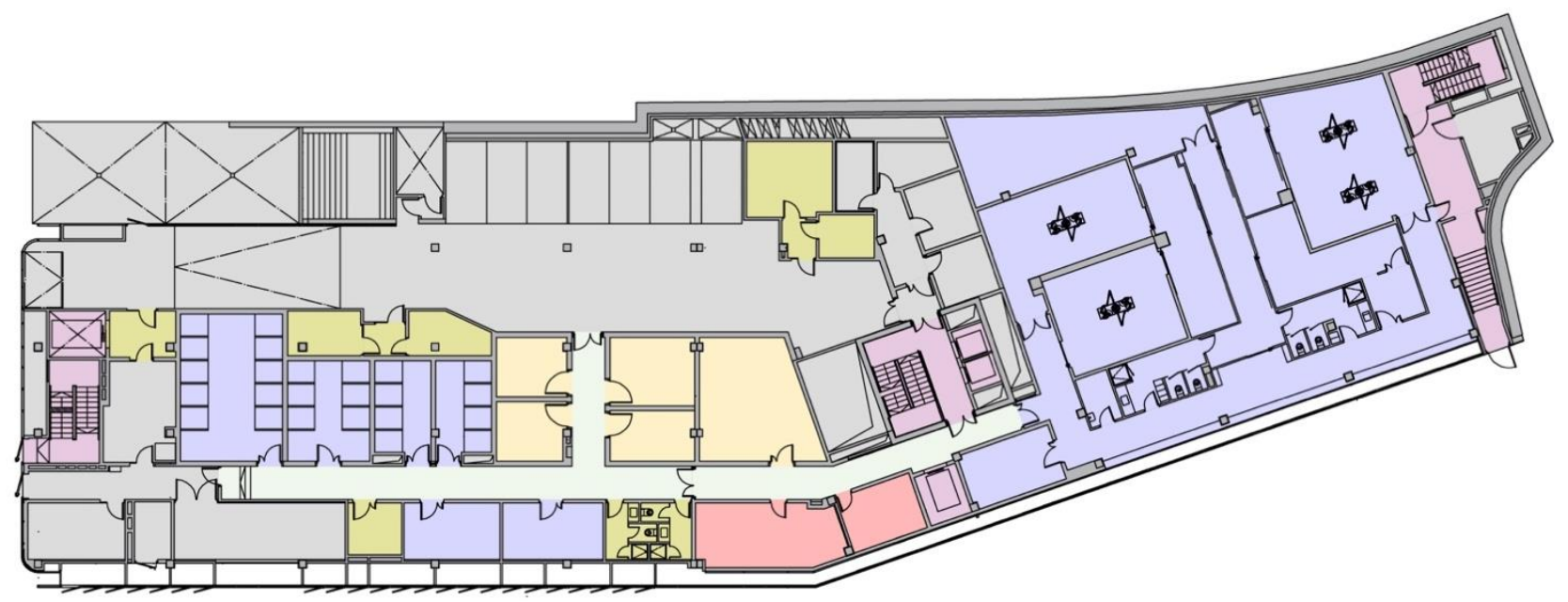

Planta Semisótano

Escala: 1/500

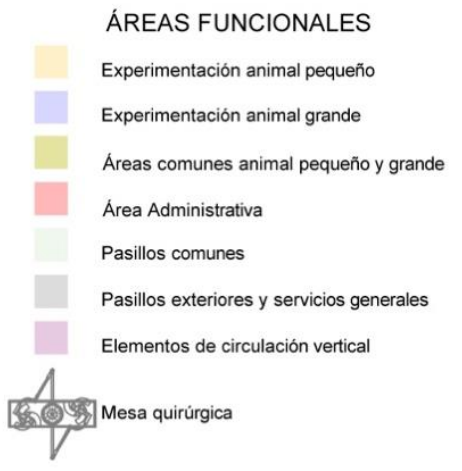




\section{DOCUMENTACIÓN GRÁFICA II}

IISA

\section{Ficha 28: IISA - 04}

Instituto de Investigación Sanitaria Aragón

\section{Identificación Tipo de Locales y Usos}

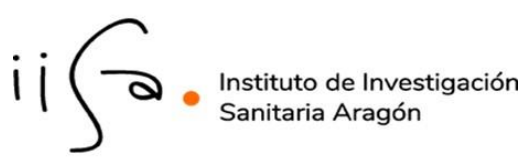

En esta ficha se muestran los planos de distribución en planta que componen el centro de experimentación animal y en los que se reflejan los locales que lo conforman, quedando identificado cada tipo de local por el código de color correspondiente y el uso del local por el código numérico, según las leyendas de los planos.

Fuente: Elaboración propia.

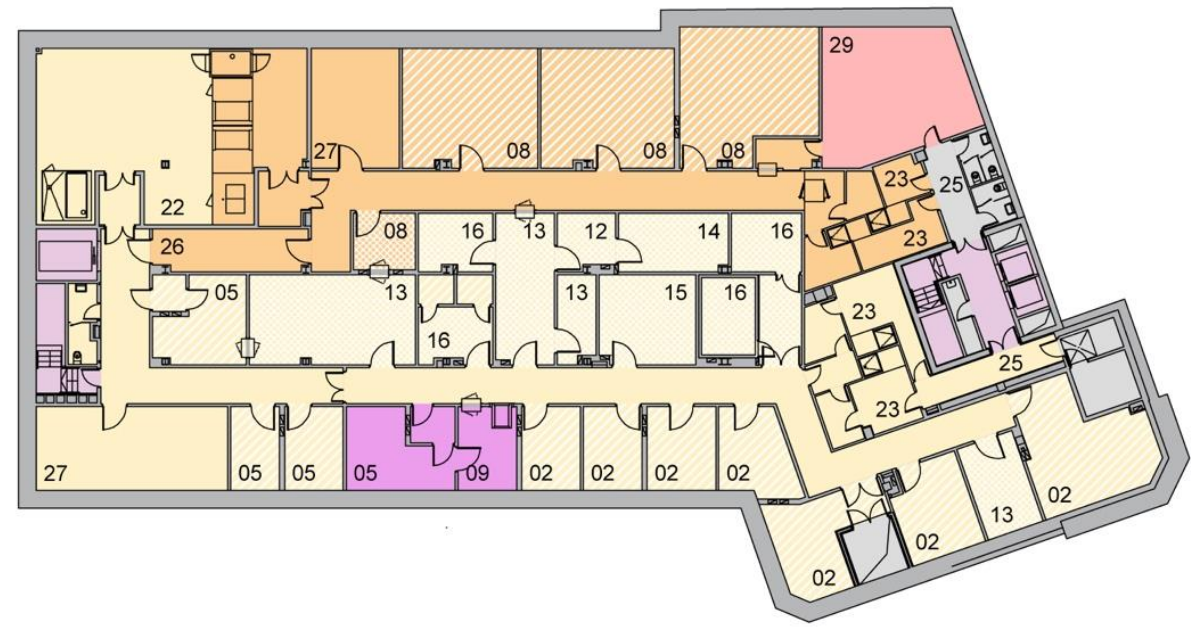

Planta Sótano -1

Escala: $1 / 500$

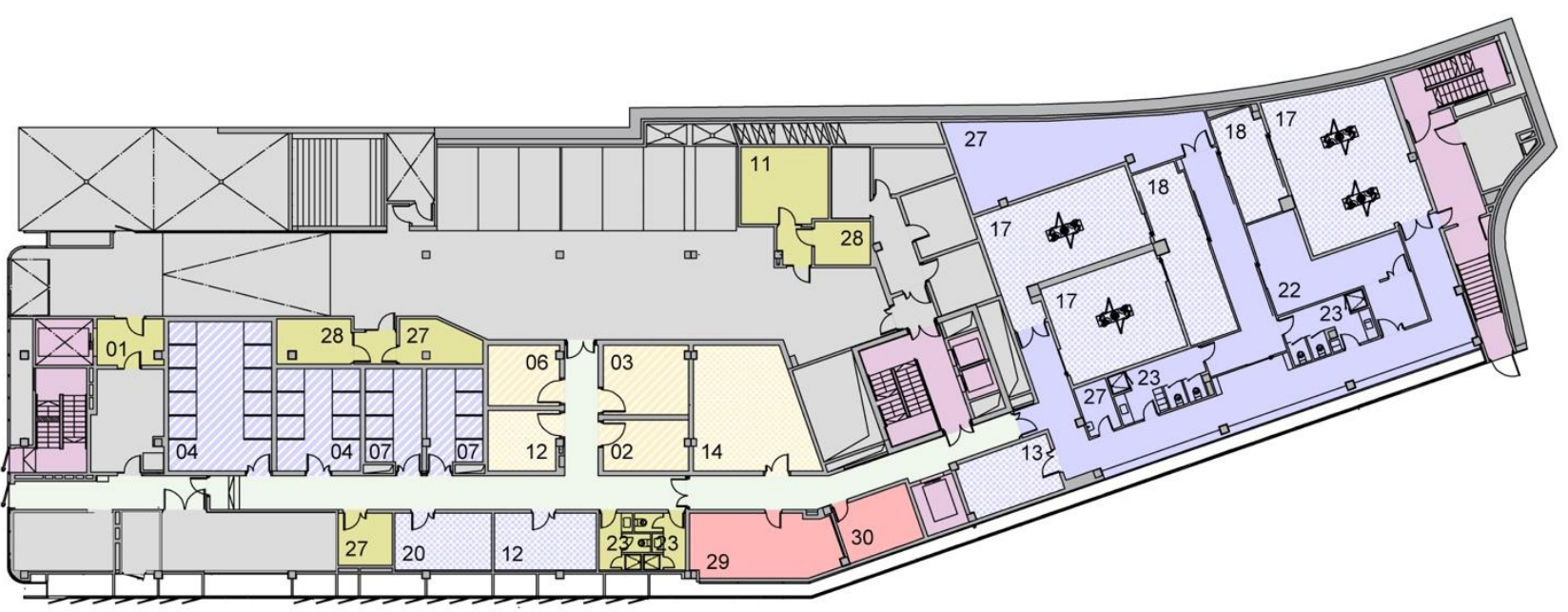

Planta Semisótano

Escala: $1 / 500$

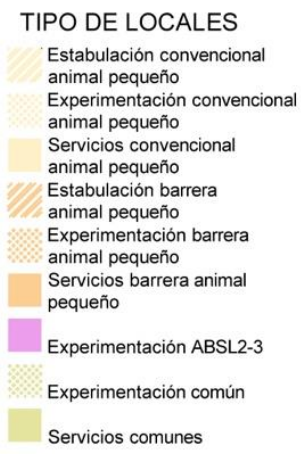

TIPO DE LOCALES

convencion

nvenciona

pequeño

Servicios comunes
Estabulación animal

grande

Experimentación animal

grande

Servicios animal grande

Experimentación animales

acuáticos

Area administrativa

Pasillos comunes

Pasillos exteriores

servicios generales

Elementos circulación

vertical
IDENTIFICACIÓN USO LOCALES

01 Recepción animal

02 Estabulación convencional roedores

03 Estabulación convencional conejos

04 Estabulación convencional animal grande

05 Cuarentena roedores

06 Cuarentena conejos

07 Cuarentena animal grande

08 Estabulación barrera animal pequeño

09 Experimentación ABSL2 - 09* ABSL3

10 Experimentación peces

11 Lavado animal

12 Preparación anim

13 Procedimientos

14 Microcirugia

15 Comportamiento

16 Imagen
17 Quirófano experimental

18 Preparación médica

19 A. material estéril

20 Necropsias

21 Cirugia cadáveres

22 Lavado y esterilización

23 Vestuarios / Aseos

24 Esclusa animales

25 Esclusa personas

26 Esclusa materiales

27 Almacén / archivo

28 Servicios

29 Despacho

30 Sala reuniones

31 Pasillo

32 Otros 
PRESENTACIÓN

VHIR

http://www.vhir.org/portal1/
Ficha 29: VHIR - 01

Institut de Recerca Hospital Universitari Vall d'Hebron

Febrero 2020

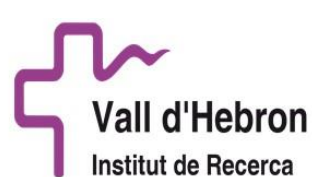

Institut de Recerca

\section{Acreditación del Instituto}

Desde su creación, en 1994, el Institut de Recerca Hospital Universitari Vall d'Hebron (VHIR) trabaja para identificar y aplicar nuevas soluciones a los problemas de salud de la sociedad y contribuir a extenderlas en el mundo. EL VHIR fue acreditado como Instituto de Investigación en Salud por el Instituto de Salud Carlos III, en el año 2009, siendo uno de los cinco primeros en ser acreditados en España y reconociendo la investigación traslacional de excelencia realizada en el Hospital Universitario Vall d'Hebron.

\section{Composición}

El VHIR se trata de una institución del sector público que promueve y desarrolla la investigación, la innovación y la docencia biosanitaria del Hospital Universitario Vall d'Hebron, el hospital de Barcelona y el más grande del Instituto Catalán de la Salud. Entre sus patrones están la Consejería de Salud, la Consejería de Economía y Conocimiento (somos un centro CERCA, la entidad dependiente de este Departamento), del HUVH, el Banco de Sangre y Tejidos, la Universidad Autónoma de Barcelona, de la que es instituto de investigación acreditado, y el Vall d'Hebron Instituto de Oncología, que junto con el VHIR forma parte del Instituto Acreditado del Campus Vall d'Hebron por el Instituto de Salud Carlos III.

\section{Misión}

La misión del instituto y su personal investigador es investigar para solucionar los problemas de salud de las personas. Su tarea no es sólo básica o traslacional, sino que son líderes en investigación clínica. Tiene las camas del hospital a menos de 50 metros de los laboratorios y sus enfermos se beneficiarán de su investigación. En eso creen, por eso se esfuerzan. Y así lo entienden los líderes de la industria, que apuestan por su hospital, convirtiéndolo en referencia mundial para hacer sus primeros ensayos clínicos.

\section{Áreas de investigación}

Las áreas de investigación del instituto se centran el ocho grandes áreas: Neurociencias; Investigación en cirugía; Obstetricia, pediatría y genética; Oncología; Biología vascular y metabolismo; Enfermedades infecciosas; Enfermedades digestivas y hepáticas; Enfermedades immunomediades y terapias innovadoras. 


\section{CARACTERÍSTICAS PRINCIPALES}

Institut de Recerca Hospital Univeritari Vall d'Hebron

Ficha 30: VHIR - 02

VHIR

Centro de experimentación animal

\section{DATOS IDENTIFICACIÓN DEL INSTITUTO}

\begin{tabular}{|lr} 
Hospital asociado & Hospital Universitario Vall d'Hebron \\
Localidad & Barcelona \\
Año acreditación & 2009 \\
Fecha toma de datos & 2017 \\
\hline
\end{tabular}

\section{CENTRO EXPERIMENTACIÓN ANIMAL}

Características generales centro experimentación animal

Superficie del centro experimentación animal

$\square<750 \mathrm{~m}^{2} \quad \square 750-1.500 \mathrm{~m}^{2}$
Superficie experimentación animal grande

$\bigotimes<200 \mathrm{~m}^{2} \quad \square 200-400 \mathrm{~m}^{2}$
Superficie experimentación animal pequeño

$\square<500 \mathrm{~m}^{2} \quad \square 500-1.000 \mathrm{~m}^{2}$

Tipo de centro de experimentación animal

\Usuario $\quad$ \Cría

Acreditación AAALAC

$\square$ Sí $\quad$ \NO

Tipo de experimentación

Animal pequeño

\Convencional $\quad$ Barrera $\bigotimes$ Contención riesgo biológico

Nivel de Bioseguridad $\square$ BSL1 $\bigotimes$ BSL2 $\square$ BSL3 $\square$ BSL4

Animal grande

\Convencional $\square$ Barrera $\square$ Contención riesgo biológico

\section{Organización centro experimentación animal}

Edificio ubicado en el hospital

Tipo de edificio

Año construcción centro experimentación

$\square$ Anterior año 2.009

Posterior año 2009

№ de edificios en que se distribuye $\square$ Uno $\quad$ Varios

№ de plantas en que se distribuye $\square$ Una $\quad$ Varias

Tipo de división en plantas $\quad \square \mathrm{NP}$

\Área animal grande / Área animal pequeño

$\square$ Área animalario / Área experimentación

$\square$ Experimentación animal /Servicios

$\square$ Cirugía experimental / Experimentación animal pequeño

Tipo de planta en la que se ubica

$\triangle$ Bajo rasante $\square$ A cota "0" $\square$ Sobre rasante

Accesos exteriores independientes invest./animales $\bigotimes$ Sí $\square$ NO

Circulación vertical acceso animales

Circulación vertical interior animales

冈sí $\square$ NO

凶sí $\square$ NO

Transporte vertical independiente limpio/sucio

Áreas animal grande/pequeño independizadas

Ubicación zona administrativa

Externa al área experimentación animal

凶sí $\square$ No
3. ÁREA EXPERIMENTACIÓN ANIMAL GRANDE

Edificio Meditarránea

Organización área experimentación animal grande

Superficie experimentación animal grande

$\bigotimes<200 \mathrm{~m}^{2} \quad \square 200-400 \mathrm{~m}^{2} \quad \square>400 \mathrm{~m}^{2}$ № de plantas en que se distribuye $\quad$ Una $\square$ Varias

Tipo división para varias plantas

$\square$ Área animalario / Área experimentación

$\square$ Área animal grande / Área animal pequeño

Tipo de planta en la que se ubica

$\square$ Bajo rasante $\triangle$ A cota “0" $\square$ Sobre rasante

Circulación vertical acceso animales $\square$ sí $\quad$ NO

Accesos independientes investigadores/animales 邓sí $\square$ NO

Áreas animal grande/pequeño independizadas $\square$ Sí $\square N O$

Zonas compartidas de animal grande y pequeño

QVestuarios $\triangle$ Pasillos investigadores $\triangle$ Almacenes

$\square$ Áreas lavado $\square$ Pasillos animales $\square$ Salas preparación

$\square$ Otras

Circulación vertical interior animales grandes $\square$ sí $\quad$ NO

Áreas de experimentación

囚Área quirúrgica experimental $\square$ Necropsias

$\square$ Experimentación con cadáveres $\square$ Área Imagen

$\square$ otros

\section{1. Área estabulación animal grande}

\section{Características generales área estabulación animal grande}

Superficie locales alojamiento animal grande

$\bigotimes<50 \mathrm{~m}^{2} \quad \square>50 \mathrm{~m}^{2}$

Especies animales

\Cerdo $\quad$ Øoveja* $\quad$ \Cabra*

$\square$ Perro* $\square$ Gato* $\quad \square$ otras*

*Ocasionalmente

Tipo de alojamiento

囚Convencional $\square$ Barrera $\square$ Contención riesgo biológico Conejos estabulados con animales grandes $\square$ sí $\bigotimes N O$ № Locales de alojamiento

\2 Ud $\square>2$ Ud

Zona recuperación post anestésica

邓sí $\square$ NO

Locales de servicio

Sala limpieza y aclimatación

Sala necropsias

$\square$ sí 凶NO

Sistema almacenaje residuos animal

$\square$ sí $\bigotimes$ NO

$\square$ Cámara congelación-20 $\quad$ Congelador -20C $\square$ Almacén 


\section{Organización del área estabulación animal grande}

Tipo de planta en la que se ubica

$\square$ Bajo rasante $\square$ A cota "0"

$\square$ Sobre rasante

Circulación vertical acceso animales

$\square$ sí $\triangle \mathrm{NO}$

Accesos independientes para cuidadores y animales $\bigotimes \mathrm{Sí} \square \mathrm{NO}$ Estabulación animal grande/pequeño independizada $\square$ sí $\bigotimes N O$ Zonas compartidas de animal grande y pequeño

\Pasillos \Almacenes $\square$ Otras

\section{Sistemas de estabulación animal grande}

\section{Tipo de boxes}

$\bigotimes$ Realizados in situ

囚Fijos

\Sobre forjado $\square$ Sobre fosa de purines

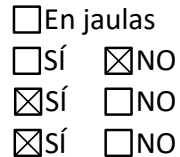

Refuerzo en paramentos
Curva sanitaria en suelo

Entreplanta técnica superior

$\square$ Transitable $\quad$ No transitable

Planta técnica inferior

$\square$ sí $\quad \mathrm{NO}$

冈sí $\square$ NO

Luz natural área estabulación

Fotoperiodo $12 \mathrm{~h}$ luz/oscuridad

\section{2. Área quirúrgica experimental animal grande}

Características generales área quirúrgica experimental

Superficie área quirúrgica animal grande
$\bigotimes<70 \mathrm{~m}^{2}$
$\square 70-100 \mathrm{~m}^{2}$
$\square>100 \mathrm{~m}$

Salas quirúrgicas

囚Quirófano simple $\square$ Quirófano doble $\square$ Quirófano múltiple Quirófano modulable

Diseño tipo quirófanos asistenciales

Sistema retransmisión imagen

Área experimentación cadáveres

Entreplanta técnica superior

$\square$ Transitable

$\bigotimes$ No transitable

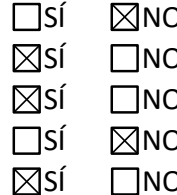

Luz natural quirófanos

$\square$ sí $\quad \mathrm{NO}$

\section{Organización del área quirúrgica experimental}

Tipo de planta en la que se ubica

\section{$\square$ Bajo rasante $\bigotimes$ A cota “0" $\square$ Sobre rasante}

Circulación vertical interna animales acceso al área $\square$ Sí $\bigotimes N O$

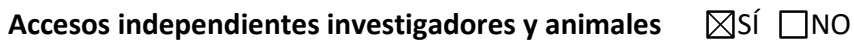

Área quirúrgica animal grande/pequeño indep.

Zonas compartidas de animal grande y pequeño

$\square$ sí $\bigotimes N O$
$\triangle$ Pasillos
QVestuarios
$\square$ Preparación animal
$\square$ Preparación médica
$\square$ otros

Configuración pasillos área quirúrgica

\Pasillo único

$\square$ Doble pasillo

4. ÁREA EXPERIMENTACIÓN ANIMAL PEQUEÑO

Edificio Cellex

Características generales área experimentación animal pequeño

Superficie experimentación animal pequeño

$\begin{array}{lcc}\square<500 \mathrm{~m}^{2} & \square 500-1.000 \mathrm{~m}^{2} & \square>1.000 \mathrm{~m}^{2} \\ \text { Especies animales } & \text { *Ocasionalmente } \\ \text { 冈Roedores } & \square \text { Logomorfos } & \square \text { Animales acuáticos }\end{array}$

Unidades de experimentación

\Convencional $\bigotimes$ Barrera $\bigotimes$ Contención riesgo biológico

Nivel de bioseguridad

$\square$ BSL1 $\triangle \mathrm{BSL} 2 \square \mathrm{BSL} 3 \square \mathrm{BSL4}$

Organización área experimentación animal pequeño

№ de plantas en que se distribuye

$\square$ Una planta $\quad$ Dos plantas $\square$ Tres plantas

Tipo de planta en la que se ubica

\Bajo rasante $\square$ A cota “0" $\square$ Sobre rasante

Circulación vertical animales

$\triangle$ De acceso al área $\quad$ Circulación interior $\quad \square$ No

Experimentación a. grande/pequeño independizada $\bigotimes$ sí $\square$ NO

Características constructivas área experimentación a. pequeño

Divisiones interiores

\Modular $\square$ Realizada in situ

Revestimientos verticales

$\square$ Pintura epoxi $\square$ PVC rollo $\quad$ Resina fenólica $\square$ Otros

Protección contra choques

$\square$ sí $\quad$ NO

Pavimentos

XPVC rollo $\square$ Resinas epoxi $\square$ Otros

Curva sanitaria en suelo

凶sí $\square$ NO

Techos

$\square$ Autoportante $\square$ Falso techo continuo $\quad$ Instalaciones vistas Carpinterías de puertas

Tipo

\Abatible $\square$ Corredera $\quad$ Manual $\square$ Automática

Acabados

\Resina fenólica $\square$ Metálica lacada $\square$ Acero Inox

$\square$ Otros

Refuerzo inferior/parachoques puerta: $\quad$ \í $\square$ NO

Mirilla

凶sí $\square$ NO

$\square$ Vidrio $\square$ Vidrio + clapeta $\quad \square$ Vidrio con vinilo rojo $\square$ Digital

lluminación

Iluminación natural

Fotoperiodo 12h luz/oscuridad $\quad$ \í $\square$ NO

$\square$ sí $\quad$ NO

lluminación auxiliar en estabulación (luz roja) $\quad$ \Sí $\square$ NO

Ruidos y vibraciones

Elementos absorción acústica en estabulación $\square$ sí $\quad$ NO

Alarmas fuera del espectro audible animales $\square$ sí $\quad$ NO

Fondo sonoro continuo

$\square$ sí $\quad$ NNO

Acceso personas controlada

Sistemas control, monitorización y alarmas

Control centralizado

\í $\square$ NO

Paneles indicadores parámetros en salas

$\triangle \mathrm{T}$

$\triangle \mathrm{Hr}$

\sí $\square$ No

$\triangle$ sí $\square$ NO

$\triangle$ Presión diferencial 


\subsection{Unidad experimentación convencional animal pequeño \\ Características generales unidad convencional animal pequeño}

Superficie experimentación convencional animal pequeño
$\square<500 \mathrm{~m}^{2}$
$\square 500-1.000 \mathrm{~m}^{2}$
$\bigotimes>1.000 \mathrm{~m}^{2}$

Superficie estabulación convencional animal pequeño

$\square<100 \mathrm{~m}^{2} \quad \square 100-200 \mathrm{~m}^{2} \quad \quad>>200 \mathrm{~m}^{2}$

Especies animales

囚Rata $\quad$ Ratón $\square$ Cobaya $\square$ Hámster

$\square$ Jerbo $\square$ Conejo $\square$ Acuáticos $\square$ Otros

Conejos estabulados con animal pequeño $\quad \mathrm{NP} \quad \square \mathrm{sí} \quad \square$ NO

№ salas estabulación roedores

$\square \leq 5$ Ud $\quad \square>5$ Ud

№ salas estabulación conejos

$\square=1$ Ud $\quad \square>1$ Ud $\quad$ NP

Tipo de jaula

$\square$ Reutilizable

$\square$ Estática

Tipo suministro bebida

冈Biberones

冈Desechable

$\bigotimes$ Ventilada individualmente

Salas experimentación

Procedimientos

Área microcirugía

Área imagen

Área comportamiento

Otras

$\square$ Automático

\section{Organización unidad convencional animal pequeño}

№ de planta en que se distribuye
$\square$ Una planta
$\triangle$ Varias plantas

Unidad independiente a animal grande

Tipo de distribución

$\square$ Pasillo simple $\square$ Pasillo doble

Estabulación colindante a sala lavado

Sala cuarentena con SAS

Sala lavado y esterilización

囚Compartida con barrera

$\square$ Uso exclusivo convencional

\section{Equipamiento sala lavado y esterilización}

Equipos de vaciado

Aspirador virutas

Equipos de lavado y esterilización

$\square$ Lava racks $\square$ Lava jaulas $\square$ Lava biberones $\bigotimes$ Autoclave

Equipos de llenado

Dispensador viruta

Equipo llenado biberones

\sí $\square$ NO
4.2. Unidad experimentación barrera animal pequeño

\sí $\square$ NO

Características generales unidad experimentación barrera

Superficie experimentación barrera animal pequeño
$\square<200 \mathrm{~m}^{2}$
\>200 $\mathrm{m}^{2}$

Superficie estabulación barrera animal pequeño

$\square<50 \mathrm{~m}^{2}$

$\bigotimes>50 \mathrm{~m}^{2}$

Especies animales

\Rata $\quad$ QRatón $\square$ Otros

№ salas estabulación roedores

$\square=1$ Ud

$\bigotimes \geq 2$ Ud

Tipo de jaula

$\square$ Reutilizable

$\square$ Estática

囚esechable

Tipo suministro bebida

\Biberones $\square$ Automático

Salas experimentación

$\square=1$ Ud

$\bigotimes>2$ Ud

Sistema acceso personas
$\square$ SAS personas
冈Ducha de aire

Sistema acceso materiales

\Autoclave

\Ventana SAS UV

$\square$ CabinaVPH

Sistema acceso animales

\Ventana SAS

$\square$ otros

Organización unidad experimentación barrera animal pequeño

№ de plantas en que se distribuye

\Una planta $\square$ Varias plantas

Unidad independiente a convencional a. pequeño $\square$ sí $\bigotimes N O$ Zonas compartidas

\Almacenes $\quad$ \sala lavado $\quad$ Vestuarios

Tipo de distribución

囚Pasillo simple $\square$ Pasillo doble $\square$ Pasillo Triple

Área personal en interior barrera $\quad$ Sí $\square$ NO

Acceso animales

$\square$ SAS desde cuarentena $\quad$ SAS desde otro local

Acceso materiales desde

\Sala lavado-esterilización $\bigotimes$ Otros

Barrera materiales comunicada con

囚Almacén material limpio $\square$ Pasillo

Mantenimiento de instalaciones

$\square$ Registros en falso techo $\square$ Planta técnica superior

\Instalaciones vistas $\square$ Planta registrable inferior 
DOCUMENTACIÓN GRÁFICA I

Ficha 31: VHIR - 03

VHIR

Institut de Recerca Hospital Universitari Vall d’Hebron

Identificación Áreas Funcionales

En esta ficha se muestran los planos de distribución en planta que componen el centro de experimentación animal y en los que se reflejan la distribución y organización de las distintas áreas funcionales que lo componen, quedando identificada cada área funcional por el código de color correspondiente, según la leyenda del plano.

Fuente: Elaboración propia.

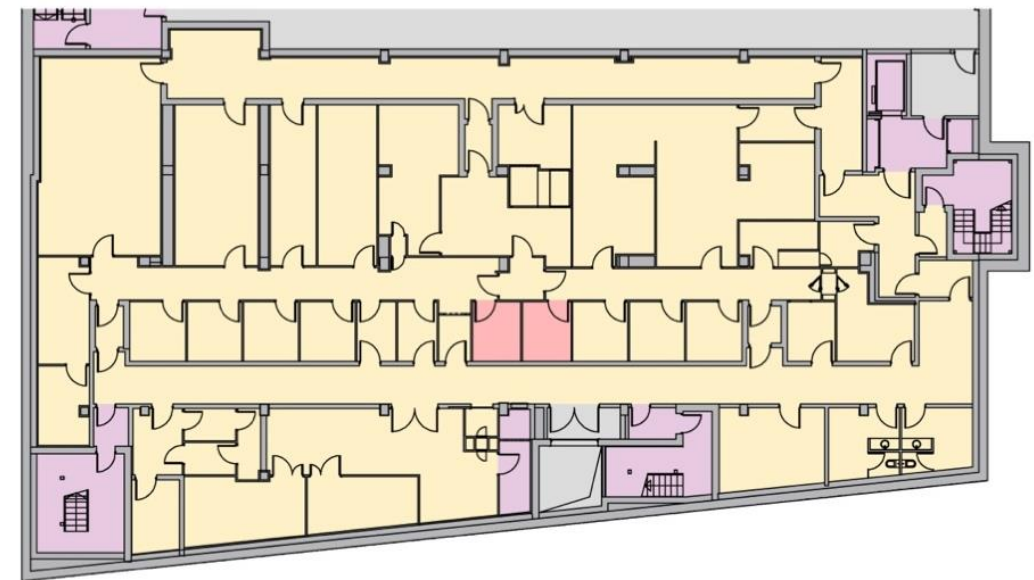

Planta Sótano -2. Edificio Cellex

Escala: $1 / 500$

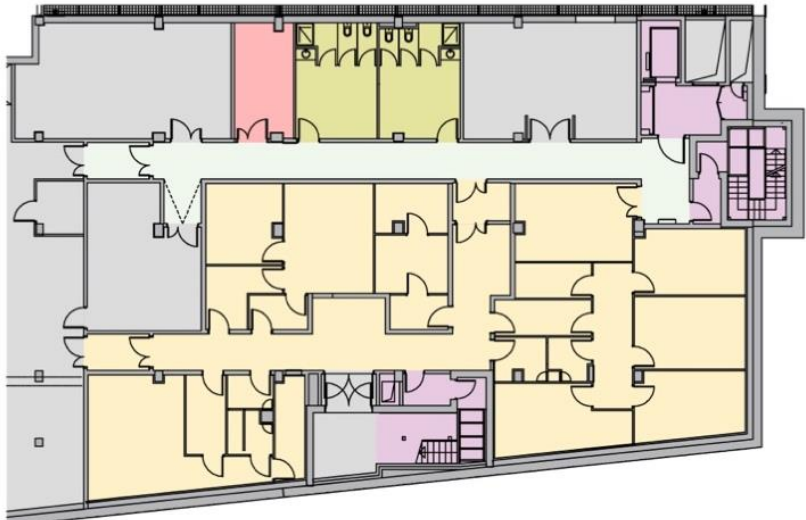

Planta Sótano -1. Edificio Cellex

Escala: $1 / 500$

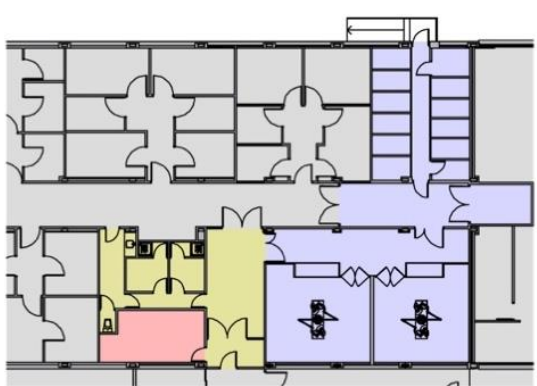

Planta Baja. Edificio Mediterránia Escala: $1 / 500$ 


\section{DOCUMENTACIÓN GRÁFICA ॥}

Ficha 32: VHIR - 04

VHIR

Institut de Recerca Hospital Universitari Vall d'Hebron

\section{Identificación Tipo de Locales y Usos}

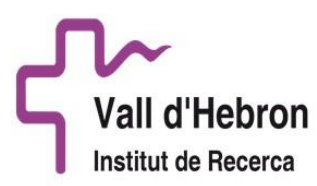

En esta ficha se muestran los planos de distribución en planta que componen el centro de experimentación animal y en los que se reflejan los locales que lo conforman, quedando identificado cada tipo de local por el código de color correspondiente y el uso del local por el código numérico, según las leyendas de los planos.

Fuente: Elaboración propia.

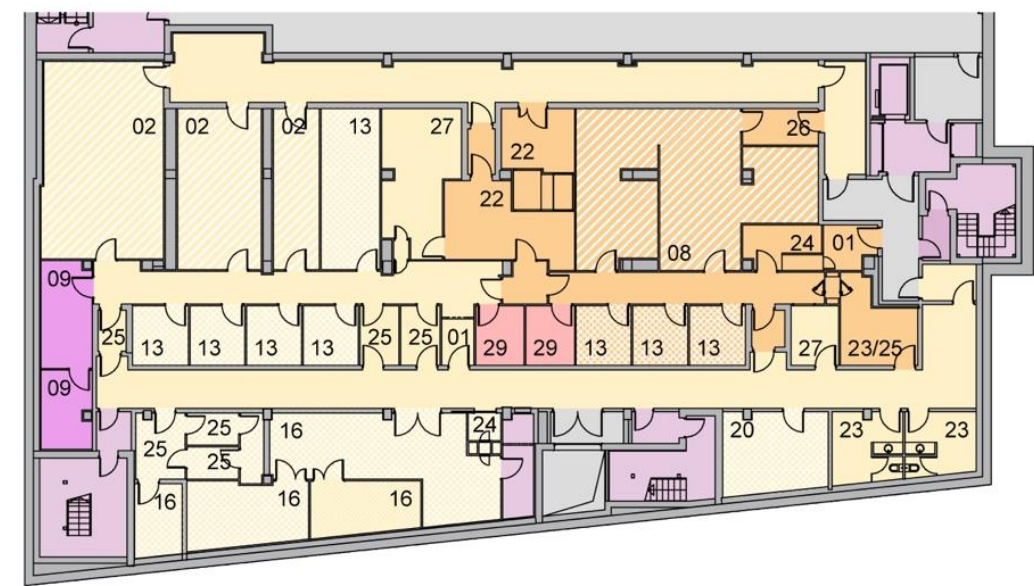

Planta Sótano -2. Edificio Cellex

Escala: $1 / 500$

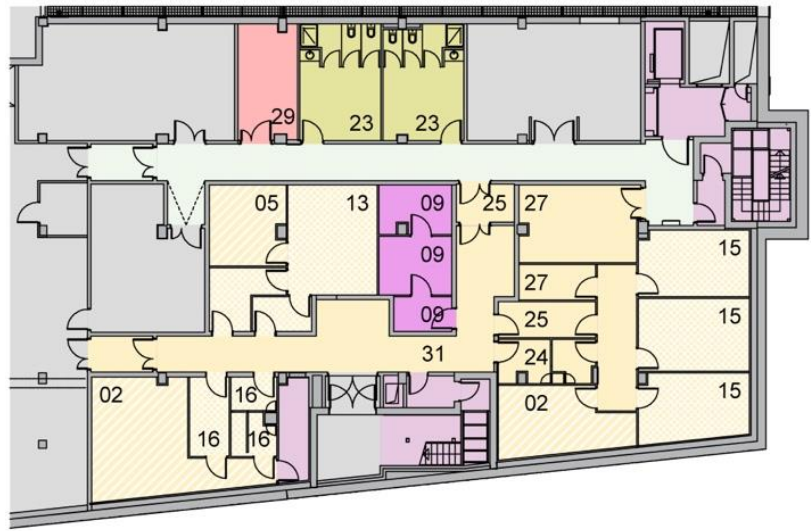

Planta Sótano -1. Edificio Cellex Escala: $1 / 500$

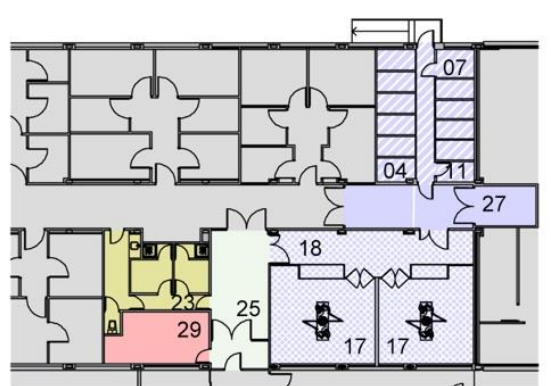

Planta Baja. Edificio Mediterránia Escala: $1 / 500$

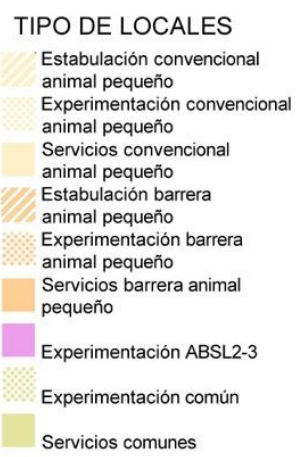

grande

Experimentación animal

grande

Servicios animal grande

Experimentación animales

acuáticos

Área administrativa

Pasillos comunes

Pasillos exteriores y

Elementos circulación

vertical
IDENTIFICACIÓN USO LOCALES

01 Recepción animal

02 Estabulación convencional roedores

03 Estabulación convencional conejos

04 Estabulación convencional animal grande

05 Cuarentena roedores

07 Cuarentena animal grande

08 Estabulación barrera animal pequeño

09 Experimentación $A B S L 2-00^{*} A B S L 3$

10 Experimentación peces

11 Lavado animal

12 Preparación animal

13 Procedimientos

14 Microcirugia

15 Comportamiento

16 Imagen
17 Quirófano experimental 18 Preparación médica 19 A. material estéril 20 Necropsias

21 Cirugia cadáveres 22 Lavado y esterilización 23 Vestuarios / Aseos 24 Esclusa animales 25 Esclusa personas 26 Esclusa materiales 27 Almacén / archivo

28 Servicios

29 Despacho

30 Sala reuniones

30 Sala reuniones

31 Pasillo 
PRESENTACIÓN

IGTP

http://www.germanstrias.org/es-index/
Ficha 33: IGTP - 01

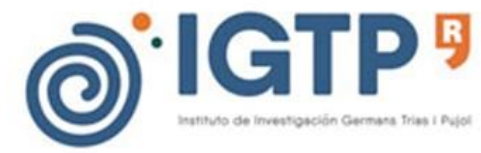

\section{Acreditación del Instituto}

El Instituto de Investigación Germans Trias i Pujol (IGTP) desde su creación en el año 1995, se ha convertido en un centro de primer nivel dedicado a la investigación sobre cuestiones relacionadas con la salud y las enfermedades de las personas, siendo uno de los cinco primeros institutos acreditados por Instituto de Salud Carlos III el 25 de febrero de 2009.

\section{Composición}

El IGTP es un centro público de investigación paraguas de la actividad investigadora del Hospital Universitario Germans Trias i Pujol, y a la vez forma parte del campus biomédico de Can Ruti. Sus instalaciones se encuentran en el Campus Can Ruti de Badalona, donde está fuertemente conectado con el resto de instituciones que realizan investigación como la Universidad Autónoma de Barcelona, el Instituto Catalán de Oncología, el Instituto de Investigación contra la Leucemia Josep Carreras, el Instituto de Medicina Predictiva y Personalizada del Cáncer y el Instituto de Investigación del Sida, entre otros.

\section{Misión}

El centro de investigación público IGTP, situado en Badalona, siendo su misión crear un entorno multidisciplinar y multi-institucional que permita hacer investigación traslacional con la máxima eficiencia para mejorar la salud y la calidad de vida de las personas.

\section{Áreas de investigación}

El Instituto de investigación Germans Trias i Pujol lleva a cabo la investigación en 9 grandes áreas: Ciencias de la conducta y abuso de sustancias; Inmunología e inflamación; Enfermedades cardiovasculares y respiratorias; Enfermedades infecciosas; Enfermedades endocrinas y del metabolismo, de los huesos y de los riñones; Enfermedades del hígado y del aparato digestivo; Cáncer; Neurociencias; y Salud comunitaria. 


\section{CARACTERÍSTICAS PRINCIPALES}

IGTP

Instituto de Investigación Germans Trias y Pujol
Ficha 34: IGTP - 02 (2) IGTP

Centro de experimentación animal

\section{DATOS IDENTIFICACIÓN DEL INSTITUTO}

Hospital asociado Hospital Universitario Germans Trias y Pujol Localidad

Año acreditación

Fecha toma de datos

Badalona

2009

2016

\section{CENTRO EXPERIMENTACIÓN ANIMAL}

Características generales centro experimentación animal

Superficie del centro experimentación animal
$\square<750 \mathrm{~m}^{2}$
$\square 750$ - $1.500 \mathrm{~m}^{2}$

$\bigotimes>1.500 \mathrm{~m}^{2}$

Superficie experimentación animal grande
$\square<200 \mathrm{~m}^{2}$
$\square 200-400 \mathrm{~m}^{2}$
$\bigotimes>400 \mathrm{~m}^{2}$

Superficie experimentación animal pequeño
$\square<500 \mathrm{~m}^{2}$
$\square 500-1.000 \mathrm{~m}^{2}$
$\bigotimes>1.000 \mathrm{~m}^{2}$

Tipo de centro de experimentación animal

\Usuario $\quad$ \Cría

Acreditación AAALAC

$\square$ sí $\quad$ \NO

Tipo de experimentación

Animal pequeño

\Convencional $\quad$ Barrera $\bigotimes$ Contención riesgo biológico

Nivel de Bioseguridad $\square$ BSL1 $\square$ BSL2 $\triangle \mathrm{BSL} 3 \square \mathrm{BSL4}$

Animal grande

\Convencional $\square$ Barrera $\square$ Contención riesgo biológico

\section{Organización centro experimentación animal}

Edificio ubicado en el hospital

Tipo de edificio

冈Nueva planta

\sí $\square$ NO

Año construcción centro experimentación

$\square$ Anterior año $2.009 \quad$ \Posterior año 2009

№ de edificios en que se distribuye $\quad$ Uno $\square$ Varios

№ de plantas en que se distribuye $\square$ Una $\quad$ Varias

Tipo de división en plantas $\square$ NP

$\square$ Área animal grande / Área animal pequeño

$\square$ Área animalario / Área experimentación

囚Experimentación animal /Servicios

$\square$ Cirugía experimental / Experimentación animal pequeño

Tipo de planta en la que se ubica

$\bigotimes$ Bajo rasante $\square$ A cota "0" $\square$ Sobre rasante

Accesos exteriores independientes invest./animales $\bigotimes$ sí $\square$ NO

Circulación vertical acceso animales

$\square$ sí 冈No

Circulación vertical interior animales

$\square$ sí 冈NO

Transporte vertical independiente limpio/sucio

Áreas animal grande/pequeño independizadas

Ubicación zona administrativa

Externa al área experimentación animal

\section{3. ÁREA EXPERIMENTACIÓN ANIMAL GRANDE}

Organización área experimentación animal grande

Superficie experimentación animal grande

$\square<200 \mathrm{~m}^{2} \quad \square 200-400 \mathrm{~m}^{2} \quad \square>400 \mathrm{~m}^{2}$

№ de plantas en que se distribuye $\quad$ Una $\square$ Varias

Tipo división para varias plantas

$\square$ Área animalario / Área experimentación

$\square$ Área animal grande / Área animal pequeño

Tipo de planta en la que se ubica

$\square$ Bajo rasante $\square$ A cota “0” $\square$ Sobre rasante

Circulación vertical acceso animales $\square$ sí $\quad$ NO

Accesos independientes investigadores/animales $\bigotimes \mathrm{sí} \quad \square \mathrm{NO}$

Áreas animal grande/pequeño independizadas $\quad$ sí $\square$ NO

Zonas compartidas de animal grande y pequeño

\Vestuarios $\square$ Pasillos investigadores $\bigotimes$ Almacenes

$\square$ Áreas lavado $\square$ Pasillos animales $\square$ Salas preparación

$\square$ Otras

Circulación vertical interior animales grandes $\quad \square$ sí $\quad$ \NO

Áreas de experimentación

\Área quirúrgica experimental $\quad$ Necropsias

$\square$ Experimentación con cadáveres $\quad$ Área Imagen

$\square$ Otros

\section{1. Área estabulación animal grande}

Características generales área estabulación animal grande

Superficie locales alojamiento animal grande

$\square<50 \mathrm{~m}^{2} \quad \quad \nabla>50 \mathrm{~m}^{2}$

Especies animales

囚Cerdo $\quad$ Øoveja* $\square$ Cabra*

$\square$ Perro* $\square$ Gato* $\quad \square$ Otras*

*Ocasionalmente

Tipo de alojamiento

冈Convencional $\square$ Barrera $\square$ Contención riesgo biológico Conejos estabulados con animales grandes $\square$ sí $\square$ NO № Locales de alojamiento

$\square 2$ Ud $\quad$ \> 2 Ud

Zona recuperación post anestésica

Locales de servicio

Sala limpieza y aclimatación

Sala necropsias

\sí $\square$ No

Sistema almacenaje residuos animal

\Cámara congelación-20ㅇ $\square$ Congelador -20ㅡㅁ $\square$ Almacén 


\section{Organización del área estabulación animal grande}

Tipo de planta en la que se ubica

$\square$ Bajo rasante $\triangle$ A cota " 0 "

$\square$ Sobre rasante

Circulación vertical acceso animales

$\square$ sí $\triangle N \mathrm{NO}$

Accesos independientes para cuidadores y animales $\bigotimes$ sí $\square$ NO

Estabulación animal grande/pequeño independizada $\bigotimes \mathrm{sí} \square \mathrm{NO}$

Zonas compartidas de animal grande y pequeño

$\square$ Pasillos $\quad$ DAlmacenes $\square$ Otras

Sistemas de estabulación animal grande

Tipo de boxes

$\begin{array}{ll}\square \text { Realizados in situ } & \text { QPrefabricados } \\ \square \text { Fijos } & \text { MModulares }\end{array}$

$\square$ Sobre forjado $\quad$ Sobre fosa de purines $\square$ En jaulas Refuerzo en paramentos perimetrales de boxes: $\quad$ sí $\square$ NO

Curva sanitaria en suelo

Entreplanta técnica superior

$\square$ Transitable $\quad$ No transitable

Planta técnica inferior

Luz natural área estabulación

Fotoperiodo $12 \mathrm{~h}$ luz/oscuridad

\sí $\square$ NO

凶sí $\square$ No

冈sí $\square$ NO

凶Sí $\square$ NO

凶sí $\square$ No

\section{2. Área quirúrgica experimental animal grande}

Características generales área quirúrgica experimental

Superficie área quirúrgica animal grande

\begin{tabular}{|c|c|}
\hline$\square 70-100 \mathrm{~m}^{2}$ & $\bigotimes>100 \mathrm{~m}$ \\
\hline Salas quirúrgicas & \\
\hline \Quirófano simple $\square$ Quirófano doble & $\square$ Quirófano múltiple \\
\hline Quirófano modulable & $\square$ NO \\
\hline Diseño tipo quirófanos asistenciales & $\square$ NO \\
\hline Sistema retransmisión imagen & $\square$ NO \\
\hline Área experimentación cadáveres & $\square$ sí $\quad$ NNO \\
\hline Entreplanta técnica superior & 凶sí $\square$ No \\
\hline
\end{tabular}

$\square$ Transitable $\quad$ No transitable

Luz natural quirófanos

Organización del área quirúrgica experimental

Tipo de planta en la que se ubica

$\square$ Bajo rasante $\square$ A cota “0" $\square$ Sobre rasante

Circulación vertical interna animales acceso al área $\square$ sí $\bigotimes N O$

Accesos independientes investigadores y animales $\square$ sí $\bigotimes N \mathrm{NO}$

Área quirúrgica animal grande/pequeño indep. $\quad \square S i ́$ NO

Zonas compartidas de animal grande y pequeño
$\square$ Pasillos
$\square$ Vestuarios
$\square$ Preparación animal
$\square$ Preparación médica
$\square$ Otros

Configuración pasillos área quirúrgica

\Pasillo único

$\square$ Doble pasillo
4. ÁREA EXPERIMENTACIÓN ANIMAL PEQUEÑO

Características generales área experimentación animal pequeño

Superficie experimentación animal pequeño
$\square<500 \mathrm{~m}^{2}$
$\square 500-1.000 \mathrm{~m}^{2}$
$\bigotimes>1.000 \mathrm{~m}^{2}$
Especies animales
*Ocasionalmente

\Roedores $\quad$ LLogomorfos

Unidades de experimentación

\Convencional $\quad$ Barrera $\bigotimes$ Contención riesgo biológico

Nivel de bioseguridad

$\square$ BSL1 $\square$ BSL2 \BSL3 $\square$ BSL4

Organización área experimentación animal pequeño

№ de plantas en que se distribuye

\Una planta $\square$ Dos plantas $\square$ Tres plantas

Tipo de planta en la que se ubica

$\square$ Bajo rasante $\quad$ A cota "0" $\square$ Sobre rasante

Circulación vertical animales

$\square$ De acceso al área $\square$ Circulación interior $\quad$ No

Experimentación a. grande/pequeño independizada $\bigotimes$ sí $\square$ NO

Características constructivas área experimentación a. pequeño

Divisiones interiores

\Modular $\square$ Realizada in situ

Revestimientos verticales

$\square$ Pintura epoxi $\square$ PVC rollo $\quad$ Resina fenólica $\square$ Otros

Protección contra choques

凶sí $\square$ No

Pavimentos

\PVC rollo $\square$ Resinas epoxi $\square$ Otros

Curva sanitaria en suelo

凶sí $\square$ NO

Techos

\Autoportante $\square$ Falso techo continuo $\square$ Instalaciones vistas Carpinterías de puertas

Tipo

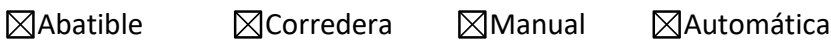

Acabados

\Resina fenólica $\quad \square$ Metálica lacada $\square$ Acero Inox

冈otros

Refuerzo inferior/parachoques puerta: $\square$ sí $\quad$ NO

Mirilla

凶sí $\square$ NO

$\square$ Vidrio $\square$ Vidrio + clapeta $\quad$ Vidrio con vinilo rojo $\square$ Digital lluminación

Iluminación natural

$\square$ sí 冈NO

Fotoperiodo $12 \mathrm{~h}$ luz/oscuridad

\Sí $\square$ NO

Iluminación auxiliar en estabulación (luz roja) \sí $\square$ NO

Ruidos y vibraciones

Elementos absorción acústica en estabulación $\square$ sí $\quad$ \NO

Alarmas fuera del espectro audible animales $\square$ sí $\quad$ \NO

Fondo sonoro continuo $\square$ \í \NO

Acceso personas controlada

Sistemas control, monitorización y alarmas

Control centralizado

\sí $\square$ No

Paneles indicadores parámetros en salas

$\bigotimes \mathrm{T}$ a $\quad$ $\quad$ Hr

邓sí $\square$ No

\sí $\square$ No

$\triangle$ Presión diferencial 


\subsection{Unidad experimentación convencional animal pequeño \\ Características generales unidad convencional animal pequeño}

Superficie experimentación convencional animal pequeño
$\square<500 \mathrm{~m}^{2}$
$\square 500-1.000 \mathrm{~m}^{2}$
$\nabla>1.000 \mathrm{~m}^{2}$

Superficie estabulación convencional animal pequeño
$\bigotimes<100 \mathrm{~m}^{2}$
$\square 100-200 \mathrm{~m}^{2}$
$\square>200 \mathrm{~m}^{2}$

Especies animales

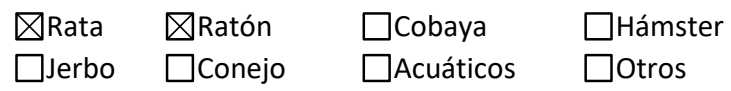

Conejos estabulados con animal pequeño $\quad$ NP $\square$ sí $\square$ NO

№ salas estabulación roedores

$\bigotimes \leq 5$ Ud $\square>5$ Ud

№ salas estabulación conejos

$\square=1$ Ud $\square>1$ Ud $\quad$ WN

Tipo de jaula

$\bigotimes$ Reutilizable

冈stática

$\square$ Desechable

Tipo suministro bebida

\Biberones

\Ventilada individualmente

Salas experimentación

Procedimientos

Área microcirugía

Área imagen

Área comportamiento

$\square$ Automático

Otros

\section{Organización unidad convencional animal pequeño}

№ de plantas en que se distribuye

\Una planta $\square$ Varias plantas

Unidad independiente a animal grande

Tipo de distribución

\Pasillo simple $\square$ Pasillo doble

Estabulación colindante a sala lavado

\sí $\square$ NO

\sí $\square$ NO

\sí $\square$ NO

$\square$ sí $\bigotimes N O$

$\square$ sí $\quad \mathrm{NO}$

Sala cuarentena con SAS

Sala lavado y esterilización

\Compartida con barrera $\square$ Uso exclusivo convencional

\section{Equipamiento sala lavado y esterilización}

Equipos de vaciado

Aspirador virutas

$\square$ sí \NO

Equipos de lavado y esterilización

$\square$ Lava racks $\bigotimes$ Lava jaulas $\bigotimes$ Lava biberones $\square$ Autoclave Equipos de llenado

Dispensador viruta

凶sí $\square$ NO

Equipo llenado biberones
4.2. Unidad experimentación barrera animal pequeño

凶sí $\square$ NO

Características generales unidad experimentación barrera

Superficie experimentación barrera animal pequeño
$\square<200 \mathrm{~m}^{2}$
$\triangle>200 \mathrm{~m}^{2}$

Superficie estabulación barrera animal pequeño

$\square<50 \mathrm{~m}^{2} \quad \square>50 \mathrm{~m}^{2}$

Especies animales

囚Rata $\quad$ QRatón $\square$ Otros

№ salas estabulación roedores

$\begin{array}{ll}\square=1 \text { Ud } & \square \geq 2 \text { Ud } \\ \text { Tipo de jaula } & \square \text { Desechable } \\ \square \text { Reutilizable } & \square \text { Ventilada individualmente } \\ \square \text { Estática } & \end{array}$

Tipo suministro bebida

冈Biberones $\square$ Automático

Salas experimentación

$\square=1$ Ud $\quad \square>2$ Ud

Sistema acceso personas

\SAS personas

$\square$ Ducha de aire

Sistema acceso materiales

\Autoclave

\Ventana SAS UV $\quad$ CabinaVPH

Sistema acceso animales

\Ventana SAS

$\square$ Otros

Organización unidad experimentación barrera animal pequeño

№ de plantas en que se distribuye

囚Una planta $\square$ Varias plantas

Unidad independiente a convencional a. pequeño $\square$ sí $\bigotimes N O$ Zonas compartidas

\Almacenes $\quad$ \sala lavado $\quad$ Vestuarios

Tipo de distribución

囚Pasillo simple $\square$ Pasillo doble $\square$ Pasillo Triple

Área personal en interior barrera $\square$ sí $\bigotimes N O$

Acceso animales

$\square$ SAS desde cuarentena \SAS desde otro local

Acceso materiales desde

$\square$ Sala lavado-esterilización 囚Otros

Barrera materiales comunicada con

囚Almacén material limpio $\square$ Pasillo

Mantenimiento de instalaciones

$\square$ Registros en falso techo $\bigotimes$ Planta técnica superior

$\square$ Instalaciones vistas $\quad$ Planta registrable inferior 


\section{DOCUMENTACIÓN GRÁFICA I}

IGTP

Identificación Áreas Funcionales

\section{Germans Trias i Pujol Research Institute}

En esta ficha se muestran los planos de distribución en planta que componen el centro de experimentación animal y en los que se reflejan la distribución y organización de las distintas áreas funcionales que lo componen, quedando identificada cada área funcional por el código de color correspondiente, según la leyenda del plano.

Fuente: Elaboración propia.

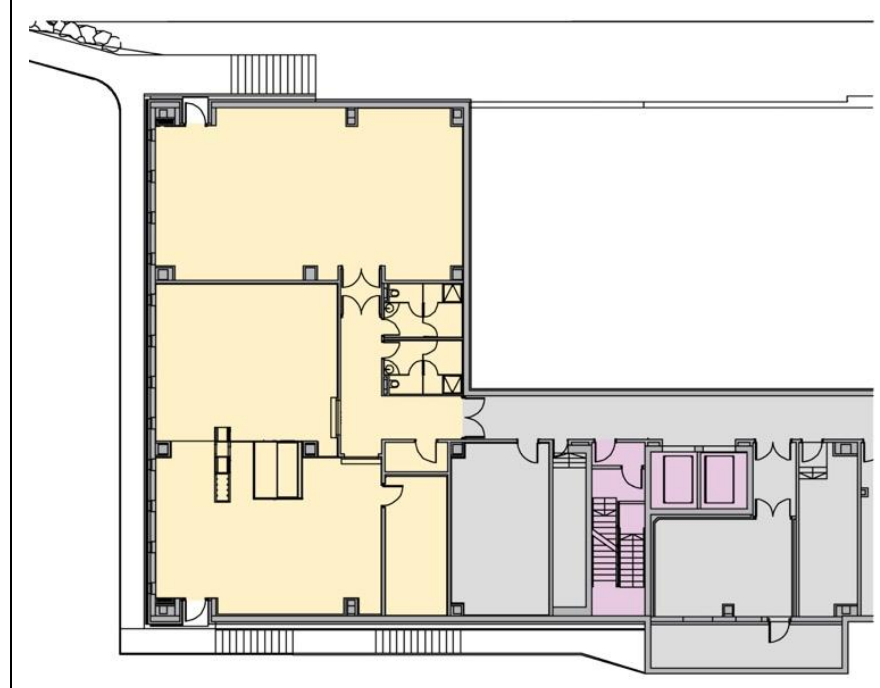

Planta Sótano -1

Escala: $1 / 500$

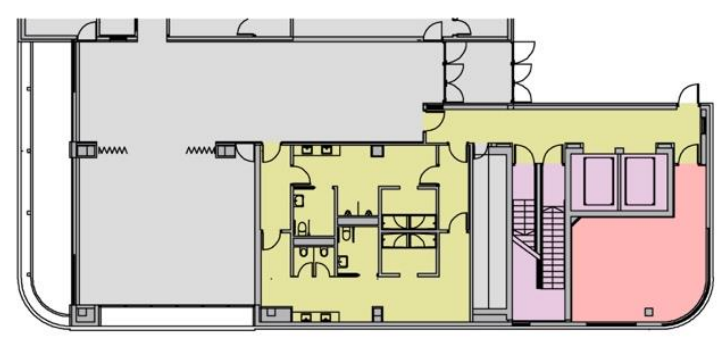

Planta Baja

Escala: $1 / 500$

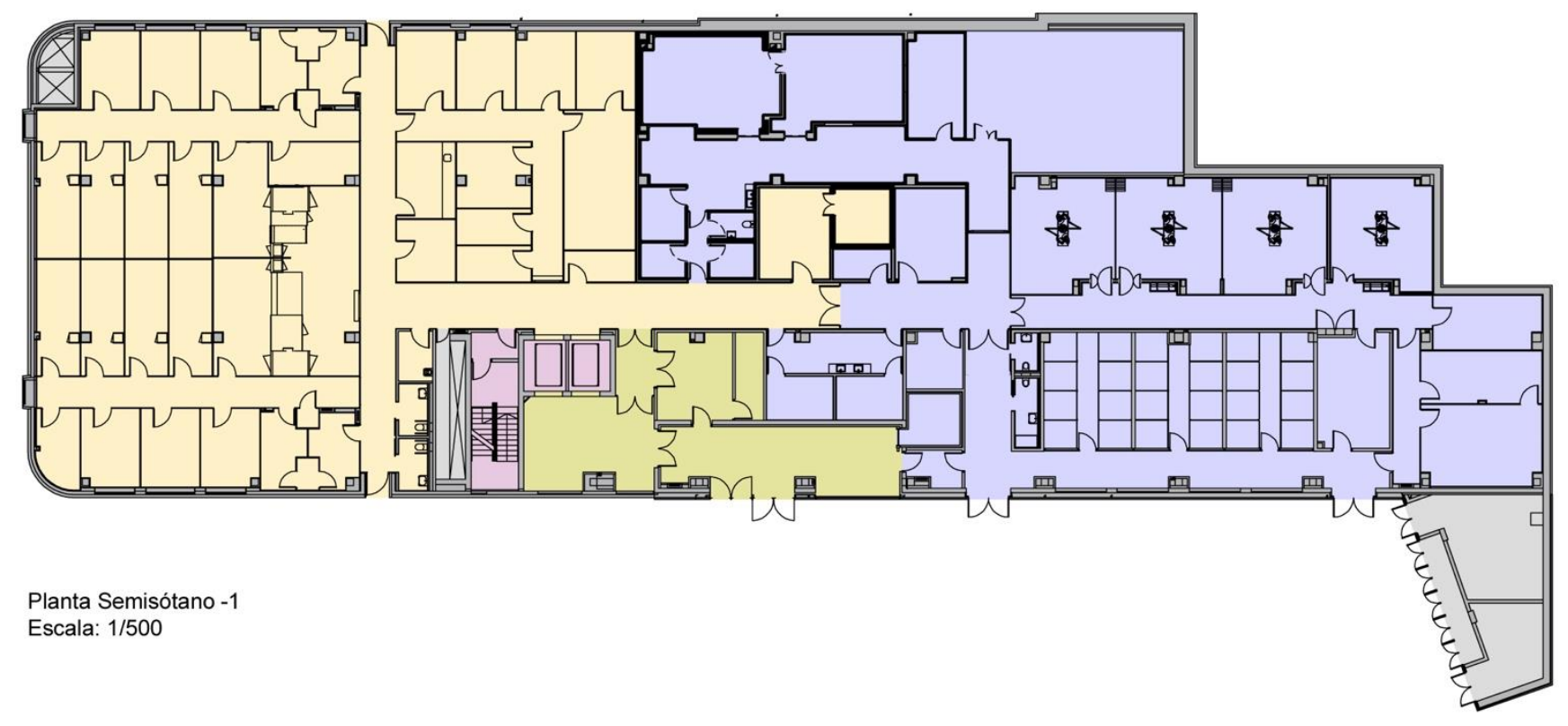

Planta Semisótano -1

Escala: 1/500

ÁREAS FUNCIONALES

Experimentación animal pequeño

Experimentación animal grande

Áreas comunes animal pequeño y grande

Area Administrativa

Pasillos comunes

Pasillos exteriores y servicios generales

Elementos de circulación vertical 


\section{DOCUMENTACIÓN GRÁFICA II \\ Ficha 36: IGTP - 04 \\ IGTP \\ Germans Trias i Pujol Research Institute \\ Identificación Tipo de Locales y Usos}

En esta ficha se muestran los planos de distribución en planta que componen el centro de experimentación animal y en los que se reflejan los locales que lo conforman, quedando identificado cada tipo de local por el código de color correspondiente y el uso del local por el código numérico, según las leyendas de los planos.

Fuente: Elaboración propia.

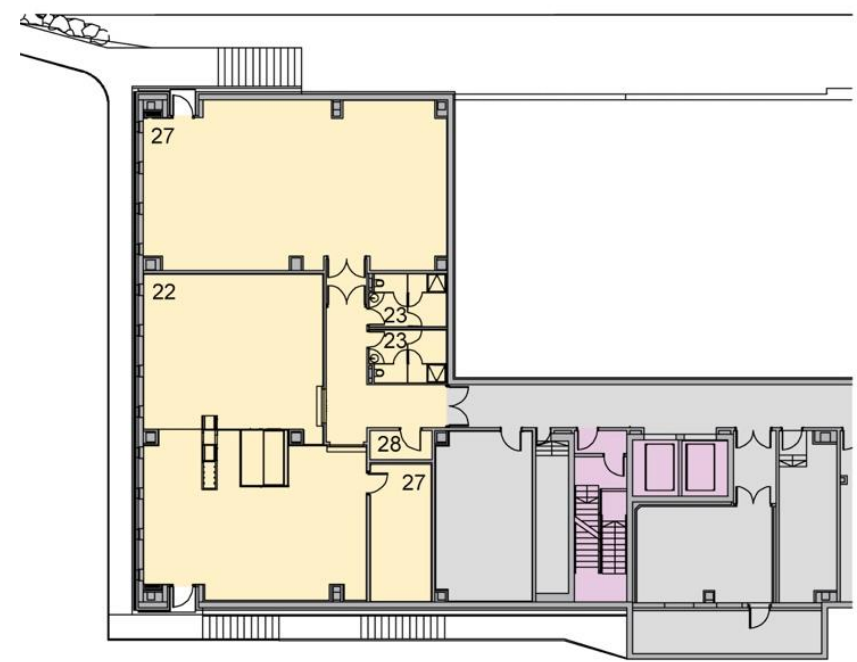

Planta Sótano -1 Escala: 1/500

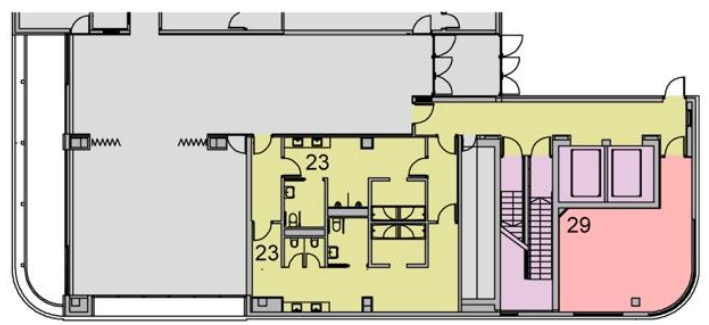

Planta Baja

Escala: 1/500
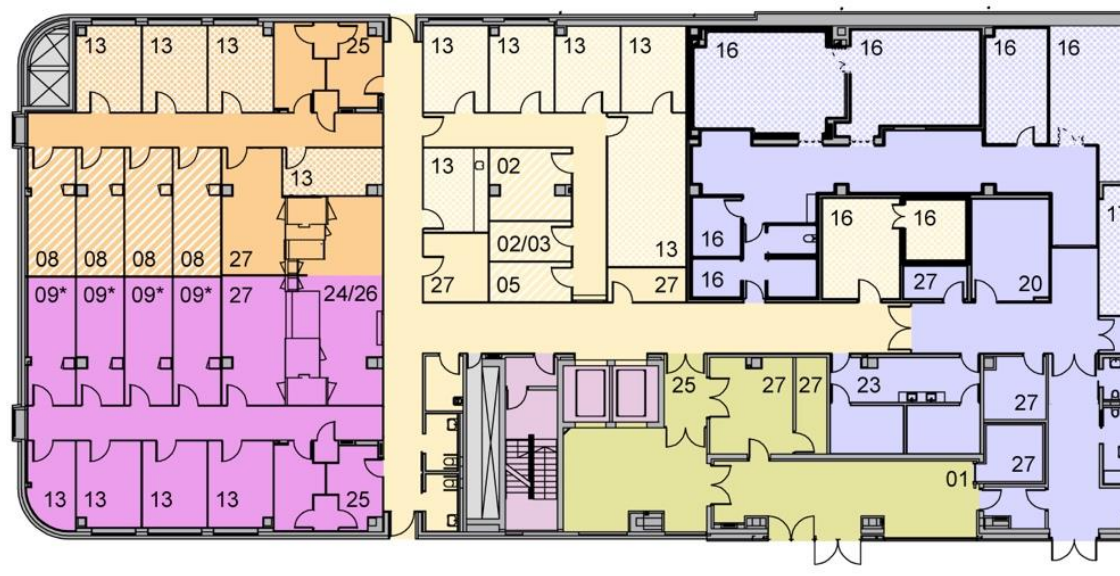

Planta Semisótano -1

Escala: $1 / 500$
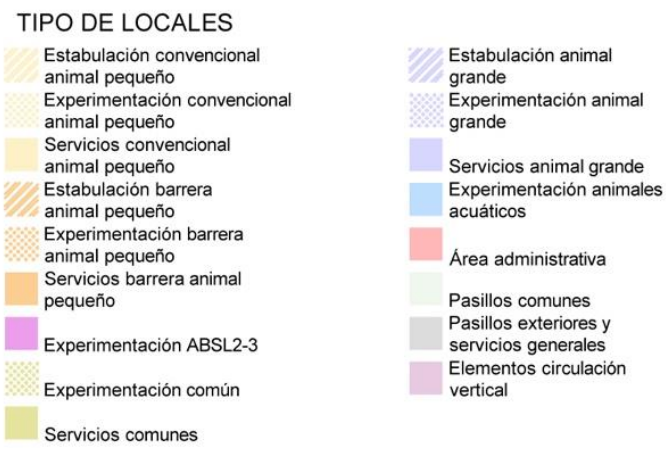

IDENTIFICACIÓN USO LOCALES

01 Recepción anima

02 Estabulación convencional roedores

03 Estabulación convenciona

Sstabulación convencional anims

05 Cuarenten ronves

06 Cuarentena conejos

77 Cuarenten animos

8 Estabulación

Expequeño

10 Experimentación peces

11 Lavado animal

12 Preparación animal

13 Procedimientos

14 Microcirugia

15 Comportamiento

16 Imagen
17 Quirófano experimental 18 Preparación médica

19 A. material estér

20 Necropsias

21 Cirugia cadáveres

22 Lavado y esterilizacion

24 Vestuarios/Aseos

25 Esclusa personas

25 Esclusa personas

26 Esclusa materiale

27 Almacen $/$

28 Servicios

30 Sala reuniones

31 Pasillo

32 Pasilio 


\section{PRESENTACIÓN}

IIS La Fe

https://www.iislafe.es/es/

\section{Ficha 37: IIS La Fe - 01}

Instituto de Investigación Sanitaria La Fe

Febrero 2020

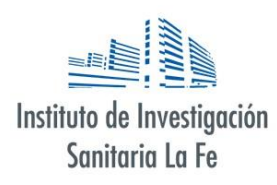

Senterigación

\section{Acreditación del Instituto}

El Instituto de Investigación sanitaria La Fe (IIS La Fe) fue acreditado por el Instituto de Salud Carlos III dependiente del Ministerio de Ciencia Innovación y Tecnología el 23 de abril de 2009, y de nuevo re-acreditado en 2014. Siendo el primer hospital de la Comunidad Valenciana y el sexto de España en recibir dicha distinción. La acreditación es el reconocimiento a una trayectoria consolidada a lo largo de los últimos años, impulsando y promoviendo la investigación biomédica traslacional de excelencia, así como la docencia y la formación postgrado, en el hospital y en su área de influencia.

\section{Composición}

El IIS La Fe es el ámbito de investigación biomédica creado entre el Hospital Universitario y Politécnico La Fe, la Universidad de Valencia, la Universidad Politécnica de Valencia, el Consejo Superior de Investigaciones Científicas, la Fundación para la Investigación del Hospital Universitario La Fe de la Comunidad Valenciana y la Fundación IVI.

\section{Misión}

La misión del instituto es impulsar, promover y fomentar la investigación de excelencia, el conocimiento científico y tecnológico y su posterior traslación al sector productivo, así como la docencia y la formación

\section{Áreas de investigación}

Las principales áreas de investigación del instituto son las siguientes ocho: Oncología y Hematología; Patología vascular; Neurociencias y salud mental; Patología digestiva y hepática; Innovación en diagnóstico y terapia; Infección, inflamación y cronicidad; Fertilidad y medicina materno infantil; Imagen y tecnologías aplicadas a la salud. 


\section{CARACTERÍSTICAS PRINCIPALES}

IIS La Fe

Instituto de Investigación Sanitaria La Fe

Ficha 38: IIS La Fe - 02

Centro de experimentación animal

\section{DATOS IDENTIFICACIÓN DEL INSTITUTO}

\section{Hospital asociado}

Localidad

Año acreditación

Fecha toma de datos

\section{CENTRO EXPERIMENTACIÓN ANIMAL}

Características generales centro experimentación animal

Superficie del centro experimentación animal
$\square<750 \mathrm{~m}^{2}$
$\bigotimes 750$ - $1.500 \mathrm{~m}^{2}$

$\square>1.500 \mathrm{~m}^{2}$

Superficie experimentación animal grande

$\bigotimes<200 \mathrm{~m}^{2} \quad \square 200-400 \mathrm{~m}^{2}$

$\square>400 \mathrm{~m}^{2}$

Superficie experimentación animal pequeño

$\square<500 \mathrm{~m}^{2} \quad \square 500-1.000 \mathrm{~m}^{2}$
Tipo de centro de experimentación animal

\Usuario $\quad$ \Cría

Acreditación AAALAC

$\square$ Sí $\quad$ \NO

Tipo de experimentación

Animal pequeño

\Convencional $\quad$ Barrera $\square$ Contención riesgo biológico

Nivel de Bioseguridad $\square$ BSL1 $\square$ BSL2 $\square$ BSL3 $\square$ BSL4

Animal grande

凶Convencional $\square$ Barrera $\square$ Contención riesgo biológico

\section{Organización centro experimentación animal}

Edificio ubicado en el hospital

Tipo de edificio

Año construcción centro experimentación

$\square$ Anterior año 2.009

\Posterior año 2009

№ de edificios en que se distribuye $\quad$ Uno $\square$ Varios

№ de plantas en que se distribuye $\quad$ Una $\square$ Varias

Tipo de división en plantas $\quad$ QNP

$\square$ Área animal grande / Área animal pequeño

$\square$ Área animalario / Área experimentación

$\square$ Experimentación animal /Servicios

$\square$ Cirugía experimental / Experimentación animal pequeño

Tipo de planta en la que se ubica

$\triangle$ Bajo rasante $\square$ A cota "0" $\square$ Sobre rasante

Accesos exteriores independientes invest./animales $\bigotimes$ Sí $\square$ NO

Circulación vertical acceso animales

Circulación vertical interior animales

\Sí $\square$ No

Transporte vertical independiente limpio/sucio $\square$ NP $\square$ sí \NO

Áreas animal grande/pequeño independizadas $\square$ sí $\bigotimes N \mathrm{NO}$

Ubicación zona administrativa

Externa al área experimentación animal

\section{3. ÁREA EXPERIMENTACIÓN ANIMAL GRANDE}

\section{Organización área experimentación animal grande}

Superficie experimentación animal grande
$\bigotimes<200 \mathrm{~m}^{2}$
$\square 200-400 \mathrm{~m}^{2}$
$\square>400 \mathrm{~m}^{2}$

№ de plantas en que se distribuye

\Una

Tipo división para varias plantas

$\square$ Área animalario / Área experimentación

$\square$ Área animal grande / Área animal pequeño

Tipo de planta en la que se ubica

\Bajo rasante $\square$ A cota “0” $\square$ sobre rasante

Circulación vertical acceso animales $\quad$ \í $\square$ NO

Accesos independientes investigadores/animales $\bigotimes \mathrm{sí} \quad \square \mathrm{NO}$

Áreas animal grande/pequeño independizadas $\square$ sí $\quad$ NO

Zonas compartidas de animal grande y pequeño

$\triangle$ Vestuarios $\triangle$ Pasillos investigadores $\triangle$ Almacenes

\Áreas lavado $\triangle$ Pasillos animales $\square$ Salas preparación

囚otras

Circulación vertical interior animales grandes

$\square$ sí $\quad \mathrm{NO}$

Áreas de experimentación

\Área quirúrgica experimental

$\square$ Experimentación con cadáveres

$\square$ otros

\section{$\square$ Necropsias \\ 囚Área Imagen}

\section{1. Área estabulación animal grande}

Características generales área estabulación animal grande

Superficie locales alojamiento animal grande

$\bigotimes<50 \mathrm{~m}^{2} \quad \square>50 \mathrm{~m}^{2}$

Especies animales

凶Cerdo

$\square$ Perro*

囚oveja*

$\square$ Gato*

$\square$ Cabra*

*Ocasionalmente

Tipo de alojamiento

\Convencional $\square$ Barrera $\square$ Contención riesgo biológico Conejos estabulados con animales grandes $\square$ sí $\triangle N \mathrm{NO}$ № Locales de alojamiento
$\square 2 \mathrm{Ud}$
$\bigotimes>2$ Ud

Zona recuperación post anestésica

凶sí $\square$ NO

Locales de servicio

Sala limpieza y aclimatación

$\square$ sí $\triangle N \mathrm{NO}$

Sala necropsias

$\square$ sí $\bigotimes$ No

Sistema almacenaje residuos animal

$\square$ Cámara congelación-20 $\quad$ Congelador -20ㄷ $\square$ Almacén 


\section{Organización del área estabulación animal grande}

Tipo de planta en la que se ubica

$\triangle$ Bajo rasante $\square$ A cota " 0 "

$\square$ Sobre rasante

Circulación vertical acceso animales

凶sí $\square$ NO

Accesos independientes para cuidadores y animales $\square$ sí $\square N O$ Estabulación animal grande/pequeño independizada $\square$ sí $\bigotimes N O$ Zonas compartidas de animal grande y pequeño

\Pasillos \Almacenes \Otras

\section{Sistemas de estabulación animal grande}

\section{Tipo de boxes}

$\square$ Realizados in situ $\quad$ Prefabricados

$\square$ Fijos $\quad$ MModulares

$\square$ Sobre forjado $\quad$ Sobre fosa de purines $\bigotimes$ En jaulas

Refuerzo en paramentos perimetrales de boxes: $\quad$ sí $\square$ NO

Curva sanitaria en suelo

Entreplanta técnica superior

\Transitable $\square$ No transitable

Planta técnica inferior

Luz natural área estabulación

Fotoperiodo $12 \mathrm{~h}$ luz/oscuridad

\sí $\square \mathrm{NO}$

凶sí $\square$ NO

$\square$ Sí $\bigotimes N \mathrm{NO}$

$\square$ sí $\quad \mathrm{NO}$

凶sí $\square$ NO

\section{2. Área quirúrgica experimental animal grande}

\section{Características generales área quirúrgica experimental}

Superficie área quirúrgica animal grande

$\square<70 \mathrm{~m}^{2} \quad \square 70-100 \mathrm{~m}^{2} \quad \square>100 \mathrm{~m}$

Salas quirúrgicas

囚Quirófano simple $\square$ Quirófano doble Quirófano múltiple Quirófano modulable $\quad$ \í $\square$ NO

Diseño tipo quirófanos asistenciales $\quad$ \Í $\square$ NO

Sistema retransmisión imagen $\quad$ \sí $\square$ NO

Área experimentación cadáveres $\square$ sí $\quad$ \NO

Entreplanta técnica superior $\quad$ \Sí $\square$ NO

$\triangle$ Transitable $\square$ No transitable

Luz natural quirófanos

$\square$ sí $\quad$ No

\section{Organización del área quirúrgica experimental}

Tipo de planta en la que se ubica

$\triangle$ Bajo rasante $\square$ A cota "0" $\square$ Sobre rasante

Circulación vertical interna animales acceso al área $\square$ sí $\bigotimes N \mathrm{NO}$

Accesos independientes investigadores y animales $\square S i ́$ \NO

Área quirúrgica animal grande/pequeño indep.

$\square$ sí $\bigotimes$ No

Zonas compartidas de animal grande y pequeño
$\triangle$ Pasillos
\Vestuarios
冈Preparación animal
囚Preparación médica

$\square$ Otros

Configuración pasillos área quirúrgica

$\triangle$ Pasillo único

$\square$ Doble pasillo
4. ÁREA EXPERIMENTACIÓN ANIMAL PEQUEÑO

Características generales área experimentación animal pequeño

Superficie experimentación animal pequeño

$\square<500 \mathrm{~m}^{2} \quad \bigotimes 500-1.000 \mathrm{~m}^{2} \quad \square>1.000 \mathrm{~m}^{2}$

Especies animales

\Roedores $\quad$ LLogomorfos $\bigotimes$ Animales acuáticos

Unidades de experimentación

\Convencional $\quad$ Barrera $\square$ Contención riesgo biológico

Nivel de bioseguridad

$\square \mathrm{BSL1} \square \mathrm{BSL} 2 \square \mathrm{BSL} 3 \square \mathrm{BSL4}$

\section{Organización área experimentación animal pequeño}

№ de plantas en que se distribuye

\Una planta $\square$ Dos plantas $\square$ Tres plantas

Tipo de planta en la que se ubica

\Bajo rasante $\square$ A cota " 0 " $\square$ Sobre rasante

Circulación vertical animales

$\triangle$ De acceso al área $\square$ Circulación interior $\quad \square$ No

Experimentación a. grande/pequeño independizada $\square$ Sí $\bigotimes N O$

Características constructivas área experimentación a. pequeño

Divisiones interiores

\Modular $\square$ Realizada in situ

Revestimientos verticales

$\square$ Pintura epoxi $\square$ PVC rollo $\quad$ Resina fenólica $\square$ otros

Protección contra choques $\square$ sí $\square$ NO

Pavimentos

\PVC rollo $\square$ Resinas epoxi $\square$ Otros

Curva sanitaria en suelo

\sí $\square$ No

Techos

\Autoportante $\square$ Falso techo continuo $\square$ Instalaciones vistas Carpinterías de puertas

Tipo

\Abatible $\square$ Corredera $\quad$ Manual $\square$ Automática

Acabados

\Resina fenólica $\square$ Metálica lacada $\square$ Acero Inox

$\square$ otros

Refuerzo inferior/parachoques puerta: $\square$ sí $\quad$ NO

Mirilla $\square$ Sí \NO

$\square$ Vidrio $\square$ Vidrio + clapeta $\quad \square$ Vidrio con vinilo rojo $\square$ Digital lluminación

lluminación natural $\square$ sí \NO

Fotoperiodo 12h luz/oscuridad $\quad$ \sí $\square$ NO

lluminación auxiliar en estabulación (luz roja) \sí $\square$ NO

Ruidos y vibraciones

Elementos absorción acústica en estabulación $\square$ sí $\quad$ \NO

Alarmas fuera del espectro audible animales $\square$ sí $\quad$ \NO

Fondo sonoro continuo $\square$ sí $\quad$ \NO

Acceso personas controlada

\Sí $\square$ NO

Sistemas control, monitorización y alarmas

Control centralizado \sí $\square$ NO

Paneles indicadores parámetros en salas $\square$ sí $\quad$ NO
$\square$ Ta
$\square \mathrm{Hr}$
$\square$ Presión diferencial 


\subsection{Unidad experimentación convencional animal pequeño \\ Características generales unidad convencional animal pequeño}

Superficie experimentación convencional animal pequeño
$\square<500 \mathrm{~m}^{2}$
$\bigotimes 500-1.000 \mathrm{~m}^{2}$
$\square>1.000 \mathrm{~m}^{2}$

Superficie estabulación convencional animal pequeño

$\bigotimes<100 \mathrm{~m}^{2} \quad \square 100-200 \mathrm{~m}^{2} \quad \square>200 \mathrm{~m}^{2}$

Especies animales

\Rata $\quad$ Ratón $\square$ Cobaya $\square$ Hámster

$\square$ Jerbo $\quad$ Conejo $\square$ Acuáticos $\square$ Otros

Conejos estabulados con animal pequeño $\square$ NP $\quad$ Sí $\square$ NO

№ salas estabulación roedores

$\bigotimes \leq 5$ Ud $\quad \square>5$ Ud

№ salas estabulación conejos

$\bigotimes=1$ Ud $\square>1$ Ud $\square$ NP

Tipo de jaula

囚eutilizable

冈stática

Tipo suministro bebida

冈Biberones

$\square$ Desechable

$\bigotimes$ Ventilada individualmente

Salas experimentación

Procedimientos

Área microcirugía

Área imagen

Área comportamiento

Otros

$\square$ Automático

\section{Organización unidad convencional animal pequeño}

№ de plantas en que se distribuye

囚Una planta $\square$ Varias plantas

Unidad independiente a animal grande

Tipo de distribución

$\square$ Pasillo simple $\quad$ Pasillo doble

Estabulación colindante a sala lavado

Sala cuarentena con SAS

Sala lavado y esterilización

囚Compartida con barrera

$\square$ Uso exclusivo convencional

\section{Equipamiento sala lavado y esterilización}

Equipos de vaciado

Aspirador virutas

Equipos de lavado y esterilización

$\square$ Lava racks $\bigotimes$ Lava jaulas $\bigotimes$ Lava biberones $\bigotimes$ Autoclave

Equipos de llenado

Dispensador viruta

Equipo llenado biberones

\sí $\square$ NO

\sí $\square$ NO

$\square$ sí $\quad \mathrm{NO}$
4.2. Unidad experimentación barrera animal pequeño

\sí $\square$ NO

Características generales unidad experimentación barrera

Superficie experimentación barrera animal pequeño
$\bigotimes<200 \mathrm{~m}^{2}$
$\square>200 \mathrm{~m}^{2}$

Superficie estabulación barrera animal pequeño

$\bigotimes<50 \mathrm{~m}^{2}$

$\square>50 \mathrm{~m}^{2}$

Especies animales

\Rata $\quad$ QRatón $\square$ Otros

№ salas estabulación roedores

$\square=1$ Ud

$\bigotimes \geq 2$ Ud

Tipo de jaula

囚Reutilizable

$\square$ Estática

$\square$ Desechable

Tipo suministro bebida

\Biberones $\square$ Automático

Salas experimentación

$\square=1$ Ud

$\bigotimes>2$ Ud

Sistema acceso personas
$\square$ SAS personas
冈Ducha de aire

Sistema acceso materiales

\Autoclave

Sistema acceso animales

\Ventana SAS

\Ventana SAS UV $\quad$ CabinaVPH

$\square$ sí $\bigotimes N O$

\section{Organización unidad experimentación barrera animal pequeño}

№ de plantas en que se distribuye
\Una planta
$\square$ Varias plantas

Unidad independiente a convencional a. pequeño $\square$ sí $\bigotimes N O$ Zonas compartidas

\Almacenes $\quad$ Ssala lavado $\quad$ Vestuarios

Tipo de distribución

\Pasillo simple $\square$ Pasillo doble $\square$ Pasillo Triple

Área personal en interior barrera $\quad \square$ sí $\quad$ NO

Acceso animales

$\square$ SAS desde cuarentena $\quad$ SAS desde otro local

Acceso materiales desde

\Sala lavado-esterilización $\bigotimes$ Otros

Barrera materiales comunicada con

囚Almacén material limpio $\square$ Pasillo

Mantenimiento de instalaciones

$\square$ Registros en falso techo $\triangle$ Planta técnica superior

$\square$ Instalaciones vistas $\square$ Planta registrable inferior 


\section{DOCUMENTACIÓN GRÁFICA I}

IIS La Fe

Identificación Áreas Funcionales

\section{Ficha 39: IIS La Fe - 03}

Instituto de Investigación Sanitaria La Fe

\section{㱐: \\ Instituto de Investigación \\ Sanitaria La Fe}

En esta ficha se muestran los planos de distribución en planta que componen el centro de experimentación animal y en los que se reflejan la distribución y organización de las distintas áreas funcionales que lo componen, quedando identificada cada área funcional por el código de color correspondiente, según la leyenda del plano.

Fuente: Elaboación propia.

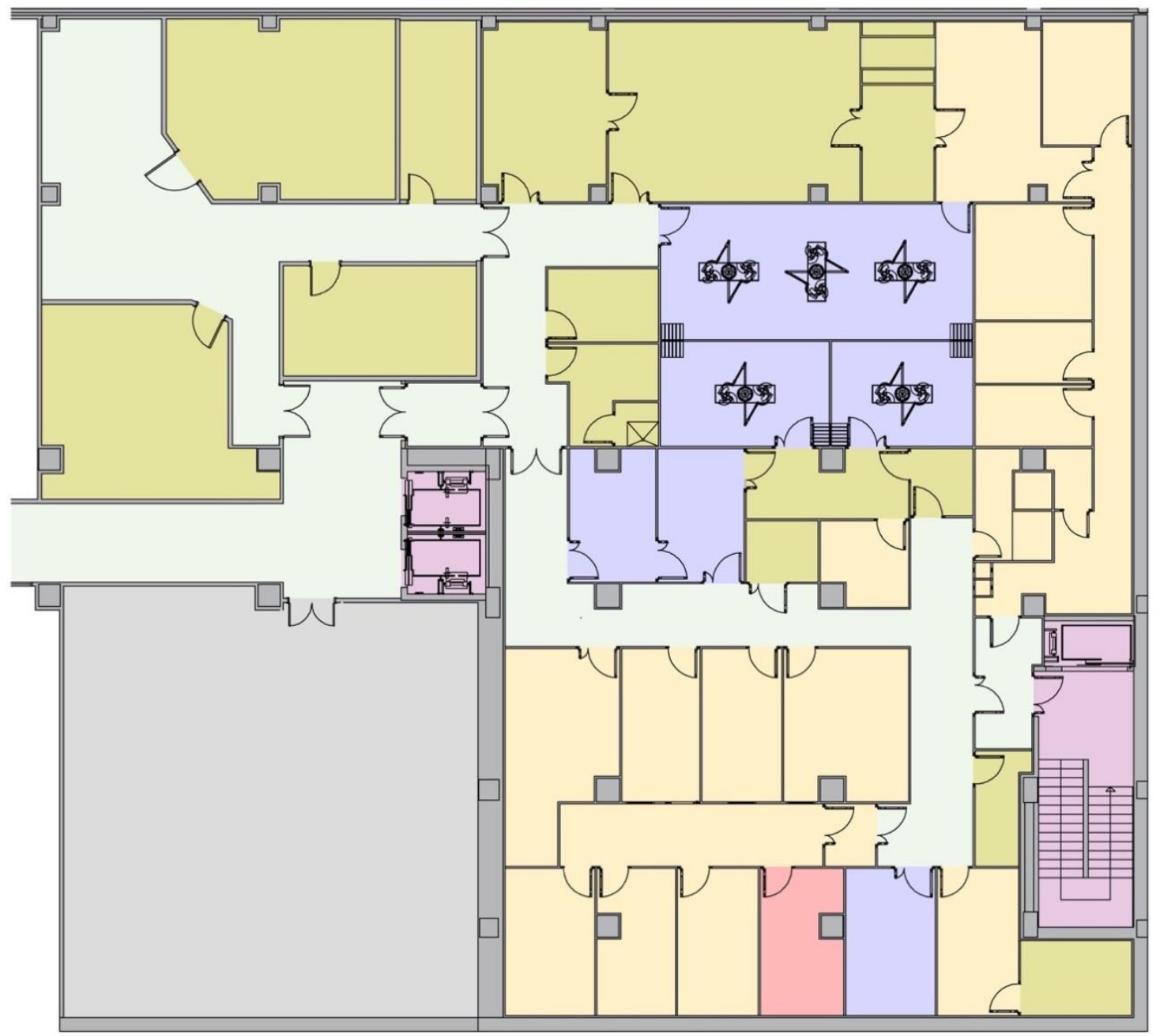

Planta Sótano -1

Escala: $1 / 250$

ÁREAS FUNCIONALES

Experimentación animal pequeño

Experimentación animal grande

Áreas comunes animal pequeño y grande

Área Administrativa

Pasillos comunes

Pasillos exteriores y servicios generales

Elementos de circulación vertical 


\section{DOCUMENTACIÓN GRÁFICA II}

IIS La Fe

\section{Ficha 40: IIS La Fe - 04}

Instituto de Investigación Sanitaria La Fe

\section{Identificación Tipo de Locales y Usos}

\section{㱐:}

Instituto de Investigación Sanitaria La Fe

En esta ficha se muestran los planos de distribución en planta que componen el centro de experimentación animal y en los que se reflejan los locales que lo conforman, quedando identificado cada tipo de local por el código de color correspondiente y el uso del local por el código numérico, según las leyendas de los planos.

Fuente: Elaboración propia.

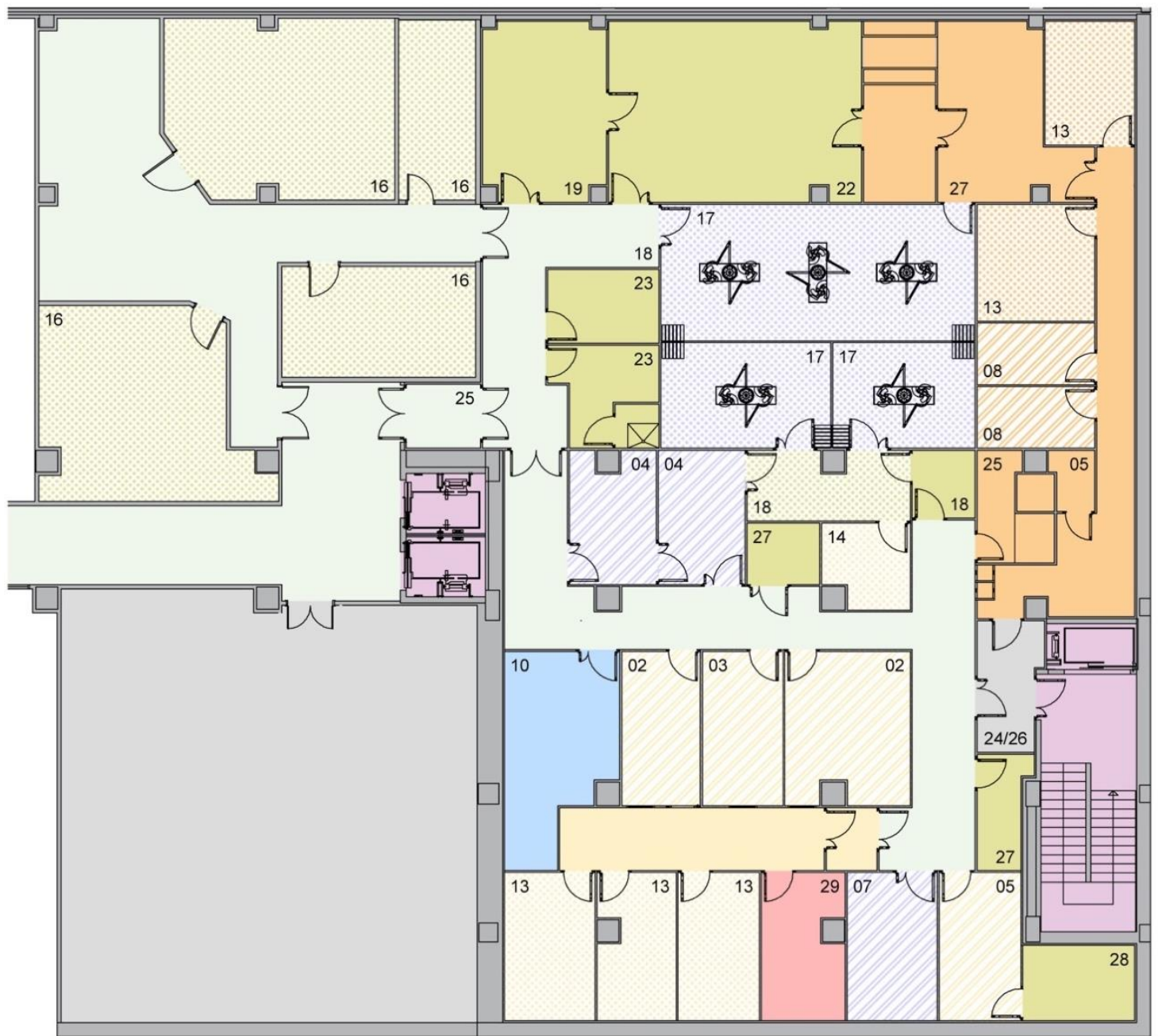

Planta Sótano -1

Escala: $1 / 250$

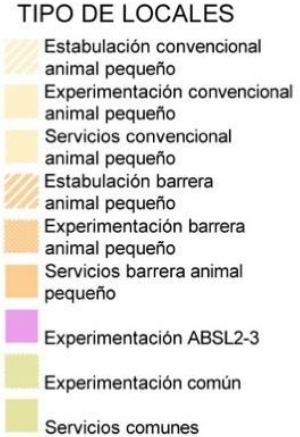

LOCALES

Experimentación convenciona

nimal pequeño

nimal pequeño

pequeción barrera

pequeño

Servicios comunes

\section{IDENTIFICACIÓN USO LOCALES}

01 Recepción animal

02 Estabulación convencional roedores 03 Estabulación convencional conejos 04 Estabulación convencional animal grande 05 Cuarentena roedores

06 Cuarentena conejos

07 Cuarentena animal grande
08 Estabulación barrera animal pequeño

08 Estabulación barrera animal pequeño

10 Experimentación ABSL2

10 Experimentación pece

12 Preparación anima

13 Procedimientos

14 Microcirugía

15 Comportamiento

16 Imagen
17 Quirófano experimenta 18 Preparación médic 20 Necropsias 21 Cirugia cadáveres 22 Lavado y esterilización 23 Vestuarios / Aseos 24 Esclusa animales 25 Esclusa personas 26 Esclusa materiales 27 Almacén / archivo 28 Servicios

29 Despacho 30 Sala reuniones 31 Pasillo 
Las respuestas que nos aporte son completamente anónimas, por lo que no se dispondrá de ningún dato que pueda identificarle. La información solo se utilizará para realizar un análisis de las opiniones de los usuarios de los centros de experimentación animal de los institutos de investigación sanitaria, para que a partir de su puesta en común se puedan establecer criterios que puedan ser de interés en el diseño y construcción de futuros centros. La información se tratará de acuerdo a la normativa de protección de datos vigente.

\section{ORGANIZACIÓN Y DISEÑO}

1.1. ¿Es o ha sido usuario del centro de experimentación animal? 冈Sí $\square$ No

1.2. ¿Participó activamente en la fase de elaboración de necesidades, diseño o construcción del centro?

$\square$ Sí $\quad$ No

Me incorporé en la fase final de construcción.

1.3. ¿Considera que los accesos de personal, animales, material limpio y residuos al centro de experimentación animal están adecuadamente diseñados? Indique cuáles no y por qué.

\Sí

$\square$ No $\square$ Personal $\square$ Animales $\square$ Material limpio $\square$ Residuos Aunque el planteamiento inicial ha variado y los residuos habitualmente se retiran por el acceso de personal.

1.4. ¿Considera que la organización del centro y distribución de áreas es la correcta? Indique qué modificaría.

$\square$ Sí $\quad$ No

Como planteamiento de base independizaría las áreas de experimentación de animal grande y pequeño.

1.5. ¿Considera que las circulaciones interiores del centro son las adecuadas? Indique qué modificaría.

$\square$ Sí $\quad$ No

Se mezcla la circulación de animal grande y pequeño con el riesgo de contaminación cruzada que conlleva.

1.6. ¿Considera que los diferentes locales que componen el centro están correctamente dimensionados? Indique cuál no.

凶Sí $\square$ No

Aunque ampliaría la zona de lavado y esterilización.

1.7. ¿Considera necesario el diseño de una planta técnica para facilitar el funcionamiento de las zonas más sensibles del centro? 凶Sí $\square$ No

Siempre que tenga la altura suficiente para ser operativa.

1.8. ¿Considera que la instalación tiene capacidad para adecuarse a necesidades futuras del centro?

$\square$ sí $\quad$ No

La ampliación está condicionada por los criterios de gestión establecidos por el instituto.

1.9. ¿Remarcaría algún concepto de diseño que podría servir de ejemplo en el diseño de centros futuros? Indique cuál.

$\square$ Sí $\quad$ No

1.10. ¿Cómo valoraría el resultado del diseño y organización de la instalación?

$\square$ Malo $\quad$ Regular $\square$ Bueno $\square$ Muy Bueno

\section{CARACTERÍSTICAS CONSTRUCTIVAS Y EQUIPAMIENTO}

2.1. ¿Considera adecuado el sistema constructivo y los materiales de acabado que componen los boxes de estabulación de animal grande? Indique cuál no y por qué.

$\square$ Sí

\No $\square$ Techos $\square$ Revestimientos verticales $\square$ Pavimentos Son poco ergonómicos al estar muy elevados con respecto al pavimento y tampoco tienen una buena evacuación de residuos.

2.2. ¿Considera adecuado el sistema constructivo y los materiales de acabado que componen el área quirúrgica de animal grande? Indique cuáles no y por qué.

$\triangle S i ́$

$\square$ No $\square$ Techos $\square$ Revestimientos verticales $\square$ Pavimentos

2.3. ¿Considera adecuados el sistema constructivo y los materiales de acabado que componen el área de estabulación y experimentación animal pequeño? Indique cuáles no y por qué. $\triangle S i ́$

$\square$ No $\square$ Techos $\square$ Revestimientos verticales $\square$ Pavimentos

2.4. ¿Considera adecuados el tipo, los acabados y herrajes de la carpintería de puertas instalados? Indique cuáles no y por qué. $\triangle \mathrm{Sí}$

$\square$ No $\square$ Tipo $\square$ Acabados $\square$ Herrajes

Aunque instalaría mirillas en las puertas.

2.5. ¿Complementaría la sala de lavado y esterilización con algún otro tipo de equipamiento? Indique cuál.

\Sí $\square$ No

Mejoraría los equipos de acceso a la barrera.

2.6. ¿Realizaría alguna mejora constructiva en el centro? Indique cuál.

\Sí $\square$ No

Colocaría paneles de indicación de la Ta, $\mathrm{HR}$ y presión en las puertas exteriores de las salas de estabulación.

2.7. ¿Remarcaría alguna característica constructiva que podría servir de ejemplo en el diseño de centros futuros? Indique cuál. \Sí $\square$ No

Los elementos divisorios modulares y los tabiques móviles de los quirófanos, aportan gran versatilidad al centro.

2.8. ¿Cómo valoraría el resultado de las características constructivas?

$\square$ Malo $\square$ Regular $\quad$ Bueno $\square$ Muy Bueno




\section{ENCUESTA DE OPINIÓN}

\section{Centros de experimentación animal de los Institutos de Investigación Sanitaria}

\section{INSTRUCCIONES PARA CUMPLIMENTAR LA ENCUESTA}

Las respuestas que nos aporte son completamente anónimas, por lo que no se dispondrá de ningún dato que pueda identificarle. La información solo se utilizará para realizar un análisis de las opiniones de los usuarios de los centros de experimentación animal de los institutos de investigación sanitaria, para que a partir de su puesta en común se puedan establecer criterios que puedan ser de interés en el diseño y construcción de futuros centros. La información se tratará de acuerdo a la normativa de protección de datos vigente.

\section{ORGANIZACIÓN Y DISEÑO}

1.1. ¿Es o ha sido usuario del centro de experimentación animal? 凶Sí $\square$ No

1.2. ¿Participó activamente en la fase de elaboración de necesidades, diseño o construcción del centro?

\Sí $\square$ No

1.3. ¿Considera que los accesos de personal, animales, material limpio y residuos al centro de experimentación animal están adecuadamente diseñados? Indique cuáles no y por qué.

凶sí

$\square$ No $\square$ Personal $\square$ Animales $\square$ Material limpio $\square$ Residuos

1.4. ¿Considera que la organización del centro y distribución de áreas es la correcta? Indique qué modificaría.

\Sí $\square$ No

1.5. ¿Considera que las circulaciones interiores del centro son las adecuadas? Indique qué modificaría.

$\square$ Sí $\bigotimes$ No

El área de experimentación convencional dispone de doble pasillo: sucio y limpio. A día de hoy no se hace ese uso, entre otros motivos porque no todas las salas de estabulación tienen conexión con ese pasillo y porque no es posible garantizar que todo el mundo haga un uso adecuado de los mismos.

1.6. ¿Considera que los diferentes locales que componen el centro están correctamente dimensionados? Indique cuáles no.

$\square$ sí $\quad$ No

Las salas de estabulación de roedores son pequeñas, no tienen posibilidad de alojar una cabina de cambio. Además, la sala de lavado y esterilización no es capaz de alojar todo el equipamiento necesario en el centro.

1.7. ¿Considera necesario el diseño de una planta técnica para facilitar el funcionamiento de las zonas más sensibles del centro? $\square$ sí $\bigotimes$ No

1.8. ¿Considera que la instalación tiene capacidad para adecuarse a necesidades futuras del centro?

$\square$ Sí $\bigotimes$ No

1.9. ¿Remarcaría algún concepto de diseño que podría servir de ejemplo en el diseño de centros futuros? Indique cuál.

$\square$ Sí $\quad$ No

1.10. ¿Cómo valoraría el resultado del diseño y organización de la instalación?

$\square$ Malo $\square$ Regular $\quad$ Bueno $\square$ Muy Bueno

\section{CARACTERÍSTICAS CONSTRUCTIVAS Y EQUIPAMIENTO}

2.1. ¿Considera adecuado el sistema constructivo y los materiales de acabado que componen los boxes de estabulación de animal grande? Indique cuáles no y por qué.

$\square$ Sí

\No $\square$ Techos $\quad$ Revestimientos verticales $\square$ Pavimentos A pesar de haber reforzado las aristas vivas con elementos metálicos, son elementos que los animales siguen deteriorando.

2.2. ¿Considera adecuado el sistema constructivo y los materiales de acabado que componen el área quirúrgica de animal grande? Indique cuáles no y por qué.

$\square$ sí

\No $\square$ Techos $\square$ Revestimientos verticales $\square$ Pavimentos Los quirófanos no tienen protección radiológica. En fase de obra no se dejaron previstas las placas necesarias para instalar lámparas quirúrgicas.

2.3. ¿Considera adecuados el sistema constructivo y los materiales de acabado que componen el área de estabulación y experimentación animal pequeño? Indique cuáles no y por qué. 凶Sí

$\square$ No $\square$ Techos $\square$ Revestimientos verticales $\square$ Pavimentos

2.4. ¿Considera adecuados el tipo, los acabados y herrajes de la carpintería de puertas instalados? Indique cuáles no y por qué. $\square$ Sí

\No $\square$ Tipo $\square$ Acabados $\quad$ Herrajes

No todas las puertas tienen muelles cierra puertas

2.5. ¿Complementaría la sala de lavado y esterilización con algún otro tipo de equipamiento? Indique cuál.

凶í́ $\square$ No

2.6. ¿Realizaría alguna otra mejora constructiva en el centro? Indique cuál.

$\square$ Sí $\quad$ No

2.7. ¿Remarcaría alguna característica constructiva que podría servir de ejemplo en el diseño de centros futuros? Indique cuál. $\square$ Sí $\bigotimes$ No

2.8. ¿Cómo valoraría el resultado de las características constructivas?

$\square$ Malo $\square$ Regular $\quad$ Bueno $\square$ Muy Bueno




\section{Centros de experimentación animal de los Institutos de Investigación Sanitaria}

INSTRUCCIONES PARA CUMPLIMENTAR LA ENCUESTA

Las respuestas que nos aporte son completamente anónimas, por lo que no se dispondrá de ningún dato que pueda identificarle. La información solo se utilizará para realizar un análisis de las opiniones de los usuarios de los centros de experimentación animal de los institutos de investigación sanitaria, para que a partir de su puesta en común se puedan establecer criterios que puedan ser de interés en el diseño y construcción de futuros centros. La información se tratará de acuerdo a la normativa de protección de datos vigente.

\section{ORGANIZACIÓN Y DISEÑO}

1.1. ¿Es o ha sido usuario del centro de experimentación animal? \Sí $\square$ No

1.2. ¿Participó activamente en la fase de elaboración de necesidades, diseño o construcción del centro?

\sí $\square$ No

1.3. ¿Considera que los accesos de personal, animales, material limpio y residuos al centro de experimentación animal están adecuadamente diseñados? Indique cuáles no y por qué.

凶í́

$\square$ No $\square$ Personal $\square$ Animales $\square$ Material limpio $\square$ Residuos 1.4. ¿Considera que la organización del centro y distribución de áreas es la correcta? Indique qué modificaría.

$\square$ Sí $\quad$ No

Evitaría la servidumbre de paso entre salas de estabulación

1.5. ¿Considera que las circulaciones interiores del centro son las adecuadas? Indique qué modificaría.

\í $\square$ No

1.6. ¿Considera que los diferentes locales que componen el centro están correctamente dimensionados? Indique cuáles no.

\Sí $\square$ No

1.7. ¿Considera necesario el diseño de una planta técnica para facilitar el funcionamiento de las zonas más sensibles del centro? $\square$ Sí $\quad$ No

1.8. ¿Considera que la instalación tiene capacidad para adecuarse a necesidades futuras del centro?

\í $\square$ No

1.9. ¿Remarcaría algún concepto de diseño que podría servir de ejemplo en el diseño de centros futuros? Indique cuál.

凶Sí $\square$ No

La organización del área quirúrgica experimental

1.10. ¿Cómo valoraría el resultado del diseño y organización de la instalación?

$\square$ Malo $\square$ Regular $\quad$ Bueno $\square$ Muy Bueno

\section{CARACTERÍSTICAS CONSTRUCTIVAS Y EQUIPAMIENTO}

2.1. ¿Considera adecuado el sistema constructivo y los materiales de acabado que componen los boxes de estabulación de animal grande? Indique cuáles no y por qué.

$\triangle \mathrm{Sí}$

$\square$ No $\square$ Techos $\square$ Revestimientos verticales $\square$ Pavimentos

2.2. ¿Considera adecuado el sistema constructivo y los materiales de acabado que componen el área quirúrgica de animal grande? Indique cuáles no y por qué.

$\bigotimes$ Sí

$\square$ No $\square$ Techos $\square$ Revestimientos verticales $\square$ Pavimentos

2.3. ¿Considera adecuados el sistema constructivo y los materiales de acabado que componen el área de estabulación y experimentación animal pequeño? Indique cuáles no y por qué. \Sí

$\square$ No $\square$ Techos $\square$ Revestimientos verticales $\square$ Pavimentos 2.4. ¿Considera adecuados el tipo, los acabados y herrajes de la carpintería de puertas instalados? Indique cuáles no y por qué. \Sí

$\square$ No $\square$ Tipo $\square$ Acabados $\square$ Herrajes

2.5. ¿Complementaría la sala de lavado y esterilización con algún otro tipo de equipamiento? Indique cuál.

\sí $\square$ No

2.6. ¿Realizaría alguna mejora constructiva en el centro? Indique cuál.

$\square$ Sí $\quad$ No

2.7. ¿Remarcaría alguna característica constructiva que podría servir de ejemplo en el diseño de centros futuros? Indique cuál. $\square$ sí $\square$ No

2.8. ¿Cómo valoraría el resultado de las características constructivas?

$\square$ Malo $\square$ Regular $\quad$ Bueno $\square$ Muy Bueno




\section{ENCUESTA DE OPINIÓN}

\section{Centros de experimentación animal de los Institutos de Investigación Sanitaria}

INSTRUCCIONES PARA CUMPLIMENTAR LA ENCUESTA

Las respuestas que nos aporte son completamente anónimas, por lo que no se dispondrá de ningún dato que pueda identificarle. La información solo se utilizará para realizar un análisis de las opiniones de los usuarios de los centros de experimentación animal de los institutos de investigación sanitaria, para que a partir de su puesta en común se puedan establecer criterios que puedan ser de interés en el diseño y construcción de futuros centros. La información se tratará de acuerdo a la normativa de protección de datos vigente.

\section{ORGANIZACIÓN Y DISEÑO}

1.1. ¿Es o ha sido usuario del centro de experimentación animal? 凶Sí $\square$ No

1.2. ¿Participó activamente en la fase de elaboración de necesidades, diseño o construcción del centro?

凶sí $\square$ No

1.3. ¿Considera que los accesos de personal, animales, material limpio y residuos al centro de experimentación animal están adecuadamente diseñados? Indique cuáles no y por qué.

凶sí

$\square$ No $\square$ Personal $\square$ Animales $\square$ Material limpio $\square$ Residuos

1.4. ¿Considera que la organización del centro y distribución de áreas es la correcta? Indique qué modificaría.

\Sí $\square$ No

Se podría mejorar, pero a pesar de las limitaciones de espacio, el centro funciona bien.

1.5. ¿Considera que las circulaciones interiores del centro son las adecuadas? Indique qué modificaría.

\Sí $\square$ No

1.6. ¿Considera que los diferentes locales que componen el centro están correctamente dimensionados? Indique cuáles no.

$\square$ Sí $\bigotimes$ No

Algunos de los locales de estabulación de animal grande no cumplen el dimensionamiento necesario a día de hoy, para alojar los animales de experimentación.

1.7. ¿Considera necesario el diseño de una planta técnica para facilitar el funcionamiento de las zonas más sensibles del centro? $\square$ Sí $\quad$ No

1.8. ¿Considera que la instalación tiene capacidad para adecuarse a necesidades futuras del centro?

\Sí $\square$ No

Las salas actualmente disponibles podrían cambiar de uso fácilmente. El aumento de superficie disponible para el centro depende del criterio del instituto.

1.9. ¿Remarcaría algún concepto de diseño que podría servir de ejemplo en el diseño de centros futuros? Indique cuál.

\Sí $\square$ No

La organización del área de experimentación de animal pequeño.

1.10. ¿Cómo valoraría el resultado del diseño y organización de la instalación?

$\square$ Malo $\square$ Regular $\square$ Bueno $\quad$ Muy Bueno

\section{CARACTERÍSTICAS CONSTRUCTIVAS Y EQUIPAMIENTO}

2.1. ¿Considera adecuado el sistema constructivo y los materiales de acabado que componen los boxes de estabulación de animal grande? Indique cuáles no y por qué.

\Sí

$\square$ No $\square$ Techos $\square$ Revestimientos verticales $\square$ Pavimentos Aunque hoy en día existen mejores soluciones para los problemas que ocasionan los animales en los acabados de paramentos horizontales y verticales.

2.2. ¿Considera adecuado el sistema constructivo y los materiales de acabado que componen el área quirúrgica de animal grande? Indique cuáles no y por qué.

凶Sí

$\square$ No $\square$ Techos $\square$ Revestimientos verticales $\square$ Pavimentos

2.3. ¿Considera adecuados el sistema constructivo y los materiales de acabado que componen el área de estabulación y experimentación animal pequeño? Indique cuáles no y por qué. 凶Sí

$\square$ No $\square$ Techos $\square$ Revestimientos verticales $\square$ Pavimentos 2.4. ¿Considera adecuados el tipo, los acabados y herrajes de la carpintería de puertas instalados? Indique cuáles no y por qué.

\Sí
$\square$ No
$\square$ Tipo $\square$ Acabados
$\square$ Herrajes

2.5. ¿Complementaría la sala de lavado y esterilización con algún otro tipo de equipamiento? Indique cuál.

凶sí $\square$ No

Aspirador de virutas y dispensador de virutas.

2.6. ¿Realizaría alguna mejora constructiva en el centro? Indique cuál.

凶í $\square$ No

Las instalaciones siempre se pueden mejorar, dependen de la asignación presupuestaria disponible

2.7. ¿Remarcaría alguna característica constructiva que podría servir de ejemplo en el diseño de centros futuros? Indique cuál.

$\square$ Sí $\bigotimes$ No

2.8. ¿Cómo valoraría el resultado de las características constructivas?

$\square$ Malo $\square$ Regular $\quad$ Bueno $\square$ Muy Bueno




\section{Centros de experimentación animal de los Institutos de Investigación Sanitaria}

INSTRUCCIONES PARA CUMPLIMENTAR LA ENCUESTA

Las respuestas que nos aporte son completamente anónimas, por lo que no se dispondrá de ningún dato que pueda identificarle. La información solo se utilizará para realizar un análisis de las opiniones de los usuarios de los centros de experimentación animal de los institutos de investigación sanitaria, para que a partir de su puesta en común se puedan establecer criterios que puedan ser de interés en el diseño y construcción de futuros centros. La información se tratará de acuerdo a la normativa de protección de datos vigente.

\section{ORGANIZACIÓN Y DISEÑO}

1.1. ¿Es o ha sido usuario del centro de experimentación animal? \Sí $\square$ No

1.2. ¿Participó activamente en la fase de elaboración de necesidades, diseño o construcción del centro?

\Sí $\square$ No

1.3. ¿Considera que los accesos de personal, animales, materia limpio y residuos al centro de experimentación animal están adecuadamente diseñados? Indique cuáles no y por qué.

凶í

$\square$ No $\square$ Personal $\square$ Animales $\square$ Material limpio $\square$ Residuos 1.4. ¿Considera que la organización del centro y distribución de áreas es la correcta? Indique qué modificaría.

\í $\square$ No

Aunque hubiera sido deseable independizar la zona de experimentación de animal grande del pequeño.

1.5. ¿Considera que las circulaciones interiores del centro son las adecuadas? Indique qué modificaría.

\Sí $\square$ No

Aunque la circulación inicial ha variado por las modificaciones realizadas en el centro.

1.6. ¿Considera que los diferentes locales que componen el centro están correctamente dimensionados? Indique cuáles no.

\Sí $\square$ No

1.7. ¿Considera necesario el diseño de una planta técnica para facilitar el funcionamiento de las zonas más sensibles del centro? $\square$ Sí $\quad$ No

1.8. ¿Considera que la instalación tiene capacidad para adecuarse a necesidades futuras del centro?

\í $\square$ No

1.9. ¿Remarcaría algún concepto de diseño que podría servir de ejemplo en el diseño de centros futuros? Indique cuál.

$\square$ Sí $\square$ No

1.10. ¿Cómo valoraría el resultado del diseño y organización de la instalación?

$\square$ Malo $\square$ Regular $\square$ Bueno $\quad$ Muy Bueno

\section{CARACTERÍSTICAS CONSTRUCTIVAS Y EQUIPAMIENTO}

2.1. ¿Considera adecuado el sistema constructivo y los materiales de acabado que componen los boxes de estabulación de animal grande? Indique cuáles no y por qué.

$\triangle S i ́$

$\square$ No $\square$ Techos $\square$ Revestimientos verticales $\square$ Pavimentos

2.2. ¿Considera adecuado el sistema constructivo y los materiales de acabado que componen el área quirúrgica de animal grande? Indique cuáles no y por qué.

凶í

$\square$ No $\square$ Techos $\square$ Revestimientos verticales $\square$ Pavimentos

2.3. ¿Considera adecuados el sistema constructivo y los materiales de acabado que componen el área de estabulación y experimentación animal pequeño? Indique cuáles no y por qué.

凶í

$\square$ No $\square$ Techos $\square$ Revestimientos verticales $\square$ Pavimentos

2.4. ¿Considera adecuados el tipo, los acabados y herrajes de la carpintería de puertas instalados? Indique cuáles no y por qué. $\triangle \mathrm{Sí}$

$\square$ No $\square$ Tipo $\square$ Acabados $\square$ Herrajes

2.5. ¿Complementaría la sala de lavado y esterilización con algún otro tipo de equipamiento? Indique cuál.

\Sí $\square$ No

Aspirador de virutas.

2.6. ¿Realizaría alguna mejora constructiva en el centro? Indique cuál.

\Sí $\square$ No

Los accesos a la zona de barrera.

2.7. ¿Remarcaría alguna característica constructiva que podría servir de ejemplo en el diseño de centros futuros? Indique cuál. $\square$ sí $\triangle$ No

2.8. ¿Cómo valoraría el resultado de las características constructivas?

$\square$ Malo $\square$ Regular $\square$ Bueno $\quad$ Muy Bueno




\section{ENCUESTA DE OPINIÓN}

\section{Centros de experimentación animal de los Institutos de Investigación Sanitaria}

\section{INSTRUCCIONES PARA CUMPLIMENTAR LA ENCUESTA}

Las respuestas que nos aporte son completamente anónimas, por lo que no se dispondrá de ningún dato que pueda identificarle. La información solo se utilizará para realizar un análisis de las opiniones de los usuarios de los centros de experimentación animal de los institutos de investigación sanitaria, para que a partir de su puesta en común se puedan establecer criterios que puedan ser de interés en el diseño y construcción de futuros centros. La información se tratará de acuerdo a la normativa de protección de datos vigente.

\section{ORGANIZACIÓN Y DISEÑO}

1.1. ¿Es o ha sido usuario del centro de experimentación animal? $\square$ Sí 冈No

1.2. ¿Participó activamente en la fase de elaboración de necesidades, diseño o construcción del centro?

凶í $\square$ No

1.3. ¿Considera que los accesos de personal, animales, materia limpio y residuos al centro de experimentación animal están adecuadamente diseñados? Indique cuáles no y por qué.

囚Sí

$\square$ No $\square$ Personal $\square$ Animales $\square$ Material limpio $\square$ Residuos 1.4. ¿Considera que la organización del centro y distribución de áreas es la correcta? Indique qué modificaría.

囚í

1.5. ¿Considera que las circulaciones interiores del centro son las adecuadas? Indique qué modificaría.

\Sí $\square$ No

1.6. ¿Considera que los diferentes locales que componen el centro están correctamente dimensionados? Indique cuáles no.

\Sí $\square$ No

1.7. ¿Considera necesario el diseño de una planta técnica para facilitar el funcionamiento de las zonas más sensibles del centro? \í $\square$ No

1.8. ¿Considera que la instalación tiene capacidad para adecuarse a necesidades futuras del centro?

\í $\square$ No

Tiene capacidad para introducir nuevo equipamiento voluminoso.

1.9. ¿Remarcaría algún concepto de diseño que podría servir de ejemplo en el diseño de centros futuros? Indique cuál.

\Sí $\square$ No

Independizar el área de experimentación de animal grande del pequeño por plantas.

1.10. ¿Cómo valoraría el resultado del diseño y organización de la instalación?

$\square$ Malo $\square$ Regular $\square$ Bueno $\quad$ Muy Bueno

\section{CARACTERÍSTICAS CONSTRUCTIVAS Y EQUIPAMIENTO}

2.1. ¿Considera adecuado el sistema constructivo y los materiales de acabado que componen los boxes de estabulación de animal grande? Indique cuáles no y por qué.

\Sí

$\square$ No $\square$ Techos $\square$ Revestimientos verticales $\square$ Pavimentos

2.2. ¿Considera adecuado el sistema constructivo y los materiales de acabado que componen el área quirúrgica de animal grande? Indique cuáles no y por qué.

囚sí

$\square$ No $\square$ Techos $\square$ Revestimientos verticales $\square$ Pavimentos

2.3. ¿Considera adecuados el sistema constructivo y los materiales de acabado que componen el área de estabulación y experimentación animal pequeño? Indique cuáles no y por qué.

囚Sí

$\square$ No $\square$ Techos $\square$ Revestimientos verticales $\square$ Pavimentos 2.4. ¿Considera adecuados el tipo, los acabados y herrajes de la carpintería de puertas instalados? Indique cuáles no y por qué. \Sí

$\square$ No $\square$ Tipo $\square$ Acabados $\square$ Herrajes

2.5. ¿Complementaría la sala de lavado y esterilización con algún otro tipo de equipamiento? Indique cuál.

$\square$ Sí $\quad$ No

2.6. ¿Realizaría alguna mejora constructiva en el centro? Indique cuál.

\Sí $\square$ No

Todo es mejorable, pero la calidad de la instalación es muy buena. 2.7. ¿Remarcaría alguna característica constructiva que podría servir de ejemplo en el diseño de centros futuros? Indique cuál. 凶í $\square$ No

El sistema de divisiones modulares autoportante.

2.8. ¿Cómo valoraría el resultado de las características constructivas?

$\square$ Malo $\square$ Regular $\square$ Bueno $\quad$ Muy Bueno




\section{Centros de experimentación animal de los Institutos de Investigación Sanitaria}

\section{INSTRUCCIONES PARA CUMPLIMENTAR LA ENCUESTA}

Las respuestas que nos aporte son completamente anónimas, por lo que no se dispondrá de ningún dato que pueda identificarle. La información solo se utilizará para realizar un análisis de las opiniones de los usuarios de los centros de experimentación animal de los institutos de investigación sanitaria, para que a partir de su puesta en común se puedan establecer criterios que puedan ser de interés en el diseño y construcción de futuros centros. La información se tratará de acuerdo a la normativa de protección de datos vigente.

\section{ORGANIZACIÓN Y DISEÑO}

1.1. ¿Es o ha sido usuario del centro de experimentación animal? $\bigotimes S i$

$\square$ No

1.2. ¿Participó activamente en la fase de elaboración de necesidades, diseño o construcción del centro?

$\square$ Sí $\quad$ No

1.3. ¿Considera que los accesos de personal, animales, material limpio y residuos al centro de experimentación animal están adecuadamente diseñados? Indique cuáles no y por qué.

\í

$\square$ No $\square$ Personal $\square$ Animales $\square$ Material limpio $\square$ Residuos

1.4. ¿Considera que la organización del centro y distribución de áreas es la correcta? Indique qué modificaría.

凶í $\square$ No

1.5. ¿Considera que las circulaciones interiores del centro son las adecuadas? Indique qué modificaría.

\Sí $\square$ No

1.6. ¿Considera que los diferentes locales que componen el centro están correctamente dimensionados? Indique cuáles no.

\Sí $\square$ No

1.7. ¿Considera necesario el diseño de una planta técnica para facilitar el funcionamiento de las zonas más sensibles del centro? $\square$ Sí $\bigotimes$ No

Aunque facilitaría las tareas de mantenimiento.

1.8. ¿Considera que la instalación tiene capacidad para adecuarse a necesidades futuras del centro?

凶Sí $\square$ No

1.9. ¿Remarcaría algún concepto de diseño que podría servir de ejemplo en el diseño de centros futuros? Indique cuál.

邓Sí $\square$ No

La organización del área quirúrgica experimental y la zona de barrera.

1.10. ¿Cómo valoraría el resultado del diseño y organización de la instalación?

$\square$ Malo $\square$ Regular $\square$ Bueno $\quad$ Muy Bueno

\section{CARACTERÍSTICAS CONSTRUCTIVAS Y EQUIPAMIENTO}

2.1. ¿Considera adecuado el sistema constructivo y los materiales de acabado que componen los boxes de estabulación de animal grande? Indique cuáles no y por qué.

$\triangle S i ́$

$\square$ No $\square$ Techos $\square$ Revestimientos verticales $\square$ Pavimentos

2.2. ¿Considera adecuado el sistema constructivo y los materiales de acabado que componen el área quirúrgica de animal grande? Indique cuáles no y por qué.

$\triangle S i ́$

$\square$ No $\square$ Techos $\square$ Revestimientos verticales $\square$ Pavimentos

2.3. ¿Considera adecuados el sistema constructivo y los materiales de acabado que componen el área de estabulación y experimentación animal pequeño? Indique cuáles no y por qué. $\triangle \mathrm{Sí}$

$\square$ No $\square$ Techos $\square$ Revestimientos verticales $\square$ Pavimentos

2.4. ¿Considera adecuados el tipo, los acabados y herrajes de la carpintería de puertas instalados? Indique cuáles no y por qué. 叉Sí
$\square$ No
$\square$ Tipo $\square$ Acabados
$\square$ Herrajes

2.5. ¿Complementaría la sala de lavado y esterilización con algún otro tipo de equipamiento? Indique cuál.

\sí $\square$ No

Siempre hay equipamiento para completar, pero en este caso, más bien lo hemos eliminado. El aspirador de virutas no funcionaba adecuadamente con la viruta mojada y se ha dejado de usar.

2.6. ¿Realizaría alguna mejora constructiva en el centro? Indique cuál.

\Sí $\square$ No

Mejoraría el sistema de climatización.

2.7. ¿Remarcaría alguna característica constructiva que podría servir de ejemplo en el diseño de centros futuros? Indique cuál. $\square$ sí $\quad$ No

2.8. ¿Cómo valoraría el resultado de las características constructivas?

$\square$ Malo $\square$ Regular $\square$ Bueno $\quad$ Muy Bueno




\section{ENCUESTA DE OPINIÓN}

\section{Centros de experimentación animal de los Institutos de Investigación Sanitaria}

INSTRUCCIONES PARA CUMPLIMENTAR LA ENCUESTA

Las respuestas que nos aporte son completamente anónimas, por lo que no se dispondrá de ningún dato que pueda identificarle. La información solo se utilizará para realizar un análisis de las opiniones de los usuarios de los centros de experimentación animal de los institutos de investigación sanitaria, para que a partir de su puesta en común se puedan establecer criterios que puedan ser de interés en el diseño y construcción de futuros centros. La información se tratará de acuerdo a la normativa de protección de datos vigente.

\section{ORGANIZACIÓN Y DISEÑO}

1.1. ¿Es o ha sido usuario del centro de experimentación animal? 凶Sí $\square$ No

1.2. ¿Participó activamente en la fase de elaboración de necesidades, diseño o construcción del centro?

凶Sí $\square$ No

1.3. ¿Considera que los accesos de personal, animales, materia limpio y residuos al centro de experimentación animal están adecuadamente diseñados? Indique cuáles no y por qué.

$\square$ sí

$\triangle$ No $\square$ Personal $\square$ Animales $\square$ Material limpio $\square$ Residuos Los animales acceden a través de un montacargas destinado compartido también con el personal, suministros y residuos. Además, la escalera de acceso es exterior.

1.4. ¿Considera que la organización del centro y distribución de áreas es la correcta? Indique qué modificaría.

$\triangle$ Sí $\square$ No

La zona administrativa que se sitúa en una zona periférica la ubicaría en una zona con luz natural.

1.5. ¿Considera que las circulaciones interiores del centro son las adecuadas? Indique qué modificaría.

\Sí $\square$ No

1.6. ¿Considera que los diferentes locales que componen el centro están correctamente dimensionados? Indique cuáles no.

凶sí $\square$ No

1.7. ¿Considera necesario el diseño de una planta técnica para facilitar el funcionamiento de las zonas más sensibles del centro? $\square$ sí $\quad$ No

Aunque la planta técnica sería una solución ideal, existen otras alternativas muy válidas.

1.8. ¿Considera que la instalación tiene capacidad para adecuarse a necesidades futuras del centro?

凶sí $\square$ No

Las galerías verticales previstas aportan gran flexibilidad.

1.9. ¿Remarcaría algún concepto de diseño que podría servir de ejemplo en el diseño de centros futuros? Indique cuál.

凶Sí $\square$ No

El sistema de distribución de triple pasillo del área de experimentación de animal pequeño. Permite realizar visitas y controles específicos sin tener que portar indumentaria complementaria.

1.10. ¿Cómo valoraría el resultado del diseño y organización de la instalación?

$\square$ Malo $\square$ Regular $\square$ Bueno $\quad$ Muy Bueno

\section{CARACTERÍSTICAS CONSTRUCTIVAS Y EQUIPAMIENTO}

2.1. ¿Considera adecuado el sistema constructivo y los materiales de acabado que componen los boxes de estabulación de animal grande? Indique cuáles no y por qué.

\Sí

$\square$ No $\square$ Techos $\square$ Revestimientos verticales $\square$ Pavimentos

2.2. ¿Considera adecuado el sistema constructivo y los materiales de acabado que componen el área quirúrgica de animal grande? Indique cuáles no y por qué.

$\triangle \mathrm{Sí}^{\prime}$

$\square$ No $\square$ Techos $\square$ Revestimientos verticales $\square$ Pavimentos

2.3. ¿Considera adecuados el sistema constructivo y los materiales de acabado que componen el área de estabulación y experimentación animal pequeño? Indique cuáles no y por qué.

\Sí

$\square$ No $\square$ Techos $\square$ Revestimientos verticales $\square$ Pavimentos

2.4. ¿Considera adecuados el tipo, los acabados y herrajes de la carpintería de puertas instalados? Indique cuáles no y por qué. 凶Sí

$\square$ No $\square$ Tipo $\square$ Acabados Herrajes

2.5. ¿Complementaría la sala de lavado y esterilización con algún otro tipo de equipamiento? Indique cuál.

\section{$\square$ Sí $\quad$ No}

2.6. ¿Realizaría alguna mejora constructiva en el centro? Indique cuál.

\í $\square$ No

La altura del montacargas debería ser más alto para poder transportar los palets de las jaulas.

Las puertas del animalario no son suficientemente estancas y se han tenido que complementar.

2.7. ¿Remarcaría alguna característica constructiva que podría servir de ejemplo en el diseño de centros futuros? Indique cuál. \í $\square$ No

Dejar las instalaciones vistas para facilitar su mantenimiento.

2.8. ¿Cómo valoraría el resultado de las características constructivas?

$\square$ Malo $\square$ Regular $\square$ Bueno $\quad$ Muy Bueno




\section{Centros de experimentación animal de los Institutos de Investigación Sanitaria}

INSTRUCCIONES PARA CUMPLIMENTAR LA ENCUESTA

Las respuestas que nos aporte son completamente anónimas, por lo que no se dispondrá de ningún dato que pueda identificarle. La información solo se utilizará para realizar un análisis de las opiniones de los usuarios de los centros de experimentación animal de los institutos de investigación sanitaria, para que a partir de su puesta en común se puedan establecer criterios que puedan ser de interés en el diseño y construcción de futuros centros. La información se tratará de acuerdo a la normativa de protección de datos vigente.

\section{ORGANIZACIÓN Y DISEÑO}

1.1. ¿Es o ha sido usuario del centro de experimentación animal? \Sí $\square$ No

1.2. ¿Participó activamente en la fase de elaboración de necesidades, diseño o construcción del centro?

\section{\Sí $\square$ No}

1.3. ¿Considera que los accesos de personal, animales, material limpio y residuos al centro de experimentación animal están adecuadamente diseñados? Indique cuáles no y por qué. 凶í

$\square$ No $\square$ Personal $\square$ Animales $\square$ Material limpio $\square$ Residuos

1.4. ¿Considera que la organización del centro y distribución de áreas es la correcta? Indique qué modificaría.

\í $\square$ No

Aunque es preferible tener distribuido en una única planta, se ha conseguido una buena distribución

1.5. ¿Considera que las circulaciones interiores del centro son las adecuadas? Indique qué modificaría.

\Sí $\square$ No

1.6. ¿Considera que los diferentes locales que componen el centro están correctamente dimensionados? Indique cuáles no. 凶í $\square$ No

1.7. ¿Considera necesario el diseño de una planta técnica para facilitar el funcionamiento de las zonas más sensibles del centro? 凶sí $\square$ No

Aunque hay otras alternativas, es muy buena opción si está correctamente diseñada con la altura suficiente.

1.8. ¿Considera que la instalación tiene capacidad para adecuarse a necesidades futuras del centro?

\Sí $\square$ No

1.9. ¿Remarcaría algún concepto de diseño que podría servir de ejemplo en el diseño de centros futuros? Indique cuál.

\Sí $\square$ No

La compartimentación de la sala con la ubicación de equipos de barrera.

1.10. ¿Cómo valoraría el resultado del diseño y organización de la instalación?

$\square$ Malo $\square$ Regular $\square$ Bueno $\quad$ Muy Bueno

\section{CARACTERISTICAS CONSTRUCTIVAS Y EQUIPAMIENTO}

2.1. ¿Considera adecuado el sistema constructivo y los materiales de acabado que componen los boxes de estabulación de animal grande? Indique cuáles no y por qué.

$\triangle S i ́$

$\square$ No $\square$ Techos $\square$ Revestimientos verticales $\square$ Pavimentos

2.2. ¿Considera adecuado el sistema constructivo y los materiales de acabado que componen el área quirúrgica de animal grande? Indique cuáles no y por qué.

\Sí

$\square$ No $\square$ Techos $\square$ Revestimientos verticales $\square$ Pavimentos

2.3. ¿Considera adecuados el sistema constructivo y los materiales de acabado que componen el área de estabulación y experimentación animal pequeño? Indique cuáles no y por qué. $\triangle \mathrm{Sí}$

$\square$ No $\square$ Techos $\square$ Revestimientos verticales $\square$ Pavimentos

2.4. ¿Considera adecuados el tipo, los acabados y herrajes de la carpintería de puertas instalados? Indique cuáles no y por qué.

叉Sí
$\square$ No
$\square$ Tipo
$\square$ Acabados
$\square$ Herrajes

2.5. ¿Complementaría la sala de lavado y esterilización con algún otro tipo de equipamiento? Indique cuál.

\sí $\square$ No

Nos quedamos sin presupuesto suficiente y tuvimos que prescindir de la compra de varios equipos.

2.6. ¿Realizaría alguna mejora constructiva en el centro? Indique cuál.

$\square$ Sí $\quad$ No

2.7. ¿Remarcaría alguna característica constructiva que podría servir de ejemplo en el diseño de centros futuros? Indique cuál. \Sí $\square$ No

Los tabiques modulares de las salas quirurgicas

2.8. ¿Cómo valoraría el resultado de las características constructivas?

$\square$ Malo $\square$ Regular $\square$ Bueno $\quad$ Muy Bueno




\section{ENCUESTA DE OPINIÓN}

\section{Centros de experimentación animal de los Institutos de Investigación Sanitaria}

INSTRUCCIONES PARA CUMPLIMENTAR LA ENCUESTA

Las respuestas que nos aporte son completamente anónimas, por lo que no se dispondrá de ningún dato que pueda identificarle. La información solo se utilizará para realizar un análisis de las opiniones de los usuarios de los centros de experimentación animal de los institutos de investigación sanitaria, para que a partir de su puesta en común se puedan establecer criterios que puedan ser de interés en el diseño y construcción de futuros centros. La información se tratará de acuerdo a la normativa de protección de datos vigente.

\section{ORGANIZACIÓN Y DISEÑO}

1.1. ¿Es o ha sido usuario del centro de experimentación animal? 凶Sí $\square$ No

1.2. ¿Participó activamente en la fase de elaboración de necesidades, diseño o construcción del centro?

凶sí $\square$ No

1.3. ¿Considera que los accesos de personal, animales, material limpio y residuos al centro de experimentación animal están adecuadamente diseñados? Indique cuáles no y por qué.

$\square$ sí

\No $\square$ Personal $\triangle$ Animales $\bigotimes$ Material limpio $\bigotimes$ Residuos El ascensor no tiene la dimensión suficiente para transportar las jaulas de cerdos. Hubiera sido deseable disponer de dos montacargas para separar el material limpio del sucio.

1.4. ¿Considera que la organización del centro y distribución de áreas es la correcta? Indique qué modificaría.

$\square$ Sí $\quad$ No

Hubiera sido deseable independizar el área de estabulación de animal grande del pequeño y distribuirlo en la misma planta que la experimentación de animal grande para evitar desplazamientos verticales de animales.

1.5. ¿Considera que las circulaciones interiores del centro son las adecuadas? Indique qué modificaría.

$\square$ Sí $\quad$ No

El paso por la zona de estabulación de animal grande es inevitable, por lo que para garantizar la asepsia es obligatorio adoptar procedimientos de trabajo específicos.

1.6. ¿Considera que los diferentes locales que componen el centro están correctamente dimensionados? Indique cuáles no.

\sí $\square$ No

1.7. ¿Considera necesario el diseño de una planta técnica para facilitar el funcionamiento de las zonas más sensibles del centro? $\triangle$ Sí $\square$ No

Sin duda. Uno de los problemas existentes es que el personal de limpieza es variable y es fundamental que esté informado sobre las condiciones y procedimientos dentro del centro.

1.8. ¿Considera que la instalación tiene capacidad para adecuarse a necesidades futuras del centro?

$\square$ Sí $\bigotimes$ No

1.9. ¿Remarcaría algún concepto de diseño que podría servir de ejemplo en el diseño de centros futuros? Indique cuál.

\section{$\square$ Sí $\quad$ No}

1.10. ¿Cómo valoraría el resultado del diseño y organización de la instalación?

$\square$ Malo $\square$ Regular $\quad$ Bueno $\square$ Muy Bueno
2. CARACTERÍSTICAS CONSTRUCTIVAS Y EQUIPAMIENTO

2.1. ¿Considera adecuado el sistema constructivo y los materiales de acabado que componen los boxes de estabulación de animal grande? Indique cuáles no y por qué.

$\square$ Sí

$\triangle$ No $\square$ Techos $\triangle$ Revestimientos verticales $\triangle$ Pavimentos No se han seleccionado adecuadamente

2.2. ¿Considera adecuado el sistema constructivo y los materiales de acabado que componen el área quirúrgica de animal grande? Indique cuáles no y por qué.

凶Sí

$\square$ No $\square$ Techos $\square$ Revestimientos verticales $\square$ Pavimentos

2.3. ¿Considera adecuados el sistema constructivo y los materiales de acabado que componen el área de estabulación y experimentación animal pequeño? Indique cuáles no y por qué. \í

$\square$ No $\square$ Techos $\square$ Revestimientos verticales $\square$ Pavimentos 2.4. ¿Considera adecuados el tipo, los acabados y herrajes de la carpintería de puertas instalados? Indique cuáles no y por qué. $\square$ sí
$\triangle$ No
$\square$ Tipo $\square$ Acabados
\Herrajes

Los muelles cierra-puertas no funcionan bien.

2.5. ¿Complementaría la sala de lavado y esterilización con algún otro tipo de equipamiento? Indique cuál.

\í $\square$ No

Se dispone únicamente del equipamiento básico necesario.

2.6. ¿Realizaría alguna mejora constructiva en el centro? Indique cuál.

\Sí $\square$ No

Reforzaría los paramentos verticales de las cochiqueras.

2.7. ¿Remarcaría alguna característica constructiva que podría servir de ejemplo en el diseño de centros futuros? Indique cuál. $\square$ Sí $\quad$ No

2.8. ¿Cómo valoraría el resultado de las características constructivas?

$\square$ Malo $\square$ Regular $\quad$ Bueno $\square$ Muy Bueno




\section{DESARROLLO DE LA INVESTIGACIÓN}

\subsection{Institutos de Investigación Sanitaria Acreditados}

La acreditación de los Institutos de Investigación Sanitaria surge a partir de la Ley 16/2003, de cohesión y calidad del Sistema Nacional de Salud, en cuyo articulado sobre investigación participó activamente el Instituto de Salud Carlos III28, y en la que se le asigna, entre otras, las funciones de fomentar la investigación en salud y contribuir a la vertebración de la investigación en el Sistema Nacional de Salud mediante la acreditación de institutos y redes de investigación cooperativa para concretar la investigación en los objetivos previstos en el plan y fomentar la investigación de excelencia.

Es a partir de la aprobación de dicha ley, en la que se establece que se promueva la configuración de Institutos de Investigación Sanitaria mediante la asociación de centros de investigación que serán acreditados por el Ministerio de Sanidad y Consumo a propuesta del ISCIII o de las comunidades autónomas, cuando se desarrolló con más precisión la naturaleza y las distintas características que deberían reunir los institutos para su inserción en el sistema español de ciencia y de salud, y que quedaron reflejadas en el Real Decreto 339, de 27 de febrero de 2004, sobre acreditación de Institutos de Investigación Sanitaria.

Los IIS son entidades dedicadas a la investigación básica y aplicada, creadas mediante la asociación a los hospitales del Sistema Nacional de Salud, de las universidades, organismos públicos de investigación y otros centros públicos o privados de investigación, a los efectos de constituir institutos de investigación multidisciplinares. La acreditación como IIS es un reconocimiento de la excelencia de los resultados científicos y de los retornos beneficiosos (sanitarios, sociales y económicos) producto de la labor investigadora en el entorno hospitalario.

Se trata con ello potenciar la investigación en los hospitales, siendo el hospital el centro docente e investigador y dotándolo de los instrumentos necesarios para; por una parte, resolver las cuestiones que surgen de la relación del profesional sanitario con el paciente y la población; por otra, constituir el lugar idóneo donde ubicar instalaciones científico-tecnológicas y para captación de talento; y, por último, crear un entorno asistencial, docente e investigador de calidad al servicio de los alumnos de grado, los especialistas en formación y los profesionales sanitarios.

\footnotetext{
${ }^{28}$ El Instituto de Salud Carlos III (ISCIII) es el principal Organismo Público de Investigación, que financia, gestiona y ejecuta la investigación biomédica en España. Adscrito orgánicamente al Ministerio de Economía y Competitividad (Real Decreto $345 / 2012$ ) y funcionalmente, tanto a este mismo como al Ministerio de Sanidad, Servicios Sociales e Igualdad (Real Decreto 200/2012), tiene como misión principal el fomento de la generación de conocimiento científico en ciencias de la salud y el impulso de la innovación en la atención sanitaria y en la prevención de la enfermedad.
} 
La misión principal de los Institutos de Investigación Sanitaria es realizar investigación traslacional ${ }^{29}$, de la máxima calidad, traduciendo los resultados de la investigación básica, clínica, epidemiológica, de servicios sanitarios y de salud pública al Sistema Nacional de Salud, al Sistema Español de Ciencia y Tecnología, al paciente y a la sociedad en general. En la Figura 07 se muestra la importancia tanto de la investigación básica como de la preclínica y clínica en el desarrollo de un fármaco. Observamos como se parte de la investigación básica, que persigue un mejor conocimiento de los mecanismos moleculares, bioquímicos y celulares implicados en el desarrollo de una enfermedad, para la búsqueda de dianas terapeúticas y nuevas moléculas que identifiquen posibles candidatos a fármaco; en la fase intermedia, denominada desarrollo preclínico, se realiza la experimentación in vitro y la experimentación en animales; para en una última y definitiva fase, denominada desarrollo clínico, realizar los ensayos en humanos, necearios para tener la aprobación para el desarrollo de un nuevo fármaco.

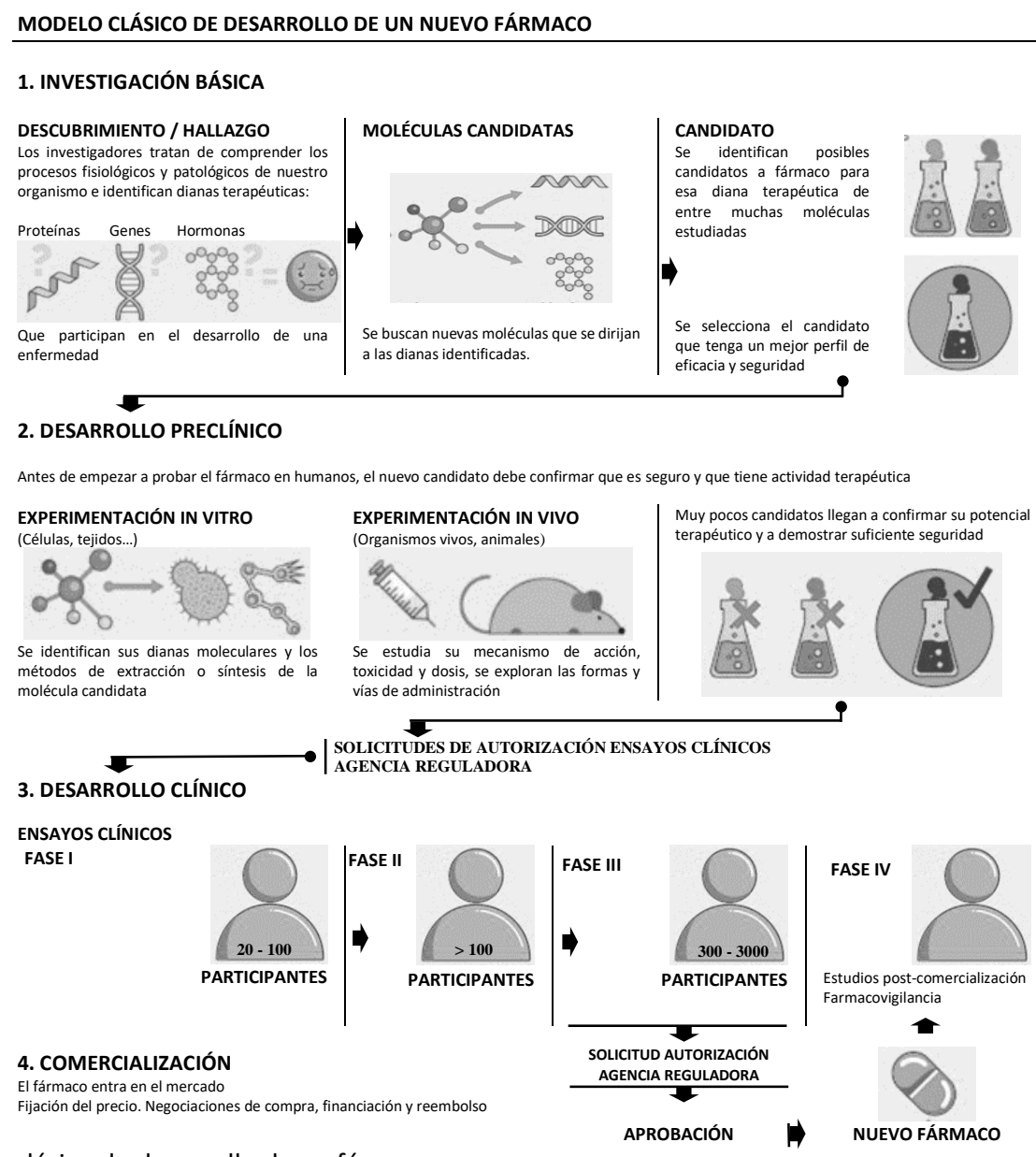

Figura 07. Modelo clásico de desarrollo de un fármaco.

Fuente. Interés Público en la Innovación Biomédica. p.19.

\footnotetext{
${ }^{29}$ Este tipo de investigación surge de la necesidad de estrechar lazos entre la investigación básica y la aplicada, y consiste en trasladar los conocimientos obtenidos por las ciencias básicas para la búsqueda de intervenciones terapéuticas (tratamiento) o preventivas eficaces (prevención de enfermedades) con el objetivo de mejorar de la salud y calidad de vida de la población.
} 
El objetivo general de los Institutos de Investigación Sanitaria es que todo el conocimiento generado a partir de la investigación biomédica de excelencia se traduzca, finalmente, en el tratamiento y prevención de enfermedades y en la mejora de la salud y calidad de vida de la población, y como objetivos específicos se encuentran, entre otros, favorecer la captación de fondos públicos y privados de financiación de la investigación, definir estrategias comunes, priorizar líneas estratégicas de investigación en salud y áreas de interés clínico, potenciar alianzas con otros grupos de investigación y promover la formación de profesionales.

Estos institutos necesitan para acreditarse al menos estar constituidos por un Hospital y una Universidad y disponer en el contexto hospitalario de un espacio físico propio destinado a la investigación donde se produzca la integración e interacción de los grupos de investigación. Además, es necesario cumplir otros requisitos como tener un vínculo jurídico y una estructura organizativa que ampare la asociación de los centros que integran el instituto, un plan estratégico de investigación, un comité científico externo, un plan de formación e investigación, servicios de apoyo, una guía de buenas prácticas de investigación, así como el registro de personal y de datos de las actividades de $1+D+i$.

El proceso de acreditación de los IIS es un proceso dinámico objeto de revisión continuo por parte de todos los agentes implicados que consta de varias etapas. Por una parte, está la autoevaluación que se recomienda realizar a los centros con carácter previo a la presentación de la solicitud con el fín de comprobar que el nivel de cumplimiento de su organización es acorde a los criterios establecidos por el instituto. Por otra parte, está la validación por la comunidad autónoma correspondiente, para lo que primeramente, el instituto deberá realizar la solicitud de acreditación al director del Instituto de Salud Carlos III o al órgano competente de la Comunidad Autónoma, para a continuación, poder evaluarla y emitir el informe final de auditoría por parte del equipo auditor del ISCIII para su posterior remisión a la Comisión de Evaluación de acreditaciones de Institutos de Investigación Sanitaria. En base a los informes de carácter científico-técnico elaborados por la comisión de evaluación de acreditaciones, el órgano instructor, que puede ser el Instituto de Salud Carlos III y las comunidades autónomas, formularán las propuestas de resolución y a través de la Secretaría de Estado de Investigación, Desarrollo e Innovación, se elevará al titular del Ministerio de Economía y Competitividad, que resolverá el procedimiento concediendo o denegando la acreditación

Una vez notificada la acreditación, ésta tiene un periodo de vigencia de cinco años que puede ser prorrogable por el mismo ministerio previa evaluación de las actividades científicas y de gestión realizadas en los últimos cinco años, y será ese mismo órgano al que le corresponderá en su caso, la revocación o no concesión de prórroga de las acreditaciones. 
Posteriormente, entra en vigor el Real Decreto 279/2016, sobre la acreditación de los Institutos de Investigación Biomédica o Sanitaria, con el objetivo de adaptar la acreditación de los institutos a la Ley de Investigación Biomédica de 2007, y garantizar que responden a la finalidad de dicha ley.

A fecha 1 de febrero 2020, se encuentran acreditados los siguientes treinta y un Institutos de Investigación Sanitaria, que están listados por fecha de acreditación:

1 IDIBAPS Institut d'investigaciones Biomédicas August Pi Y Sunyer. 25 de febrero de 2009

2 IBIS Instituto de Biomedicina De Sevilla. 25 de febrero de 2009

3 IDIBELL Institut d'investigació Biomédica de Bellvitge. 25 de febrero de 2009

4 IR-HUVH Institut de Recerca Hospital Universitari Vall D'hebron. 25 de febrero de 2009

5 IGTP Institut d'investigació en Ciéncies de la Salut Germans Trias I Pujol. 25 febrero de 2009

6 IIS La Fe Fundación para la Investigación del Hospital Universitario La Fe. 23 abril de 2009

7 idis Instituto de Investigación Sanitaria de Santiago de Compostela. 10 de marzo de 2010

8 IdiPAZ Instituto de Investigación Sanitaria Hospital La Paz. 19 de abril de 2010

9 IIS-PRINCESA II Sanitaria Hospital Universitario de La Princesa. 29 de octubre de 2010

10 IISFJD Instituto de Investigación Sanitaria Fundación Jiménez Díaz. 16 de diciembre de 2010

11 IIB SANT PAU Instituto de Investigación Biomédico Sant Pau. 7 de marzo de 2011

12 IRICYS Instituto Ramón y Cajal de Investigación Sanitaria. 14 de marzo de 2011

13 i+12 Instituto de Investigación Hospital 12 De Octubre. 14 de marzo de 2011

14 INCLIVA Instituto de Investigación Sanitaria Fundación para la Investigación Del Hospital Clínico de Valencia. 19 de septiembre de 2011

15 IMIBIC Instituto Maimónides de Investigación Biomédica de Córdoba. 19 de septiembre 2011

16 IIS BIODONOSTIA Instituto de Investigación Sanitaria Biodonostia. 17 de octubre de 2011

17 liSGM Instituto de Investigación Sanitaria Gregorio Marañón. 21 de mayo de 2012

18 IdISSC Instituto de Investigación Sanitaria del Hospital Clínico San Carlos. 21 de mayo de 2012

19 IBSAL Instituto de Investigación Biómedica de Salamaca. 17 de febrero de 2014

20 IMIM Instituto Hospital del Mar de Investigaciones Biomédicas. 17 de febrero de 2014

21 IRB LÉRIDA Instituto de Investigación Biomédica de Lérida. 25 de febrero de 2014

22 IDIPHIM IIS Instituto de Investigación Sanitaria Puerta de Hierro. 29 de mayo de 2014

23 IIS BIOCRUCES Biocruces Health Research Institute. 15 de enero de 2015

24 IBIMA Instituto de Investigación Biomédica de Málaga. 15 de enero de 2015

25 IMIB Instituto Murciano de Investigación Biosanitaria Virgen de La Arrixaca. 15 de enero 2015

26 idival Instituto de Investigación Marqués de Valdecilla. 10 de marzo de 2015

27 INIBIC Instituto de Investigación Biomédica A Coruña. 10 de marzo de 2015

28 IIS Aragón Instituto de Investigación Sanitaria Aragón. 18 de mayo de 2015

29 ibs.GRANADA Instituto de Investigación Biosanitaria de Granada. 30 de noviembre de 2015

30 IDISNA Instituto de Investigación Sanitaria de Navarra. 24 de enero de 2019

31 IdISBa Instituto de Investigación Sanitaria Islas Baleares. 24 de enero de 2019 
El diseño y configuración de cada instituto vendrá determinado por la estructura científica y las diferentes líneas o áreas de investigación que se quieran llevar a cabo. Para poder desarrollar esa investigación, habitualmente, los institutos disponen de servicios de apoyo a la investigación, que son instalaciones que integran infraestructuras y grandes equipamientos dedicados a la realización de técnicas especializadas, siendo su objetivo principal potenciar la investigación en el área biomédica mediante la puesta a disposición de los investigadores de infraestructuras científicas que, por sus características, superan, en general, las posibilidades de adquisición y utilización por parte de grupos individuales de investigación, y de personal cualificado que ofrezca apoyo técnico y científico especializado. Entre las diferentes plataformas de apoyo a la investigación que disponen habitualmente los Institutos de Investigación Sanitaria se encuentran: cultivos celulares, microscopía, biobanco, investigación clínica, metabolómica y proteómica y la experimentación animal.

El presente trabajo de investigación se centra exclusivamente en el denominado centro de experimentación animal de los Institutos de Investigación Sanitaria Acreditados y específicamente se analizan las centros de experimentación animal de los siguientes diez institutos acreditados:

1. IdiPAZ Instituto de Investigación Sanitaria Hospital La Paz Madrid

2. $\mathrm{i}+12$ Instituto de Investigación Hospital 12 De Octubre Madrid

3. IiSGM Instituto de Investigación Sanitaria Gregorio Marañón Madrid

4. IRICYS Instituto Ramón y Cajal de Investigación Sanitaria Madrid

5. IIS Biodonostia Instituto de Investigación Sanitaria Biodonostia Gipuzkoa

6. IIS Biocruces Instituto de Investigación Sanitaria Biocruces Bizkaia

7. IISA IIS Aragón Instituto de Investigación Sanitaria Aragón Zaragoza

8. VHIR IR-HUVH Institut de Recerca Hospital Universitari Vall D’hebron Barcelona

9. IGTP Institut d'investigació en Ciéncies de la Salut Germans Trias I Pujo Barcelona 10. IIS La Fe Fundación para la Investigación del Hospital Universitario La Fe Valencia 


\subsection{Centros de experimentación animal}

Se denomina centro de experimentación animal a toda instalación, edificio, grupo de edificios u otros locales, incluidos aquellos no totalmente cerrados o cubiertos, así como las instalaciones móviles y todo el conjunto de medios personales y materiales organizados por su titular para la cría, el suministro o la utilización de animales de experimentación (RD 1201/2005 art.3).

Cada centro de experimentación animal está basado en la actividad que se quiera desarrollar, fijada fundamentalmente por los proyectos y líneas de investigación a llevar a cabo, así como por la formación que se quiera impartir. Es por ello que la base de diseño de todo centro será el plan funcional elaborado por profesionales conocedores de los objetivos propuestos. Entre los conceptos que en ese documento se recogen y que van a ser el punto de partida del diseño del centro se encuentran los siguientes: tipo de centro, tipología de animales, estado sanitario, tipo de local de alojamiento para los animales, así como las áreas de experimentación necesarias.

\subsubsection{Tipo de centro de experimentación animal}

En función de la actividad que se va a desarrollar con las diferentes colonias de animales, se pueden distinguir tres tipos de centros: centro de cría, centro suministrador y centro de usuario.

- Centro de cría, siendo el centro en el que se crían animales de experimentación.

- Centro suministrador, siendo cualquier establecimiento que suministra y mantiene animales de experimentación, no nacidos en el mismo centro.

- Centro de usuario, cualquier establecimiento en el que se utilicen animales de experimentación.

Hay que tener en cuenta que los centros criadores, suministradores y usuarios con carácter previo al inicio de su funcionamiento, tienen que ser inscritos en el Registro General de Explotaciones Ganaderas ${ }^{30}$, y en el caso de que algún centro simultanee actividades de cría, suministro o usuario de animales de experimentación en el registro se incluirán toda ellas (RD 53/2013). En el caso de los institutos de investigación sanitaria es muy habitual que los centros aparte de usuarios también críen animales para experimentación propia. Conocer si un centro va a ser de cría es importante ya que, según analizaremos más adelante, en función del estado sanitario en el que se quieran producir los animales, las instalaciones para alojarlos pueden requerir exigencias constructivas y de organización específicas que pueden condicionar el planteamiento general del centro.

${ }^{30} \mathrm{RD}$ 479/2004, de 26 de marzo, por el que se establece y regula el Registro General de Explotaciones Ganaderas. 


\subsubsection{Sistemas de gestión de calidad en los animalarios}

En el ámbito de la experimentación animal existen varios modelos de gestión de calidad que pueden aplicarse. Por una parte, está el modelo específico de gestión de los animalarios como es la acreditación AAALAC Internacional; y por la otra, están los modelos generalistas que son de aplicación también a otros sectores como pueden ser: ISO 9001 y Buenas Prácticas de Laboratorios BPL.

La realidad es que estas acreditaciones son voluntarias, pero compromete a científicos, gerentes y administradores a llevar a cabo una evaluación independiente y rigurosa que se pretende traducir en mejores prácticas y resultados de investigación.

ISO 9001 es una norma sobre sistema de gestión de la calidad reconocida internacionalmente, siendo un referente a nivel mundial. Una de las principales fortalezas es que es de aplicación en cualquier tipo de organización y sector, ya que al centrarse en los procesos y en la satisfacción del cliente, el sistema es aplicable tanto a proveedores de servicios como a productos.

El concepto de Buenas Prácticas de Laboratorio BPL, surge de la industria farmacéutica como una parte de las Buenas Prácticas de Producción en el que se establecían los elementos específicos que un laboratorio debía tener en cuenta para conseguir que los resultados fueran confiables. Si bien el primer documento independiente de BPL estuvo dirigido a los laboratorios de control de los medicamentos, con el paso del tiempo se extendió a todo tipo de laboratorios de experimentación. En este sistema de calidad se involucra a la organización de un laboratorio de investigación en los procesos organizativos, de manera que se establezcan las condiciones bajo las cuales se planifican, realizan, controlan, registran, archivan e informan los estudios realizados por el laboratorio.

AAALAC International, Asociación Internacional para la Evaluación y Acreditación del Cuidado de Animales de Laboratorio es una organización privada, no gubernamental, que promueve el trato humanitario de los animales en las actividades científicas mediante programas voluntarios de evaluación y acreditación. Aunque también toma como referencia otras publicaciones especializadas para obtener información complementaria sobre procedimientos o técnicas relacionados con el cuidado y uso de los animales de laboratorio, la acreditación AAALAC se basa en la Guía para el cuidado y uso de animales de laboratorio ${ }^{31}$ como su estándar principal para evaluar los programas de cuidado y uso de animales de laboratorio. Con dicha acreditación se busca no solo cumplir con las normas locales, nacionales e internacionales que regulan las investigaciones con animales, sino también con los estándares aceptados a nivel internacional de dicha guia.

\footnotetext{
${ }^{31}$ National Research Council. 2011. Guide for the Care and Use of Laboratory Animals. 8th ed. Washington, DC: The National Academy Press.
} 
AAALAC es principalmente un sistema de acreditación revisado por pares que evalúa la organización y procedimientos en programas de cuidado y uso de animales para asegurar el uso apropiado de animales, salvaguardar el bienestar de los animales (garantizando el alojamiento, la gestión, los procedimientos de técnicos, etc.) así como los riesgos de seguridad y salud del personal. AAALAC destaca el concepto de que la calidad del cuidado y uso del animal produce datos científicos de calidad (FELASA 2004, pp. 103-118).

Lograr un estándar de control de calidad puede influir positivamente en la moral y la autoestima de los usuarios y el personal que trabaja en las propias instalaciones. El premio representa el reconocimiento de pares contra una norma independiente y puede proporcionar aseguramiento de normas del cuidado y uso de animales, mejorando así la calidad de los estudios y contribuyendo a la regla de las tres Rs. Además, después de todo el duro trabajo de implementación del sistema de gestión y del registro, los beneficios no son solo internos, ya que informar a los clientes y otras partes interesadas del hecho de que la instalación ha logrado tal reconocimiento puede obtener significativos beneficios comerciales y promocionales (FELASA 2004, pp. 103-118).

A fecha febrero de 2020, en España se encuentran acreditados por AAALAC únicamente nueve centros de experimentación animal: CIC bioGUNE, CIC biomaGUNE, Envigo CRS S.A.U., GlaxoSmithKline Inc., Institut d'Investigació Biomedica de Bellvitge (IDIBELL), Noveprim Europe Ltd., Parc Recerca Biomédica de Barcelona (PRBB), Spanish National Cancer Research Centre (CNIO) y Zoetis.

Entre todos los centros acreditados caben destacar los animalarios del Instituto de Investigación Sanitaria de Bellvitge IDIBELL, y el animalario del PRBB que es en el que realiza su experimentación animal el Instituto Hospital del Mar de Investigaciones Biomédicas IMIM. Por otra parte, caben mencionar otros dos de los animalarios acreditados: el CICbiomaGUNE y el CICbioGUNE, ya que por una parte, el CICbiomaGUNE aunque no es una institución que está dentro del órgano de gobierno del IIS biodonostia, sí que tienen establecidos convenios de colaboración entre ellos; y, por la otra, el CICbioGUNE, ya que el IIS biocruces tiene establecido una red de alianzas con este agente biotecnológico. Además de haber visitado los centros anteriormente identificados y participado en el diseño y construcción de los dos últimos, con el fin de ampliar conocimientos sobre este tipo de instalaciones y poder tener información sobre instalaciones punteras del sector, también se han podido visitar las instalaciones del Centro Nacional de Investigaciones Oncológicas (CNIO). Por lo tanto, de los nueve centros acreditados por AAALAC se han visitado cinco de ellos. 


\subsubsection{Animales utilizados en experimentación}

El empleo de animales de laboratorio para el desarrollo de ensayos en biomedicina ha representado y representa una fuente sustanciosa de avances científicos, especialmente biomédicos. De este modo, puede decirse que la mayor parte del estado de bienestar sanitario del que gozamos hoy se lo debemos a estos estudios, ya que el estudio de muchas enfermedades, así como de las causas que las originan, diagnóstico de las mismas y tratamientos efectivos ha sido posible mediante el empleo, casi exclusivamente a veces, de animales de experimentación. Esta mejora de las condiciones de vida aparejada a una mayor longevidad como especie se debe principalmente al estudio de las ramas nutricional, higiénica, médica y quirúrgica. Es por ello importante resaltar que, para el progreso histórico de todas ellas, especialmente de las dos últimas, ha sido y seguirá siendo vital el empleo de seres vivos (Míguez 2016, p. 37).

Generalmente, se entiende por animal de laboratorio a cualquier animal vertebrado, es decir, animales de laboratorio tradicionales, animales de granja, especies silvestres y especies acuáticas, producidos o utilizado en la investigación, para la realización de pruebas o para la enseñanza (National Research Council 2011, p. 2).

Hay que tener en cuenta que los animales que se usan para la investigación deben ser de alta calidad a fin de garantizar la validez de los datos, es por ello que la adquisición de los animales debe efectuarse legalmente, preferentemente en instituciones reconocidas que suministren y garanticen animales de alta calidad ${ }^{32}$, desalentando enérgicamente el empleo de primates silvestres no humanos capturados. Además, siempre que sea posible, se usarán animales criados para fines de investigación y se evitará usar otros, a menos que se cumpla con una justificación científica o que constituyan la única fuente disponible y apropiada. Todos los animales utilizados en experimentación deben ir acompañados por documentación que indique su procedencia, es decir, certificados sanitarios y otros tipos de certificados veterinarios, datos sanitarios y relativos a la raza, al estatus genético y a la identificación del animal (Comisión OIE 2019, p.7.).

\footnotetext{
32 En actualidad existen diferentes empresas suministradoras de modelos animales específicos tales como Charles River, Harlan Laboratories, Taconic y The Jackson Laboratory, entre otros.
} 


\subsubsection{Especies animales utilizados en experimentación}

En investigación biomédica es posible utilizar todas las especies animales. Lo importante es escoger aquella que mejor se adapte al tipo de estudio que se pretende iniciar o continuar, y, para ello, hay que tener presente al menos tres aspectos: la enfermedad que se desea estudiar, el tipo, tamaño y facilidad o no para la obtención de las muestras que son necesarias en el estudio y las características anatómicas o fisiológicas de la especie con la que se desea trabajar (Pérez 2014, p.8).

A continuación, se hace una breve exposición de las especies animales más utilizadas en los institutos de investigación visitados y la finalidad de la experimentación con ellos.

\section{Roedores y logomorfos}

Entre las especies más usadas en experimentación animal se encuentra el ratón de laboratorio seguido por la rata blanca. El ratón es la especie más utilizada por los investigadores principalmente por su buena adaptación a vivir en el animalario, con un mantenimiento sencillo y económico debido a su talla pequeña, corto tiempo intergeneracional y escasa longevidad, además de por su elevada prolificidad y buena actividad reproductiva a lo largo del año y porque soportan bien la consanguinidad, entre otros motivos. Además, comparten junto a los seres humanos el honor de ser los animales mamíferos mejor estudiados a todos los niveles, incluido el genético. Se emplean sobre todo para ensayos toxicológicos (mutagénesis, carcinogénesis), inmunológicos (estudios de histocompatibilidad, por ejemplo), oncología, medicina comparada y geriatría.

La segunda especie más empleada en investigaciones biomédicas es la rata, que comparte la mayoría de características con el ratón, pero a mayor escala y es precisamente por su mayor tamaño lo que la hace idónea para determinados ensayos en los que el tamaño del ratón es insuficiente. Es un animal modelo para trabajar en inmunogenética y, sobre todo, para trasplante de órganos. También es sujeto de elección para el estudio de enfermedades cardiovasculares y epilepsia, así como para el estudio de enfermedades genéticas complejas, como el cáncer, la diabetes, la obesidad y la hipertensión. (Míguez 2016, pp. 45-46).

Otros roedores utilizados habitualmente en experimentación animal, aunque no tan frecuentemente como el ratón o la rata son la cobaya, el hámster y el gerbillo. La cobaya se trata de un roedor de origen andino (Perú y Bolivia) cuya incorporación al laboratorio no está clara, pero se sabe que ocurrió en algún momento del siglo XX. Conocidos como "conejillos de indias", su elección como animal de experimentación se debió principalmente a su tamaño, algo menor al del conejo y con un manejo mucho más sencillo (Giráldez 2008, p. 205). Se utiliza sobre todo en obtención de sueros y vacunas, medicina 
comparada, patologías auditivas y estudios nutricionales sobre la vitamina $\mathrm{C}$, ácido fólico, etc. Existen asimismo estudios oncológicos en cobayas, aunque no son frecuentes (Míguez 2016, p. 47).

El hámster no se ha introducido como animal de experimentación hasta los años treinta del pasado siglo. Ha servido como modelo para los estudios de microcirculación sanguínea y por su especial característica de desarrollar espontáneamente cardiopatías en la vejez; por otra parte, también se utiliza en investigación oncológica. Es de gran susceptibilidad a las enfermedades infecciosas y un buen modelo de otras patologías como la diabetes y especialmente de las caries dentales (Giráldez 2008, p. 205).

En cuanto al gerbillo existe cierta confusión en su denominación, pues se le encuentra citado como gerbil, lo que es un patente anglicismo y en otras ocasiones como gerbo, lo cual es erróneo pues el gerbo es otra especie animal muy semejante, pero de mayor tamaño que habita en los desiertos norteafricanos; así es que su verdadero nombre en español es gerbillo o merión (Meriones ungiculatus) y su origen es de Mongolia. Son animales sociables que no deben vivir aislados sino en grupo y en cuanto a su actividad tienen un curioso comportamiento: no se limitan a ser activos durante la noche, lo son también de día, pero adormilándose cada dos horas, sin duda, para poder mantener esa actividad a lo largo de las 24 horas. En la actualidad se utiliza en investigación como modelo en estudios de epilepsia, en oncología y en estudios de envejecimiento (Giráldez 2008, p. 206).

El conejo que también es ampliamente utilizado en experimentación, en la actualidad se clasifica como logomorfo en vez de como roedor ya que se ha determinado que la estructura dentaria no es tan cercana a los ratones o cobayas. Se trata de un animal con un sistema nervioso inestable, lo que los predispone a padecer problemas relacionados con el estrés, la obesidad y la debilidad ósea. En general, suelen ser propensos al padecimiento de patologías muy variadas y es por ello muy importante monitorizar adecuadamente su estado de salud. Es muy frecuente su uso en cirugía, oftalmología, ensayo de fármacos y pruebas relacionadas con tóxicos (Míguez 2016, p. 47).

\section{Animales de granja}

Aunque para experimentación animal se prefiere el empleo de animales de dimensiones reducidas por razones económicas y de manejo, determinados estudios, así como la totalidad de ensayos quirúrgicos con perspectivas a su aplicación en seres humanos, requieren de animales cuyo tamaño visceral sea similar al humano. En estos casos, lo más común es emplear el cerdo, la oveja y la cabra, aunque también se pueden usar la vaca y el caballo. Estos dos últimos tienen mayor coste y mantenimiento más difícil, pero se suelen emplear en estudios de producción de anticuerpos e investigación fetal. En la actualidad existen numerosos estudios que avalan el enorme parecido entre 
la especie de cerdo Sus scrofa domesticus y el ser humano, tanto anatómica como fisiológicamente, y al igual que la oveja, son especialmente apreciados en el campo quirúrgico, pero a diferencia de esta última, cuyo uso útil queda relegado en muchos casos al aparato reproductor, el cerdo es más útil comparativamente para el resto de órganos y tejidos. Paradójicamente, la cerda tiene nulo interés comparativo a nivel de aparato reproductor por las enormes diferencias anatómicas. Los cerdos son muy utilizados en el campo de la patología cardíaca, gracias a la enorme similitud del sistema cardiovascular porcino con respecto al humano, empezando por la forma del corazón, junto con el hecho de que las dimensiones y funcionamiento, especialmente en el campo de la cirugía mínimamente invasiva. Destacan los ensayos sobre radiología intervencionista, colocación de stents intramurales, ensayos de infarto y el desarrollo de técnicas de bypass (Míguez 2016, p. 48-52).

\section{Carnívoros}

El empleo de perros y gatos en laboratorio es uno de los más controvertidos en la Unión Europea y en el conjunto de occidente, debido a las protestas de activistas en defensa de los animales, incluso al activismo científico ya que basa muchos de sus argumentos en contra de la experimentación con estos animales por su condición como carnívoros, porque su fisiología dista bastante del funcionamiento orgánico humano y por la estrecha relación de afecto que mantienen con los seres humanos. A esto hay que sumar que su uso mayoritario es para experimentación con fines veterinarios, por lo que cae en el compromiso de suponer un símil válido al que supondría experimentar con seres humanos para curar a otros seres humanos. Por una parte, el gato se emplea principalmente para estudios sobre oncología, neurología, gastroenterología, patologías respiratorias, virología, parasitología y medicina veterinaria; y, por la otra, el uso del perro es principalmente para investigación quirúrgica, parasitología, toxicología y medicina veterinaria (Míguez 2016, p. 47-48).

\section{Animales de sangre fría}

La investigación con animales de sangre fría está relativamente extendida, aunque su uso está legalmente mucho menos limitado que el de cualquier mamífero. Fundamentalmente es por las diferencias respecto de los seres humanos que a menudo hacen que su empleo sea residual y que los estudios realizados en anfibios, reptiles y peces no sean extrapolables al ser humano, por lo que la línea de investigación requiere del empleo posterior de mamíferos para testeo. Entre los diferentes estudios para los que se utilizan estos animales están los estudios farmacológicos (Míguez 2016, p.52).

Cabe mencionar en este apartado a los peces ya que, si bien su uso en investigación ha sido tradicionalmente poco destacable, el pez cebra Danio rerio es un modelo animal emergente con muchas cualidades que lo posicionan como una alternativa atractiva para realizar investigación biomédica básica dado la alta fecundidad, el rápido desarrollo desde el estadio embrionario hasta 
adulto y el bajo costo de la infraestructura, los insumos y los reactivos necesarios para su crianza y reproducción (Vargas-Vargas 2017, 86-96).

\section{Insectos}

Otra especie que nos encontramos en la investigación biomédica es la Drosophila melanogaster, también conocida como la mosca de la fruta, que es un pequeño insecto que se encuentra por todo el mundo y que no representa ningún riesgo para la agricultura ni para el hombre. En cambio, ha resultado ser un organismo tremendamente valioso para la investigación biomédica, particularmente en los campos de la genética y la biología de desarrollo. Uno de los factores más críticos para los estudios genéticos es el tiempo generacional. Un ciclo vital corto facilita la experimentación genética, de ahí que la mosca de la fruta se haya convertido en uno de los organismos favoritos de los genetistas (Rincón Limas 2009, p. 84).

\section{Clasificación de las especies animales en base al tamaño del animal}

En los institutos de investigación, atendiendo al tamaño de las especies animales más utilizadas en experimentación biomédica se pueden diferenciar dos áreas específicas: el área de experimentación de animales grandes y el área de experimentación de animales pequeños ${ }^{33}$.

Se consideran animales pequeños los ratones, ratas, hámsteres, cobayas, jerbos, peces e insectos; $y$, animales grandes los perros, gatos, y los animales de granja entre los que los más utilizados están los cerdos, las ovejas y las cabras.

Los conejos por su parte, están en una categoría entre los pequeños y grandes animales, ya que se consideran animales grandes debido a que los requisitos para la cirugía siguen las directrices de animales grandes; sin embargo, como veremos más adelante, lo habitual es que los conejos se alojen junto a las salas de estabulación de los animales pequeños, los roedores.

Con el fin de acotar la investigación, y atendiendo a las especies más utilizadas en los institutos visitados, el presente trabajo se ha centrado en el estudio de las áreas de experimentación; por una parte, de los animales pequeños como son los roedores; $y$, por la otra, los animales grandes como son el cerdo, la oveja y la cabra. Aunque cada vez es más frecuente encontrar áreas de experimentación para animales acuáticos, en especial el pez cebra, y aunque existen centros en los que se experimenta

\footnotetext{
${ }^{33}$ Las especies animales utilizados en la investigación animal se pueden clasificar en función de múltiples parámetros, en este caso concreto, la clasificación se ha realizado teniendo en cuenta los condicionantes específicos que establecen las diferentes especies en la organización y distribución de áreas por lo que se ha tomado como referencia la clasificación establecida por el manual Division of technical resources 2012, pp. 2/65-2/73.
} 
con insectos, el estudio pormenorizado de las áreas de experimentación para animales acuáticos e insectos quedan fuera del alcance de este estudio.

La investigación parte de la base de analizar estas dos áreas de experimentación de animal grande y animal pequeño de manera independiente, debido a que los requisitos de partida de diseño para las dos áreas son muy diferentes y también por la necesidad de separar ambas áreas, ya que los grandes animales pueden ser muy ruidosos, y por lo tanto, se recomienda que estén ubicados lejos de las zonas más tranquilas del animalario como son la zona de animales pequeños, laboratorios de investigación y áreas administrativas.

\subsubsection{Tipos de animales utilizados en experimentación}

Es muy importante que los animales utilizados sean realmente los idóneos para la investigación que se quiera llevar a cabo para que el ensayo arroje resultados contrastables, ya que el uso de animales no adecuados conduce irreversiblemente a la obtención de resultados erróneos, por lo que en estos casos es necesario repetir las pruebas siendo esto, motivo de aumento del costo de las mismas, además de una irresponsabilidad desde el punto de vista ético y moral por estar trabajando con seres vivos (Hernández 2006, pp. 252-256).

A continuación, se analizan los diferentes tipos de animales que se utilizan habitualmente en investigación como son los animales definidos por su estado sanitario, los animales genéticamente definidos, los modificados genéticamente y los definidos por el tipo de agente biológico con el que han sido inoculados, ya que cada tipo de animal definirá unas condiciones concretas para la experimentación.

\section{Animales definidos por su estado sanitario}

Uno de los factores que pueden influir significativamente en los resultados científicos, aparte de ser motivo de inquietud respecto a la sanidad y seguridad en el trabajo, es el estado sanitario de los animales, que está determinado por un complejo multifactorial en el que interactúan además de la biología del animal y el perfil genético, las condiciones ambientales del alojamiento, así como las prácticas y manejo al que son sometidos estos animales. Es por ello que el perfil sanitario de los animales deberá ser apropiado para el uso previsto y su estado sanitario deberá conocerse antes de iniciar la investigación con el fin de garantizar la validez de los resultados.

Los animales de laboratorio se clasifican en cincos diferentes categorías higiénico-sanitarias, condicionadas por la fuente de obtención, las condiciones de cría del animal, así como la presencia o ausencia de microorganismos patógenos, siendo los patógenos a controlar los parásitos, virus, bacterias y hongos (Fuentes 2008, pp. 8-11). 


\section{Categoría I: Animal Haloxénico - Convencional}

Son aquellos animales mantenidos sin ninguna condición o proceso especial, tradicionalmente llamados convencionales, a los que se les exige estar libres de evidencia clínica de enfermedad infecciosa, especialmente las transmisibles al hombre, tanto en el examen clínico como post-mortem.

\section{Categoría II: Animal Miroxénico}

Son aquellos animales convencionales mantenidos bajo condiciones sanitarias estrictas. Son animales que albergan una fracción inoculada de microorganismos no patógenos tomadas de la microbiota de un haloxénico; y deben mantener o ser del mismo status de la Categoría I y, además, estar libres de ciertos patógenos.

\section{Categoría III: Animal Gnotobiótico con microbiota conocida}

Son animales derivados de cesárea a los que se les introducen voluntariamente especies microbianas conocidas, y suelen ser mantenidos en aisladores para prevenir la contaminación por patógenos. Deben ser del mismo estatus de la categoría ll y, además, se les exige estar libres de ciertos patógenos. Categoría IV: Animal Heteroxénico - Libre de gérmenes patógenos específicos SPF

Son comparables a los animales libre de gérmenes patógenos específicos (Specific Pathogen Free, SPF), siendo animales que se obtienen por cesárea a partir de un animal axénico o gnotobiótico con microbiota definida para ser transferidos a un aislador o zona protegida en sistemas cerrados denominados en barrera; una vez trasladados a la zona de barrera, los animales se reproducen normalmente constituyendo una población libre de patógenos. Las ventajas de utilizar esta categoría en experimentación es que la probabilidad de que sobrevivan es mayor por no tener enfermedades debilitantes. Estos animales deben ser del mismo estatus de la categoría III y, además, se les exige estar libres de casi todos los agentes patógenos.

\section{Categoría V: Animal Axénicos - Libre de gérmenes GF}

Son animales que no albergan ninguna especie microbiana viviente detectable y son conocidos como Germ Free o Anéxicos. Son animales derivados por histerotomía (cesárea) o histerectomía aséptica, criados y mantenidos en aisladores o sistemas cerrados estériles que están libres de todo organismo demostrable (virus, bacterias, hongos y parásitos).

Aunque el estado sanitario exigible a cada especie animal vendrá determinado por la investigación que se quiera desarrollar, la realidad es que los animales libres de patógenos específicos SPF se han convertido rápidamente en el estándar mínimo aceptado para la investigación.

Las colonias de animales SPF requieren unas condiciones de alojamiento muy específicas de manera que deben ser transferidos a un aislador o a un sistema de barrera o zona protegida, ya que se trata 
de que se encuentren aislados de los agentes exteriores que les pueden llegar a perjudicar. Los sistemas de barrera en el contexto del diseño de los animalarios, que analizaremos más adelante junto con la tipología de alojamientos, consisten en una combinación de sistemas físicos y criterios de trabajo para que conjuntamente minimicen la transferencia de agentes de las enfermedades animales o humanas de un lado de la barrera a la otra.

Por otra parte, hay que tener en cuenta que con el fin de garantizar el estado sanitario de los animales, debe existir un cuidadoso y persistente monitoreo microbiológico en los sistemas de barreras. El control microbiológico a los animales de laboratorio se recomienda para detectar la presencia de microorganismos no deseados o para conocer los cambios microbiológicos en el ambiente y así poder evaluar los procedimientos rutinarios de desinfección, ya que pueden influir en los resultados de la pruebas, tienen una influencia negativa en el estado de los animales, pueden acabar infectando a otras especies, incluso al hombre, $y$, además, tienen una influencia negativa en el resultado de la producción de los animales (Grupo de Trabajo de FELASA sobre la Salud de los Animales 1996).

\section{Animales genéticamente definidos}

Utilizar en un estudio un perfil genético conocido puede reducir la variabilidad en los datos experimentales resultantes de una deriva genética e incrementar la reproducibilidad de los resultados. Los animales definidos genéticamente se utilizan para responder a preguntas específicas de la investigación y son el producto de programas de reproducción sofisticados y controlados que deberán ser validados por un seguimiento genético periódico.

La homogeneidad genética o animales genéticamente estandarizados o definidos se consigue mediante consanguinidad elevada entre sujetos. Para ello se deben cruzar más de 20 generaciones de hermano y hermana con el fin de disponer de animales cuyos genes sean idénticos, con perfil genético propio, estables durante largos períodos de tiempo, con variabilidad fenotípica mínima, sensibles a los cambios ambientales y con distribución mundial. Este tipo de animales es necesario criarlos y mantenerlos en ambientes controlados que cumplan con los requerimientos específicos para cada especie, además de garantizar el bienestar animal (Benavides 2003, pp. 105-107).

\section{Animales modificados genéticamente}

Un animal genéticamente modificado, también denominado animal transgénico o modificado mediante ingeniería genética o clonado, es aquel que ha sido sometido a una modificación genética de sus genomas nucleares o mitocondriales debido a una intervención humana deliberada, o la descendencia de dicho animal o animales, si han heredado dicha modificación. El uso de animales transgénicos o clonados debe realizarse con arreglo a la normativa específica en vigor. Será necesario 
satisfacer y evaluar las necesidades en materia de cría y bienestar relacionadas con fenotipos anómalos de esos animales y de aquellos que han heredado mutaciones espontáneas y mutagénesis inducida y que se consideran de riesgo. Además, se deben llevar registros de los requisitos en materia de biocontención, información genética y fenotípica e identificación individual; registros que deberán ser comunicados por el proveedor de los animales al receptor (Comisión OIE 2019, p.8).

\section{Animales definidos por el riesqo biológico}

En ocasiones, para poder llevar a cabo ciertos experimentos es necesario infectar intencionadamente los animales con patógenos humanos o animales, y en función de los peligros que entrañan los microorganismos infecciosos con los que se va a experimentar, estos se clasifican en cuatro grupos de riesgo $1,2,3$ y $4 .{ }^{34}$

Grupo de riesgo 1 (riesgo individual y poblacional escaso o nulo). Microorganismos que tienen pocas probabilidades de provocar enfermedades en el ser humano o los animales.

Grupo de riesgo 2 (riesgo individual moderado, riesgo poblacional bajo). Agentes patógenos que pueden provocar enfermedades humanas o animales, pero que tienen pocas probabilidades de entrañar un riesgo grave para el personal de laboratorio, la población, el ganado o el medio ambiente. La exposición en el laboratorio puede provocar una infección grave, pero existen medidas preventivas y terapéuticas eficaces y el riesgo de propagación es limitado.

Grupo de riesgo 3 (riesgo individual elevado, riesgo poblacional bajo). Agentes patógenos que suelen provocar enfermedades humanas o animales graves, pero que de ordinario no se propagan de un individuo a otro. Existen medidas preventivas y terapéuticas eficaces.

Grupo de riesgo 4 (riesgo individual y poblacional elevado). Agentes patógenos que suelen provocar enfermedades graves en el ser humano o los animales y que se transmiten fácilmente de un individuo a otro, directa o indirectamente. Normalmente no existen medidas preventivas y terapéuticas eficaces."

El Real Decreto 664/1997 sobre la protección de los trabajadores contra los riesgos relacionados con la exposición a agentes biológicos durante el trabajo, establece la clasificación de los agentes biológicos en cuatro grupos de riesgo (Figura 08) definidos en función del riesgo de infección y teniendo en cuenta que dentro de la definición de agentes biológicos se incluyen a los

\footnotetext{
${ }^{34}$ Esta clasificación se ha extraído del Manual de Bioseguridad en el Laboratorio de la OMS 3a edición, en el que se insta a los distintos países a elaborar una clasificación nacional de los microorganismos en función de los cuatro niveles de riesgo descritos. En España, esa clasificación se recoge en el RD 664/1997 de 12 de mayo, sobre la protección de los trabajadores contra los riesgos relacionados con la exposición a agentes biológicos durante el trabajo.
} 
microorganismos, con inclusión de los genéticamente modificados, a los cultivos celulares y a los endoparásitos humanos, susceptibles de originar cualquier tipo de infección, alergia o toxicidad.

\begin{tabular}{cccc}
\hline $\begin{array}{c}\text { Agente biológico } \\
\text { del grupo de riesgo }\end{array}$ & Riesgo infeccioso & $\begin{array}{c}\text { Riesgo de propagación a } \\
\text { la colectividad }\end{array}$ & $\begin{array}{c}\text { Profilaxis o } \\
\text { tratamiento eficaz }\end{array}$ \\
\hline 1 & Poco probable que cause enfermedad & No & Innecesario \\
\hline 2 & $\begin{array}{c}\text { Pueden causar una enfermedad y } \\
\text { constituir un peligro para los trabajadores }\end{array}$ & Poco probable & Posible generalmente \\
\hline 3 & $\begin{array}{c}\text { Pueden provocar una enfermedad grave y } \\
\text { constituir un serio peligro para los } \\
\text { trabajadores }\end{array}$ & $\begin{array}{c}\text { Plente } \\
\text { Provocan una enfermedad grave y } \\
\text { constituyen un serio peligro para los } \\
\text { trabajadores }\end{array}$ & $\begin{array}{c}\text { No conocido en la } \\
\text { actualidad }\end{array}$ \\
\hline
\end{tabular}

Figura 08. Grupo de riesgo de los agentes biológicos.

Fuente. Guía técnica para la evaluación y prevención de riesgos relacionados con la exposición de agentes biológicos p.12.

Como analizaremos más adelante, estos animales deben estar alojados en instalaciones diseñadas y equipadas para experimentar con cada tipo de agente biológico concreto, ya que según aumenta el nivel de riesgo, los requerimientos de las instalaciones serán más exigentes. 


\subsubsection{Conceptos generales. Las barreras}

Los centros de experimentación animal deben contemplar las áreas necesarias para poder realizar la investigación. De esta manera, aparte de las salas de alojamiento de animales, el centro deberá disponer de las salas de experimentación específicas en las que llevar a cabo la investigación, los locales de servicio para dotarlos de los suministros básicos y de las instalaciones necesarias para garantizar un buen entorno y calidad de vida, así como el área destinada al personal trabajador del propio animalario, siempre asegurando el bienestar animal y garantizando las condiciones de trabajo y seguridad del personal.

Teniendo en cuenta los considerandos hasta el momento expuestos para el diseño y organización de la instalación, es fundamental tener en cuenta; por una parte, las especies animales con las que se va a experimentar; $y$, por otra parte, el estado sanitario, condición genética y agentes patógenos con los que se va a experimentar.

Por lo tanto, los locales de alojamiento además de estar diseñados para proporcionar a cada especie un entorno, alimentos, agua y los cuidados anteriormente descritos, deberán estar diseñados para garantizar la bioseguridad ${ }^{35}$, bioprotección y biocontención ${ }^{36}$ del centro; $y$, para ello, se deberán tener en cuenta las denominadas barreras, que en el contexto del diseño de la instalación de animales consisten en una combinación de sistemas físicos y criterios de trabajo para que conjuntamente minimicen la transferencia de agentes de un lado de la barrera a la otra.

A la hora de establecer las barreras relacionadas con el espacio físico, se debe tener en cuenta el micro y macro ambiente en el que se van a alojar, teniendo en cuenta que el microambiente es el entorno físico inmediato que rodea al animal, es decir, el recinto primario tal como la jaula, cubeta, tanque o establo y que contiene todos los recursos que necesitan los animales; y, que el macroambiente lo constituye el entorno físico del recinto secundario, tales como una habitación, un granero o un hábitat al aire libre (National Research Council 2011, p. 42). Una barrera se puede crear tanto en el macro como en el micro ambiente, siendo habitual el uso de una combinación de ellas (Neil 2003, pag 33).

Por otra parte, en cuanto a las barreras relacionadas con los criterios de trabajo, resulta fundamental establecer los procedimientos normalizados de trabajo a llevar a cabo en la propia instalación, que no

\footnotetext{
35 La bioseguridad o seguridad biológica (biosafety) es el término utilizado para referirse a los principios, técnicas y prácticas aplicadas con el fin de evitar la exposición no intencional a patógenos y toxinas, o su liberación accidental, es decir, con el establecimiento y ejecución de procedimientos para minimizar el riesgo en el uso, manipulación y propagación de microorganismos patógenos. En cambio, la bioprotección o protección biológica (biosecurity) se refiere a las medidas de protección de la institución y del personal destinadas a reducir el riesgo de pérdida, robo, uso incorrecto, desviaciones o liberación intencional de patógenos o toxinas. Organización mundial de la salud 2005, p. 49.

${ }^{36}$ La biocontención está relacionada con los factores físicos y constructivos asociados al diseño y al proceso constructivo del edificio que albergará estas actividades, y, por lo tanto, recaerá en el equipo responsable del diseño del centro.
} 
son otra cosa que la guía para la realización de las tareas rutinarias en los que se especifica qué se debe hacer, cómo y cuándo.

Las barreras pueden dividirse; por una parte, en función del objetivo de las mismas, en barreras de inclusión y exclusión; y, por otra parte, en función del tipo de protección que genera en primarias y secundarias.

Se establecen barreras de inclusión para evitar la fuga de agentes de la enfermedad de los animales de la unidad hacia el exterior. Las barreras de inclusión pueden establecerse para poner en cuarentena o aislar animales de estado de salud desconocido o para contener animales intencionadamente infectados con patógenos humanos o animales; con ellas se pretende confinar dentro de la instalación el riesgo que padecen los animales.

Las barreras de exclusión, en cambio, se establecen para prevenir la entrada de infecciones e infestaciones de animales de fuentes externas, $y$, con frecuencia, para proteger el estado de salud de los animales de laboratorio, virus libres de anticuerpos, animales inmunodeprimidos y valiosas especies de animales modificadas genéticamente.

Es importante señalar que una barrera de exclusión mantiene las cosas fuera, pero no previene que el material infeccioso se escape del ambiente; por otra parte, la barrera de inclusión, que está diseñada para contener infecciones dentro de una determinada área, hará poco para prevenir una enfermedad infecciosa que desde el exterior pueda introducirse dentro de la barrera. Es por ello que, en ocasiones, resulta necesario combinar características de una barrera de exclusión y de inclusión, además de requerir una combinación de barreras de factores físicos y operativos.

\section{Las barreras primarias}

Las barreras primarias comprenden tanto las medidas empleadas para la protección individual de los trabajadores, los denominados EPI, como los sistemas para evitar la dispersión de contaminantes, siendo ambos de gran importancia en el ámbito de la prevención y seguridad en el trabajo.

Los EPIs más utilizados en los animalarios son: batas, monos, calzas, pijamas, gorros, guantes, mascarilla; $y$, entre los equipos cuya función es evitar la dispersión de los distintos agentes empleados, impidiendo su efecto perjudicial sobre el personal laboral, cabe destacar el uso de las cabinas de bioseguridad, jaulas ventiladas individualmente, cabinas de cambio de jaulas y aisladores.

a) Las Cabinas de bioseguridad (Figura 09) se utilizan para la manipulación de muestras de laboratorio y distintos procedimientos con animales, generalmente roedores, tales como administración de productos, necropsias, cambio de jaulas, etc., y en función del grado de 
protección que ofrecen tanto al operario como a las muestras manipuladas, se distinguen tres clases:

- Las cabinas de bioseguridad de Clase I se caracterizan por suministrar protección al ambiente y al personal, siendo su mayor desventaja que no protege al producto. Son equipos de presión negativa dotados de un extractor que aspira el aire de la cabina y lo envía al exterior a través de un filtro HEPA.

- Las cabinas de bioseguridad de Clase ll se caracterizan por suministrar protección al ambiente, al personal y al producto, y están diseñadas de manera que no existe contacto entre la muestra y el aire ambiente del laboratorio. En este tipo de cabina se genera un flujo vertical de aire limpio sobre la muestra que actúa como barrera. Existen hasta cuatro subtipos dentro de esta clase de cabina ( $\mathrm{A}, \mathrm{BI}, \mathrm{BII}$ y $\mathrm{BIII})$, diferenciándose principalmente en aspectos mecánicos (proporción de aire recirculado, velocidad y presión del flujo de aire, etc.).

- Las cabinas de Clase III o aisladores son las que ofrecen mayor grado de protección. Estos equipos están totalmente aislados, de manera que para trabajar en su interior, es necesario hacer uso de los guantes fijados a la estructura del equipo y que se proyectan hacia dentro. El flujo de aire pasa a través de filtros HEPA, pudiéndose crear ambientes interiores de presión negativa o positiva según las necesidades del trabajo.
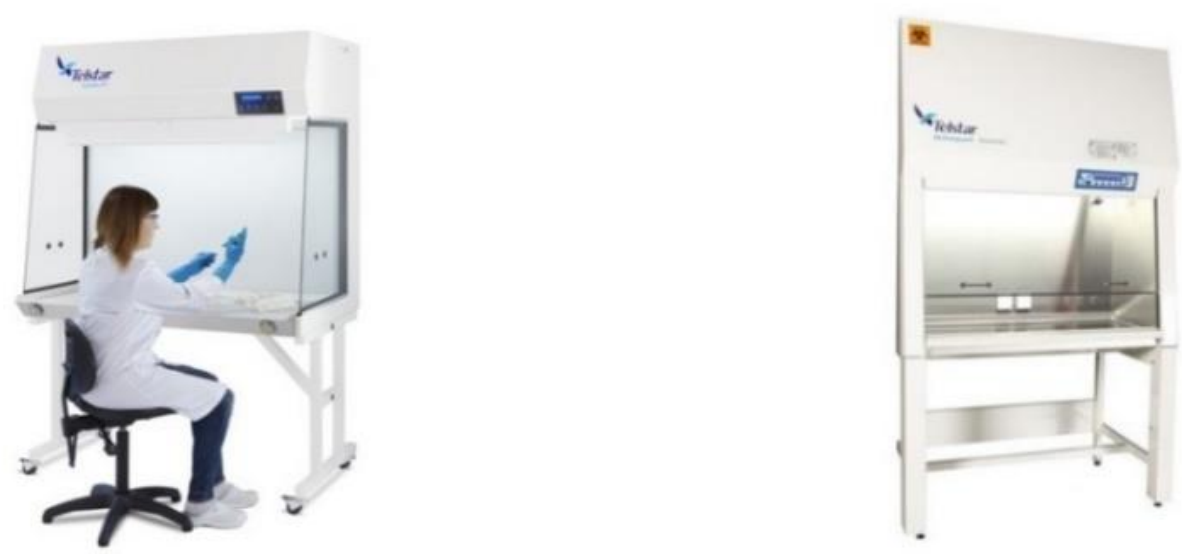

Figura 09. Cabina de seguridad biológica.

Fuente. Telstar.

b) Los racks ventilados (Figura 10) son estanterías ventiladas en las que se integran las jaulas cerradas y especialmente diseñadas para proporcionarles una ventilación individual también denominados mini-aisladores, que a través de la filtración del aire del macroambiente, independiza cada una de ellas creando un microambiente controlado en cada una de las jaulas. Estos dispositivos cuentan con una tapa que se conecta a través de un conducto al sistema de ventilación con filtración absoluta, estando equipados con filtros HEPA del flujo de aire en la impulsión y extracción, pudiendo ajustarse a presión negativa o positiva en función de los requerimientos específicos de 
la experimentación realizada. La estantería cuenta con un panel de control que permite registrar la temperatura, la humedad, las renovaciones de aire y el estado de los filtros. Los racks ventilados permiten alojar diferentes tamaños de jaulas, y son empleados bien para estabular a los roedores en condiciones de aislamiento de forma que evitan la dispersión de posibles agentes, o bien para crear un microambiente estéril.
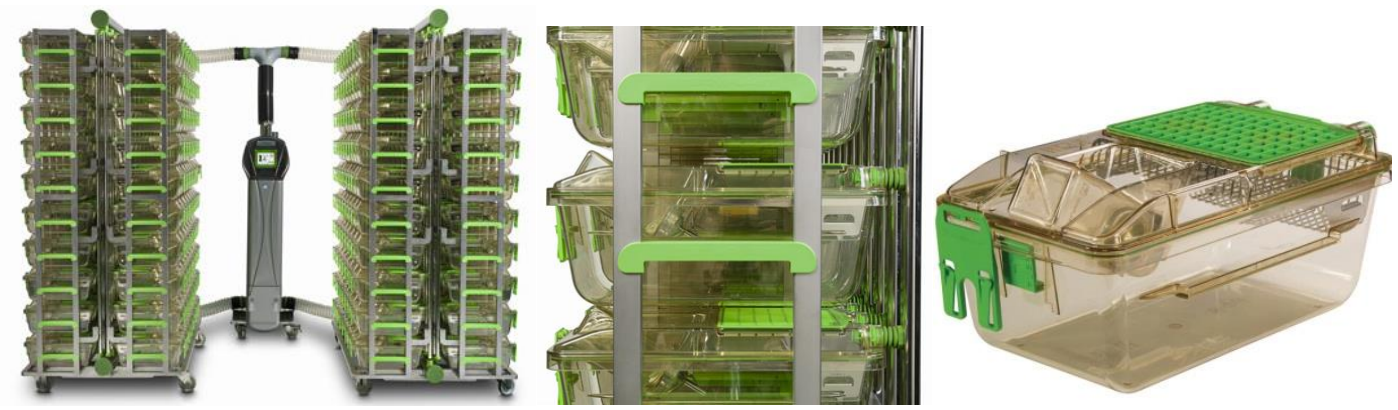

Figura 10. Sistema de alojamiento de jaulas autoventilada en racks para roedores.

Fuente. Techniplast.

c) Las estaciones de trabajo para cambio de jaulas (Figura 11) son equipos diseñados para realizar el cambio de jaulas de los roedores que están estabulados en racks autoventilados, normalmente suelen ser portátiles, y su objetivo es conseguir la máxima protección de los animales, evitando la exposición y previniendo la contaminación cruzada.
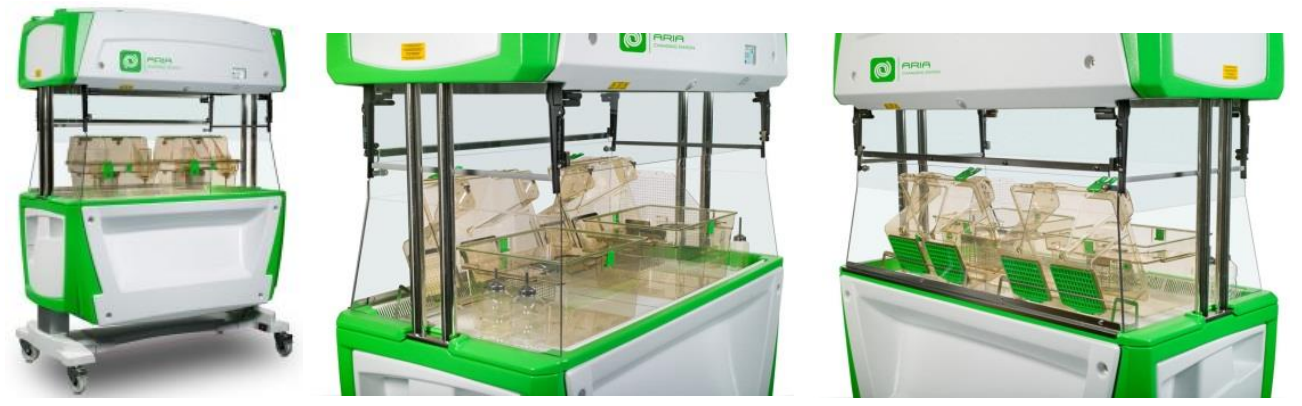

Figura 11. Cabina para cambio de jaulas.

Fuente. Techniplast.

d) Los aisladores flexibles (Figura 12) lo constituyen un receptáculo de PVC cerrado, a modo de burbuja, apoyado sobre una estructura metálica en el cual pueden mantenerse varias jaulas de animales aislados del ambiente exterior a través de la filtración absoluta del aire. Para poder manipular los animales en su interior, el sistema dispone de unos guantes cortos, fijados a través de anillos de goma y cinta de PVC para poder sustituirlas fácilmente. En cambio, para poder introducir, retirar materiales y desinfectar, se utiliza un túnel de acceso rígido, con doble tapa de cierre externa e interna. 

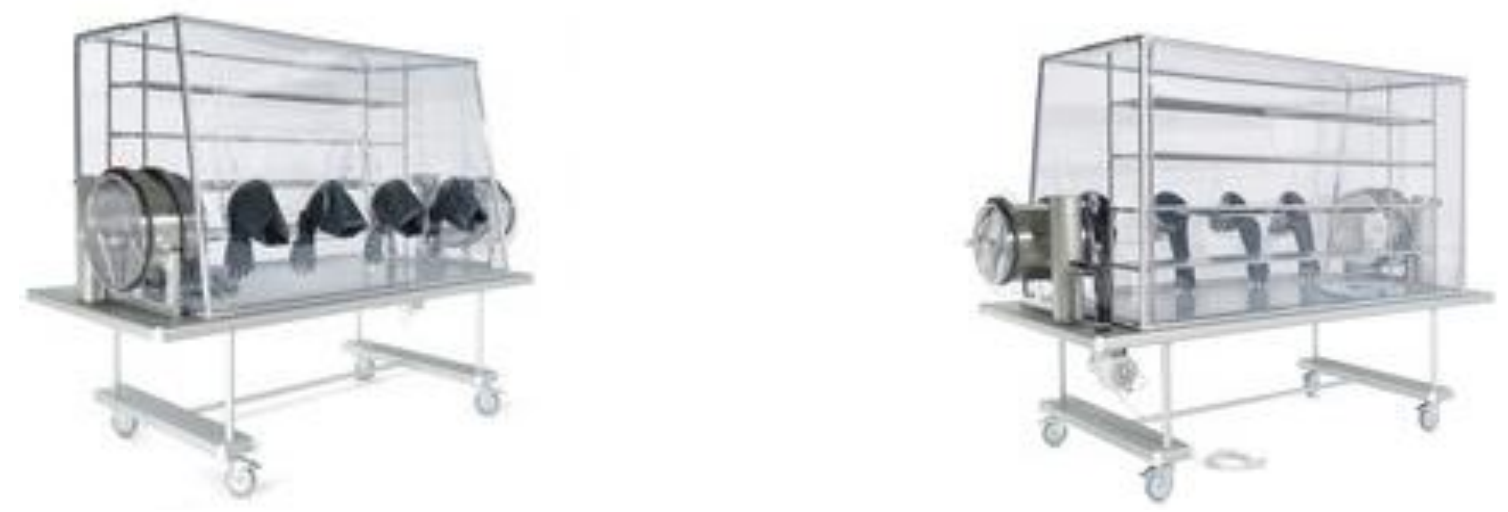

Figura 12. Aislador flexible para animales. Fuente. Metall plastic.

Tanto las jaulas ventiladas individualmente como los aisladores, son equipos que no sólo sirven para alojar animales de experimentación inmunodeficientes, sino también para mantener animales genéticamente modificados, libres de gérmenes o inoculados con microorganismos patógenos. En todos los casos el aislamiento, las condiciones de esterilidad, el control del ambiente y la capacitación del personal son requisitos fundamentales para el desarrollo de investigaciones.

\section{Las barreras secundarias}

Las barreras secundarias son las denominadas colectivas o de instalaciones, están relacionadas con la construcción e ingeniería de las instalaciones, y tienen como función proteger el medio exterior de los riesgos contenidos en el propio animalario; por lo tanto, deben estar diseñadas, organizadas, construidas y mantenidas con idea de controlar los flujos de personal, animales, material limpio y sucio entre la instalación y el exterior, así como para optimizar los procesos de limpieza, desinfección, esterilización y eliminación de residuos y proporcionar cierto grado de autonomía a la instalación. 


\section{ANÁLISIS DE LOS DATOS OBTENIDOS}

El presente estudio se ha centrado en los centros de experimentación animal de los Institutos de Investigación Sanitaria Acreditados por el Instituto de Salud Carlos III. Las primeras acreditaciones las obtuvieron los institutos de investigación IDIBAPS, IBIS, IDIBELL, VHIR y IGTP ${ }^{37}$ en el año 2009, como consecuencia del RD 339/2004 siendo, en muchos casos, centros con una larga trayectoria y fruto de proyectos iniciados años atrás.

A fecha uno de febrero de 2020 se encuentran acreditados los siguientes treinta y un Institutos de Investigación Sanitaria: IDIBAPS, IBIS, IDIBELL, VHIR, IGTP, IIS La Fe, idis, IdiPAZ, IIS-PRINCESA, IISFJD, IIB SANT PAU, IRICYS, i+12, INCLIVA, IMIBIC, IIS Biodonostia, IiSGM, IdISSC, IBSAL, IMIM, IRB LÉRIDA, IDIPHIM, IIS Biocruces, IBIMA, IMIB, IDIVAL, INIBIC, IISA, IBS GRANADA, IDISNA, IdISBa. En la época en que se realizó la toma de datos, entre las fechas junio del año 2015 y diciembre del año 2017, únicamente estaban acreditados los primeros veintinueve institutos.

De todos los institutos acreditados, se han estudiado las instalaciones correspondientes a los siguientes trece centros de experimentación animal: IDIBAPS, IDIBELL, VHIR, IGTP, IIS La Fe, IdiPAZ, IRICYS, i+12, IIS Biodonostia, IISGM, IMIM, IIS Biocruces, IISA. Debido fundamentalmente a la falta de una información completa y suficiente como para poder introducirlos todos dentro de la muestra, la investigación se ha centrado en el análisis pormenorizado de los siguientes diez Institutos de Investigación Sanitaria Acreditados:

\begin{tabular}{|c|c|c|}
\hline liPAZ & Instituto de Investigación Sanitaria Hospital La Paz & Madrid \\
\hline 12 & Instituto de Investigación Hospital 12 De Octubre & Madrid \\
\hline liSGM & _ Instituto de Investigación Sanitaria Gregorio Marañón & Madrid \\
\hline IRICYS & _Instituto Ramón y Cajal de Investigación Sanitaria & Madrid \\
\hline IIS Biodonostia & _ Instituto de Investigación Sanitaria Biodonostia & Gipuzkoa \\
\hline IIS Biocruces & Instituto de Investigación Sanitaria Biocruces & Bizkaia \\
\hline IISA_ & _IIS Aragón Instituto de Investigación Sanitaria Aragón & Zaragoza \\
\hline VHIR & _ IR-HUVH Institut de Recerca Hospital Universitari Vall D’hebron & Barcelona \\
\hline IGTP & _ Institut d'investigació en Ciéncies de la Salut Germans Trias I Pujol_ & Barc \\
\hline IISI & Fundación para la Investigación del Hospital Universitario La Fe & Valencia \\
\hline
\end{tabular}

\footnotetext{
${ }^{37}$ Las siglas correspondientes a la abreviatura de cada instituto de investigación sanitaria quedan identificadas en el capítulo denominado Glosario.
} 
Además, la investigación se ha complementado con la visita a diversos centros de experimentación animal de reconocido prestigio como son:

CNIO Centro Nacional de Investigaciones Oncológicas Madrid

CIC BioGUNE Centro de Investigación Cooperativa en Biociencias Bizkaia CIC BiomaGUNE Centro de Investigación Cooperativa en Biomateriales Gipuzkoa PRBB Parque de Investigación Biomédica de Barcelona Barcelona $\mathrm{UCL}$ Unidad Anatomía patológica University College London Londres

Aunque el estudio se centra en los diez institutos anteriormente identificados, durante el análisis de los datos obtenidos se pueden mencionar puntualmente conceptos particulares de cualquiera de los centros visitados.

Este trabajo se ha estructurado de tal manera que; primeramente, se analiza la configuración general del centro de experimentación animal; para a continuación, realizar un estudio pormenorizado de las dos principales áreas funcionales que lo componen: por una parte, el área de experimentación de animal grande, en el que también se analizan las principales unidades que lo componen: la unidad de estabulación de animal grande y la unidad quirúrgica experimental; y, por la otra, el área de experimentación de animal pequeño con el estudio de sus unidades principales: unidad de experimentación convencional y unidad de experimentación en barrera (Figura 13).

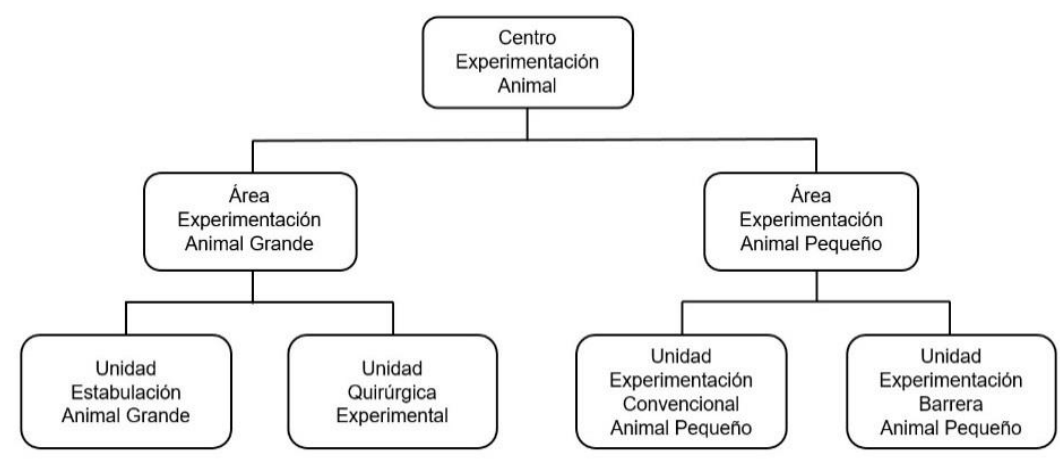

Figura 13. Esquema estructural de los centros de experimentación animal.

Fuente. Elaboración propia.

Las características generales, así como la organización y distribución de las unidades principales de los centros objeto del estudio se encuentran reflejados en las fichas de toma de datos de cada instituto. En ellas se recoge la descripción general del instituto, las características del centro de experimentación animal, la documentación gráfica estandarizada con su escala correspondiente, así como la encuesta de opinión anónima realizada a los responsables de los centros.

Para analizar la organización de los centros y de cada una de las áreas y unidades sometidas análisis, se ha tomado como referencia la documentación gráfica estandarizada de la toma de datos. A partir de esa documentación, para analizar cada uno de los aspectos del estudio, se ha seleccionado la parte 
del plano correspondiente y sobre él se han destacado las partes importantes de cara a facilitar la interpretación tanto de la organización como de los accesos y flujos de trabajo establecidos, pero no sobre su dimensionamiento, por lo que para obtener cualquier dato sobre el dimensionamiento será necesario consultar las fichas de la toma de datos, ya que los planos en ellas representados son los que están adecuados a su escala correspondiente. Además, junto a cada plano se hace una breve descripción de la parte sometida a estudio.

Para hacer una puesta en común de los resultados obtenidos de las características principales y del criterio organizativo, y poder así realizar un análisis comparativo de los criterios adoptados en los diferentes institutos que se analizan a lo largo del desarrollo de la tesis, se ha optado por resumir las más importantes en una tabla tipo (Figura 14). En ella se listan los parámetros que definen las características que se quieren analizar, se identifican cuáles son las características comunes a la mayoría de ellos y se identifica qué institutos cumplen dichas características; además, se determinan las características particulares o específicas, que son aquellas que las cumplen solo unos determinados institutos, reflejándose así mismo, qué institutos las cumplen. Por último, de cada una de las partes analizadas se realiza una síntesis del estudio realizado.

Tabla tipo

\begin{tabular}{c|lc|c}
\hline Parámetros & Características comunes & $\begin{array}{l}\text { Institutos con } \\
\text { características } \\
\text { comunes }\end{array}$ & $\begin{array}{c}\text { Institutos con } \\
\text { características } \\
\text { específicas }\end{array}$ \\
\hline & & \\
\hline
\end{tabular}

Figura 14. Tabla tipo.

Fuente. Elaboración propia.

Teniendo en cuenta que el alcance de la investigación es de tipo descriptivo, posteriormente, a partir de la puesta en común de los resultados obtenidos del análisis de la investigación se ha realizado una descripción detallada de las diferentes soluciones organizativas planteadas. De este modo, se han cumplido los objetivos específicos inicialmente planteados, que no han sido más que las guías de la investigación para conseguir el objetivo final: que el estudio aporte conocimiento suficiente para ser de utilidad en el diseño y construcción de futuros centros. 


\subsection{Organización y diseño del centro de experimentación animal}

El centro de experimentación animal de los institutos sometidos a estudio lo componen principalmente las siguientes áreas funcionales: el área de experimentación animal grande y el área de experimentación animal pequeño.

El estudio pormenorizado de cada una de las dos áreas se realiza a posteriori en apartados específicos. En este caso se trata de comprender la organización general planteada para el conjunto de la instalación teniendo en cuenta que el centro de experimentación animal forma parte de una de las plataformas que componen los Institutos de Investigación Sanitaria; y por lo tanto el planteamiento de su organización puede estar condicionada por decisiones tomadas por los responsables de los institutos de investigación sanitaria y no específicamente por los responsables de la experimentación animal.

El análisis de la organización y diseño conceptual se ha estructurado en los siguientes cuatro apartados:

1. Se expone a través de representaciones gráficas estandarizadas las diferentes plantas en las que se ha configurado el centro y junto a cada una de ellas se realiza una breve descripción de sobre su ordenación.

2. Se contextualiza este tipo de instalaciones a través del análisis de las características generales que lo definen.

3. Se realiza un examen detallado de la organización implantada, de los accesos exteriores diseñados, así como de las circulaciones interiores y flujos de trabajo resultantes.

4. Se hace una síntesis del trabajo desarrollado.

\subsubsection{Representaciones gráficas de la distribución en planta}

De cada uno de los centros de experimentación animal se han desarrollado unos planos de planta estandarizados que permiten realizar un análisis gráfico de la organización planteada en cada caso. Con estas representaciones gráficas se pretende tener una visión específica de su configuración general y de los distintos accesos diseñados.

Para facilitar el estudio, en los planos de distribución en planta se ha identificado por código de colores el área funcional al que pertenece cada local. De esta manera, se representa en amarillo el área de experimentación animal pequeño, en azul el área de experimentación animal grande, en verde oscuro las áreas comunes para experimentación con animal grande y pequeño, en verde claro los pasillos de 
distribución comunes, en rojo el área administrativa, en gris los pasillos exteriores y servicios generales y en rosa los núcleos de comunicación vertical.

Por otra parte, con el fin de realizar una lectura sencilla de las circulaciones del centro, se identifica con una flecha roja los puntos de acceso al edificio. También se reflejan las circulaciones planteadas para personal que se representa mediante línea continua de color azul; para el suministro de animales, mediante línea continua de color rojo; para el suministro de materiales, con línea continua color verde; incluso para la retirada de residuos, con línea de trazos color verde. Además, también se representa el sentido de los flujos de trabajo mediante las flechas dibujadas junto a cada línea (Figura15).

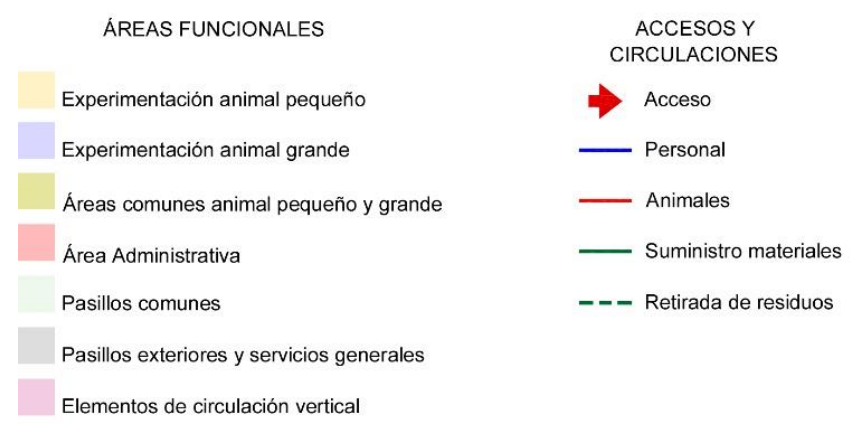

Figura 15. Leyenda centro experimentación animal.

Fuente. Elaboración propia.

*Esta leyenda se hace extensible a las figuras 16-25.

Los centros de experimentación animal se alojan mayoritariamente en un único edificio, aunque no siempre se ha conseguido distribuir todo el centro en una única planta. En ocasiones, se ha tenido que organizar dividiéndolo en dos plantas y en algún caso incluso en tres. Entre los casos en los que ha sido necesario realizar esta división en plantas observamos que el criterio adoptado para cada caso es diferente. Es por ello que el trabajo se desarrolla a partir de una clasificación previa realizada en función del número de edificios, así como del número de plantas en los que se distribuye el centro. Además, junto a cada una de las representaciones gráficas se hace una breve descripción de la configuración general del centro de experimentación animal. 


\section{Centros distribuidos en varios edificios}

La experimentación animal del VHIR se aborda en diferentes edificios del recinto del Hospital Universitario Vall d'Hebron (Figura 16). Para esta investigación se han seleccionado el antiguo Estabulario ubicado en el edificio Meditarránia en el que existe un área para experimentación animal tanto para grandes como pequeños animales y en el Estabulario Cellex del Instituto de Oncología Vall d’Hebrón destinado a la investigación con animal pequeño.

En el presente estudio abordamos el planteamiento de la instalación realizada para la experimentación con animal pequeño del Edificio Cellex, y el diseño planteado únicamente para la experimentación de animal grande del edificio Mediterránia.

En el Edificio Mediterránia la experimentación con animal grande se desarrolla en una planta con acceso directo desde el exterior, de manera que los animales, los suministros y los residuos acceden directamente a la zona de experimentación animal sin afectar al funcionamiento del resto del edificio. Además, comparte con el área de experimentación de animal pequeño zonas de circulación y de servicios.

El Edifico Cellex es un edificio de reciente construcción distribuido en dos plantas bajo rasante. Aunque los accesos al edificio a nivel de planta baja están segregados para independizar la circulación del personal de la de los animales, suministros y residuos; al estar el centro de experimentación distribuido en plantas bajo rasante, es necesario hacer uso de elementos de comunicación vertical para el acceso del personal como para los animales, materiales y residuos, que en este caso son de uso común.

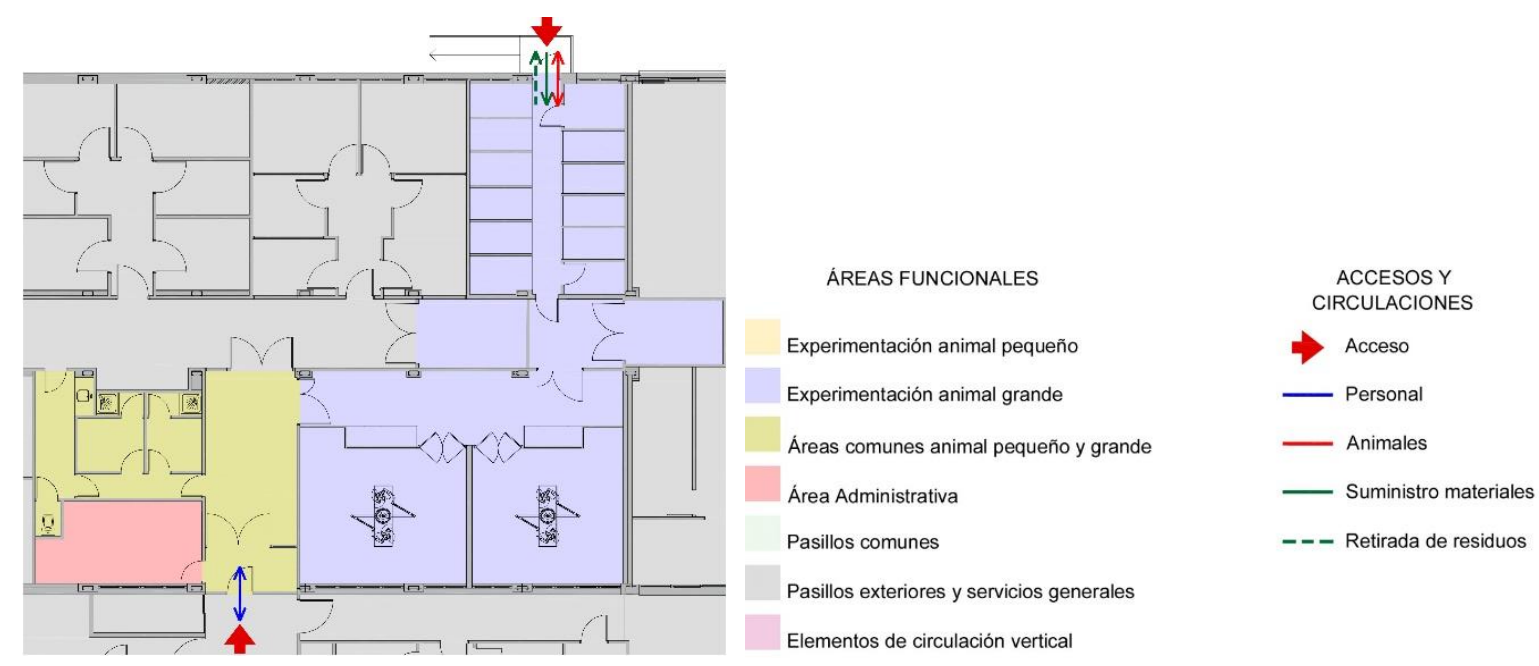

Área experimentación animal grande. Edificio Meditarránia. HUVH 


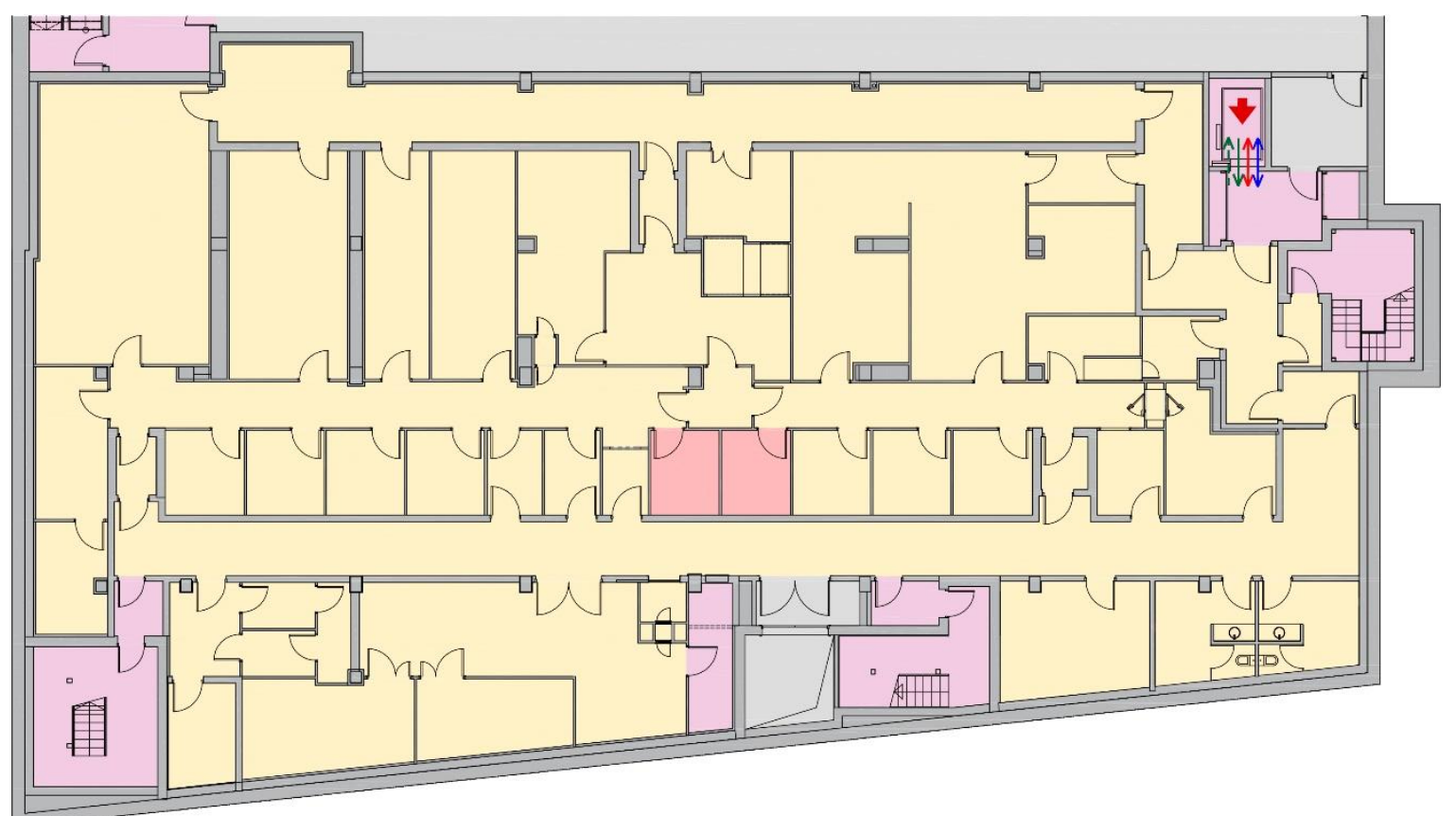

Área experimentación animal pequeño planta sótano -1. Edificio Cellex. HUVH

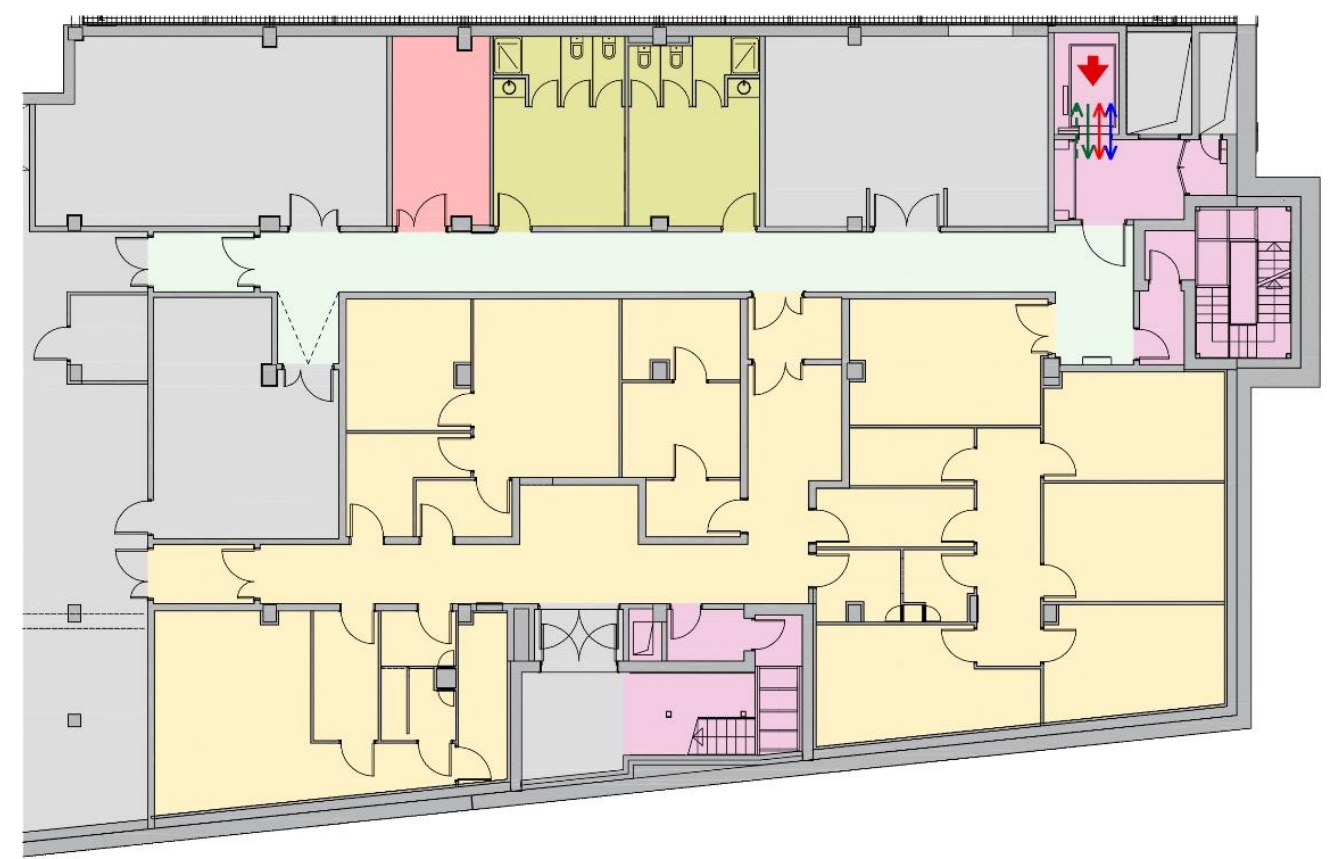

Área experimentación animal pequeño planta sótano -2. Edificio Cellex. HUVH

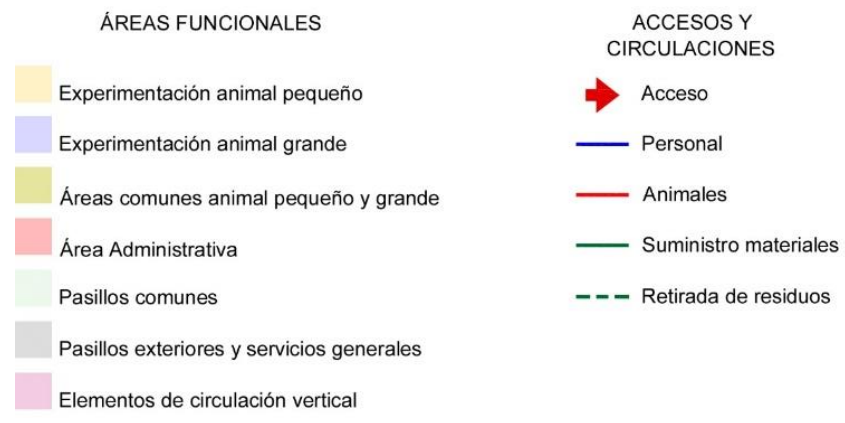

Figura 16. Organización centro experimentación animal VHIR (S/E). Fuente. Elaboración propia. 


\section{Centros distribuidos en una única planta}

La mayoría de los centros de experimentación se encuentran distribuidos en un único edificio y en una única planta: i+12, IiSGM, IRYCIS, IIS Biodonostia y IIS La Fe.

El centro de experimentación animal del instituto i+12 (Figura 17) se distribuye en un edificio existente del hospital y en una única planta con acceso directo desde el exterior en la que los accesos del personal se encuentran independizados de la de los animales, suministros y residuos. La superficie disponible así como el programa funcional necesario para el desarrollo de la actividad ha conllevado que tanto las zonas de circulación, como algunas zonas concretas de servicios y de experimentación tengan que ser compartidas entre la experimentación de animal grande y pequeño.

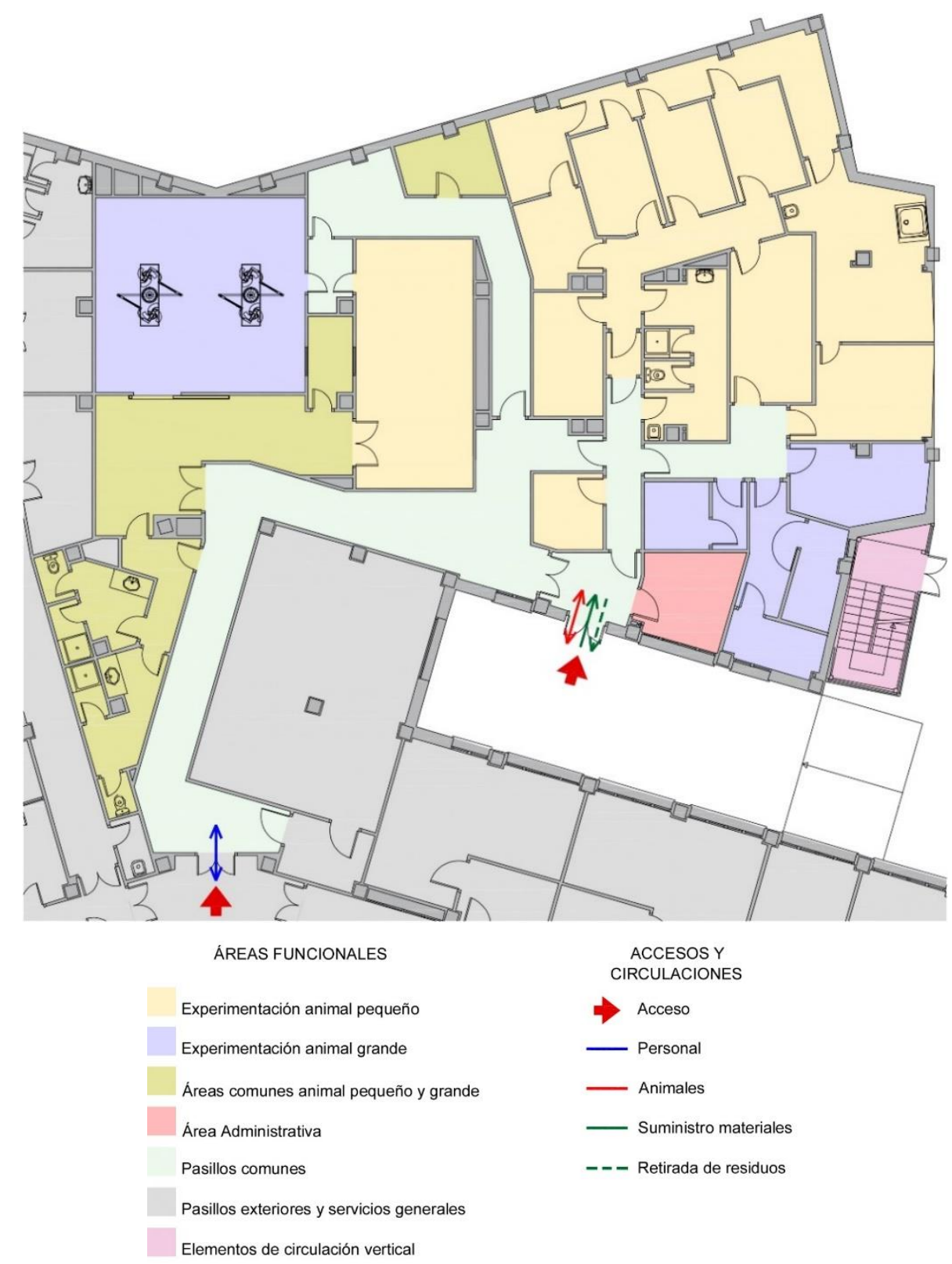

Figura 17. Organización centro experimentación animal i+12 (S/E). Fuente. Elaboración propia. 
El centro de experimentación animal del instituto liSGM (Figura 18) se desarrolla en un edificio antiguo del hospital que ha sido ampliado mediante módulos prefabricados. Se distribuye en una única planta baja que cuenta con dos accesos directos desde el exterior para independizar el personal de los animales, suministros y residuos. A pesar de ello, la superficie disponible no ha sido suficiente para independizar las áreas de estabulación de animal grande y pequeño, de manera que para el desarrollo de la actividad es necesario que tanto las zonas de circulación, como algunas zonas concretas de servicios tengan que ser compartidas para ambas actividades.
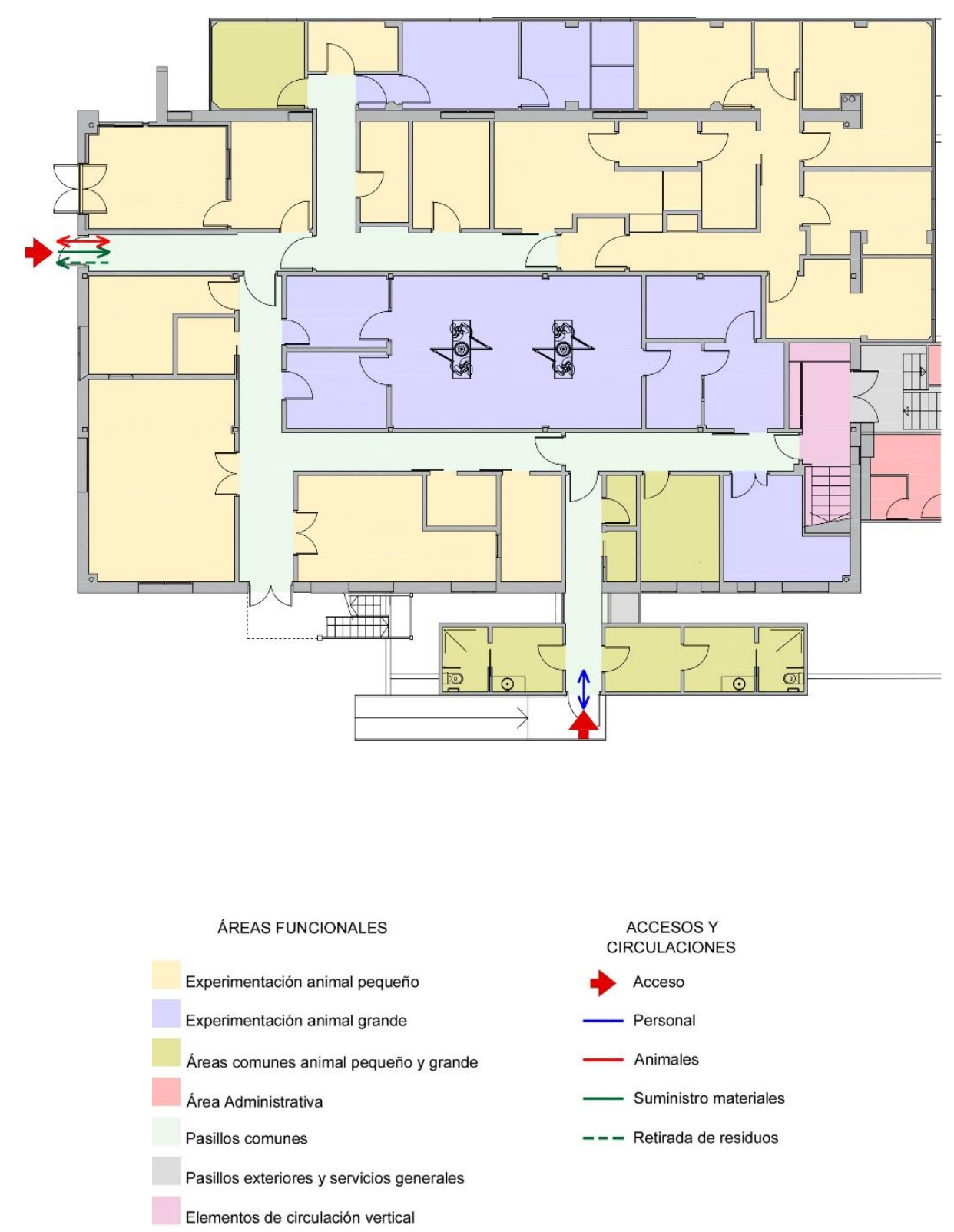

Figura 18. Organización centro experimentación animal liSGM (S/E).

Fuente. Elaboración propia. 
El centro de experimentación animal del instituto IRYCIS (Figura 19) se distribuye en un edificio existente del hospital y en una única planta con acceso directo desde el exterior a través de la que se introducen los animales, los suministros y se retiran los residuos; el personal, en cambio, accede desde la planta de acceso principal. Para el desarrollo de la actividad, es necesario compartir las zonas de circulación y algunas zonas concretas de servicios.
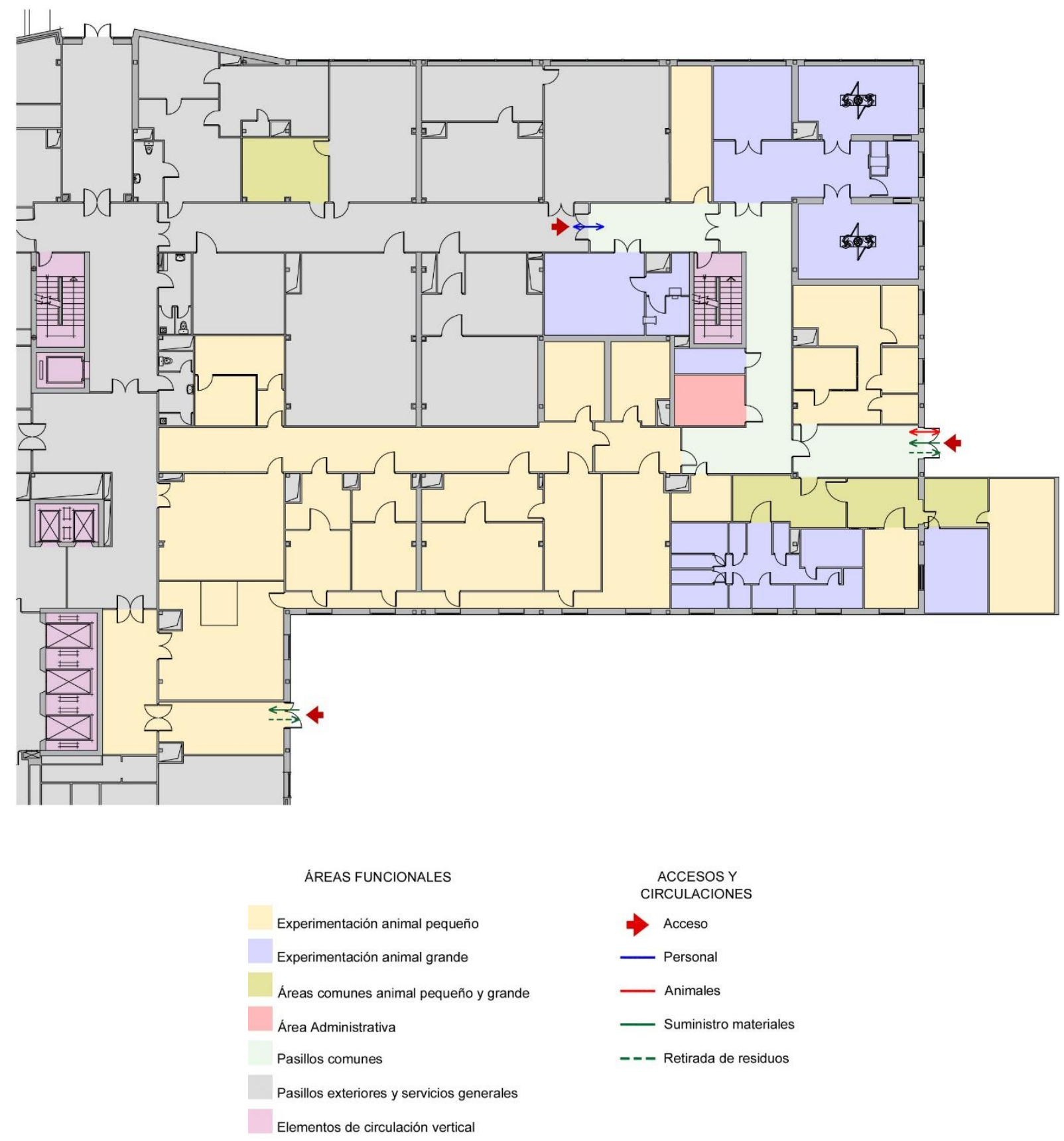

Figura 19. Organización centro experimentación animal IRYCIS (S/E).

Fuente. Elaboración propia. 
El centro de experimentación animal del instituto IIS Biodonostia (Figura 20) se distribuye en una única planta semisótano con acceso directo desde el exterior, en un edificio del hospital inicialmente construido para otro fin. Con la estructura de hormigón ejecutada se distribuyó en el edificio el programa funcional del instituto. A pesar de desarrollarse todo el centro de experimentación animal en una única planta, no se ha conseguido independizar las áreas de animal grande y pequeño, por lo que resulta necesario compartir aparte de las zonas de circulación y servicios, incluso alguna sala destinada a preparación animal. Los diferentes accesos planteados permiten que los animales, suministros y residuos accedan directamente desde el exterior a la planta de experimentación, mientras que el personal accede desde la planta principal del edificio, por lo que hace uso de elementos de comunicación vertical.

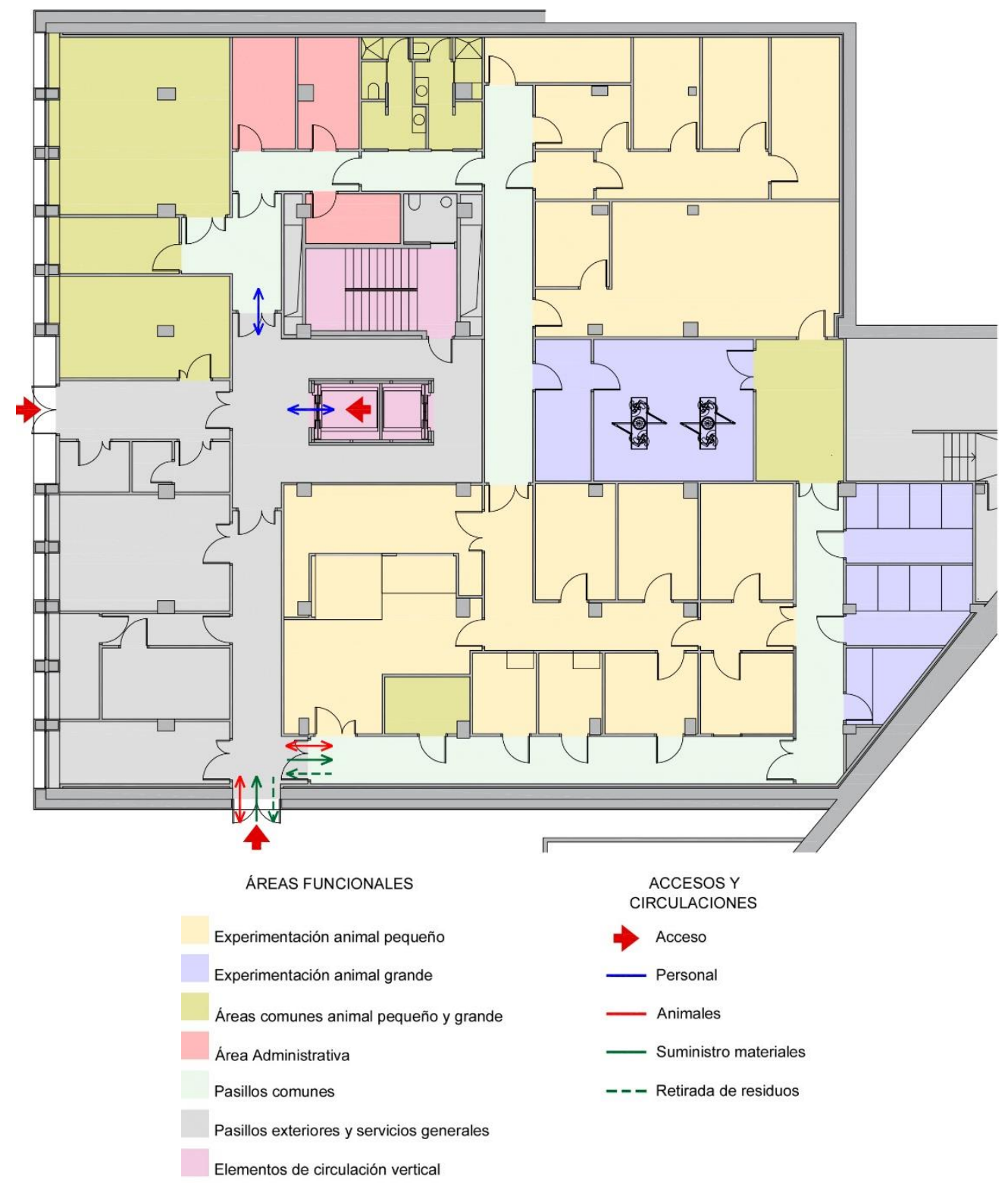

Figura 20. Organización centro experimentación animal IIS Biodonostia (S/E). Fuente. Elaboración propia. 
El centro de experimentación animal del instituto IIS La Fe (Figura 21) se distribuye en una única planta bajo rasante, por lo que es necesario hacer uso de elementos de comunicación vertical para poder trasladar los animales, suministros y residuos al centro. Para ello el animalario dispone de un núcleo de comunicación vertical de uso propio. El personal en cambio, hace uso de los ascensores comunes del edificio. La superficie disponible, así como el programa funcional necesario para el desarrollo de la actividad, ha conllevado que tanto las zonas de circulación, como algunas zonas de servicios y experimentación tengan que ser compartidas entre la experimentación de animal grande y pequeño.

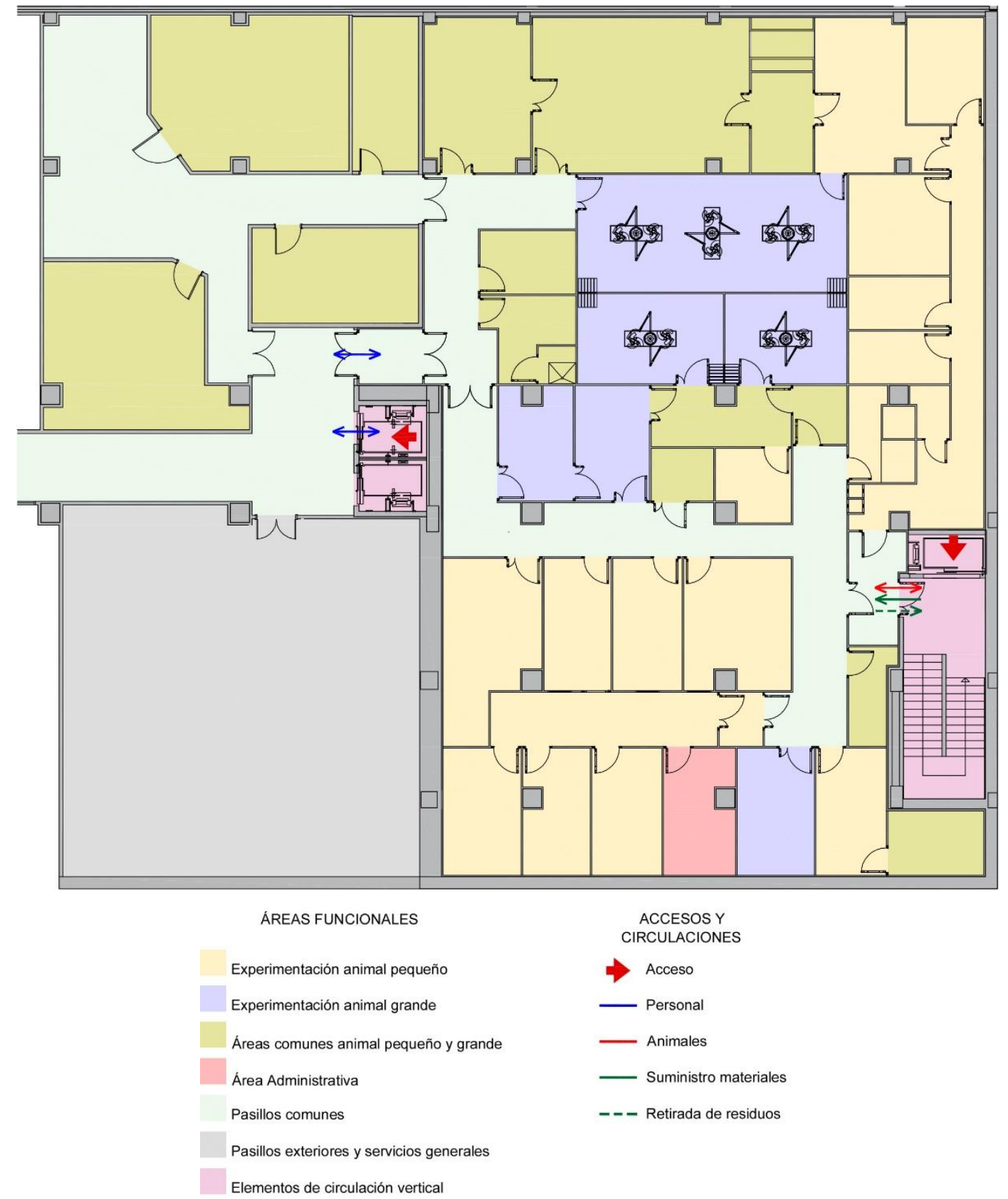

Figura 21. Organización centro experimentación animal IIS La Fe (S/E). Fuente. Elaboración propia. 


\section{Centros distribuidos en varias plantas}

Por otra parte, nos encontramos los centros que por diversos motivos no se han distribuido en una única planta y que para la implantación de las necesidades completas del centro han sido necesarias dos o incluso en algún caso, tres plantas. (IdiPAZ, IIS Biocruces, IISA, IGTP).

El centro de experimentación animal del instituto IGTP (Figura 22) se integra en un edificio de nueva construcción. Debido a la orografía del terreno, la organización en plantas tiene un desarrollo vertical inverso distribuido en tres plantas diferentes, de manera que en la planta de acceso se distribuye la zona de vestuarios para cambio del personal del centro; en la planta semisótano -1 con acceso directo desde el exterior se distribuye el centro de experimentación de animal grande y pequeño, de manera que las dos actividades son independientes entre si; y por último, en la planta sótano -2 se distribuyen los locales de servicio para el desarrollo de la actividad tales como sala de lavado y esterilización y almacenes. Este sistema de distribución conlleva que la actividad de investigación se realice en una única planta, pero todo el material que tiene que ser lavado y esterilizado deba ser trasladado de planta a través de elementos de comunicación vertical.

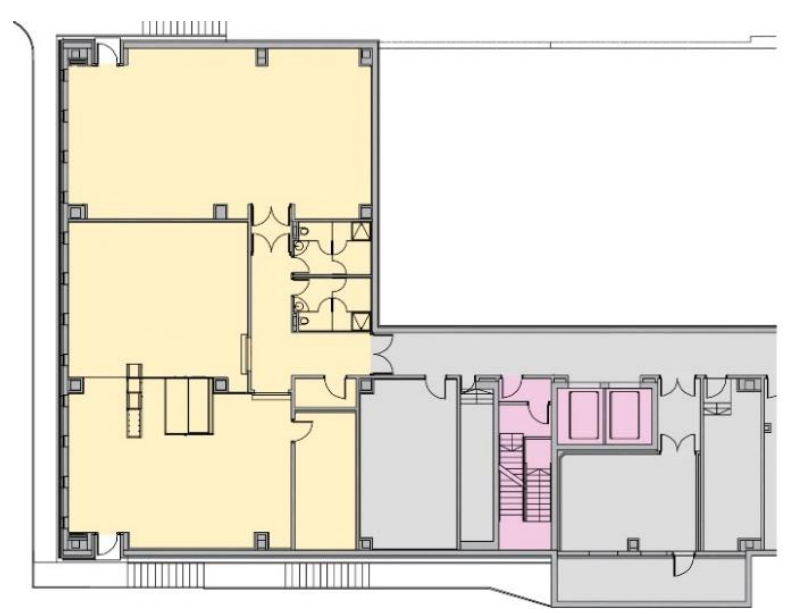

Planta Sótano -2. Centro experimentación animal.

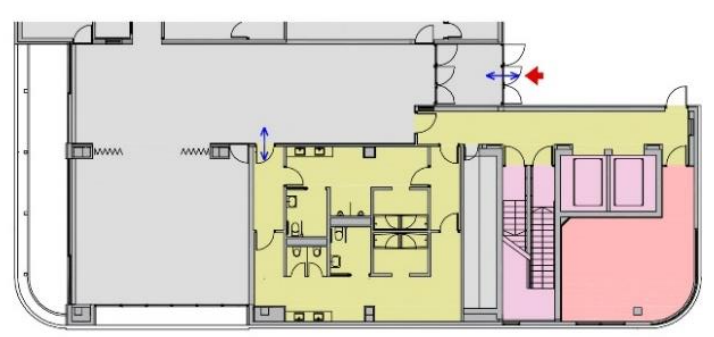

Planta Baja. Centro experimentación animal.

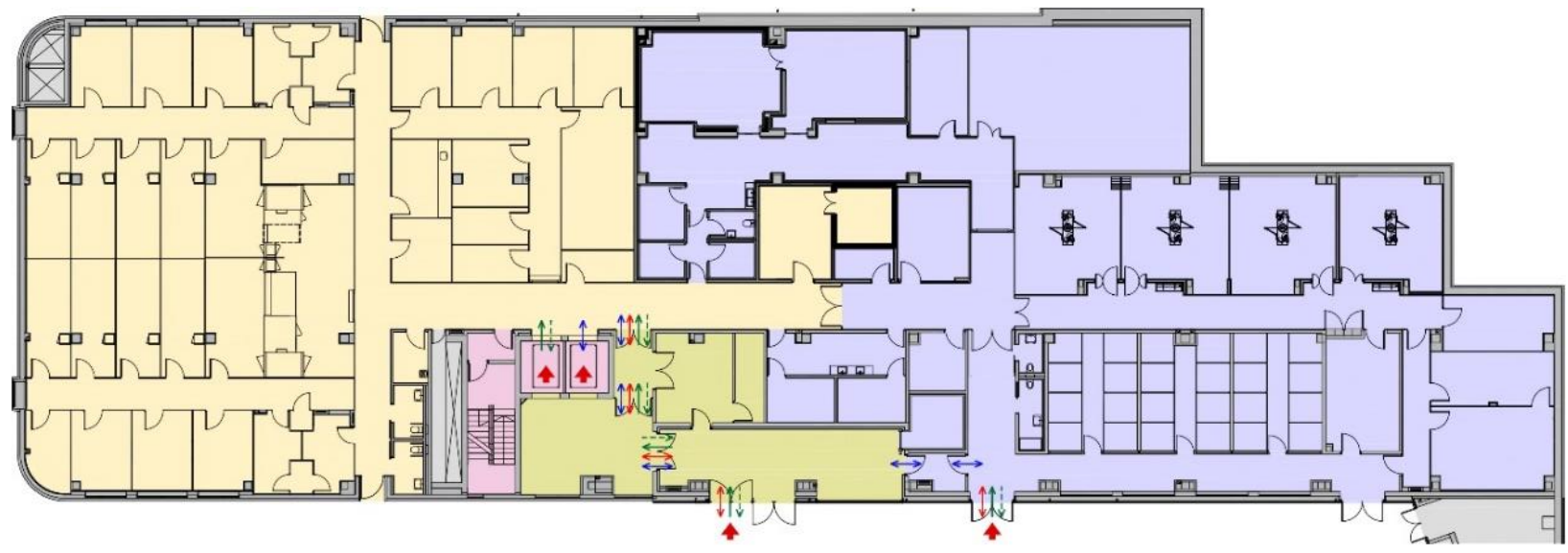

Planta Semisótano -1. Centro experimentación animal.

Figura 22. Organización centro experimentación animal IGTP (S/E).

Fuente. Elaboración propia. 
El centro de experimentación animal del instituto IdiPAZ (Figura 23) se ha distribuido en un edificio de nueva construcción, y en dos plantas diferentes, en el que se ha priorizado mantener el área de estabulación animal grande y pequeño en una única planta denominada planta sótano -2, y el área de experimentación de animal pequeño y grande en otra planta diferente en planta sótano-1. Este criterio de distribución no ha evitado que existan zonas de circulación independientes para el área de experimentación de animal grande y pequeño, lo que conlleva que el personal responsable del bienestar animal realice su trabajo en una misma planta; en cambio, son los animales los que se tienen que trasladar de la planta de estabulación a la planta de experimentación quirúrgica ubicada en la planta sótano-1. El edificio dispone de accesos diferenciados de manera que el personal accede desde la entrada principal del edificio y hace uso de los elementos de comunicación vertical comunes, mientras que los animales, materiales y suministros disponen de un acceso y elemento de comunicación vertical independiente.

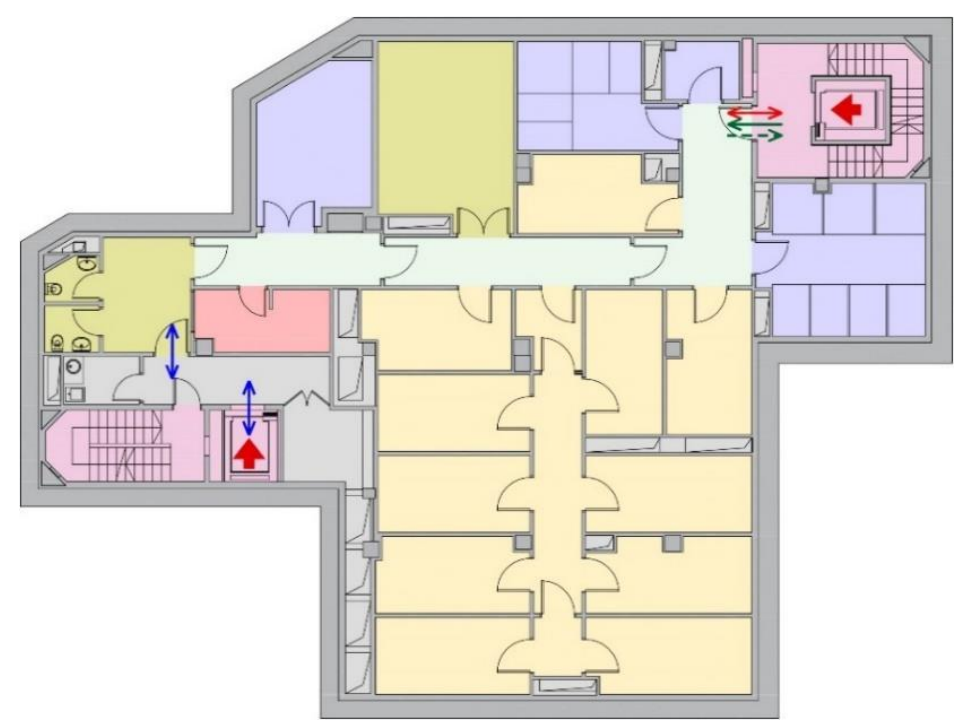

Planta sótano -2. Área estabulación animal grande y pequeño

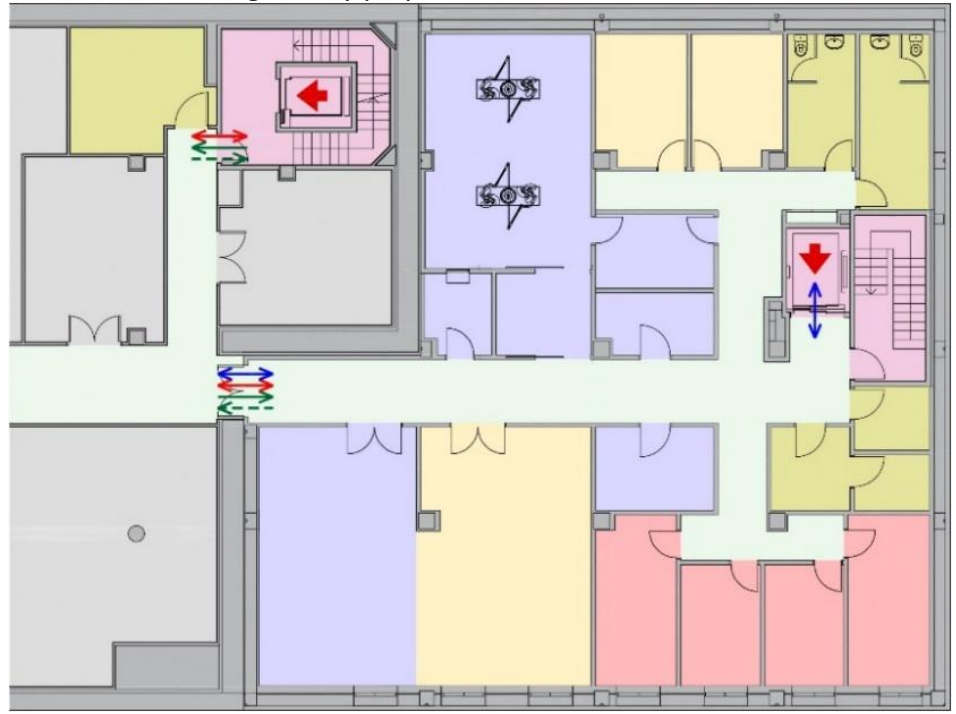

Planta sótano -1. Área experimentación animal grande/ pequeño

Figura 23. Organización centro experimentación animal IdiPAZ (S/E).

Fuente. Elaboración propia. 
El centro de experimentación animal del instituto IIS Biocruces (Figura 24) se ha integrado en un edificio de nueva construcción. Se encuentra distribuido en dos plantas, de manera que en la planta semisótano con acceso directo desde el exterior se ha distribuido el área de experimentación de animal grande, y en la denominada planta sótano -1 se desarrolla el área de experimentación de animal pequeño. Con esta distribución se ha conseguido; por una parte, que las dos áreas sean totalmente independientes; $y$, por la otra, que los animales una vez introducidos en el centro no tengan que ser trasladados de una planta a otra, de manera que toda la investigación se desarrolla en la misma planta. Por el contrario, son los responsables del cuidado de los animales los que tienen que desplazarse de planta para el desarrollo de la actividad. El edificio dispone de accesos propios para los animales, suministros y residuos e independientes al del personal del centro; además, internamente, para poder acceder a la planta de experimentación animal pequeño se han diseñado elementos de comunicación vertical independientes para ambos tránsitos.

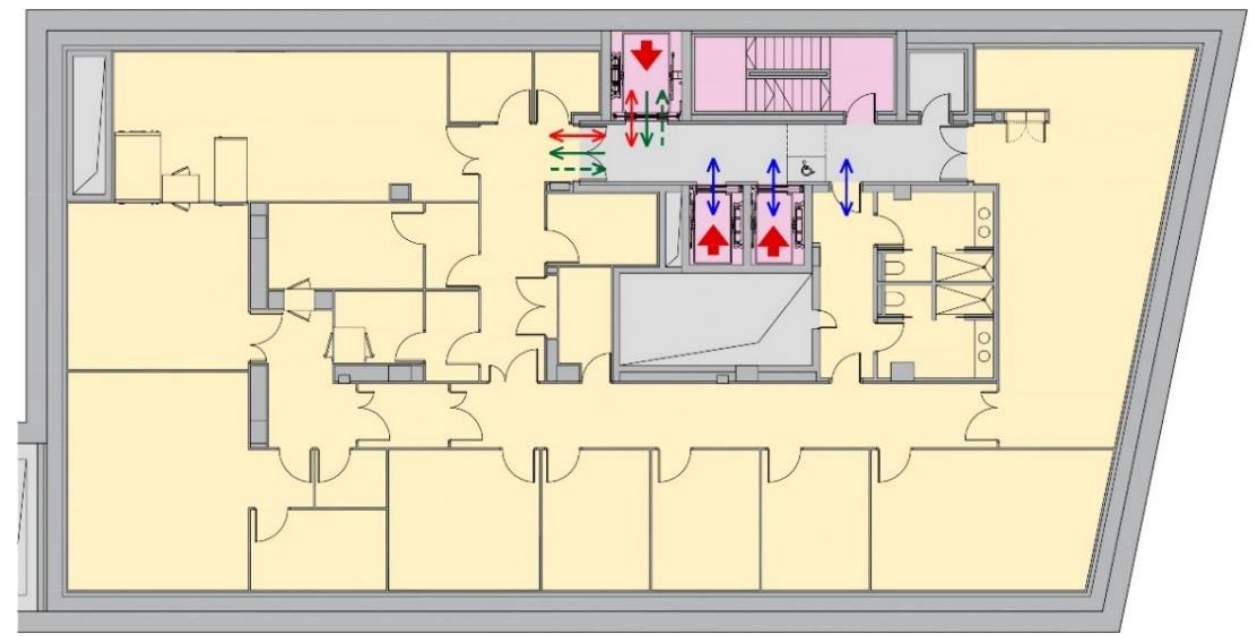

Planta semisótano. Área experimentación animal grande.

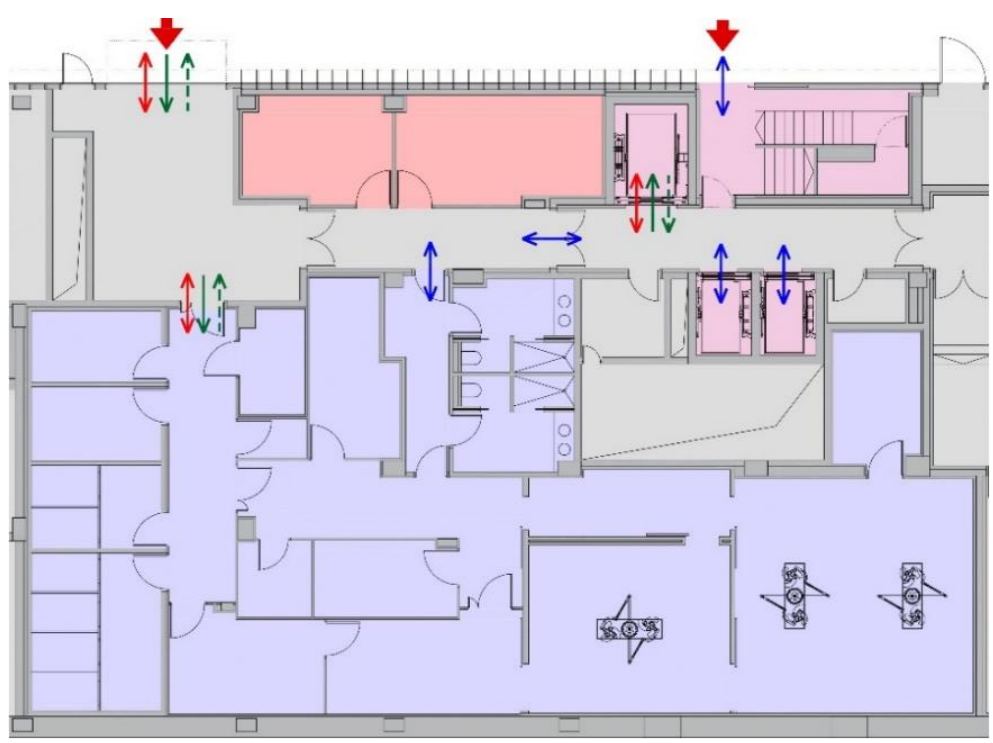

Planta sótano -1. Área experimentación animal pequeño

Figura 24. Organización centro experimentación animal IISBiocruces (S/E).

Fuente. Elaboración propia. 
El centro de experimentación animal del instituto IISA (Figura 25) se encuentra distribuido en dos plantas, en un edificio de nueva construcción. Por una parte, en la planta semisótano con acceso directo desde el exterior se ha distribuido el área quirúrgica experimental tanto para animal grande como pequeño; y, por la otra, en la denominada planta sótano -1 se desarrolla el área de experimentación de animal pequeño. De esta manera, observamos que existen dos áreas de experimentación de animal pequeño; una para el área de microcirugía que está integrada en el área de experimentación de animal grande y otra área totalmente independiente para el resto de investigación con animal pequeño.

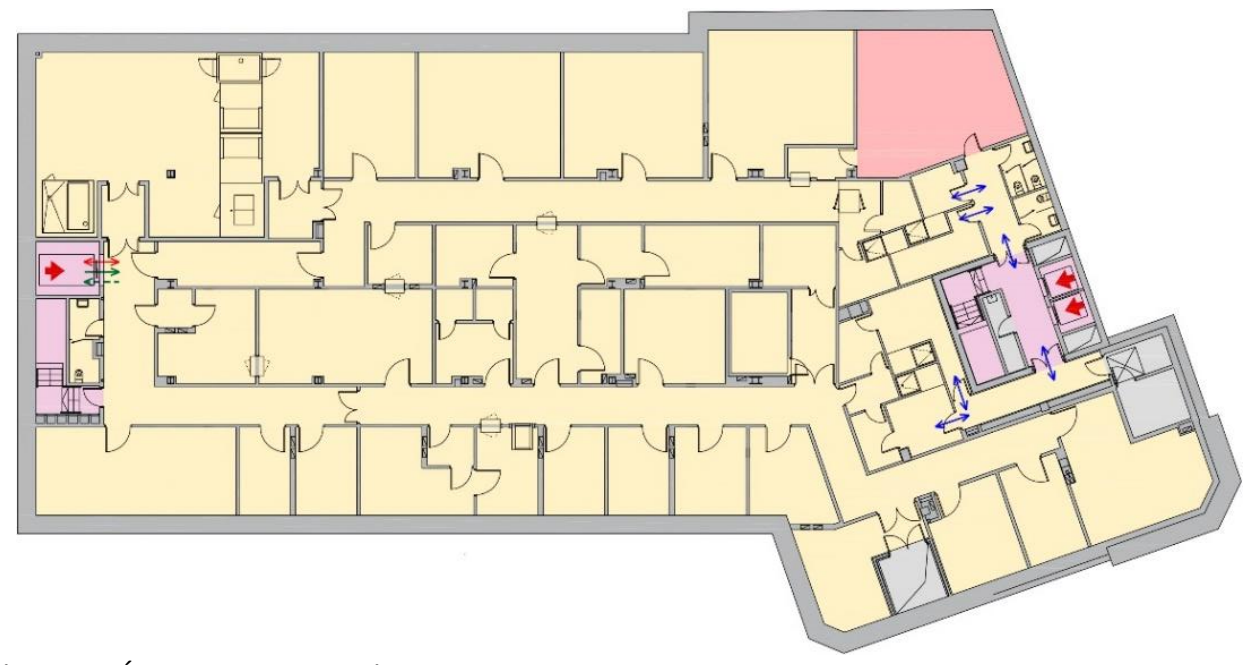

Planta sótano -1. Área experimentación animal pequeño

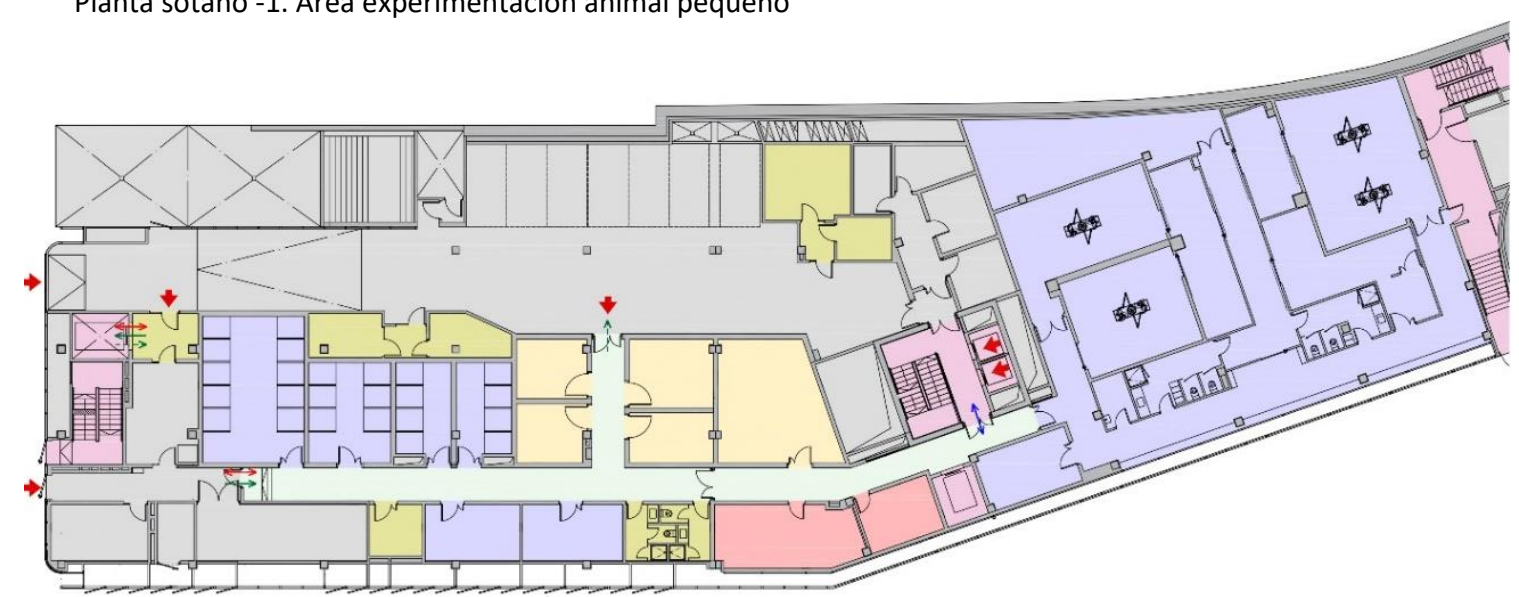

Planta semisótano. Área quirúrgica experimental.

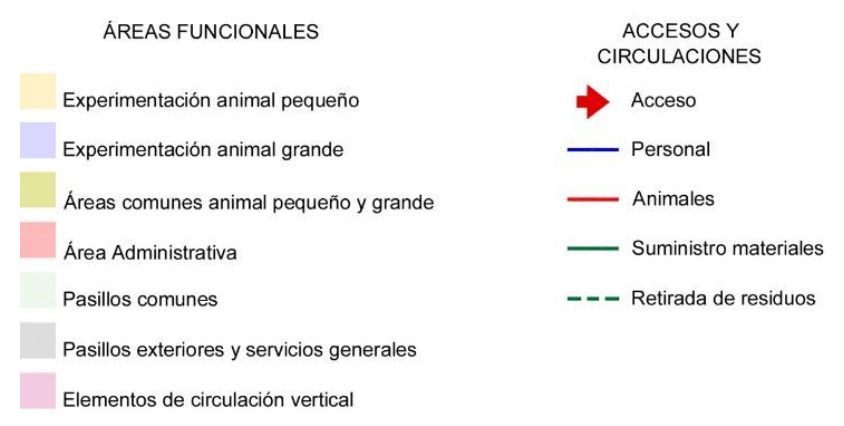

Figura 25. Organización centro experimentación animal IISA (S/E). Fuente. Elaboración propia. 


\subsubsection{Características generales del centro de experimentación animal}

Las características generales fundamentales que definen los centros de experimentación animal quedan recogidas en las fichas de toma de datos elaborada para cada uno de los institutos analizados.

Para realizar el análisis de dichas características se ha hecho una puesta en común de los resultados obtenidos; y, para ello, se ha optado por resumir las más importantes en una tabla (Tabla 01). En ella se listan los parámetros que definen las características generales del centro, se establecen cuáles son las características comunes a la mayoría de ellos y se identifica que institutos cumplen dichas características; además, se determinan las características que son particulares y específicas, reflejándose así mismo, que institutos las cumplen. El análisis se centra en los siguientes conceptos:

- El dimensionamiento del centro de experimentación en función de la superficie destinada para el desarrollo de la actividad, así como las destinadas al área de experimentación animal pequeño y grande.

- La ubicación del edificio en el que se desarrolla el centro ya que, en base al estudio realizado, estos pueden estar en las propias dependencias del complejo hospitalario, o bien en dependencias ajenas al hospital, en un centro asociado al instituto.

- La distribución del centro en uno o varios edificios, así como si se trata de un centro diseñado en un edificio de nueva construcción, o si, por el contrario, el programa de necesidades se ha tenido que desarrollar en una edificación existente.

- La fecha de construcción o rehabilitación del centro de experimentación. Los centros se han divido en dos franjas; entre los construidos o reformados con fecha anterior al año 2009, y los inaugurados con posterioridad al año 2009.

- El tipo de animales de experimentación utilizados en estos centros, así como el tipo de alojamientos diseñados. 
Tabla 01. Características generales del centro de experimentación animal.

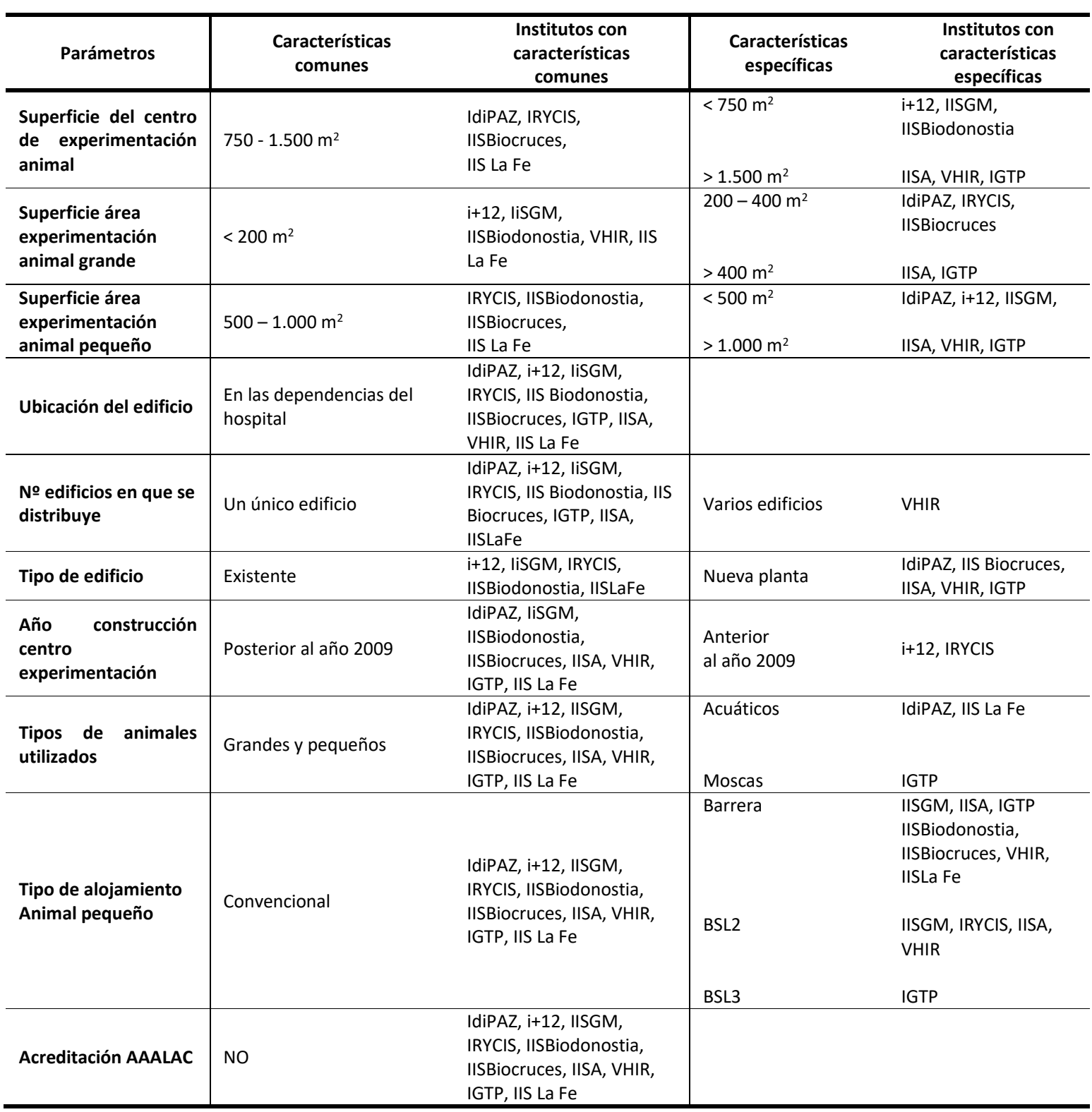

Fuente. Elaboración propia.

\section{Dimensionamiento}

El dimensionamiento de los centros de experimentación animal es muy variable, observamos como la mayoría se distribuyen en un rango de superficies comprendidas entre los 750 y $1.500 \mathrm{~m}^{2}$ (IdiPAZ, IRYCIS, IISBiocruces, IIS La Fe). Entre los que disponen de una superficie inferior a $750 \mathrm{~m}^{2}$ se encuentran el i+12, IISGM, IISBiodonostia; mientras que los institutos IISA, VHIR, IGTP son los que mayor dimensionamiento presentan con una superficie superior a los $1500 \mathrm{~m}^{2}$.

Centrándonos en la superficie destinada al área de experimentación de animal pequeño, observamos como la mayor superficie de cada centro está destinada a esta actividad de manera que la mayoría de los centros destinan una superficie comprendida entre los 500 y 1.000 m2 (IRYCIS, IISBiodonostia, 
IISBiocruces, IIS La Fe). Además, destacan tres centros (IISA, VHIR, IGTP) por el mayor dimensionamiento de esta área, con una superficie superior a los $1.000 \mathrm{~m} 2$.

El área destinada a experimentación de animal grande, en cambio, suele ser inferior a $200 \mathrm{~m}^{2}(\mathrm{i}+12$, liSGM, IISBiodonostia, VHIR, IIS La Fe). Por otra parte, los centros que presentan un mayor dimensionamiento de esta área son el IISA e IGTP con una superficie superior a $400 \mathrm{~m}^{2}$.

\section{Ubicación}

Según el estudio realizado, todos los institutos disponen del centro de experimentación animal en las dependencias del recinto hospitalario, bien en edificaciones compartidas con otras infraestructuras del hospital o bien en edificaciones independientes de uso exclusivo del instituto. Esta situación que se da en todos los casos estudiados, no siempre es así, ya que entre varios de los institutos visitados y que por diversos motivos no se han incorporado a la muestra (IDIBAPS, IMIM, IDIBELL) se ha observado como parte de la experimentación animal del instituto se realiza en otros centros con los que el instituto de investigación tiene alianzas. De manera que en el caso del IDIBAPS realiza su investigación en la Facultad de Medicina de la Universidad de Barcelona. Por otra parte, está el IDIBELL que si bien una parte de la investigación la desarrolla en el Estabulario IDIBELL situado en el edificio del Institut Catalá d'Oncologia del recinto hospitalario del Hospital de Bellvitge, la investigación la complementa en el Estabulario Bellvitge, que está ubicado en el campus Bellvitge de la Universidad de Barcelona. En el caso del Instituto de Investigación Sanitaria Hospital del Mar (IMIM), realiza su experimentación en las instalaciones del Parque de Investigación Biomédica de Barcelona (PRBB), siendo esta una de las infraestructuras más grandes del sur de Europa destinada a la biomedicina.

\section{Tipo de distribución}

La mayoría de los centros de experimentación se desarrollan en un único edificio, si bien existe algún centro (VHIR) que se organiza en varios edificios diferentes. En este caso, a pesar de que la investigación se realiza en el recinto hospitalario, el instituto originariamente se desarrollaba en un único edificio hasta la construcción en el año 2017 de un nuevo edificio para investigación específica con animal pequeño. En la fecha de la visita, la investigación se realiza en dos edificios diferentes del Hospital: por una parte, el antiguo Estabulario ubicado en el edificio Meditarránia del que en el presente análisis solo se trata el área de experimentación de animal grande; y, por la otra, el Estabulario Cellex del Instituto de Oncología Vall d’Hebrón en el que se investiga con animal pequeño y que se ha incorporado a la muestra.

La elección de la ubicación del centro de experimentación animal es extremadamente importante y merece una seria consideración. Incluso cuando ya existe una instalación de experimentación animal, 
puede ser más práctico y económico construir una nueva en otro sitio que actualizar una instalación existente, ya que puede ser muy difícil, y a veces incluso imposible, incorporar los complejos requerimientos de instalaciones así como implantar un flujo de circulación ideal en las estructuras existentes (Neil 2003, p. 16).

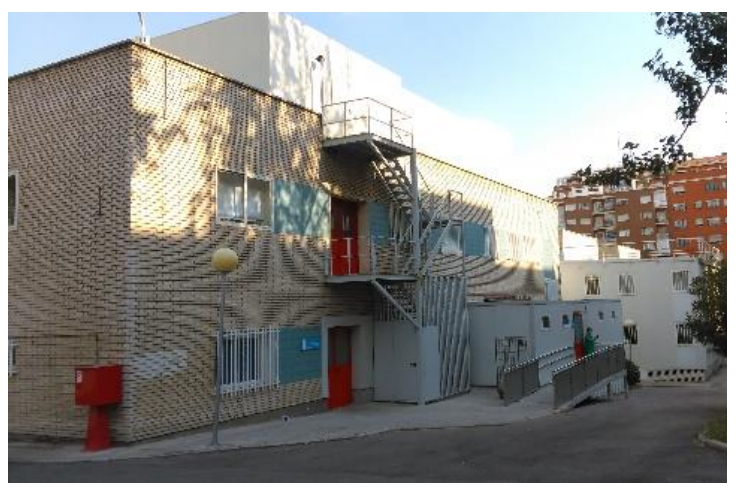

Figura 26. Edificio liSGM.

Fuente. Elaboración propia.

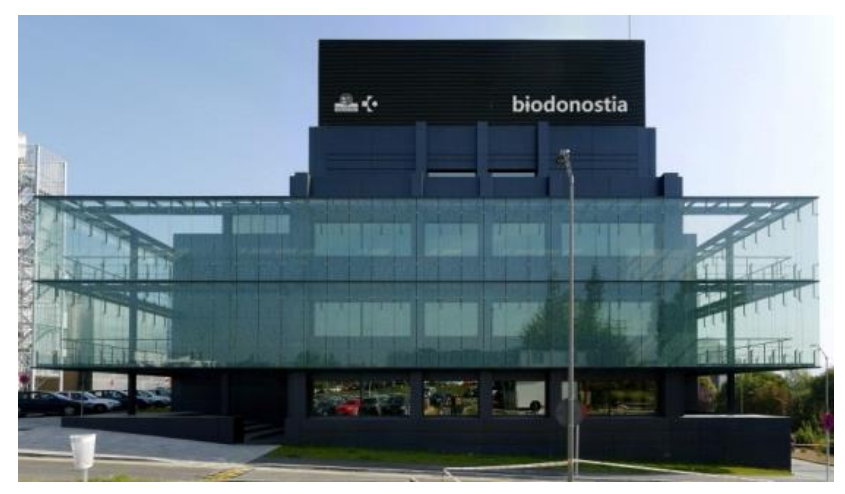

Figura 27. Edificio IIS Biodonostia.

Fuente. Elaboración propia.

En este sentido, observamos cómo en la mitad de los casos, los centros de experimentación estudiados se han tenido que distribuir en edificios existentes (IISGM, IISBiodonostia, IISLaFe, i+12, IRYCIS; Figura: 26,27,30,31,32) por lo que el planteamiento de organización y diseño se ha tenido que limitar a adaptar las necesidades del programa a una planta y volumetría definida, con unos accesos y circulaciones interiores ya predeterminados. Como casos particulares caben mencionar por una parte el liSGM (Imagen 26), que se distribuye en un edificio existente del hospital que ha sido ampliado a base de módulos prefabricados para adaptarse a las necesidades de la plataforma de animalario; $y$, por otra el IIS Biodonostia (Imagen 27), ya que el instituto completo se ha desarrollado en un edificio que inicialmente se diseñó para otro uso hospitalario, pero en el que finalmente se decidió implantar el Instituto de Investigación Sanitaria, una vez ejecutada la estructura de hormigón del edificio.

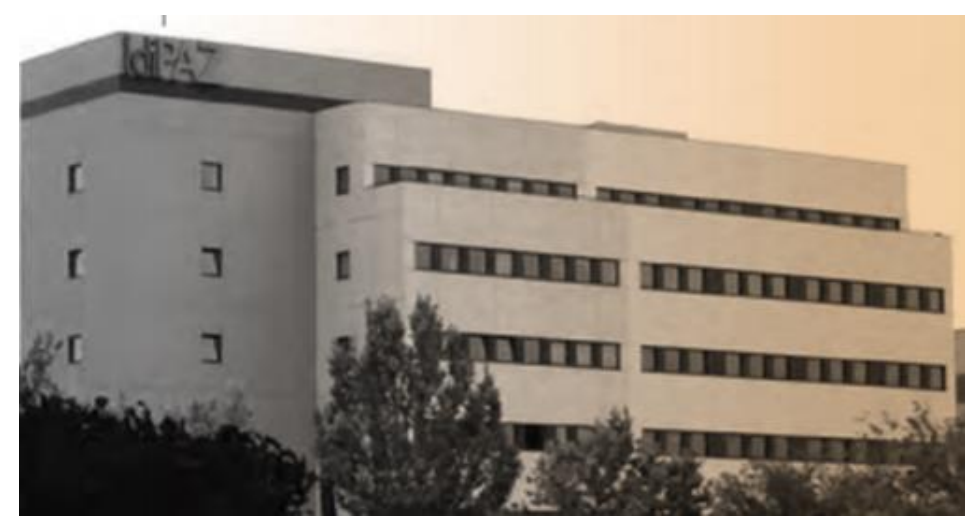

Figura 28. Edificio IdiPAZ. Fuente. IdiPAZ.

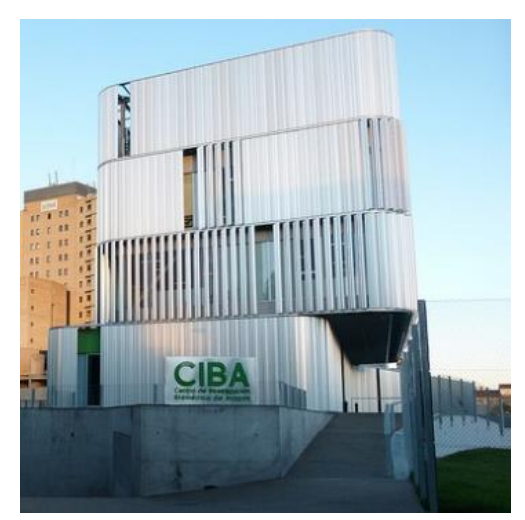

Figura 29. Edificio IISA. Fuente. Ciba.

En cambio, en los casos en los que el centro se ha acondicionado en un edificio de nueva construcción (IdiPAZ, IISA, IIS Biocruces, VHIR, IGTP; Figura 28,29,33,34,35), a pesar de disponer a la hora de diseñar 
mayor flexibilidad para adaptar la arquitectura a las necesidades requeridas, las limitaciones impuestas han sido debidas a la disponibilidad de suelo, circunstancias urbanísticas, afecciones del entorno, incluso por las prioridades establecidas por los responsables del instituto entre las diferentes líneas y plataformas de investigación, entre otras.

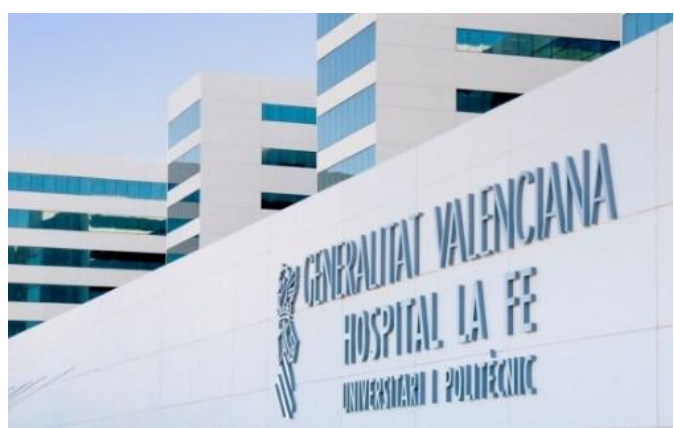

Figura 30. Edificio IIS La Fe. Fuente. IIS La Fe.

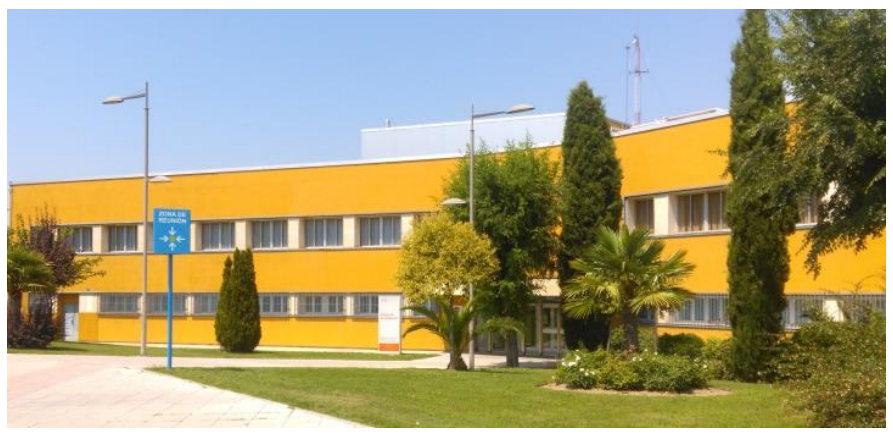

Figura 31. Edificio i+12.

Fuente. Elaboración propia.

\section{Fecha de construcción}

Analizando el año de construcción o reforma de los centros se observa como la mayoría de los centros tienen una antigüedad inferior a diez años, de manera que se han puesto en servicio con posterioridad al año 2009, año de las primeras acreditaciones de los institutos. Entre los centros construidos con anterioridad al año 2009 se encuentran el i+12 e IRYCIS (Figura 31, 32), siendo el más antiguo de todos el IRYCIS. Este centro en concreto se reformó en el año 2000 sobre un animalario ya existente.

Entre los centros más modernos se encuentran IIS Biocruces, VHIR e IGTP (Imagen 33,34,35), puestos en servicio entre los años 2017 y 2018.

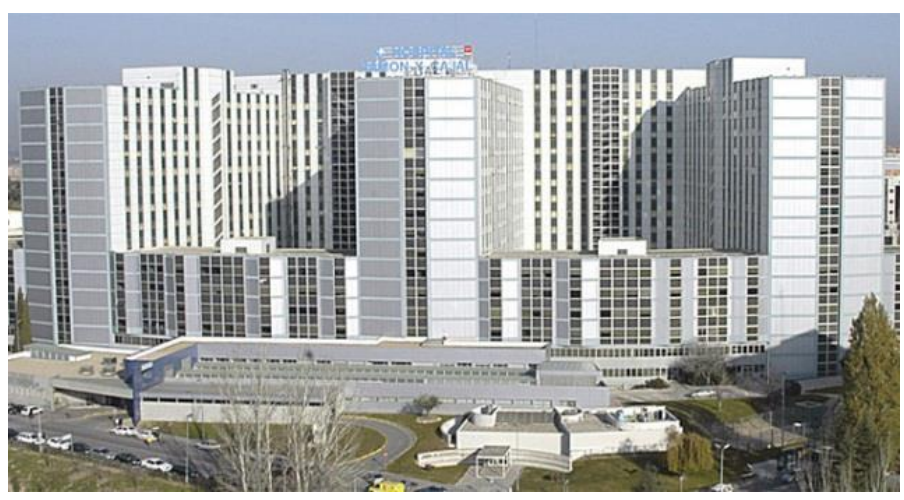

Figura 32. Edificio IRYCIS. Fuente. IRYCIS.

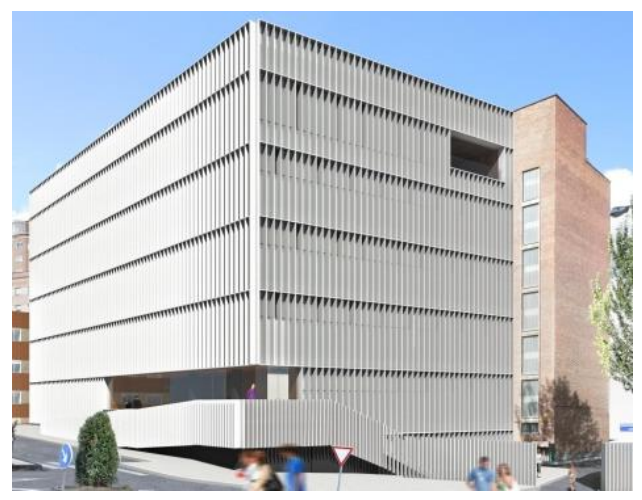

Figura 33. Edificio IIS Biocruces. Fuente. Elaboración propia.

Lo habitual es que la edificación en la que se distribuye el centro de experimentación animal esté realizada con estructura de hormigón armado, aunque existe algún caso (IISGM) en el que la ampliación del instituto se ha realizado a base de módulos prefabricados. Esto se debe a la falta de asignación presupuestaria suficiente para acometer una nueva edificación con la complejidad que estos institutos requieren, que ha permitido de una manera relativamente controlada ampliar las 
instalaciones existentes y así aumentar la actividad en investigación del centro. Por su parte, el IDIBELL, se acondicionó sobre la planta cubierta de un edificio de hormigón, siendo un añadido realizado a base estructura metálica y elementos prefabricados.

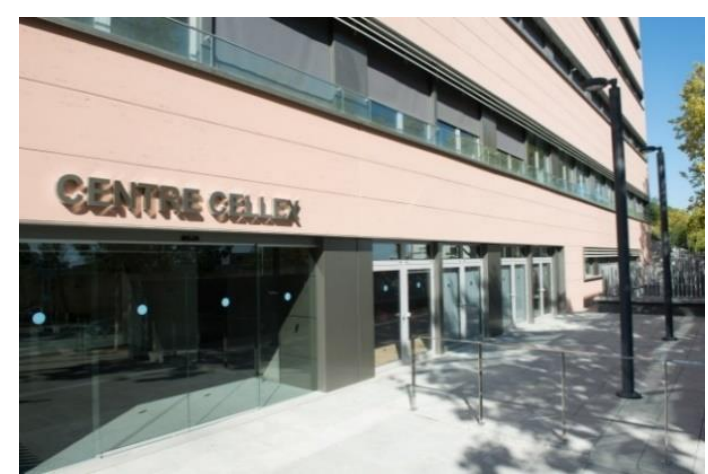

Figura 34. Edificio Cellex VHIR. Fuente. Elaboración propia.

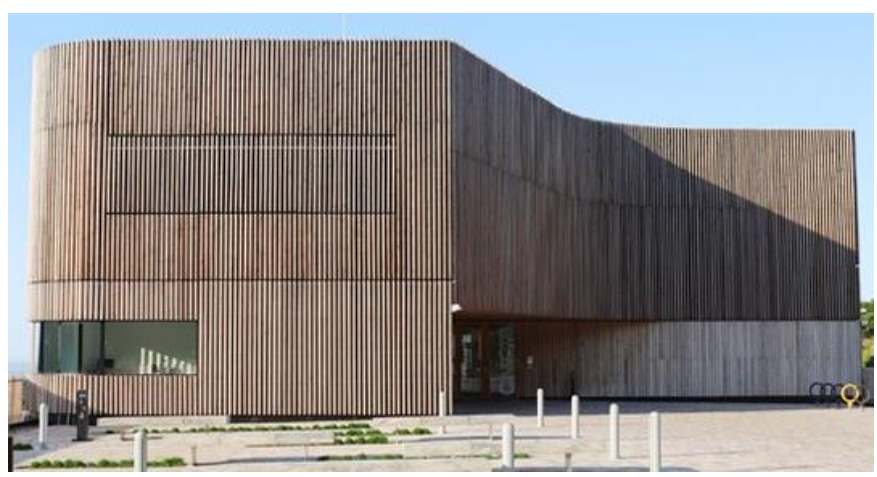

Figura 35. Edificio IGTP. Fuente. IGTP.

\section{Animales de experimentación}

Las especies animales más utilizadas en experimentación biomédica, se pueden diferenciar en dos grandes grupos: los animales pequeños (ratones, ratas, hámsteres, cobayas) y los animales grandes (cerdos, ovejas, cabras), disponiendo todos los institutos analizados estas dos grandes áreas. Entre ellos, el IDIPAZ junto con el IIS La Fe son los institutos que en el momento de realizar la visita disponen, además, de instalaciones para investigación con animales acuáticos, aunque muchos de los restantes centros visitados tienen en mente introducir próximamente esta especie cuyo peso en investigación se ha multiplicado en los últimos años. Como caso particular se encuentra el IGTP en el que también se investiga con moscas.

Ninguno de los centros incluidos en la muestra dispone de acreditación AAALAC Internacional, distintivo que garantiza que el centro de experimentación animal, además de cumplir con las normas locales, nacionales e internacionales que regulan las investigaciones con animales, también cumple con los estándares aceptados a nivel internacional de la guía Guide for the care and use of laboratory animals. De entre todos los institutos de investigación visitados, únicamente el Instituto IDIBELL y el PRBB, instalaciones en las que realiza la investigación el IMIM, son los que disponen esta acreditación. Además, también disponían esta acreditación los centros de experimentación animal visitados del CIC biogune, $\mathrm{ClC}$ biomagune y el CNIO.

Los locales de alojamiento son los locales donde van a vivir normalmente los animales con los que se va a experimentar. Hay que tener en cuenta que para obtener unos resultados científicos válidos y garantizar el bienestar animal resulta fundamental en ciertos casos disponer de salas de ambiente controlado. Es por ello que los locales de alojamiento además de estar diseñados para garantizar los servicios básicos de los animales, deben estar diseñados para garantizar la bioseguridad, 
bioprotección y biocontención requerida en cada proyecto de investigación. Si bien se ha observado que, en las zonas de estabulación de animal grande, en general, no se requiere de condiciones ambientales expecionales y por tanto, lo habitual es que estén alojados de manera convencional; en el caso de la estabulación de animal pequeño existen diversas tipologías de centros, en cuanto al nivel de bioseguridad exigido. De esta manera, el IGTP es el único centro visitado de nivel de bioseguridad ABSL3, mientras que los institutos (IISGM, IISA, VHIR) disponen de instalaciones ABSL2. Por otra parte, aunque algunos de los centros visitados comentan ser capaces de mantener el estado sanitario SPF de los roedores mediante el alojamiento en cubetas autoventiladas, la mayoría de los institutos (IISGM, IISA, IGTP, IIS Biodonostia, IIS Biocruces, VHIR, IIS La Fe) disponen de instalaciones en barrera para experimentación con animal pequeño.

En función de la actividad que se va a desarrollar en el centro se pueden distinguir tres tipos de centros: de cría, suministrador y usuario. Todos los centros analizados se tratan de centros de usuario para el caso de la experimentación animal grande, por el contrario, en el caso de la experimentación de animal pequeño, lo habitual es los centros también críen animales para su propia investigación. 


\subsubsection{Criterio organizativo del centro de experimentación animal}

Los conceptos fundamentales que definen el criterio organizativo de los centros de experimentación animal quedan recogidos en las fichas de toma de datos elaborada para cada uno de los institutos analizados.

El estudio de la organización y del diseño se ha dividido teniendo en cuenta por un parte la organización general e interrelación de las principales unidades funcionales del centro; y, por otra, haciendo un análisis de la organización pormenorizada de cada una de las áreas de experimentación que lo conforman: el área de experimentación animal grande y el área de experimentación animal pequeño. Utilizaremos por tanto el término centro de experimentación para referirnos a la instalación completa que comprende la experimentación animal de ambas áreas, tanto la de animal grande como la de pequeño.

Como veremos durante este análisis, aunque no todos los centros de experimentación se han distribuido tomando como punto de partida el concepto de área de experimentación de animal grande y pequeño, para este estudio se ha optado por este criterio de análisis debido a las exigencias de partida tan diferentes que se plantean a la hora de organizar cada una de estas áreas.

Hay que tener en cuenta que unas instalaciones bien planificadas, bien diseñadas, correctamente construidas, adecuadamente mantenidas y gestionadas es muy importarte para el uso y cuidado de animales, ya que garantiza el desarrollo de la actividad eficiente, económica y segura. Para ello, en la fase de planificación y diseño se deberían considerar la participación por una parte de personal experimentado en el diseño, instalaciones y funcionamiento de los animalarios, y por otra, los representantes de los usuarios de esas instalaciones (National Research Council 2011, p. 133).

Esta fase inicial trata fundamentalmente de analizar la organización de las diferentes unidades funcionales que contemplan este tipo de centros como son: el área administrativa, el área de experimentación de animal grande y el área de experimentación de animal pequeño, considerando los accesos, y los elementos de circulación vertical y horizontal necesarios, que deben estar diseñados de tal manera que la circulación establecida sea siempre desde las zonas limpias hacia las zonas sucias.

Para ello es necesario conocer la organización general que deben cumplir los centros de experimentación animal. Si bien en lo referente a la distribución de estos centros no existe una normativa de aplicación específica que determine el esquema u organización interna, sí existen diversas guías y manuales que establecen recomendaciones y directrices a tener en cuenta en esta fase. 
De entre las diferentes guías existentes se ha seleccionado el esquema organizativo reflejado en la publicación Planning and designing animal facilities (Figura 36). En él se muestran las diferentes unidades que conforman un centro genérico, así como la interrelación entre ellos y los flujos de trabajo. Observamos cómo se muestran tres accesos diferenciados: uno para el personal, otro para la recepción animal, y un tercero para la retirada de residuos. Los animales una vez pasado por la zona de cuarentena, en el caso de que fuera necesario, son trasladados a la zona de alojamiento de animales que le corresponda en función de la especie y tipo de animal. La experimentación se realiza bien en las salas de procedimientos, bien en las salas específicas de experimentación como son el área quirúrgica, la zona de procedimientos especiales, sala de necropsias o eutanasia.

A los animales, aparte de proporcionarles alojamiento hay que proporcionarles los cuidados necesarios, suministrarles comida y bebida, asegurar unas buenas condiciones de higiene, incluso asegurar su bienestar ${ }^{38}$. Para ello en el esquema se plantea un segundo acceso que sirve tanto para los suministros como para la retirada de residuos generados en el centro.

Por último, vemos como se plantea un tercer acceso a través de una zona destinada al personal; tanto para los responsables del cuidado de los animales como para los investigadores y compuesta por su zona administrativa, zona de conferencias y zona de descanso entre otros; desde la que se accede a la zona de experimentación.

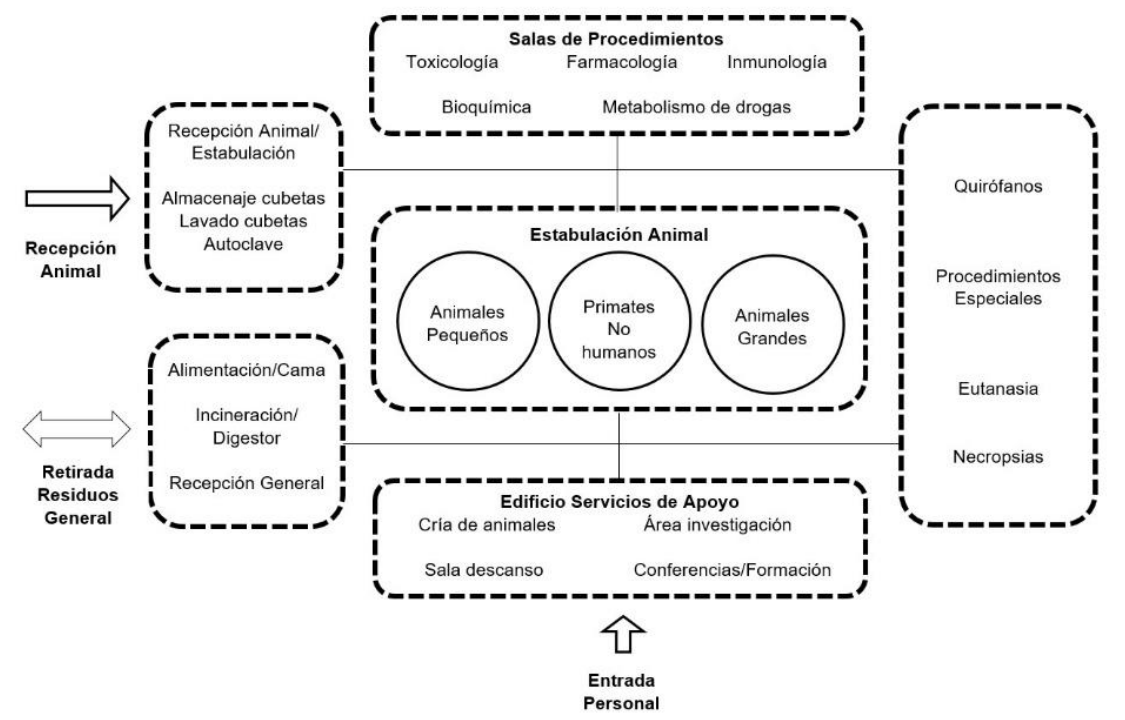

Figura 36. Esquema organización centros de experimentación animal.

Fuente. Hessler 2009, c 4, p. 29.

\footnotetext{
38 Los principales principios del bienestar animal que recoge la normativa vigente, están el que los animales se utilicen sólo cuando sea imprescindible dando preferencia a la alternativa in vitro, emplear del mínimo número de animales necesarios, disponer de espacios e instalaciones adecuadas para cada tipo de animal regulando el tamaño de las jaulas y establos y el número máximo de animales por unidad de confinamiento, posibilitar la sociabilización de los animales que lo precisan, facilitarles una alimentación adecuada, darles un trato y tratamientos respetuosos, producirles el mínimo dolor posible, utilizar sistemas de sacrificio respetuoso, disponer de una adecuada atención veterinaria y no utilizar en experimentación animales salvajes o de especies protegidas.
} 
Por otra parte, a la hora de definir la ubicación física del centro de experimentación animal dentro de un edificio, y poder garantizar los accesos adecuados anteriormente descritos tales como: la recepción de animales, los suministros y la retirada de residuos, así como la accesibilidad a los usuarios se recomienda tener en consideración los siguientes conceptos (Neil 2003, p. 16):

a) Facilitar el acceso desde el exterior del edificio al propio animalario para la entrega de animales y suministros, así como la retirada de residuos disponiendo de un acceso directo desde el exterior e intentando realizar el menor recorrido interior posible.

Además, es necesario garantizar la correcta comunicación entre las diferentes áreas funcionales teniendo en cuenta el concepto de asepsia progresiva de manera que las circulaciones estén organizadas desde las zonas limpias hacia las sucias. En caso de tener que hacer uso de elementos de comunicación vertical se recomienda que dispongan de un mínimo de dos montacargas; uno para limpio y otro para sucio. En el caso de que no fuera posible, siempre se podrían aplicar medidas organizativas de uso para poder limpiar y esterilizar el ascensor entre los diferentes usos, así como usar contenedores seguros y herméticos tanto para los productos estériles, como para los deshechos. Además, el acceso a ellos debería limitarse únicamente a los trabajadores del mismo y deberían de contar con un vestíbulo previo con el fin de amortiguar los cambios de presión diferencial ocasionados por el movimiento del ascensor.

b) Ordenar las circulaciones para el tránsito del personal del animalario e investigador, el de animales, el de suministro de materiales y la retirada de residuos, minimizando los recorridos interiores para el traslado de los animales. En este sentido, el centro debe estar organizado de manera que por una parte, el acceso al animalario sea restringido; y, por la otra, para evitar la circulación de los animales, cubetas y residuos por las zonas públicas del edificio. Además, siempre que sea posible, tanto el área de estabulación como la zona de experimentación deberían estar dentro del área de experimentación animal para evitar el traslado de animales y de esta manera evitar el posible estrés que esto pueda causar en los animales, los posibles efectos en la investigación, el peligro de contaminación, así como la exposición del personal externo al animalario a los alérgenos de los animales.

c) Este tipo de instalaciones deben estar en funcionamiento 24 horas al día durante todos los días del año. Por ello es necesario dotarlos de los suministros básicos seguros tales como agua, evacuación de aguas residuales, gases medicinales, sistemas de seguridad y control, energía eléctrica, iluminación y sistema de climatización, teniendo en cuenta que se deben considerar los equipos de reemplazo necesarios en caso de emergencia. 
d) La unidad de animalario y experimentación animal es una de las plataformas del instituto de investigación sanitaria que mayores exigencias de calidad de aire puede llegar a necesitar, ya que al ser salas de ambiente controlado, la calidad del aire tanto en las instalaciones en barrera como en los quirófanos experimentales es crítica para su correcto funcionamiento. Es por ello fundamental ubicarlo en una planta en la que se garantice el suministro de la cantidad y calidad de aire necesaria en la instalación.

Con el fin de realizar un análisis comparativo de las características de organización y diseño de los centros de experimentación animal se ha optado por resumir las más importantes en una tabla (Tabla02). En ella se listan los parámetros que definen la organización de los centros, se identifican cuáles son las características comunes a la mayoría de ellos y se identifica qué institutos cumplen dichas características; además, también se relacionan las características específicas, que son particulares y específicas y también se refleja que institutos las cumplen. El análisis se centra en los siguientes conceptos:

- El número y tipo de plantas en la que se distribuye el centro es importante, ya que una división en plantas o plantas ubicadas sobre o bajo rasante, conllevan inevitablemente el desarrollo de unos elementos de comunicación vertical específicos para el centro tanto para el acceso de suministros como para el desarrollo de la actividad interna.

- La distribución general de las tres áreas principales establecidas: área de experimentación animal grande, área de experimentación animal pequeño y el área administrativa.

- Los accesos exteriores al centro; se pretende analizar cómo se ha organizado en cada caso el acceso del personal, de los animales, el suministro de materiales, así como la retirada de residuos.

- Los elementos de distribución interior y elementos de comunicación vertical interior necesarios para el funcionamiento del centro. Se considera interesante estudiar como se distribuyen interiormente los pasillos de circulación hasta llegar a cada área, así como el número de elementos de comunicación vertical y los usos asignados a cada uno de ellos. 
Tabla 02. Organización centro de experimentación animal.

\begin{tabular}{|c|c|c|c|c|}
\hline Parámetros & $\begin{array}{l}\text { Características } \\
\text { comunes }\end{array}$ & $\begin{array}{c}\text { Institutos con } \\
\text { características } \\
\text { comunes } \\
\end{array}$ & $\begin{array}{l}\text { Características } \\
\text { específicas }\end{array}$ & $\begin{array}{l}\text { Institutos con } \\
\text { características } \\
\text { Específicas }\end{array}$ \\
\hline $\begin{array}{l}\text { № de plantas en que se } \\
\text { distribuye }\end{array}$ & Una única planta & $\begin{array}{l}\text { i+12, liSGM, IRYCIS, } \\
\text { IISBiodonostia, IIS La Fe }\end{array}$ & $\begin{array}{l}\text { Dos plantas } \\
\text { Tres plantas }\end{array}$ & $\begin{array}{l}\text { IdiPAZ, } \\
\text { IISBiocruces, IISA, } \\
\text { VHIR } \\
\text { IGTP }\end{array}$ \\
\hline Tipo de división & $\begin{array}{l}\text { Área experimentación } \\
\text { animal pequeño y grande } \\
\text { divididos }\end{array}$ & IISBiocruces, VHIR & $\begin{array}{l}\text { Animal grande y } \\
\text { pequeño estabulado en } \\
\text { la misma planta } \\
\text { Cirugía experimental y } \\
\text { animal pequeño } \\
\text { divididos } \\
\text { Experimentación } \\
\text { animal en una planta y } \\
\text { servicios en otras }\end{array}$ & $\begin{array}{l}\text { IdiPAZ } \\
\text { IISA } \\
\text { IGTP }\end{array}$ \\
\hline $\begin{array}{l}\text { Tipo de planta en la que } \\
\text { se ubica }\end{array}$ & Planta a cota cero & $\begin{array}{l}\text { i+12, liSGM, IRYCIS, } \\
\text { IISBiodonostia }\end{array}$ & $\begin{array}{l}\text { Bajo rasante } \\
\text { Mixto }\end{array}$ & $\begin{array}{l}\text { IdiPAZ, IIS La Fe } \\
\text { IISBiocruces, IISA, } \\
\text { VHIR, IGTP }\end{array}$ \\
\hline $\begin{array}{l}\text { Configuración áreas } \\
\text { animal grande y } \\
\text { pequeño }\end{array}$ & No independizadas & $\begin{array}{l}\text { IdiPAZ, i+12, liSGM, } \\
\text { IRYCIS, IIS Biodonostia, } \\
\text { IISA, IIS La Fe }\end{array}$ & Independizadas & $\begin{array}{l}\text { IISBiocruces, } \\
\text { VHIR, IGTP }\end{array}$ \\
\hline $\begin{array}{l}\text { Ubicación de la zona } \\
\text { administrativa en el área } \\
\text { de experimentación }\end{array}$ & $\begin{array}{l}\text { Externa al área de } \\
\text { experimentación animal }\end{array}$ & $\begin{array}{l}\text { liSGM, IISBiodonostia, } \\
\text { IISBiocruces, VHIR, IGTP }\end{array}$ & $\begin{array}{l}\text { Dentro del área de } \\
\text { experimentación } \\
\text { animal }\end{array}$ & $\begin{array}{l}\text { IdiPAZ, i+12, } \\
\text { IRYCIS, IISA, } \\
\text { IISLaFe }\end{array}$ \\
\hline Accesos exteriores & $\begin{array}{l}\text { Independizados los accesos } \\
\text { para animales y personal } \\
\text { investigador }\end{array}$ & $\begin{array}{l}\text { IdiPAZ, i+12, IiSGM, } \\
\text { IRYCIS, IISBiodonostia, } \\
\text { IISBiocruces, IISA, VHIR, } \\
\text { IGTP, IIS La Fe }\end{array}$ & & \\
\hline $\begin{array}{l}\text { Elementos de circulación } \\
\text { vertical }\end{array}$ & $\begin{array}{l}\text { No necesitan ascensores } \\
\text { para el acceso al centro ni } \\
\text { para traslados verticales } \\
\text { internos }\end{array}$ & $\begin{array}{l}\text { i+12, liSGM, IRYCIS, } \\
\text { IISBiodonostia }\end{array}$ & $\begin{array}{l}\text { Si se necesitan } \\
\text { ascensores para el } \\
\text { acceso al centro } \\
\text { Si existes traslados } \\
\text { verticales internos }\end{array}$ & $\begin{array}{l}\text { IdiPAZ, } \\
\text { IISBiocruces, IISA, } \\
\text { IIS La Fe } \\
\text { VHIR, IGTP }\end{array}$ \\
\hline
\end{tabular}

Fuente. Elaboración propia.

\section{Número y tipo de plantas}

En el estudio realizado se observa que la organización de los centros no sigue una directriz única, de manera que, aunque la mayoría de los centros se distribuyen en una única planta, existen varios casos (IdiPAZ, IIS Biocruces, IISA, VHIR) en los que el centro se distribuye en dos plantas, incluso en algún caso en tres (IGTP).

En los casos en los que ha sido necesario realizar una división por plantas, esta división no se ha realizado siguiendo directrices comunes, sino que ocurre más bien lo contrario, que cada centro ha establecido unos criterios propios. De esta manera, podemos destacar cuatro casos de distribución diferentes en función del criterio de división establecido:

1. Un primer caso en el que se prioriza mantener todos los animales estabulados en una misma planta tanto el animal grande como pequeño; $y$, en otra diferente, el área de experimentación de animal grande y pequeño. Este sistema de distribución requiere del traslado de los animales de la 
planta de estabulación a la planta de experimentación, lo que supone un trasiego importante de animales dentro del edificio (IdiPAZ).

2. Un segundo caso en el que el centro se distribuye en dos plantas, de manera que la división se realiza distribuyendo en una planta el área de estabulación y experimentación de animal grande y en otra diferente el área de estabulación y experimentación de animal pequeño. De esta manera se evita tener que compartir áreas para del desarrollo dentro de cada unidad, si bien lo más probable es que el responsable del cuidado y bienestar animal se tenga que desplazar de planta para el desarrollo de su trabajo diario, ya que lo habitual es que sea una única persona la responsable de los animales (IIS Biocruces).

3. Un tercer caso en el que el centro se distribuye en dos plantas de manera que la división se realiza distribuyendo en una planta todo el área de experimentación quirúrgica, tanto la microcirugía con animales pequeños como la cirugía con animales grandes, incluso la zona de estabulación de los animales tanto pequeños como grandes; y en otra planta diferente, el área de experimentación de animal pequeño destinado a otro tipo de investigación diferente a la microcirugía. De esta manera, observamos que existen dos áreas de experimentación de animal pequeño, una para el área de microcirugía que está integrada en el área de estabulación de animal grande y otra área totalmente independiente para el resto de investigación con animal pequeño (IISA).

4. Un cuarto caso en el que el centro se distribuye en tres plantas, de manera que en una planta se distribuye la zona de vestuarios para cambio de ropa del personal investigador; en una segunda planta el área de estabulación y experimentación de animal tanto grande como pequeño; y en una tercera, el área de lavado y esterilización de cajas, así como la zona logística de almacenes (IGTP).

La mayoría de los centros están ubicados en plantas con acceso directo desde el exterior, si bien encontramos algunos casos (IdiPAZ, IISBiocruces, IISA, VHIR, IIS La Fe) en los que bien el centro completo o parte de la instalación se encuentra situada en una planta bajo rasante, por lo que es necesario de hacer uso de elementos de circulación vertical para introducir los animales al centro.

\section{Distribución del área experimentación animal grande y pequeño}

A pesar de que las necesidades y la actividad a desarrollar en el área de experimentación de animal grande son muy diferentes a la del animal pequeño, observamos como en algunos centros no se ha conseguido independizar completamente las dos actividades. De manera que en algunos casos existen salas de experimentación compartidas (IdiPAZ, i+12, IIS Biodonostia, IRYCIS), lo que ha generado que para el correcto funcionamiento del centro se hayan establecido una serie de procedimientos específicos de uso y limpieza de las salas compartidas. En otros casos en cambio (IiSGM, IISA, IIS La 
Fe), las áreas compartidas se reducen a los pasillos de circulación internos y locales para almacenamiento de suministros y residuos.

Aparte de la organización del área de estabulación y experimentación animal en sí, la ubicación del área administrativa dentro del conjunto de la instalación tiene su importancia. Esta área es una zona en la que el personal puede llevar ropa de calle, y suele estar compuesta por una oficina para el responsable de la instalación, así como sala de reuniones, de descanso y de conferencias. Esta zona debería situarse para que sirva de zona de acceso al animalario, de manera que los trabajadores, investigadores y visitantes puedan ser recibidos antes de entrar a las zonas de seguridad de la instalación (Division of technical resources 2016, p. 134). Además, implantar esta área en una zona exterior facilita la posibilidad de proporcionar luz natural a estas zonas de trabajo. Aunque, hay que tener en cuenta que este concepto de distribución no siempre evita la necesidad de considerar alguna zona de trabajo administrativo en el interior de la zona de experimentación (Neil 2003, p. 30).

En cuanto a la ubicación del área administrativa con relación a las áreas de estabulación y experimentación animal, sin bien observamos que en la mayoría de los casos la zona administrativa se encuentra en una zona externa del área de experimentación, de manera que para acceder al área de experimentación es necesario pasar por una zona de vestuarios específicamente diseñada para el cambio de ropa y/o calzas que hacen la función de frontera entre la zona exterior y la zona de experimentación para el personal que va a trabajar en él; existen varios casos (IdiPAZ, i+12, IRYCIS, IISLa Fe) en los que la zona administrativa se encuentra integrada en el área de experimentación animal.

\section{Accesos exteriores}

Ordenar las circulaciones y flujos de trabajo desde el punto de entrada hasta la llegada al centro, es fundamental tanto para poder asegurar la correcta comunicación con las diferentes áreas funcionales como para garantizar la asepsia necesaria en cada área.

En cuanto a los accesos y circulaciones interiores hasta el propio centro de experimentación se refiere, tenemos que tener presente que los centros alojados en edificios existentes tienen unos accesos desde el exterior y circulaciones interiores hasta la entrada del propio centro ya impuestas, sobre los que normalmente es complicado actuar.

Teniendo en cuenta este dato, observamos cómo en ciertos institutos (i+12, liSGM, IRYCIS, IIS Biodonostia), aunque el centro de experimentación se ha distribuido en un edificio existente, se ha conseguido desarrollarlo en una única planta que dispone de acceso directo desde el exterior, de manera que se evita el uso de aparatos elevadores para poder realizar el ingreso de animales, 
suministros y retirada de residuos. En estos casos, observamos como existen dos accesos diferenciados al centro; uno para personal y otro para los animales, suministros y residuos.

En los casos en los que no se ha podido realizar la distribución a nivel de cota cero, la tendencia es que el desarrollo se realice en plantas bajo rasante (IdiPAZ, VHIR, IIS La Fe), aunque observamos varios casos no incluidos en la muestra (IDIBAPS, IDIBELL) en los que el centro de experimentación animal se desarrolla en una última planta del edificio. En estos casos resulta inevitable el uso de elementos de comunicación vertical para poder acceder al centro de experimentación animal, siendo lo habitual que se disponga de un núcleo de ascensores para acceso del personal independiente del diseñado para el acceso de animales, suministro de materiales y la retirada de los residuos.

Entre los centros que se encuentran distribuidos en varias plantas lo habitual es que alguna de ellas se sitúe a nivel de cota cero (IIS Biocruces, IISA, IGTP), mientras que en el resto de los casos, se han ubicado en plantas bajo rasante.

\section{Distribución interior y comunicación vertical interior}

El diseño de las circulaciones interiores definirá los flujos de trabajo en el conjunto del centro de experimentación animal, y, por lo tanto, la interrelación entre las diferentes áreas de experimentación. En función de la organización en plantas realizada, el diseño puede afectar únicamente a los pasillos de distribución interior o también a los elementos de comunicación vertical.

Los centros que están distribuidos en varias plantas (IdiPAZ, IIS Biocruces, IISA, VHIR, IGTP) o las ubicada en plantas bajo rasante (IIS La Fe) necesitan inevitablemente elementos de circulación vertical interior. Observamos como en ocasiones, esta comunicación vertical puede ser solo necesaria para poder introducir los animales, los suministros, así como para retirar los residuos (IIS Biocruces, IISA, IIS La Fe).

En el caso concreto de IIS Biocruces, como hemos comentado anteriormente, la distribución por plantas se ha realizado distribuyendo en una planta el área de experimentación de animal grande, y en otra diferente, el área de experimentación de animal pequeño. De esta manera, una vez recepcionados los animales en cada área de estabulación, la experimentación se realizará en esa misma planta; y, por lo tanto, solo el personal al cuidado de los animales y los investigadores tienen que desplazarse de planta haciendo uso de los ascensores diseñados para el personal del conjunto edificatorio. En este caso concreto, existe un solo montacargas que sirve para acceder al animalario ubicado en planta sótano -2 por el que circulan tanto los animales, como los suministros y residuos. Además, este montacargas también lo utilizan el resto de plataformas del instituto para el traslado de equipamiento voluminoso. 
En el instituto IISA ocurre algo similar, ya que la distribución del centro en dos plantas se ha realizado de forma que la actividad en cada una de ellas es totalmente independiente. En la planta semisótano se distribuye el área de cirugía y microcirugía experimental; y en la planta sótano -1, el área de experimentación de animal pequeño. De esta manera, una vez que los animales ingresan en la zona de experimentación, no es necesario volver a trasladarlos verticalmente.

Por otra parte, en el caso del IIS La Fe, al estar distribuido el centro de experimentación animal en una planta bajo rasante, se ha diseñado un elevador para uso exclusivo del animalario, tanto para el suministro de animales, de materiales y la retirada de residuos.

En estos tres casos mencionados, el personal utiliza otros elevadores independientes y destinados únicamente para uso del personal, tanto del animalario como del resto de plataformas del instituto.

Entre los centros distribuidos en dos plantas diferentes se encuentran el IdiPAZ y el VHIR. En ambos casos las dos plantas se encuentran ubicadas en plantas bajo rasantes, por lo que es necesario hacer uso de los elementos de comunicación vertical para el acceso de los animales, suministros y residuos. Además, en el caso concreto del IdiPAZ, el área de estabulación se distribuye en una planta diferente al de la experimentación animal, lo que conlleva un traslado vertical interno de los animales desde el área de estabulación al área de experimentación. En este caso se ha instalado un montacargas para uso del animalario, mientras que el personal del animalario, hace uso de un ascensor independiente y destinado al personal del instituto.

Por otra parte, en el caso del VHIR, aunque la organización del área de experimentación de animal pequeño en dos plantas se ha intentado realizar de manera que no sea necesario tener que trasladar los animales de planta una vez ingresados los animales en el centro, el área de imagen inevitablemente se ha tenido que distribuir en dos plantas, para lo que se ha diseñado un aparato elevador para uso exclusivo de esta zona. Aunque lo habitual es que el personal disponga de elementos de circulación vertical independientes al de los animales, en este caso, existe un único montacargas compartido para uso tanto del personal, como de los animales, suministros y retirada de residuos.

Otro caso en el que es necesario el uso de elementos de comunicación vertical es el IGTP, ya que el desarrollo del centro de experimentación se realiza en tres plantas diferentes. Observamos como para ello se disponen de dos elementos de comunicación vertical, que en principio están diseñados uno para uso del personal, y otro para el traslado de material sucio y limpio desde el centro de experimentación a la planta de lavado y esterilización. En este caso, los animales acceden 
directamente a la planta de estabulación y experimentación, por lo que no es necesario trasladar verticalmente ni los animales, ni los suministros.

Analizados los centros en los que es necesario hacer uso de elementos de circulación vertical para el desarrollo de la actividad investigadora, observamos como lo habitual es que se diseñe un único elemento específico destinado al transporte de animales, material limpio y residuos; $y$, por lo tanto, que no se realice ninguna segregación para la circulación del material limpio y sucio. Además, en ocasiones, estos montacargas no son elementos de uso exclusivo para el área de experimentación animal, sino que este elemento es utilizado también para el transporte de elementos voluminosos a otras plataformas del instituto de investigación. El personal en cambio, normalmente utiliza otros elevadores independientes y destinados únicamente para uso del personal, tanto del animalario como del resto de plataformas del instituto.

Es muy importante analizar detenidamente el dimensionamiento del montacargas a instalar en la fase de obra, ya que tiene que estar diseñado acorde al equipamiento que va a tener que trasladar, y por lo tanto es fundamental conocer el dimensionamiento de los carros de transporte de animales, de las jaulas, de los palets y del equipamiento voluminoso en general, ya que se han observado varios casos en el que el equipamiento comprado presentaba dificultades para poder introducirlo en el montacargas instalado en el edifico. 


\subsubsection{Síntesis de la organización y diseño del centro de experimentación animal}

En este tipo de institutos lo habitual es que la unidad de animalario y experimentación animal, sea una de las plataformas críticas en cuanto a exigencias de calidad de aire, y que, por lo tanto, condicione la organización del Instituto de Investigación Aanitaria. En función de la investigación que se quiera llevar a cabo, existen dos unidades concretas de ambiente controlado con altas exigencias climáticas como son, el área de estabulación de animales pequeños y el área quirúrgica experimental. Esta circunstancia conlleva que las exigencias del centro de experimentación acaben estableciendo una serie de condicionantes muy importantes para su ubicación dentro de la propia edificación, y en consecuencia, en la organización del Instituto de Investigación Sanitaria.

En el presente estudio hemos visto que el análisis de las necesidades generales del centro de experimentación animal, junto con las necesidades globales del resto de plataformas que conforman el instituto de investigación, han determinado la ubicación del centro en el conjunto edificatorio, que no siempre ha tenido el beneplácito de los usuarios finales o del propio equipo responsable del diseño. Como hemos visto, lo habitual es que estos centros estén situados en una planta con acceso directo desde el exterior ya que evita el traslado de animales por el interior del edificio, y por consiguiente molestias de ruidos y olores al resto de usuarios del instituto, aunque no siempre ha sido posible.

El resultado de la investigación muestra que cada instituto, y específicamente el centro de experimentación animal ha sido diseñado en función de las líneas y proyectos de investigación de cada centro, así como por ciertos factores impuestos que varían en función de si se trata de un centro ubicado en un edificio de nueva construcción o un edificio existente. En este sentido, aunque el diseño de la instalación en un nuevo edificio permite tener la oportunidad de organizar desde el origen el diseño de los accesos y circulaciones interiores tanto para el personal investigador y al cuidado de los animales, como para los animales, suministros y residuos; la realidad es que, en la mayoría de los casos, los centros se han tenido que distribuir en edificaciones existentes.

A pesar de todo, en ambos casos existen una serie de limitaciones impuestas que en el caso de las nuevas edificaciones están relacionadas con la disponibilidad de suelo, de la orografía del terreno, de las circunstancias urbanísticas y de las afecciones al entorno, entre otros; mientras que las limitaciones en las edificaciones existentes tienen que ver con la necesidad de confinar el centro en una planta y volumetría, con unos accesos principales y circulaciones interiores ya predeterminados. Además, en ambos casos, uno de los condicionantes comunes ha tenido que ver con la asignación presupuestaria disponible para la construcción del instituto y/o centro de experimentación. 
En las ocasiones en las que la organización de las diferentes áreas no ha sido posible realizarla tal y como hubiera sido deseable para el equipo de diseño ni tampoco desde el punto de vista de los propios responsables del animalario, para conseguir un adecuado funcionamiento del centro ha sido necesario complementarlo con procedimientos de trabajo específicos.

Debido al dimensionamiento de este tipo de instalaciones en los que lo habitual es que los centros tengan una superficie comprendida entre los 750 y $1.500 \mathrm{~m}^{2}$, lo normal es que exista una única persona responsable del cuidado y bienestar animal tanto para los animales grandes como para los pequeños. Es por ello que normalmente la instalación completa se desarrolla en un mismo edificio. Por otra parte, aunque lo deseable sería poder distribuir todo el centro de experimentación animal en una misma planta con el fin de evitar el traslado interior vertical tanto de los animales como de los responsables al cuidado de ellos, la realidad es que no en todos los casos se ha conseguido.

Teniendo en cuenta el análisis de la organización realizada, en base al número de edificio y número de plantas en los que se ha distribuido el centro, así como el tipo de división realizado, se pueden establecer seis tipologías de organización de los centros analizados:

1. Una primera tipología en el que el centro se ha distribuido en diferentes edificios. Si bien en uno de los edificios la experimentación se realiza únicamente con animal pequeño, en otro de los edificios, se experimenta tanto con animal grande como con pequeño.

2. Una segunda tipología en el que el centro se ha distribuido en un único edificio y en una misma planta.

3. Una tercera tipología en la que el centro se distribuye en dos plantas de manera que la división se realiza distribuyendo en una planta toda el área de estabulación de animal grande y pequeño, y en otra diferente el área de experimentación de animal grande y pequeño.

4. Una cuarta tipología en la que el centro se distribuye en dos plantas, de manera que la división se realiza distribuyendo en una planta el área de estabulación y experimentación de animal grande y en otra diferente el área de estabulación y experimentación de animal pequeño.

5. Una quinta tipología en la que el centro se distribuye en dos plantas de manera que la división se realiza distribuyendo en una planta todo el área de experimentación quirúrgica, tanto la microcirugía como la cirugía con animales grandes, incluso la zona de estabulación de los animales tanto pequeños como grandes; y en otra planta diferente, el área de experimentación de animal pequeño.

6. Una sexta tipología en la que el centro se distribuye en tres plantas; en una primera planta se distribuye la zona de vestuarios y cambio de personal; en una segunda planta se desarrolla el área de estabulación y experimentación de animal tanto grande como pequeño; y, en una tercera planta el área de lavado y esterilización de cajas, así como la zona logística de almacenes. 
La mayoría de los centros se han distribuido en una única planta, aunque no siempre se ha conseguido independizar las áreas de experimentación de animal grande del pequeño, siendo habitual que los pasillos de circulación y los locales de servicio sean compartidos en ambas actividades. En algunos casos concretos, incluso se comparten también salas de experimentación, por lo que ha sido necesario establecer procedimientos de trabajo específicos para el desarrollo de la actividad.

En todos los casos se han planteado varios accesos al edificio para poder diferenciar las circulaciones de las personas de los animales, suministros y residuos. Además, esta política de segregación es la que se ha mantenido en casi todos los casos para plantear y distribuir los núcleos de comunicación vertical interior para el uso y funcionamiento del centro.

Los centros que están situados en una planta sin acceso directo exterior, o que se encuentran divididas en varias plantas, necesitan de un núcleo de comunicación vertical para su funcionamiento. Aunque la situación ideal en estos casos sería disponer unos elementos independientes y propios del centro de experimentación para el transporte de animales, material limpio, retirada de residuos y del personal, en especial cuando la distribución del centro requiera el traslado interior de los animales de la zona de estabulación al área de experimentación; la realidad es que normalmente solo se dispone de un único montacargas para el traslado de los animales, suministros y residuos, sin realizar ningún tipo de segregación del material limpio del sucio, y que su uso sea compartido con otras plataformas de experimentación del instituto. En cambio, el personal habitualmente utiliza otros elevadores independientes y destinados únicamente para uso del personal, tanto del animalario como del resto de plataformas del instituto.

Entre los responsables de las instalaciones visitadas existen discrepancias de opiniones en cuanto al tipo de división más adecuado, para el caso de tener que distribuir el centro en varias plantas. Desde el punto de vista de los responsables del bienestar animal, teniendo en cuenta que debido al dimensionamiento de este tipo de centros estos profesionales tienen que hacerse cargo tanto de los pequeños como de los grandes animales, tener alojados todas las especies animales en la misma planta evita su traslado vertical interior, aunque esta situación puede obligar a tener que trasladar de planta tanto los animales grandes como los pequeños. El criterio de otros usuarios, en cambio, para elegir un tipo u otro de distribución está condicionado por la ubicación del área de lavado y esterilización dentro de centro de experimentación, ya que la ubicación de esta unidad en la misma planta que la estabulación de animales se considera crítica para el funcionamiento del área de experimentación de animal pequeño. En cuanto a la ubicación del área administrativa, todos los usuarios coincidían en que era positivo instalarlo cerca del área de experimentación animal, pero en el exterior en una zona con luz natural. 


\subsection{Organización y diseño del área de experimentación animal grande}

El área de experimentación de animal grande está fundamentalmente enfocado a la actividad mayoritaria que en él se desarrolla: la cirugía experimental. Este servicio habitualmente se diseña para prestar apoyo en los procedimientos quirúrgicos necesarios para la investigación y proveer tanto del material como de las técnicas quirúrgicas necesarias para la formación de los profesionales del sistema sanitario en cualquiera de las especialidades quirúrgicas y medico quirúrgicas. Desde el ámbito docente, tiene como objetivo organizar y dar soporte a la realización de cursos de formación en técnicas quirúrgicas, microquirúrgicas, laparoscópicas, anestésicas, entre otros. Para la realización de esas prácticas quirúrgicas resulta necesario disponer de modelos animales que se asemejen a la fisiología humana.

El estudio de la organización y diseño del área de experimentación de animal grande se ha dividido teniendo en cuenta; por una parte, la organización general e interrelación de las principales unidades funcionales que lo componen; $y$, por otra, haciendo un análisis pormenorizado de las características y organización de las unidades más importantes del área: la unidad de estabulación de animal grande y la unidad de cirugía experimental. Como veremos durante el análisis, aunque existen otras unidades de experimentación dentro del área de experimentación de animal grande, este estudio se ha centrado específicamente en las dos unidades mencionadas, por ser la actividad quirúrgica la actividad principal del área y la unidad de estabulación fundamental para su desarrollo. 


\subsection{1. Área de experimentación animal grande}

El área de experimentación de animal grande es una zona específica dentro del centro de experimentación animal destinada a la investigación con los animales que por su tamaño se consideran grandes como son el cerdo, la oveja y la cabra entre otros.

El objetivo de este apartado es analizar el contexto global de la complejidad del área de experimentación de animal grande. Se trata de analizar cómo se ha organizado esta área en cada uno de los institutos investigados, estudiando primeramente las diferentes unidades que lo componen y los condicionantes generales de su organización, para a continuación, a partir de las representaciones gráficas estandarizadas de los diferentes institutos, realizar un análisis y puesta en común de las diferentes soluciones planteadas.

\subsubsection{Unidades que componen el área de experimentación de animal grande}

El diseño de las instalaciones y su complejidad dependerá del tamaño de la instalación, de las líneas de investigación, así como del número y especies animales con los que se va a experimentar, que serán los que definan la composición definitiva del área. Las principales unidades que componen el área de experimentación animal grande son las siguientes:
a) Unidad de estabulación de animal grande
b) Unidad quirúrgica experimental
c) Unidad de diagnóstico por imagen
d) Zona de vestuario, aseo y duchas
e) Zona administrativa

a) Unidad de estabulación de animal grande. Compuesta por los locales de alojamiento que son los locales donde van a vivir normalmente los animales con los que se va a experimentar y las áreas de servicio necesarias para garantizar el cuidado y bienestar animal, así como las condiciones de trabajo y seguridad del personal. Estas áreas de servicio se corresponden fundamentalmente con los locales necesarios para dotarlos de los suministros básicos y de las instalaciones necesarias para garantizar un buen entorno y calidad de vida.

b) Unidad quirúrgica experimental. Es una zona diseñada para prestar apoyo en los procedimientos quirúrgicos necesarios para la investigación y proveer tanto del material como de las técnicas quirúrgicas necesarias para la formación de los profesionales del sistema sanitario en cualquiera de las especialidades quirúrgicas y medico quirúrgicas. Además, entre las funciones que normalmente ofrece está el cuidado de los animales sometidos a intervenciones quirúrgicas tanto en el periodo preoperatorio como en el postoperatorio. La mayoría de los programas quirúrgicos contemplan las áreas compuestas por los quirófanos y las zonas de apoyo quirúrgico 
necesarios para el desarrollo de la actividad como son: el área de preparación médica, la zona de preparación de animales, los almacenes de material y equipos y el área de lavado y esterilización.

c) Unidad de diagnóstico por imagen. Compuesta por las salas de imagen avanzadas entre las que se encuentran la resonancia magnética de imagen (RMI), la tomografía por emisión de positrones (PET), la tomografía computarizada (TC) y fluoroscopia entre otros, siendo una unidad que se está convirtiendo en crítica en la investigación animal. Este tipo de instalaciones tienen los mismos criterios de diseño que para las instalaciones de humanos, a excepción del tamaño, que a menudo suelen ser menores. A la hora de diseñar este tipo de instalaciones es necesario tener en cuenta consideraciones tales como la necesidad de aislarla de toda fuente de vibración para garantizar la estabilidad a las mismas, así como aislarlo de las fuentes de interferencias, ya que por ejemplo, para el caso concreto de la RMI debe considerarse el aislamiento de las fuentes de grandes objetos metálicos en movimiento. Por otra parte, hay que tener en cuenta que son equipos pesados, por lo que la estructura del edificio debe ser capaz de soportarlos, y que además, suelen requerir protecciones radiológicas, así como considerar zonas de seguridad de exclusión de personas para evitar campos magnéticos.

d) Zona de vestuario, aseo y duchas. Considerada como zona de frontera situada a la entrada del animalario y destinada a realizar un cambio de ropa para reducir el riesgo de la introducción de agentes en las zonas de experimentación, así como para facilitar y propiciar la higiene personal de los trabajadores, además de poder garantizar las condiciones de seguridad de los trabajadores del centro de experimentación.

e) Zona administrativa. Destinada al desarrollo de los trabajos administrativos, para realizar reuniones así como centro de información para el personal, en el que poder incluir libros, revistas, boletines informativos y catálogos, entre otros, incluso para que los trabajadores puedan tomar su descanso. 


\subsubsection{Condicionantes de organización del área de experimentación animal grande}

El diseño de las instalaciones deberá contemplar la especie a ser operada, así como la complejidad de los procedimientos que se realizarán, teniendo en cuenta que la instalación será más grande y más compleja en función del número y tamaño de los animales o del aumento de la complejidad de los procedimientos (National Research Council 2011, p. 144).

Para comprender la complejidad de la organización y los flujos de trabajo de esta área tomamos como referencia el esquema a continuación reflejado (Figura 37). En él observamos cómo todo se desarrolla en torno a la zona de experimentación animal, que consta de dos unidades específicas: la unidad de estabulación y la unidad de experimentación de animal grande y que habitualmente comprende el área quirúrgica y el área de diagnóstico por imagen. Atendiendo a los accesos principales, se observan dos accesos diferenciados: uno para el personal responsable del cuidado y bienestar de los animales y del personal investigador; $y$, otro diferente para introducir los animales y los suministros y retirar los residuos generados. Ambas circulaciones disponen de un vestíbulo previo de entrada al área de experimentación animal que hace la función de frontera. También quedan identificados los flujos de trabajo del área, de manera que en azul se refleja la circulación del personal, en rojo la de los animales, en verde de trazo continuo la de los suministros, y en verde de trazo discontinuo la de los residuos.

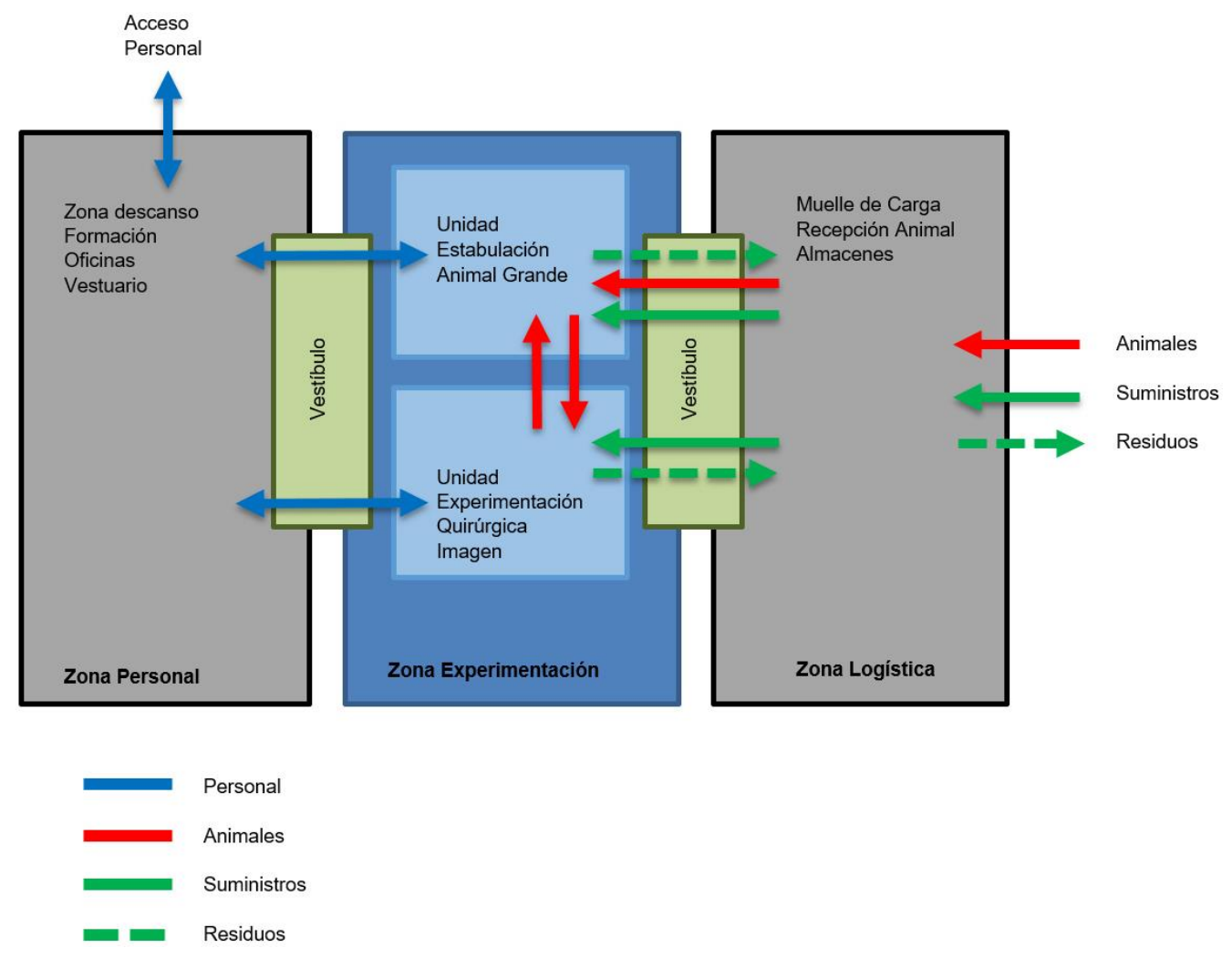

Figura 37. Diagrama de flujos del área de experimentación animal grande. Fuente. Elaboración propia. 


\section{Condicionantes de organización de la unidad de estabulación de animal grande}

La unidad de estabulación de animal grande la componen fundamentalmente los locales de alojamiento donde van a vivir los animales con los que se va a experimentar y las áreas de servicio necesarias para garantizar el cuidado y bienestar animal, así como las condiciones de trabajo y seguridad del personal.

En general, las zonas de estabulación de animal grande deben diseñarse y gestionarse con vistas a evitar el acceso de personas no autorizadas y la entrada o la huida de animales, garantizando una circulación ordenada para el personal al cuidado de los animales, para el suministro de material limpio, para el desplazamiento de los animales al área quirúrgica, así como para la retirada de residuos y teniendo presente el concepto de asepsia progresiva. Atendiendo a la comunicación de la unidad de estabulación de animal grande con otras áreas funcionales con las que tiene relación, a la hora de implantar esta unidad en el conjunto edificatorio deberían tenerse en cuenta los siguientes considerandos (Figura 38):

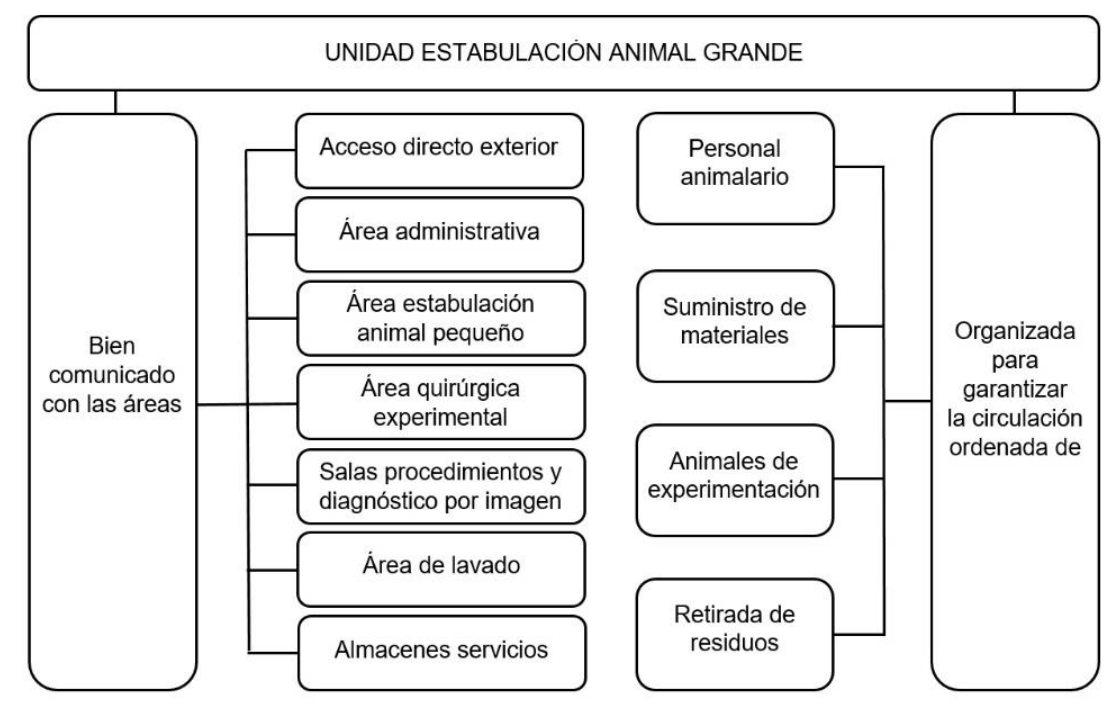

Figura 38. Esquema de relaciones de la unidad de estabulación de animal grande. Fuente. Elaboración propia.

- El suministro de animales al centro va a ser habitual, y estos animales, que son bastante ruidosos, hay que trasladarlos hasta la zona de estabulación. Es por ello que conviene, en la medida de lo posible, para evitar molestias al resto de los usuarios del instituto, que la zona de estabulación de animales grandes esté situado en una planta con acceso directo al exterior y lo más cercano a este acceso.

- Los animales recepcionados en el centro requieren de unos trámites administrativos que deben ser gestionados por el personal del animalario, por lo que la zona administrativa, 
aunque es deseable que se sitúe en una zona periférica de la instalación, es recomendable que esté bien comunicada con la zona de estabulación de animal grande.

Dado que es habitual que los profesionales responsables de garantizar los cuidados y bienestar animal sean los mismos para la zona de estabulación de animal pequeño y grande, conviene que las dos zonas estén, en la medida de lo posible, cerca, bien comunicados, pero a su vez separados, con el fin de garantizar la asepsia necesaria en cada caso e incluso para evitar las molestias de ruido que pudieran ocasionar los animales grandes a los pequeños.

Hay que tener en cuenta que la finalidad fundamental de estos animales grandes es realizar prácticas quirúrgicas, por lo que conviene que el área quirúrgica, así como otras zonas de experimentación con animal grande, como pueden ser las salas de diagnóstico por imagen, estén situados cerca del área de estabulación de animal grande, con el fin de reducir las circulaciones interiores y, en consecuencia, la posibilidad de contaminación en otras áreas del centro.

Las áreas de servicio necesarias para garantizar los suministros básicos de los animales, como son los almacenes para el material limpio y equipos, conviene que se sitúen en una zona cercana a la estabulación de animales.

Los animales grandes son animales muy sucios y se requiere de una limpieza habitual de los equipos necesarios para el desarrollo de la actividad, por lo que es necesario disponer de una buena comunicación entre la sala de estabulación y la sala de lavado.

\section{Condicionantes de organización de la unidad quirúrgica experimental}

La actividad mayoritaria del área de experimentación de animal grande es la cirugía experimental. Para analizar la complejidad de la organización de esta unidad hemos tomado como referencia el esquema del Canadian Council on Animal Care (Figura 39), que refleja los locales que la componen, así como las relaciones entre ellos. Cada tipo de trazado de línea que los une establece una prioridad diferente que varía desde lo fundamental, a lo altamente recomendado o simplemente recomendado para conseguir la asepsia necesaria en cada una de las zonas. De esta manera, observamos que los animales son trasladados desde la zona de estabulación a una zona de realización de pruebas o a la zona de preparación animal para a continuación trasladarlos al quirófano. Una vez realizada la práctica quirúrgica, los animales pueden ser trasladados a una zona de recuperación animal para a posteriori trasladarlos al área de estabulación o en caso de que sean terminales, ser trasladados a una zona de almacenaje de residuos animales para su recogida por parte del gestor autorizado. Por otra parte, nos muestra cómo el personal médico accede directamente al quirófano previo paso por la zona de 
vestuarios y zona de lavado. Para el correcto funcionamiento de la unidad quirúrgica, además, se recomienda disponer de locales de servicio como son los locales de almacenaje varios y los laboratorios de apoyo.

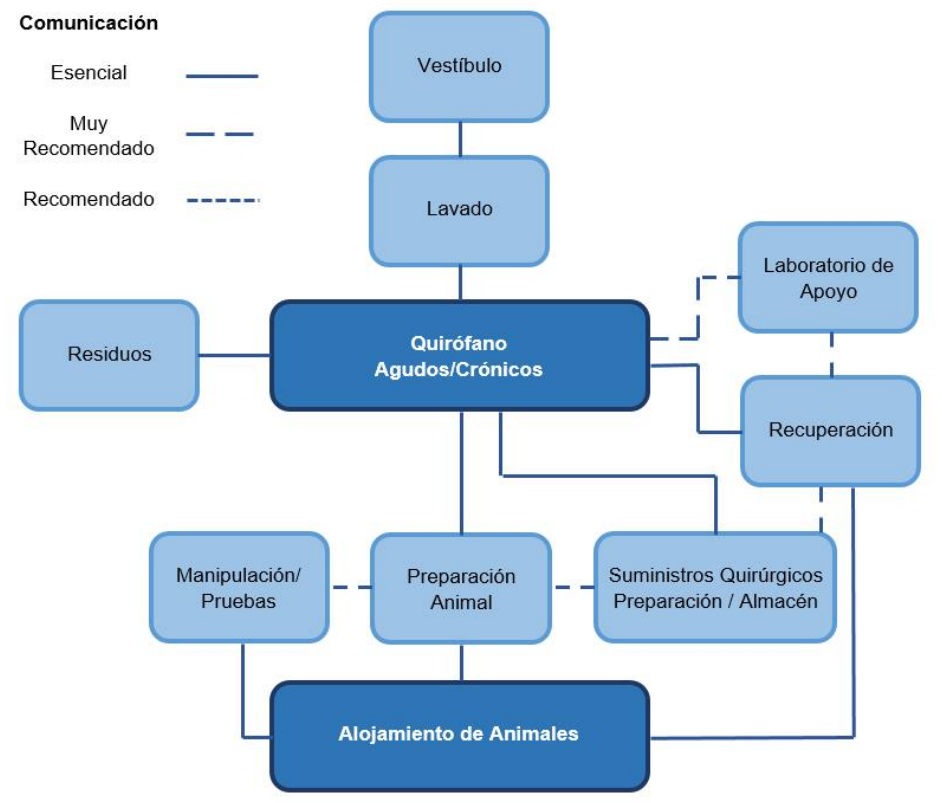

Figura 39. Esquema organizativo área experimentación animal reelaborado.

Fuente. Neil 2003, pag 41.

En lo referente a la comunicación del área quirúrgica con otras áreas funcionales, si bien el área quirúrgica hospitalaria tiene que tener una buena comunicación con las unidades asistenciales tales como las urgencias, la unidad de cuidados intensivos y la hospitalización entre otros, además de los servicios necesarios para el desarrollo de la actividad, el área quirúrgica experimental tendrá que estar bien comunicado con el área de estabulación de animal grande, sala de recuperación postoperatoria, el área de lavado y esterilización, así como con el área de servicios logísticos para almacenamiento de equipos, material limpio y residuos (Figura 40).

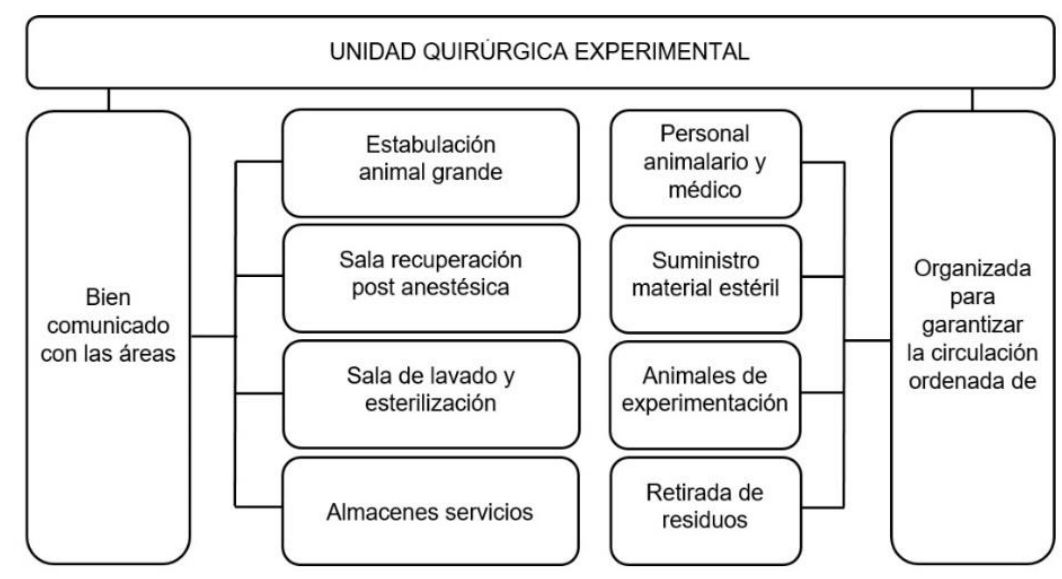

Figura 40. Esquema de relaciones de la unidad quirúrgica.

Fuente. Elaboración propia. 
Además, los locales deberán estar organizados de tal manera que se garantice una circulación ordenada para el personal médico, el suministro de material estéril, el desplazamiento de los animales hasta el área quirúrgica, así como la retirada de residuos siguiendo el concepto de asepsia progresiva. Es por ello que, en cuanto a la implantación del área de cirugía experimental en el conjunto edificatorio en el que se aloje, se deberían considerar los siguientes conceptos:

- El bloque quirúrgico debe estar lo suficientemente independizado de otras áreas para reducir al mínimo la posibilidad de contaminación. A su vez, debe ser fácilmente accesible para el personal que trabajará en la sala de operaciones.

- La sala quirúrgica debe estar ubicada de manera que los animales puedan ser trasladados fácilmente y realizando el mínimo recorrido posible desde los locales de alojamiento al quirófano, con el fin de minimizar la posibilidad de transmisión de enfermedades (Neil 2003, p. 41).

- Las áreas de apoyo también deben estar diseñadas para minimizar el flujo de tráfico y separar las no relacionadas con la actividad de la sala de operaciones. Aunque la separación se logra mejor mediante barreras físicas, también puede lograrse por la distancia entre las zonas o, dado el caso, mediante la programación de la limpieza y desinfección entre las diferentes actividades (National Research Council 2011, p. 144).

- El material quirúrgico reutilizable se debe lavar y esterilizar, por lo que conviene que exista una buena comunicación entre el quirófano y el área de lavado y esterilización. 


\subsubsection{Representaciones gráficas de la distribución del área de experimentación animal grande}

A partir de los planos en planta estandarizados que se han desarrollado de cada uno de los centros de experimentación animal, y que se encuentran recogidos en las fichas de toma de datos, se ha seleccionado exclusivamente el área destinada a la experimentación de animal grande. Con estas representaciones gráficas se pretende tener una visión específica de su configuración y de las distintas circulaciones diseñadas (Figuras: 41-51).

Para facilitar el estudio, en los planos de distribución en planta se ha identificado por código de colores el área funcional al que pertenece y por código numérico el tipo de local que es. Los puntos de acceso quedan identificados por flechas de color rojo y, además, para localizar fácilmente la ubicación de los quirófanos, se ha incluido la simbología que representa la mesa quirúrgica. Por otra parte, con el fin de realizar una lectura sencilla de las diferentes circulaciones, también se reflejan los flujos de trabajo planteados para el personal que se representa mediante línea continua de color azul; para el suministro de animales, mediante línea continua de color rojo; para el suministro de materiales, con línea continua color verde; incluso para la retirada de residuos, con línea de trazos color verde. Además, también se representa el sentido de los flujos de trabajo mediante las flechas dibujadas junto a cada línea. Por último, junto a cada una de las representaciones gráficas se hace una breve descripción de la configuración del área de experimentación de animal grande.

ÁREAS FUNCIONALES

Experimentación animal pequeño
Experimentación animal grande
Áreas comunes animal pequeño y grande
Área Administrativa
Pasillos comunes
Pasillos exteriores y servicios generales
Elementos de circulación vertical

IDENTIFICACIÓN USO LOCALES

$\begin{array}{ll}01 \text { Recepción animal } & 17 \text { Quirófano experimental } \\ 02 \text { Estabulación convencional roedores } & 18 \text { Preparación médica } \\ 03 \text { Estabulación convencional conejos } & 19 \text { A. material estéril } \\ 04 \text { Estabulación convencional animal grande } & 20 \text { Necropsias } \\ 05 \text { Cuarentena roedores } & 21 \text { Cirugía cadáveres } \\ 06 \text { Cuarentena conejos } & 22 \text { Lavado y esterilización } \\ 07 \text { Cuarentena animal grande } & 23 \text { Vestuarios / Aseos } \\ 08 \text { Estabulación barrera animal pequeño } & 24 \text { Esclusa animales } \\ 09 \text { Experimentación ABSL2 - 09* ABSL3 } & 25 \text { Esclusa personas } \\ \text { 10 Experimentación peces } & 26 \text { Esclusa materiales } \\ \text { 11 Lavado animal } & 27 \text { Almacén / archivo } \\ \text { 12 Preparación animal } & 28 \text { Servicios } \\ \text { 13 Procedimientos } & 29 \text { Despacho } \\ \text { 14 Microcirugía } & 30 \text { Sala reuniones } \\ 15 \text { Comportamiento } & 31 \text { Pasillo } \\ 16 \text { Imagen } & 32 \text { Otros }\end{array}$

ACCESOSY CIRCULACIONES

$\Rightarrow$ Acceso

- Personal

- Animales

- Suministro materiales

- - - Retirada de residuos

Figura 41. Leyenda área experimentación animal grande.

Fuente. Elaboración propia.

*Esta leyenda se hace extensible a las figuras 42-51. 
El área de experimentación de animal grande del instituto IdiPAZ (Figura 42) se desarrolla en dos plantas bajo rasante en las que no existe acceso directo desde el exterior. Para acceder a las diferentes plantas, por una parte, existe un montacargas para el suministro de animales, materiales y retirada de residuos; $y$, por otra, un ascensor para el personal investigador y responsables del bienestar animal. En la denominada planta sótano -2 se desarrolla el área de estabulación de animal grande junto al área de estabulación de animal pequeño; y en planta sótano -1 se distribuyen las zonas de experimentación de animal grande, tales como el área quirúrgica y el área de experimentación con cadáveres, de manera que en ambas plantas se comparten pasillos de circulación y locales de servicio.

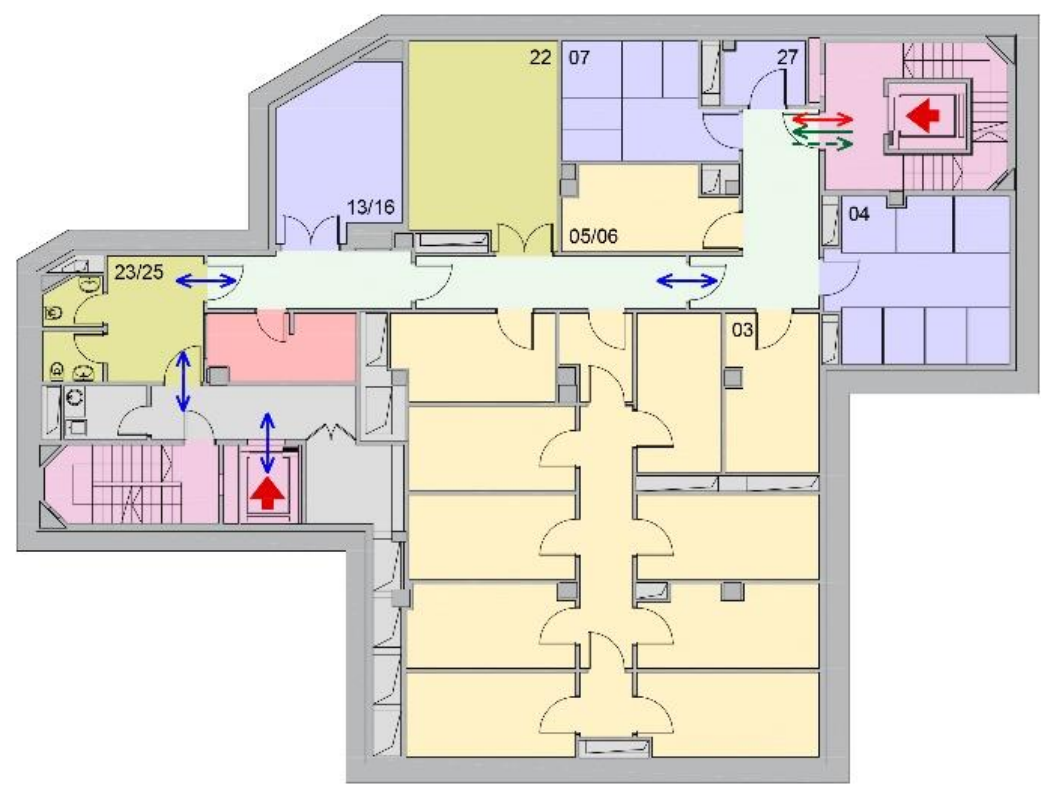

Planta sótano -2

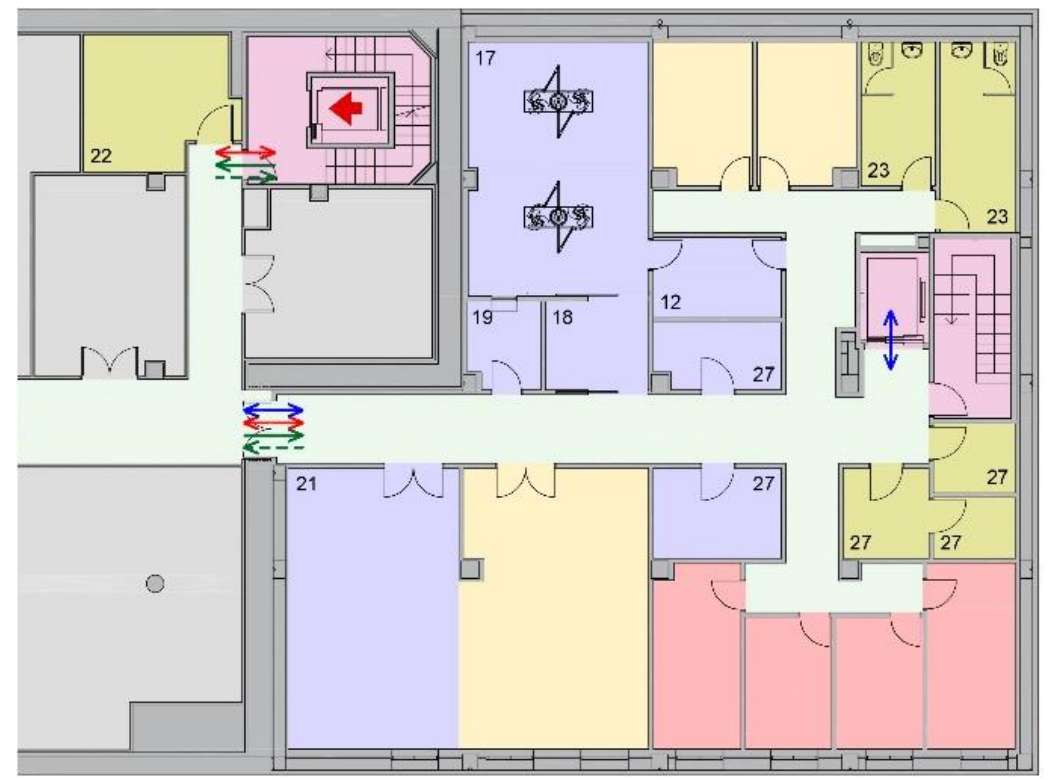

Planta sótano -1

Figura 42. Área experimentación animal grande IdiPAZ (S/E).

Fuente. Elaboración propia. 
El área de experimentación de animal grande del instituto i+12 (Figura 43) se configura en una única planta con dos accesos directos desde el exterior en el que se segregan los accesos para el personal del de los animales, el suministro de materiales y la retirada de residuos. El área no se desarrolla como una entidad independiente, sino que se integra en el conjunto del centro de experimentación animal grande junto con el área de experimentación de animal pequeño. De esta manera, las zonas de circulación interior para el personal, los animales, los suministros y residuos, así como algunos locales de servicio entre los que se encuentran los vestuarios, son comunes a ambas áreas de experimentación.

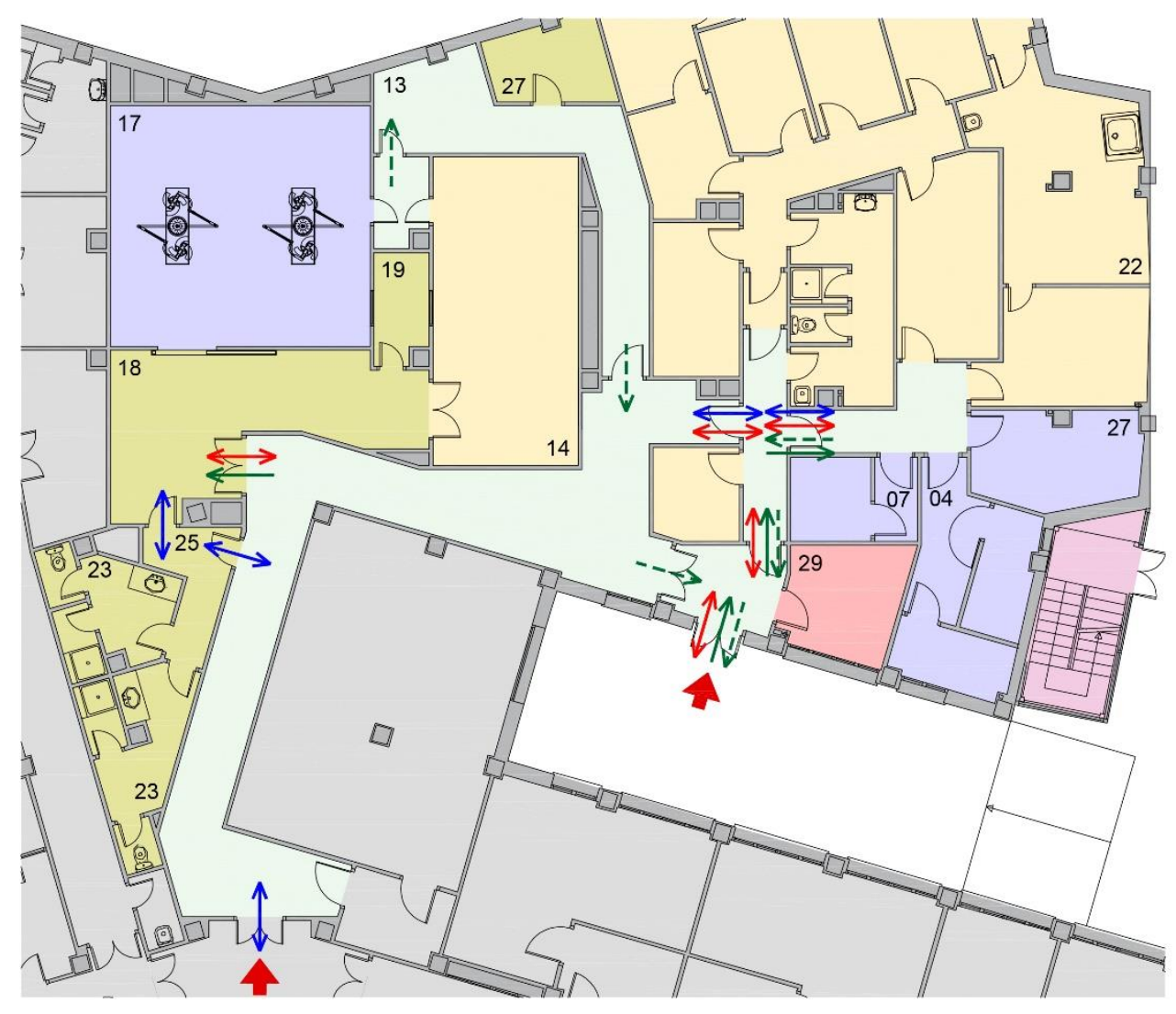

ÁREAS FUNCIONALES

Experimentación animal pequeño
Experimentación animal grande
Áreas comunes animal pequeño y grande
Área Administrativa
Pasillos comunes
Pasillos exteriores y servicios generales
Elementos de circulación vertical

IDENTIFICACIÓN USO LOCALES

01 Recepción animal
02 Estabulación convencional roedores
03 Estabulación convencional conejos
04 Estabulación convencional animal gran
05 Cuarentena roedores
06 Cuarentena conejos
07 Cuarentena animal grande
08 Estabulación barrera animal pequeño
09 Experimentación ABSL2 - 09* ABSL3
10 Experimentación peces
11 Lavado animal
12 Preparación animal
13 Procedimientos
14 Microcirugia
15 Comportamiento
16 Imagen

17 Quirófano experimental 18 Preparación médica 19 A. material estéril 21 Cirugía cadáveres 22 Lavado y esterilización 23 Vestuarios / Aseos 24 Esclusa animales 25 Esclusa personas 26 Esclusa materiales 27 Almacén / archivo 28 Servicios 29 Despacho 30 Sala reuniones 31 Pasillo 32 Otros

Figura 43. Área experimentación animal grande i+12 (S/E). Fuente. Elaboración propia. 
El área de experimentación de animal grande del instituto liSGM (Figura 44) se distribuye en una única planta con acceso directo desde el exterior, de manera que los accesos para el personal están separados de las de suministro de animales, de materiales y de la retirada de residuos. Esta área se integra en la misma planta que el área de experimentación de animal pequeño, de manera que comparten pasillos de distribución interior y locales de servicios varios.

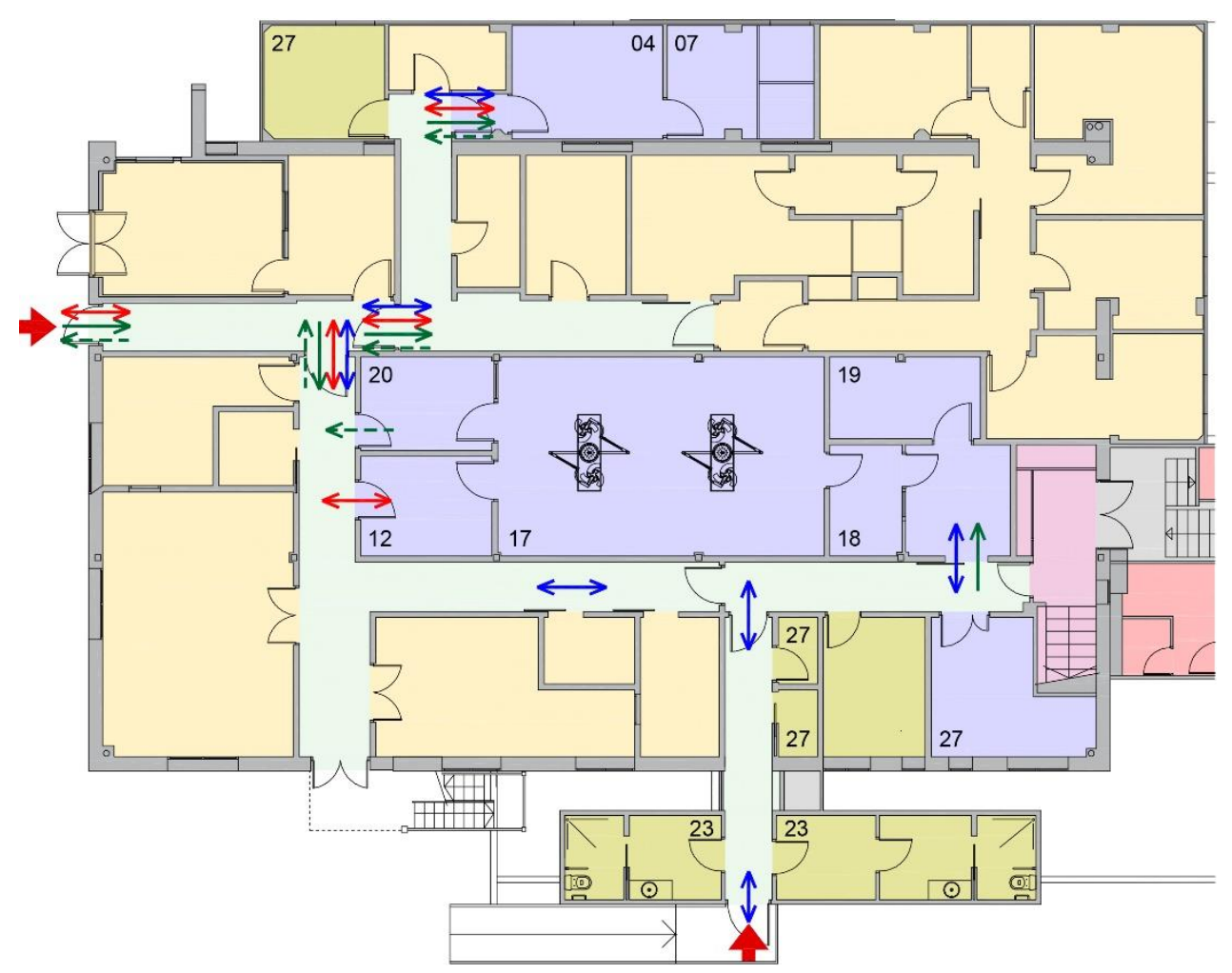

ÁREAS FUNCIONALES

Experimentación animal pequeño
Experimentación animal grande
Áreas comunes animal pequeño y grande
Área Administrativa
Pasillos comunes
Pasillos exteriores y servicios generales
Elementos de circulación vertical

IDENTIFICACIÓN USO LOCALES

01 Recepción animal
02 Estabulación convencional roedores
03 Estabulación convencional conejos
04 Estabulación convencional animal grande
05 Cuarentena roedores
06 Cuarentena conejos
07 Cuarentena animal grande
08 Estabulación barrera animal pequeño
09 Experimentación ABSL2 $-09^{\star} A B S L 3$
10 Experimentación peces
11 Lavado animal
12 Preparación animal
13 Procedimientos
14 Microcirugia
15 Comportamiento
16 Imagen

17 Quirófano experimenta 18 Preparación médica 19 A. material estéril 21 Cirugia cadáveres 22 Lavado y esterilización 23 Vestuarios / Aseos 24 Esclusa animales 25 Esclusa personas 26 Esclusa materiales 27 Almacén / archivo 28 Servicios 29 Despacho 31 Pasillo 32 Otros

Figura 44. Área experimentación animal grande liSGM (S/E). Fuente. Elaboración propia. 
El área de experimentación de animal grande del instituto IRYCIS (Figura 45) se distribuye en una única planta con acceso directo desde el exterior, de manera que los accesos para el personal están separados de las de suministro de animales, de materiales y de la retirada de residuos. Esta área se desarrolla en una planta junto con el área de experimentación de animal pequeño, de manera que comparten pasillos de distribución interior y locales de servicios varios.

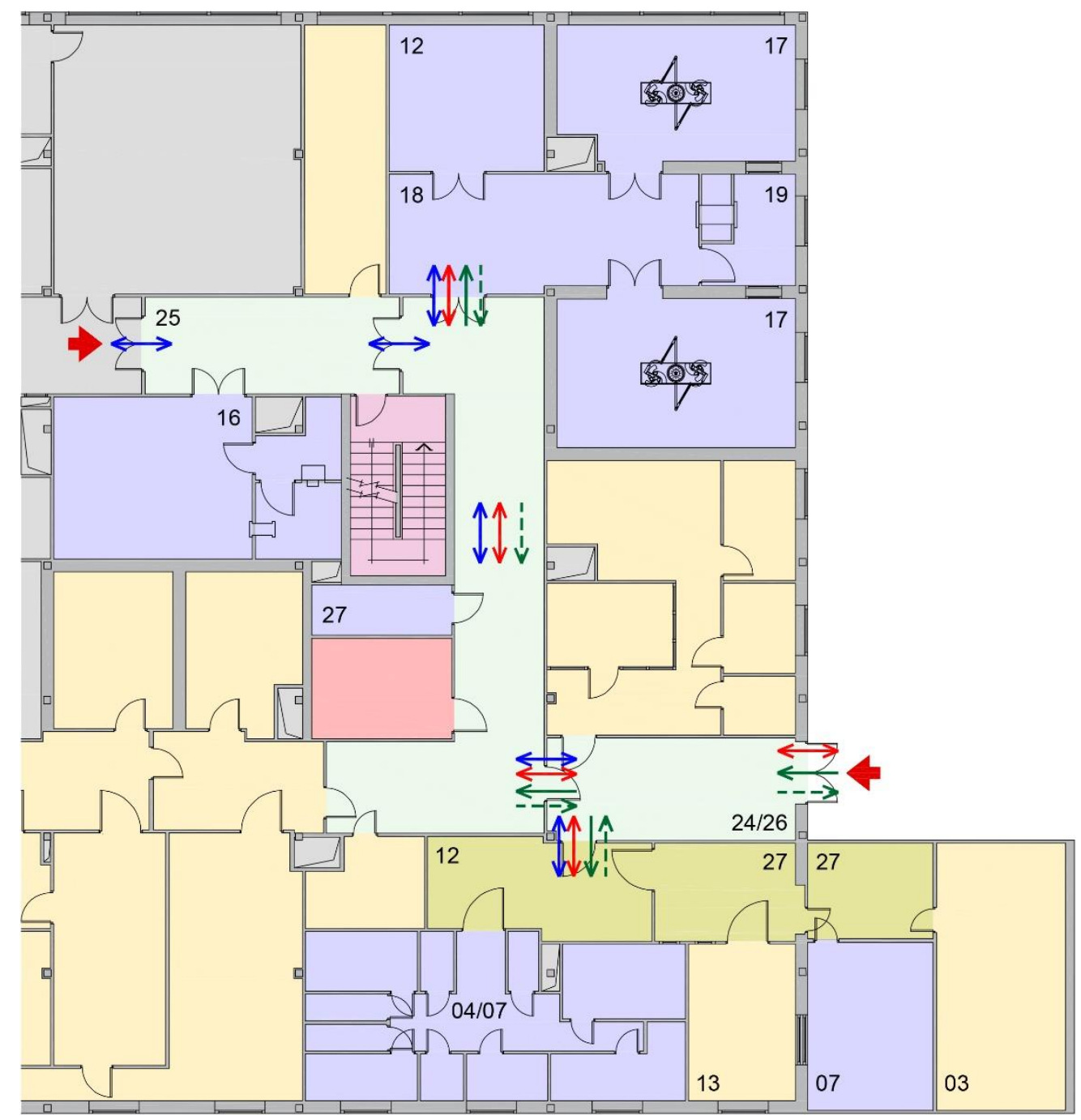

ÁREAS FUNCIONALES

Experimentación animal pequeño
Experimentación animal grande
Áreas comunes animal pequeño y grande
Área Administrativa
Pasillos comunes
Pasillos exteriores y servicios generales
Elementos de circulación vertical

$$
\text { IDENTIFICACIÓN USO LOCALES }
$$

$\begin{array}{ll}\text { 01 Recepción animal } & 17 \text { Quirófano experimental } \\ 02 \text { Estabulación convencional roedores } & 18 \text { Preparación médica } \\ 03 \text { Estabulación convencional conejos } & 19 \text { A. material estéril } \\ 04 \text { Estabulación convencional animal grande } & 20 \text { Necropsias } \\ 05 \text { Cuarentena roedores } & 21 \text { Cirugia cadáveres } \\ 06 \text { Cuarentena conejos } & 22 \text { Lavado y esterilización } \\ 07 \text { Cuarentena animal grande } & 23 \text { Vestuarios / Aseos } \\ 08 \text { Estabulación barrera animal pequeño } & 24 \text { Esclusa animales } \\ 09 \text { Experimentación ABSL2 - 09* ABSL3 } & 25 \text { Esclusa personas } \\ \text { 10 Experimentación peces } & 26 \text { Esclusa materiales } \\ \text { 11 Lavado animal } & 27 \text { Almacén / archivo } \\ \text { 12 Preparación animal } & 28 \text { Servicios } \\ \text { 13 Procedimientos } & 29 \text { Despacho } \\ \text { 14 Microcirugia } & 30 \text { Sala reuniones } \\ \text { 15 Comportamiento } & 31 \text { Pasillo } \\ 16 \text { Imagen } & 32 \text { Otros }\end{array}$

ACCESOSY CIRCULACIONES
$\Rightarrow$ Acceso

- Personal

— Suministro materiales

- - - Retirada de residuos

Figura 45. Área experimentación animal grande IRYCIS (S/E). Fuente. Elaboración propia. 
El área de experimentación de animal grande del instituto IISBiodonostia (Figura 46) se desarrolla en una única planta con varios accesos directos desde el exterior para independizar los accesos del personal del de los animales, el suministro de materiales y la retirada de residuos. Esta área se integra en la misma planta que el área de experimentación de animal pequeño, de manera que ambas actividades comparten pasillos de distribución interior, locales de servicios varios, incluso el área de preparación animal.

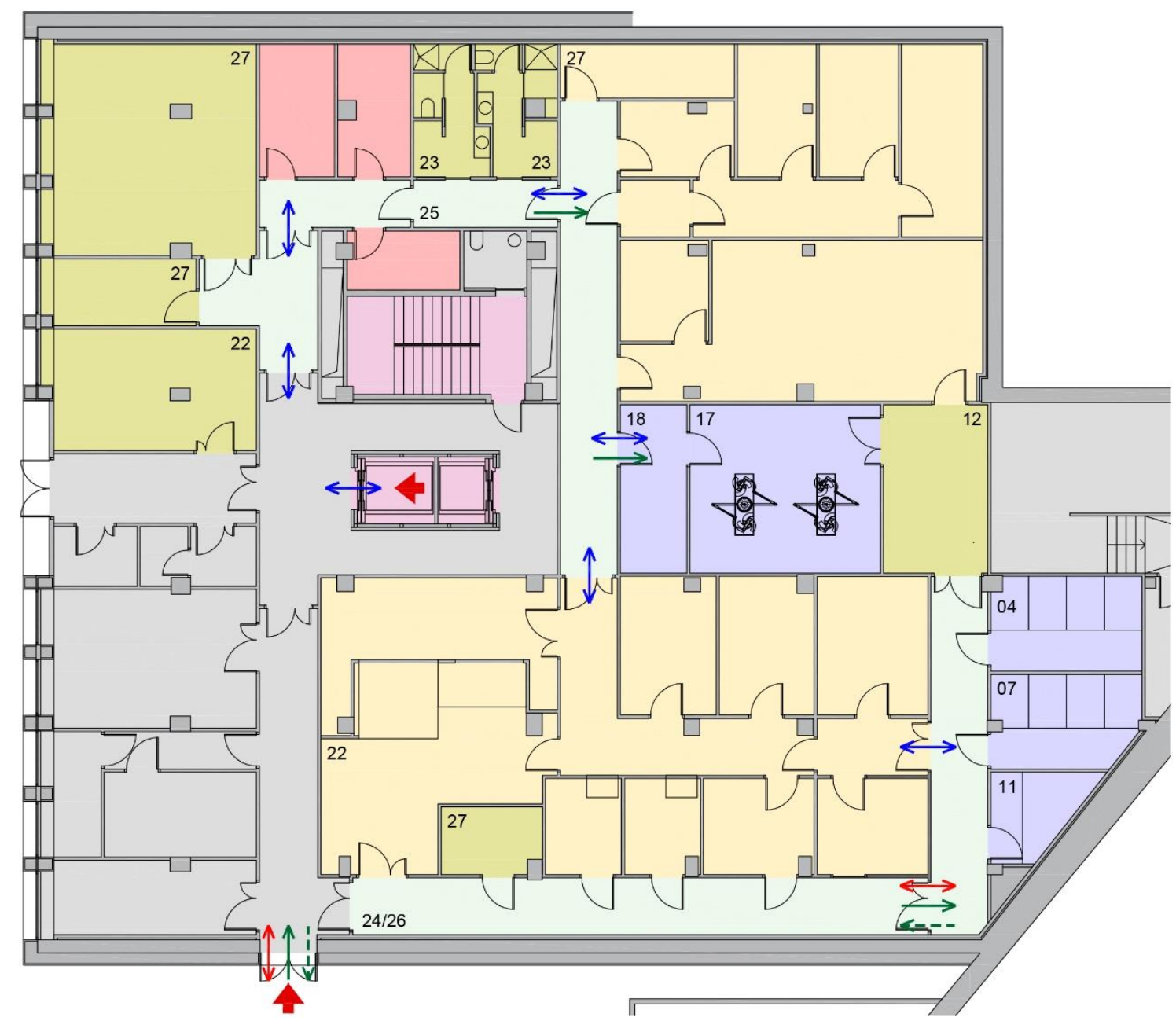

ÁREAS FUNCIONALES

Experimentación animal pequeño
Experimentación animal grande
Áreas comunes animal pequeño y grande
Área Administrativa
Pasillos comunes
Pasillos exteriores y servicios generales
Elementos de circulación vertical

IDENTIFICACIÓN USO LOCALES

01 Recepción animal
02 Estabulación convencional roedores
03 Estabulación convencional conejos
04 Estabulación convencional animal gran
05 Cuarentena roedores
06 Cuarentena conejos
07 Cuarentena animal grande
08 Estabulación barrera animal pequeño
09 Experimentación ABSL2 - $09^{\star}$ ABSL3
10 Experimentación peces
11 Lavado animal
12 Preparación animal
13 Procedimientos
14 Microcirugía
15 Comportamiento
16 Imagen

17 Quirófano experimental 18 Preparación médica 19 A. material estéril 21 Cirugia cadáveres 22 Lavado y esterilización 23 Vestuarios / Aseos 24 Esclusa animales 25 Esclusa personas 26 Esclusa materiales 27 Almacén / archivo 28 Servicios 29 Despacho 30 Sala reuniones 31 Pasillo

Figura 46. Área experimentación animal grande IIS Biodonostia (S/E). Fuente. Elaboración propia. 
El área de experimentación de animal grande del instituto IISBiocruces (Figura 47) se distribuye en una única planta con dos accesos directos desde el exterior, de manera que los accesos para el personal quedan independizados de la de los animales, el suministro de materiales y la retirada de residuos. El área se configura como una entidad independiente al resto del centro de experimentación animal, compartiendo únicamente con el área de experimentación de animal pequeño el área administrativa que se sitúa en una zona exterior a la zona experimental.

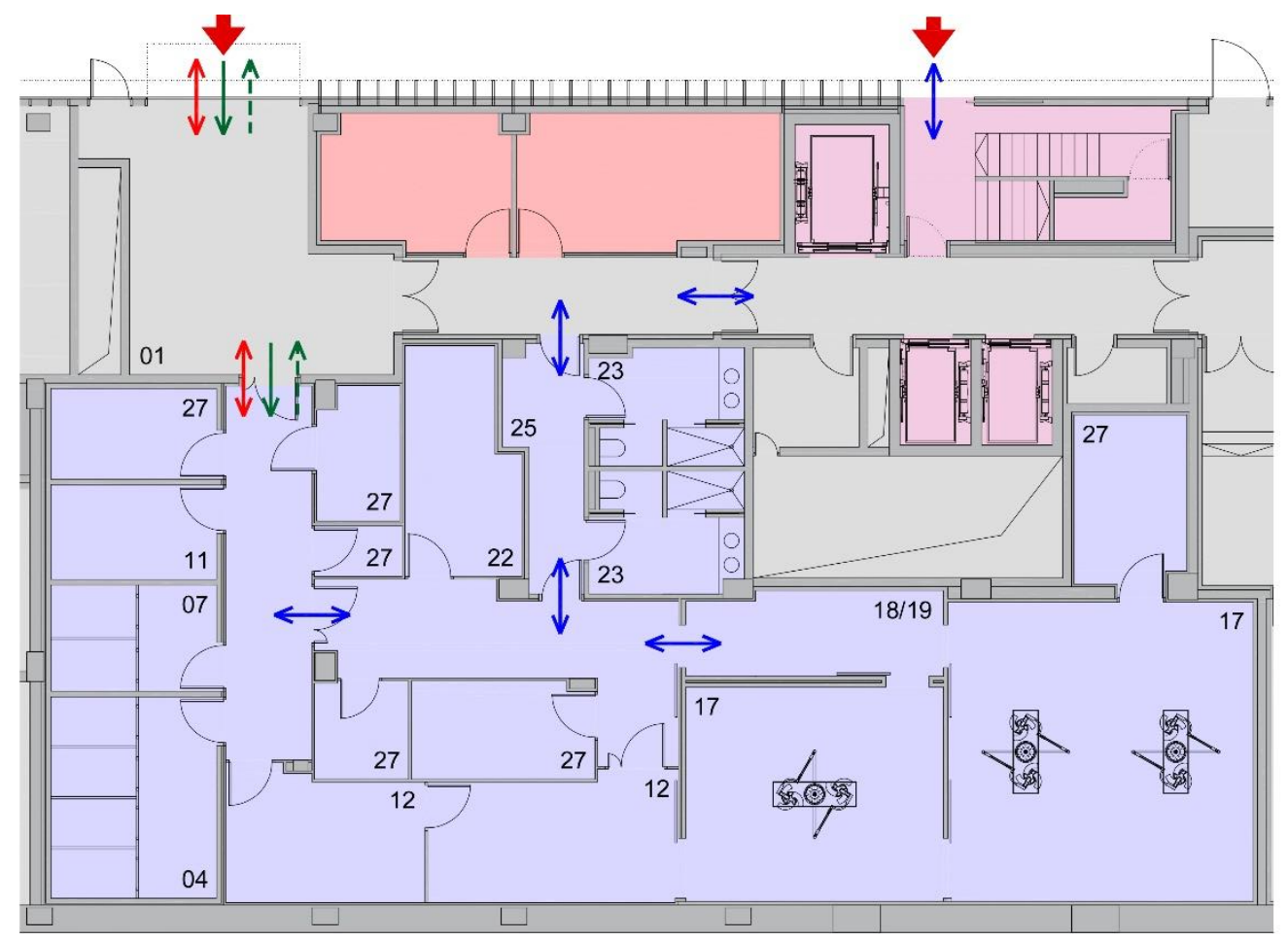

ÁREAS FUNCIONALES

Experimentación animal pequeño
Experimentación animal grande
Áreas comunes animal pequeño y grande
Área Administrativa
Pasillos comunes
Pasillos exteriores y servicios generales
Elementos de circulación vertical

\begin{tabular}{|c|c|c|}
\hline \multicolumn{2}{|c|}{ IDENTIFICACIÓN USO LOCALES } & ACCESOS Y \\
\hline 01 Recepción animal & 17 Quirófano experimental & Acceso \\
\hline 02 Estabulación convencional roedores & 18 Preparación médica & \\
\hline 03 Estabulación convencional conejos & 19 A. material estéril & - Personal \\
\hline 04 Estabulación convencional animal grande & 20 Necropsias & \\
\hline 05 Cuarentena roedores & 21 Cirugía cadáveres & Animales \\
\hline 06 Cuarentena conejos & 22 Lavado y esterilización & \\
\hline 07 Cuarentena animal grande & 23 Vestuarios / Aseos & - Suministro materiales \\
\hline 08 Estabulación barrera animal pequeño & 24 Esclusa animales & \\
\hline 09 Experimentación ABSL2 - 09* ABSL3 & 25 Esclusa personas & - - Retirada de residuos \\
\hline 10 Experimentación peces & 26 Esclusa materiales & \\
\hline 11 Lavado animal & 27 Almacén / archivo & \\
\hline 12 Preparación animal & 28 Servicios & \\
\hline 13 Procedimientos & 29 Despacho & \\
\hline 14 Microcirugia & 30 Sala reuniones & \\
\hline 15 Comportamiento & 31 Pasillo & \\
\hline 16 Imagen & 32 Otros & \\
\hline
\end{tabular}

Figura 47. Área experimentación animal grande IIS Biocruces (S/E).

Fuente. Elaboración propia. 
El área de experimentación de animal grande del instituto IISA (Figura 48) se distribuye en una planta con acceso directo desde el exterior, por el que acceden directamente al área los animales, el suministro de materiales y la retirada de residuos. En cambio, el personal accede desde la planta principal de acceso al edificio situado en una planta superior, por lo que hace uso de elementos de comunicación vertical para acceder al área de experimentación. En esta misma planta se desarrolla toda la experimentación quirúrgica del centro, tanto de animal grande como pequeño, de manera que en el área de estabulación de animal grande se integra el área de estabulación de animal pequeño, y en una zona anexa, el área de microcirugía junto con el área quirúrgica.

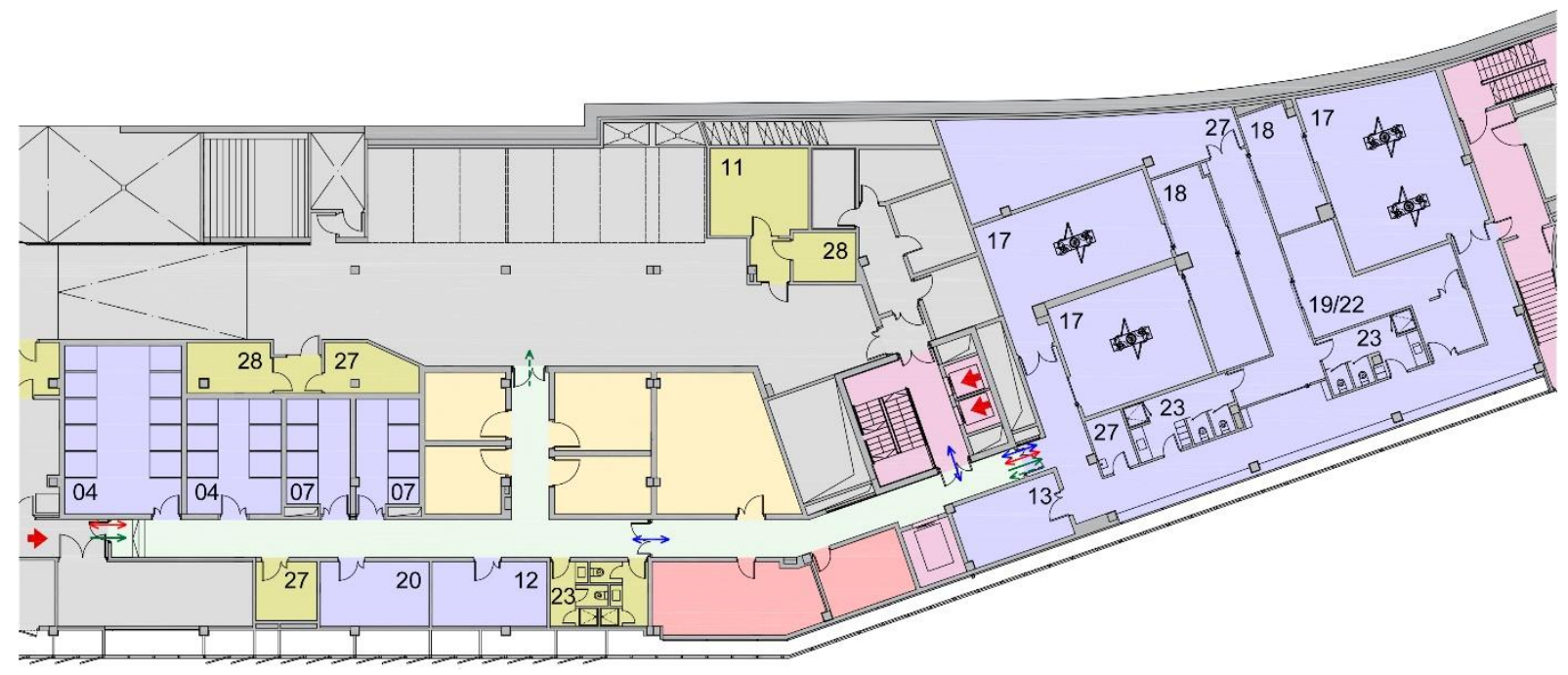

ÁREAS FUNCIONALES

Experimentación animal pequeño

Experimentación animal grande

Áreas comunes animal pequeño y grande

Área Administrativa

Pasillos comunes

Pasillos exteriores y servicios generales

Elementos de circulación vertical
IDENTIFICACIÓN USO LOCALES

01 Recepción animal
02 Estabulación convencional roedores
03 Estabulación convencional conejos
04 Estabulación convencional animal grande
05 Cuarentena roedores
06 Cuarentena conejos
07 Cuarentena animal grande
08 Estabulación barrera animal pequeño
09 Experimentación ABSL2 - 09* ABSL3
10 Experimentación peces
11 Lavado animal
12 Preparación animal
13 Procedimientos
14 Microcirugia
15 Comportamiento
16 Imagen

17 Quirófano experimental 18 Preparación médica 19 A. material estéril 20 Necropsias 21 Cirugia cadáveres 23 Vestuarios / Aseos 24 Esclusa animales 25 Esclusa personas 26 Esclusa materiales
27 Almacén / archivo 28 Servicios

29 Despacho

30 Sala reuniones

31 Pasillo 32 Otros

Figura 48. Área experimentación animal grande IISA (S/E).

Fuente. Elaboración propia. 
El área de experimentación de animal grande del instituto VHIR (Figura 49) se desarrolla en una única planta con acceso directo desde el exterior, en el que están independizados los accesos del personal del de los animales, del suministro de materiales y de la retirada de residuos. Esta área se distribuye en una misma zona junto con el área de experimentación de animal pequeño, limitándose las zonas compartidas entre ambos a vestuarios de cambio y pasillos de circulación interior.

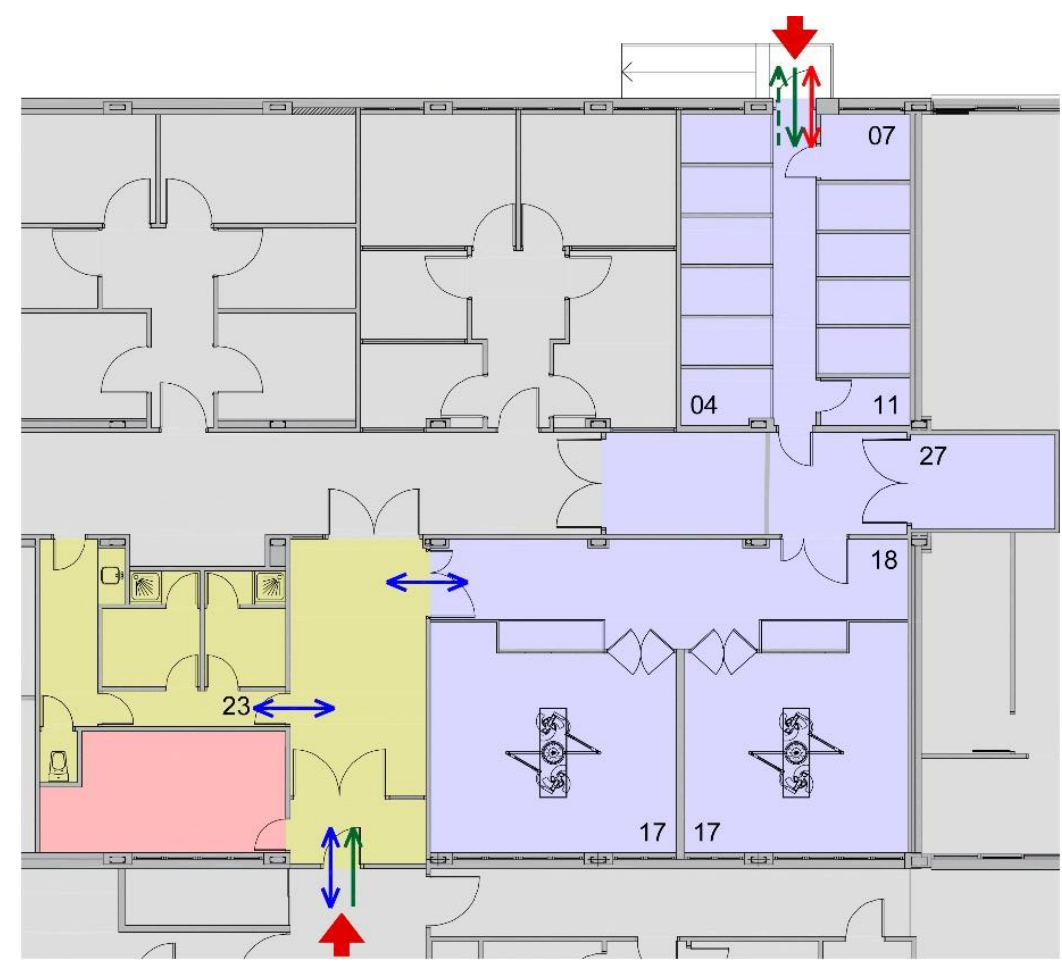

ÁREAS FUNCIONALES

Experimentación animal pequeño
Experimentación animal grande
Áreas comunes animal pequeño y grande
Área Administrativa
Pasillos comunes
Pasillos exteriores y servicios generales
Elementos de circulación vertical

IDENTIFICACIÓN USO LOCALES

01 Recepción animal
02 Estabulación convencional roedores
03 Estabulación convencional conejos
04 Estabulación convencional animal grande
05 Cuarentena roedores
06 Cuarentena conejos
07 Cuarentena animal grande
08 Estabulación barrera animal pequeño
09 Experimentación ABSL2 - 09* ABSL3
10 Experimentación peces
11 Lavado animal
12 Preparación animal
13 Procedimientos
14 Microcirugia
15 Comportamiento
16 Imagen

17 Quirófano experimental

18 Preparación médica

19 A. material estéril

20 Necropsias

21 Cirugía cadáveres

22 Lavado y esterilización

23 Vestuarios / Aseos

24 Esclusa animales

25 Esclusa personas

26 Esclusa materiales

27 Almacén / archivo

28 Servicios

29 Despacho

30 Sala reuniones

31 Pasillo

32 Otros

Figura 49. Área experimentación animal grande VHIR (S/E).

Fuente. Elaboración propia. 
El área de experimentación de animal grande del instituto IGTP (Figura 50) se distribuye en una planta semisótano con acceso directo desde el exterior para el acceso de animales, suministro de materiales y la retirada de residuos. El personal, en cambio, accede al edificio desde la planta de acceso principal, para a través de elementos de circulación vertical acceder al área de estabulación de animal grande. Esta área se desarrolla en la misma planta que la experimentación de animal pequeño, pero se ha configurado como una unidad totalmente independiente, limitándose los locales compartidos a los vestuarios de cambio del personal ubicados en la planta de acceso principal del edificio. Además del área quirúrgica experimental, en este centro el área de imagen destinada a animal grande adquiere gran importancia, ya que dispone de una resonancia magnética de $3 \mathrm{~T}$, fluoriscopia, laparoscopia y endoscopia 3D.

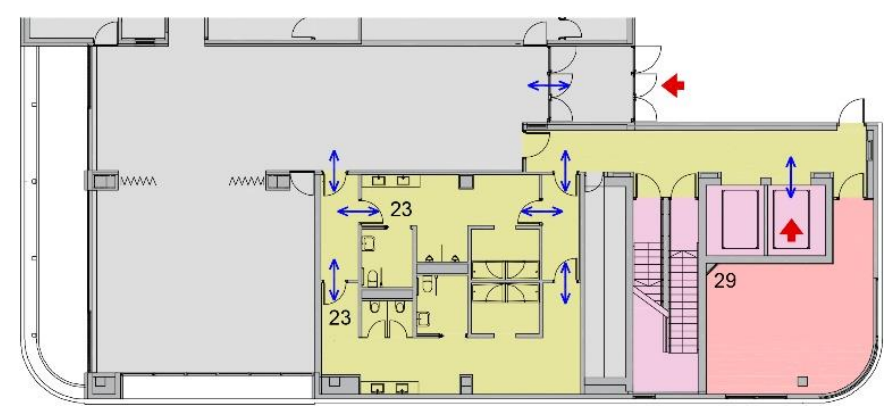

Planta Baja

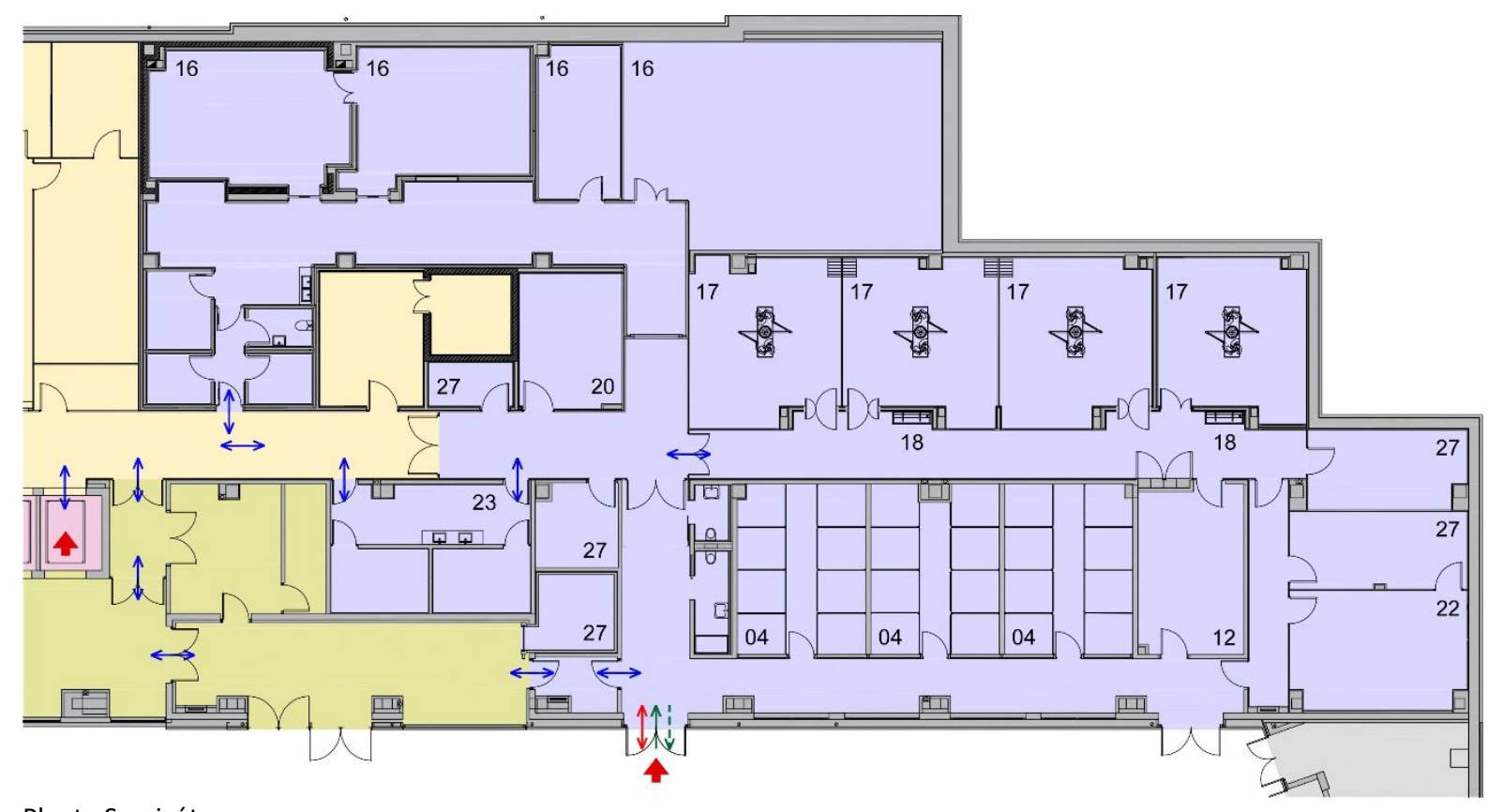

Planta Semisótano

Figura 50. Área experimentación animal grande IGTP (S/E).

Fuente. Elaboración propia. 
El área de experimentación de animal grande del instituto IIS La FE (Figura 51) se distribuye en una única planta bajo rasante, de manera que se dispone de un núcleo de comunicación vertical para uso del animalario, estando los accesos del personal separados de los suministros de animales, de los materiales y de la retirada de residuos. Esta área se integra en la misma planta que el área de experimentación de animal pequeño, de manera que ambas actividades comparten pasillos de distribución interior y locales de servicios varios. Además, se dispone de un área de imagen para todo tipo de animales compuesto por un equipamiento multimodal de PET/RM que integra la tecnología de resonancia magnética (RM) con la de Tomografía por Emisión de Positrones (PET).

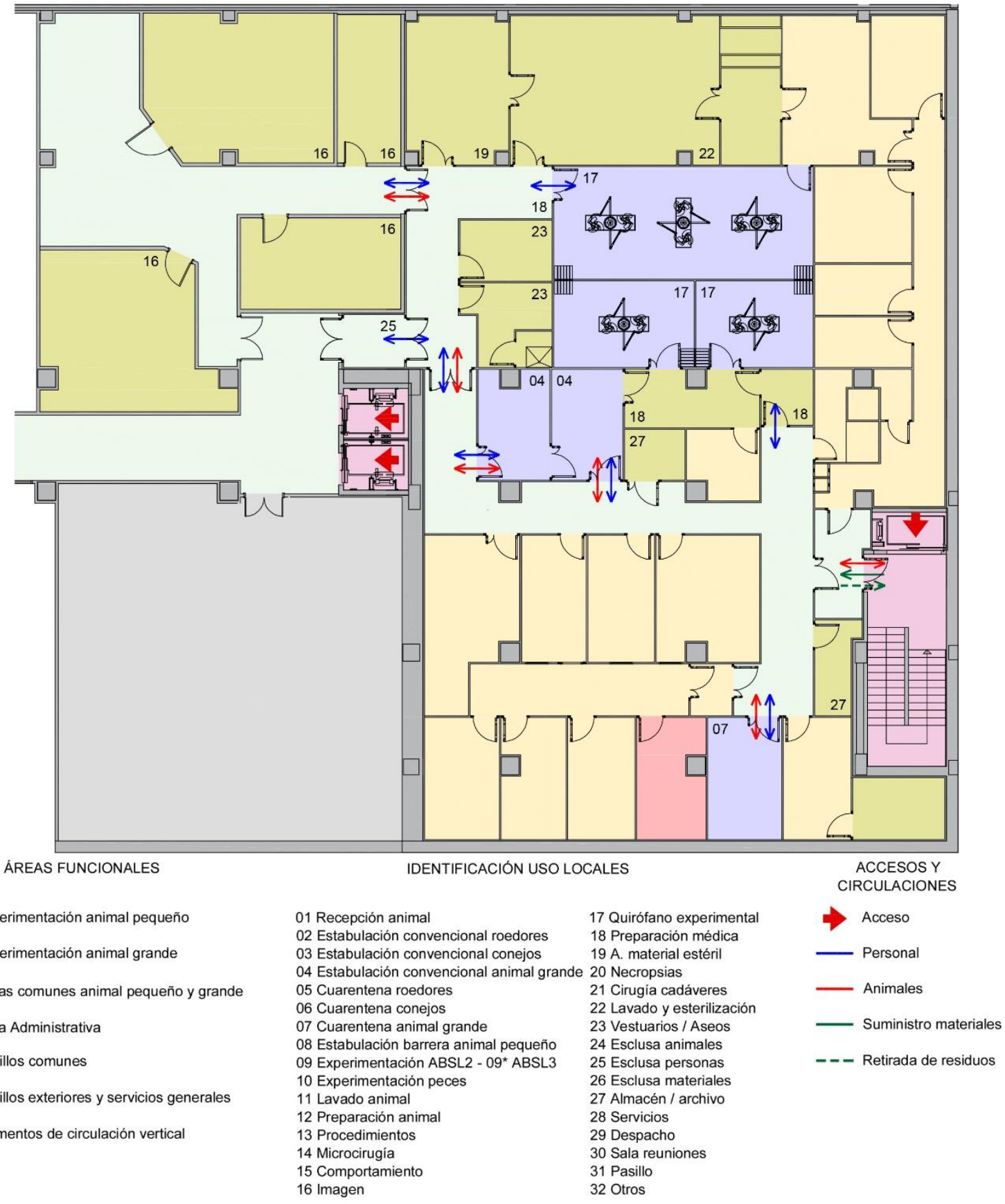

Figura 51. Área experimentación animal grande IIS La Fe (S/E).

Fuente. Elaboración propia. 


\subsubsection{Criterio organizativo del área de experimentación animal grande}

Los conceptos que definen la organización del área de experimentación de animal grande quedan recogidos en las fichas de toma de datos elaborada para cada uno de los institutos. En este apartado se pretende hacer una puesta en común de los resultados obtenidos sobre la organización y distribución del área de experimentación de animal grande. Con ello, se trata de ver cómo está configurada la instalación, si aparte de la unidad de estabulación y la de cirugía experimental se disponen de otras unidades de experimentación y cómo se han organizado los diferentes flujos de trabajo.

Para realizar el análisis de las características de organización y distribución principales se ha hecho una puesta en común de los resultados obtenidos; y, para ello, se ha optado por resumir las más importantes en una tabla (Tabla 03). En ella se listan los parámetros que definen las características generales del centro, se establecen cuáles son las características comunes a la mayoría de ellos y se identifica qué institutos cumplen dichas características; además, se determinan las características que son particulares y específicas, reflejándose así mismo, cuales son los institutos que las cumplen. El análisis se centra en los siguientes conceptos:

- El dimensionamiento del área, el número de plantas en las que se distribuye, así como el tipo de planta, y por lo tanto, ver los tipos de desplazamientos que se producen para el ingreso de los animales al área de experimentación de animal grande, tanto horizontalmente como verticalmente.

- Analizar a través de qué tipo de pasillos se realiza el traslado de animales desde la zona de estabulación al área quirúrgica y otras zonas de experimentación y, por tanto, analizar el grado de independencia del área de experimentación de animal grande con respecto al área de experimentación de animal pequeño.

- Analizar las unidades que componen el área de experimentación de animal grande, si aparte de la unidad quirúrgica experimental existen otras, así como su ubicación en el conjunto de la instalación. 
Tabla 03. Organización área de experimentación animal grande.

\begin{tabular}{|c|c|c|c|c|}
\hline Parámetros & $\begin{array}{l}\text { Características } \\
\text { comunes }\end{array}$ & $\begin{array}{l}\text { Institutos con } \\
\text { características } \\
\text { comunes }\end{array}$ & $\begin{array}{l}\text { Características } \\
\text { específicas }\end{array}$ & $\begin{array}{c}\text { Institutos con } \\
\text { características } \\
\text { específicas } \\
\end{array}$ \\
\hline $\begin{array}{l}\text { Superficie área } \\
\text { experimentación } \\
\text { animal grande }\end{array}$ & $<200 \mathrm{~m}^{2}$ & $\begin{array}{l}\text { i+12, liSGM, } \\
\text { IISBiodonostia, VHIR, } \\
\text { IIS La Fe }\end{array}$ & $\begin{array}{l}200-400 \mathrm{~m}^{2} \\
>400 \mathrm{~m}^{2}\end{array}$ & $\begin{array}{l}\text { IdiPAZ, IRYCIS, } \\
\text { IISBiocruces } \\
\text { IISA, IGTP }\end{array}$ \\
\hline $\begin{array}{l}\text { № de plantas en que } \\
\text { se distribuye }\end{array}$ & Una única planta & $\begin{array}{l}\text { i+12, liSGM, IRYCIS, } \\
\text { IISBiodonostia, } \\
\text { IISBiocruces, IISA, } \\
\text { VHIR, IGTP, IIS La Fe }\end{array}$ & Varias plantas & IdiPAZ \\
\hline $\begin{array}{l}\text { Tipo de planta en la } \\
\text { que se ubica }\end{array}$ & A cota 0 & $\begin{array}{l}\text { i+12, liSGM, IRYCIS, } \\
\text { IISBiodonostia, } \\
\text { IISBiocruces, IISA, } \\
\text { VHIR, IGTP }\end{array}$ & Bajo rasante & IdiPAZ, IIS La Fe \\
\hline $\begin{array}{l}\text { Circulación vertical } \\
\text { interior animales }\end{array}$ & No existe & $\begin{array}{l}\text { i+12, liSGM, IRYCIS, } \\
\text { IISBiodonostia, } \\
\text { IISBiocruces, IISA, } \\
\text { VHIR, IGTP, IIS La Fe }\end{array}$ & SI & IdiPAZ \\
\hline $\begin{array}{l}\text { Relación con el área } \\
\text { de experimentación } \\
\text { de animal pequeño }\end{array}$ & $\begin{array}{l}\text { Áreas animal grande y } \\
\text { pequeño compartidas }\end{array}$ & $\begin{array}{l}\text { IdiPAZ, i+12, IISGM, } \\
\text { IRYCIS, IISBiodonostia, } \\
\text { IIS La Fe, VHIR }\end{array}$ & $\begin{array}{l}\text { Áreas animal grande y } \\
\text { pequeño totalmente } \\
\text { independizadas }\end{array}$ & $\begin{array}{l}\text { IISBiocruces, IISA, } \\
\text { IGTP }\end{array}$ \\
\hline $\begin{array}{l}\text { Traslado de animales } \\
\text { desde el área de } \\
\text { estabulación al área } \\
\text { quirúrgica }\end{array}$ & $\begin{array}{l}\text { Por pasillos exclusivos del } \\
\text { área de experimentación } \\
\text { animal }\end{array}$ & $\begin{array}{l}\text { IISBiocruces, IISA, } \\
\text { VHIR, IGTP }\end{array}$ & $\begin{array}{l}\text { Por pasillos compartidos } \\
\text { con área animal } \\
\text { pequeño }\end{array}$ & $\begin{array}{l}\text { IdiPAZ, i+12, liSGM, } \\
\text { IRYCIS, IIS La Fe, } \\
\text { IISBiodonostia }\end{array}$ \\
\hline $\begin{array}{l}\text { Otras áreas de } \\
\text { experimentación } \\
\text { animal grande } \\
\end{array}$ & $\begin{array}{l}\text { Área diagnóstico por } \\
\text { imagen }\end{array}$ & $\begin{array}{l}\text { IdiPAZ, IRYCIS, IGTP, } \\
\text { IIS La Fe }\end{array}$ & $\begin{array}{l}\text { Experimentación } \\
\text { cadáveres }\end{array}$ & IdiPAZ \\
\hline $\begin{array}{l}\text { Ubicación del área } \\
\text { administrativa }\end{array}$ & $\begin{array}{l}\text { Externa al área } \\
\text { experimentación }\end{array}$ & $\begin{array}{l}\text { liSGM, IISBiodonostia, } \\
\text { IISBiocruces, VHIR, } \\
\text { IGTP }\end{array}$ & $\begin{array}{l}\text { Integrada en el área de } \\
\text { experimentación }\end{array}$ & $\begin{array}{l}\text { IdiPAZ, i+12, IISA, } \\
\text { IRYCIS, IIS La Fe }\end{array}$ \\
\hline
\end{tabular}

Fuente. Elaboración propia.

\section{Dimensionamiento, Número y tipo de plantas}

Observamos cómo el dimensionamiento del área de experimentación animal grande de cada centro es muy variable, por lo que el análisis se ha realizado agrupando las áreas por rango de superficies. De esta manera observamos cómo la mitad de los institutos ( i+12, IiSGM, IISBiodonostia, VHIR, IIS La Fe) destinan una superficie inferior a $200 \mathrm{~m}^{2}$ al área de experimentación de animal grande y solo dos de ellos han realizado una apuesta mayor por la investigación en esta área (IISA, IGTP) destinando una superficie superior a $400 \mathrm{~m}^{2}$. El dimensionamiento del resto de los centros se sitúa entre los 200-400 $m^{2}$.

La mayoría de las áreas de experimentación de animal grande se distribuyen en una única planta, sin embargo, observamos un caso en el que esta área se ha distribuido en dos plantas (IdiPAZ). En este caso concreto, la división se ha realizado disponiendo en una planta bajo rasante el área de estabulación y, en otra diferente, también bajo rasante, la zona de experimentación de animal grande. Este criterio de distribución obliga por una parte, a que los animales tengan que ingresar en el centro a través de elementos de comunicación vertical; $y$, por la otra, a que una vez ingresados tengan que ser desplazados a la planta de experimentación también mediante elementos de transporte vertical interior. 
Por otra parte, lo habitual es que las áreas de experimentación de animal grande se distribuyan en plantas con acceso directo desde el exterior por el que se introducen directamente los animales, los suministros de materiales y se retiran los residuos generados, por lo que el ingreso de los animales al centro se realiza sin tener que hacer uso de elementos de comunicación vertical. En cambio, el acceso del personal al área de experimentación animal se suele realizar desde el acceso principal del edificio en el que se aloja, de manera que los accesos están totalmente independizados.

Existen varios casos en los que el área de alojamiento de animal grande se encuentra en una planta sin acceso directo desde el exterior, en una planta bajo rasante (IdiPAZ, IIS La Fe). En estos casos se dispone de un montacargas para el transporte de animales y suministro de materiales; para el traslado de personas, en cambio, existen ascensores independientes, de manera que no se mezclan con el transporte de animales.

\section{Relación con el área de experimentación de animal pequeño}

No en todos los casos se ha conseguido independizar totalmente el área de experimentación animal grande del pequeño, de manera que en los casos en los que existen zonas de uso compartidas (IdiPAZ, i+12, IISGM, IRYCIS, IISBiodonostia, IIS La Fe, VHIR) las áreas que se comparten son principalmente los vestuarios, pasillos de distribución interior tanto para personal como para animales, almacenes, salas de lavado, incluso en algún caso se comparte sala de preparación animal.

Entre las áreas de experimentación de animal grande que se distribuyen de manera independiente al área de experimentación de animal pequeño se encuentran los institutos (IIS Biocruces, IGTP, IISA). Llama la atención un caso (IISA) que dispone de un área específica destinada a la cirugía experimental en el que se desarrolla toda la actividad quirúrgica del centro, tanto la de animales grandes como la de los animales pequeños, pero en salas independizadas.

En los centros que no se dispone de un área de experimentación de animal grande independizado del área de experimentación pequeño ocurre que en casi todos los casos (IdiPAZ, i+12, IiSGM, IRYCIS, IIS La Fe, IISBiodonostia) los pasillos de circulación necesarios para el traslado de los animales desde la zona de estabulación al área quirúrgica son compartidos con la circulación de animal pequeño. Observamos un caso particular (VHIR) en el que la distribución de áreas permite trasladar los animales a través de una zona de uso exclusivo para animal grande.

\section{Unidades que componen el área de experimentación animal grande}

Como hemos comentado anteriormente, esta área de experimentación se compone de una zona donde se estabulan los animales grandes y otra zona compuesta por las salas de experimentación. Analizando las salas de experimentación, observamos que todos los institutos disponen de quirófanos 
experimentales destinados a realizar prácticas quirúrgicas. Además, nos encontramos casos concretos en los que se disponen otras áreas de experimentación, tales como sala de prácticas con cadáveres (IdiPAZ) o área de imagen (IRYCIS, IdiPAZ, IGTP, IIS La Fe). Entre los institutos que han hecho una mayor apuesta por el área de imagen destinado a experimentación de animal grande se encuentra el IGTP. Este centro de medicina comparativa y bioimagen, para la experimentación con animal grande, dispone de una sala de resonancia magnética de 3 Tesla, fluoroscopia y una sala de RX para intervencionismo con arco quirúrgico y ecógrafo. Por otra parte, el IIS La Fe, dispone de la plataforma de radiología experimental, dotado de un equipamiento multimodal de PET/RM que integra la tecnología de resonancia magnética (RM) con la de Tomografía por Emisión de Positrones (PET) para estudios con animales de cualquier tamaño, además de equipos radiográficos. El resto de los institutos que disponen de algún local especifico destinado a imagen (IdiPAZ, IRYCIS) se reducen a salas de Rayos X.

En relación a la implantación del área administrativa, observamos que no hay una clara determinación en los centros investigados, ya que en la mitad de los casos el área administrativa se ubica en una zona exterior al área de experimentación, y en la otra mitad se integra en el área de experimentación animal.

En cuanto a la posibilidad de modificación o ampliación de esta área de experimentación para adaptarse a futuros proyectos de investigación, vemos que en general, estas ampliaciones dependerían de la reorganización de la actividad de los locales colindantes, ya que los institutos analizados tienen actividad en cada una de las estancias disponibles. Observamos cómo en algunos casos en los que el área de experimentación no se sitúa en una planta accesible desde el exterior, se ha dejado la previsión de galerías para introducir posible equipamiento futuro.

Atendiendo a la organización en su conjunto, esta área funcional de experimentación de animal grande, vemos que no siempre se ha configurado como un área independiente formada por su área de estabulación y área de experimentación, sino que encontramos diferentes tipologías de organización:

1. El área de experimentación de animal grande se desarrolla como una unidad funcional específica y compacta, de manera independiente para el desarrollo de la actividad (IISBiocruces, IGTP).

2. Se crea una unidad funcional específica de cirugía experimental que comprende toda la actividad quirúrgica del centro, tanto para animal grande como pequeño. Esta unidad se compone del área quirúrgica y de microcirugía del centro, las áreas de estabulación de animal grande y pequeño, así como de los locales de servicio necesarios para el desarrollo de la actividad quirúrgica (IISA).

3. El área de experimentación de animal grande se desarrolla en el conjunto de la experimentación de animal pequeño compartiendo zonas de circulación, vestuarios, almacenes, incluso en algún caso locales de procedimientos (IdiPAZ, i+12, IiSGM, IRYCIS, IISBiodonostia, VHIR, IIS La Fe). 


\subsubsection{Síntesis del área de experimentación animal grande}

Como síntesis de todo lo estudiado podemos decir que el análisis de las premisas generales del área de experimentación de animal grande, junto con las necesidades del área de experimentación de animal pequeño, incluso las globales del resto de plataformas del Instituto de Investigación Sanitaria, son las que acaban determinando la ubicación del área de experimentación de animal grande dentro del conjunto edificatorio y, por lo tanto, el punto de partida para el desarrollo de la propia unidad.

La mayoría de las áreas de experimentación de animal grande se distribuyen en una planta con acceso directo desde el exterior y en una única planta, por lo que no es habitual hacer uso de elementos de comunicación vertical para el desarrollo de la investigación.

Se observa cómo debido a la falta de disponibilidad de espacio suficiente, solo en algunos casos se ha podido independizar el área de experimentación de animal grande del pequeño, siendo habitual que se compartan vestuarios y pasillos de distribución interior.

La investigación principal realizada en el área de experimentación de animal grande es la cirugía experimental, bien para realizar las intervenciones quirúrgicas necesarias en el desarrollo de procedimientos experimentales, o bien para la realización de prácticas y adquirir la destreza necesaria en cualquiera de las especialidades quirúrgicas y medico-quirúrgicas, así como en técnicas anestésicas o laparoscópicas, entre otras. Es por ello que todos los institutos tienen quirófanos experimentales. Además de los quirófanos, otras de las unidades de experimentación que nos hemos encontrado son las salas para la realización de prácticas con cadáveres y área de diagnóstico por imagen. Esta última área adquiere gran importancia en ciertos institutos.

En el presente estudio se observa que la configuración del área de experimentación animal grande de los institutos, a pesar de tener objetivos de investigación comunes, se puede organizar de múltiples maneras bajo criterios de organización y circulación variados, haciendo que cada instituto tenga unas características particulares y propias. Además, podemos concluir que el área de experimentación de animal grande no siempre se ha organizado como una unidad funcional específica con su área de estabulación y área de experimentación, sino que encontramos diferentes tipologías de organización de esta área:

1. El área de experimentación de animal grande se desarrolla como una unidad funcional específica y compacta, planificando un área independiente para el desarrollo de la actividad.

2. Se crea una unidad funcional específica de cirugía experimental que comprende toda la actividad quirúrgica del centro, tanto para experimentación con animal grande como pequeño. Esta unidad se compone del área quirúrgica de animal grande y del área de microcirugía de animal pequeño, 
de las áreas de estabulación de animal grande y pequeño, así como del conjunto de locales de servicio necesarios para el desarrollo de la actividad quirúrgica.

3. El área de experimentación de animal grande se desarrolla integrado con el conjunto de la experimentación de animal pequeño compartiendo zonas de circulación, vestuarios, locales para almacenamiento, incluso en algún caso locales de procedimientos. 


\subsubsection{Unidad de estabulación animal grande}

La unidad de estabulación de animal grande la componen los locales de alojamiento que son las salas donde van a vivir normalmente los animales con los que se va a experimentar y las áreas de servicio necesarias para garantizar el cuidado y bienestar animal, así como las condiciones de trabajo y seguridad del personal. Estas áreas de servicio se corresponden fundamentalmente con las áreas necesarias para dotarlos de los suministros básicos, y de las instalaciones necesarias para garantizar un buen entorno y calidad de vida.

En este apartado se analizan los locales que componen habitualmente esta unidad, para a continuación analizar las características generales de cada uno de los institutos. Por otra parte, tomando como referencia las recomendaciones establecidas en las diferentes guías publicadas, y a partir de las representaciones gráficas estandarizadas de la unidad de estabulación de animal grande, se estudia la organización, la configuración de los accesos diseñados, así como los sistemas constructivos de la unidad de estabulación de animal grande de los diferentes centros investigados.

\subsubsection{Locales que componen la unidad de estabulación animal grande}

La definición de necesidades y el dimensionamiento de esta unidad normalmente está predeterminado por las líneas de investigación del centro, así como por los criterios establecidos para la gestión del suministro de animales y para la retirada de residuos de la propia unidad de estabulación. Entre los locales necesarios para garantizar la recepción, cuidados y bienestar animal se encuentran los siguientes:
a) Zona de descarga
b) Sala limpieza y aclimatación
c) Locales de alojamiento
d) Salas de procedimientos
e) Sala de necropsias
f) Locales de servicio

a) Zona de descarga. Zona donde se realiza la descarga de animales y materiales, en la que existe una zona específica donde se realiza la recepción animal para a continuación proceder a su ingreso en el animalario. No siendo una dependencia exclusiva del animalario, habitualmente se plantea como el punto de entrada principal del equipamiento y de los materiales de grandes dimensiones que se reciben en la instalación, así como para la entrada de todos los animales, tanto de los grandes como de los pequeños destinados a la experimentación. Constituye, además, el punto de entrega de los residuos animales que se generan en la instalación al gestor encargado de la retirada y el tratamiento de los mismos. 
b) Sala limpieza y aclimatación. Destinada a la limpieza y aclimatación de los animales que ingresen en el animalario, para realizarles un examen detallado y estén bajo observación.

c) Locales de alojamiento. La zona de estabulación de animal grande se compone habitualmente de al menos dos locales de alojamiento con diferentes números de boxes de estabulación, de tal manera que uno de ellos haga la función de zona de cuarentena, bien para alojar los animales recién llegados al centro hasta que se determine su estado sanitario y se evalúe y minimice el potencial riesgo sanitario, o bien para poder alojar por separado los animales enfermos o heridos.

d) Salas de procedimientos. Todos los procedimientos que pueden causar angustia a un animal deben realizarse fuera de la sala de estabulación animal, ya que un animal angustiado puede transmitir alarma e inducir estrés innecesario a otros animales. Los procedimientos pueden ser muy variados, desde la inyección o recolección de pequeñas muestras de sangre, hasta procedimientos invasivos (Neil 2003, p. 18).

Entre las salas de procedimientos se encuentra la zona de preparación prequirúrgica. Esta zona se plantea como zona de transición entre la zona de estabulación y el área quirúrgica experimental, y está diseñada para la limpieza y acondicionamiento de los animales estabulados que deben ser trasladados a los quirófanos. Esta zona de preparación animal puede estar dividida en dos zonas:

- Una zona denominada sucia, que suele estar integrada en la unidad de estabulación, y que dispone del equipamiento necesario para poder realizar la limpieza y lavado de los animales en profundidad, incluso el rasurado, y en la que se puede instalar también la balanza de pesaje de animales.

- Una zona denominada limpia, que suele estar integrada en la unidad quirúrgica, y en la que se realiza la preparación definitiva de los animales para su ingreso en los quirófanos, previsto con las tomas de gases medicinales necesarios para anestesiar a los animales, $y$, cuando sea necesario, reemplazar de forma rápida a aquellos que han sido intervenidos.

e) Sala de necropsias. Destinada a monitorear las causas de muerte como parte de la vigilancia de la salud, ya que un examen experimental post mortem detallado suele ser necesario a menudo con fines científicos. Esta sala puede no ser siempre necesaria, y dependerá del uso que se le quiera dar, ya que, si la finalidad es recolectar tejidos de animales libres de enfermedades poco después de la muerte, esta tarea se puede realizar en el propio quirófano. Sin embargo, si va a ser necesario recoger tejido de animales de estado de salud desconocido o para diagnosticar la causa de la muerte por causas desconocidas en animales grandes, entonces es muy recomendable que se incorpore una sala de necropsias (Neil 2003, p. 29). 
f) Locales de servicio. Entre los que se encuentran; por una parte, los almacenes destinados al almacenamiento del pienso, los materiales y los útiles empleados en la estabulación del animal grande; $y$, por otra, los locales destinados al almacenamiento de las carcasas y restos de animales antes de su entrega al gestor de residuos autorizado para su tratamiento y eliminación; así como el cuarto de limpieza para la conservación y almacenamiento de los productos y materiales destinados a la limpieza de esta zona del animalario. 


\subsubsection{Representaciones gráficas de la distribución de la unidad de estabulación animal grande}

Tomando como referencia los planos estandarizados que se han elaborado para cada uno de los centros de experimentación animal, y que se encuentran recogidos en las fichas de toma de datos, se ha seleccionado exclusivamente la parte correspondiente a la unidad de estabulación de animal grande. Con estas representaciones gráficas se pretende tener una visión específica de su configuración y de las distintas circulaciones diseñadas (Figuras 52-62).

Para facilitar el estudio, en los planos de distribución en planta se ha identificado por código de colores el área funcional al que pertenece y por código numérico el tipo de local que es. En los casos en los que los locales relacionados con la unidad de estabulación se ubican lejos de los locales de alojamiento de animales se ha optado por indicar mediante una flecha la dirección de su ubicación. Además, para localizar fácilmente la ubicación de los quirófanos se ha incluido la simbología que representa la mesa quirúrgica. Por otra parte, con el fin de realizar una lectura sencilla de las circulaciones, se representa; por una parte, mediante líneas de diferentes trazos y colores la dirección; y, por la otra, mediante flechas el sentido hacia donde va dirigida la circulación para el personal, para los animales, los suministros y la retirada de residuos. Por último, junto a cada una de las representaciones gráficas se hace una breve descripción de la configuración de la unidad de estabulación de animal grande.

ÁREAS FUNCIONALES

Experimentación animal pequeño

Experimentación animal grande

Áreas comunes animal pequeño y grande

Área Administrativa

Pasillos comunes

Pasillos exteriores y servicios generales

Elementos de circulación vertical
IDENTIFICACIÓN USO LOCALES

$\begin{array}{ll}01 \text { Recepción animal } & 17 \text { Quirófano experimental } \\ \text { 02 Estabulación convencional roedores } & 18 \text { Preparación médica } \\ \text { 03 Estabulación convencional conejos } & 19 \text { A. material estéril } \\ 04 \text { Estabulación convencional animal grande } & 20 \text { Necropsias } \\ 05 \text { Cuarentena roedores } & 21 \text { Cirugia cadáveres } \\ 06 \text { Cuarentena conejos } & 22 \text { Lavado y esterilización } \\ 07 \text { Cuarentena animal grande } & 23 \text { Vestuarios / Aseos } \\ 08 \text { Estabulación barrera animal pequeño } & 24 \text { Esclusa animales } \\ \text { 09 Experimentación ABSL2 - 09* ABSL3 } & 25 \text { Esclusa personas } \\ \text { 10 Experimentación peces } & 26 \text { Esclusa materiales } \\ \text { 11 Lavado animal } & 27 \text { Almacén / archivo } \\ \text { 12 Preparación animal } & 28 \text { Servicios } \\ \text { 13 Procedimientos } & 29 \text { Despacho } \\ \text { 14 Microcirugia } & 30 \text { Sala reuniones } \\ \text { 15 Comportamiento } & 31 \text { Pasillo } \\ 16 \text { Imagen } & 32 \text { Otros }\end{array}$

CIRCULACIONES

- Personal

Animales

Suministro materiales

--- Retirada de residuos

Figura 52. Leyenda unidad estabulación animal grande.

Fuente. Elaboración propia.

*Esta leyenda se hace extensible a las figuras 53-62. 
La unidad de estabulación de animal grande del instituto IdiPAZ (Figura 53) se encuentra situado en la planta sótano -2 del edificio, por lo que para acceder a ella es necesario hacer uso de elementos de comunicación vertical. Se dispone; por una parte, de un ascensor que sirve para el acceso del personal a la planta; y, por la otra, de un montacargas que sirve para introducir los animales, los suministros, incluso la retirada de residuos. Por lo tanto, se disponen de dos circuitos verticales diferenciados de acceso al área. El área de estabulación de animal grande se compone de dos salas: una compuesta por cuatro boxes y, otra, por siete boxes de estabulación. En esta zona también se estabulan los conejos y se distribuye la zona de cuarentena de animal pequeño. Además, es zona de paso para el ingreso y traslado de los animales pequeños al centro de experimentación.

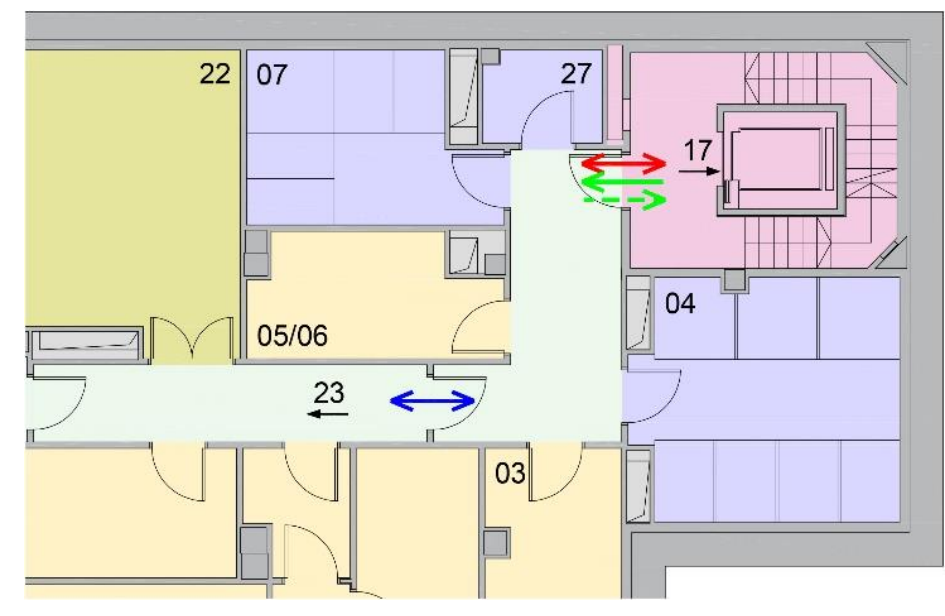

ÁREAS FUNCIONALES

Experimentación animal pequeño

Experimentación animal grande

Áreas comunes animal pequeño y grande

Área Administrativa

Pasillos comunes

Pasillos exteriores y servicios generales

Elementos de circulación vertical
IDENTIFICACIÓN USO LOCALES

$\begin{array}{ll}\text { 01 Recepción animal } & 17 \text { Quirófano experimental } \\ \text { 02 Estabulación convencional roedores } & 18 \text { Preparación médica } \\ \text { 03 Estabulación convencional conejos } & 19 \text { A. material estéril } \\ \text { 04 Estabulación convencional animal grande } & 20 \text { Necropsias } \\ \text { 05 Cuarentena roedores } & 21 \text { Cirugía cadáveres } \\ \text { 06 Cuarentena conejos } & 22 \text { Lavado y esterilización } \\ \text { 07 Cuarentena animal grande } & 23 \text { Vestuarios / Aseos } \\ \text { 08 Estabulación barrera animal pequeño } & 24 \text { Esclusa animales } \\ \text { 09 Experimentación ABSL2 - 09* ABSL3 } & 25 \text { Esclusa personas } \\ \text { 10 Experimentación peces } & 26 \text { Esclusa materiales } \\ \text { 11 Lavado animal } & 27 \text { Almacén / archivo } \\ \text { 12 Preparación animal } & 28 \text { Servicios } \\ \text { 13 Procedimientos } & 29 \text { Despacho } \\ \text { 14 Microcirugia } & 30 \text { Sala reuniones } \\ \text { 15 Comportamiento } & 31 \text { Pasillo } \\ \text { 16 Imagen } & 32 \text { Otros }\end{array}$

CIRCULACIONES

- Personal

- Animales

- Suministro materiales

- Retirada de residuos

Figura 53. Unidad estabulación animal grande IdiPAZ (S/E).

Fuente. Elaboración propia. 
La unidad de estabulación de animal grande del instituto i+12 (Figuro 54) se sitúa en una planta baja con acceso directo desde el exterior. Se disponen de dos salas de estabulación: una compuesta por dos boxes y otra por un box. No se concibe como una unidad independiente, sino que se integra en el conjunto del área de experimentación animal, siendo los pasillos de acceso compartidos. Existe un punto de acceso único al área para el acceso de personal, animales, suministros y retirada de residuos.

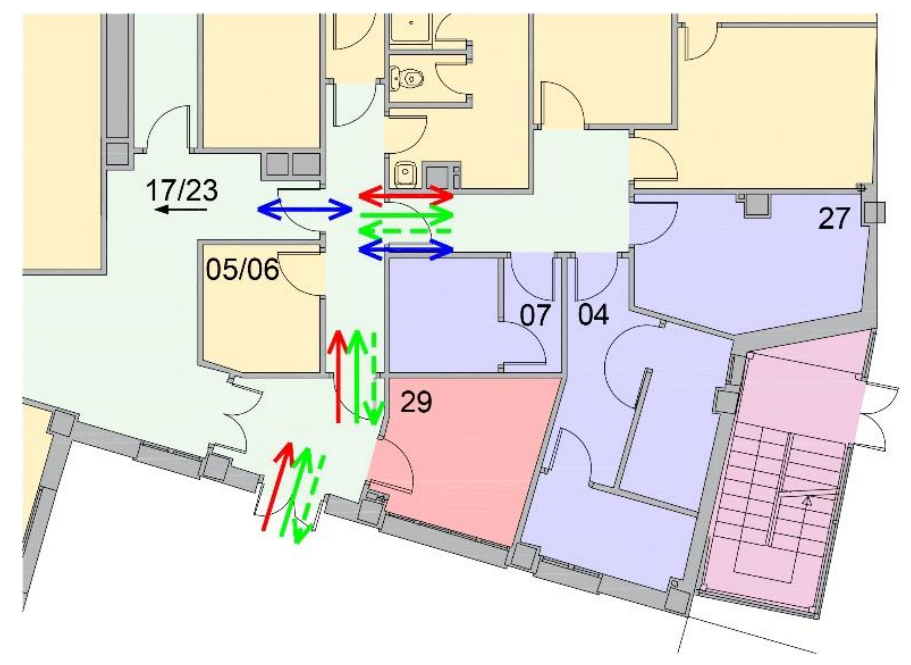

ÁREAS FUNCIONALES

Experimentación animal pequeño

Experimentación animal grande

Áreas comunes animal pequeño y grande

Área Administrativa

Pasillos comunes

Pasillos exteriores y servicios generales

Elementos de circulación vertical

\section{IDENTIFICACIÓN USO LOCALES}

01 Recepción animal
02 Estabulación convencional roedores
03 Estabulación convencional conejos
04 Estabulación convencional animal grande
05 Cuarentena roedores
06 Cuarentena conejos
07 Cuarentena animal grande
08 Estabulación barrera animal pequeño
09 Experimentación ABSL2 - 09* ABSL3
10 Experimentación peces
11 Lavado animal
12 Preparación animal
13 Procedimientos
14 Microcirugia
15 Comportamiento
16 Imagen

01 Recepción animal

17 Quirófano experimenta

18 Preparación médic

19 A. material estéril

21 Cirugía cadáveres

22 Lavado y esterilización

23 Vestuarios / Aseos

24 Esclusa animales

25 Esclusa personas

26 Esclusa materiales

27 Almacén / archivo

28 Servicios

29 Despacho

30 Sala reuniones

31 Pasillo

32 Otros
CIRCULACIONES

- Personal

Animales

Suministro materiales

- - - Retirada de residuos

Figura 54. Unidad estabulación animal grande i+12 (S/E).

Fuente. Elaboración propia. 
La unidad de estabulación de animal grande del instituto liSGM (Figura 55) se encuentra situada en una planta baja con acceso directo desde el exterior. Es una unidad pequeña que se encuentra integrada en el conjunto del centro de experimentación animal y que está compuesta por dos salas de estabulación; una con dos boxes modulares y, la otra, con jaulas móviles. Existe un solo acceso al área de estabulación, de manera que el personal, los animales, los suministros y los residuos entran y salen por la misma zona. Además, las dos salas de alojamiento están distribuidas de tal manera que para acceder a la segunda sala es obligatorio pasar por la primera.

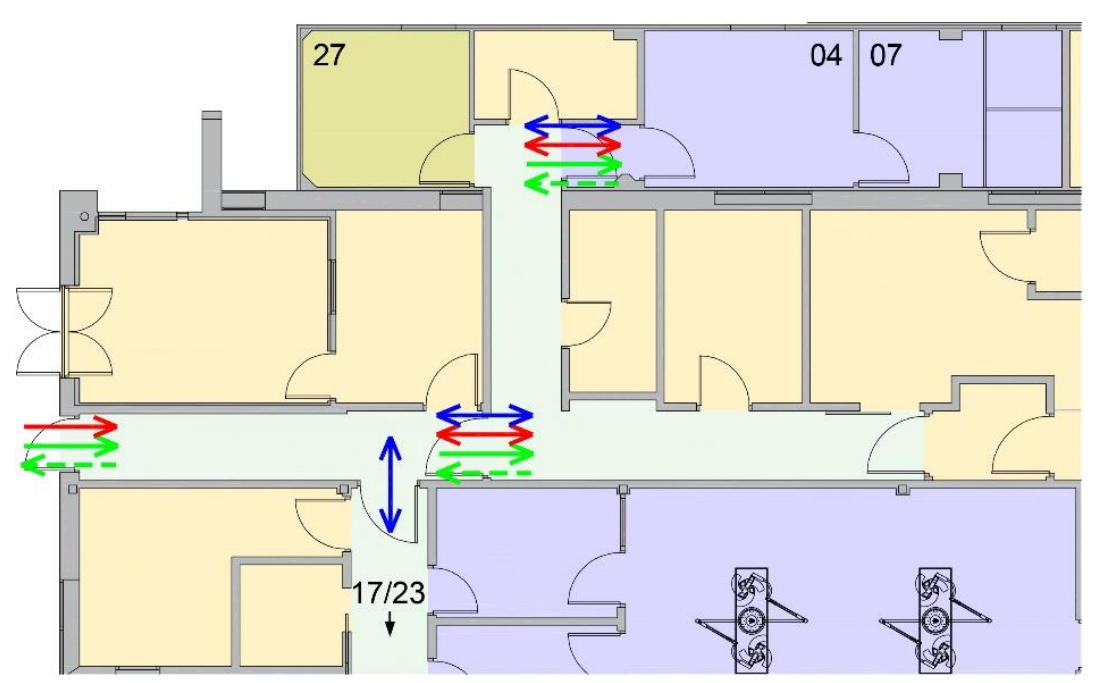

ÁREAS FUNCIONALES

Experimentación animal pequeño

Experimentación animal grande

Áreas comunes animal pequeño y grande

Área Administrativa

Pasillos comunes

Pasillos exteriores y servicios generales

Elementos de circulación vertical
IDENTIFICACIÓN USO LOCALES

$\begin{array}{ll}\text { 01 Recepción animal } & 17 \text { Quirófano experimental } \\ \text { 02 Estabulación convencional roedores } & 18 \text { Preparación médica } \\ \text { 03 Estabulación convencional conejos } & 19 \text { A. material estéril } \\ \text { 04 Estabulación convencional animal grande } & 20 \text { Necropsias } \\ 05 \text { Cuarentena roedores } & 21 \text { Cirugía cadáveres } \\ 06 \text { Cuarentena conejos } & 22 \text { Lavado y esterilización } \\ 07 \text { Cuarentena animal grande } & 23 \text { Vestuarios / Aseos } \\ 08 \text { Estabulación barrera animal pequeño } & 24 \text { Esclusa animales } \\ \text { 09 Experimentación ABSL2 - 09* ABSL3 } & 25 \text { Esclusa personas } \\ \text { 10 Experimentación peces } & 26 \text { Esclusa materiales } \\ \text { 11 Lavado animal } & 27 \text { Almacén / archivo } \\ \text { 12 Preparación animal } & 28 \text { Servicios } \\ \text { 13 Procedimientos } & 29 \text { Despacho } \\ \text { 14 Microcirugia } & 30 \text { Sala reuniones } \\ \text { 15 Comportamiento } & 31 \text { Pasillo } \\ 16 \text { Imagen } & 32 \text { Otros }\end{array}$

CIRCULACIONES

- Personal

Animales

- Suministro materiales

Retirada de residuos

Figura 55. Unidad estabulación animal grande liSGM (S/E).

Fuente. Elaboración propia. 
La unidad de estabulación de animal grande del instituto IRYCIS (Figura 56) se encuentra situada en una planta con acceso directo desde el exterior. Esta unidad está ubicada próxima al acceso exterior y está compuesta por varias salas, algunas de las cuales están destinadas al alojamiento de conejos. Existe un solo acceso al área de estabulación, de manera que el personal, los animales, los suministros y los residuos entran y salen por la misma zona.

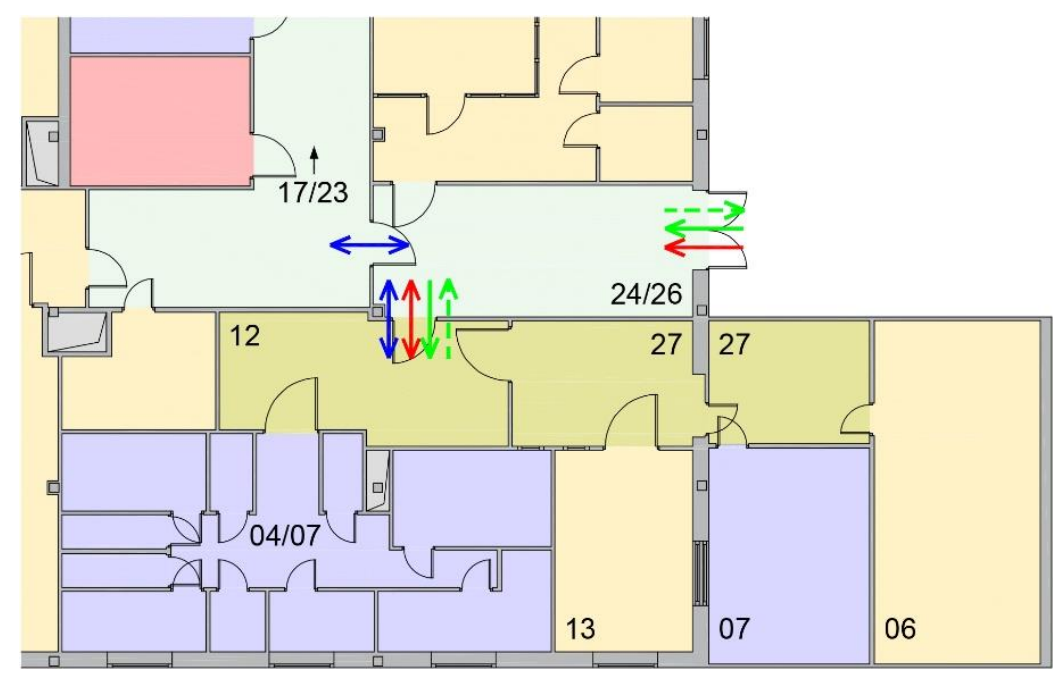

\section{ÁREAS FUNCIONALES}

Experimentación animal pequeño

Experimentación animal grande

Áreas comunes animal pequeño y grande

Área Administrativa

Pasillos comunes

Pasillos exteriores y servicios generales

Elementos de circulación vertical

\section{IDENTIFICACIÓN USO LOCALES}

01 Recepción animal

02 Estabulación convencional roedores

03 Estabulación convencional conejos

05 Cuarentena roedores 21 Cirugia cadáveres

06 Curentena roedores

07 Cuarentena animal grande

08 Estabulación barrera animal pequeño

09 Experimentación ABSL2 - 09* ABSL3

10 Experimentación peces

11 Lavado animal

12 Preparación animal

13 Procedimientos

14 Microcirugia

15 Comportamiento

16 Imagen

25 Esclusa personas
17 Quirófano experimental

18 Preparación médica

22 Lavado y esterilización

23 Vestuarios / Aseos

24 Esclusa animales

26 Esclusa materiales

27 Almacén / archivo

28 Servicios

29 Despacho

30 Sala reuniones

31 Pasillo

32 Otros
CIRCULACIONES

- Personal

- Animales

_ Suministro materiales

- - - Retirada de residuos

Figura 56. Unidad estabulación animal grande IRYCIS (S/E).

Fuente. Elaboración propia. 
La unidad de estabulación de animal grande del instituto IISBiodonostia (Figura 57) se sitúa en una planta semisótano con acceso directo desde el exterior. Se trata de una unidad compuesta por dos salas de estabulación, en las que se encuentran distribuidos cuatro boxes modulares sobre foso. El área de estabulación de animal grande dispone de varios accesos, de manera que por uno de ellos accede el personal al cuidado de los animales; por otro los animales y suministros limpio; y por un tercero se accede a la zona de preparación animal. El pasillo donde confluyen los tres accesos es una zona compartida con el área de experimentación de animal pequeño.

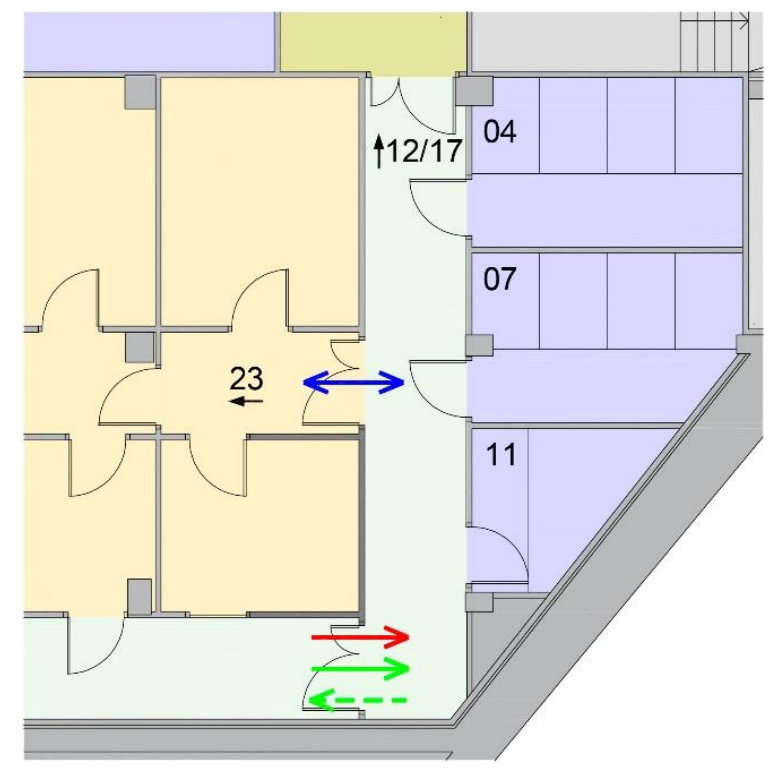

\begin{tabular}{|c|c|c|c|}
\hline ÁREAS FUNCIONALES & \multicolumn{2}{|c|}{ IDENTIFICACIÓN USO LOCALES } & CIRCULACIONES \\
\hline Experimentación animal pequeño & $\begin{array}{l}01 \text { Recepción animal } \\
02 \text { Estabulación convencional roedores }\end{array}$ & $\begin{array}{l}17 \text { Quirófano experimental } \\
18 \text { Preparación médica }\end{array}$ & — Personal \\
\hline Experimentación animal grande & $\begin{array}{l}03 \text { Estabulación convencional conejos } \\
04 \text { Estabulación convencional animal grande }\end{array}$ & $\begin{array}{l}19 \text { A. material estéril } \\
20 \text { Necropsias }\end{array}$ & — Animales \\
\hline Áreas comunes animal pequeño y grande & $\begin{array}{l}05 \text { Cuarentena roedores } \\
06 \text { Cuarentena conejos }\end{array}$ & $\begin{array}{l}21 \text { Cirugía cadáveres } \\
22 \text { Lavado y esterilización }\end{array}$ & — Suministro materiales \\
\hline Área Administrativa & $\begin{array}{l}07 \text { Cuarentena animal grande } \\
08 \text { Estabulación barrera animal pequeño }\end{array}$ & $\begin{array}{l}23 \text { Vestuarios / Aseos } \\
24 \text { Esclusa animales }\end{array}$ & --- Retirada de residuos \\
\hline Pasillos comunes & $\begin{array}{l}09 \text { Experimentación ABSL2 - 09* ABSL3 } \\
10 \text { Experimentación peces }\end{array}$ & $\begin{array}{l}25 \text { Esclusa personas } \\
26 \text { Esclusa materiales }\end{array}$ & \\
\hline Pasillos exteriores y servicios generales & $\begin{array}{l}11 \text { Lavado animal } \\
12 \text { Preparación animal }\end{array}$ & $\begin{array}{l}27 \text { Almacén / archivo } \\
28 \text { Servicios }\end{array}$ & \\
\hline Elementos de circulación vertical & $\begin{array}{l}13 \text { Procedimientos } \\
14 \text { Microcirugia } \\
15 \text { Comportamiento } \\
16 \text { Imagen }\end{array}$ & $\begin{array}{l}29 \text { Despacho } \\
30 \text { Sala reuniones } \\
31 \text { Pasillo } \\
32 \text { Otros }\end{array}$ & \\
\hline
\end{tabular}

Figura 57. Unidad estabulación animal grande IIS Biodonostia (S/E). Fuente. Elaboración propia. 
La unidad de estabulación de animal grande del instituto IISBiocruces (Figura 58) se sitúa en una planta semisótano con acceso directo desde el exterior. Se distribuye de manera compacta e independiente dentro del área de experimentación de animal grande y totalmente independizada del área de experimentación de animal pequeño. Está compuesta por dos salas que disponen de dos y cuatro boxes modulares sobre foso. El área de estabulación dispone de varios accesos: uno, para el suministro de materiales, animales y retirada de residuos; otro, para el acceso del personal al cuidado de los animales; y un tercero para el traslado de los animales al área quirúrgica.

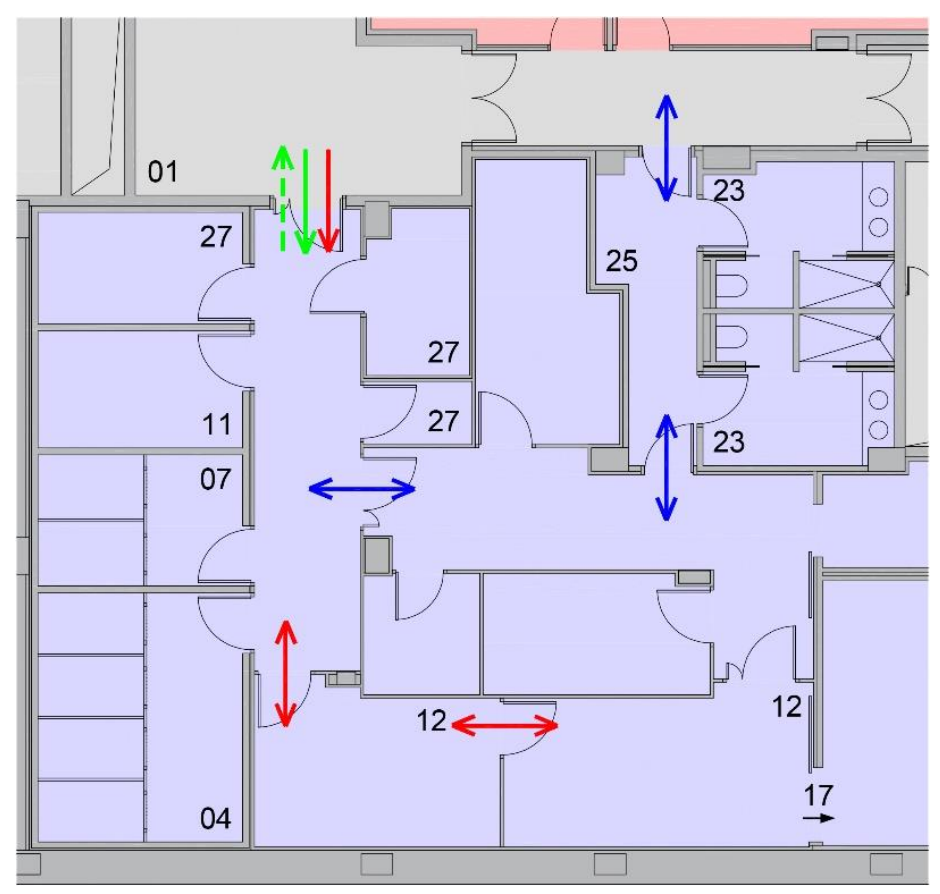

ÁREAS FUNCIONALES

Experimentación animal pequeño

Experimentación animal grande

Áreas comunes animal pequeño y grande

Área Administrativa

Pasillos comunes

Pasillos exteriores y servicios generale

Elementos de circulación vertical
IDENTIFICACIÓN USO LOCALES

01 Recepción animal
02 Estabulación convencional roedores
03 Estabulación convencional conejos
04 Estabulación convencional animal gran
05 Cuarentena roedores
06 Cuarentena conejos
07 Cuarentena animal grande
08 Estabulación barrera animal pequeño
09 Experimentación ABSL2 - 09* ABSL3
10 Experimentación peces
11 Lavado animal
12 Preparación animal
13 Procedimientos
14 Microcirugia
15 Comportamiento
16 Imagen

17 Quirófano experimental 18 Preparación médica 19 A. material estéril 21 Cirugía cadáveres 22 Lavado y esterilización 23 Vestuarios / Aseos 24 Esclusa animales 25 Esclusa personas 26 Esclusa materiales 27 Almacén / archivo 28 Servicios

30 Sala reuniones

31 Pasillo

32 Otros
CIRCULACIONES

— Personal

- Animales

_ Suministro materiales

- - - Retirada de residuos

Figura 58. Unidad estabulación animal grande IIS Biocruces (S/E).

Fuente. Elaboración propia. 
La unidad de estabulación de animal grande del instituto IISA (Figura 59) se sitúa en una planta semisótano con acceso directo desde el exterior. De esta manera, los suministros de animales, los materiales y la retirada de residuos se introducen directamente a la planta, mientras que el personal investigador accede al edificio por la entrada principal para llegar al área de estabulación a través de los elementos de comunicación vertical diseñados para tal fin. El área dispone de tres accesos diferentes: dos por el que pueden acceder los animales, suministros y la retirada de residuos; y un tercero para el acceso del personal. Debido al criterio organizativo fijado en este caso en el que toda la cirugía experimental se desarrolla en un área específica, observamos cómo los pasillos internos de circulación son zonas compartidas con el resto de los animales estabulados en el área: los conejos y roedores.

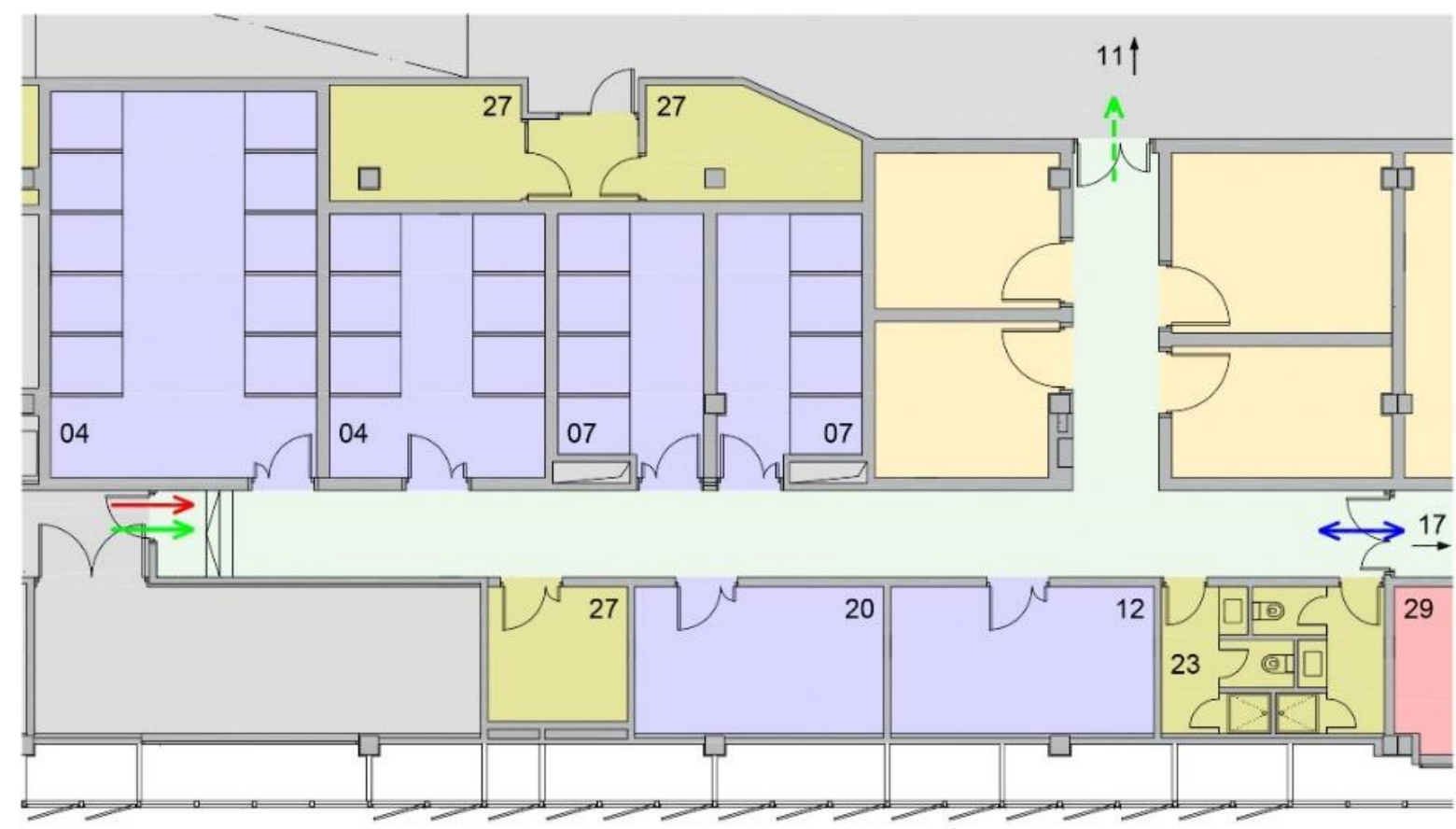

\begin{tabular}{|c|c|c|c|}
\hline ÁREAS FUNCIONALES & \multicolumn{2}{|c|}{ IDENTIFICACIÓN USO LOCALES } & CIRCULACIONES \\
\hline Experimentación animal pequeño & $\begin{array}{l}01 \text { Recepción animal } \\
02 \text { Estabulación convencional roedores }\end{array}$ & $\begin{array}{l}17 \text { Quirófano experimental } \\
18 \text { Preparación médica }\end{array}$ & - Personal \\
\hline Experimentación animal grande & $\begin{array}{l}03 \text { Estabulación convencional conejos } \\
04 \text { Estabulación convencional animal grande }\end{array}$ & $\begin{array}{l}19 \text { A. material estéril } \\
20 \text { Necropsias }\end{array}$ & - Animales \\
\hline Áreas comunes animal pequeño y grande & $\begin{array}{l}05 \text { Cuarentena roedores } \\
06 \text { Cuarentena conejos }\end{array}$ & $\begin{array}{l}21 \text { Cirugía cadáveres } \\
22 \text { Lavado y esterilización }\end{array}$ & — Suministro materiales \\
\hline Área Administrativa & $\begin{array}{l}07 \text { Cuarentena animal grande } \\
08 \text { Estabulación barrera animal pequeño }\end{array}$ & $\begin{array}{l}23 \text { Vestuarios / Aseos } \\
24 \text { Esclusa animales }\end{array}$ & --- Retirada de residuos \\
\hline Pasillos comunes & $\begin{array}{l}09 \text { Experimentación ABSL2 - 09* ABSL3 } \\
10 \text { Experimentación peces }\end{array}$ & $\begin{array}{l}25 \text { Esclusa personas } \\
26 \text { Esclusa materiales }\end{array}$ & \\
\hline Pasillos exteriores y servicios generales & $\begin{array}{l}11 \text { Lavado animal } \\
12 \text { Preparación animal }\end{array}$ & $\begin{array}{l}27 \text { Almacén / archivo } \\
28 \text { Servicios }\end{array}$ & \\
\hline Elementos de circulación vertical & $\begin{array}{l}13 \text { Procedimientos } \\
14 \text { Microcirugia } \\
15 \text { Comportamiento } \\
16 \text { Imagen }\end{array}$ & $\begin{array}{l}29 \text { Despacho } \\
30 \text { Sala reuniones } \\
31 \text { Pasillo } \\
32 \text { Otros }\end{array}$ & \\
\hline
\end{tabular}

Figura 59. Unidad estabulación animal grande IISA (S/E). Fuente. Elaboración propia. 
La unidad de estabulación de animal grande del instituto VHIR (Figura 60) se sitúa en una planta con acceso directo desde el exterior, de manera que los suministros de animales, materiales y retirada de residuos se introducen directamente desde el exterior al área de estabulación. Por otra parte, el personal investigador y el personal al cuidado de los animales accede por zonas compartidas con el área de experimentación animal pequeño, de manera que ambos circuitos confluyen en el área de estabulación.

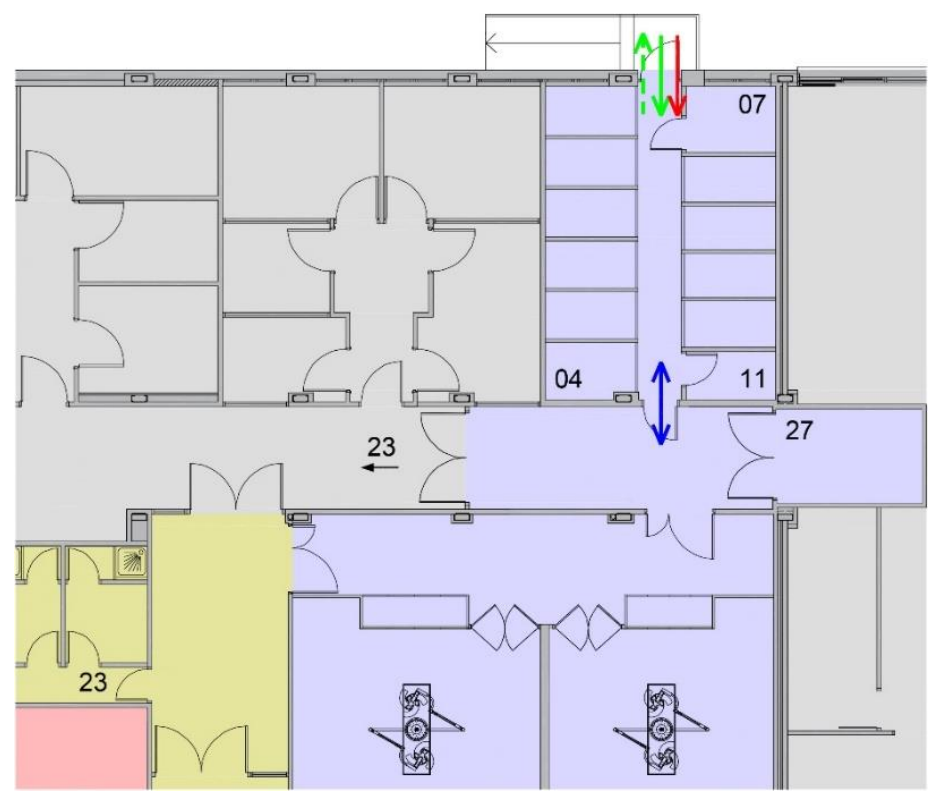

ÁREAS FUNCIONALES

Experimentación animal pequeño

Experimentación animal grande

Áreas comunes animal pequeño y grande

Área Administrativa

Pasillos comunes

Pasillos exteriores y servicios generales

Elementos de circulación vertical

\section{IDENTIFICACIÓN USO LOCALES}

01 Recepción animal

02 Estabulación convencional roedores

03 Estabulación convencional conejos

17 Quirófano experimental

18 Preparación médic

19 A. material estéril

05 Cuarentena roedores 21 Cirugía cadáveres

06 Cuarentena conejos

07 Cuarentena animal grande

08 Estabulación barrera animal pequeño

09 Experimentación ABSL2 - 09* ABSL3

10 Experimentación peces

11 Lavado animal

12 Preparación animal

13 Procedimientos

14 Microcirugia

15 Comportamiento

16 Imagen
23 Vestuarios / Aseos

24 Esclusa animales

25 Esclusa personas

26 Esclusa materiales

27 Almacén / archivo

28 Servicios

29 Despacho

30 Sala reuniones

31 Pasillo

32 Otros
22 Lavado y esterilización
CIRCULACIONES

- Personal

- Animales

_ Suministro materiales

- - - Retirada de residuos

Figura 60. Unidad estabulación animal grande VHIR (S/E).

Fuente. Elaboración propia. 
La unidad de estabulación de animal grande del instituto IGTP (Figura 61) se sitúa en una planta semisótano con acceso directo desde el exterior. Esta unidad está formada por tres salas de estabulación compuestas por ocho boxes cada una. Los suministros de animales, materiales y retirada de residuos se introducen directamente desde el exterior al área de estabulación; en cambio, el personal investigador accede al edificio por la entrada principal ubicada en la planta baja, de manera que para acceder al área de estabulación es necesario hacer uso de los elementos de comunicación vertical diseñados para tal fin.

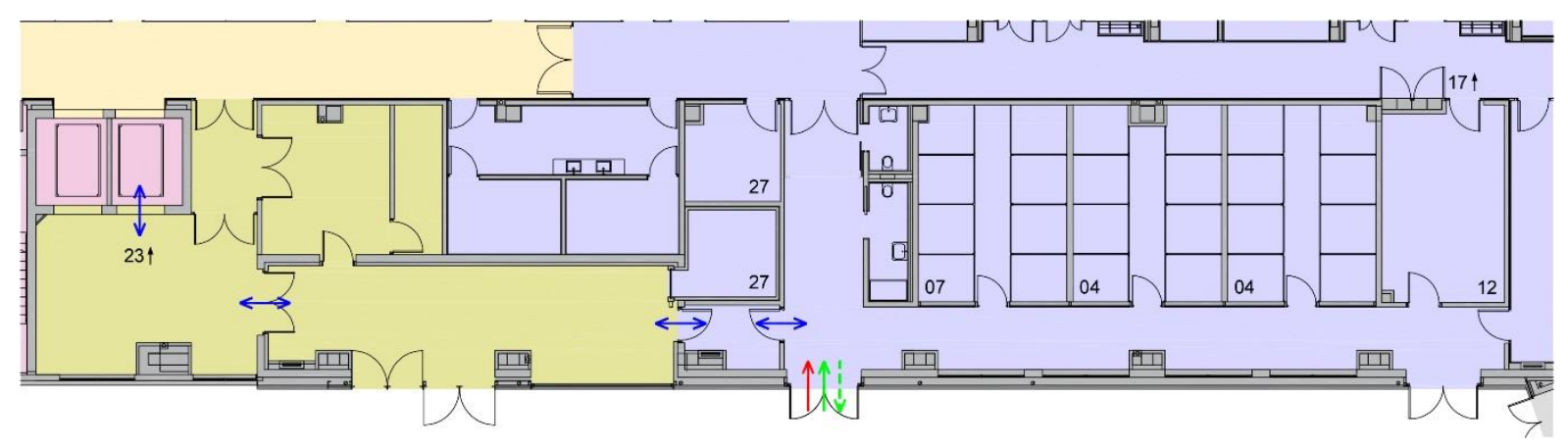

ÁREAS FUNCIONALES

Experimentación animal pequeño

Experimentación animal grande

Áreas comunes animal pequeño y grande

Área Administrativa

Pasillos comunes

Pasillos exteriores y servicios generales

Elementos de circulación vertical
IDENTIFICACIÓN USO LOCALES

\begin{tabular}{|c|c|}
\hline 01 Recepción animal & 17 Quirófano experimental \\
\hline 02 Estabulación convencional roedores & 18 Preparación médica \\
\hline 3 Estabulación convencional conejos & 19 A. material estéril \\
\hline 04 Estabulación convencional animal grande & 20 Necropsias \\
\hline 05 Cuarentena roedores & 21 Cirugía cadáveres \\
\hline 06 Cuarentena conejos & 22 Lavado y esterilización \\
\hline 7 Cuarentena animal grande & 23 Vestuarios / Aseos \\
\hline 08 Estabulación barrera animal pequeño & 24 Esclusa animales \\
\hline 09 Experimentación ABSL2 - 09* ABSL3 & 25 Esclusa personas \\
\hline 10 Experimentación peces & 26 Esclusa materiales \\
\hline 11 Lavado animal & 27 Almacén / archivo \\
\hline 12 Preparación animal & 28 Servicios \\
\hline 13 Procedimientos & 29 Despacho \\
\hline 14 Microcirugia & 30 Sala reuniones \\
\hline 5 Comportamiento & 31 Pasillo \\
\hline 16 Imagen & 32 Otros \\
\hline
\end{tabular}

01 Recepción animal

05 Cuarentena roedores

07 Cuarentena animal gran

13 Procedimientos

15 Comportamient
CIRCULACIONES

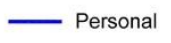

- Animales

Suministro materiales

- - - Retirada de residuos

Figura 61. Unidad estabulación animal grande IGTP (S/E).

Fuente. Elaboración propia. 
La unidad de estabulación de animal grande del instituto IIS La Fe (Figura 62) se encuentra en una planta bajo rasante en el que existe un núcleo de comunicación vertical de uso exclusivo para el animalario. Esta unidad se componde de una sala de cuarentena para animales grandes y dos salas de estabulación junto a los quirófanos que están comunicadas entre sí; una con dos corrales para alojamiento social; y otra, con cuatro habitáculos individuales prequirúrgicos. Están dispuestos de tal manera que solo una de las salas está comunicada con la zona de acceso al quirófano. No se concibe como una unidad independiente, sino que se integra en el conjunto del área de experimentación animal.

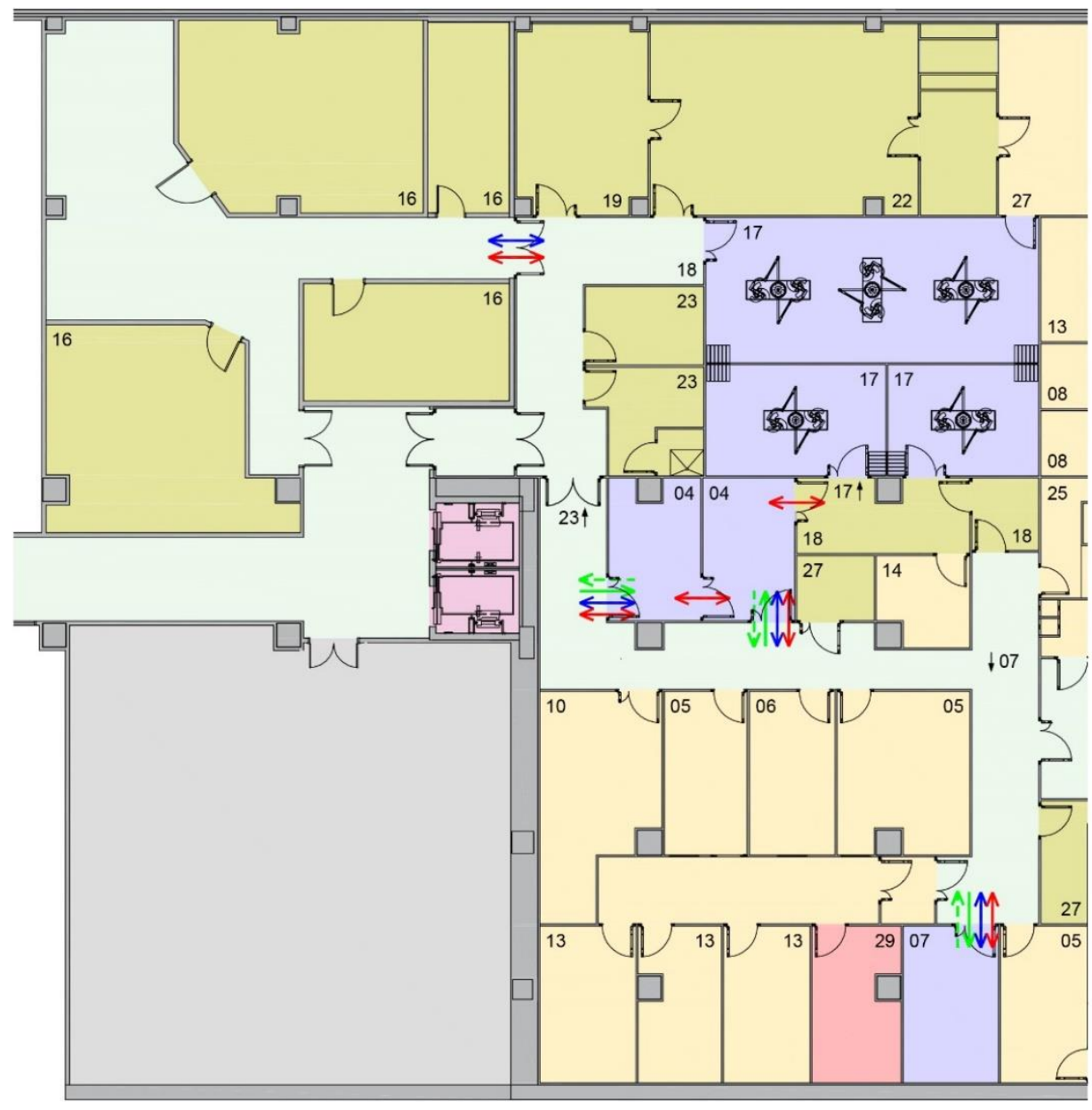

ÁREAS FUNCIONALES

Experimentación animal pequeño

Experimentación animal grande

Áreas comunes animal pequeño y grande

Área Administrativa

Pasillos comunes

Pasillos exteriores y servicios generales

Elementos de circulación vertical

\section{IDENTIFICACIÓN USO LOCALES}

01 Recepción animal

02 Estabulación convencional roedores

03 Estabulación convencional conejos

04 Estabulación convencional animal grande 20 Necropsias

05 Cuarentena roedores 21 Cirugía cadáveres

06 cuarentena con

07 Cuarentena animal grande

08 Estabulación barrera animal pequeño

09 Experimentación ABSL2 - 09* ABSL3

10 Experimentación peces

11 Lavado animal

12 Preparación animal

13 Procedimientos

14 Microcirugia

15 Comportamiento

16 Imagen
21 Cirugía cadáveres

22 Lavado y esterilización

23 Vestuarios / Aseos

24 Esclusa animales

25 Esclusa personas

26 Esclusa materiales

27 Almacén / archivo

28 Servicios

29 Despacho

30 Sala reuniones

31 Pasillo

32 Otros

Figura 62. Unidad estabulación animal grande IIS La Fe (S/E).

Fuente. Elaboración propia. 


\subsubsection{Características generales de la unidad de estabulación animal grande}

El resultado de la investigación sobre las características generales de la unidad de estabulación de animal grande se encuentra reflejado tanto en las fichas de la documentación gráfica como en la toma de datos de cada centro.

Para realizar el análisis de dichas características se ha hecho una puesta en común de los resultados obtenidos; y, para ello, se ha optado por resumir las más importantes en una tabla (Tabla 04). En ella se listan los parámetros que definen las características generales de la unidad de estabulación, se establecen cuáles son las características comunes a la mayoría de ellas y se identifica qué institutos cumplen dichas características; además, se determinan las características particulares y específicas, que son aquellas que las cumplen solo unos determinados institutos, reflejándose así mismo, los institutos que las cumplen. El análisis se centra en los siguientes conceptos:

- Analizar las especies animales estabuladas en esta área, y, por lo tanto, las más utilizadas en experimentación de animal grande y las que eventualmente se utilizan.

- Conocer el dimensionamiento del centro analizando la superficie destinada al alojamiento de los animales, así como el número de salas y boxes de estabulación.

- Estudiar el tipo de alojamiento diseñado para estas especies.

- Analizar los locales de servicio de esta área, así como el sistema de almacenaje de residuos animales utilizado en cada caso, previa a su retirada por el gestor autorizado correspondiente. 
Tabla 04. Características generales unidad estabulación animal grande.

\begin{tabular}{|c|c|c|c|c|}
\hline Parámetros & $\begin{array}{l}\text { Características } \\
\text { comunes }\end{array}$ & $\begin{array}{c}\text { Institutos con } \\
\text { características } \\
\text { comunes } \\
\end{array}$ & $\begin{array}{l}\text { Características } \\
\text { específicas }\end{array}$ & $\begin{array}{c}\text { Institutos con } \\
\text { características } \\
\text { específicas } \\
\end{array}$ \\
\hline $\begin{array}{l}\text { Superficie locales } \\
\text { alojamiento animal } \\
\text { grande }\end{array}$ & $<50 \mathrm{~m}^{2}$ & $\begin{array}{l}\text { IdiPAZ, i+12, liSGM, } \\
\text { IISBiodonostia, } \\
\text { IISBiocruces, VHIR, IISLaFe }\end{array}$ & $>50 \mathrm{~m}^{2}$ & $\begin{array}{l}\text { IRYCIS, IISA, } \\
\text { IGTP }\end{array}$ \\
\hline Especies animales & Cerdo, Oveja, Cabra & $\begin{array}{l}\text { IdiPAZ, i+12, IiSGM, } \\
\text { IRYCIS, IISBiodonostia, } \\
\text { IISBiocruces, IGTP, IISA, } \\
\text { VHIR, IIS La Fe }\end{array}$ & Perro/Gato & IdiPAZ, IRYCIS \\
\hline $\begin{array}{l}\text { Conejos estabulados } \\
\text { con animal grande }\end{array}$ & NO & $\begin{array}{l}\text { i+12, liSGM, } \\
\text { IISBiodonostia, } \\
\text { IISBiocruces, VHIR, IGTP, } \\
\text { IIS La Fe }\end{array}$ & $\mathrm{SI}$ & $\begin{array}{l}\text { IdiPAZ, IISA, } \\
\text { IRYCIS }\end{array}$ \\
\hline Tipo de alojamiento & $\begin{array}{l}\text { Cuarentena } Y \\
\text { Convencional }\end{array}$ & $\begin{array}{l}\text { IdiPAZ, i+12, IiSGM, } \\
\text { IRYCIS, IISBiodonostia, } \\
\text { IISBiocruces, IISA, VHIR, } \\
\text { IGTP, IIS La Fe }\end{array}$ & & \\
\hline $\begin{array}{l}\text { № locales de } \\
\text { alojamiento }\end{array}$ & $2 \mathrm{Ud}$ & $\begin{array}{l}\text { IdiPAZ, i+12, liSGM, } \\
\text { IRYCIS, IISBiodonostia, } \\
\text { IISBiocruces, VHIR, IISLaFe }\end{array}$ & $>2 \mathrm{Ud}$ & IGTP, IISA \\
\hline $\begin{array}{l}\text { Sala limpieza y } \\
\text { aclimatación }\end{array}$ & NO & $\begin{array}{l}\text { IdiPAZ, i+12, IiSGM, } \\
\text { IRYCIS, IISBiodonostia, , } \\
\text { VHIR, IGTP, IIS La Fe }\end{array}$ & $\mathrm{SI}$ & $\begin{array}{l}\text { IISBiocruces, } \\
\text { IISA }\end{array}$ \\
\hline Sala de necropsias & NO & $\begin{array}{l}\text { IdiPAZ, i+12, liSGM, } \\
\text { IRYCIS, IISBiodonostia, } \\
\text { VHIR, IIS La Fe }\end{array}$ & $\mathrm{SI}$ & $\begin{array}{l}\text { IISBiocruces, } \\
\text { IISA, IGTP }\end{array}$ \\
\hline $\begin{array}{l}\text { Sistema almacenaje } \\
\text { Residuo animal }\end{array}$ & Congelador $-20^{\circ} \mathrm{C}$ & $\begin{array}{l}\text { IdiPAZ, i+12, IiSGM, } \\
\text { IRYCIS, IISA, VHIR, IIS La Fe }\end{array}$ & $\begin{array}{l}\text { Cámara frigorífica } 4 \text { ํC } \\
\text { Almacén }\end{array}$ & $\begin{array}{l}\text { IIS Biocruces, } \\
\text { IGTP } \\
\text { IISBiodonostia }\end{array}$ \\
\hline
\end{tabular}

Fuente. Elaboración propia.

\section{Superficie del área de alojamiento de animales}

El dimensionamiento del área de estabulación de animal grande está determinado fundamentalmente por las líneas de investigación del centro, así como por los criterios de gestión implantados. Observamos cómo la mayoría de los centros tienen una superficie inferior a $50 \mathrm{~m}^{2}$ destinada al alojamiento de estos animales. Esta superficie, que es más bien reducida, atiende a que en general no interesa tener estabulados gran cantidad de animales grandes por largos periodos de tiempo, ya que los institutos están ubicados en el recinto hospitalario y estos animales se consideran sucios y ruidosos. Lo habitual es que la estancia media de estos animales en el centro sea de cuarenta y ocho horas, de manera que el suministro de los mismos se planifica según la actividad quirúrgica programada, $y$, así poder reducir tanto el número como el tiempo de estancia de los animales en el centro al mínimo.

\section{Especies animales}

La especie animal más utilizada hoy en día en cirugía experimental observamos que es el cerdo o cerdo en miniatura, ya que este tipo de modelos animales se utilizan en todos los centros de experimentación, si bien la oveja y la cabra, aunque en menor medida, también se usan. En relación al perro y el gato, observamos cómo hace unos años eran especies con las que era más habitual 
investigar, y es por lo que en el IRYCIS, la zona de estabulación se diseñó para estas especies animales. En la actualidad, en cambio, su uso es muy poco frecuente, y se reduce prácticamente a su experimentación con cadáveres (IdiPAZ).

En cuanto a los conejos se refiere, como hemos comentado anteriormente, están en una categoría entre los animales pequeños y grandes, ya que se consideran animales grandes debido a que los requisitos para la cirugía siguen las directrices de animales grandes; sin embargo, como hemos visto en este estudio, en la mayoría de los casos, los conejos se alojan junto a las salas de estabulación de Ios roedores. Como casos diferentes podemos destacar el IdiPAZ e IRYCIS. En ambos casos, los conejos se estabulan en el área de estabulación de animal grande. Por otra parte, podemos destacar el IISA, ya que al haberse diseñado específicamente un área quirúrgica experimental, en su zona de estabulación se concentran todos los animales con los que se van a realizar prácticas quirúrgicas; los animales grandes, los conejos y los roedores.

Cada especie se encuentra alojada de manera independiente en sus salas de estabulación, ya que los animales deben de estar alojados en locales separados por cada especie: en primer lugar, porque las especies que sean incompatibles no pueden alojarse en el mismo local; además, en el caso concreto de los depredadores y sus presas, deberán estar fuera del alcance de su vista, olfato u oído; y, en segundo lugar, porque cada especie y grupo de edad de los animales requiere unas condiciones ambientales en cuanto a temperatura y humedad relativa diferentes ( RD53/2013 Anexo II).

\section{Tipo de locales de alojamiento}

En este tipo de centros, los animales grandes están alojados de manera convencional, siendo lo habitual que existan dos locales de alojamiento diferentes, de tal manera de que uno de ellos se pueda utilizar como área de estabulación general y, el otro, como zona de cuarentena o como zona de aislamiento, según establezcan las necesidades del centro (Tabla 05). Como centros que destacan por su mayor dimensionamiento de esta área están, por una parte, el IGTP, que dispone de tres salas de alojamiento con ocho boxes cada una; y, por la otra, el IISA, que dispone de cuatro salas de alojamiento para animal grande con un total de veinticuatro boxes para alojamiento de cerdos.

Observamos como los corrales o boxes de alojamiento de animales, en la mayoría de los casos, se han diseñado para alojar la especie actualmente más utilizada en cirugía experimental: el cerdo o cerdo en miniatura. 


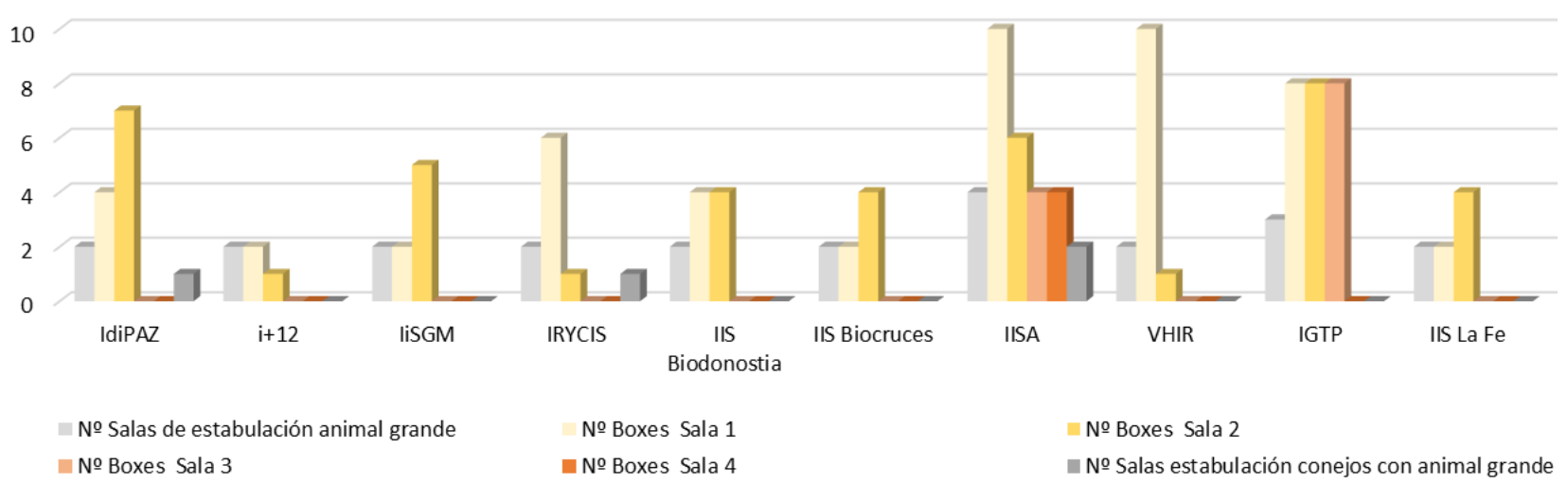

Tabla 05. Identificación de salas y boxes de estabulación en área alojamiento animal grande.

Fuente. Elaboración propia.

El dimensionamiento mínimo del recinto donde van a vivir los animales viene definido en el RD53/2013 (Figura 63). En ella observamos cómo las dimensiones del recinto varían en función de la especie animal y de su peso corporal, de manera que en función de dichos parámetros se establecen tanto las dimensiones mínimas del recinto en $\mathrm{m}^{2}$, así como la superficie mínima y de reposo necesaria por animal. En el caso de los ovinos se establece la altura mínima de separación entre recintos, incluso la longitud necesaria para el comedero.

\begin{tabular}{l|c|c|c|c|c}
\hline \multicolumn{1}{c}{ Cuadro 7.2 Ovinos y caprinos } \\
$\begin{array}{l}\text { Peso corporal } \\
(\mathrm{kg})\end{array}$ & $\begin{array}{c}\text { Dimensión } \\
\text { mínima del } \\
\text { recinto } \\
(\mathrm{m} 2)\end{array}$ & $\begin{array}{c}\text { Superficie } \\
\text { mínima de } \\
\text { suelo/ } \\
\text { animal } \\
\text { (m2/animal) }\end{array}$ & $\begin{array}{c}\text { Altura } \\
\text { mínima de } \\
\text { las } \\
\text { separaciones } \\
\text { entre recintos }\end{array}$ & $\begin{array}{c}\text { Longitud de } \\
\text { comedero } \\
\text { para la } \\
\text { alimentación } \\
\text { ad libitum } \\
\text { (m/animal) }\end{array}$ & $\begin{array}{c}\text { Longitud de } \\
\text { comedero } \\
\text { para la } \\
\text { alimentación } \\
\text { restringida } \\
\text { (m/animal) }\end{array}$ \\
\hline Menos de 20. & 1,0 & 0,7 & 1,0 & 0,10 & 0,25 \\
De más de 20 a 35. & 1,5 & 1,0 & 1,2 & 0,10 & 0,30 \\
De más de 35 a 60. & 2,0 & 1,5 & 1,2 & 0,12 & 0,40 \\
Más de 60. & 3,0 & 1,8 & 1,5 & 0,12 & 0,50 \\
\hline
\end{tabular}

\section{Cuadro 7.3 Cerdos y cerdos enanos}

\begin{tabular}{l|c|c|c}
\multicolumn{4}{c}{ Cuadro 7.3 Cerdos y cerdos enanos } \\
$\begin{array}{c}\text { Peso en vivo } \\
\text { (kg) }\end{array}$ & $\begin{array}{c}\text { Dimensión } \\
\text { mínima del } \\
\text { recinto* } \\
(\mathrm{m} 2)\end{array}$ & $\begin{array}{c}\text { Superficie } \\
\text { mínima de } \\
\text { suelo por } \\
\text { animal } \\
\text { (m2/animal) }\end{array}$ & $\begin{array}{c}\text { Zona de reposo } \\
\text { mínima por } \\
\text { animal (en } \\
\text { condiciones } \\
\text { térmicamente } \\
\text { neutras } \\
\text { (m2/animal) }\end{array}$ \\
\hline Hasta 5. & 2,0 & 0,20 & 0,10 \\
De más de 5 a 10. & 2,0 & 0,25 & 0,11 \\
De más de 10 a 20. & 2,0 & 0,35 & 0,18 \\
De más de 20 a 30. & 2,0 & 0,50 & 0,24 \\
De más de 30 a 50. & 2,0 & 0,70 & 0,33 \\
De más de 50 a 70. & 3,0 & 0,80 & 0,41 \\
De más de 70 a 100. & 3,0 & 1,00 & 0,53 \\
De más de 100 a 150. & 4,0 & 1,35 & 0,70 \\
Más de 150. & 5,0 & 2,50 & 0,95 \\
Verracos adultos (convencionales) & 7,5 & & 1,30 \\
\hline
\end{tabular}

Figura 63. Dimensionamiento de corrales para animales grandes. Fuente. RD 53/2013 Anexo II Sección B: Secciones específicas. 
Teniendo en cuenta que el dimensionamiento de los alojamientos viene determinado por la especie animal, la edad o peso de los mismos, así como por el número de animales que se quiere alojar, y que la especie más utilizada es el cerdo o cerdo en miniatura, la superficie destinada habitualmente es de 2,00 $\mathrm{m}^{2}$. Este dimensionamiento de los corrales permite también alojar los animales ovinos; además, como analizaremos en detalle más adelante, muchos de los centros disponen de un diseño modular de los locales de alojamiento, lo que permite no solo estabular este tipo de animales, sino que ofrece la posibilidad de unir varios boxes para ampliar la superficie disponible y, por lo tanto, poder alojar especies con requerimientos dimensionales mayores.

\section{Locales que componen la unidad}

Por otra parte, en muchos casos, la práctica quirúrgica desarrollada en esta zona es una actividad terminal, por lo que los residuos animales, tales como, cadáveres, residuos anatómicos o cualquier otro residuo contaminado, son almacenados en el centro, en locales destinados a este fin hasta su retirada por el gestor autorizado correspondiente. En lo referente al sistema de almacenaje de residuos animales, la mayoría de los centros disponen de congeladores de $-20^{\circ} \mathrm{C}$, si bien observamos cómo algunos centros se organizan con un simple local de almacenamiento, y en otros casos, se ha diseñado una cámara frigorífica por debajo de los $4^{\circ} \mathrm{C}$ para su almacenamiento durante un periodo determinado de tiempo y acorde a la normativa autonómica de gestión de residuos vigente.

En relación al resto de las diferentes salas que completan esta unidad, observamos que en la mayoría de los casos no existe una zona de recepción animal específica, sino que la recepción animal se realiza en el punto de entrega de los animales al edificio. Además, es muy habitual que la zona de limpieza y aclimatación sea la zona destinada a cuarentena, siendo unos pocos casos los que disponen de una zona específica para este uso (IIS Biocruces, IISA). Por otra parte, es muy habitual que las tareas de necropsias se realicen en el propio quirófano, es por lo que nos encontramos unos pocos casos en los que se dispone de una sala específica destinada a este fin (IIS Biocruces, IISA, IGTP). 


\subsubsection{Criterio organizativo de la unidad de estabulación animal grande}

Los conceptos que definen la organización de la unidad de estabulación animal grande quedan recogidos en las fichas de toma de datos elaborada para cada uno de los institutos. En este apartado se pretende hacer una puesta en común de los resultados obtenidos sobre la organización y distribución de la unidad de estabulación de animal grande.

Las salas de estabulación son los locales donde van a vivir los animales con los que se va a experimentar y donde confluyen los distintos tráficos de la unidad: los animales, el personal responsable del cuidado y bienestar animal, el suministro de materiales y la retirada de residuos.

Para comprender la organización de la unidad de estabulación, hemos de tener presentes; por una parte, la importancia de la segregación de los accesos del personal, de los suministros, animales y retirada de residuos comentada anteriormente; $y$, por otra parte, los flujos de trabajo internos del área de estabulación de animal grande (Figura 64). Según observamos en el esquema, los animales se reciben en una zona destinada a la recepción animal. Los animales grandes son animales que es habitual que lleguen sucios, por lo que previo al ingreso, se suele lavarles para a continuación trasladarlos a la zona de estabulación. Desde esta zona serán trasladados a la zona de experimentación para una vez finalizada la investigación bien reingresarlos en la zona de estabulación previo paso por la zona de recuperación postanestésica, o bien trasladarlos a la zona de almacenaje de residuo animal, hasta su retirada por parte del gestor autorizado correspondiente.

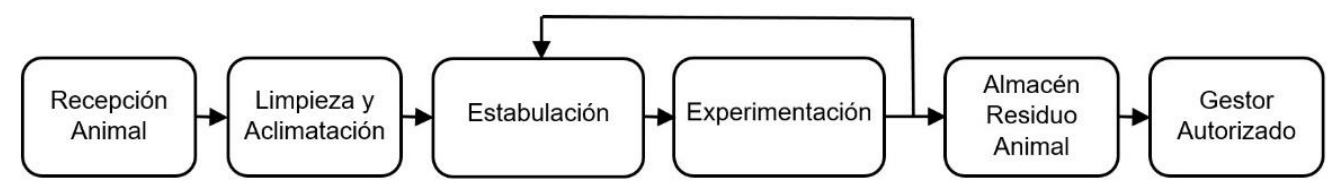

Figura 64. Esquema flujos de trabajo zona estabulación animal grande.

Fuente. Elaboración propia.

A la hora de diseñar las salas de alojamiento de animales, hay que tener en cuenta que es muy importante considerar no solo las necesidades actuales, sino también los posibles requerimientos futuros, ya que en la mayoría de los animalarios, el uso de animales varía de acuerdo a los cambios del personal investigador y de los proyectos a desarrollar (Neil 2003, p. 17). 
Para realizar el análisis de la distribución y organización de la unidad se ha hecho una puesta en común de los resultados obtenidos; $y$, para ello, se ha optado por resumir las características más importantes que lo definen en una tabla (Tabla 06). En ella se listan los parámetros que definen la organización de la unidad de estabulación, se establecen cuáles son las características comunes a la mayoría de ellas y se identifica qué institutos cumplen dichas características; además, se determinan las características que son particulares y específicas, reflejándose así mismo, qué institutos las cumplen. El análisis se centra en los siguientes conceptos:

- Ubicación de la planta, es decir, si se trata de un animalario ubicado en una planta a cota cero para lo cual no hace falta ningún elemento de comunicación vertical o en otras plantas diferentes.

- Tipos de accesos para organizar los suministros de animales, materiales, residuos y personal del centro.

- Comó se ha configurado la organización del área de estabulación de animal grande en relación al área de estabulación de animal pequeño; si son áreas totalmente independizadas, y en el caso de que no lo sean, estudiar cuáles son las áreas compartidas y las posibles afecciones.

Tabla 06. Organización unidad estabulación animal grande.

\begin{tabular}{|c|c|c|c|c|}
\hline Parámetros & $\begin{array}{l}\text { Características } \\
\text { comunes }\end{array}$ & $\begin{array}{l}\text { Institutos con } \\
\text { características } \\
\text { comunes }\end{array}$ & $\begin{array}{l}\text { Características } \\
\text { específicas }\end{array}$ & $\begin{array}{l}\text { Institutos con } \\
\text { características } \\
\text { específicas }\end{array}$ \\
\hline $\begin{array}{l}\text { Tipo de planta en la } \\
\text { que se ubica }\end{array}$ & Planta a cota cero & $\begin{array}{l}\text { i+12, liSGM, IRYCIS, } \\
\text { IISBiodonostia, } \\
\text { IISBiocruces, IISA, VHIR, } \\
\text { IGTP }\end{array}$ & Bajo rasante & IdiPAZ, IIS La Fe \\
\hline $\begin{array}{l}\text { Elementos de } \\
\text { circulación vertical }\end{array}$ & $\begin{array}{l}\text { No necesitan ascensores } \\
\text { para acceder al animalario }\end{array}$ & $\begin{array}{l}\text { i+12, liSGM, IRYCIS, } \\
\text { IISBiodonostia, } \\
\text { IISBiocruces, IISA, VHIR, } \\
\text { IGTP }\end{array}$ & $\begin{array}{l}\text { Si necesitan ascensores } \\
\text { para acceder al } \\
\text { animalario } \\
\text { Si necesitan ascensores } \\
\text { para traslados internos }\end{array}$ & $\begin{array}{l}\text { IdiPAZ, IIS La Fe } \\
\text { IdiPAZ }\end{array}$ \\
\hline $\begin{array}{l}\text { Accesos } \\
\text { independientes para } \\
\text { cuidadores /animales }\end{array}$ & SI & $\begin{array}{l}\text { IdiPAZ, IISBiodonostia, } \\
\text { IISBiocruces, IISA, VHIR, } \\
\text { IGTP }\end{array}$ & NO & $\begin{array}{l}\text { i+12, liSGM, } \\
\text { IRYCIS, IIS La Fe }\end{array}$ \\
\hline $\begin{array}{l}\text { Áreas estabulación } \\
\text { animal grande y } \\
\text { pequeño } \\
\text { independizadas }\end{array}$ & NO & $\begin{array}{l}\text { IdiPAZ, i+12, IiSGM, } \\
\text { IRYCIS, IISBiodonostia, } \\
\text { IISA, VHIR, IGTP, IIS La Fe }\end{array}$ & SI & IISBiocruces \\
\hline Zonas compartidas & $\begin{array}{l}\text { Vestuarios, Pasillos, } \\
\text { Almacenes }\end{array}$ & $\begin{array}{l}\text { IdiPAZ, i+12, IiSGM, } \\
\text { IRYCIS, IISBiodonostia, } \\
\text { IISA, VHIR, IGTP, IIS La Fe }\end{array}$ & $\begin{array}{l}\text { Comparten solo } \\
\text { vestuarios }\end{array}$ & VHIR, IGTP \\
\hline
\end{tabular}

Fuente. Elaboración propia.

\section{Ubicación en planta}

Según el estudio realizado, en la mayoría de los casos la estabulación de animal grande se distribuye en una planta con acceso directo desde el exterior, si bien en los casos en los que no se ha podido distribuir en este tipo de planta, la tendencia es ubicarlo en plantas bajo rasante (IdiPAZ, IIS La Fe). Es por lo tanto, en estos casos, cuando es necesario hacer uso de elementos de comunicación vertical para poder recepcionar los animales en la unidad de estabulación. En el caso conreto del IdiPAZ, 
también es necesario hacer uso internamente del elemento de comunicación vertical para trasladar los animales de la zona de estabulación a la zona de experimentación.

\section{Accesos}

Observamos que, aunque no siempre se ha conseguido, en la mayoría de los casos se dispone de dos accesos diferentes e independientes; uno para el acceso de personal y otro diferente para el suministro de animales, material limpio y retirada de residuos (IdiPAZ, IISBiodonostia, IISBiocruces, IISA, VHIR, IGTP).

\section{Organización con respecto al área de experimentación animal pequeño}

En cuanto a la independización completa de las áreas de estabulación de animal grande y pequeño, podemos concluir que solo en un caso (IIS Biocruces) son áreas totalmente independientes, en el sentido de que no comparten áreas de servicio, tales como, vestuarios, pasillos o almacenes. En el resto de los casos, si bien observamos algunos casos en los que la única área de servicio que es compartida es la zona de vestuario para cambio del personal al cuidado de los animales (VHIR, IGTP), lo habitual es que, además de los vestuarios, compartan también pasillos y almacenes.

En algún caso, el área de estabulación y experimentación animal grande se ha conseguido distribuir de forma compacta, de manera que se han evitado largos recorridos de circulación desde el área de estabulación de animal grande al área quirúrgica (IIS Biodonosti, IIS Biocruces, VHIR, IGTP). 


\subsubsection{Sistemas de estabulación animal grande}

Todos los animales deben ser alojados en condiciones que proporcionen espacio suficiente, así como contar con las estructuras y recursos adecuados para garantizar las necesidades físicas, fisiológicas y de comportamiento. Los entornos que no satisfacen las necesidades de los animales pueden dar lugar a un desarrollo cerebral anormal, disfunción fisiológica y trastornos del comportamiento, y eso puede comprometer tanto el bienestar animal como la validez científica. Además, un recinto de alojamiento apropiado también debe tener en cuenta las necesidades sociales de los animales, ya que los animales sociales deben alojarse en parejas estables o en grupos de individuos compatibles (National Research Council 2011, p. 50).

Como veremos durante el presente estudio, existen diferentes sistemas de alojamiento para los animales grandes, pero a la hora de diseñar cualquiera de esos sistemas, aparte de tener en cuenta la normativa vigente ${ }^{39}$, es importante tener presente los siguientes considerandos (National Research Council 2011, p. 51):

- Satisfacer las necesidades fisiológicas y de conducta de los animales incluyendo la micción y la defecación, el mantenimiento de la temperatura corporal, los movimientos normales y postura, y cuando esté indicado, la reproducción.

- Los animales deben permanecer limpios y secos de acuerdo a los requerimientos de cada especie.

- La instalación tiene que tener una ventilación adecuada.

- Los animales tienen que tener acceso al agua y al alimento.

- El recinto primario debe proporcionar un entorno seguro que no permita el escape de los animales.

- El recinto debe estar diseñado y fabricado para evitar el atrapamiento accidental de animales.

- Debe estar libre de bordes afilados o proyecciones que puedan causar lesiones a los animales o a las personas

- Se debe permitir la observación de los animales con la mínima molestia para ellos.

Para realizar el análisis de los diferentes sistemas de estabulación para animal grande adoptados en los centros se ha hecho una puesta en común de los resultados obtenidos; $y$, para ello, se ha optado por resumir las características más importantes en una tabla (Tabla 07). En ella se listan los parámetros que definen los sistemas constructivos de la estabulación, se establecen cuáles son las características comunes a la mayoría de ellos y se identifica qué institutos cumplen dichas características; además,

\footnotetext{
${ }^{39}$ RD 53/2013 de 1 de febrero, por el que se establecen las normas básicas aplicables para la protección de los animales
} utilizados en experimentación y otros fines científicos, incluyendo la docencia. 
se determinan las características que son particulares y específicas, reflejándose así mismo, cuales son los institutos que las cumplen. El análisis se centra en los siguientes conceptos:

- La composición de los boxes de estabulación, para ello se estudia si son boxes prefabricados o realizados in situ, si son modulares o fijos, la altura de los elementos divisorios entre boxes y por último, el tipo de box definido por el sistema de recogida y evacuación de los excrementos producidos por los animales: sobre foso, sobre pavimento o en jaulas.

- Las características constructivas generales del área de estabulación, tales como, la existencia o no de luz natural, la disposición de una planta inferior accesible y registrable y los materiales de acabado empleados.

- Los suministros básicos e instalaciones dotadas al área de estabulación, tales como la zona de recuperación postanestésica y el tipo de iluminación establecido.

Tabla 07. Sistemas constructivos de estabulación animal grande.

\begin{tabular}{|c|c|c|c|c|}
\hline Parámetros & $\begin{array}{l}\text { Características } \\
\text { comunes }\end{array}$ & $\begin{array}{l}\text { Institutos con } \\
\text { características } \\
\text { comunes }\end{array}$ & $\begin{array}{l}\text { Características } \\
\text { específicas }\end{array}$ & $\begin{array}{c}\text { Institutos con } \\
\text { características } \\
\text { específicas }\end{array}$ \\
\hline Boxes prefabricados & 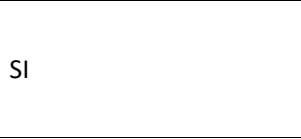 & $\begin{array}{l}\text { IdiPAZ, IiSGM, } \\
\text { IISBiodonostia, } \\
\text { IISBiocruces, IISA, IGTP, IIS } \\
\text { La Fe }\end{array}$ & Realizados in situ & $\begin{array}{l}\mathrm{i}+12, \quad \text { IRYCIS, } \\
\text { VHIR }\end{array}$ \\
\hline Boxes modulares & $\mathrm{SI}$ & $\begin{array}{l}\text { IdiPAZ, IiSGM, } \\
\text { IISBiodonostia, } \\
\text { IISBiocruces, IISA, VHIR, } \\
\text { IGTP, IIS La Fe }\end{array}$ & NO & $\mathrm{i}+12$, IRYCIS \\
\hline $\begin{array}{l}\text { Altura divisiones } \\
\text { entre boxes }\end{array}$ & Divisiones a media altura & $\begin{array}{l}\text { IdiPAZ, i+12, liSGM, } \\
\text { IRYCIS, IISBiodonostia, } \\
\text { IISBiocruces, IISA, VHIR, } \\
\text { IGTP, IIS La Fe }\end{array}$ & & \\
\hline $\begin{array}{l}\text { Tipo boxes de } \\
\text { alojamiento }\end{array}$ & Sobre foso & $\begin{array}{l}\text { IISBiodonostia, } \\
\text { IISBiocruces, IISA, IGTP }\end{array}$ & Sobre pavimento & $\begin{array}{l}\text { IdiPAZ, i+12, } \\
\text { IRYCIS, VHIR }\end{array}$ \\
\hline & & & En jaulas & liSGM, IIS La Fe \\
\hline $\begin{array}{l}\text { Refuerzo paramentos } \\
\text { verticales boxes }\end{array}$ & SI & $\begin{array}{l}\text { liSGM, IISBiodonostia, } \\
\text { IISBiocruces, IISA, IGTP }\end{array}$ & NO & $\begin{array}{l}\text { IdiPAZ, i+12, } \\
\text { IRYCIS, VHIR }\end{array}$ \\
\hline Curva sanitaria & SI & $\begin{array}{l}\text { IdiPAZ, i+12, liSGM, } \\
\text { IRYCIS, IISBiodonostia, } \\
\text { IISBiocruces, IISA, VHIR, } \\
\text { IGTP, IIS La Fe }\end{array}$ & & \\
\hline Iluminación natural & NO & $\begin{array}{l}\text { IdiPAZ, IISBiodonostia, } \\
\text { IISBiocruces, IISA, IGTP, } \\
\text { IIS La Fe }\end{array}$ & SI & $\begin{array}{l}\text { i+12, liSGM, } \\
\text { IRYCIS, VHIR, } \\
\text { IGTP }\end{array}$ \\
\hline $\begin{array}{l}\text { Planta inferior } \\
\text { acondicionada }\end{array}$ & $\mathrm{SI}$ & $\begin{array}{l}\text { IdiPAZ, IISBiocruces, IISA, } \\
\text { IGTP }\end{array}$ & NO & $\begin{array}{l}\text { i+12, liSGM, } \\
\text { IRYCIS, } \\
\text { IISBiodonostia, } \\
\text { VHIR, IIS La Fe }\end{array}$ \\
\hline $\begin{array}{l}\text { Planta técnica } \\
\text { superior transitable }\end{array}$ & NO & $\begin{array}{l}\text { IdiPAZ, i+12, liSGM, } \\
\text { IRYCIS, IISBiodonostia, } \\
\text { IISBiocruces, IISA, VHIR, } \\
\text { IGTP, IIS La Fe }\end{array}$ & & \\
\hline
\end{tabular}

Fuente. Elaboración propia. 


\section{Composición boxes de estabulación}

El diseño de las zonas de estabulación requiere de la mayor flexibilidad posible para poder cumplir con las necesidades de la investigación, no solo para las establecidas en el momento del diseño, sino también para poder adaptarse a las necesidades futuras. En este sentido es importante que los cambios se puedan implantar sin tener que realizar grandes modificaciones en las instalaciones existentes. De esta manera, la zona de alojamiento debería diseñarse para poder alojar especies diferentes con el paso del tiempo (Division of technical resources 2016, p. 134).

Según el estudio realizado, observamos que en la mayoría de los estabularios de animal grande los boxes de alojamiento se han realizado con elementos modulares, si bien los centros más antiguos se han ejecutado in situ con elementos de compartimentación tradicionales como son los tabiques de ladrillo raseados y pintados i+12, IRICYS o incluso con revestimiento cerámico IDIBAPS (Figura 65).

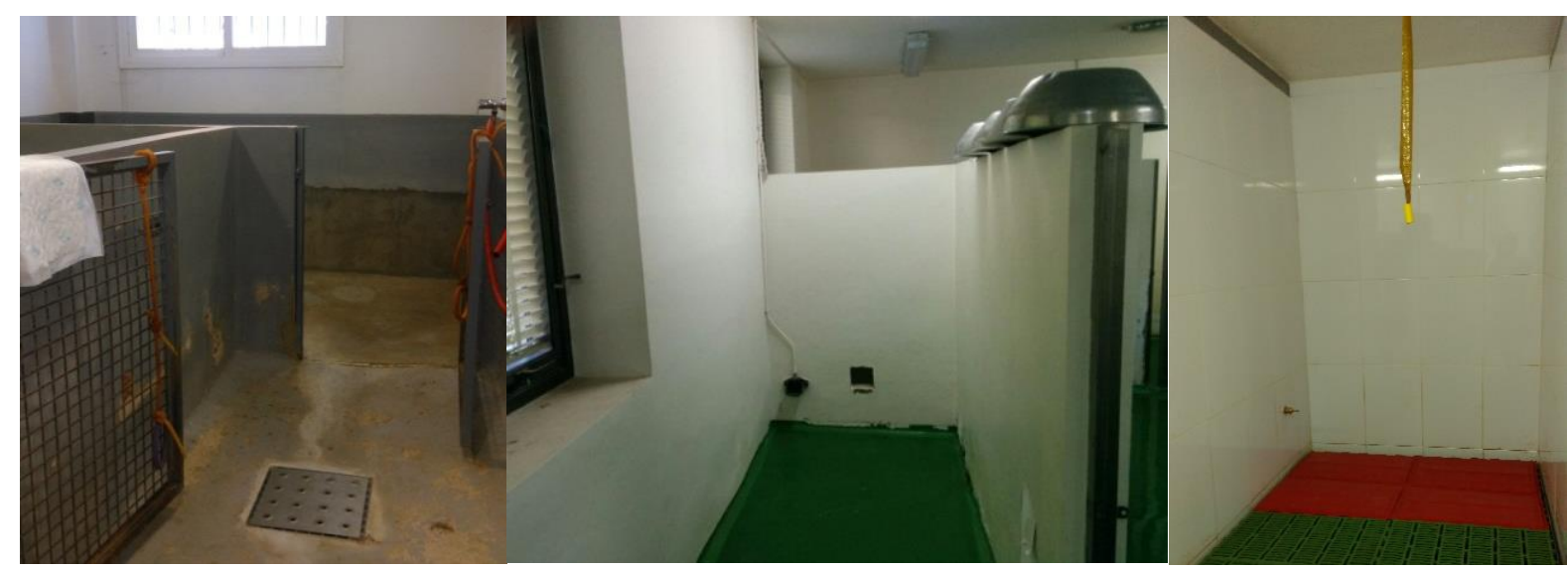

Figura 65. Compartimentación tradicional estabulación animal grande.

Fuente. Elaboración propia.

Por otra parte, vemos cómo entre los elementos modulares podemos diferenciar entre los que están realizados en taller según un diseño predeterminado; $y$, por la otra, los suministrados por diferentes casas comerciales y compuesto por paneles realizados a base de polipropileno (IISBiocruces, liSGM, IISA, IIS Biodonostia, IGTP). Entre las divisiones de boxes realizadas en taller se encuentra el IdiPAZ, que está compuesto por una estructura de bastidores de acero inoxidable y de paneles ciegos en su parte inferior realizados a base de resina fenólica (Figura 66). Estos sistemas de compartimentación prefabricada modular son los que posibilitan modificar la compartimentación de las zonas de estabulación de manera sencilla y permiten poder alojar animales de mayores dimensiones, y, por tanto, dotar a la instalación de mayor flexibilidad de cara al futuro.

En muchos casos, fundamentalmente en los que los boxes se han realizado con elementos modulares, se observa cómo el paramento vertical perimetral se ha optado por forrarlo con un elemento resistente al desgaste de los animales; en algún caso mediante los mismos paneles a los utilizados en 
la compartimentación de boxes (IISGM); y, en otros, incluso con forros de acero inoxidable (IIS Biocruces, IISA, IIS Biodonostia). En los centros analizados, los tabiques de separación entre boxes tienen una altura intermedia, si bien hemos visto algún caso (IDIBAPS) en el que los tabiques de separación eran continuos de suelo a techo.
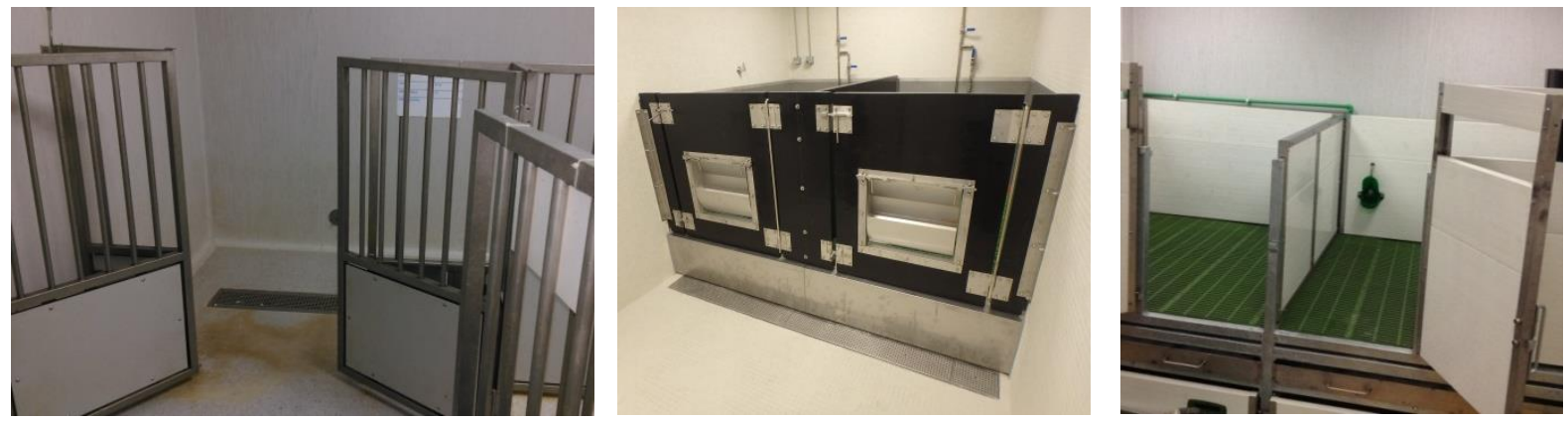

Figura 66. Compartimentación modular estabulación animal grande.

Fuente. Elaboración propia.

\section{Sistemas constructivos}

En cuanto al tipo de box definido por el sistema de recogida y evacuación de los excrementos producidos por los animales existen casuísticas diferentes. Por una parte, observamos cómo en algunos centros (IdiPAZ, i+12, IRYCIS) la estabulación de animales se realiza sobre el pavimento (Figura67). En este sistema de estabulación los residuos generados por los animales caen sobre el pavimento de la sala y para proceder a su retirada y limpieza, es habitual el uso de agua a presión, por lo que el pavimento debe estar correctamente impermeabilizado y diseñado con las pendientes suficientes y sumideros adecuados para garantizar la evacuación de las aguas residuales, siendo recomendable el uso de materiales continuos y antideslizantes como elementos de acabado.

Este sistema de estabulación puede ser una buena opción en los casos en los que la zona de estabulación se desarrolla sobre una losa de hormigón a la que se puede dar la pendiente necesaria para garantizar la limpieza de las salas y el rebaje suficiente para poder realizar el paquete de impermeabilización que garantice la estanqueidad del pavimento con respecto a la planta inferior. En cambio, puede ser un problema en los casos en los que se desarrolle sobre forjados, si no se ha previsto su implantación y en los que esté limitado la formación de pendientes necesaria para garantizar la correcta y rápida evacuación de los residuos.

Por otra parte, la normativa vigente establece que las paredes, los techos y los suelos deben estar recubiertos de un material impermeable cuando sea necesario y resistente al gran desgaste causado por los animales y las operaciones de limpieza. Ese material de revestimiento no debe ser perjudicial para la salud de los animales ni propiciar el que los animales se lastimen. Los dispositivos o accesorios 
deben protegerse especialmente para evitar que los animales los estropeen o se hieran (RD 53/2013 Anexo II).
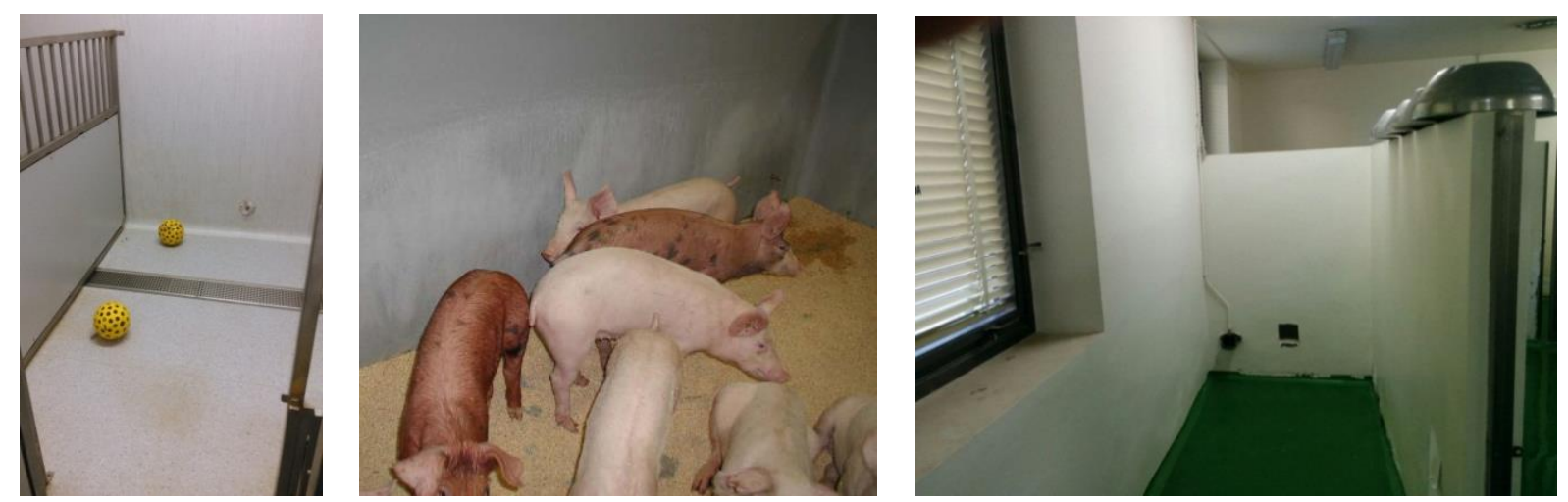

Figura 67. Sistemas de estabulación sobre pavimento animal grande.

Fuente. Elaboración propia.

Los materiales de acabado del pavimento habitualmente son a base de hormigón o de recrecido de mortero de cemento acabado en pintura o resina epoxi ( $i+12$, IRYCIS), o bien, con pavimento de PVC en rollo con juntas termosoldadas (IdiPAZ). En todos los casos, el encuentro entre el revestimiento vertical y horizontal se realiza mediante una curva sanitaria perimetral con el fin de evitar la acumulación de residuos y facilitar la limpieza.

Como se observa en las fotos, tanto los paramentos verticales como los horizontales que están en contacto con los animales grandes, son elementos que sufren una agresión permanente por parte de estos. Es por ello que se deberían evitar todo tipo de juntas en las salas de estabulación, ya que se convierten en puntos débiles a partir de los cuales comienza el deterioro del paramento. En el caso del i+12 (Figura 68), la unión del perfil metálico para el refuerzo de esquina con el raseo ha constituido el punto débil para que los animales estabulados hayan conseguido desprender el revestimiento vertical. Lo mismo ha ocurrido, en el caso del IdiPAZ, que las justas termosoldadas han sido el punto crítico para dañar tanto el revestimiento del paramento vertical como el del horizontal.
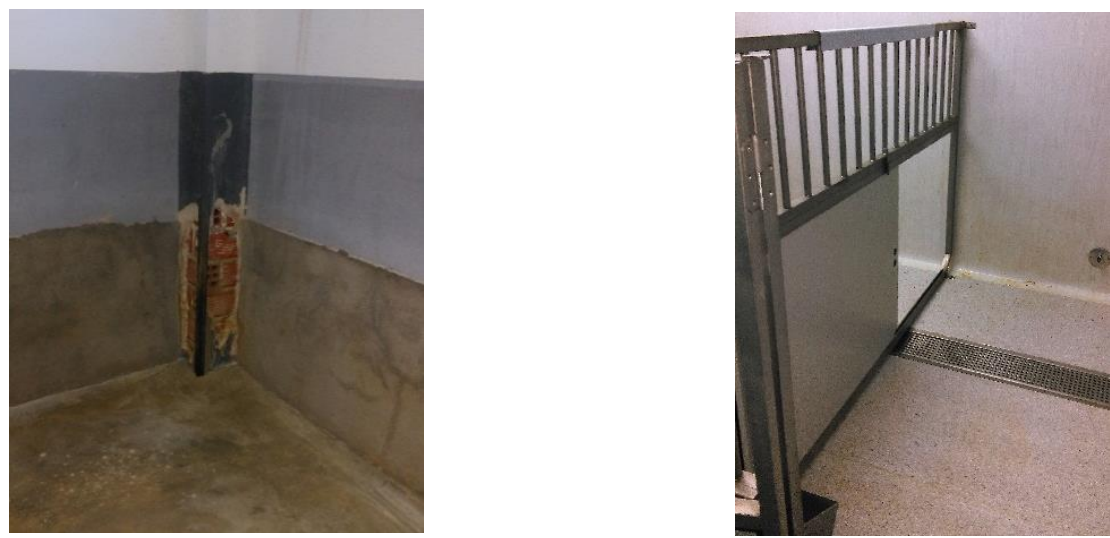

Imagen 68. Deterioro revestimiento en estabulación animal grande.

Fuente. Elaboración propia. 
Por otra parte, observamos cómo la tendencia en la elección del sistema estabulación de las nuevas instalaciones es realizarlo sobre foso (IIS Biodonostia, IIS Biocruces, IISA, IGTP). La característica fundamental de este sistema de estabulación es que se crea un foso para la recogida de excrementos de los animales, de tal manera que los animales se apoyan sobre un pavimento modular ranurado a través del cual se filtran todos los residuos generados por los animales para ser recogidos en el foso inferior que debe ser estanco e impermeable. Este foseado permite la posibilidad de distribuir una red de aspersores con agua caliente a presión para facilitar la limpieza de dichos excrementos. Otra de las ventajas que ofrece este sistema de pavimento modular es el poder instalar placas calefactadas para su uso como box de recuperación postoperatorio (Imagen 69 y 71).

En cuanto al material de acabado de los fosos de recogida de excrementos, interesa que sean materiales lo más impermeables posibles que a su vez permitan una rápida evacuación de los residuos. Observamos que los materiales habituales son a base de pinturas y resinas epoxi y, en algún caso, con el fin de garantizar una mayor protección frente al riesgo de inundación de la planta inferior, se ha optado por forrarlo formando un vaso estanco de acero inoxidable.

Aunque lo deseable sería que este foso se pudiera crear desde la cota del pavimento de planta hacia abajo, se observa cómo lo habitual es que el foso se cree sobre el propio forjado de planta, de tal manera que entre el pavimento de acabado y el foso se crea una altura de un peldaño aproximadamente. Para solventar esta circunstancia, se observa que en algún caso, (IDIBAPS) se ha optado por realizar un chaflán de pendiente pronunciada que evita el peldaño mencionado.
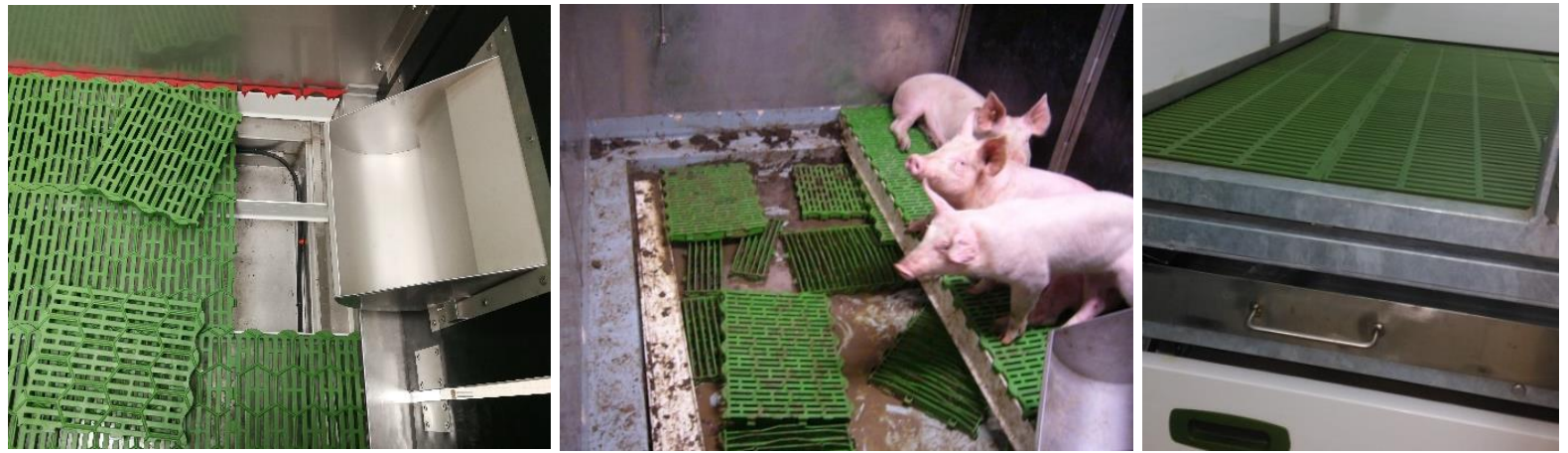

Figura 69. Sistema de estabulación sobre foso animal grande. Fuente. Elaboración propia.

Por último, observamos también que en algunos casos la estabulación se realiza en jaulas (IiSGM, IIS La Fe). Este tipo de alojamiento formado por jaulas elevadas e independientes (Figura 70) dispone de ruedas que permiten cambiarlos de ubicación, y puede ser útil en los casos en los que no se ha previsto desde el inicio la opción de estabular este tipo de animales. Tiene la versatilidad de que en un momento determinado la sala se puede destinar a otro uso retirando las jaulas, pero tiene el inconveniente de que los animales quedan estabulados muy altos con respecto al pavimento, lo que 
dificulta el manejo de los mismos. Cada jaula tiene un suministro independiente de agua, y los residuos generados por los animales caen sobre las bandejas de las jaulas, facilitando la limpieza. En estos sistemas de alojamiento, el pavimento de las salas están realizados a base de PVC en rollo con juntas termosoldadas, con la curva sanitaria perimetral como elemento de remate entre el revestimiento vertical y horizontal.
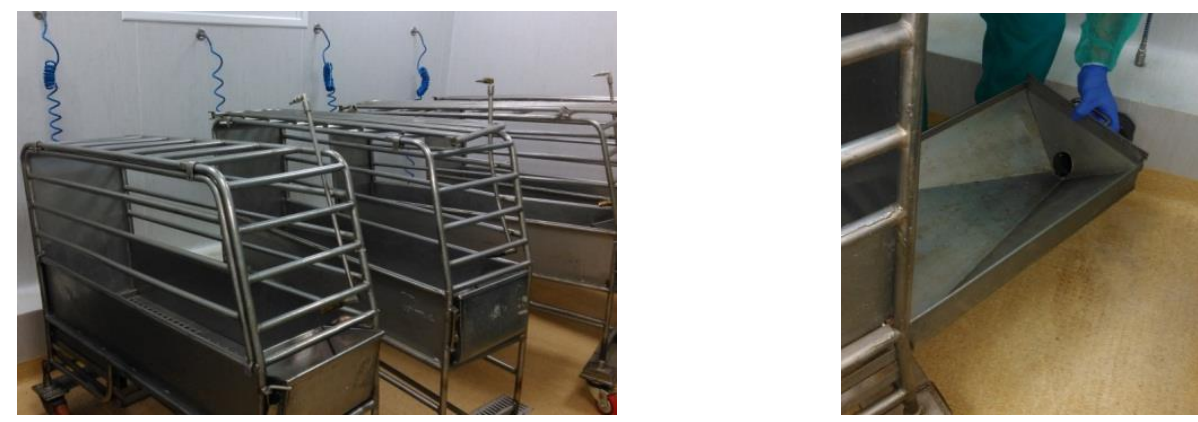

Figura 70. Sistema de estabulación en jaulas.

Fuente. Elaboración propia.

\section{Suministros e instalaciones básicas}

Los suministros básicos necesarios para los animales en la zona de estabulación son la bebida y la comida; y la cama en el caso de que los animales sean estabulados sobre pavimento. Vemos que en muchos casos en la zona de estabulación se ha habilitado una zona específica para la recuperación postanestésica de los animales. En estos casos, lo habitual es dotar al box de estabulación de los gases medicinales necesarios para su recuperación, e incluso la instalación de placas calefactadas para el caso de estabulación sobre foso (Figura 71).
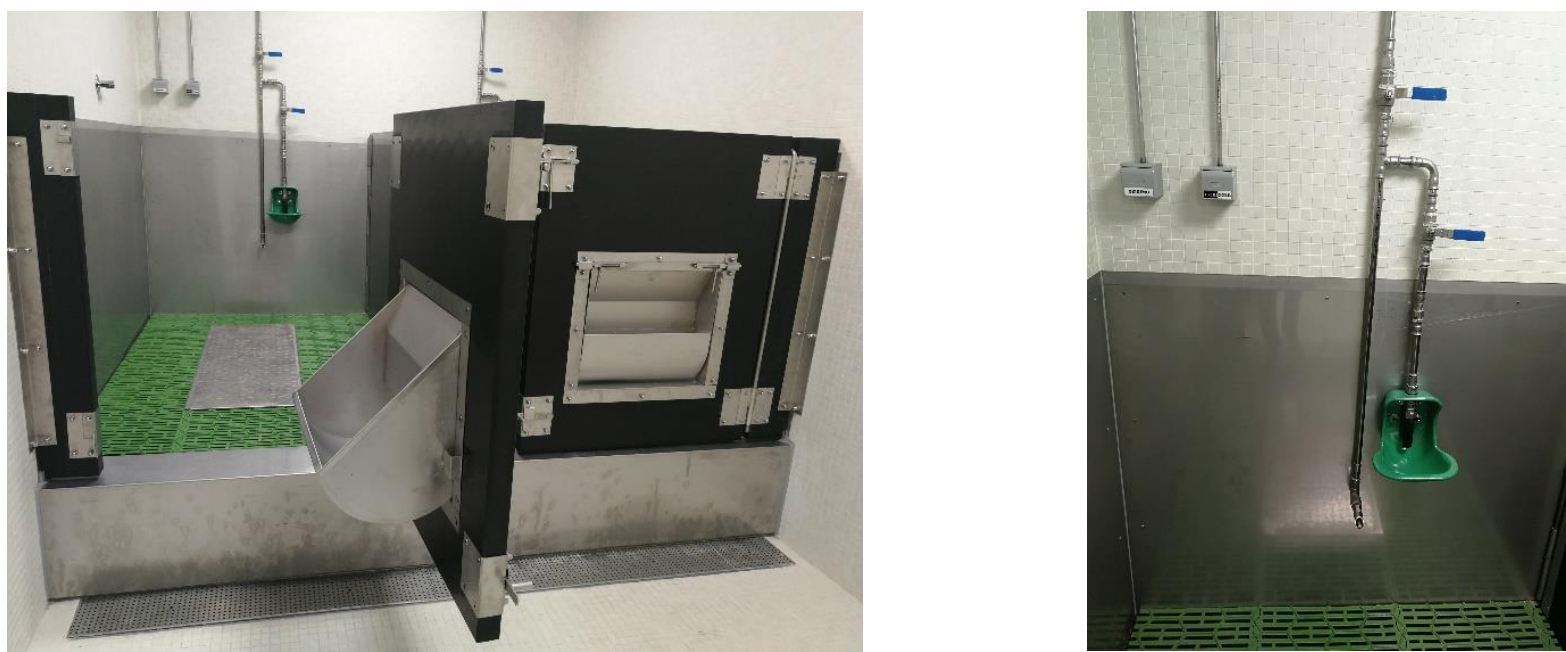

Figura 71. Box recuperación postanestésica con gases medicinales y placas calefactadas. Fuente. Elaboración propia.

La presencia de ventanas en una zona de alojamiento de animales puede suponer un riesgo potencial para la seguridad; $y$, en general deberían evitarse, ya que también pueden generar problemas relacionados con el control de la temperatura de la zona e incluso interferir en el control estricto del 
fotoperiodo. Sin embargo, en situaciones específicas, las ventanas pueden proporcionar un medio ambiental de enriquecimiento para algunas especies, tales como primates no humanos (.National Research Council 2011, p. 137).

Según el estudio realizado, en la mitad de los casos las salas de alojamiento de animal grande disponen de luz natural (i+12, liSGM, IRYCIS, VHIR, IIS La Fe), si bien existen algunos casos en los que además de luz natural también tienen la posibilidad de ventilación natural. En los casos en los que no existe luz natural se ha previsto un sistema de iluminación controlada mediante fotoperiodo para satisfacer las necesidades biológicas de los animales y así poder garantizar un ciclo adecuado de luz y oscuridad. En algunos casos, el sistema de iluminación incluso dispone de regulación lumínica, lo que permite ajustarse a las necesidades de diferentes especies.

Los locales de alojamiento de animales deben ser capaces de garantizar las condiciones de ventilación, temperatura y humedad adaptadas a cada especie, por lo que siempre que existan animales estabulados, las instalaciones deben estar en funcionamiento las 24 horas al día. Como criterio general, el aire en las salas de alojamiento se debe renovar con intervalos frecuentes, y, en condiciones normales, el régimen de ventilación debería ser de 15 a 20 renovaciones de aire por hora. Por otra parte, cada especie animal requiere unas condiciones ambientales específicas; en este sentido, las líneas directrices establecidas para la temperatura ambiental óptima de las especies porcina, caprina, ovina y bovina se establece en un rango de $10-24^{\circ} \mathrm{C}$. La humedad relativa óptima de los locales de alojamiento se establece en $55 \%+/-10 \%$, debiéndose evitar los índices inferiores al $40 \%$ y superiores al $70 \%$ de humedad relativa durante periodos prolongados (RD 1201/2005 Anexo II).

Además de suministrar el aire limpio necesario, es necesario también mantener el bajo nivel de olores, gases nocivos, polvo y agentes infecciosos de cualquier tipo. En el caso concreto de los animales grandes hay que tener en cuenta que el sistema de ventilación deberá estar también diseñado para neutralizar los fuertes olores generados. Es recomendable que las operaciones de mantenimiento se puedan realizar sin tener que interrumpir la actividad de las salas. Para ello, existen diversas estrategias de diseño que facilitan la accesibilidad para el mantenimiento, tales como: la dotación de una planta técnica sobre el local, así como la disposición de galerías de instalaciones accesibles y pasillos de servicio colindantes. La determinación del diseño de un sistema u otro viene definido fundamentalmente por lo crítico que sea para la investigación que las tareas de mantenimiento se realicen sin provocar interrupciones en el recinto. Como hemos visto en la presente investigación, estos animalarios no disponen de una planta técnica a través de la cual realizar las tareas de mantenimiento de las instalaciones, ya que, en general, no se considera una sala crítica o de ambiente controlado en la cual el acceso para realizar las tareas de mantenimiento sea critica, por lo que las 
tareas de mantenimiento se realizan a través del falso techo de los pasillos colindantes y de la propia sala.

Lo que sí observamos en todos los estabularios, es que con el fin de minimizar lo máximo posible los accesos a las salas en aras a preservar el ambiente, en las puertas de acceso se han dispuesto dispositivos, tales como ojos de buey o mirillas electrónicas que permiten la visión del estado general de la sala sin tener que acceder a ella.

En el caso concreto de la estabulación de animal grande, además, hay que tener presente las afecciones que el uso de la instalación puede tener en otras áreas del centro, fundamentalmente por la posibilidad que existe de provocar inundación y filtraciones de agua en la planta inferior, debido a la gran cantidad de agua necesaria para su limpieza. Entre los centros investigados observamos cómo muchos de ellos se encuentran distribuidos en plantas en las que no existe riesgo de afección por inundación a otras unidades de investigación, ya que se encuentran bien en plantas en contacto con el terreno, o bien en plantas que disponen de una planta técnica inferior para el mantenimiento de las instalaciones (IdiPAZ, i+12, liSGM, IRYCIS, IIS Biodonostia, VHIR, IIS La Fe). En el resto de los casos, bajo el área de estabulación de animal grande se sitúan áreas de experimentación bien relacionadas con la actividad del centro de experimentación animal o con otras áreas de investigación o servicios del instituto. 


\subsubsection{Síntesis de la unidad de estabulación animal grande}

Las áreas de estabulación de animal grande se tienden a diseñarlas para poder estabular la especie animal más utilizada hoy en día en cirugía experimental: el cerdo y cerdo en miniatura. Si bien hace años la experimentación con perros y gatos era habitual, hoy en día la experimentación con perros se limita prácticamente a su experimentación con cadáveres.

En el presente estudio observamos como los conejos habitualmente se estabulan en el área de experimentación de animal pequeño, si bien encontramos algunos casos reducidos en los que se estabulan junto con el animal grande.

La investigación mayoritaria realizada con animal grande es la cirugía, actividad totalmente programada, siendo en la mayoría de los casos animales terminales. Teniendo en cuenta este criterio y que la mayoría de los institutos se encuentran en el recinto hospitalario, el dimensionamiento de las salas de estabulación se ha realizado de manera que la estancia en el centro de los animales sea la menor posible, lo cual permite tener un área de estabulación reducida a cambio de un servicio de suministro de animales más frecuente. De esta manera, la mayoría de las áreas de estabulación disponen de dos salas de alojamiento, una de las cuales se usa como zona de cuarentena.

El área de estabulación de animal grande se tiende a ubicarlo en una planta con acceso directo desde el exterior con el fin de evitar traslados verticales interiores de los animales, y de esta manera minimizar las afecciones de estos animales en el resto del instituto. Además, lo habitual es que existan dos accesos diferentes que permitan segregar los accesos de los animales, suministros y retirada de residuos de la del personal del centro.

Actualmente, los boxes de estabulación se diseñan con elementos modulares a media altura para ofrecer mayor flexibilidad a la instalación, ya que posibilitan modificar la compartimentación de las zonas para poder alojar animales de mayores dimensiones sin tener que realizar grandes cambios en la instalación.

Entre los diferentes tipos de estabulación definidos por el sistema de recogida y evacuación de excrementos, se observa que la tendencia es realizarlos sobre foso, solución que permite crear un vaso estanco con la pendiente necesaria para poder limpiar y evacuar adecuadamente todos los residuos generados. Si bien lo recomendable sería que el foso se creara desde la cota del pavimento de planta hacia abajo, lo habitual es que el foso se cree sobre el propio forjado, de tal manera que entre el pavimento de acabado y el foso se crea una altura de un peldaño aproximadamente. Además, se observa que en las salas más modernas se han dispuesto gases anestésicos, así como placas calefactadas para la recuperación postanestésica de los animales. 
Aunque existen salas de alojamiento de animales grandes que disponen de luz natural, en los casos en los que la iluminación es artificial, se ha previsto de un sistema de iluminación controlada mediante fotoperiodo para satisfacer las necesidades biológicas de los animales y así poder garantizar un ciclo adecuado de luz y oscuridad.

Los locales de alojamiento de animales deben ser capaces de garantizar las condiciones de ventilación, temperatura y humedad adaptadas a cada especie, por lo que siempre que existan animales estabulados, las instalaciones deben estar en funcionamiento las 24 horas al día. En el caso concreto de los animales grandes, además, hay que tener en cuenta que el sistema de ventilación deberá estar diseñado para neutralizar los fuertes olores generados. Como hemos visto en la presente investigación, estos animalarios no disponen de una planta técnica a través de la cual realizar las tareas de mantenimiento de las instalaciones, ya que, en general, no se considera una sala en la cual el acceso para realizar las tareas de mantenimiento sea critica. Lo habitual es que con el fin de minimizar lo máximo posible los accesos a las salas en aras a preservar la calidad del aire ambiental, en las puertas de acceso se han dispuesto dispositivos, tales como, ojos de buey o mirillas electrónicas que permiten la visión del estado general de la sala sin tener que acceder a ella.

En el diseño de la estabulación de animal grande, hay que tener presente las afecciones que el uso de la instalación puede tener en otras áreas del centro, fundamentalmente por la posibilidad que existe de provocar inundación o filtraciones de agua en la planta inferior, debido a la gran cantidad de agua necesaria para su limpieza y desinfección. En este sentido observamos cómo la mayoría de unidades de estabulación se distribuyen en plantas en contacto con el terreno o bien en plantas que disponen de una planta técnica inferior para el mantenimiento de las instalaciones. 


\subsubsection{Unidad quirúrgica experimental}

La actividad mayoritaria en el área de experimentación de animal grande es la cirugía experimental, actividad que nos encontramos en todos los institutos de investigación sanitaria investigados. Este servicio habitualmente está diseñado para prestar apoyo en los procedimientos quirúrgicos necesarios para la investigación y proveer tanto del material como de las técnicas quirúrgicas necesarias para la formación de los profesionales del sistema sanitario en cualquiera de las especialidades quirúrgicas y medico quirúrgicas. Además, entre las funciones que normalmente ofrece está el cuidado de los animales sometidos a intervenciones quirúrgicas tanto en el periodo preoperatorio como en el postoperatorio.

Para poder realizar la formación quirúrgica, aparte de disponer de un área donde poder estabular las especies animales, es fundamental disponer de un área de experimentación donde los profesionales médicos puedan realizar las prácticas quirúrgicas en las condiciones lo más similares posibles a las que se van a encontrar a posteriori en el ámbito hospitalario.

El análisis pormenorizado de la complejidad de esta unidad se afronta identificando primeramente los locales que componen la unidad; a partir de las representaciones gráficas estandarizadas de cada unidad quirúrgica se hace una breve descripción de su composición, para a continuación analizar las características generales de cada uno de los institutos investigados. Por otra parte, tomando como referencia las recomendaciones establecidas en diferentes guías publicadas, se estudia la organización, así como la configuración y circulaciones implantadas en cada caso. 


\subsubsection{Locales que componen la unidad quirúrgica experimental}

El programa funcional y la especificación de los recursos necesarios para el desarrollo de la actividad del área quirúrgica dependen especialmente de las decisiones que los responsables de la gestión del instituto hayan adoptado en relación a las líneas de investigación y necesidades del centro, a la definición de procesos y protocolos de funcionamiento, así como a las prioridades de la investigación establecidas; que tendrán que adaptarse a cada realidad concreta, así como a los condicionantes específicos de cada situación. En cuanto a los locales necesarios para el desarrollo de la actividad, la mayoría de los programas quirúrgicos contemplan las siguientes salas:
a) Vestuarios
b) Preparación médica
c) Preparación animal
d) Almacén material estéril
e) Transfer para materiales
f) Quirófanos
g) Sala recuperación postoperatoria
h) Sala procedimientos
i) Sala de lavado y esterilización
j) Almacén de equipos limpio
k) Cuarto limpieza

a) Vestuarios. Los vestuarios de cambio para el personal que va a acceder al área quirúrgica, separados por sexo y con una zona de aseo y taquillas para facilitar a los usuarios el cambio de ropa de calle por otra de uso específico para esta zona.

b) Preparación médica. El área de preparación médica para desinfección y preparación del personal previo acceso a los quirófanos, siendo recomendable ubicarlo contiguo al quirófano para tener una visión que permita el control de la actividad que se desarrolla en él. El equipamiento de esta sala es el necesario para realizar el lavado de manos con grifo quirúrgico de accionamiento no manual, dispensadores antisépticos, secador de manos automático y reloj. Además, es habitual disponer de espacio para la colocación de estantes para guardar el material desechable de protección como son los guantes, gorros, máscaras, etc., así como la recogida de envoltorios de papel.

c) Preparación animal. Zona destinada a preparar el animal previo acceso al quirófano en el que se realizan tareas tales como el rasurado, limpieza, desinfección, incluso anestesiado, para una vez preparado el animal trasladarlo directamente al quirófano.

d) Almacén de material estéril. Destinado al almacenamiento del material estéril que es necesario utilizar en el quirófano. Este local es habitual ubicarlo colindante al quirófano y dotarlo de un transfer de materiales para introducir directamente el material estéril al quirófano. 
e) Transfer para materiales. El diseño de transfer para materiales sirve para introducir los materiales al quirófano sin tener que realizar una apertura de puertas. La ventana SAS pasa-materiales garantiza una mínima apertura de la ventana y, por lo tanto, reduce el riesgo de contaminación del quirófano.

f) Quirófano. Es el local donde se realiza la intervención quirúrgica y está dotado del equipamiento necesario para el desarrollo de la actividad, como son las torres de cirugía y anestesia, lámparas quirúrgicas, mesas de operaciones, paneles técnicos y equipos de retransmisión de imágenes, entre otros.

g) Sala de recuperación postoperatoria. Local donde ingresan los animales no terminales que han sido sometidos a una intervención quirúrgica con anestesia general, regional o sedación, y en el que recibirán los cuidados necesarios hasta su traslado al área de estabulación.

h) Sala de procedimientos. Se concibe como una zona de apoyo al área quirúrgica para la realización de procedimientos experimentales, necropsias, tratamiento clínico o procedimientos de laboratorio de diagnóstico, entre otros.

i) Sala de lavado y esterilización. Para el acondicionamiento, limpieza y esterilización del material empleado en los quirófanos experimentales, que estará dotado con los equipos e instalaciones necesarias para su funcionamiento.

j) Almacén de equipos limpio. Destinado al almacenamiento de material limpio que se emplee en los quirófanos, material de farmacia y fungible, así como para la ubicación de aquellos equipos portátiles que no necesiten estar de manera permanente en el interior de los quirófanos, tales como, los de radiodiagnóstico e intensificadores de imagen, láser quirúrgico, respirador y lámpara portátil. La programación de estos locales posibilita un mantenimiento y limpieza adecuado de los quirófanos, además de disponer de circulaciones libre de obstáculos. Su número, disposición y tamaño está relacionado con la actividad quirúrgica programada, dimensión y diseño del bloque y por el tipo de intervenciones por especialidades.

k) Cuarto de limpieza. Para la conservación y almacenamiento de los productos y materiales destinados a la limpieza y desinfección del área quirúrgica. 


\subsubsection{Representaciones gráficas de la distribución de la unidad quirúrgica experimental}

A partir de los planos en planta estandarizados que se han desarrollado de cada uno de los centros de experimentación animal, y que se encuentran recogidos en las fichas de toma de datos, se ha seleccionado exclusivamente el área destinada a la unidad quirúrgica experimental. Con estas representaciones gráficas se pretende tener una visión específica de su configuración y de las distintas circulaciones diseñadas (Figuras 72-82).

Para facilitar el estudio, en los planos de distribución en planta se ha identificado por código de colores el área funcional al que pertenece y por código numérico el tipo de local que es. Para los casos en los que los locales relacionados con el área quirúrgica experimental se ubican lejos de los quirófanos se ha optado por indicar mediante una flecha la dirección de su ubicación. Además, para localizar fácilmente la ubicación de los quirófanos se ha incluido la simbología que representa la mesa quirúrgica.

Por otra parte, con el fin de realizar una lectura sencilla de las circulaciones, se representa mediante líneas de diferentes trazos y colores la dirección, y mediante flechas, el sentido hacia donde va dirigida la circulación para el personal, para los animales, los suministros y la retirada de residuos.

Por último, junto a cada una de las representaciones gráficas, se hace una breve descripción de la configuración de la unidad, de la disposición de los locales, de la tipología de distribución que se ha aplicado, así como del criterio de circulaciones establecidas.

ÁREAS FUNCIONALES

Experimentación animal pequeño

Experimentación animal grande

Áreas comunes animal pequeño y grande

Área Administrativa

Pasillos comunes

Pasillos exteriores y servicios generales

Elementos de circulación vertical
IDENTIFICACIÓN USO LOCALES

01 Recepción animal
02 Estabulación convencional roedores
03 Estabulación convencional conejos
04 Estabulación convencional animal grande
05 Cuarentena roedores
06 Cuarentena conejos
07 Cuarentena animal grande
08 Estabulación barrera animal pequeño
09 Experimentación ABSL2 - 09* ABSL3
10 Experimentación peces
11 Lavado animal
12 Preparación animal
13 Procedimientos
14 Microcirugía
15 Comportamiento
16 Imagen

\section{cional roedores}

05 Cuarentena roedores

07 Cuarentena animal

08 Estabulación barrera animal pequeño

10 Experimentación peces
17 Quirófano experimental

18 Preparación médica

19 A. material estéril

20 Necropsias

21 Cirugía cadáveres

22 Lavado y esterilización

23 Vestuarios / Aseos

24 Esclusa animales

25 Esclusa personas

26 Esclusa materiales

27 Almacén / archivo

28 Servicios

29 Despacho

30 Sala reuniones

31 Pasillo

32 Otros
CIRCULACIONES

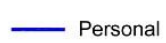

- Animales

Suministro materiales

- - - Retirada de residuos

Figura 72. Leyenda unidad quirúrgica experimental.

Fuente. Elaboración propia.

*Esta leyenda se hace extensible a las figuras 73-82. 
La unidad quirúrgica del instituto Idipaz (Figura 73) se compone de un núcleo compacto en el que los locales de servicio se desarrollan alrededor del único quirófano con dos mesas del área quirúrgica, que se encuentra integrado en el área de experimentación de animal pequeño. De esta manera observamos cómo los vestuarios de personal no son de uso exclusivo del área quirúrgica, siendo necesario discurrir por pasillos de uso común al animal grande y pequeño para llegar a la zona de preparación médica. El área de esterilización y lavado, así como el almacenamiento de residuos y cadáveres, son locales de servicio compartidos con el animal pequeño. En este caso se dispone de un único pasillo de distribución y es desde este pasillo donde se segregan las diferentes circulaciones de manera que el personal médico, los animales y los suministros acceden al quirófano por locales diferentes específicamente diseñados para cada uno de ellos.

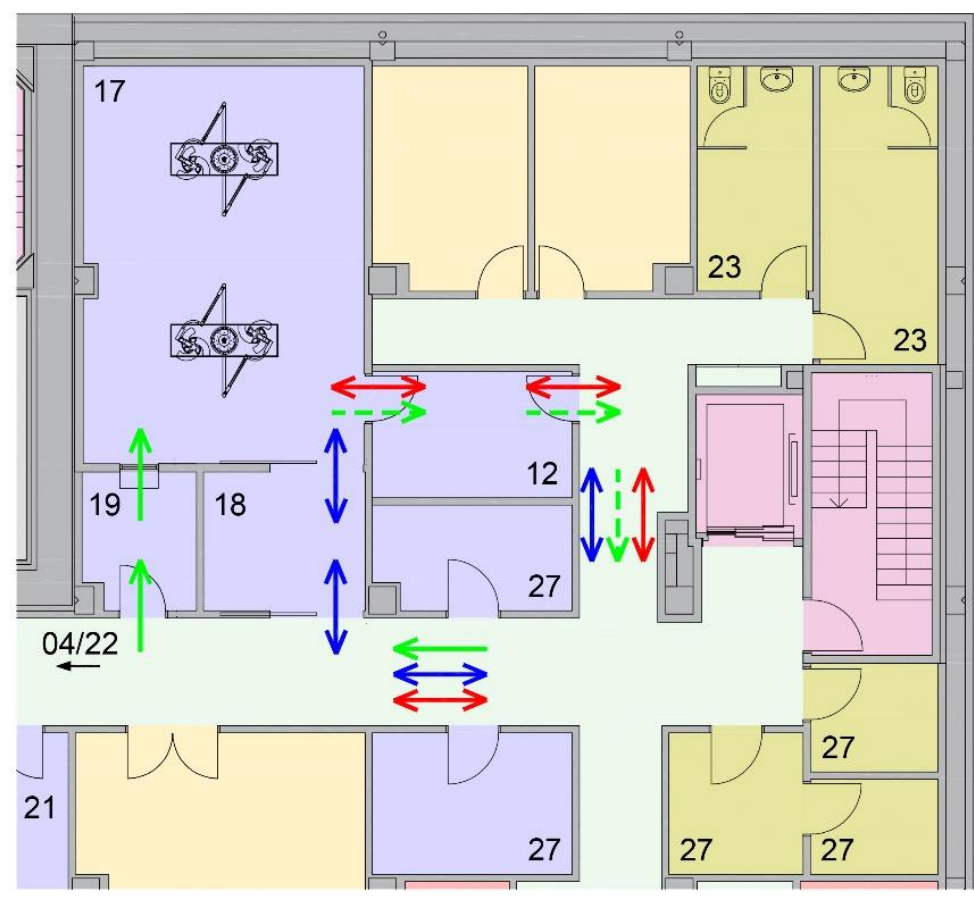

ÁREAS FUNCIONALES

Experimentación animal pequeño

Experimentación animal grande

Áreas comunes animal pequeño y grande

Área Administrativa

Pasillos comunes

Pasillos exteriores y servicios generales

Elementos de circulación vertical
IDENTIFICACIÓN USO LOCALES

$\begin{array}{ll}01 \text { Recepción animal } & 17 \text { Quirófano experimental } \\ 02 \text { Estabulación convencional roedores } & 18 \text { Preparación médica } \\ 03 \text { Estabulación convencional conejos } & 19 \text { A. material estéril } \\ 04 \text { Estabulación convencional animal grande } & 20 \text { Necropsias } \\ 05 \text { Cuarentena roedores } & 21 \text { Cirugia cadáveres } \\ 06 \text { Cuarentena conejos } & 22 \text { Lavado y esterilización } \\ 07 \text { Cuarentena animal grande } & 23 \text { Vestuarios / Aseos } \\ 08 \text { Estabulación barrera animal pequeño } & 24 \text { Esclusa animales } \\ \text { 09 Experimentación ABSL2 - 09* ABSL3 } & 25 \text { Esclusa personas } \\ \text { 10 Experimentación peces } & 26 \text { Esclusa materiales } \\ \text { 11 Lavado animal } & 27 \text { Almacén / archivo } \\ \text { 12 Preparación animal } & 28 \text { Servicios } \\ 13 \text { Procedimientos } & 29 \text { Despacho } \\ 14 \text { Microcirugia } & 30 \text { Sala reuniones } \\ 15 \text { Comportamiento } & 31 \text { Pasillo } \\ 16 \text { Imagen } & 32 \text { Otros }\end{array}$

CIRCULACIONES

- Personal

- Animales

Suministro materiales

- Retirada de residuos

Figura 73. Organización unidad quirúrgica Idipaz (S/E).

Fuente. Elaboración propia. 
La unidad quirúrgica del instituto i+12 (Figura 74) se compone de un único quirófano doble, disponiendo de los locales de servicio alrededor del quirófano. Los vestuarios de personal son compartidos con el área de experimentación de animal pequeño y tienen acceso directo a la zona de preparación médica. Por otra parte, tanto la zona de preparación médica como el almacén de material estéril, que tienen acceso directo al quirófano, también son locales compartidos con el área de microcirugía destinado a la experimentación con animal pequeño. Esta configuración la consideramos como pasillo doble porque hay una separación de circulaciones, de manera que por una parte hay un punto común de acceso al quirófano para el personal médico, material estéril y animales; y otro punto de salida diferente para la retirada de residuos, si bien al final ambos recorridos confluyen en el mismo pasillo.

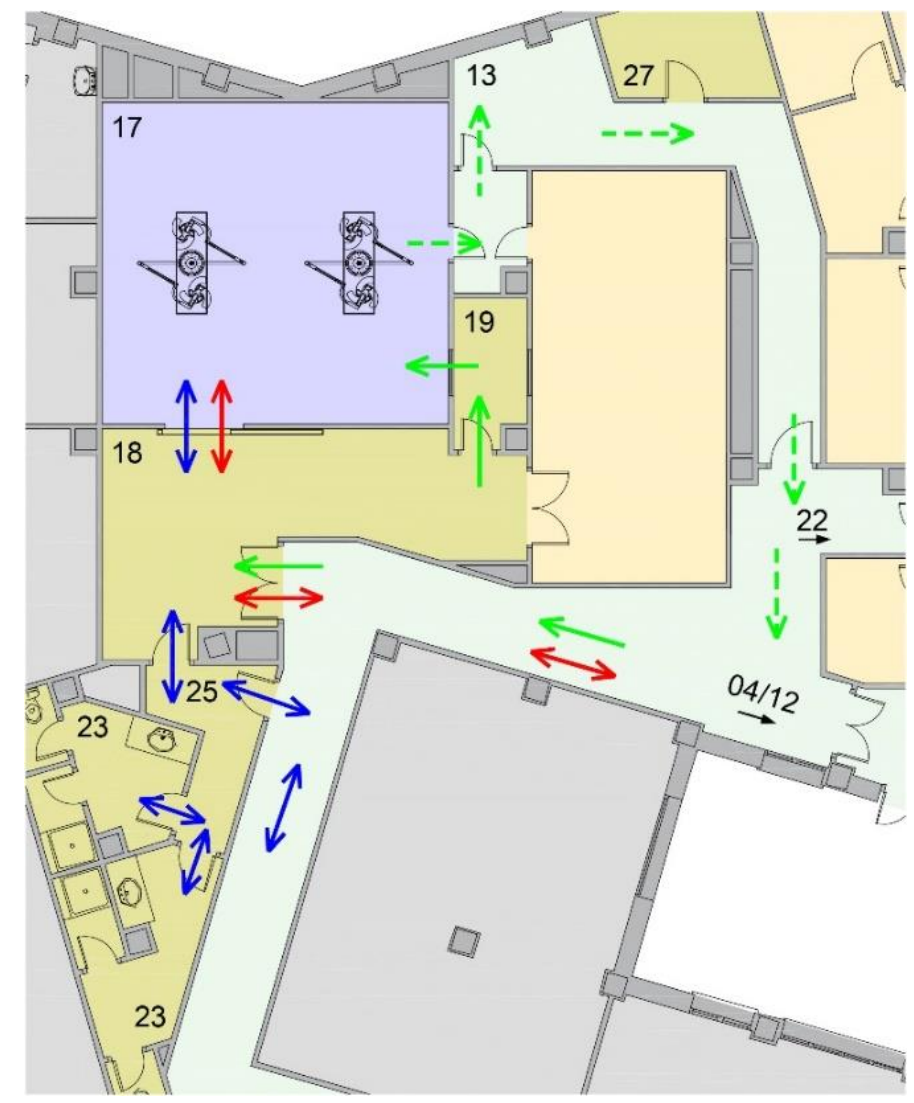

ÁREAS FUNCIONALES

Experimentación animal pequeño

Experimentación animal grande

Áreas comunes animal pequeño y grande

Área Administrativa

Pasillos comunes

Pasillos exteriores y servicios generales

Elementos de circulación vertical
IDENTIFICACIÓN USO LOCALES

01 Recepción animal
02 Estabulación convencional roedores
03 Estabulación convencional conejos
04 Estabulación convencional animal gran
05 Cuarentena roedores
06 Cuarentena conejos
07 Cuarentena animal grande
08 Estabulación barrera animal pequeño
09 Experimentación ABSL2 - 09* ABSL3
10 Experimentación peces
11 Lavado animal
12 Preparación animal
13 Procedimientos
14 Microcirugia
15 Comportamiento
16 Imagen

17 Quirófano experimental

18 Preparación médic

19 A. material estéril

21 Cirugia cadáveres

22 Lavado y esterilización

23 Vestuarios / Aseos

24 Esclusa animales

25 Esclusa personas

26 Esclusa materiales

27 Almacén / archivo

28 Servicios

29 Despacho

30 Sala reuniones

31 Pasillo

32 Otros
CIRCULACIONES

— Personal

- Animales

- - - Retirada de residuos

Figura 74. Organización unidad quirúrgica i+12 (S/E).

Fuente. Elaboración propia. 
La unidad quirúrgica del instituto IISGM (Figura 75) se compone de un único quirófano con dos mesas alrededor del que se distribuyen el resto de locales que dan servicio a la unidad, tales como, el área de preparación médica, el almacén de material estéril, el área de preparación animal y el local de retirada de residuos. Los vestuarios de personal no son de uso exclusivo del área quirúrgica y es necesario discurrir por pasillos de uso común al animal grande y pequeño para llegar a la zona de preparación médica. El área de esterilización y lavado, así como el almacenamiento de residuos y cadáveres son locales de servicio compartidos con el animal pequeño. En este caso se dispone de dos pasillos de distribución diferenciados: uno, a través del que acceden los animales y se retiran los residuos; $y$, otro, a través del cual accede el personal médico y el material estéril. Además, la zona de preparación médica, de la preparación animal y de los residuos se disponen en locales contiguos con puertas de acceso directas al quirófano.

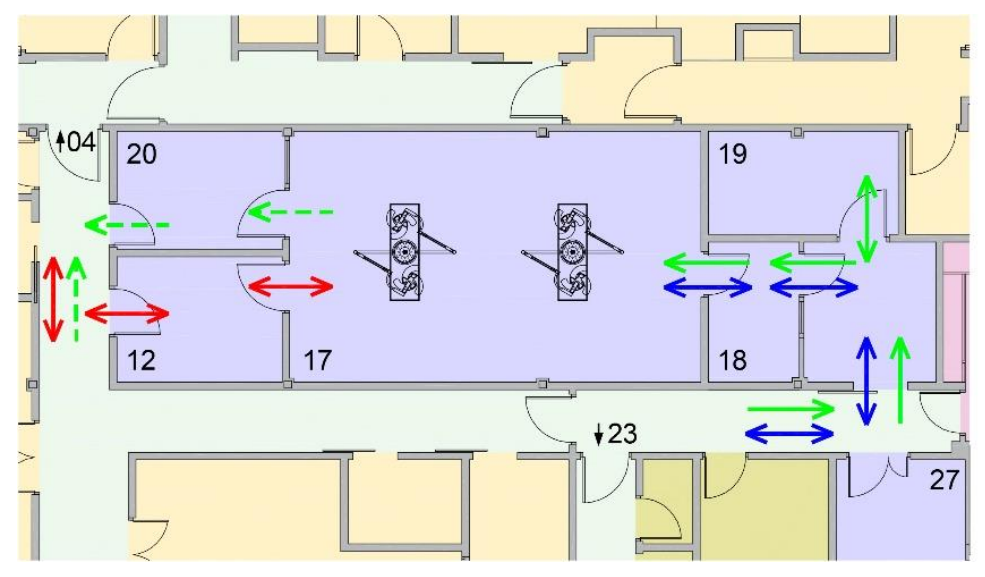

\begin{tabular}{|c|c|c|c|}
\hline ÁREAS FUNCIONALES & \multicolumn{2}{|c|}{ IDENTIFICACIÓN USO LOCALES } & CIRCULACIONES \\
\hline Experimentación animal pequeño & 01 Recepción animal & 17 Quirófano experimental & — Personal \\
\hline \multirow[t]{2}{*}{ Experimentación animal grande } & $\begin{array}{l}02 \text { Estabulación convencional roedores } \\
03 \text { Estabulación convencional conejos }\end{array}$ & $\begin{array}{l}18 \text { Preparación médica } \\
19 \text { A. material estéril }\end{array}$ & \multirow[t]{2}{*}{ Animales } \\
\hline & 04 Estabulación convencional animal grande & 20 Necropsias & \\
\hline Áreas comunes animal pequeño y grande & $\begin{array}{l}05 \text { Cuarentena roedores } \\
06 \text { Cuarentena conejos }\end{array}$ & $\begin{array}{l}21 \text { Cirugia cadáveres } \\
22 \text { Lavado y esterilización }\end{array}$ & - Suministro materiales \\
\hline Área Administrativa & 07 Cuarentena animal grande & 23 Vestuarios / Aseos & --- Retirada de residuos \\
\hline Pasillos comunes & $\begin{array}{l}08 \text { Estabulación barrera animal pequeño } \\
09 \text { Experimentación } A B S L 2-09^{\star} A B S L 3\end{array}$ & 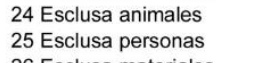 & \\
\hline \multirow[t]{2}{*}{ Pasillos exteriores y servicios generales } & $\begin{array}{l}10 \text { Experimentación peces } \\
11 \text { Lavado animal }\end{array}$ & $\begin{array}{l}26 \text { Esclusa materiales } \\
27 \text { Almacén / archivo }\end{array}$ & \\
\hline & 12 Preparación animal & 28 Servicios & \\
\hline \multirow[t]{4}{*}{ Elementos de circulación vertical } & 13 Procedimientos & 29 Despacho & \\
\hline & 14 Microcirugía & 30 Sala reuniones & \\
\hline & 15 Comportamiento & 31 Pasillo & \\
\hline & 16 Imagen & 32 Otros & \\
\hline
\end{tabular}

Figura 75. Organización unidad quirúrgica IISGM (S/E).

Fuente. Elaboración propia. 
La unidad quirúrgica del instituto IRYCIS (Figura76) se compone de un núcleo compuesto por dos quirófanos simples en el que se comparten para ambos quirófanos los locales de servicio, tales como el almacén de material estéril, zona de preparación médica y preparación animal. Por otra parte, el vestuario, el área de lavado y esterilización, así como el almacenamiento de residuos y cadáveres son locales de servicio compartidos con el animal pequeño. En este caso se dispone de un único pasillo de distribución, de manera que para poder acceder o salir del quirófano, tanto el personal médico, como los animales como los materiales están obligados a pasar por la zona de preparación médica.

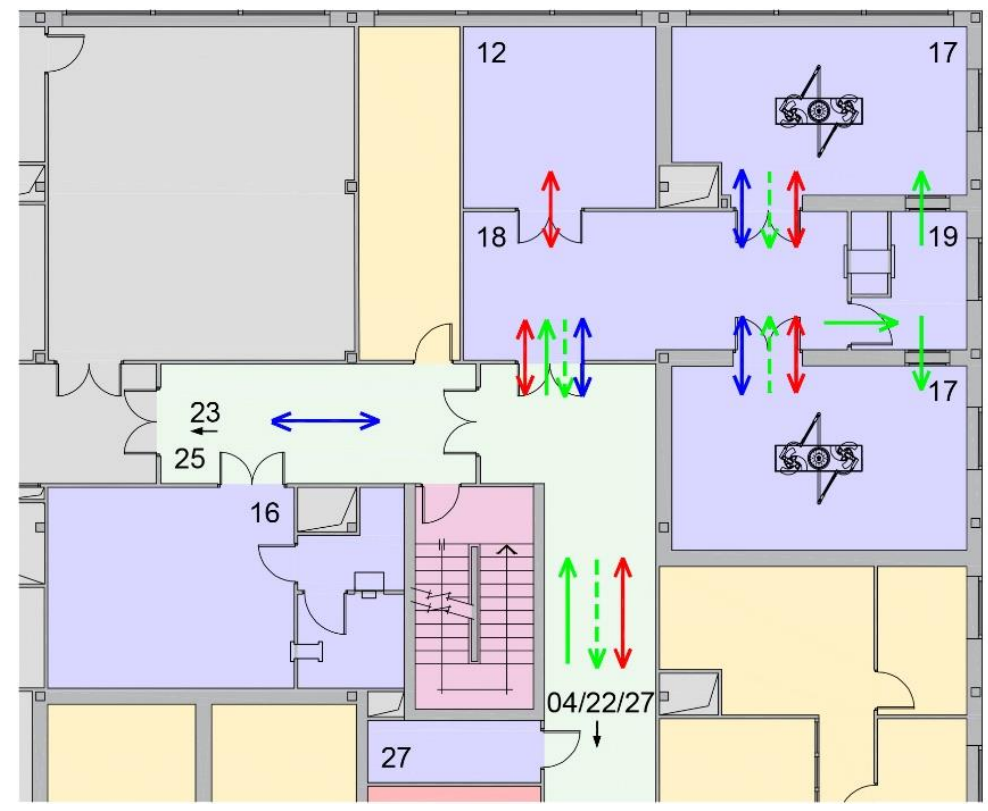

ÁREAS FUNCIONALES

Experimentación animal pequeño

Experimentación animal grande

Áreas comunes animal pequeño y grande

Área Administrativa

Pasillos comunes

Pasillos exteriores y servicios generales

Elementos de circulación vertical
IDENTIFICACIÓN USO LOCALES

01 Recepción animal
02 Estabulación convencional roedores
03 Estabulación convencional conejos
04 Estabulación convencional animal grande
05 Cuarentena roedores
06 Cuarentena conejos
07 Cuarentena animal grande
08 Estabulación barrera animal pequeño
09 Experimentación ABSL2 - $09^{\star}$ ABSL3
10 Experimentación peces
11 Lavado animal
12 Preparación animal
13 Procedimientos
14 Microcirugia
15 Comportamiento
16 Imagen

17 Quirófano experimental 18 Preparación médica 19 A. material estéril 20 Necropsias

21 Cirugia cadáveres 22 Lavado y esterilización 23 Vestuarios / Aseos 24 Esclusa animales 25 Esclusa personas 26 Esclusa materiales 27 Almacén / archivo 28 Servicios 29 Despacho 30 Sala reuniones 31 Pasillo 32 Otros
CIRCULACIONES

- Personal

- Animales

__ Suministro materiales

- - - Retirada de residuos

Figura 76. Organización unidad quirúrgica IRICYS (S/E).

Fuente. Elaboración propia. 
La unidad quirúrgica del instituto IISBiodonostia (Figura 77) se compone de un quirófano con dos mesas. En este caso, la zona de preparación médica es compartida con el almacén de material estéril, y la zona de preparación animal es compartida tanto para el animal grande como para el pequeño. Los vestuarios de personal no son de uso exclusivo del área quirúrgica y es necesario discurrir por pasillos de uso común al animal grande y pequeño para llegar a la zona de preparación médica. El área de esterilización y lavado, así como el almacenamiento de residuos y cadáveres son locales de servicio compartidos con el animal pequeño. En este caso se disponen de dos pasillos de distribución; uno para el personal médico y material limpio; y, otro, para los animales y la retirada de los residuos.

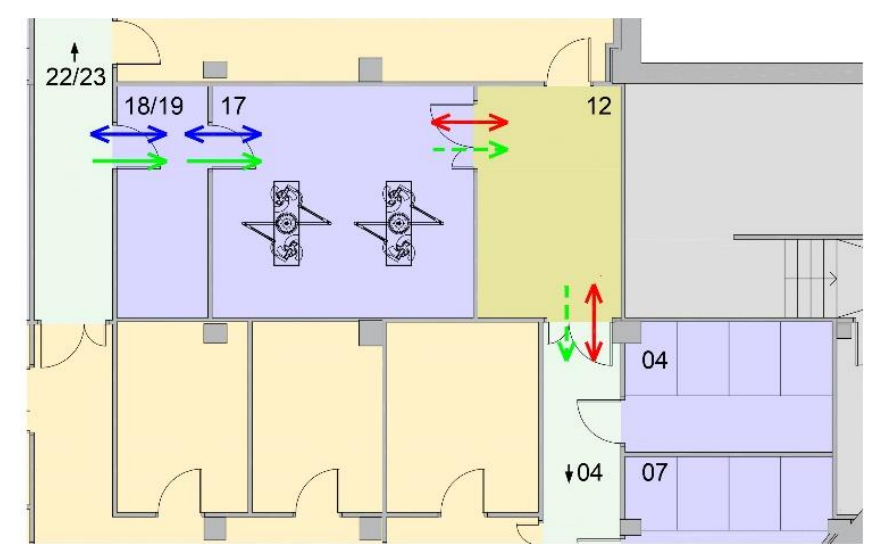

ÁREAS FUNCIONALES

Experimentación animal pequeño

Experimentación animal grande

Áreas comunes animal pequeño y grande

Área Administrativa

Pasillos comunes

Pasillos exteriores y servicios generales

Elementos de circulación vertical
IDENTIFICACIÓN USO LOCALES

$\begin{array}{ll}\text { 01 Recepción animal } & 17 \text { Quirófano experimental } \\ 02 \text { Estabulación convencional roedores } & 18 \text { Preparación médica } \\ 03 \text { Estabulación convencional conejos } & 19 \text { A. material estéril } \\ \text { 04 Estabulación convencional animal grande } & 20 \text { Necropsias } \\ 05 \text { Cuarentena roedores } & \text { 21 Cirugia cadáveres } \\ 06 \text { Cuarentena conejos } & 22 \text { Lavado y esterilización } \\ 07 \text { Cuarentena animal grande } & 23 \text { Vestuarios / Aseos } \\ 08 \text { Estabulación barrera animal pequeño } & 24 \text { Esclusa animales } \\ 09 \text { Experimentación ABSL2 - 09* ABSL3 } & 25 \text { Esclusa personas } \\ \text { 10 Experimentación peces } & 26 \text { Esclusa materiales } \\ \text { 11 Lavado animal } & 27 \text { Almacén / archivo } \\ \text { 12 Preparación animal } & 28 \text { Servicios } \\ \text { 13 Procedimientos } & 29 \text { Despacho } \\ \text { 14 Microcirugia } & 30 \text { Sala reuniones } \\ \text { 15 Comportamiento } & 31 \text { Pasillo } \\ 16 \text { Imagen } & 32 \text { Otros }\end{array}$

CIRCULACIONES

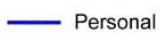

- Animales

__ Suministro materiales

- - - Retirada de residuos

Figura 77. Organización unidad quirúrgica IIS Biodonostia (S/E).

Fuente. Elaboración propia. 
La unidad quirúrgica del instituto IISBiocruces (Figura 78) se compone de dos quirófanos, uno simple y uno con dos mesas de operaciones. Ambos quirófanos comparten la zona de preparación médica desde la que se accede a ambos quirófanos y en la que también se almacena el material estéril. La zona de preparación animal, en cambio, se ubica colindante al quirófano simple, de manera que para acceder al quirófano doble es necesario pasar por el quirófano simple. Existen vestuarios de personal propios para acceso directo al área quirúrgica, el área de esterilización y lavado también es de uso exclusivo del área quirúrgica y se dispone de un local propio destinado al almacenamiento de equipos quirúrgicos. En este caso se dispone de dos pasillos diferenciados de distribución; uno para el personal médico y material limpio; y, otro, para los animales y la retirada de los residuos

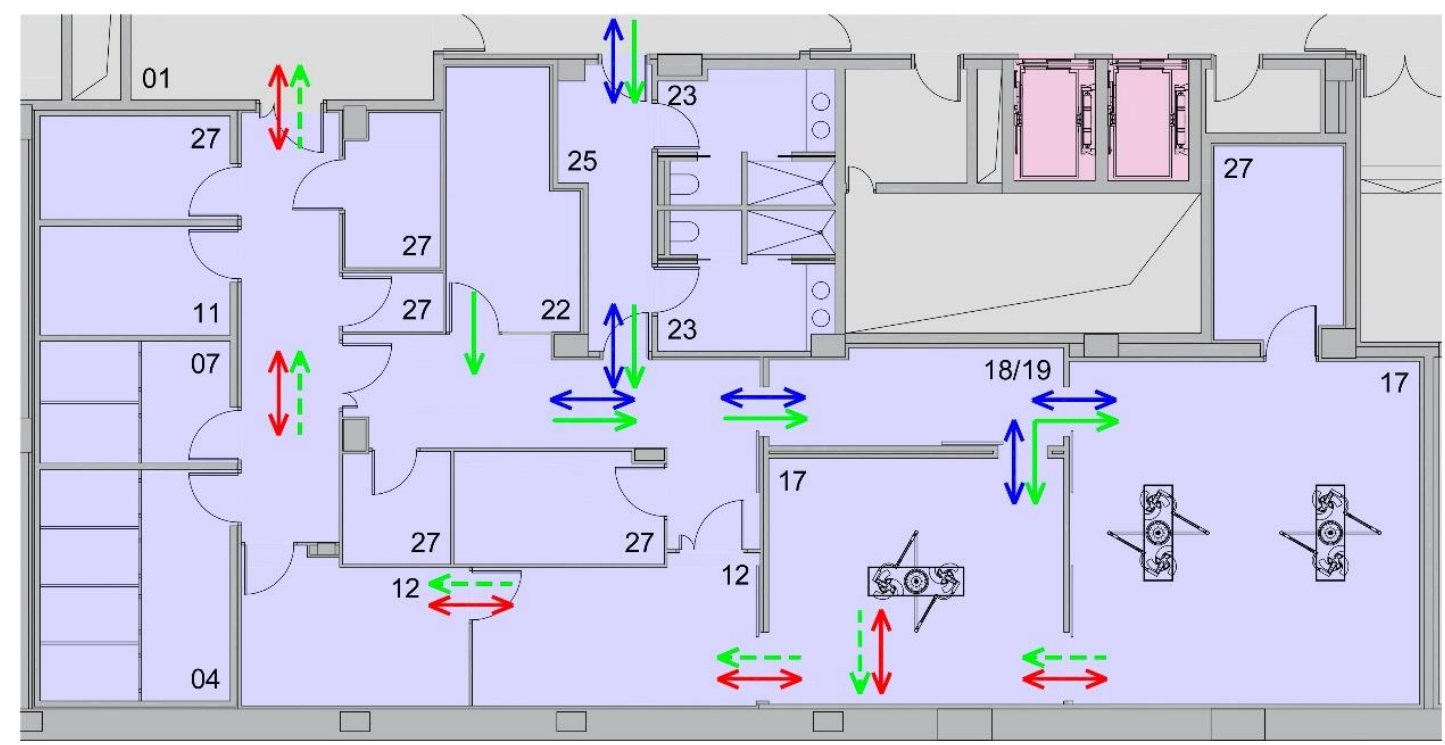

ÁREAS FUNCIONALES

Experimentación animal pequeño

Experimentación animal grande

Áreas comunes animal pequeño y grande

Área Administrativa

Pasillos comunes

Pasillos exteriores y servicios generales

Elementos de circulación vertical

\section{IDENTIFICACIÓN USO LOCALES}

01 Recepción animal
02 Estabulación convencional roedores
03 Estabulación convencional conejos
04 Estabulación convencional animal grande
05 Cuarentena roedores
06 Cuarentena conejos
07 Cuarentena animal grande
08 Estabulación barrera animal pequeño
09 Experimentación ABSL2 - $09^{\star}$ ABSL3
10 Experimentación peces
11 Lavado animal
12 Preparación animal
13 Procedimientos
14 Microcirugia
15 Comportamiento
16 Imagen

17 Quirófano experimental 18 Preparación médica 19 A. material estéril

21 Cirugia cadáveres 22 Lavado y esterilización 23 Vestuarios / Aseos 24 Esclusa animales 25 Esclusa personas 26 Esclusa materiales 27 Almacén / archivo 28 Servicios 29 Despacho 30 Sala reuniones 31 Pasillo 32 Otros

Figura 78. Organización unidad quirúrgica IIS Biocruces (S/E). Fuente. Elaboración propia. 
La unidad quirúrgica del instituto IISA (Figura 79) se compone de tres quirófanos: dos simples y uno doble. Los quirófanos simples comparten la zona de preparación médica con acceso directo a cada quirófano. Además, dispone de vestuarios de personal propios con acceso directo a la unidad, de un local destinado a almacenamiento de equipos quirúrgicos dentro del área, y una sala de esterilización y lavado, también de uso exclusivo del área quirúrgica. En este caso la distribución planteada se considera de pasillo doble porque hay una segregación de circulaciones para acceder al quirófano que garantiza unas condiciones asépticas concretas. De esta manera, por una parte, acceden los animales y salen los residuos; $y$, por la otra, acceden el personal médico y el material estéril, si bien es cierto que al final todas las circulaciones convergen en el pasillo exterior de la unidad quirúrgica.

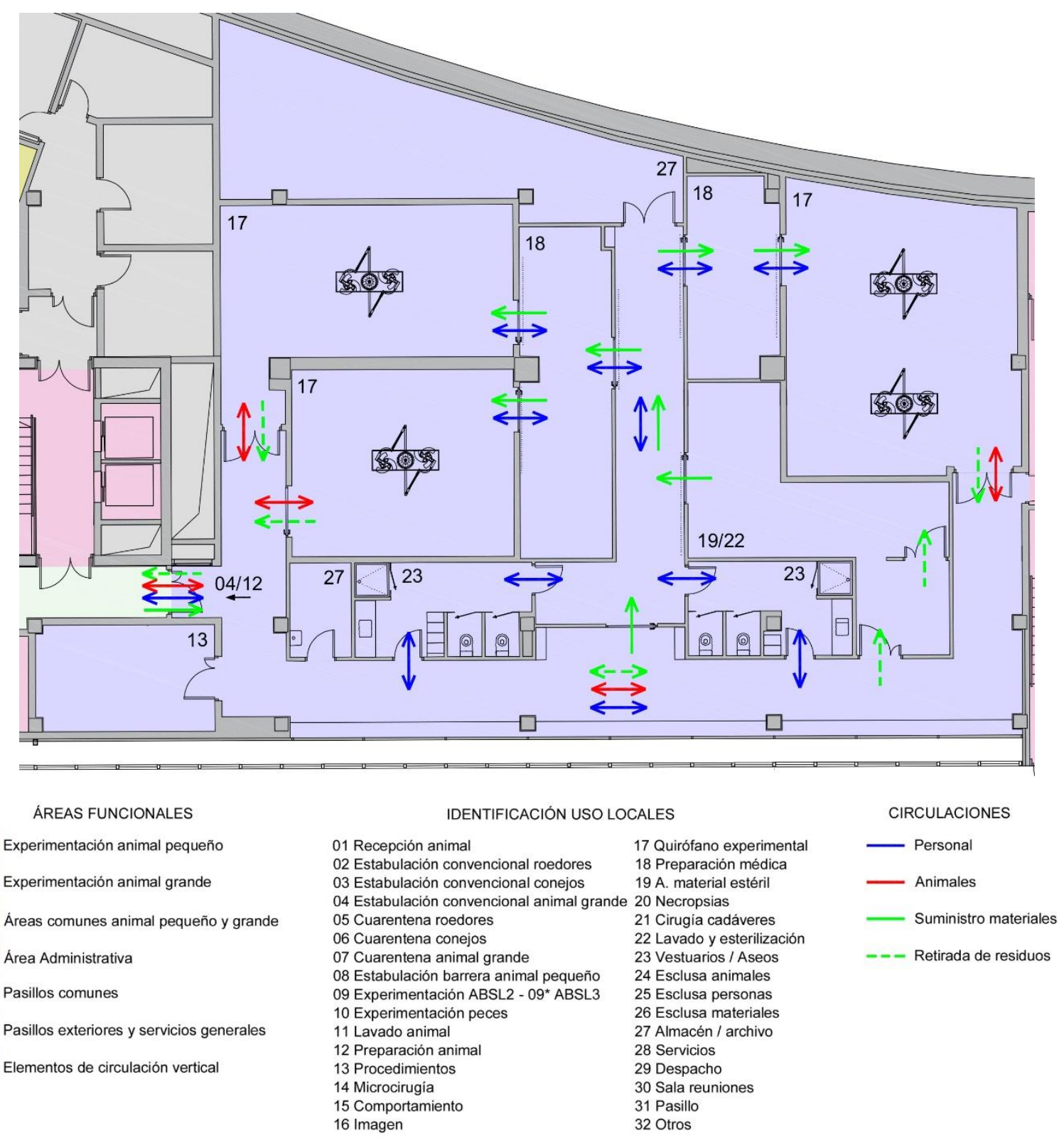

Figura 79. Organización unidad quirúrgica IISA (S/E).

Fuente. Elaboración propia. 
La unidad quirúrgica del instituto VHIR (Figura 80) se compone de dos quirófanos simples con una zona de preparación médica común que también sirve como almacén de material y preparación animal. Los vestuarios de personal no son de uso exclusivo del área quirúrgica, pero se encuentra en una zona próxima a esta. En este caso se dispone de dos pasillos de distribución, de manera que a la zona de preparación médica, por una parte, accede el personal médico y el material estéril; y por otro, los animales y la retirada de los residuos. Al haber una única puerta de acceso al quirófano, todo el tráfico de entradas y salidas tienen que pasar obligatoriamente por esta zona.

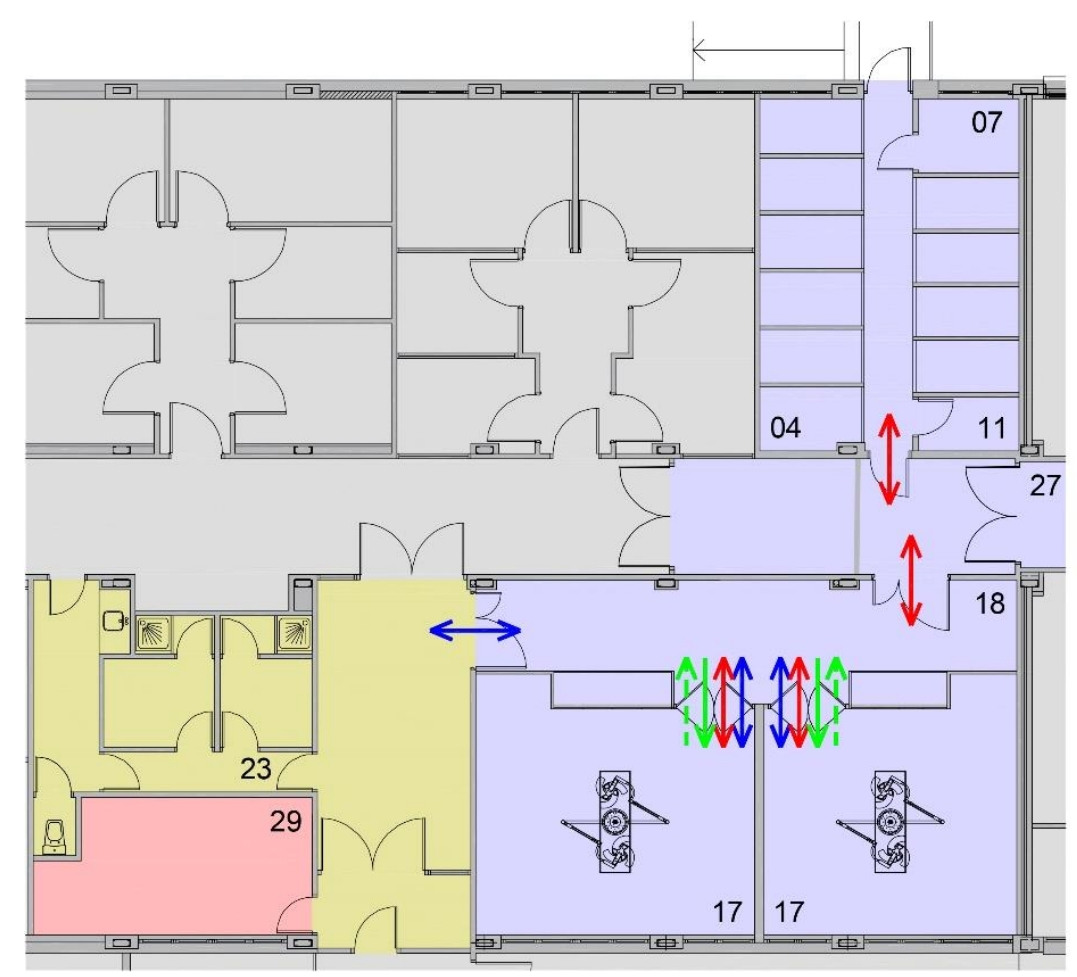

ÁREAS FUNCIONALES

Experimentación animal pequeño

Experimentación animal grande

Áreas comunes animal pequeño y grande

Área Administrativa

Pasillos comunes

Pasillos exteriores y servicios generales

Elementos de circulación vertical

\section{IDENTIFICACIÓN USO LOCALES}

01 Recepción animal
02 Estabulación convencional roedores
03 Estabulación convencional conejos
04 Estabulación convencional animal grand
05 Cuarentena roedores
06 Cuarentena conejos
07 Cuarentena animal grande
08 Estabulación barrera animal pequeño
09 Experimentación ABSL2 - 09* ABSL3
10 Experimentación peces
11 Lavado animal
12 Preparación animal
13 Procedimientos
14 Microcirugia
15 Comportamiento
16 Imagen

CIRCULACIONES

17 Quirófano experimental

18 Preparación médica

19 A. material estéril

20 Necropsias

21 Cirugia cadáveres

22 Lavado y esterilización

23 Vestuarios / Aseos

24 Esclusa animales

25 Esclusa personas

26 Esclusa materiales

27 Almacén / archivo

28 Servicios

29 Despacho

30 Sala reuniones

31 Pasillo

32 Otros

Figura 80. Organización unidad quirúrgica VHIR (S/E).

Fuente. Elaboración propia. 
La unidad quirúrgica del instituto IGTP (Figura 81) es una de las que mayores dimensiones tiene, ya que se compone de cuatro quirófanos simples realizados con tabiques móviles, lo que le confiere mayor versatilidad a la unidad quirúrgica. En este caso, la zona de preparación médica se ubica en el pasillo exterior al quirófano, de manera que se comparte cada dos quirófanos. Los locales de servicio se desarrollan a lo largo del pasillo del área quirúrgica, disponiendo de unos vestuarios de personal propios y colindantes a la unidad. Se dispone de un único pasillo de distribución y existe un único punto de entrada a cada quirófano a través del cual entran y salen tanto el personal médico, como los animales, los suministros y los residuos.

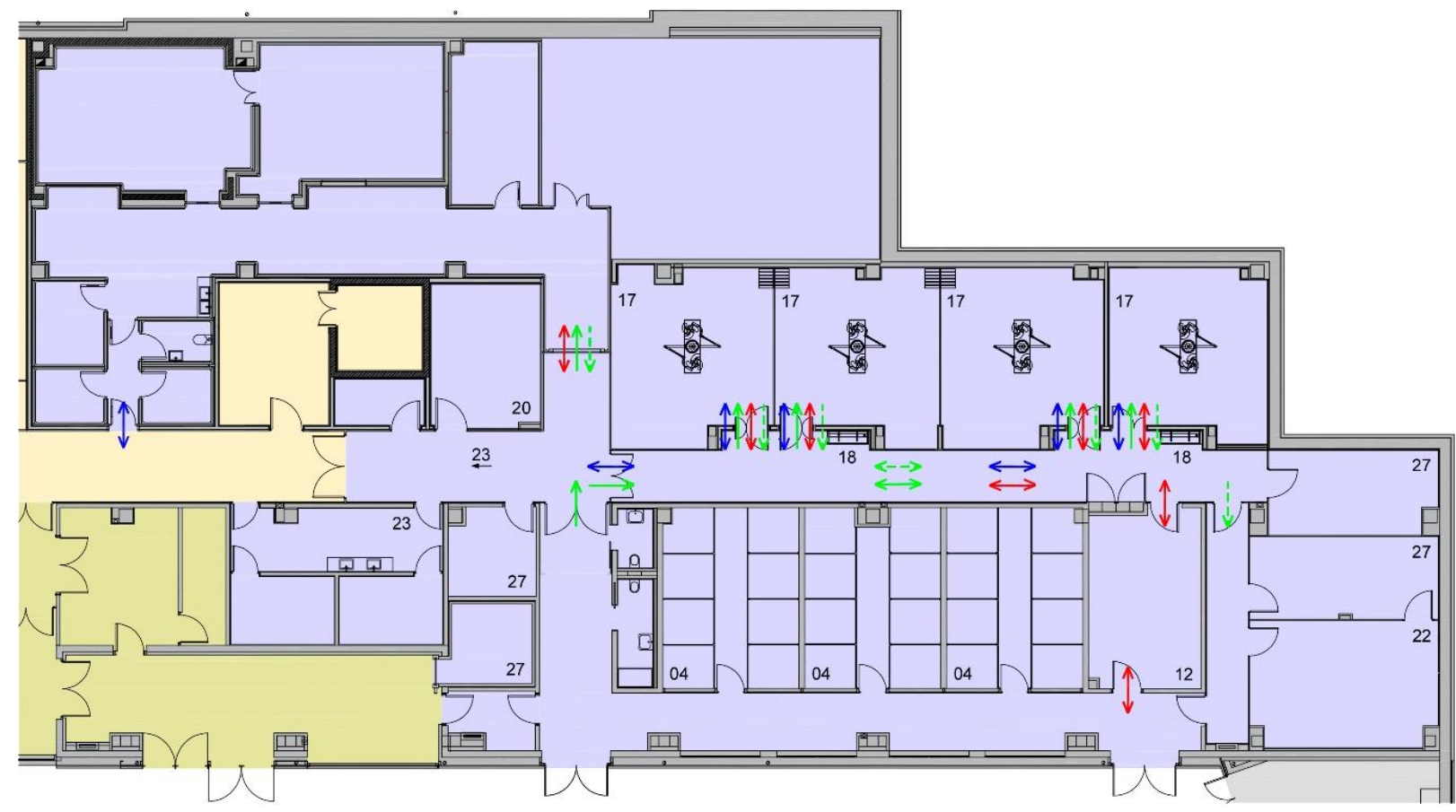

ÁREAS FUNCIONALES

Experimentación animal pequeño

Experimentación animal grande

Áreas comunes animal pequeño y grande

Área Administrativa

Pasillos comunes

Pasillos exteriores y servicios generales

Elementos de circulación vertical
IDENTIFICACIÓN USO LOCALES

$\begin{array}{ll}01 \text { Recepción animal } & 17 \text { Quirófano experimental } \\ 02 \text { Estabulación convencional roedores } & 18 \text { Preparación médica } \\ \text { 03 Estabulación convencional conejos } & 19 \text { A. material estéril } \\ \text { 04 Estabulación convencional animal grande } & 20 \text { Necropsias } \\ 05 \text { Cuarentena roedores } & 21 \text { Cirugia cadáveres } \\ 06 \text { Cuarentena conejos } & 22 \text { Lavado y esterilización } \\ 07 \text { Cuarentena animal grande } & 23 \text { Vestuarios / Aseos } \\ 08 \text { Estabulación barrera animal pequeño } & 24 \text { Esclusa animales } \\ \text { 09 Experimentación ABSL2 - 09* ABSL3 } & 25 \text { Esclusa personas } \\ \text { 10 Experimentación peces } & 26 \text { Esclusa materiales } \\ 11 \text { Lavado animal } & 27 \text { Almacén / archivo } \\ \text { 12 Preparación animal } & 28 \text { Servicios } \\ \text { 13 Procedimientos } & 29 \text { Despacho } \\ \text { 14 Microcirugia } & 30 \text { Sala reuniones } \\ 15 \text { Comportamiento } & 31 \text { Pasillo } \\ 16 \text { Imagen } & 32 \text { Otros }\end{array}$

\section{CIRCULACIONES}

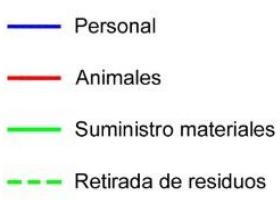

— Personal

Retirada de residuos

Figura 81. Organización unidad quirúrgica IGTP (S/E).

Fuente. Elaboración propia. 
La unidad quirúrgica del instituto IIS La Fe (Figura 82) se compone de tres quirófanos modulables que a través de la compartimentación mediante tabiques móviles permiten disponer de una gran sala de hasta cinco mesas quirúrgicas. Los locales de servicio se desarrollan alrededor del quirófano y es necesario discurrir por pasillos de uso común al animal grande y pequeño. El área de esterilización y lavado, así como el almacenamiento de residuos y cadáveres, son locales de servicio compartidos con el animal pequeño. En este caso se disponen de circuitos diferenciados para separar el acceso del personal médico y material estéril del de animales y residuos.

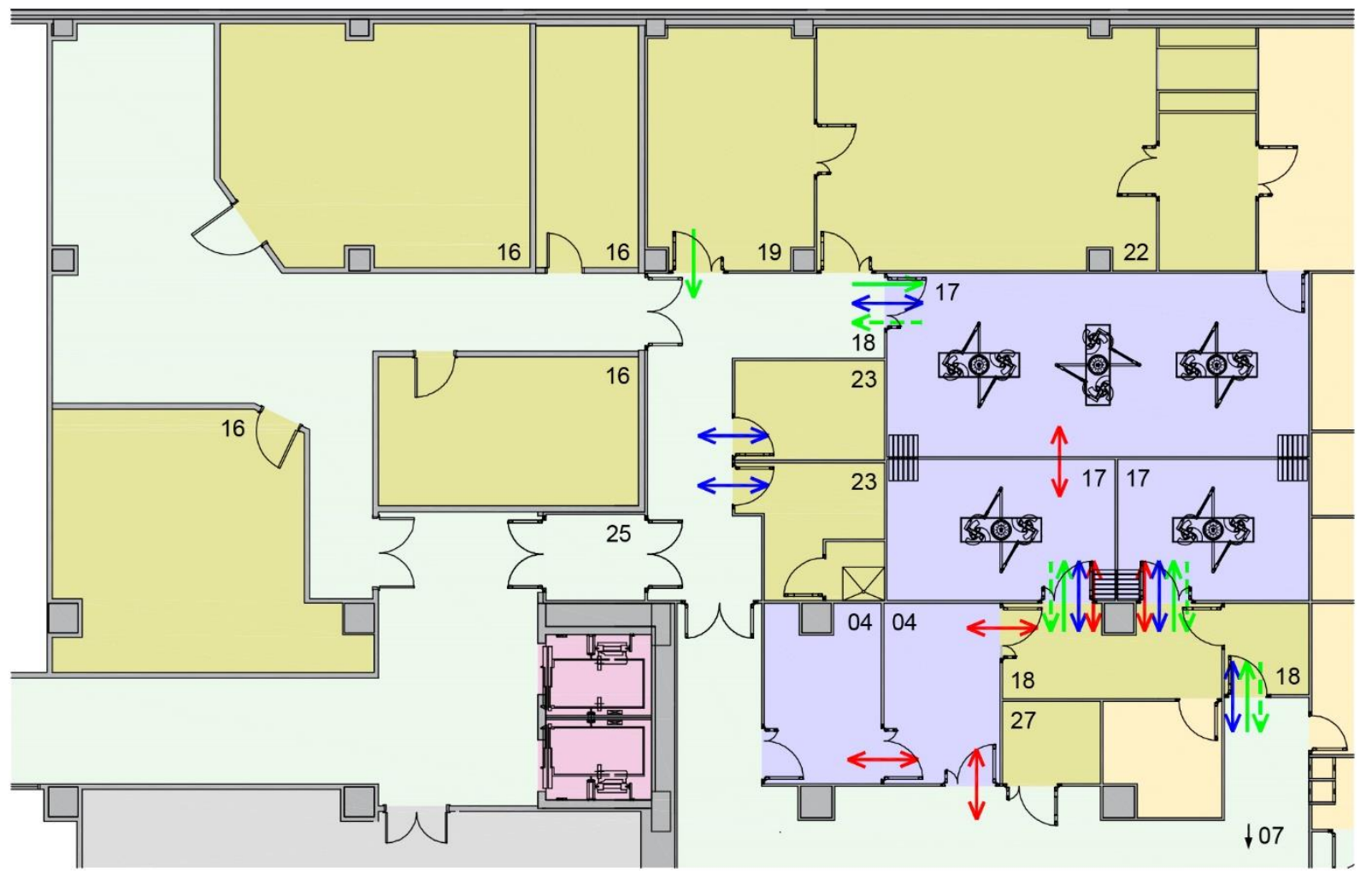

ÁREAS FUNCIONALES

Experimentación animal pequeño

Experimentación animal grande

Áreas comunes animal pequeño y grande

Área Administrativa

Pasillos comunes

Pasillos exteriores y servicios generale

Elementos de circulación vertical

\section{IDENTIFICACIÓN USO LOCALES}

01 Recepción animal
02 Estabulación convencional roedores
03 Estabulación convencional conejos
04 Estabulación convencional animal gran
05 Cuarentena roedores
06 Cuarentena conejos
07 Cuarentena animal grande
08 Estabulación barrera animal pequeño
09 Experimentación ABSL2 - 09* ABSL3
10 Experimentación peces
11 Lavado animal
12 Preparación animal
13 Procedimientos
14 Microcirugía
15 Comportamiento
16 Imagen

17 Quirófano experimental 18 Preparación médica 19 A. material estéril 21 Cirugia cadáveres 22 Lavado y esterilización 23 Vestuarios / Aseos 24 Esclusa animales

25 Esclusa personas 26 Esclusa materiales 27 Almacén / archivo 28 Servicios 30 Sala reuniones 31 Pasillo 32 Otros
CIRCULACIONES

— Personal

- Animales

_ Suministro materiales

- - - Retirada de residuos

Figura 82. Organización unidad quirúrgica IIS La Fe (S/E). Fuente. Elaboración propia. 


\subsubsection{Características generales de la unidad quirúrgica experimental}

El resultado de la investigación sobre las características generales de la unidad quirúrgica experimental de animal grande se encuentra reflejado tanto en las fichas de la documentación gráfica como en la toma de datos de cada centro.

Para realizar el análisis de dichas características se ha hecho una puesta en común de los resultados obtenidos; $y$, para ello, se ha optado por resumir las más importantes en una tabla (Tabla 08). En ella se listan los parámetros que definen las características generales de la unidad quirúrgica, se establecen cuáles son las características comunes a la mayoría de ellas y se identifica los institutos que cumplen dichas características; además, se determinan las características que son particulares y específicas, reflejándose así mismo, los institutos que las cumplen. El análisis se centra en los siguientes conceptos:

- La superficie destinada al bloque quirúrgico experimental, así como la destinada a cada quirófano en función del uso asignado.

- El uso de la unidad quirúrgica, es decir, si se ha configurado para un uso independiente y exclusivo para el animal pequeño, o por el contrario, si el uso es compartido con el animal pequeño.

- Analizar si, aparte de los quirófanos, existen otros locales destinados a la realización de prácticas quirúrgicas.

- El número y tipo de quirófanos que se han diseñado: cuántos quirófanos se disponen, con cuántas mesas quirúrgicas y si la arquitectura permite que estas salas sean modulables o no.

- Analizar someramente las características del diseño constructivo general del área quirúrgica. 
Tabla 08. Características generales unidad de cirugía experimental.

\begin{tabular}{|c|c|c|c|c|}
\hline Parámetros & Características comunes & $\begin{array}{l}\text { Institutos con } \\
\text { características } \\
\text { comunes } \\
\end{array}$ & $\begin{array}{l}\text { Características } \\
\text { específicas }\end{array}$ & $\begin{array}{l}\text { Institutos con } \\
\text { características } \\
\text { específicas }\end{array}$ \\
\hline $\begin{array}{l}\text { Superficie quirófanos } \\
\text { experimentales }\end{array}$ & $<70 \mathrm{~m}^{2}$ & $\begin{array}{l}\text { IdiPAZ, i+12, IiSGM, } \\
\text { IRYCIS, IISBiodonostia, } \\
\text { VHIR }\end{array}$ & $\begin{array}{l}70-100 \mathrm{~m}^{2} \\
>100 \mathrm{~m}^{2} \\
\end{array}$ & $\begin{array}{l}\text { IISBiocruces, IIS La Fe } \\
\text { IISA, IGTP }\end{array}$ \\
\hline $\begin{array}{l}\text { Quirófanos de uso } \\
\text { exclusivo animal } \\
\text { grande }\end{array}$ & $\mathrm{SI}$ & $\begin{array}{l}\text { IdiPAZ, i+12, liSGM, } \\
\text { IRYCIS, IISBiodonostia, } \\
\text { IISBiocruces, IISA, } \\
\text { VHIR, IGTP, IIS La Fe }\end{array}$ & & \\
\hline $\begin{array}{l}\text { Área } \\
\text { experimentación } \\
\text { cadáveres }\end{array}$ & NO & $\begin{array}{l}\text { i+12, liSGM, IRYCIS, } \\
\text { IISBiodonostia, } \\
\text { IISBiocruces, IISA, } \\
\text { VHIR, IGTP, IIS La Fe }\end{array}$ & $\mathrm{SI}$ & IdiPAZ \\
\hline $\begin{array}{l}\text { Sistemas de } \\
\text { retransmisión imagen }\end{array}$ & SI & $\begin{array}{l}\text { IISBiodonostia, } \\
\text { IISBiocruces, IISA, } \\
\text { VHIR, IGTP, IIS La Fe }\end{array}$ & NO & $\begin{array}{l}\text { IdiPAZ, i+12, liSGM, } \\
\text { IRYCIS }\end{array}$ \\
\hline \multirow[t]{2}{*}{ № quirófanos } & 1 UD & $\begin{array}{l}\text { IdiPAZ, i+12, liSGM, } \\
\text { IISBiodonostia }\end{array}$ & 2 UD & $\begin{array}{l}\text { IRYCIS, IISBiocruces, } \\
\text { VHIR }\end{array}$ \\
\hline & & & $>2$ UD & IISA, IGTP, IIS La Fe \\
\hline \multirow[t]{2}{*}{ Tipo de quirófanos } & Doble & $\begin{array}{l}\text { IdiPAZ, i+12, liSGM, } \\
\text { IISBiodonostia, } \\
\text { IISBiocruces, IISA, }\end{array}$ & Simple & $\begin{array}{l}\text { i+12, IRYCIS, IGTP, } \\
\text { IISLaFe, IISA, } \\
\text { IISBiocruces, VHIR }\end{array}$ \\
\hline & & & Triple & IIS La Fe \\
\hline $\begin{array}{l}\text { Quirófanos } \\
\text { modulables }\end{array}$ & NO & $\begin{array}{l}\text { IdiPAZ, i+12, liSGM, } \\
\text { IRYCIS, IISBiodonostia, } \\
\text { IISBiocruces, IISA, } \\
\text { VHIR }\end{array}$ & $\mathrm{SI}$ & IGTP, IIS La Fe \\
\hline $\begin{array}{l}\text { Características de } \\
\text { diseño tipo quirófano } \\
\text { asistenciales }\end{array}$ & SI & $\begin{array}{l}\text { IdiPAZ, i+12, IiSGM, } \\
\text { IRYCIS, IISBiodonostia, } \\
\text { IISBiocruces, IISA, } \\
\text { VHIR, IGTP, IIS La Fe }\end{array}$ & & \\
\hline $\begin{array}{l}\text { Entreplanta técnica } \\
\text { transitable }\end{array}$ & NO & $\begin{array}{l}\text { IdiPAZ, i+12, IISGM, } \\
\text { IRYCIS, IISBiodonostia, } \\
\text { IISBiocruces, IISA, } \\
\text { VHIR, IGTP, IIS La Fe }\end{array}$ & & \\
\hline $\begin{array}{l}\text { Luz natural área } \\
\text { experimentación }\end{array}$ & NO & $\begin{array}{l}\text { i+12, IISGM, } \\
\text { IISBiodonostia, } \\
\text { IISBiocruces, IISA, } \\
\text { VHIR }\end{array}$ & SI & IdiPAZ, IRYCIS \\
\hline
\end{tabular}

Fuente. Elaboración propia.

\section{Dimensionamiento del área quirúrgica}

Todos los institutos investigados disponen de un área de cirugía experimental para la realización de prácticas quirúrgicas. Esas prácticas quirúrgicas son habituales realizarlas con animales pequeños en la denominada área de microcirugía y con animales grandes en la denominada área quirúrgica. En el presente estudio nos centramos únicamente en el estudio del área quirúrgica para experimentación con animal grande.

Observamos cómo el área destinada al desarrollo de los quirófanos es muy variable, siendo lo habitual que la superficie del bloque quirúrgico sea inferior a $70 \mathrm{~m}^{2}$, considerando únicamente la superficie de los quirófanos del área de experimentación. En cuanto al mayor dimensionamiento de esta área destacan dos institutos (IGTP, IISA), cuya superficie es superior a los $100 \mathrm{~m}^{2}$. Por otra parte, si bien la 
superficie recomendable para el diseño de los quirófanos asistenciales se establece en torno a los $40 \mathrm{~m}^{2}$ (El bloque quirúrgico estándares y recomendaciones 2009, p. 124), siendo necesarios cada vez quirófanos más grandes debido a los avances tecnológicos; en los quirófanos experimentales observamos como el área de los quirófanos simples ronda los $20-40 \mathrm{~m}^{2}$, mientras que los dobles disponen de una superficie comprendida entre 35-60 $\mathrm{m}^{2}$ útiles.

\section{Uso de la unidad quirúrgica}

Los quirófanos destinados a experimentación con animal grande son de uso exclusivo para este tipo de animales en todos los centros investigados. El hecho de que no en todos los casos se haya podido independizar esta unidad de la de experimentación de animal pequeño ha originado que zonas comunes, tales como, los pasillos, vestuarios y almacenes sean de uso común para ambas áreas.

\section{Instalaciones complementarias}

Observamos cómo en algún caso se han diseñado instalaciones complementarias a los quirófanos para el desarrollo de las prácticas quirúrgicas. Como caso particular se puede mencionar el IdiPAZ, ya que, además de disponer de un área quirúrgica con una configuración similar a los quirófanos hospitalarios, se ha diseñado una zona para experimentación con cadáveres para alojar varias mesas móviles en una sala compartida con el área de microcirugía (Figura 83).
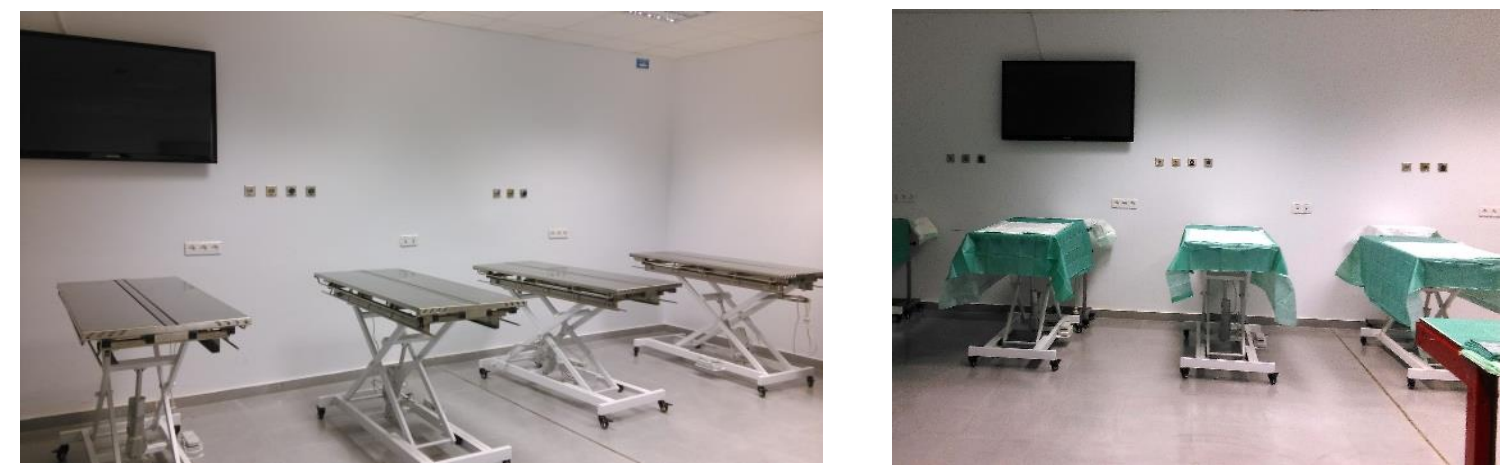

Figura 83. Sala experimentación con cadáveres. Fuente. Elaboración propia.

Otro de los conceptos de diseño relacionados con la flexibilidad de la instalación y presente en los quirófanos experimentales construidos recientemente (IIS Biodonostia, IIS Biocruces, IISA, VHIR, IGTP, IIS La Fe), tiene relación con la posibilidad de retransmitir en streaming las prácticas quirúrgicas realizadas en los quirófanos. La disposición de sistemas audiovisuales integrados en el equipamiento del propio quirófano, así como el diseño de las instalaciones complementarias tanto en la sala de operaciones como en las salas de reuniones del instituto permiten globalizar la formación en prácticas quirúrgicas, reduciendo el número de modelos animales y obteniendo el máximo de difusión de los resultados en una sola operación. 


\section{Número y tipo de quirófanos}

Aunque el número de quirófanos que componen el área quirúrgica es muy variable, lo habitual es que sea superior a uno, si bien nos encontramos casos en los que se dispone de un único quirófano (IdiPAZ, i+12, liSGM, IISBiodonostia; Tabla 09).

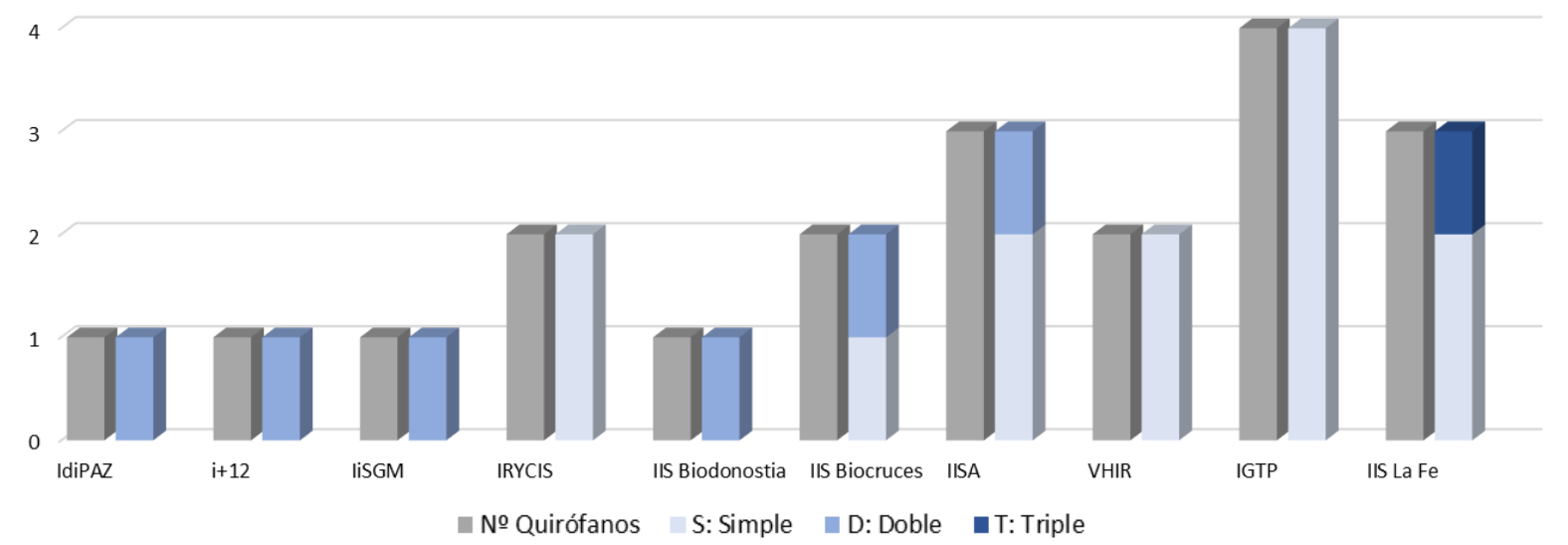

Tabla 09. Número de quirófanos y mesas área quirúrgica experimental. Fuente. Elaboración propia.

En cuanto a la configuración de los quirófanos, como analizaremos detenidamente en el apartado de diseño y organización, vemos que están configurados para experimentar con la especie animal más utilizada; el cerco o cerdo en miniatura y diseñados como si fueran quirófanos hospitalarios con los locales de servicio necesarios para el correcto desarrollo de la actividad; si bien, la fundamental característica diferencial es el número de mesas que nos encontramos en la sala de operaciones. Aunque existen centros en los que hay quirófanos con una única mesa de operaciones (IRYCIS, IIS Biocruces; Figura 84), en la mayoría de los casos existen quirófanos con dos mesas quirúrgicas (IdiPAZ, i+12, liSGM, IIS Biodonostia, IIS Biocruces, IISA; Figuras 86 y 87). E incluso encontramos un caso concreto en el que se han instalado tres mesas (IIS La Fe).
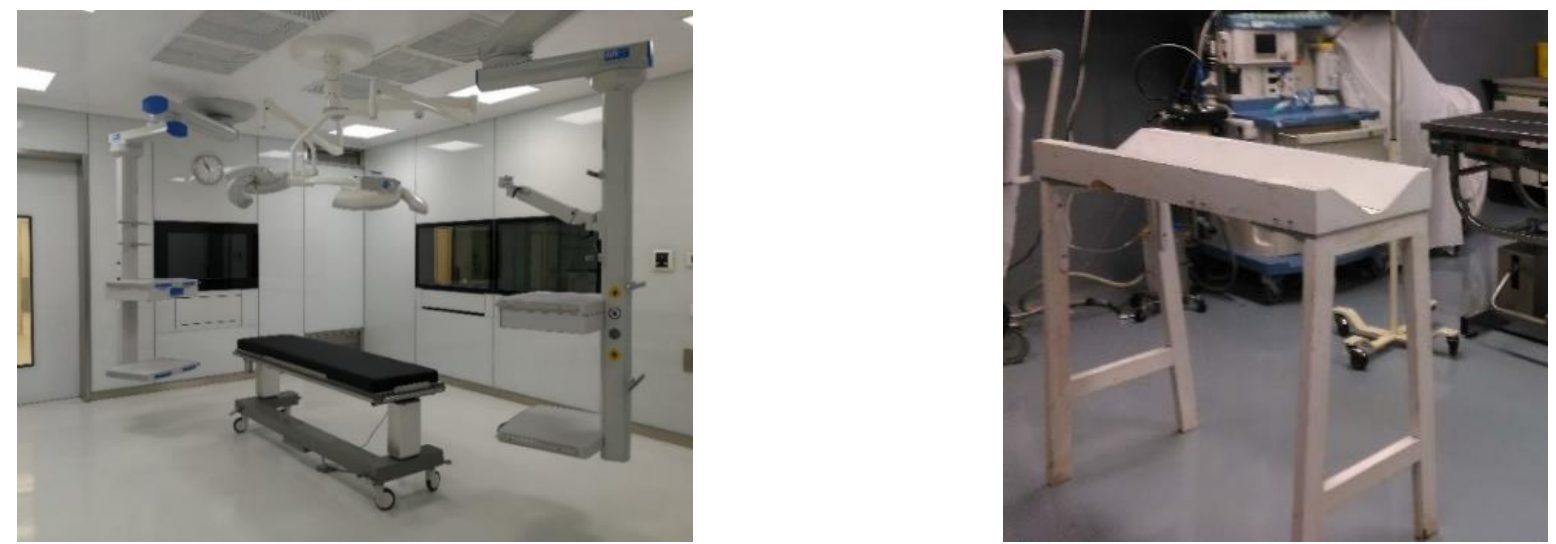

Figura 84. Quirófano simple IIS Biocruces; Fuente. Elaboración propia.

Figura 85. Mesa quirúrgica IdiBAPS; Fuente. Elaboración propia. 
La mesa quirúrgica veterinaria que habitualmente se instala suele ser de tipo móvil, de estructura de acero inoxidable y con columnas elevadoras (Figura 84). En un caso concreto (IdiBAPS; Figura 85) aún observamos el tipo mesa de madera antiguamente utilizada.

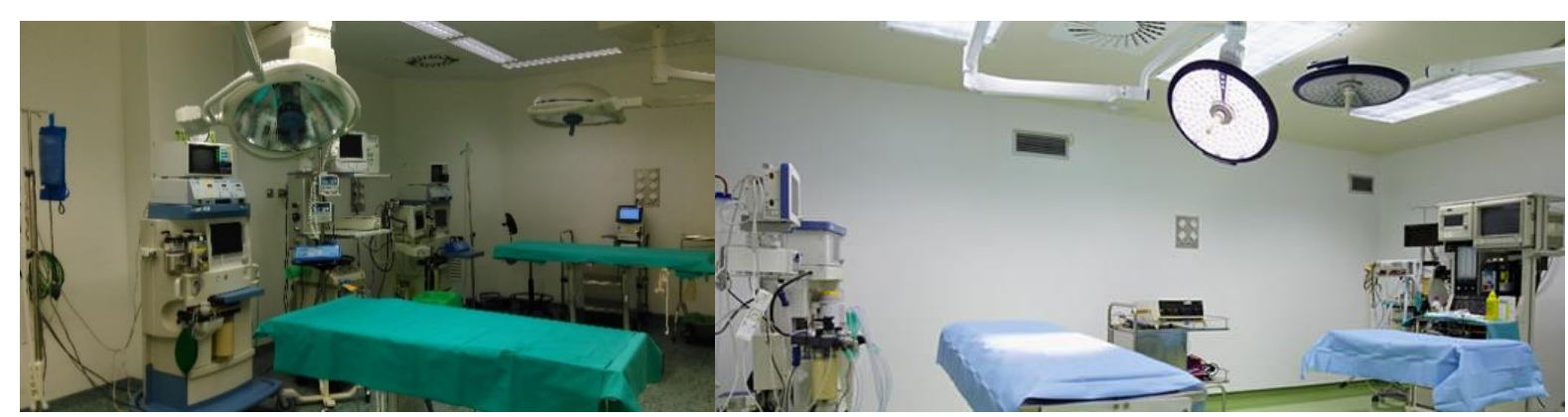

Figura 86. Quirófano doble IdiPAZ; Fuente. Elaboración propia.

Figura 87. Quirófano doble IIS Biodonostia; Fuente. IIS Biodonostia.

Además, se observa cómo en varias áreas quirúrgicas construidas en los últimos años (IGTP, IIS La Fe; Figuras 88 y 89), es habitual que la compartimentación entre quirófanos sea modulable, de manera que mediante el desplazamiento de los tabiques móviles de separación entre diferentes quirófanos se aumenta la capacidad de las estancias para poder incrementar el número de puestos quirúrgicos. En el caso concreto del IGTP, de tener cuatro puestos de manera compartimentada, se pueden llegar a alcanzar hasta un total de ocho estaciones de trabajo debido a la flexibilidad que se dispone.

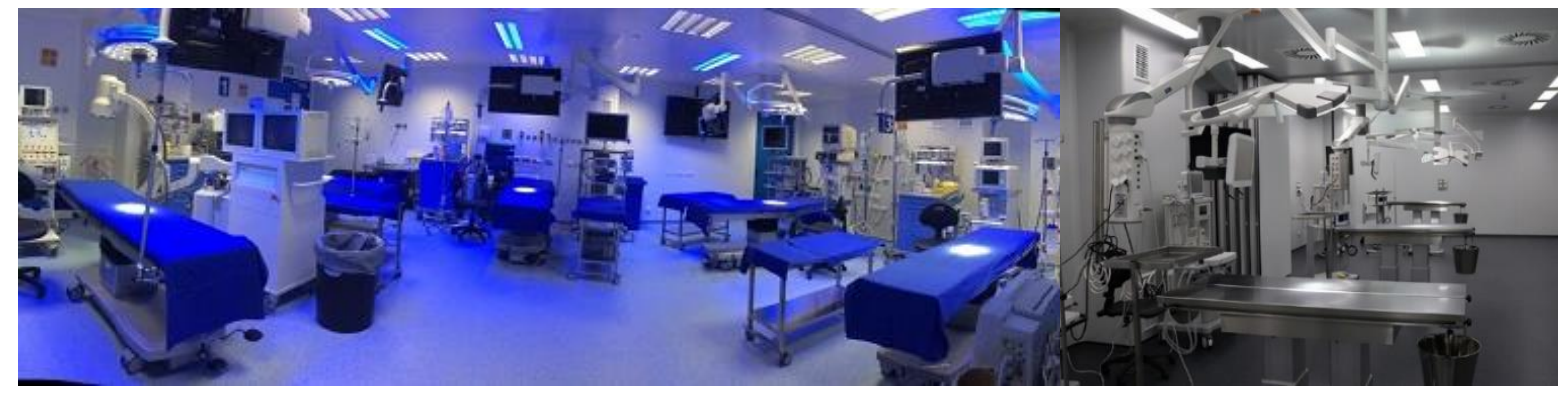

Figura 88. Quirófano modular IIS La Fe; Fuente. IIS La Fe; Figura 89. Quirófano modular IGTP; Fuente. IGTP.

En otros casos en los que el dimensionamiento de la sala lo ha permitido, hemos visto que con el paso del tiempo los quirófanos que inicialmente estaban diseñados para una o dos mesas, se han complementado con la instalación de alguna mesa quirúrgica más (i+12, IRYCIS, IISGM; Figura 90 y 91). 


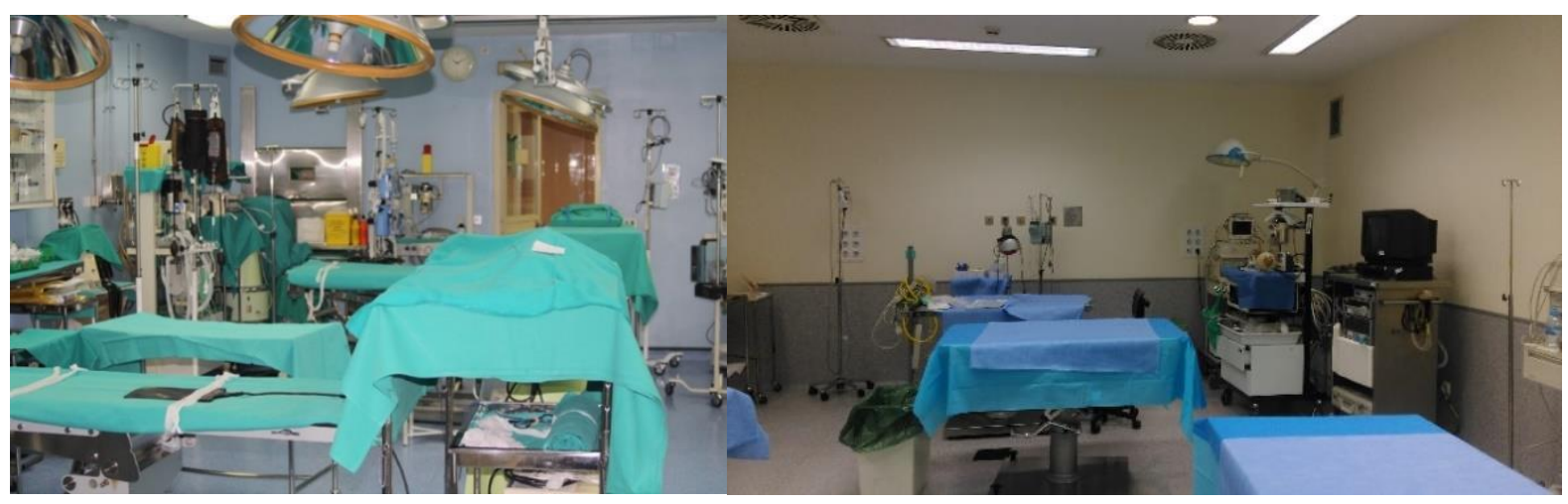

Figura 90. Quirófano doble liSGM; Fuente. liSGM.

Figura 91. Quirófano doble i+12; Fuente. Elaboración propia.

\section{Características de diseño constructivo}

Uno de los objetivos fundamentales de este tipo de quirófanos es la formación, de manera que están diseñados para que los profesionales médicos puedan adquirir la destreza necesaria para su aplicación en el ámbito hospitalario. Además, deben permitir abordar ensayos científicos de mayor complejidad como la valoración de dispositivos médicos, quirúrgicos y biomateriales, así como la realización de ensayos que requieran el trasplante de órganos. Es por ello que, atendiendo a las características del diseño constructivo observamos cómo la tendencia de las áreas quirúrgicas experimentales es diseñarlos como si fueran quirófanos asistenciales con los locales de servicio necesarios, así como con los materiales de acabado similares a los que nos encontramos en el ámbito hospitalario. Siguiendo las directrices generales de facilidad de asepsia, los acabados utilizados son continuos y lisos, con el mínimo número de uniones y fáciles de mantener y reparar, resistentes a la humedad y a los agentes de limpieza y desinfección, con encuentros curvos entre en pavimento y paramento vertical con el fin de garantizar una correcta limpieza y desinfección.

Entre los materiales de acabado que nos encontramos en los paramentos verticales de los quirófanos experimentales están los siguientes:

- Revestimiento vertical a base de pintura epoxi (IRYCIS, IiSGM, IIIS Biodonostia).

- Revestimiento vertical a base de láminas de PVC en rollo con juntas termosoldadas, forrando todo el paramento vertical completo hasta el techo, o bien hasta una altura aproximada de 1,20m (IdiPAZ, I+12, IISA).

- Divisiones realizadas con paneles farmacéuticos (IGTP, VHIR, IIS La Fe), compuesta por paneles de resina fenólica con juntas selladas.

- Divisiones realizadas con paneles modulares registrables acabados en vidrio (IIS Biocruces)

Los acabados de los paramentos horizontales, en cambio, es habitual que estén realizados a base de pavimentos continuos, bien a base de resinas epoxi o bien a base de láminas de PVC en rollo con juntas termosoldadas, estando los encuentros entre el paramento horizontal y vertical rematados con piezas curvas que evitan la acumulación de polvo y facilitan su limpieza. 
Por otra parte, el equipamiento que habitualmente nos encontramos corresponde a lámparas cenitales, torre de cirugía y anestesia, paneles técnicos y equipos de video para retransmisión quirúrgica, entre otros.

Como hemos comentado en el estudio del área de experimentación de animal grande, no todos los institutos tienen un área de imagen para experimentación con animal grande; pero sí es habitual, que los quirófanos se hayan diseñado con la protección radiológica necesaria para poder hacer uso de equipos específicos de imagen en la propia sala de operaciones (IiSGM, IISBiodonostia, IISBiocruces, IISA, VHIR, IGTP, IIS La Fe).

Observamos cómo el área quirúrgica experimental se ha desarrollado prácticamente en todos los casos en zonas sin luz natural. Los casos distribuidos con luz natural se reducen al área de experimentación con cadáveres (IdiPAZ) y, como caso particular, los quirófanos del IRYCIS.

Los quirófanos se consideran salas de ambiente controlado, es por ello que en general, resulta recomendable que en el diseño se consideren conceptos que garanticen el control requerido en estas salas. En este sentido, observamos; por una parte, cómo en la mayoría de los casos (IdiPAZ, i+12, IiSGM, IRYCIS, IISBiodonostia, IISBiocruces) disponen de esclusas colindantes a las salas que permiten evitar la contaminación de agentes patógenos entre áreas, así como un control de las diferencias de presión que permite asegurar que el flujo de aire circule en la dirección adecuada; por otra parte, con el fin de garantizar la hermeticidad de las salas, el diseño de transfers para materiales que, garantiza una apertura mínima de puertas, lo encontramos en los institutos (IdiPAZ, i+12, IRYCIS).

Otra manera de garantizar el ambiente de las salas es poder realizar las tareas de mantenimiento sin tener que acceder a ellas. En el caso concreto de los quirófanos experimentales hemos visto cómo no se dispone de una planta técnica a través de la cual realizar las tareas de mantenimiento de las instalaciones, sino que, el mantenimiento importante se realiza bien por galerías colindantes accesibles o bien a través de pasillos.

En cuanto al diseño de la climatización, el tipo de unidad quirúrgica a diseñar vendrá determinada por las necesidades establecidas por la propiedad, que permitirá definir el nivel de riesgo, para establecer los parámetros necesarios y así poder realizar la elección del tipo de sistema de climatización más conveniente para cada caso.

En función del tipo de cirugía que se va a desarrollar, los quirófanos asistenciales se clasifican en tres tipos: 
- Clase A. Quirófanos de alta tecnología destinados a trasplantes de corazón, pulmón e hígado, cirugía cardíaca extracorpórea y de aorta o cirugía ortopédica de prótesis.

- $\quad$ Clase B. Quirófanos convencionales, de urgencias y de cirugía mayor ambulatoria destinados al resto de intervenciones quirúrgicas.

- Clase C. Quirófanos de cirugía menor ambulatoria y salas de partos destinados a intervenciones ambulatorias y partos.

Además, en el diseño de los quirófanos del ámbito hospitalario se debe tener en cuenta lo establecido en la norma UNE 100713, que clasifica estos locales como Clase I, con exigencias muy elevadas desde el punto de vista higiénico por lo que requiere de tres niveles de filtración de aire (El bloque quirúrgico estándares y recomendaciones 2009, p. 156).

Por otra parte, la clasificación de los quirófanos en función de la concentración de partículas en suspensión es de suma importancia, ya que cuantifica la calidad del aire en quirófanos y nos proporciona una valoración objetiva para determinar el tipo de cirugía a realizar en cada quirófano (Módulo IV ISO 14644, p.11. https://es.calameo.com/read/000163451ea29bfd0319e). El conjunto de normas UNE EN ISO 14644, y más concretamente, la Parte 1 Salas Limpias y locales anexos controlados, están desarrolladas para salas limpias tal como se consideran en la industria farmacéutica, y aunque no son de aplicación en entornos hospitalarios, sirven como referencia para el diseño del sistema de climatización de los quirófanos. Esta clasificación varía de Clase ISO 1 (mayor exigencia de calidad de aire) a ISO 9, definido por el valor máximo de la concentración de partículas permitido.

Tabla 10. Tipo de quirófano y clasificación

\begin{tabular}{|c|c|c|c|c|}
\hline $\begin{array}{c}\text { Tipo de } \\
\text { quirófano }\end{array}$ & $\begin{array}{l}\text { Denominación } \\
\text { quirófano }\end{array}$ & Tipo de intervención & UNE 100713-2005 & $\begin{array}{l}\text { UNE EN ISO - } \\
14644-1: 2000\end{array}$ \\
\hline Tipo A & $\begin{array}{l}\text { Quirófanos de } \\
\text { alta tecnología }\end{array}$ & $\begin{array}{l}\text { *Trasplante de órganos } \\
\text { *Cirugía cardiaca } \\
\text { *Cirugía vascular } \\
\text { *Cirugía ortopédica con } \\
\text { implantes } \\
\text { *Neurocirugía }\end{array}$ & Clase I & ISO 5 \\
\hline Tipo B & $\begin{array}{l}\text { Quirófanos } \\
\text { convencionales }\end{array}$ & $\begin{array}{l}\text { *Cirugía convencional y de } \\
\text { urgencia } \\
\text { *Cirugía mayor ambulatoria } \\
\text { * Resto de operaciones }\end{array}$ & Clase I & ISO 7 \\
\hline Tipo C & $\begin{array}{l}\text { Quirófanos de } \\
\text { cirugía menor } \\
\text { ambulatoria }\end{array}$ & $\begin{array}{l}\text { *Cirugía menor ambulatoria } \\
\text { *Salas de partos }\end{array}$ & Clase I & ISO 8 \\
\hline
\end{tabular}

Fuente. NTP 859. Ventilación general en hospitales. 2010. 
En la Tabla 10 se refleja de manera esquemática la equivalencia entre las diferentes clasificaciones establecidas para el diseño de los quirófanos asistenciales en base a las normas y parámetros analizados anteriormente. En ella observamos las prestaciones que tiene cada tipo de quirófano, el tipo de intervención que se puede realizar en él, así como su clasificación en base a las normas UNE e ISO analizadas.

En los ambientes hospitalarios las partículas en suspensión son preocupantes especialmente por la capacidad de transportar agentes infecciosos, alérgenos o patógenos en general. Lo cierto es que no hay una relación estricta y segura entre la presencia de partículas en suspensión en un ambiente determinado y la presencia de microorganismos viables y/o potencialmente patógenos en ese mismo ambiente, ya que puede ocurrir que exista un número elevado de partículas y que estás sean inocuas o al revés, que haya pocas partículas y que estén cargadas de agentes patógenos. No obstante, desde un punto de vista estadístico, y así lo muestran muy diversos estudios, la probabilidad de encontrar agentes microbianos viables en un entorno con elevadas concentraciones de partículas es más alta que en un entorno con bajas concentraciones de partículas (Pastor, 2016)

El uso de los quirófanos de experimentación animal es una actividad totalmente programada, la circulación de los animales está protocolizada, en los que, además, se debe poder realizar cualquier práctica quirúrgica que sea necesaria llevar a cabo en el ámbito hospitalario. Por lo tanto, en función del tipo de intervención a llevar a cabo en el quirófano deberíamos considerar que sea clase A. Pero hay que tener en cuenta que hay dos diferencias principales con respecto a los quirófanos del ámbito hospitalario; por una parte, la presencia de personal médico es superior; $y$, por la otra, al experimentar con animales terminales o con animales en los que es necesario ver la evolución durante un periodo corto de tiempo, las infecciones nosocomiales no tienen la importancia que tienen en el ámbito hospitalario. Es por todo ello que, a la hora de diseñar estos quirófanos y atendiendo a la concentración de partículas en suspensión se suele a asimilar a los quirófanos convencionales ClaseB. 


\subsubsection{Criterio organizativo de la unidad quirúrgica experimental}

El quirófano es el local en el que se realiza la intervención quirúrgica y donde confluyen los distintos tráficos de la unidad: los animales, el personal investigador, el material estéril, el material usado y los residuos. La importancia de la organización y distribución de los quirófanos y de los locales de servicio principales que componen el área radica en que definirá las diferentes circulaciones asociadas y, por lo tanto, el grado de asepsia de la unidad.

Para analizar la organización del área quirúrgica experimental, hemos tomado como referencia; por una parte, los criterios de distribución en planta y los flujos de trabajo establecidos en las diferentes guías y manuales para la organización específica del área de cirugía experimental; y, por la otra, los criterios de circulación establecidos para el área quirúrgica hospitalaria.

Entre los diferentes manuales y guías relacionados con la organización del área de cirugía experimental, se ha seleccionado el esquema representado en Design Requeriments Manual NIH, ya que refleja de forma sencilla la distribución genérica en planta de los locales que componen la unidad y su organización, de tal manera que quedan reflejados los principales flujos de trabajo de la unidad (Figura 92).

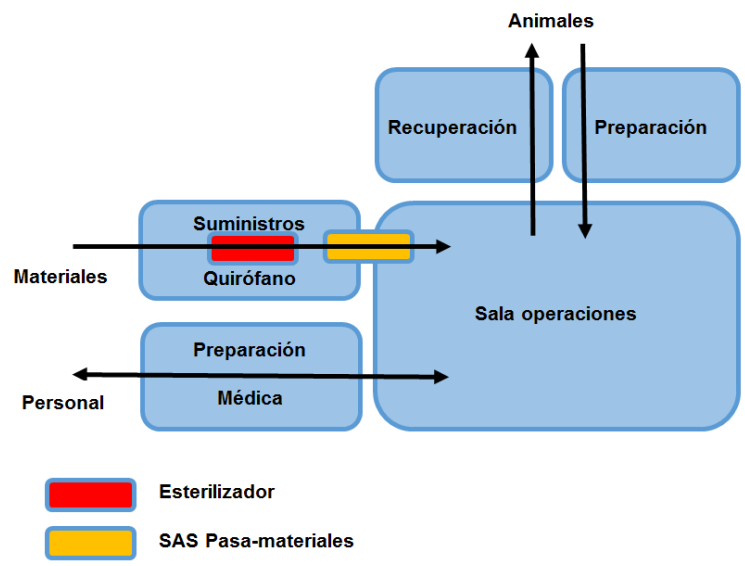

Figura 92. Flujos de trabajo unidad cirugía experimental. Fuente. Division of technical resources 2016, p. 142.

En él observamos cómo toda la organización se desarrolla a partir de la implantación de la sala de operaciones, de manera que colindante a ella se distribuyen los diferentes locales para acceso de personal, animales y materiales. Esta disposición de los locales hace la función de esclusa y permite evitar la contaminación de agentes patógenos entre áreas, ya que favorece el control de las diferencias de presión entre zonas y posibilita asegurar que el flujo de aire circule en la dirección adecuada. Atendiendo a los flujos de trabajo observamos tres circuitos diferentes: uno para los animales que desde al área de estabulación animal son trasladados al quirófano previo paso por una zona de preparación animal, para una vez finalizada la intervención quirúrgica volver a la zona de 
recuperación postanestésica, o, si el animal es terminal, trasladarlo al área de almacenamiento de residuo animal; un segundo circuito para el personal medico que accede y sale del quirófano previo paso por la zona de preparación médica para la colocación del atuendo y realizar el lavado de manos; $y$, un tercero para introducir el material quirúrgico esterilizado a los quirófanos.

Atendiendo a los criterios organizativos del ámbito hospitalario, observamos cómo existe un consenso en la separación del área quirúrgica por zonas en función del mayor o menor riesgo de infección. De esta manera, tomando como referencia el grado de asepsia necesaria en cada zona que compone el área quirúrgica hospitalaria y asimilándolo al área quirúrgica experimental, nos encontramos que con el fin de eliminar lo máximo posible las fuentes de contaminación y poder garantizar las condiciones ambientales necesarias en la mesa de operaciones, el área quirúrgica se divide en tres zonas principales de restricción progresiva (Figura 93):

- Zona Negra: es la primera zona de restricción que funciona como zona amortiguadora de protección, que comprende las zonas periféricas de administración, vestuarios y aseos. A esta zona se permite el acceso con bata clínica y es donde el personal se coloca el atuendo quirúrgico.

- Zona Gris: para acceder a esta zona se requiere portar el uniforme completo de pijama y comprende la sala de preparación médica, sala de preparación animal, sala de recuperación postanestésica, sala de equipos y local para material estéril.

- Zona Blanca: es el área que comprende la sala de operaciones, que es el local donde se lleva a cabo la intervención quirúrgica, la zona de mayor exigencia aséptica y, por lo tanto, la de mayor restricción.

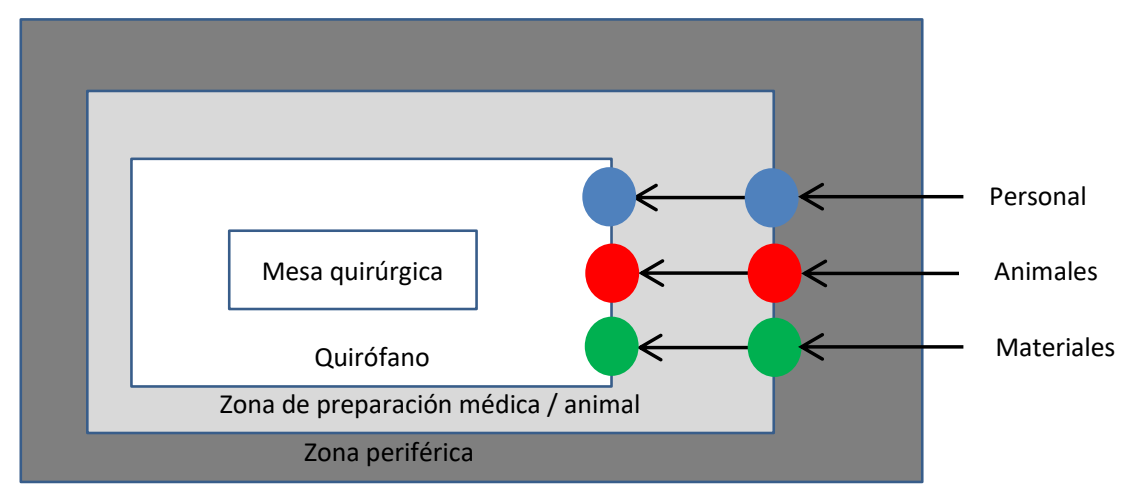

Figura 93. Esquema organización básica circulaciones en función del grado de asepsia necesaria. Fuente. Elaboración propia.

Uno de los temas en los que no existe una clara determinación, y sobre el que existe una disparidad de opiniones es en el criterio de diseño para el tránsito dentro de la unidad quirúrgica, de manera que podemos encontrar soluciones válidas realizadas mediante pasillo único o bien, mediante pasillo 
doble. En este sentido, aunque el diseño de los bloques quirúrgicos hospitalarios ha estado basado en la necesidad de disponer de una circulación limpia y otra sucia, desde hace tiempo se ha demostrado que este criterio de segregación de pasillos es ajena a toda evidencia científica (España. Ministerio de sanidad y Política Social 2009, p. 107).

En el caso del pasillo único, se producen cruces del material limpio con el sucio y de los pacientes con los médicos. Este criterio de diseño conlleva la aplicación de un exhaustivo procedimiento de trabajo, entre los que se incluiría el uso de recipientes y contenedores seguros precintados. En cambio, en el caso de distribución mediante pasillo doble, el principio general es establecer una única dirección de flujo de manera que siempre se circule desde la zona limpia a la sucia, para que una vez esterilizados los materiales, puedan volver a la zona limpia. Tomando como base este principio existen diferentes variaciones posibles que quedan reflejados en los siguientes esquemas (Figura 94).

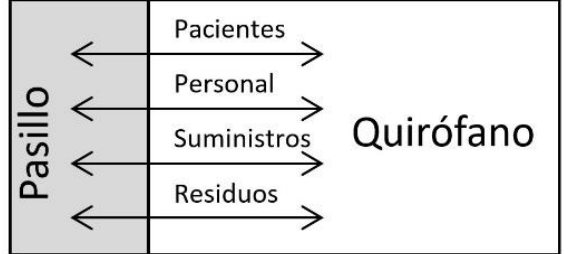

Pasillo único: los pacientes, el personal, los suministros y los residuos hacen uso del mismo pasillo, no existe segregación de circulaciones.

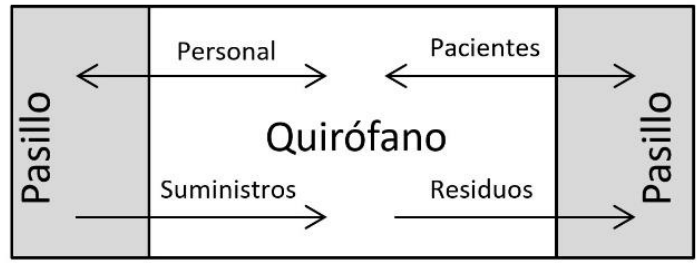

Doble Pasillo: los pacientes y los residuos son segregados del personal y los suministros.

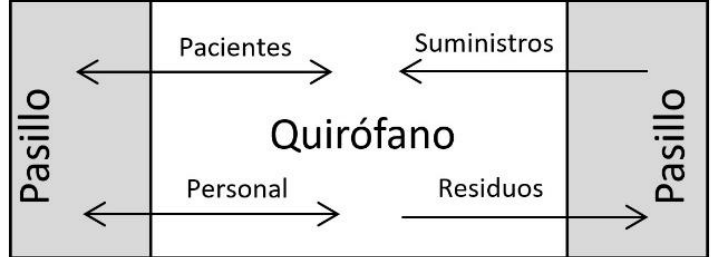

Doble Pasillo: el personal y los pacientes son segregados de los suministros y residuos.

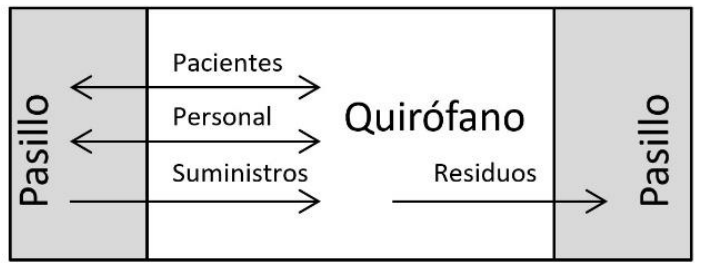

Doble Pasillo: el personal, los pacientes y los suministros son segregados de los residuos.

Figura 94. Relación entre quirófano y las políticas de segregación de circulaciones.

Fuente. NHS States 1991, p. 8-9.

La implantación de diseño de un tipo u otro afecta directamente a la organización del personal y a la disciplina de trabajo, por lo que en su decisión estaría implicado tanto el equipo de diseño como los responsables del área de experimentación. Entre otros motivos, porque si bien desde el punto de vista de aprovechamiento de la edificabilidad y optimización de recursos, la solución de pasillo único es la más adecuada, esta opción requiere por parte de los profesionales del cumplimiento estricto de los procedimientos de trabajo establecidos.

Los quirófanos son salas de ambiente controlado, por lo que, aparte de los criterios de organización y uso de las circulaciones anteriormente analizados, en el diseño del área quirúrgica se deben 
considerar también otros conceptos organizativos que permitan garantizar las condiciones ambientales requeridas en el quirófano, tales como:

- La disposición de esclusas colindantes a las salas para evitar la contaminación de agentes patógenos entre áreas, ya que permite el control de las diferencias de presión entre zonas; y, además, permite asegurar que el flujo de aire circule en la dirección adecuada. Para ello es fundamental garantizar que la apertura de puertas esté controlada de manera que no se puedan abrir simultáneamente.

- La limitación del número de puertas en el quirófano es importante, ya que cuantas más aperturas haya en la envolvente del quirófano, más probabilidades existe de contaminación y de pérdida de presión. Por ello, es importante que aparte de que el cierre sea hermético, la apertura de puertas esté automatizada para que su cierre sea lo más rápida posible y con accionamiento mediante proximidad, codo o rodilla para evitar que tengan que hacer uso de las manos.

- El diseño de transfer para materiales sirve para introducir el instrumental, los materiales, los suministros, incluso retirar los residuos gracias a su mínima apertura, y por lo tanto, sin tener que realizar una apertura de puertas, de manera que se limita el número de accesos al quirófano y, por lo tanto, reduce el riesgo de contaminación.

- En general, excepto para el equipamiento que sea utilizado de manera continuada en el quirófano, el diseño de locales para almacenamiento de equipos en zonas colindantes al quirófano permite, por una parte, que no se tenga que recurrir al propio quirófano ni a los pasillos como sistema de almacenamiento; y, por la otra, facilita y garantiza la limpieza de los quirófanos.

Para el diseño de los quirófanos experimentales, aparte de los criterios hasta ahora analizados, hay que tener en cuenta que se deberá contemplar la especie a ser operada, así como, la complejidad de los procedimientos que se realizarán, teniendo en cuenta que la instalación será más grande y más compleja en función del número y tamaño de los animales o del aumento de la complejidad de los procedimientos.

Con el fin de realizar una lectura sencilla de la organización de las áreas quirúrgicas experimentales de los institutos investigados, se ha optado por resumirlas en una tabla (Tabla 11), en la que se reflejan los parámetros que definen las características de organización más importantes, identificando cuáles son las características comunes a la mayoría de las áreas quirúrgicas e identificando qué institutos cumplen dichas características; además, se determinan las características particulares o específicas, 
que son aquellas que las cumplen solo unos determinados institutos, reflejándose así mismo, qué institutos las cumplen. El análisis se centra en los siguientes conceptos:

- Analizar la implantación del área quirúrgica en el conjunto edificatorio.

- Analizar si el área de cirugía experimental de animal grande se ha organizado de manera independiente al área de experimentación de animal pequeño; y en el caso de que no se haya independizado, estudiar qué locales de servicio son los compartidos y si ha sido necesario implantar procedimientos de trabajo específicos para el desarrollo de la actividad.

- Analizar los diferentes locales de servicio que componen la unidad quirúrgica, así como su ubicación, lo cual predeterminará los flujos de trabajo para los animales, personal médico, suministro de materiales y retirada de residuos.

- $\quad$ Analizar el tipo de configuración de los pasillos diseñados en cada caso.

Tabla 11. Organización unidad quirúrgica experimental animal grande.

\begin{tabular}{|c|c|c|c|c|}
\hline Parámetros & Características comunes & $\begin{array}{l}\text { Institutos con } \\
\text { características } \\
\text { comunes }\end{array}$ & $\begin{array}{l}\text { Características } \\
\text { específicas }\end{array}$ & $\begin{array}{l}\text { Institutos con } \\
\text { características } \\
\text { específicas }\end{array}$ \\
\hline $\begin{array}{l}\text { Tipo de planta en la } \\
\text { que se ubica }\end{array}$ & A cota cero & $\begin{array}{l}\text { i+12, IISGM, IRYCIS, } \\
\text { IISBiodonostia, } \\
\text { IISBiocruces, IISA, } \\
\text { VHIR, IGTP }\end{array}$ & Bajo Rasante & IdiPAZ, IIS La Fe \\
\hline $\begin{array}{l}\text { Independizado del } \\
\text { área quirúrgica } \\
\text { animal pequeño }\end{array}$ & NO & $\begin{array}{l}\text { IdiPAZ, i+12, liSGM, } \\
\text { IRYCIS, IISBiodonostia, } \\
\text { VHIR, IIS La Fe }\end{array}$ & SI & $\begin{array}{l}\text { IISBiocruces, IISA, } \\
\text { IGTP }\end{array}$ \\
\hline $\begin{array}{l}\text { Zonas compartidas } \\
\text { con animal pequeño }\end{array}$ & Pasillos y vestuarios & $\begin{array}{l}\text { IdiPAZ, i+12, IiSGM, } \\
\text { IRYCIS, IISBiodonostia, } \\
\text { VHIR, IIS La Fe }\end{array}$ & $\begin{array}{l}\text { Preparación animal } \\
\text { Preparación médica }\end{array}$ & $\begin{array}{l}\text { IISBiodonostia } \\
\mathrm{i}+12\end{array}$ \\
\hline $\begin{array}{l}\text { Ubicación vestuarios } \\
\text { en área quirúrgica }\end{array}$ & $\begin{array}{l}\text { Contiguos al área } \\
\text { quirúrgica }\end{array}$ & $\begin{array}{l}\text { i+12, IISBiocruces, } \\
\text { IISA, IGTP, IIS La Fe }\end{array}$ & En zonas comunes & $\begin{array}{l}\text { IdiPAZ, IiSGM, IRYCIS, } \\
\text { IISBiodonostia, VHIR }\end{array}$ \\
\hline $\begin{array}{l}\text { Área preparación } \\
\text { médica }\end{array}$ & Exclusiva para personal & $\begin{array}{l}\text { IdiPAZ, liSGM, } \\
\text { IISBiodonostia, } \\
\text { IISBiocruces, IISA }\end{array}$ & $\begin{array}{l}\text { Compartida con acceso } \\
\text { animales } \\
\text { En pasillo }\end{array}$ & $\begin{array}{l}\text { i+12, VHIR, IIS La Fe, } \\
\text { IRYCIS } \\
\text { IGTP }\end{array}$ \\
\hline Local material estéril & $\begin{array}{l}\text { Compartido con zona } \\
\text { preparación médica }\end{array}$ & $\begin{array}{l}\text { IIBiodonostia, } \\
\text { IISBiocruces, IISA, } \\
\text { VHIR, IGTP, IIS La Fe }\end{array}$ & Local independiente & $\begin{array}{l}\text { IdiPAZ, i+12, IRYCIS, } \\
\text { liSGM }\end{array}$ \\
\hline Preparación animal & En el área quirúrgica & $\begin{array}{l}\text { IdiPAZ, IiSGM, IRYCIS, } \\
\text { IISBiodonostia, } \\
\text { IISBiocruces, VHIR, } \\
\text { IGTP, IIS La Fe }\end{array}$ & En zonas periféricas & $i+12$, IISA \\
\hline $\begin{array}{l}\text { Área lavado y } \\
\text { esterilización } \\
\text { material quirúrgico }\end{array}$ & $\begin{array}{l}\text { Compartido con otras } \\
\text { áreas experimentación } \\
\text { animal }\end{array}$ & $\begin{array}{l}\text { IdiPAZ, i+12, liSGM, } \\
\text { IRYCIS, IISBiodonostia, } \\
\text {, VHIR, IIS La Fe }\end{array}$ & $\begin{array}{l}\text { Exclusivo quirófano } \\
\text { animal grande }\end{array}$ & $\begin{array}{l}\text { IISBiocruces, IISA, } \\
\text { IGTP }\end{array}$ \\
\hline $\begin{array}{l}\text { Configuración } \\
\text { pasillos a. quirúrgica }\end{array}$ & Pasillo Doble & $\begin{array}{l}\text { i+12, liSGM, } \\
\text { IISBiodonostia, } \\
\text { IISBiocruces, VHIR }\end{array}$ & Pasillo Único & $\begin{array}{l}\text { IdiPAZ, IRYCIS, IGTP, } \\
\text { IIS La Fe }\end{array}$ \\
\hline
\end{tabular}

Fuente. Elaboración propia.

\section{Planta de ubicación}

En el ámbito hospitalario, el bloque quirúrgico es una de las áreas críticas en cuanto a las exigencias de la calidad de aire, por lo que en general, se recomienda que esté ubicado en la última planta del edificio para garantizar la facilidad en el mantenimiento de la instalación. Además, la ubicación y 
posicionamiento del bloque quirúrgico dentro del hospital condiciona también la ubicación del resto de áreas con las que está directamente relacionado, como son la UCl, las urgencias, la CMA y el área de hospitalización.

Sin embargo, en el caso de los quirófanos experimentales observamos que el criterio utilizado para la implantación del área quirúrgica es diferente al establecido en el ámbito hospitalario, siendo lo habitual que los quirófanos se distribuyan en plantas con acceso directo desde el exterior, bien en plantas bajas o plantas semisótanos, ya que, en general, lo que se prioriza en estos casos es la cercanía al área de estabulación de animal grande. En los casos en los que no se ha podido distribuir en este tipo de plantas, la tendencia es ubicarlas en plantas bajo rasante (IdiPAZ, IIS La Fe).

\section{Configuración independiente al área de experimentación animal pequeño}

En general, el área quirúrgica no se ha conseguido configurar como una unidad independiente del resto del centro de experimentación. Encontramos tres casos en los que la organización se realiza generando un área independizada (IIS Biocruces, IISA, IGTP).

En el resto de los casos, lo habitual es que el área quirúrgica se distribuya dentro del conjunto del centro de experimentación animal, de manera que las instalaciones generales, tales como, los vestuarios de cambio y los pasillos de distribución sean comunes tanto para el área quirúrgica como para el centro de experimentación animal en general.

Como casuísticas especiales se pueden mencionar el IIS Biodonostia y el i+12, ya que en el primer caso el área de preparación animal es tanto para el animal pequeño como para el grande. Es por ello que para garantizar el correcto funcionamiento del centro se ha establecido un procedimiento de trabajo específico para el uso de esa sala y, por lo tanto, ambas actividades deben estar coordinadas para poder conseguir la asepsia necesaria. Por otra parte, en el i+12, la zona de preparación médica es un área compartida tanto para los profesionales que van a realizar las prácticas en el quirófano con animales grandes, como para los que van a realizar las prácticas de microcirugía con animal pequeño.

\section{Locales de servicio}

Los locales de servicios relacionados con la actividad quirúrgica, como son los locales de almacenamiento de residuos y cadáveres, así como los locales de lavado y esterilización de material quirúrgico, son áreas que habitualmente se comparten con los animales pequeños, y que se distribuyen en zonas periféricas al área quirúrgica.

En relación a la ubicación de los vestuarios, no en todos los casos se ha podido diseñar un núcleo para uso exclusivo del área quirúrgica, si bien observamos que el grado máximo de asepsia en las 
instalaciones quirúrgicas se consigue cuando el vestuario de cambio de personal está comunicado directamente con la zona de preparación médica o con un pasillo limpio de uso exclusivo del área quirúrgica (IISA, i+12, IIS Biocruces, IIS La Fe).

En la mayoría de los casos se dispone de un área de preparación médica contigua a los quirófanos, y en los casos en los que se ha podido, se ha utilizado para compartirlo como punto de acceso a varios quirófanos (IIS Biocruces, IISA, IRICYS, VHIR, IIS La Fe). Lo que no se ha conseguido en todos ellos es que esta zona de prequirófano sea de uso exclusivo para el personal investigador, ya que vemos algunos casos en los que esta zona de preparación médica sirve de punto de acceso también de los animales (i+12, IRYCIS, VHIR). Además, en un caso concreto vemos que se comparte el uso como punto de acceso de los animales pequeños al área de microcirugía (i+12) o como zona de paso obligado para acceso a los quirófanos tanto para el personal, como para los animales, el material estéril y la retirada de residuos (IRICYS).

Por otra parte, la zona de preparación animal habitualmente se ubica en un local colindante al quirófano con acceso directo a este (IdiPAZ, i+12, liSGM, IIS Biodonostia, IIS Biocruces, IIS La Fe). En otros casos, en vez de en locales que componen el bloque quirúrgico, se ubica en locales del área de estabulación animal (IISA). Existe un caso especial (IIS Biodonostia) en el que el área de preparación animal es tanto para el animal pequeño como para el grande. Es por ello que para garantizar el correcto funcionamiento del centro se ha establecido un procedimiento de trabajo específico para el uso de esa sala y, por lo tanto, ambas actividades deben estar coordinadas para poder conseguir la asepsia necesaria.

Aunque lo habitual es que el almacén de material estéril sea un local compartido con la zona de preparación médica, existen algunos casos en los que este acceso se ha independizado de manera que existe una zona de preparación médica de acceso para el personal, y otra diferente para el acceso de material estéril a través de transfer de materiales al quirófano (IdiPAZ, i+12, IRICYS).

Una de las áreas necesarias para el desarrollo de la actividad es el área de lavado y esterilización del material quirúrgico. Aunque esta actividad mayoritariamente se desarrolla en locales exteriores al área quirúrgica, siendo su uso compartido con otras plataformas del instituto que también requieren de estos servicios, existen algunos casos en los que esta unidad se distribuye de forma exclusiva dentro del área quirúrgica (IIS Biocruces, IISA, IGTP).

\section{Tipo de configuración de pasillos}

La mezcla de factores tales como el número de quirófanos, el número de mesas quirúrgicas en cada sala de operaciones, la ubicación de los locales de servicio, así como el tipo de configuración de pasillo 
seleccionado hacen que la organización de esta área no siga un patrón específico, resultando una distribución particular en cada caso.

Atendiendo al tipo de configuración de pasillo seleccionado, vemos que no existe una tendencia clara que defina el diseño de un modelo de pasillo simple o de pasillo doble. Teniendo en cuenta, por una parte, la organización y distribución de las áreas quirúrgicas comentadas anteriormente, y por la otra, cómo se ha organizado la circulación del personal investigador, de los animales, del material estéril y de los residuos, en base al estudio realizado, podemos establecer tres tipologías diferentes de organización de áreas quirúrgicas experimentales:

1. Distribución con pasillo único. En esta tipología se centran los casos en los que para acceder a la zona de prequirófano y preparación animal el pasillo que se utiliza es el mismo, y además, también se utiliza ese mismo pasillo para el suministro de material estéril y retirada de los residuos generados en el quirófano (IdiPAZ, IRYCIS, IGTP, IIS La Fe).

2. Distribución con pasillo doble. En esta tipología existen dos pasillos de circulación diferenciados; uno para el acceso del personal investigador y suministro de material limpio al quirófano; $y$, otro diferente desde el que se accede con los animales y se retiran los residuos (IISA, IISGM, IIS Biodonostia, IIS Biocruces, VHIR).

3. Distribución con pasillo doble. En esta tipología también existen dos pasillos de distribución, pero las circulaciones se ordenan de diferente manera al anterior; existe un pasillo para el acceso del personal investigador, material estéril y animales al quirófano, y otro diferente para la retirada de residuos del mismo $(i+12)$.

En el caso de varios institutos ( $i+12$ y IISA), observamos que, a pesar de que este tipo de distribución la hemos considerado de doble pasillo por el hecho de que el acceso y la salida del quirófano de alguno de los elementos se hace por pasillos diferentes, lo cierto es que al final ambos acaban confluyendo en un mismo pasillo. Por otra parte, llama la atención cómo en uno de los casos (IIS Biocruces), debido a la falta de disponibilidad de superficie suficiente para el desarrollo completo de los pasillos necesarios para acceder a cada uno de los quirófanos, se ha optado porque uno de ellos sirva como zona de paso para el traslado de animales y la retirada de residuos de la sala de operaciones. Esta circunstancia tan especial, obliga al centro a que la actividad de ambos quirófanos deba estar totalmente coordinada, de manera que el quirófano segundo sea en el que antes se inicie la actividad y además sea más larga, para evitar afectar al desarrollo de la actividad del primer quirófano. 


\subsubsection{Síntesis de la unidad quirúrgica experimental}

En los Institutos de Investigación Sanitaria Acreditados existe un área quirúrgica para experimentación con animal grande, bien para realizar las intervenciones quirúrgicas necesarias en el desarrollo de procedimientos experimentales, o bien para la realización de prácticas y adquirir la destreza necesaria en cualquiera de las especialidades quirúrgicas y medico-quirúrgicas, así como en técnicas anestésicas o laparoscópicas, entre otras.

Para la realización de dichas prácticas quirúrgicas, lo habitual es que se diseñen quirófanos experimentales, siendo el modelo animal más habitual utilizado el cerdo o cerdo en miniatura. Además, se observa cómo en algunos casos, para complementar las prácticas quirúrgicas se ha planteado una sala de experimentación con cadáveres.

El uso de estas áreas quirúrgicas es una actividad totalmente programada en la que la circulación de los animales está protocolizada, si bien existe una diferencia importante a tener en cuenta entre los quirófanos de experimentación animal y los quirófanos en los que se prestan servicios de salud. En los quirófanos de hospitales es fundamental garantizar la protección del paciente contra los agentes nocivos; en cambio, en el caso de la experimentación animal este aspecto no es tan crítico, ya que lo habitual es que los animales sean terminales, o bien que interese ver la evolución durante un determinado tiempo sin tener que estabularlos en el propio instituto durante un periodo largo de tiempo, por lo que las exigencias de calidad de aire pueden ser más permisivas.

Observamos también que el criterio utilizado para la implantación del área quirúrgica en el conjunto edificatorio es diferente al establecido en el ámbito hospitalario, siendo lo habitual que los quirófanos se distribuyan en plantas con acceso directo desde el exterior, bien en plantas bajas o plantas semisótanos, ya que en general, lo que se prioriza en estos casos es la cercanía al área de estabulación de animal grande. El suministro de los animales grandes al centro es constante y estos animales, que son bastante ruidosos y pueden ocasionar problemas de olores, hay que trasladarlos hasta la zona de estabulación. Es por ello que conviene en la medida de lo posible, con el fin de evitar molestias al resto de los usuarios del instituto, que la zona de estabulación de animales grandes se tienda a situarla en una planta con acceso directo al exterior y lo más cercano a este acceso.

Las instalaciones para experimentación con animal grande y pequeño tienen requerimientos de base muy diferentes debido fundamentalmente al tipo de investigación que se realiza, a las condiciones de asepsia y de bioseguridad exigibles, incluso a las exigencias de los propios animales de experimentación. Es por ello que aunque lo ideal sería poder diseñar un área de cirugía experimental totalmente independiente al área de experimentación de animal pequeño, la realidad es que a falta 
de disponer superficie suficiente para poder independizar las áreas, es muy común que ambas áreas compartan vestuarios, pasillos de distribución, locales de almacenamiento y salas de lavado y esterilización. En algunos casos, incluso se han compartido salas de preparación animal, por lo que para garantizar el correcto funcionamiento del centro se han establecido procedimientos de trabajo específicos para el uso común de la sala.

Atendiendo a las características del diseño constructivo de los quirófanos, observamos que la tendencia de las áreas quirúrgicas experimentales es diseñarlas como si fueran quirófanos asistenciales con los locales de servicio necesarios, así como con los materiales de acabado similares a los que nos encontramos en el ámbito hospitalario, siguiendo las directrices generales de facilidad de asepsia y con el equipamiento correspondiente, tales como: lámparas cenitales, torre de cirugía y anestesia, paneles técnicos y equipos de video para retransmisión quirúrgica, entre otros.

Los quirófanos se consideran salas de ambiente controlado, por lo que es recomendable que en su diseño se consideren conceptos que garanticen el control requerido en estas salas. Ubicar la sala de preparación médica, la sala de preparación animal, así como el almacén de material estéril, incluso la salida de residuos colindante a los quirófanos, realiza la función de esclusa, lo que permite tener un control de las diferencias de presión entre salas, asegurando que el flujo circule en la dirección adecuada, y, por lo tanto, evita la contaminación de agentes patógenos en la sala de operaciones. Así mismo, el grado de asepsia en la instalación mejora con la implantación de los vestuarios colindantes y con acceso directo al área quirúrgica o a la zona de preparación médica.

En cuanto al número de quirófanos que componen el área quirúrgica, aunque es muy variable, lo habitual es que sea superior a uno. Estos quirófanos experimentales que son utilizados para la formación quirúrgica de los médicos, con el fin de optimizar la superficie disponible en el centro, habitualmente son diseñados para instalar dos mesas de operaciones. En los casos en los que el dimensionamiento de la sala lo ha permitido, con el paso del tiempo incluso se ha complementado la instalación con alguna mesa quirúrgica más. La implantación de tabiques móviles como elementos divisorios entre quirófanos ofrece mayor versatilidad al uso de las salas llegando a conseguir aumentar considerablemente el número de mesas quirúrgicas disponible.

La configuración del área de cirugía experimental se puede organizar de diferentes maneras en función del criterio de distribución de pasillos seleccionado, de manera que podemos establecer tres tipologías diferentes de organización.

- Tipología 1. Distribución con pasillo único en el que tanto el personal investigador, el suministro de material limpio, los animales, incluso los residuos, acceden al quirófano por el mismo pasillo. 
- Tipología 2. Distribución con pasillo doble en el que se separa el acceso del personal investigador y suministro del material limpio al quirófano del de animales y los residuos.

- Tipología 3. Distribución con pasillo doble en el que el personal investigador, el suministro de material estéril y los animales son segregados de los residuos.

La implantación de un tipo u otro de diseño afecta directamente a la organización del personal y la disciplina de trabajo, por lo que en su decisión está habitualmente implicado tanto el equipo de diseño como los responsables del área de experimentación. Si bien la tipología de distribución con pasillo único es la solución más adecuada desde el punto de vista de aprovechamiento de la edificabilidad y optimización de recursos, esta opción en la que se produce el cruce de los investigadores con los animales y del material limpio y sucio, requiere por parte de los profesionales del cumplimiento estricto de los procedimientos de trabajo establecidos en aras a garantizar las condiciones asépticas necesarias en el quirófano. Es por ello que la tendencia es realizar una distribución de manera que exista una segregación de circulaciones a la entrada del quirófano que permite independizar la circulación limpia de la sucia, considerando la limpia la destinada al personal investigador y suministro de material estéril, y la sucia la destinada a la circulación animal y retirada de residuos.

La mezcla de factores, tales como, el número de quirófanos, el número de mesas quirúrgicas en cada sala de operaciones, la ubicación de los locales de servicio, así como el tipo de configuración de pasillo seleccionado hacen que la organización de esta área no siga un patrón específico, resultando una distribución particular en cada caso.

En base al estudio realizado y centrándonos exclusivamente en la actividad quirúrgica experimental, la mayoría de los profesionales consultados estaban de acuerdo en que siempre que fuera posible intentarían diseñar:

- Un bloque quirúrgico experimental independiente a la experimentación de animal pequeño.

- Disponer de una zona de vestuarios como frontera de acceso a la unidad quirúrgica.

- Segregar las circulaciones del personal de la de los animales, y crear vestíbulos previos al quirófano que permitan garantizar el mantenimiento de las presiones diferenciales de los quirófanos.

La explosión tecnológica de los últimos años en el desarrollo de equipamiento médico cada vez más eficiente obliga a los profesionales médicos a adquirir la destreza necesaria para su aplicación posterior en el ámbito hospitalario en aras a mejorar la calidad de vida de la población. 
Lo que este estudio aporta es una visión de las diferentes soluciones adoptadas en el diseño de las áreas quirúrgicas experimentales, de manera que a partir de su análisis permita enfocar los proyectos futuros con una visión amplia una vez conocidas las fortalezas y debilidades de cada solución adoptada, teniendo presente el objetivo final: intentar planificar, diseñar y construir lo mejor posible en aras a facilitar un funcionamiento eficiente, económico y seguro.

Intentar crear un modelo de diseño estandarizado en relación a los quirófanos experimentales para su aplicación en los Institutos de Investigación Sanitaria, que desarrollara todo lo analizado anteriormente, sería un trabajo complejo, por no decir que imposible, ya que como se ha visto, la tipología es muy variada y no existe un consenso sobre la idoneidad de una u otra tipología. No hay conceptos invariables definidos a los que agarrarse para a partir de ellos elaborar una propuesta de modelo estandarizada, ya que los diseños responden a unas líneas de investigación concretas establecidas y, por lo tanto, a unas necesidades iniciales de partida propuestas por los responsables del centro, a unas limitaciones establecidas por la propia implantación del área quirúrgica en el conjunto edificatorio y, por último, a unos criterios de organización diferentes propuestos por los propios diseñadores. 


\subsection{Organización y diseño del área de experimentación animal pequeño}

El área de experimentación de animal pequeño se concibe como un área de investigación biomédica multidisciplinar y traslacional orientada a la investigación básica, clínica, epidemiológica y a los servicios de salud. Cada instituto define sus propias áreas de investigación, siendo muy habitual el estudio en las áreas de enfermedades cardiovasculares, neurociencias y salud mental, enfermedades infecciosas y sida, oncología, epidemiología y salud pública o bioingeniería, entre otros.

Para llevar a cabo este tipo de investigación es necesario el empleo de animales de laboratorio; además, es muy importante escoger la especie animal que mejor se adapte al tipo de estudio que se pretende llevar a cabo y, para ello, hay que tener presente al menos los siguientes aspectos: la enfermedad que se desea estudiar, el tipo, tamaño y facilidad o no para la obtención de las muestras que son necesarias en el estudio y las características anatómicas o fisiológicas de la especie con la que se desea trabajar (Pérez 2014, p. 8). En el área de experimentación de animal pequeño de los centros analizados, habitualmente se experimenta con roedores, logomorfos, animales acuáticos e insectos.

El estudio de la organización y diseño del área de experimentación de animal pequeño se ha afrontado por una parte, desde el análisis de la organización general e interrelación de las diferentes unidades que lo componen; y, por la otra, haciendo un análisis pormenorizado de las características y organización de las unidades más importante del área: la unidad de experimentación convencional de animal pequeño y la unidad de experimentación en barrera de animal pequeño. Como veremos durante el análisis, aunque existen otras unidades para investigación con animal pequeño, este estudio se ha centrado específicamente en las dos unidades mencionadas, por ser las unidades que nos encontramos habitualmente en los institutos investigados. 


\subsection{1. Área de experimentación animal pequeño}

El área de experimentación de animal pequeño es una zona específica dentro del centro de experimentación animal destinado a la investigación con los animales que por su tamaño se consideran pequeños, como son, los roedores (ratones, ratas, hámsteres, cobayas o jerbos), los logomofos (conejos), los animales acuáticos (peces) e insectos (moscas).

La experimentación con animales acuáticos tiene unos requerimientos de alojamiento muy diferentes a los roedores y logomorfos. Es por ello que en este estudio se analiza cómo se ha planteado su ubicación en el conjunto del área de experimentación de animal pequeño, pero no se afronta el estudio pormenorizado del diseño de su instalación. Por otra parte, hemos visto que en estos institutos, la experimentación con insectos se centra en la experimentación con moscas. Este tipo de investigación, generalmente, no se realiza en el denominado centro de experimentación animal tal y como hemos realizado el planteamiento de este estudio, sino que se distribuye en laboratorios junto a otras plataformas del instituto. Así que, aunque en algún centro se experimenta con ellos, en este trabajo no afrontamos el estudio de las áreas de experimentación con insectos.

Por lo tanto, el estudio del área de experimentación de animal pequeño se centra específicamente en la zona destinada a investigación con roedores y logomorfos, por estar estos últimos habitualmente estabulados junto a los roedores.

El objetivo de este apartado es analizar el contexto global de la complejidad del programa del área de experimentación de animal pequeño. Se trata de analizar cómo se ha organizado esta área en su conjunto, analizando primeramente las diferentes unidades que lo componen y los condicionantes generales de la organización del área, para a continuación, a partir de las representaciones gráficas, realizar un análisis y puesta en común de las diferentes soluciones planteadas en los institutos analizados. 


\subsubsection{Unidades que componen el área de experimentación animal pequeño}

Si bien, tal y como hemos analizado en el área de experimentación de animal grande lo habitual es que los animales grandes estén estabulados de manera convencional, en el caso de los roedores nos encontramos que el tipo de alojamiento a diseñar dependerá del estado sanitario exigible al animal, de manera que nos podemos encontrar con diferentes tipos de estabulación: estabulación convencional, estabulación en barrera y estabulación de contención del riesgo biológico. Por otra parte, los animales acuáticos requieren unas instalaciones específicamente diseñadas para generar su alojamiento. Por tanto, en este estudio nos centramos en el análisis de las siguientes unidades que componen el área de experimentación animal pequeño:
a) Unidad de experimentación convencional
b) Unidad de experimentación en barrera
c) Unidad de experimentación de contención del riesgo biológico
d) Unidad de experimentación de animales acuáticos

a) Unidad experimentación convencional. La instalación convencional es aquella que no está diseñada para procedimientos especiales en los que se requiere el aislamiento de los animales y en la que los animales alojados no requieren mantener un determinado estado de sanitario para garantizar el éxito de la investigación. A pesar de todo, suele ser necesario aplicar procedimientos de trabajo determinados para reducir la probabilidad de contaminación en la instalación.

b) Unidad experimentación en barrera. Son aquellas instalaciones utilizadas para alojar y experimentar con animales de un estado sanitario definido y, por lo tanto, deben estar diseñadas y construidas para evitar la introducción de agentes patógenos que puedan infectar a los animales en esa zona alojados. Además, es fundamental que se establezcan los criterios de trabajo específicos para que conjuntamente, ambas actuaciones, minimicen la transferencia de agentes de un lado a otro de la barrera. Se trata de garantizar que, tanto el personal como los materiales que sean necesarios introducir en la zona de barrera, estén lo suficientemente limpios para evitar la contaminación interior.

c) Unidad experimentación de contención del riesgo biológico. Este tipo de instalaciones son necesarias para poder llevar a cabo experimentos en los que es necesario infectar intencionadamente a los animales con patógenos humanos o animales. Teniendo en cuenta el grupo de riesgo al que pertenecen los microorganismos investigados y la evaluación de riesgos de los trabajos a desarrollar en el centro, los animalarios pueden clasificarse en cuatro niveles de bioseguridad: NBSA1, NBSA2, NBSA3 y NBSA4, siendo el nivel 1 el de menor riesgo y el 4 el de máximo. Según se refleja en la Figura 95, los requisitos relativos a las características de diseño, el equipo y las precauciones son cada vez más estrictos a medida que aumenta el nivel de seguridad. 
Niveles de contención de los animalarios: procedimientos y equipo de seguridad

\begin{tabular}{lll}
\hline $\begin{array}{l}\text { Grupo de } \\
\text { riesgo }\end{array}$ & $\begin{array}{l}\text { Nivel de } \\
\text { Conteción }\end{array}$ & Procedimientos de laboratorio y equipo de seguridad \\
\hline 1 & NBSA-1 & Acceso restringido, ropa y guantes protectores \\
\hline 2 & NBSA-2 & $\begin{array}{l}\text { Procedimientos del NBSA-1, más señales de advertencia del riesgo. } \\
\text { CSB de clase I o II para las actividades que producen aerosoles. } \\
\text { Descontaminación de desechos y jaulas antes de lavado. }\end{array}$ \\
\hline 3 & NBSA-3 & $\begin{array}{l}\text { Procedimientos del NBSA-2, más acceso controlado. } \\
\text { CSB y ropa protectora especial para todas las actividades. }\end{array}$ \\
\hline 4 & $\begin{array}{l}\text { Procedimientos del NBSA-3, más acceso estrictamente restringido. } \\
\text { Muda de ropa antes de entrar. } \\
\text { CSB de clase III o traje de presión positiva. } \\
\text { Ducha de salida. } \\
\text { Descontaminación de todos los desechos antes de su salida de las instalaciones }\end{array}$ \\
\hline
\end{tabular}

Figura 95. Niveles de contención de los animalarios: procedimientos y equipo de seguridad.

Fuente. OMS Manual de Bioseguridad en el laboratorio p. 30.

Los animalarios de nivel de bioseguridad 1 son los apropiados para mantener a la mayoría de los animales después de la cuarentena (salvo los primates no humanos, respecto de los cuales debe consultarse a las autoridades nacionales) y para los animales que son inoculados deliberadamente con agentes del grupo de riesgo 1.

Los animalarios de nivel de bioseguridad 2 son los apropiados para el trabajo con animales a los que se inoculan deliberadamente microorganismos del grupo de riesgo 2 , y además de cumplir los requerimientos de los animalarios del nivel 1 , se deben aplicar otras precauciones de seguridad específicas de este grupo:

1. Se cumplirán todos los requisitos de los animalarios del nivel 1

2. Se colocarán señales de advertencia del peligro biológico en las puertas y otros lugares apropiados.

3. El local estará diseñado de modo que sea fácil de limpiar y mantener.

4. Las puertas deben abrirse hacia dentro y cerrarse solas.

5. La calefacción, la ventilación y la iluminación deben ser apropiadas.

6. Si se instala ventilación mecánica, el flujo de aire debe dirigirse hacia dentro. El aire utilizado se evacuará al exterior y no se reciclará a ninguna otra parte del edificio.

7. El acceso se limitará a las personas autorizadas.

8. No se admitirá ningún animal distinto de los utilizados con fines experimentales.

9. Existirá un programa de lucha contra artrópodos y roedores.

10. Si hay ventanas, estas serán seguras, irrompibles y, si se pueden abrir, llevarán rejillas a prueba de artrópodos.

11. Las superficies de trabajo habrán de ser descontaminadas con desinfectantes eficaces después del trabajo

12. Se dispondrá de CSB (clases I o II) o jaulas aislantes con suministro especial de aire y evacuación de aire a través de filtros HEPA para aquellas tareas que puedan entrañar la generación de aerosoles.

13. Se dispondrá de una autoclave in situ o cerca del animalario.

14. El material de los lechos de los animales se eliminará de modo que se reduzca al mínimo la producción de aerosoles y polvo.

15. Todos los materiales de desecho y de los lechos deben descontaminarse antes de ser eliminados.

16. Se restringirá en lo posible el uso de instrumentos punzantes o cortantes. estos se recogerán siempre en recipientes resistentes y a prueba de perforación, provistos de tapa, y serán tratados como material infeccioso.

17. El material destinado al tratamiento con autoclave o a la incineración debe transportarse sin riesgo en recipientes cerrados.

18. Las jaulas de los animales se descontaminarán después de su uso.

19. Los cadáveres de los animales serán incinerados.

20. En el local se utilizará ropa y equipo de protección, que se retirará a la salida.

21. Se instalarán lavabos y el personal se lavará las manos antes de salir del animalario.

22. Todas las lesiones, por leves que sean, deberán ser tratadas de forma apropiada, notificadas y registradas.

23. Estará prohibido comer, beber, fumar y aplicar cosméticos dentro del animalario.

24. Todo el personal deberá recibir capacitación apropiada. 
Las instalaciones necesarias para trabajar con agentes incluidos en el grupo de riesgo 3 y 4 son instalaciones con necesidades muy exigentes que requieren de un concepto de diseño con criterios de organización inversos a las instalaciones en barrera para alojamiento de animales SPF, ya que si bien en una barrera de exclusión queremos mantener al máximo las condiciones ambientales estériles para impedir que los animales se contaminen haciendo que todo el material que entre en la zona se esterilice previamente y que todo el personal se cambie de ropa y se duche antes de acceder a la barrera; en las instalaciones ABSL3 y ABSL4 ocurre todo lo contrario. Se quiere evitar que los microrganismos contaminados salgan al exterior $y$, por lo tanto, todo el material saliente deberá ser previamente esterilizado. El personal tendrá que ducharse a la salida.

d) Unidad de experimentación de animales acuáticos. El uso de los modelos comúnmente utilizados en experimentación con animal pequeño como son las ratas, ratones, cobayas, etc., tienen muchas limitaciones, especialmente en términos económicos, pues en muchas ocasiones se requieren instalaciones, equipos e insumos de alto costo. Por esta razón, $y$, también, dada la alta fecundidad y rápido desarrollo desde el estadio embrionario hasta adulto, el pez cebra surge como un modelo animal de bajo costo y gran utilidad en la investigación biomédica básica ${ }^{40}$. Los peces, generalmente, se alojan en una sala especialmente diseñada para alojar muchos estantes con tanques de agua integrados, que es donde van a vivir los peces. El agua es el medio de soporte vital para las especies acuáticas, por lo que la instalación debe ser capaz de garantizar, entre otros aspectos, la calidad del agua exigida para la experimentación.

40 Pez cebra (Danio rerio) y anestesia. Un modelo animal alternativo para realizar investigación biomédica básica. Anestesia en México 2017; volume 29 (Supli no.1) 86-96 


\subsubsection{Condicionantes de organización del área de experimentación animal pequeño}

\section{Condicionantes de organización de la unidad de experimentación convencional}

La instalación convencional no tiene que estar diseñada para procedimientos especiales en los que se requiera el aislamiento de los animales, pero sí debe estar diseñada para reducir la probabilidad de contaminación en la instalación. El diseño de estas instalaciones debe contemplar las especies con las que se va a experimentar, así como la complejidad de los procedimientos que se quieran realizar, teniendo en cuenta que la instalación será más grande y más compleja en función del número y tamaño de los animales o del aumento de la complejidad de los procedimientos.

Entre las diferentes guías y manuales que contemplan esquemas de organización y flujos de trabajo que pueden servir de referencia para comprender la configuración general de las instalaciones convencionales se ha seleccionado el reflejado en la guía Design Requirements Manual NIH (Figura96). En él observamos cómo hay una zona delimitada en rojo destinada a la experimentación animal que se desarrolla en torno al área de estabulación y procedimientos; y, en la que el trasiego de las jaulas sucias desde la sala de estabulación a la sala de lavado, para una vez limpias volver a retornarlas a la sala de estabulación, adquiere una gran importancia. Estos flujos de trabajo quedan identificados mediante las flechas representadas en negro. Atendiendo a los accesos principales, se observan dos accesos diferenciados: uno para el personal responsable del cuidado y bienestar de los animales y del personal investigador; y otro diferente para introducir los animales y los suministros y retirar los residuos generados. Ambos accesos disponen de un vestíbulo previo de entrada al área de experimentación animal que hace la función de frontera.

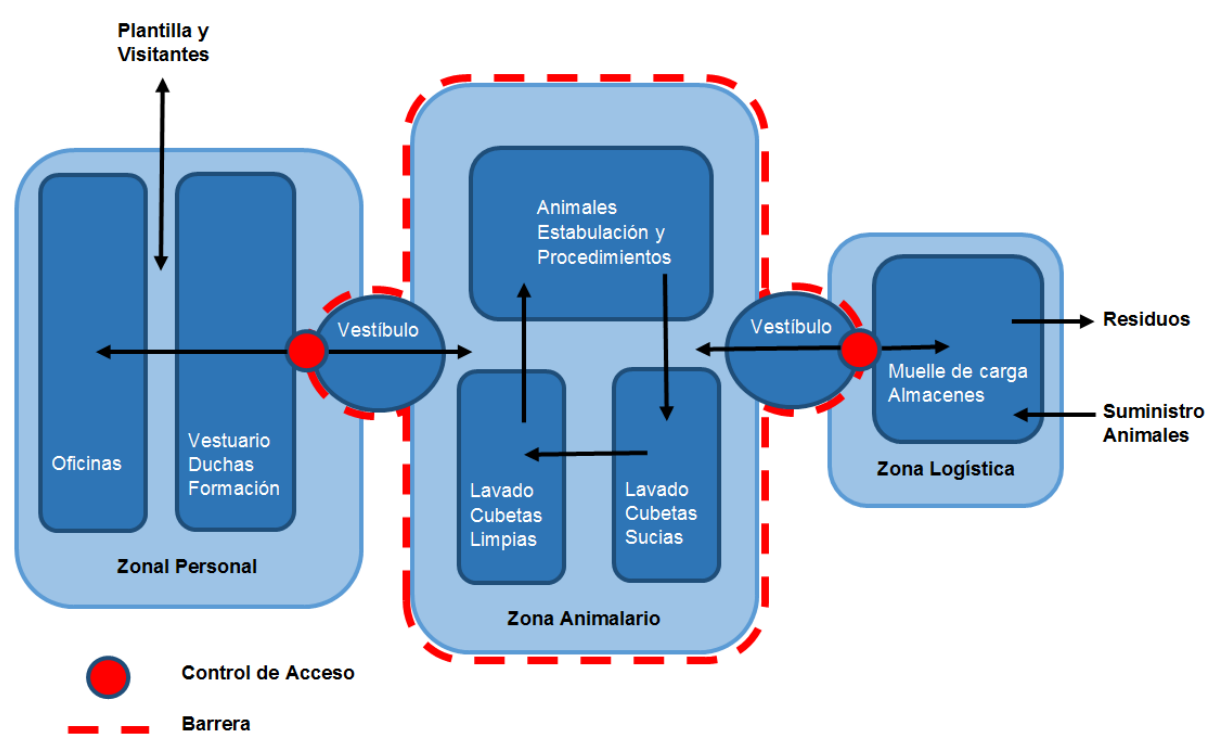

Figura 96. Diagrama de flujos del área de experimentación convencional animal pequeño.

Fuente. Division of technical resources 2016, p. 135. 


\section{Condicionantes de organización de la unidad de experimentación en barrera}

Las instalaciones en barrera deben estar diseñadas para evitar la introducción de los agentes infecciosos que puedan infectar a los animales que están alojados en ellas. Para ello, es fundamental que la instalación esté diseñada para organizar y controlar los accesos de los diferentes agentes que tienen que entrar a la zona de barrera como son las personas, los animales, los suministros y los materiales; así como para gestionar la retirada de los residuos generados en la propia experimentación. Además, en este tipo de instalaciones generalmente se experimenta con roedores, por lo que requiere una buena planificación del movimiento de jaulas limpias y sucias.

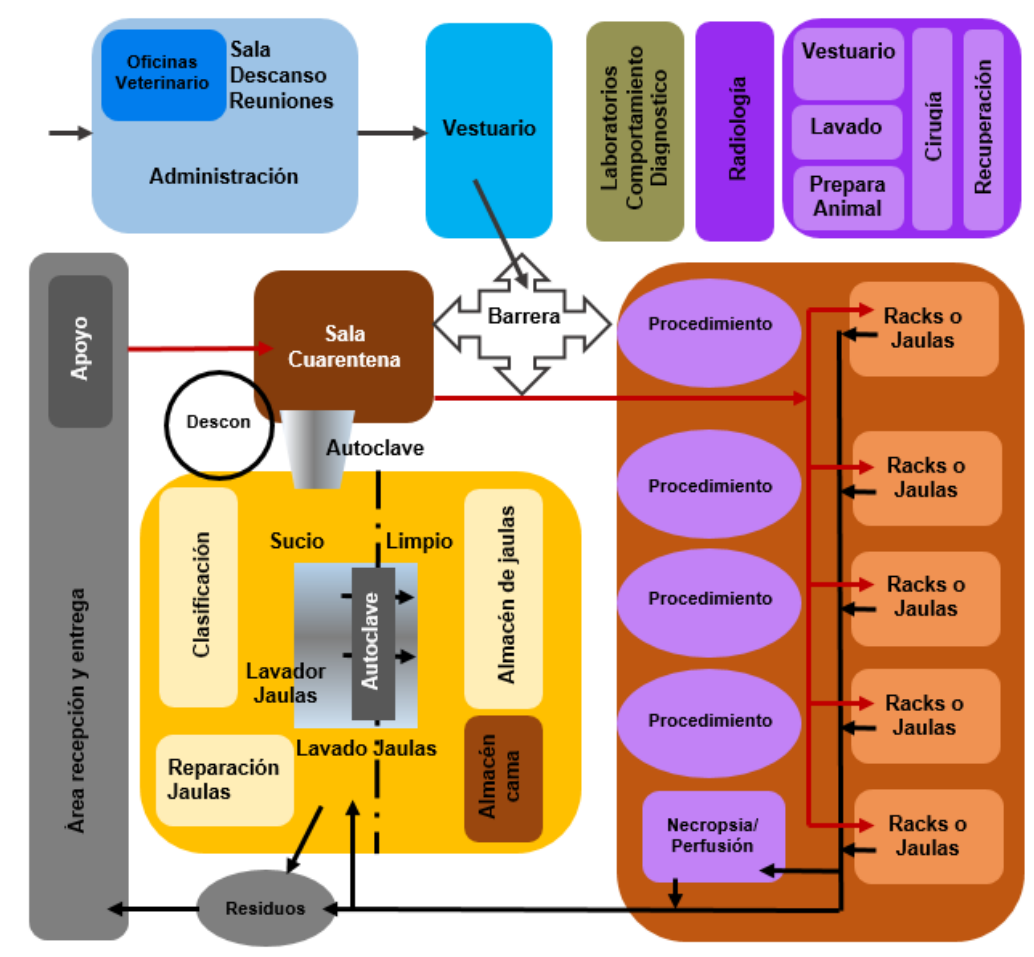

Figura 97. Esquema organización área experimentación convencional y barrera animal pequeño. Fuente. Division of technical resources 2012, p. 2-92.

Para comprender la complejidad de este tipo de instalaciones se ha seleccionado el esquema que se muestra en la guía Design requirements manual NIH (Figura 97), ya que sintetiza el conjunto de la organización de la zona de experimentación animal en el que se muestra específicamente la integración de la instalación en barrera. Centrándonos en la instalación en barrera; por una parte, observamos la circulación del personal veterinario e investigador que dispone de una zona de trabajo administrativo periférica, junto al área de descanso, para una vez pasada por la zona de vestuarios acceder a la zona de barrera; por otra parte, observamos que los animales acceden a una zona de cuarentena previo acceso a la zona de barrera. Además, todo el suministro de materiales necesario en esa área deberá acceder de manera controlada a la barrera. Existe, por tanto, una zona crítica de acceso tanto para el personal como para los animales, e incluso para los suministros. Los animales una 
vez dentro de la barrera disponen de las salas de alojamiento y procedimientos necesarios para que se desarrolle toda la investigación en esa área. Todos los residuos animales generados en las jaulas serán retirados, previo paso por la zona sucia de lavado de cajas; además, en esta sala se separarán los residuos que serán entregados al correspondiente gestor, de los materiales reutilizables. Los materiales reutilizables, una vez lavados y esterilizados vuelven a ser introducidos a la zona de almacenaje limpio para introducirlos a la barrera.

\section{Organización conjunta de la unidad de experimentación convencional y barrera}

Es habitual que en los institutos existan las dos unidades de experimentación de animal pequeño hasta ahora analizadas: convencional y en barrera, por lo que a la hora de diseñar y organizar el área de experimentación animal pequeño en su conjunto, se deberían considerar los siguientes conceptos generales:

- En general, tanto las personas como los animales y los suministros pueden dividirse en "limpios" y "sucios". Estos términos simplistas se usan para diferenciar los objetos animados e inanimados que pueden ser potenciales transportadores de infecciones o sustancias nocivas de un lugar a otro, de aquellos que no están contaminados y que no generan amenaza (Neil 2003, p. 102).

- Es fundamental considerar la organización de los flujos de trabajo desde el inicio, para facilitar el movimiento lógico del personal, de los animales, de los suministros y de los equipos dentro y fuera de la instalación, así como para decidir la ubicación de las salas de alojamiento de animales y su uso potencial, con el fin de evitar la contaminación de los animales considerados limpios.

- En general, los animales más limpios (barrera) de la instalación deberían ser atendidos fácilmente desde el lado limpio de la zona de lavado de jaulas o las áreas de almacenamiento de jaulas limpias, mientras que las salas de alojamiento de los animales más sucios (convencionales) de la instalación deberían estar bien comunicados con la zona sucia del área de lavado de jaulas (Neil 2003, p. 40).

- La sala de cuarentena se considera zona sucia, de manera que se recomienda que esté ubicada cerca de la zona sucia y de la zona de descarga de animales. Por otra parte, algunos proyectos de investigación requieran visitas frecuentes por parte de los investigadores por lo que a menudo están mejor ubicados cerca de la entrada a la instalación.

- Se deberán diseñar las barreras físicas y las diferencias de presión de aire necesarias para garantizar que el aire circule en el sentido adecuado en aras a minimizar la contaminación cruzada. 
Para analizar la organización conjunta de las dos unidades y ver esquemáticamente la posibilidad de compartir el uso de determinadas áreas de servicio, y así poder optimizar el espacio destinado a la experimentación de animal pequeño, se ha seleccionado el esquema de distribución de áreas y flujos de trabajo que nos muestra la publicación Guidelines on: Laboratory animal facilities - characterístics, design and development (Figura 98). En él observamos que la zona de barrera se desarrolla en torno al área de estabulación y procedimientos, para lo que se dispone de dos puntos de comunicación con la barrera; uno para el acceso del material limpio y otro para la salida del material sucio.

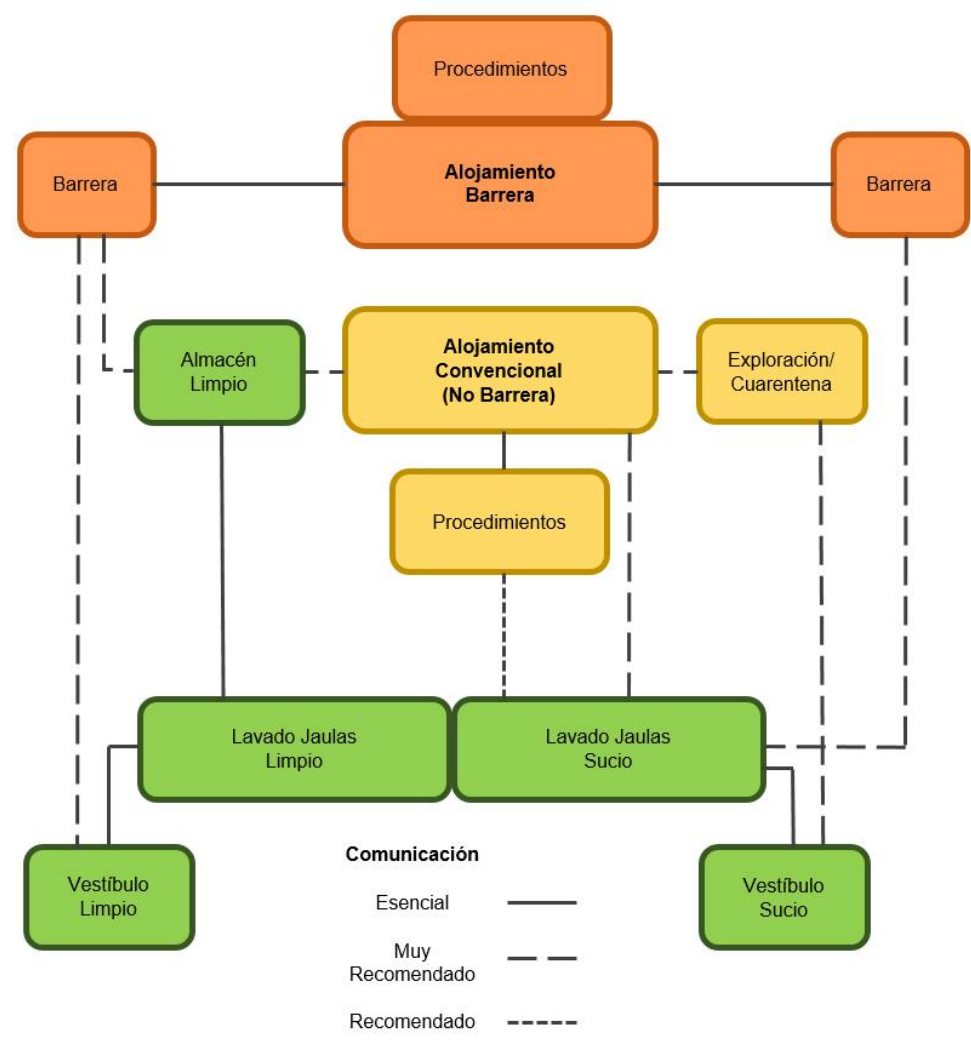

Figura 98. Esquema organización funcional experimentación en barrera y convencional reelaborado. Fuente. Neil 2003, p. 40.

Además, nos muestra los flujos de trabajo entre estos dos puntos y los locales de servicio necesarios para el cuidado de los animales como son; el área de lavado sucio y limpio, los almacenes de material limpio, así como la integración de estos locales en el conjunto de la instalación convencional para hacer un uso compartido. El esquema nos muestra en líneas de trazo continuo la comunicación entre las áreas que se considera esencial, en trazo discontinuo ancho la relación muy recomendada y, por último, en trazo discontinuo estrecho la comunicación recomendada.

Atendiendo a los accesos principales, se observan dos accesos diferenciados: uno para el acceso del material limpio; y, otro para la retirada de los residuos, que son compartidos con ambas unidades de experimentación. Ambos accesos disponen de un vestíbulo previo de entrada al área de experimentación animal que hace la función de frontera. 
Aunque el esquema solo refleja la circulación limpia y sucia, sin hacer distinción de las diferentes circulaciones que nos encontramos habitualmente en las áreas de experimentación animal, entendemos que la circulación limpia contempla los materiales limpios, los animales con un estado de salud definido y las personas, mientras que la circulación sucia se refiere a las jaulas sucias, los animales estabulados en la zona de cuarentena y los residuos generados en la experimentación.

\section{Condicionantes de organización de unidad de experimentación contención del riesqo biológico}

Las instalaciones de contención del riesgo biológico deben estar diseñadas para evitar que el agente infeccioso con el que se experimente se propague al exterior. Las características específicas de la instalación, los equipos y las prácticas de seguridad que se empleen dependerán, en gran medida, del nivel del riesgo del agente infeccioso y de si es particulado, volátil o ambos.

Aunque en este estudio no analizamos este tipo de instalaciones en profundidad, sí identificamos estas áreas y analizamos cómo se integran en el conjunto del área de experimentación de animal pequeño. Como veremos en el análisis posterior, nos encontramos varios institutos que disponen de una pequeña instalación para experimentación $A B S L 2$, y un único instituto con un área $A B S L 3$. Es por ello que consideramos interesante realizar un breve análisis de estas áreas concretas.

\section{Unidad de experimentación de contención del riesgo biológico ABSL2}

Las instalaciones ABSL2 son instalaciones en las que se experimenta con animales inoculados con agentes patógenos del grupo de riesgo 2. Estos agentes pueden provocar enfermedades humanas o animales, pero tienen pocas probabilidades de entrañar un riesgo grave para el personal del laboratorio, la población, el ganado o el medio ambiente. Aunque la exposición en el laboratorio puede provocar una infección grave, existen medidas preventivas y terapéuticas eficaces y el riesgo de propagación es limitado.

Estas instalaciones deben ser de acceso restringido, en las que es necesario colocar señales que adviertan del riesgo biológico, siendo obligatorio el uso de ropa y guantes protectores que se retirarán a la salida y en las que es necesario instalar un lavabo para que el personal se pueda lavar las manos antes de salir de la instalación. Por otra parte, para poder investigar es necesario disponer de una cabina de seguridad biológica Clase I o II para las actividades que producen aerosoles, además de un autoclave in situ o cerca de la instalación, siendo necesario descontaminar los deshechos y las jaulas de los animales después de su uso. La instalación debe diseñarse para mantenerse en depresión con respecto a los locales colindantes, siendo necesario la extracción total del aire, sin posibilidad de recirculación. 
Este tipo de instalaciones, en general, se integran en el área de experimentación convencional de animal pequeño, siendo una sala de procedimientos más, pero con las características de diseño y construcción anteriormente indicadas.

\section{Unidad de experimentación de contención del riesgo biológico ABSL3}

Las unidades de experimentación animal ABSL3 son instalaciones en las que se investiga con animales inoculados con agentes patógenos del grupo de riesgo 3. Son instalaciones de riesgo individual elevado y riesgo poblacional bajo, en las que se usan agentes patógenos que pueden provocar enfermedades humanas o animales graves, pero que de ordinario no se propagan de un individuo a otro; y para las que existen medidas preventivas y terapéuticas eficaces.

Una unidad ABSL3 es una instalación de biocontención, siendo el propósito de la contención reducir o eliminar la exposición a agentes potencialmente peligrosos del personal al cuidado de los animales, investigadores, trabajadores y el entorno exterior. Aunque los riesgos no pueden ser totalmente eliminados, se pueden reducir mediante la planificación y la adopción de acciones preventivas, por lo que aparte de tener que estar bien diseñadas y construidas, es fundamental que el personal que tenga que acceder a la instalación tenga una buena formación e información.

En cuanto a las características de diseño, estas instalaciones además de cumplir todo lo indicado para la instalación $A B S L 2$, deben estar aisladas del resto de las instalaciones y unidades de experimentación del edifico y su acceso estar restringido y controlado exclusivamente para aquellas personas que necesiten trabajar en la instalación. Por otra parte, es fundamental organizar y diseñar la instalación para que todo el personal, animales, material y residuos que salgan de la instalación estén descontaminados para evitar la propagación de los agentes patógenos al exterior.

Para comprender la organización genérica de esta unidad se ha seleccionado el esquema que nos muestra la publicación Planning and designing animal facilities (Figura 99). Se muestra cómo la zona de contención tiene una separación física con respecto a los pasillos de acceso a través de un vestíbulo o esclusa de aire con puertas enclavadas y cierre automático que deberá estar en depresión con respecto al pasillo exterior para garantizar que el flujo de aire circule en la dirección adecuada. Estas esclusas tienen que estar diseñadas para el paso de personal y material dentro y fuera de la instalación, ya que todo lo que entra y sale de las instalaciones de contención debe seguir unos estrictos protocolos. 


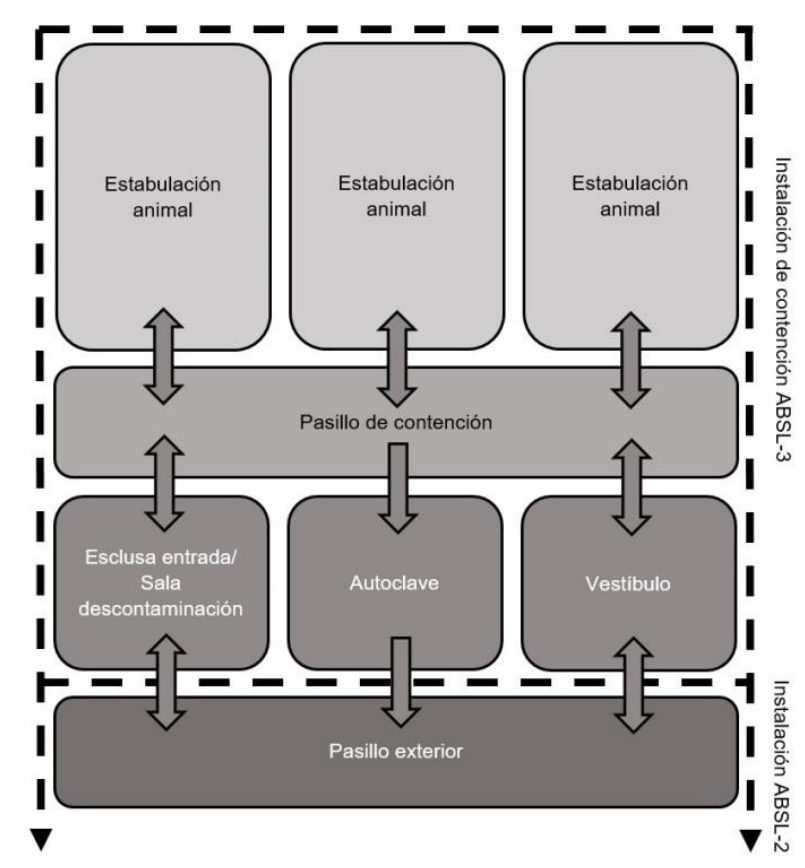

Figura 99. Esquema flujos de trabajo de una instalación de biocontención. Fuente. Hessler 2009, c 25, p. 351.

En función de los procedimientos establecidos en el centro, el personal puede ser obligado a cambiarse de ropa, ducharse y ponerse ropa protectora para entrar, requiriendo el proceso inverso para salir. En general, todos los materiales que pueden soportar la esterilización con vapor se descontaminarán pasando a través de autoclaves antes de salir de la instalación; mientras que el resto de materiales pueden descontaminarse usando descontaminación química o ser retirados a través de esclusas de aire o tanques de inmersión.

En el interior de la zona de experimentación, se debe garantizar el aislamiento de los animales y sus residuos; por lo que los animales deben alojarse en jaulas especializadas. Además, las salas en las que se alojen deben estar selladas y diseñadas para que no promuevan la acumulación de polvo y sean fáciles de desinfectar.

Desde la fase de diseño es necesario también considerar los equipos de seguridad apropiados para el desarrollo de la actividad tales como las cabinas de cambio de flujo laminar, las cabinas de seguridad biológica o las campanas para trabajo con productos químicos; ya que son equipos de dimensiones considerables que tiene repercusión directa en el dimensionamiento de las salas de experimentación. 


\section{Condicionantes de organización de la unidad de experimentación de animales acuáticos}

Aunque en el presente estudio no analizamos este tipo de instalaciones en profundidad, sí identificamos estas áreas y analizamos cómo se integran en el conjunto del área de experimentación de animal pequeño, por lo que se analiza someramente los considerandos que hay que tener presentes en el diseño de este tipo de instalaciones.

Las salas de alojamiento de animales acuáticos deben estar diseñadas y construidas para soportar la sobrecarga de los depósitos de agua en los que se van a alojar los animales, deben ser capaces de resistir las posibles fugas de agua, la humedad y la corrosión, así como para proporcionar una iluminación uniforme, controlada y evitar puntos calientes que puedan causar un crecimiento excesivo de algas. El agua es el medio de soporte vital para los animales acuáticos, y su calidad, sistemas de circulación y filtración deberán adaptarse a las necesidades específicas de cada especie. Entre otros parámetros, la temperatura del agua, la calidad, el pH, el grado de dureza y la salinidad deben ser monitorizadas y controladas. El ruido y las vibraciones pueden afectar negativamente a las especies acuáticas, por lo que es fundamental que las bombas de recirculación de agua y equipos ruidosos se ubiquen lejos de la zona de alojamiento de animales. En este tipo de instalaciones, los trabajadores están expuestos a diversos peligros como pueden ser caídas por estar el pavimento mojado o la electrocución, por lo que se deben tener presentes desde la fase de diseño.

Además de los depósitos donde se van a alojar los animales, también pueden ser necesarias otras áreas como son: espacio para procedimientos varios, zona de preparación de alimentos, espacio para almacén de equipos y comida, una zona de cuarentena para los animales que ingresan en el centro y una zona de cría. 


\subsubsection{Representaciones gráficas de la distribución del área de experimentación animal pequeño}

A partir de los planos en planta estandarizados que se han desarrollado de cada uno de los centros de experimentación animal y que se encuentran recogidos en las fichas de toma de datos, se ha seleccionado exclusivamente el área destinada a la experimentación de animal pequeño. Con estas representaciones gráficas se pretende tener una visión específica de su configuración y de las distintas circulaciones diseñadas (Figuras 100-110).

Para facilitar el estudio, en los planos de distribución en planta se ha identificado por código de colores el área funcional y la unidad de experimentación de animal pequeño al que pertenece. Por otra parte, con el fin de realizar una lectura sencilla de las diferentes entradas al área de experimentación animal pequeño, también se reflejan con flecha de color rojo los puntos de acceso principales al edificio planteados, así como los accesos para el personal que se representa mediante línea continua de color azul; para el suministro de animales, mediante línea continua de color rojo; para el suministro de materiales, con línea continua color verde; incluso para la retirada de residuos, con línea de trazos color verde. Además, también se representa el sentido de los flujos de trabajo mediante las flechas dibujadas en cada línea. Junto a cada una de las representaciones gráficas se hace una breve descripción de la configuración del área de experimentación de animal pequeño.

ÁREAS FUNCIONALES

Experimentación animal grande

Áreas comunes animal pequeño y grande

Área Administrativa

Pasillos comunes

Pasillos exteriores y servicios generales

Elementos de circulación vertical
UNIDADES EXPERIMENTACIÓN ANIMAL PEQUEÑO

Experimentación convencional animal pequeño

Experimentación barrera animal pequeño

Experimentación ABSL2 animal pequeño

Experimentación ABSL3 animal pequeño

Experimentación animales acuáticos
ACCESOS Y CIRCULACIONES

$\Rightarrow$ Acceso

- Personal

Animales

_ Suministro materiales

- - - Retirada de residuos

Figura 100. Leyenda área experimentación animal pequeño.

Fuente. Elaboración propia.

*Esta leyenda se hace extensible a las figuras 101-110. 
El área de experimentación de animal pequeño del instituto IdiPAZ (Figura 101) se desarrolla en dos plantas en las que no existe acceso directo desde el exterior. Para acceder a las diferentes plantas; por una parte, existe un montacargas para el suministro de animales, materiales y retirada de residuos; $y$, por la otra, un ascensor para el personal investigador y responsables del bienestar animal. En la denominada planta sótano -2 se desarrolla el área de estabulación y experimentación de animal convencional pequeño; y en planta sótano -1 se distribuye la zona de microcirugía y la unidad de experimentación de animales acuáticos.

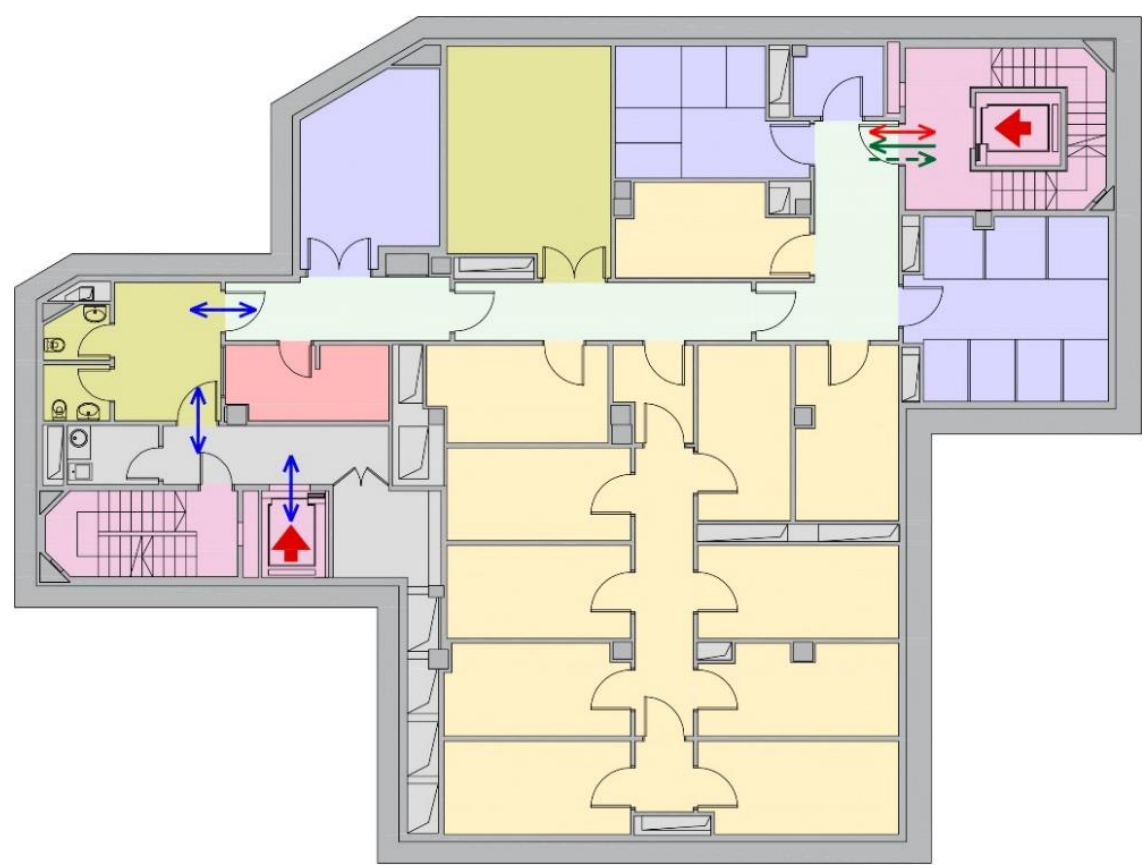

Planta Sótano -2

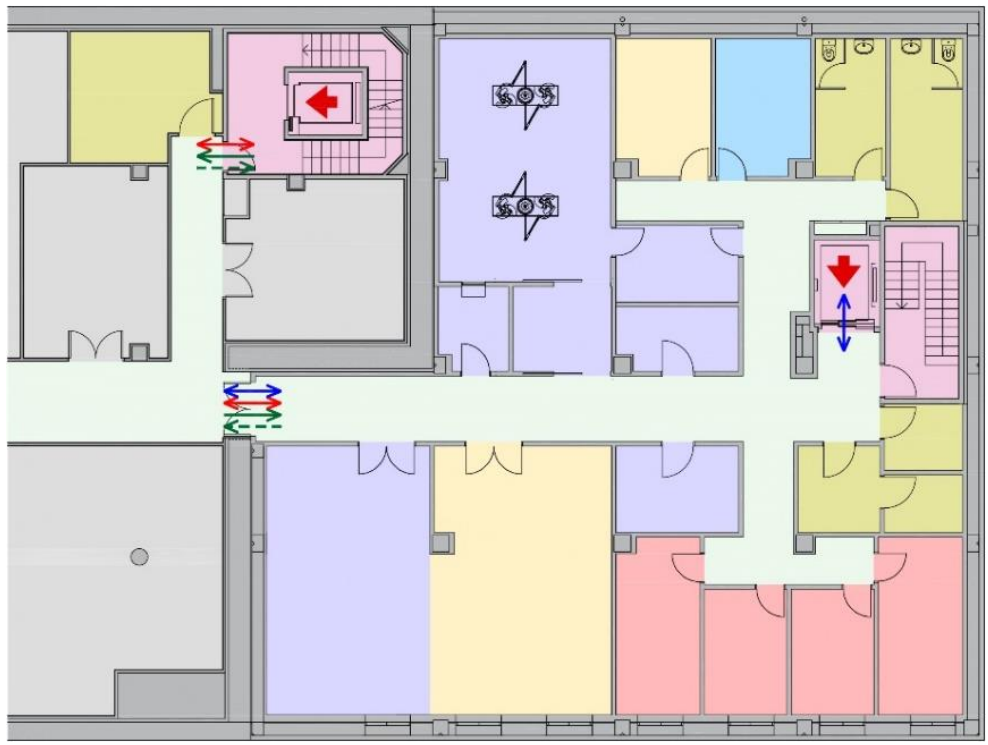

Planta Sótano -1

Figura 101. Área experimentación animal pequeño IdiPAZ (S/E).

Fuente. Elaboración propia. 
El área de experimentación de animal pequeño del instituto i+12 (Figura 102) se configura en una única planta con dos accesos directos desde el exterior en el que se segregan los accesos para el personal del de los animales, el suministro de materiales y la retirada de residuos. No se desarrolla como una entidad independiente, sino que se integra en el conjunto del centro de experimentación animal junto con el área de experimentación de animal grande. La zona de experimentación de animal pequeño está compuesta por una zona de estabulación convencional y los locales de experimentación.

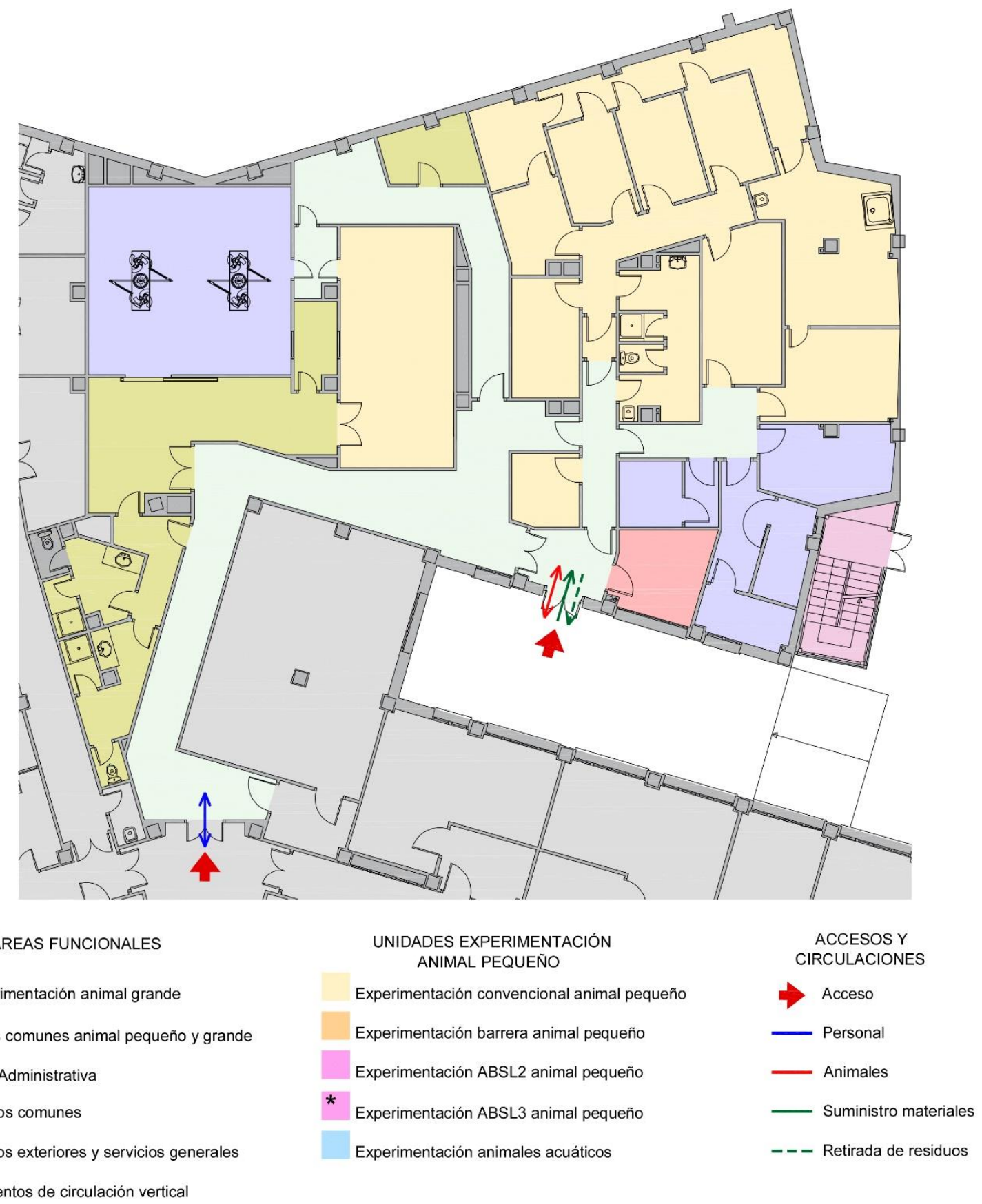

Figura 102. Área experimentación animal pequeño i+12 (S/E).

Fuente. Elaboración propia. 
El área de experimentación de animal pequeño del instituto liSGM (Figura 103) se distribuye en una única planta con acceso directo desde el exterior, de manera que los accesos para el personal están separados de las de suministro de animales, de materiales y de la retirada de residuos. Se dispone de una unidad de experimentación en barrera, una zona de estabulación convencional y un área pequeña de experimentación ABSL2; unidades que se distribuyen en la misma planta en la que se desarrolla el área de experimentación de animal grande y con la que comparten pasillos de distribución y locales de servicio.

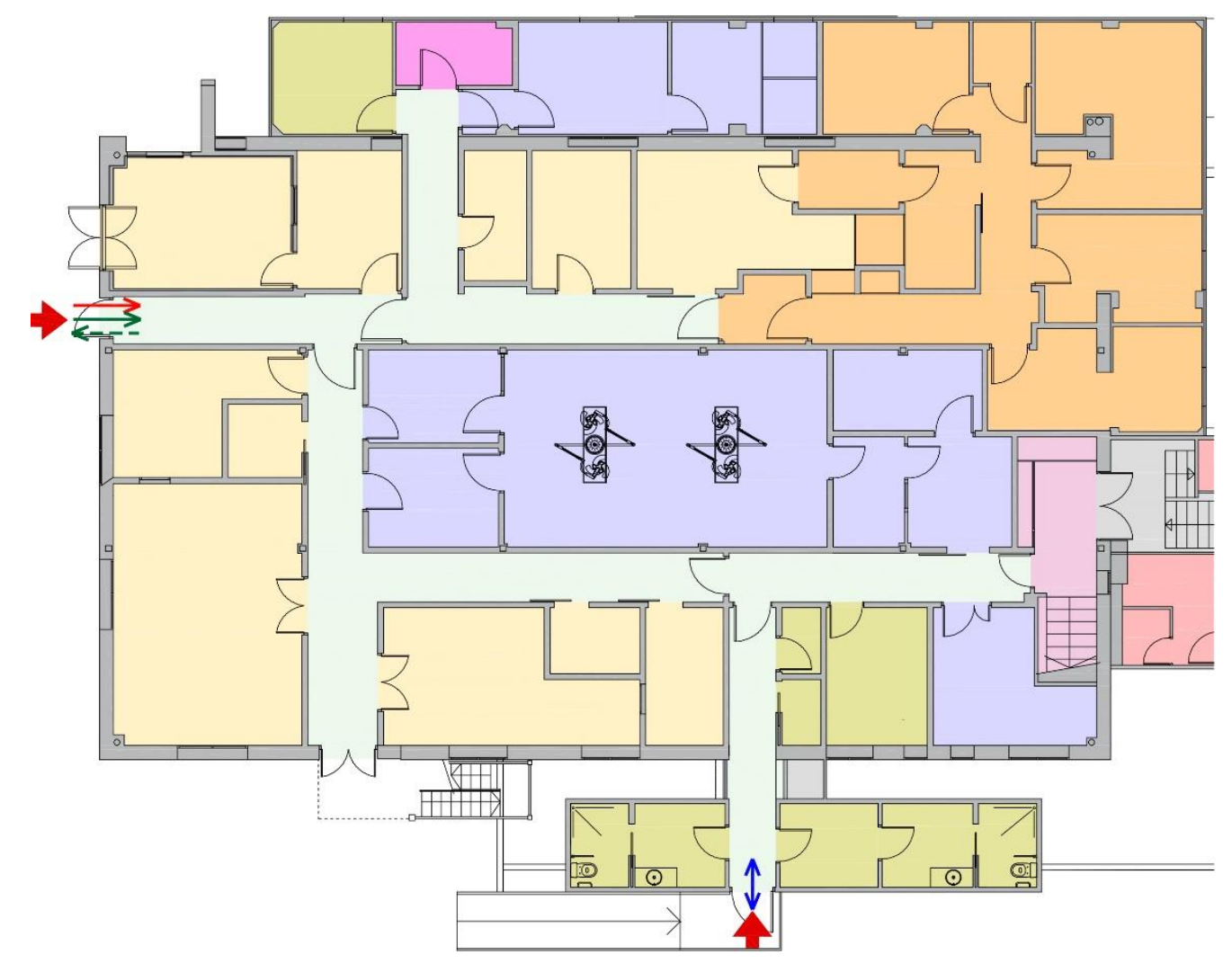

ÁREAS FUNCIONALES

Experimentación animal grande

Áreas comunes animal pequeño y grande

Área Administrativa

Pasillos comunes

Pasillos exteriores y servicios generales

Elementos de circulación vertical
UNIDADES EXPERIMENTACIÓN ANIMAL PEQUEÑO

$$
\text { Experimentación convencional animal pequeño }
$$

Experimentación barrera animal pequeño

Experimentación ABSL2 animal pequeño

Experimentación ABSL3 animal pequeño

Experimentación animales acuáticos
ACCESOS Y CIRCULACIONES

Acceso

- Personal

Animales

Suministro materiales

Retirada de residuos

Figura 103. Área experimentación animal pequeño liSGM (S/E). Fuente. Elaboración propia. 
El área de experimentación de animal pequeño del instituto IRYCIS (Figura 104) se distribuye en una única planta con acceso directo desde el exterior, de manera que los accesos para el personal están separados de las de suministro de animales, de materiales y de la retirada de residuos. La experimentación de animal pequeño se realiza fundamentalmente de manera convencional, si bien se dispone de un área más controlada para trabajo con animales inmunodeprimidos. Esta área se integra en la misma planta que la experimentación de animal grande con el que comparte pasillos de circulación y locales varios de servicios.

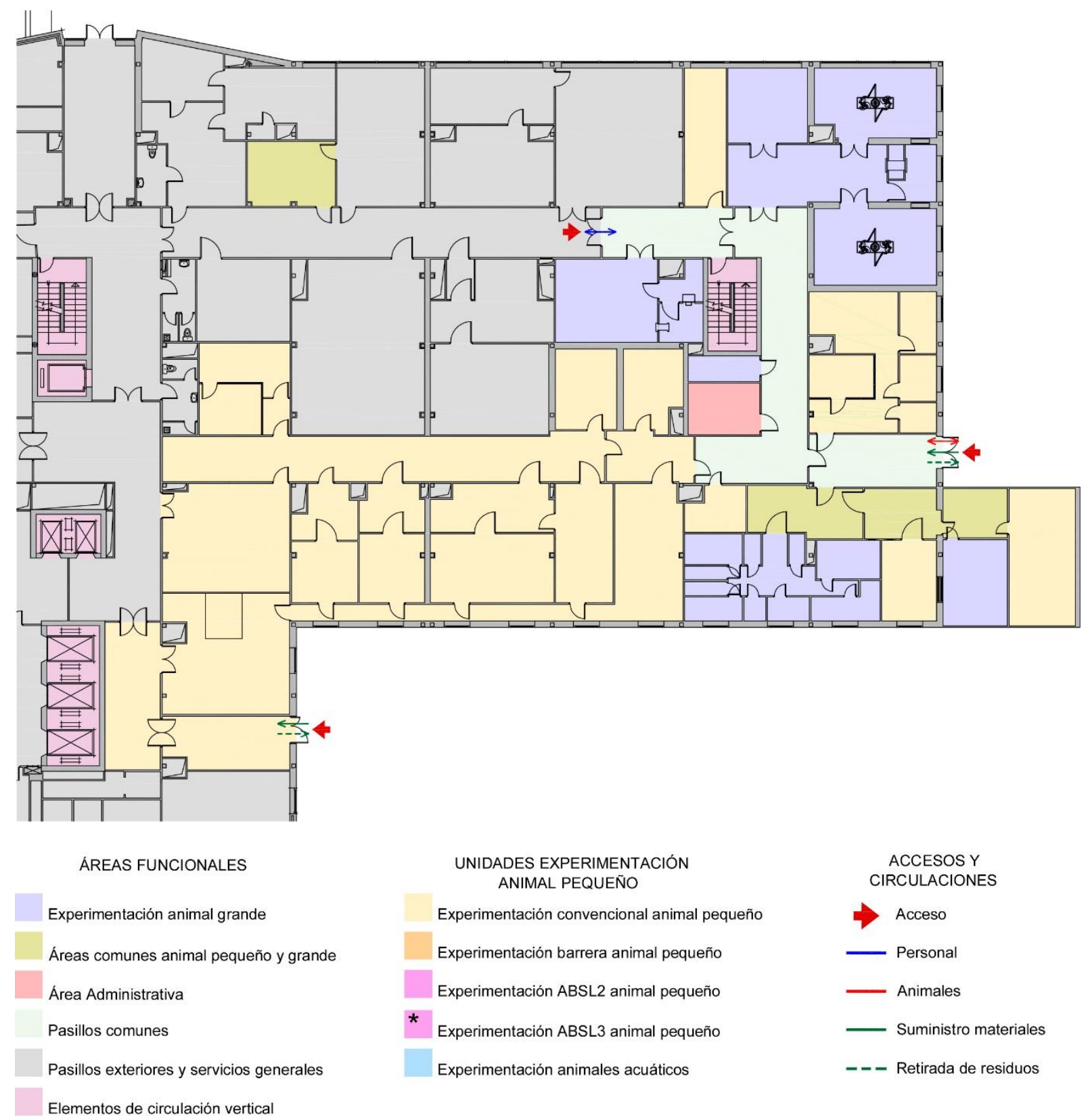

Figura 104. Área experimentación animal pequeño IRYCIS (S/E).

Fuente. Elaboración propia. 
El área de experimentación de animal pequeño del instituto IISBiodonostia (Figura 105) se desarrolla en una única planta con varios accesos directos desde el exterior para independizar los accesos del personal del de los animales, el suministro de materiales y la retirada de residuos. Esta área se integra en la misma planta que el área de experimentación de animal grande, de manera que ambas actividades comparten pasillos de distribución interior, locales de servicios varios, incluso el área de preparación animal. El área de experimentación de animal pequeño se desarrolla en dos áreas diferenciadas: una de manera convencional y otra pequeña zona de experimentación en barrera.

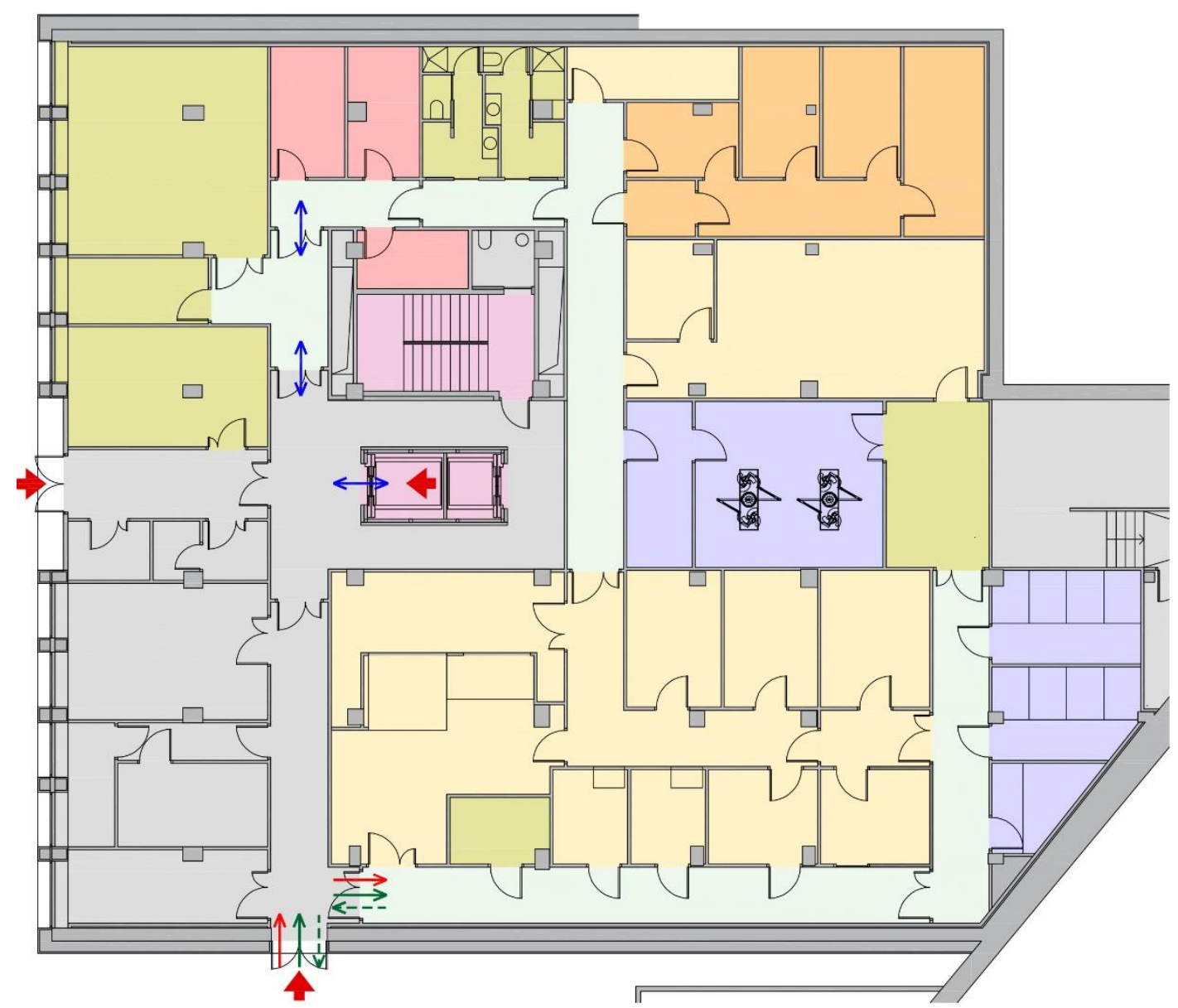

ÁREAS FUNCIONALES

Experimentación animal grande

Áreas comunes animal pequeño y grande

Área Administrativa

Pasillos comunes

Pasillos exteriores y servicios generales

Elementos de circulación vertical
UNIDADES EXPERIMENTACIÓN ANIMAL PEQUEÑO

Experimentación convencional animal pequeño

Experimentación barrera animal pequeño

Experimentación $A B S L 2$ animal pequeño

Experimentación ABSL3 animal pequeño

Experimentación animales acuáticos
ACCESOS Y CIRCULACIONES

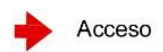

- Personal

- Animales

_- Suministro materiales

- - - Retirada de residuos

Figura 105. Área experimentación animal pequeño IIS Biodonostia (S/E). Fuente. Elaboración propia. 
El área de experimentación de animal pequeño del instituto IISBiocruces (Figura 106) se distribuye en una única planta bajo rasante, por lo que para acceder a ella es necesario hacer uso de elementos de comunicación vertical. Para ello se dispone de un núcleo compuesto por un montacargas destinado al uso de animales, materiales y residuos; $y$, por la otra, se dispone de un núcleo de ascensores para el uso del personal. El área se configura como una entidad independiente al resto del centro de experimentación animal, de manera que en esta planta se distribuye tanto la unidad de experimentación convencional como la unidad de experimentación en barrera. Por otra parte, para el acceso al área, en la propia planta se disponen de dos accesos diferenciados: uno para el personal; y otro para el suministro de animales, materiales y la retirada de residuos.

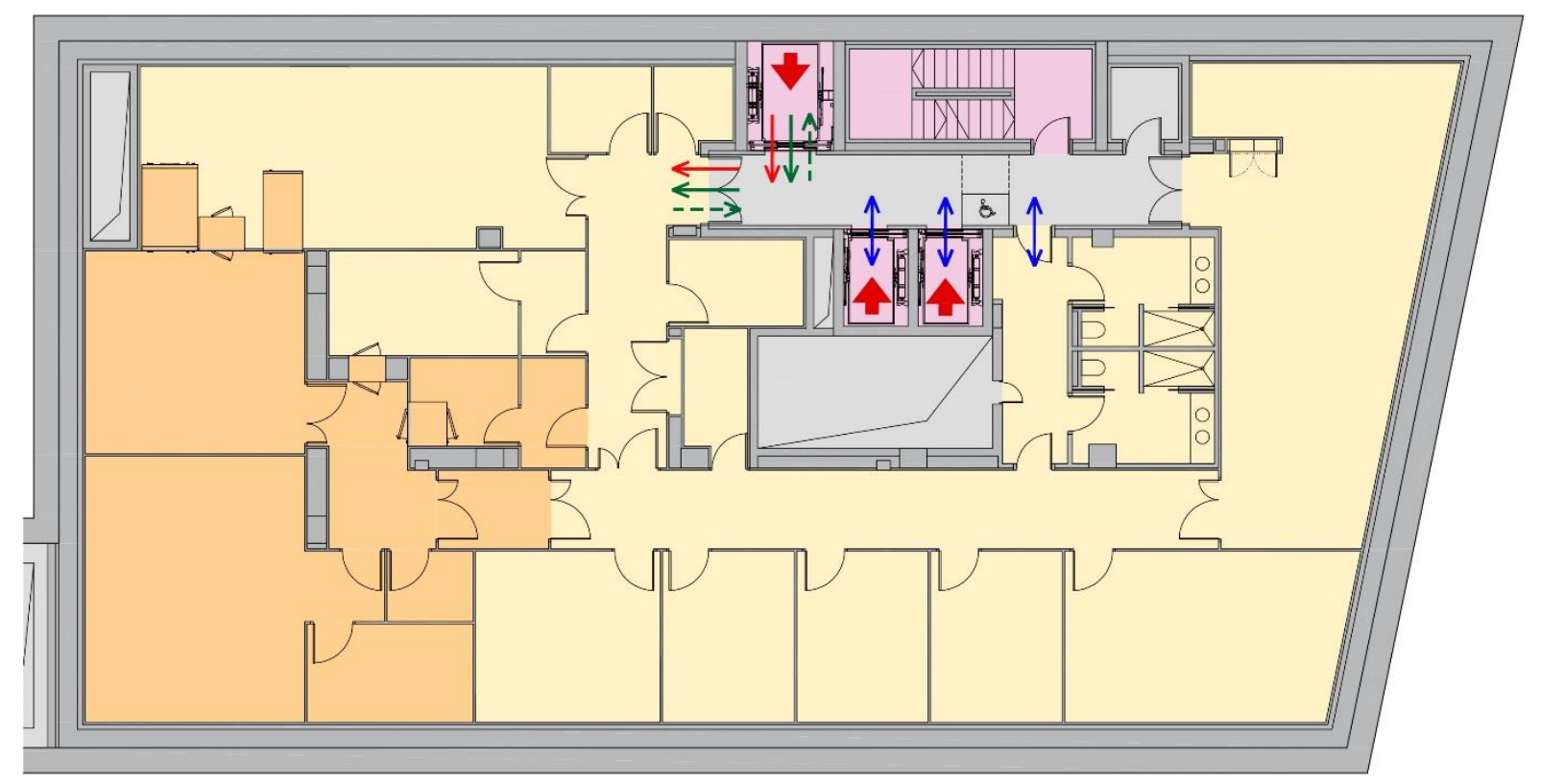

ÁREAS FUNCIONALES

Experimentación animal grande

Áreas comunes animal pequeño y grande

Área Administrativa

Pasillos comunes

Pasillos exteriores y servicios generales

Elementos de circulación vertical
UNIDADES EXPERIMENTACIÓN ANIMAL PEQUEÑO

Experimentación convencional animal pequeño

Experimentación barrera animal pequeño

Experimentación ABSL2 animal pequeño

Experimentación ABSL3 animal pequeño

Experimentación animales acuáticos
ACCESOS Y CIRCULACIONES

$\Rightarrow$ Acceso

- Personal

- Animales

- Suministro materiales

- - - Retirada de residuos

Figura 106. Área experimentación animal pequeño IIS Biocruces (S/E).

Fuente. Elaboración propia. 
El área de experimentación de animal pequeño del instituto IISA (Figura 107) se distribuye en dos plantas. La experimentación realizada en cada planta es totalmente independiente, de manera que una vez realizado el ingreso de los animales en una planta, no es necesario realizar traslados verticales interiores. Por una parte, en la planta semisótano se distribuye el área de microcirugía que integra también el área de estabulación convencional para este tipo de animales; y, por la otra, en la planta sótano -1 se desarrolla la zona de experimentación animal, tanto de manera convencional, como en barrera, e incluso se dispone de una instalación ABSL2.

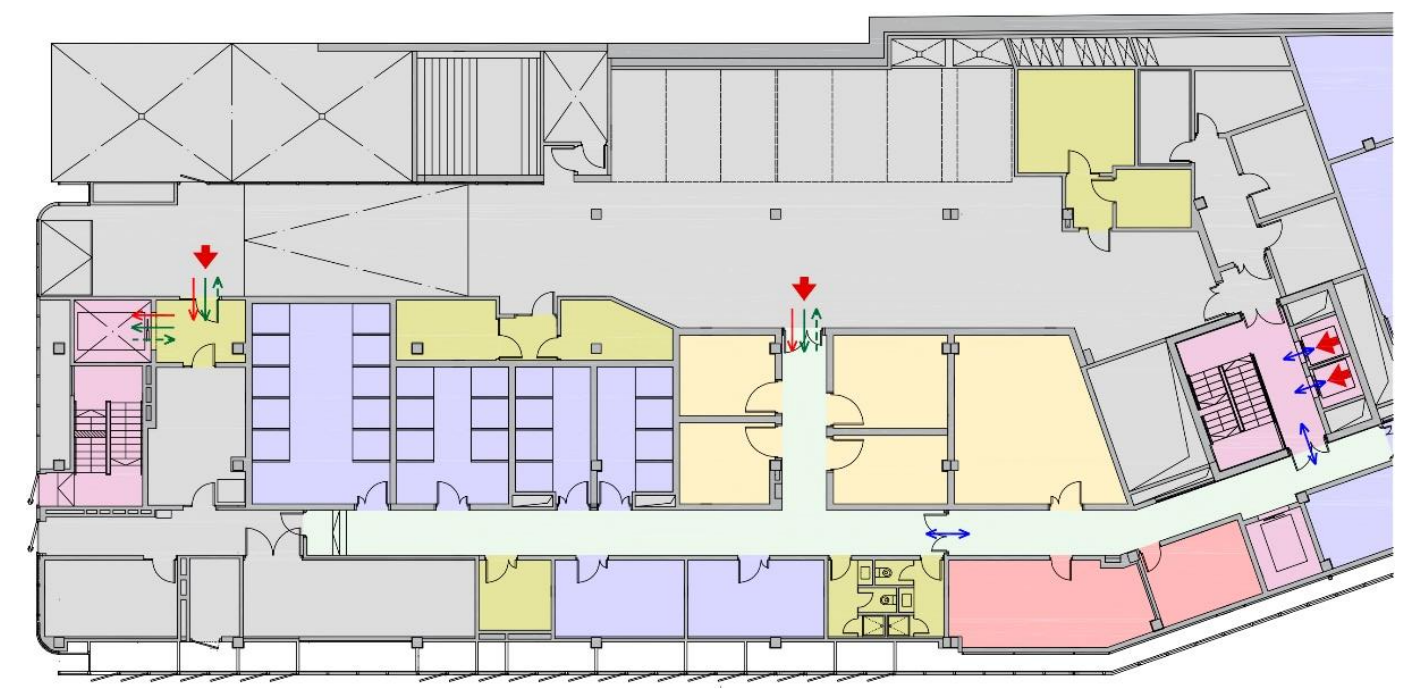

Planta semisótano

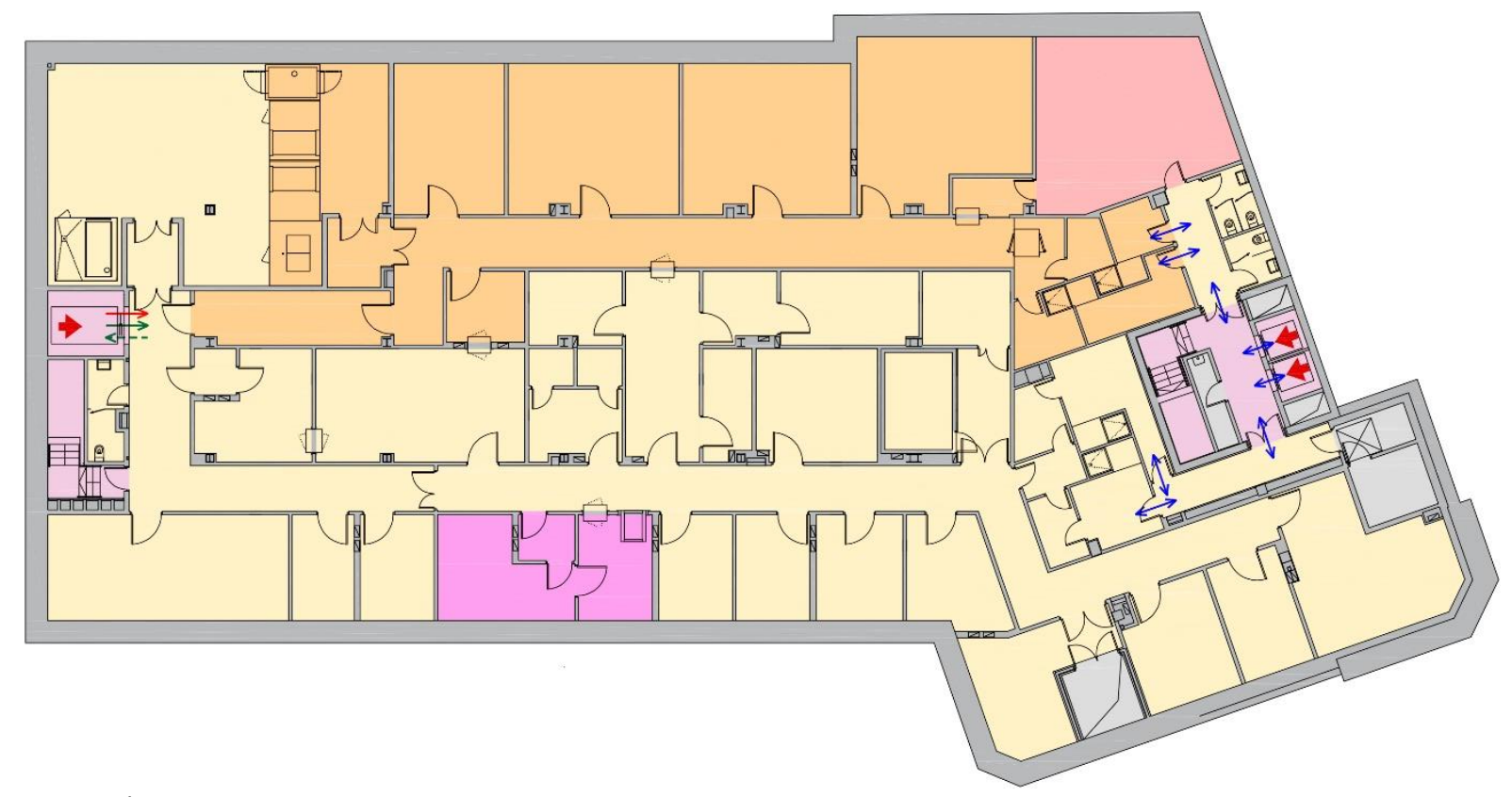

Planta Sótano -1

Figura 107. Área experimentación animal pequeño IISA (S/E).

Fuente. Elaboración propia. 
El área de experimentación de animal pequeño del instituto VHIR (Figura 108) se desarrolla en dos plantas bajo rasante, por lo que es necesario hacer uso de elementos de comunicación vertical para el ingreso de los animales en el centro. Para acceder a las plantas se dispone de un único montacargas además de un núcleo de escaleras exterior para uso tanto del personal como para el suministro de animales y materiales, incluso la retirada de residuos. Esta área está compuesta por tres unidades de experimentación: convencional, en barrera y contención ABSL2.

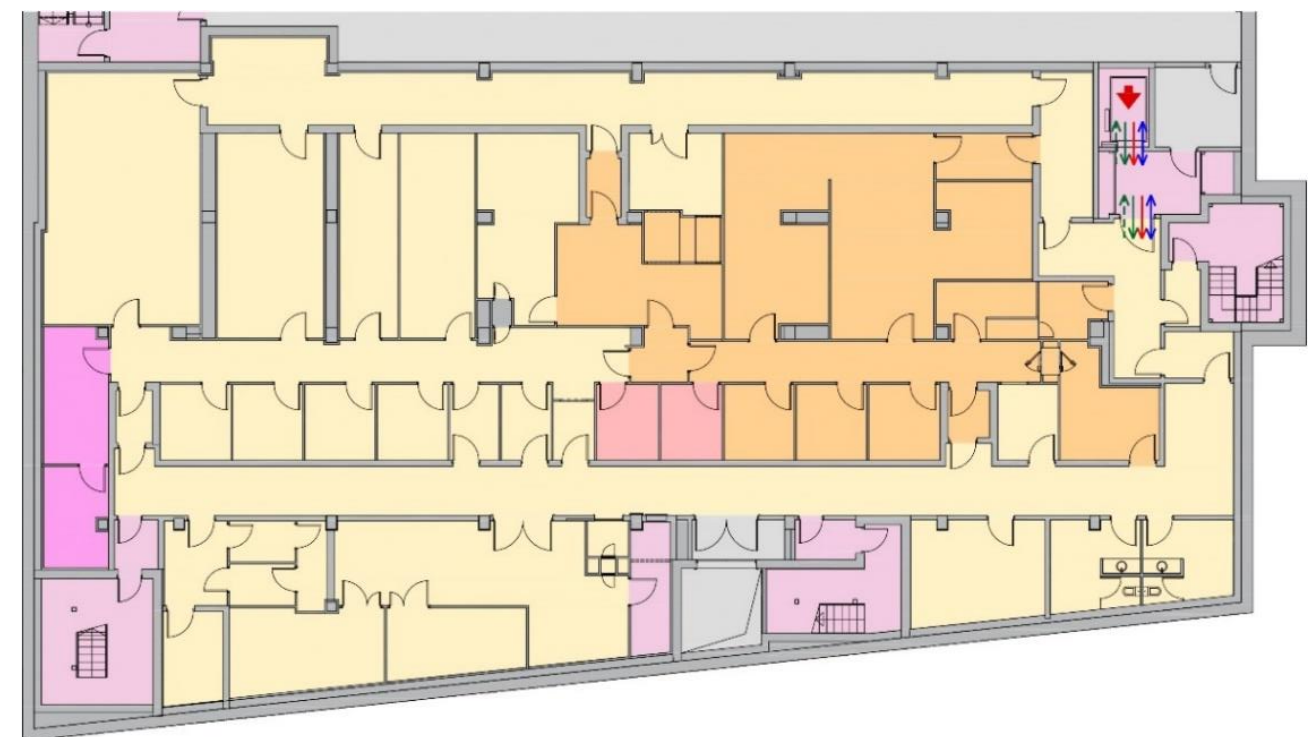

Planta Sótano -2

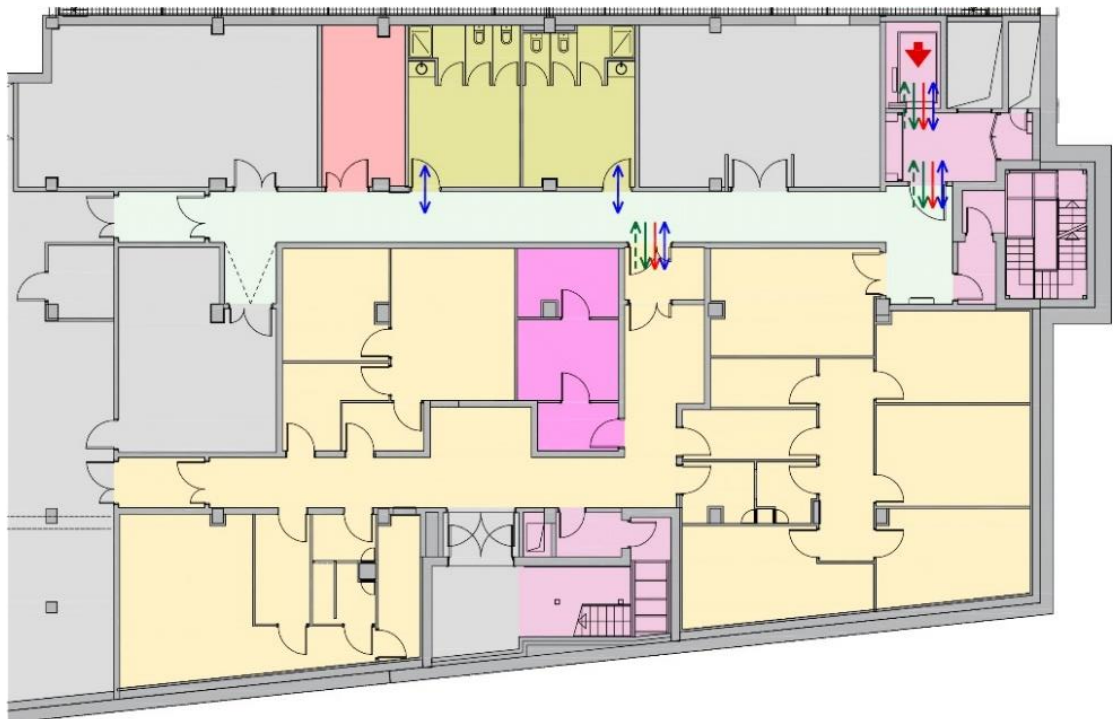

Planta Sótano -1

AREAS FUNCIONALES

Experimentación animal grande

Áreas comunes animal pequeño y grande

Área Administrativa

Pasillos comunes

Pasillos exteriores y servicios generales

Elementos de circulación vertical

Figura 108. Área experimentación animal pequeño VHIR (S/E).

Fuente. Elaboración propia.

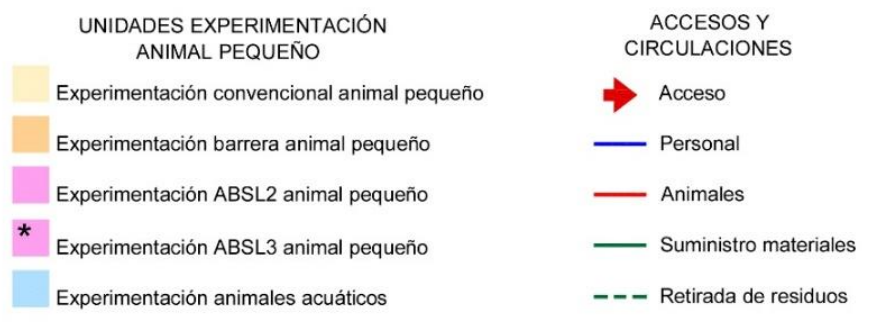

ACCESOS Y CIRCULACIONES

$\Rightarrow$ Acceso

- Personal

_ Suministro materiales

- - - Retirada de residuos 
El área de experimentación de animal pequeño del instituto IGTP (Figura 109) se distribuye en una planta semisótano con acceso directo desde el exterior para el acceso de animales, suministro de materiales y retirada de residuos. El personal, en cambio, accede al edificio desde la planta de acceso principal situada a nivel de planta baja, para a través de elementos de circulación vertical acceder al área de experimentación animal pequeño. El área se desarrolla en una única planta de manera independiente al área de experimentación de animal grande, y en la que existe una unidad de experimentación convencional, una unidad de experimentación en barrera y una unidad de contención ABSL3. En una tercera planta se distribuye el área de lavado y esterilización y los locales de servicio necesarios para el desarrollo de la actividad.
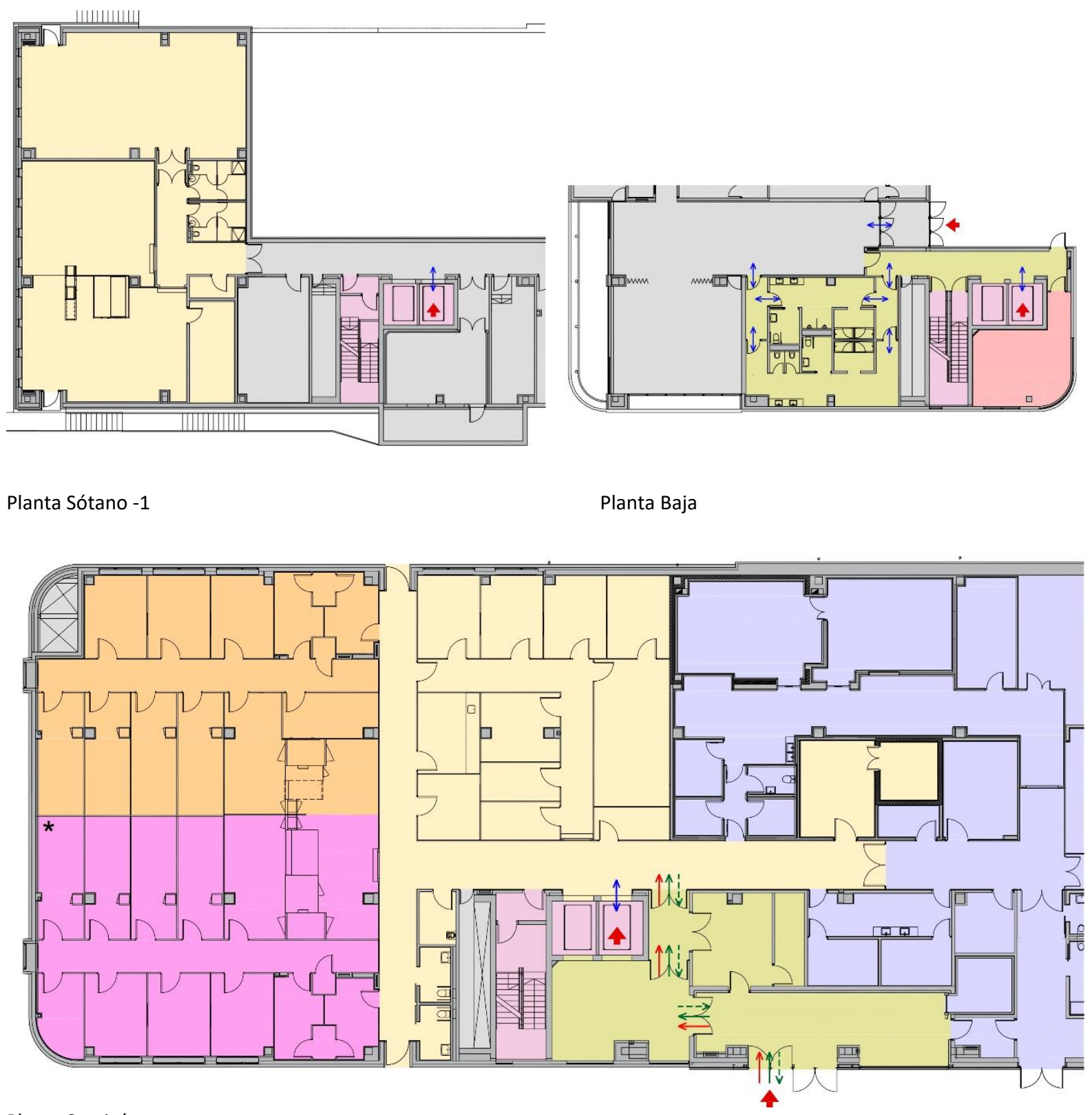

Planta Semisótano

Figura 109. Área experimentación animal pequeño IGTP (S/E).

Fuente. Elaboración propia. 
El área de experimentación de animal pequeño del instituto IIS La FE (Figura 110) se distribuye en una única planta bajo rasante, de manera que se dispone de un núcleo de comunicación vertical para uso del animalario, estando los accesos del personal separados de los del suministro de animales, de materiales y de la retirada de residuos. Esta área se integra en la misma planta que el área de experimentación de animal grande, de manera que ambas actividades comparten pasillos de distribución interior y locales de servicios varios. Esta área de experimentación de animal pequeño está compuesta por una unidad de experimentación convencional, una unidad de experimentación en barrera y una unidad de experimentación para animales acuáticos.

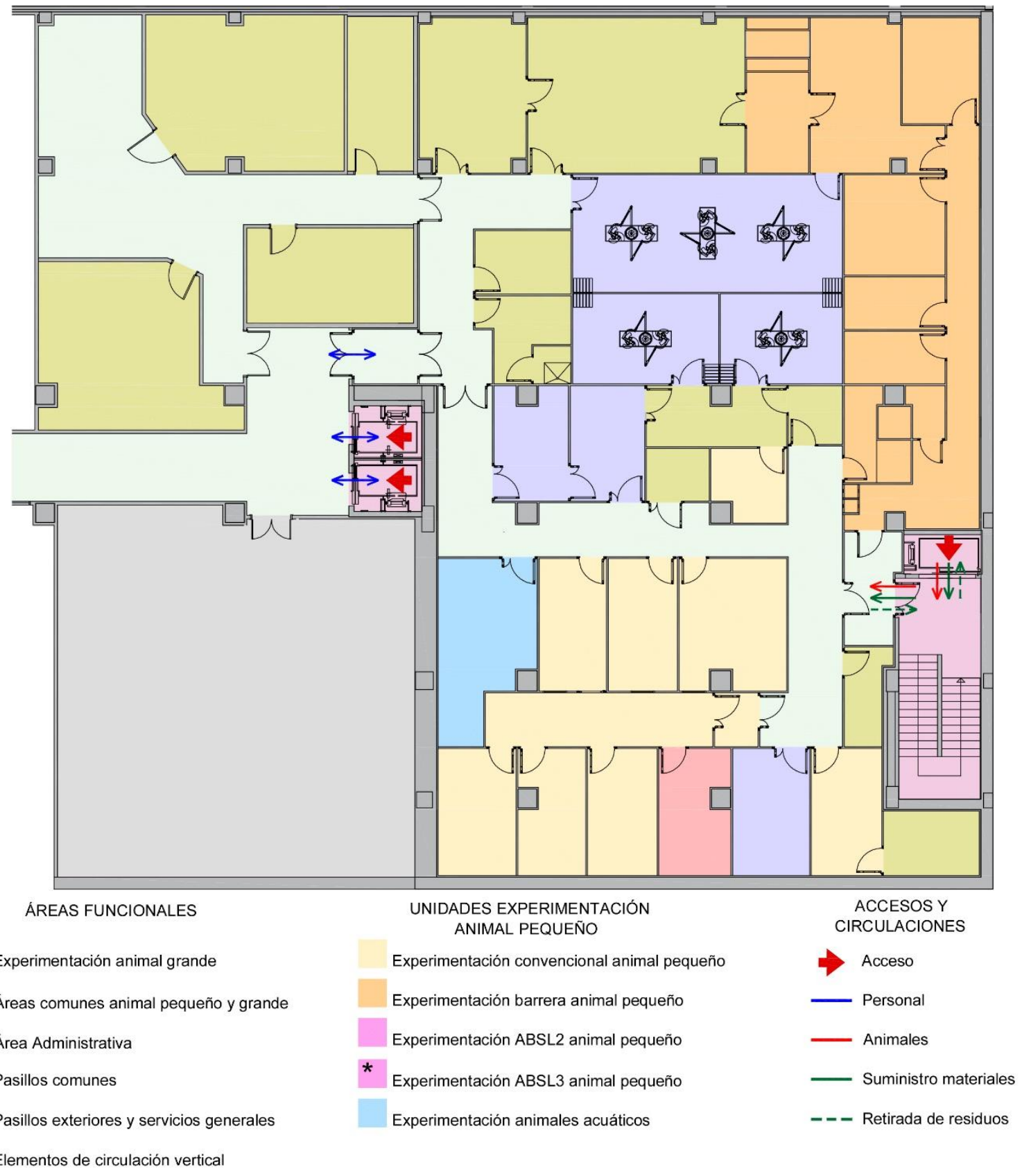

Figura 110. Área experimentación animal pequeño IIS La Fe (S/E).

Fuente. Elaboración propia. 


\subsubsection{Características generales y criterio organizativo del área de experimentación animal} pequeño

El resultado de la investigación sobre el criterio organizativo del área de experimentación animal pequeño se encuentra reflejado tanto en las fichas de la documentación gráfica como en la toma de datos de cada centro.

Para realizar el análisis de la organización se ha hecho una puesta en común de los resultados obtenidos; y, para ello, se ha optado por resumir las más importantes en una tabla (Tabla 12). En ella se listan los parámetros que definen la organización del área, se establecen cuáles son las características comunes a la mayoría de ellos y se identifica qué institutos cumplen dichas características; además, se determinan las características particulares o específicas, que son aquellas que las cumplen solo unos determinados institutos, reflejándose así mismo, cuales son los institutos que las cumplen. El análisis se centra en los siguientes conceptos:

- Analizar la superficie destinada a la experimentación de animal pequeño y el dimensionamiento del área.

- Identificar las especies animales que se utilizan en la experimentación con animal pequeño en los institutos.

- Las unidades que componen el área de experimentación de animal pequeño y su ubicación en el conjunto de la instalación.

- La organización del área de experimentación. Se trata de analizar el número de plantas en las que se distribuye, así como el tipo de planta y, por lo tanto, ver los tipos de desplazamientos que se producen para el ingreso de los animales al área de experimentación de animal pequeño, tanto horizontalmente como verticalmente. También se analiza el grado de independencia entre las diferentes unidades que componen el área de experimentación de animal pequeño, así como con el área de experimentación de animal grande. 
Tabla 12. Características generales área de experimentación animal pequeño.

\begin{tabular}{|c|c|c|c|c|}
\hline Parámetros & $\begin{array}{l}\text { Características } \\
\text { comunes }\end{array}$ & $\begin{array}{l}\text { Institutos con } \\
\text { características } \\
\text { comunes }\end{array}$ & $\begin{array}{c}\text { Características } \\
\text { específicas }\end{array}$ & $\begin{array}{l}\text { Institutos con } \\
\text { características } \\
\text { específicas }\end{array}$ \\
\hline $\begin{array}{l}\text { Superficie } \\
\text { experimentación } \\
\text { animal pequeño }\end{array}$ & $500-1.000 \mathrm{~m}^{2}$ & $\begin{array}{l}\text { IRYCIS, IISBiodonostia, } \\
\text { IISBiocruces, } \\
\text { IIS La Fe }\end{array}$ & $\begin{array}{l}<500 \mathrm{~m}^{2} \\
>1.000 \mathrm{~m}^{2}\end{array}$ & $\begin{array}{l}\text { IdiPAZ, i+12, IISGM, } \\
\text { IISA, VHIR, IGTP }\end{array}$ \\
\hline $\begin{array}{l}\text { Animales pequeños } \\
\text { utilizados en } \\
\text { experimentación }\end{array}$ & Roedores & $\begin{array}{l}\text { IdiPAZ, i+12, IRYCIS, } \\
\text { IiSGM, IISBiodonostia, } \\
\text { IISBiocruces, IISA, } \\
\text { VHIR, IGTP, IIS La Fe }\end{array}$ & $\begin{array}{l}\text { Logomorfos } \\
\text { A. Acuáticos }\end{array}$ & $\begin{array}{l}\text { IdiPAZ, i+12, IRYCIS, } \\
\text { IISBiodonostia, } \\
\text { IISBiocruces, IISA, } \\
\text { VHIR, IGTP, IIS La Fe } \\
\text { IdiPAZ, IIS La Fe }\end{array}$ \\
\hline $\begin{array}{l}\text { Unidades de } \\
\text { experimentación }\end{array}$ & Convencional & $\begin{array}{l}\text { IdiPAZ, i+12, liSGM, } \\
\text { IRYCIS, IISBiodonostia, } \\
\text { IISBiocruces, IISA, } \\
\text { VHIR, IGTP, IIS La Fe }\end{array}$ & $\begin{array}{l}\text { Barrera } \\
\text { ABSL2 } \\
\text { ABSL3 }\end{array}$ & $\begin{array}{l}\text { liSGM, } \\
\text { IISBiodonostia, } \\
\text { IISBiocruces, IISA, } \\
\text { VHIR, IGTP, IIS La Fe } \\
\text { IISGM, iRYCIS, IISA, } \\
\text { VHIR } \\
\text { IGTP }\end{array}$ \\
\hline $\begin{array}{l}\text { № de plantas en que } \\
\text { se distribuye }\end{array}$ & Una única planta & $\begin{array}{l}\text { i+12, liSGM, IRYCIS, } \\
\text { IISBiodonostia, } \\
\text { IISBiocruces, IIS La Fe }\end{array}$ & $\begin{array}{l}\text { Dos plantas } \\
\text { Tres plantas }\end{array}$ & $\begin{array}{l}\text { IdiPAZ, IISA, VHIR } \\
\text { IGTP }\end{array}$ \\
\hline $\begin{array}{l}\text { Tipo de planta en la } \\
\text { que se ubica }\end{array}$ & A cota 0 & $\begin{array}{l}\text { i+12, liSGM, IRYCIS, } \\
\text { IISBiodonostia }\end{array}$ & $\begin{array}{l}\text { Bajo rasante } \\
\text { Mixta }\end{array}$ & $\begin{array}{l}\text { IdiPAZ, IISBiocruces, } \\
\text { VHIR, IISLa Fe } \\
\text { IISA, IGTP }\end{array}$ \\
\hline Circulación vertical & De acceso al área & $\begin{array}{l}\text { IdiPAZ, IISA, } \\
\text { IISBiocruces, VHIR, } \\
\text { IISLa Fe }\end{array}$ & $\begin{array}{l}\text { No existe } \\
\text { Circulación interior }\end{array}$ & $\begin{array}{l}\text { i+12, IiSGM, IRYCIS, } \\
\text { IISBiodonostia } \\
\text { IdiPAZ, VHIR, IGTP }\end{array}$ \\
\hline $\begin{array}{l}\text { Área } \\
\text { experimentación } \\
\text { animal pequeño } \\
\text { independiente a } \\
\text { animal grande }\end{array}$ & NO & $\begin{array}{l}\text { IdiPAZ, i+12, IRYCIS, } \\
\text { liSGM, IISBiodonostia, } \\
\text { IISLaFe }\end{array}$ & SI & $\begin{array}{l}\text { IISBiocruces, IISA, } \\
\text { VHIR, IGTP }\end{array}$ \\
\hline
\end{tabular}

Fuente. Elaboración propia.

\section{Dimensionamiento área experimentación animal pequeño}

Observamos que el dimensionamiento del área de experimentación de animal pequeño de cada centro es muy variable, por lo que el análisis lo hemos realizado clasificando los institutos en función de un rango de superficies. De esta manera observamos cómo la mayoría de los institutos (IRYCIS, IISBiodonostia, IISBiocruces, IIS La Fe) destinan una superficie comprendida entre los 500 y $1.000 \mathrm{~m}^{2}$ al área de experimentación de animal pequeño. Entre los centros que han realizado una mayor apuesta en la investigación de esta área se encuentran IISA, VHIR, IGTP con una superficie superior a los $1.000 \mathrm{~m}^{2}$, mientras que el resto de los institutos destinan una superficie inferior a los $500 \mathrm{~m}^{2}$.

\section{Especies animales}

Las especies animales utilizadas en todas las áreas de experimentación de animal pequeño son los roedores y, entre ellos, los modelos animales más comunes son la rata y ratón; si bien es muy habitual encontrar zonas de estabulación para conejos (IdiPAZ, i+12, IRYCIS, IISBiodonostia, IISBiocruces, IISA, VHIR, IGTP, IIS La Fe). Entre los institutos analizados, en el momento de la visita solo el IdiPAZ y el IIS La Fe disponían de un área destinada a la experimentación con animales acuáticos, aunque muchos 
de los centros restantes tenían en mente la posibilidad de introducir próximamente esta especie cuyo peso en investigación se ha multiplicado en los últimos años.

\section{Unidades de experimentación}

Todas las áreas de experimentación de animal pequeño disponen de la unidad de experimentación convencional. Además, es muy habitual que la instalación se complemente con la unidad de experimentación en barrera (IISGM, IISBiodonostia, IISBiocruces, IISA, VHIR, IGTP, IIS La Fe). Por otro lado, se observa cómo en varios centros se ha desarrollado una zona de experimentación ABSL2 (IISGM, iRYCIS, IISA, VHIR), siendo de una sala de experimentación de dimensiones reducidas e integrada en el conjunto de la experimentación convencional de animal pequeño. En cambio, encontramos un solo caso en el que se ha diseñado una zona de contención ABSL3 integrada en el conjunto del centro de experimentación animal (IGTP).

En los casos en los que se han planteado las dos áreas de experimentación: la convencional y la de barrera, observamos que es muy habitual que los locales de servicio, tales como, la zona de vestuarios, la zona de lavado y esterilización y locales de almacenamiento sean compartidos para ambas unidades.

\section{Distribución en plantas}

Lo habitual es que el área de experimentación de animal pequeño se distribuya en una única planta. Sin embargo, observamos varios casos en los que esta área, debido al tamaño de la instalación, o bien debido al criterio de organización establecido, se ha tenido que dividir en dos plantas (IdiPAZ, IISA, VHIR) o incluso vemos algún caso que, debido a la orografía del terreno y la superficie disponible en planta, se ha organizado en tres plantas (IGTP). En el caso concreto del IdiPAZ observamos que el área de experimentación de animal pequeño se desarrolla casi todo en una sola planta, si bien el área de microcirugía y el de experimentación con animales acuáticos, se desarrollan en otra planta diferente, ambas bajo rasante. En el caso del IISA, tanto el área de microcirugía como la estabulación con experimentación de animal pequeño se desarrolla en una planta con acceso directo desde el exterior, mientras que el resto de experimentación con animal pequeño se desarrolla en una planta bajo rasante. En el caso del VHIR, el conjunto de la superficie en planta disponible, así como la superficie necesaria para la experimentación de animal pequeño ha obligado a que sea necesario hacer uso de dos plantas diferentes para el desarrollo de la actividad, ambas bajo rasante. Otro caso diferente es el del IGTP, que se distribuye en tres plantas, de manera que en la planta de acceso principal al edifico se desarrolla la zona de vestuarios de acceso al área de experimentación; en una intermedia con acceso directo desde el exterior, el área de experimentación de animal pequeño; y, en otra tercera bajo rasante, el área de lavado y esterilización, así como locales de servicio varios. 
Entre las áreas de experimentación de animal pequeño distribuidos en una única planta, es habitual que esta área se desarrolle en una planta con acceso directo desde el exterior (i+12, liSGM, IRYCIS, IISBiodonostia). En los casos en los que no ha sido posible distribuirlos en este tipo de plantas, se ha optado por distribuirlos en plantas bajo rasante. Es en estos casos precisamente en los que para el ingreso de los animales al centro es necesario hacer uso de elementos de comunicación vertical (IdiPAZ, IISA, IISBiocruces, VHIR, IISLa Fe). Como casos particulares cabe mencionar los institutos que se distribuyen en dos plantas (IdiPAZ y VHIR); en ambos casos se disponen de dos plantas destinadas a experimentación de animal pequeño que se encuentran situadas bajo rasante, por lo que todos los animales pequeños, además de hacer uso de elementos de comunicación vertical para el ingreso de los animales al centro, también tienen que ser trasladados internamente de planta para el desarrollo de la actividad.

A pesar de que las necesidades y la actividad a desarrollar en el área de experimentación de animal pequeño son muy diferentes a la del animal grande, observamos cómo no siempre se ha conseguido independizar completamente las dos actividades, de manera que en algunos casos existen salas de experimentación compartidas (IdiPAZ, i+12, IIS Biodonostia, IRYCIS), lo que ha supuesto que para el correcto funcionamiento del centro se hayan establecido una serie de procedimientos específicos de uso y limpieza de las salas compartidas. En otros casos, en cambio, (IiSGM, IIS La Fe), las áreas compartidas se reducen a los pasillos de circulación internos y locales para almacenamiento de suministros y residuos. Los centros que se desarrollan en un área totalmente independiente del animal grande son IISBiocruces, IISA, VHIR, IGTP. 


\subsubsection{Diseño constructivo del área de experimentación animal pequeño}

En el planteamiento de los centros de experimentación animal, aparte de los conceptos de organización y diseño analizados hasta ahora, para conseguir unas instalaciones eficientes también hay que tener muy presentes la correcta definición y ejecución de los sistemas constructivos.

Los materiales de acabado deben ser elegidos para facilitar su limpieza y desinfección en aras a garantizar las condiciones de asepsia necesaria en las instalaciones, así como para garantizar el bienestar animal, para lo cual hay que tener muy presentes los tres focos principales que pueden generar estrés a los animales, como son: el ruido, las vibraciones y la iluminación. Por otra parte, se debe tener en cuenta que las salas de alojamiento de animales son instalaciones que deben estar en funcionamiento 24 horas al día, por lo que es fundamental considerar los conceptos básicos de: funcionalidad, durabilidad, estabilidad y mantenimiento.

El presente estudio se centra exclusivamente en el análisis del diseño constructivo del área de experimentación animal pequeño. Se trata de analizar los sistemas que definen la arquitectura interior de las salas de experimentación animal, quedando excluido del estudio los sistemas constructivos del edificio en el que se aloja.

Se ha observado que los sistemas constructivos y materiales de acabado adoptados en todo el área de experimentación de animal pequeño se han unificado, de manera que la solución adoptada para la experimentación convencional y en barrera es la misma. Por otra parte, la salas de mayores exigencias son las salas de alojamiento de animales, siendo habitual que los criterios adoptados para la construcción de estas salas se hagan extensibles al resto del área de experimentación, por lo que el estudio se centra en estas salas específicamente.

Atendiendo a la normativa de aplicación a los centros de experimentación animal, y específicamente a lo relacionado con los materiales de acabados a utilizar en establecimientos y alojamientos de animales, debemos tener en cuenta la Directiva 2010/63/UE ${ }^{41}$ y el Real Decreto 53/2013 ${ }^{42}$.

Por una parte en la Directiva 2010/63/UE, Anexo III, en relación a los locales de alojamiento establece que: Las paredes y los suelos deben estar recubiertos de un material resistente al gran desgaste causado por los animales y las operaciones de limpieza. Ese material de revestimiento no debe ser perjudicial para la salud de los animales ni provocar que los animales se lastimen. Los dispositivos o accesorios deben protegerse especialmente para evitar que los animales los estropeen o se hieran. Por

\footnotetext{
${ }^{41}$ Directiva 2010/63/UE del Parlamento Europeo y del Consejo de 22 de septiembre de 2010 relativa a la protección de los animales utilizados para fines científicos.

42 Real Decreto 53/2013, de 1 de febrero, por el que se establecen las normas básicas aplicables para la protección de los animales utilizados en experimentación y otros fines científicos, incluyendo la docencia.
} 
otra parte, el Real Decreto 53/2013, en su Anexo II, añade a lo establecido en la directiva anteriormente mencionada, que Las paredes, los techos y los suelos deben estar recubiertos de un material impermeable cuando sea necesario. En ambos casos, vemos que se trata de directrices muy generalistas, ya que no se concretan las características específicas y, por lo tanto, permite una amplia gama de materiales a instalar.

El resultado de la investigación sobre las características constructivas se encuentra reflejado en las fichas de la toma de datos de cada centro. Para realizar el análisis de dichas características se ha hecho una puesta en común de los resultados obtenidos y, para ello, se ha optado por resumir las más importantes en una tabla (Tabla 13). En ella se listan los parámetros que definen las características constructivas del área, se establecen cuáles son las características comunes a la mayoría de ellas y se identifica qué institutos cumplen dichas características; además, se determinan las características particulares o específicas, que son aquellas que las cumplen solo unas determinadas áreas de experimentación de animal pequeño, reflejándose así mismo, cuáles son los institutos que las cumplen. El análisis se centra en los siguientes conceptos:

- Estudio de las soluciones adoptadas para la ejecución de las divisiones interiores, los pavimentos, los techos y la carpintería interior de puertas, por ser estos cuatro elementos los que conforman principalmente la arquitectura interior.

- Sistemas implantados para el control de la temperatura y humedad relativa.

- Sistemas de control de la iluminación.

- Sistemas adoptados para el control del ruido y vibraciones. 
Tabla 13. Características constructivas área experimentación animal pequeño.

\begin{tabular}{|c|c|c|c|c|}
\hline Parámetros & $\begin{array}{l}\text { Características } \\
\text { comunes }\end{array}$ & $\begin{array}{c}\text { Institutos con } \\
\text { características } \\
\text { comunes }\end{array}$ & $\begin{array}{l}\text { Características } \\
\text { específicas }\end{array}$ & $\begin{array}{l}\text { Institutos con } \\
\text { características } \\
\text { específicas } \\
\end{array}$ \\
\hline Divisiones interiores & Realizada in situ & $\begin{array}{l}\text { IdiPAZ, i+12, IRYCIS, } \\
\text { IISBiodonostia, IISA }\end{array}$ & Modular & $\begin{array}{l}\text { liSGM, } \\
\text { IISBiocruces, } \\
\text { VHIR, IGTP, IIS La } \\
\text { Fe }\end{array}$ \\
\hline $\begin{array}{l}\text { Revestimiento } \\
\text { vertical }\end{array}$ & Resina fenólica & $\begin{array}{l}\text { liSGM, IISBiocruces, VHIR, } \\
\text { IGTP, IIS La Fe }\end{array}$ & $\begin{array}{l}\text { PVC rollo } \\
\text { Pintura epoxi }\end{array}$ & $\begin{array}{l}\text { IdiPAZ, i+12 } \\
\text { IRYCIS } \\
\text { IISBiodonostia, } \\
\text { IISA }\end{array}$ \\
\hline $\begin{array}{l}\text { Protección contra } \\
\text { choques }\end{array}$ & $\mathrm{SI}$ & $\begin{array}{l}\text { i+12, IiSGM, IRYCIS, VHIR, } \\
\text { IGTP }\end{array}$ & NO & $\begin{array}{l}\text { IdiPAZ, } \\
\text { IISBiodonostia, } \\
\text { IISBiocruces, IISA, } \\
\text { IIS La Fe } \\
\end{array}$ \\
\hline Pavimento & PVC & $\begin{array}{l}\text { IdiPAZ, i+12, liSGM, } \\
\text { IRYCIS, IISA, VHIR, IGTP, } \\
\text { IIS La Fe }\end{array}$ & Resina epoxi & $\begin{array}{l}\text { IISBiodonostia, } \\
\text { IISBiocruces }\end{array}$ \\
\hline Techo & Falso techo yeso laminado & $\begin{array}{l}\text { IdiPAZ, i+12, liSGM, } \\
\text { IRYCIS, IISBiodonostia, } \\
\text { IISA }\end{array}$ & $\begin{array}{l}\text { Falso techo panel } \\
\text { autoportante } \\
\text { Techo visto }\end{array}$ & $\begin{array}{l}\text { IISBiocruces, IGTP, } \\
\text { IIS La Fe } \\
\text { VHIR }\end{array}$ \\
\hline Carpintería puertas & Abatible / manual & $\begin{array}{l}\text { IdiPAZ, i+12, liSGM, } \\
\text { IRYCIS, IISBiodonostia, } \\
\text { IISBiocruces, IISA, VHIR, } \\
\text { IGTP, IIS La Fe }\end{array}$ & Enrollable/automática & IGTP \\
\hline Acabado puertas & Resina fenólica & $\begin{array}{l}\text { liSGM, IISBiocruces, VHIR, } \\
\text { IGTP, IIS La Fe }\end{array}$ & $\begin{array}{l}\text { Metálica lacada } \\
\text { Acero inoxidable }\end{array}$ & $\begin{array}{l}\text { IdiPAZ, IRYCIS, } \\
\text { IISBiodonostia } \\
\mathrm{i}+12 \text {, IISA }\end{array}$ \\
\hline Mirillas & SI & $\begin{array}{l}\text { IdiPAZ, i+12, IiSGM, } \\
\text { IRYCIS, IISBiodonostia, } \\
\text { IISBiocruces, IISA, VHIR, } \\
\text { IGTP }\end{array}$ & NO & IIS La Fe \\
\hline Foto periodo & SI & $\begin{array}{l}\text { IdiPAZ, i+12, liSGM, } \\
\text { IRYCIS, IISBiodonostia, } \\
\text { IISBiocruces, IISA, VHIR, } \\
\text { IGTP, IIS La Fe }\end{array}$ & & \\
\hline Control Ta y HR & $\mathrm{SI}$ & $\begin{array}{l}\text { IdiPAZ, i+12, liSGM, } \\
\text { IRYCIS, IISBiodonostia, } \\
\text { IISBiocruces, IISA, VHIR, } \\
\text { IGTP, IIS La Fe }\end{array}$ & & \\
\hline
\end{tabular}

Fuente. Elaboración propia.

\section{Divisiones interiores}

Las características fundamentales que se deben considerar en la elección de la composición de las divisiones interiores, aparte de las genéricas ya mencionadas, son fundamentalmente dos: los acabados de los paramentos verticales deben ser lisos para facilitar la limpieza y desinfección, y ser resistentes al daño por impacto de los carros.

Según observamos en el estudio realizado, no existe una clara determinación por el tipo de sistema constructivo elegido para la realización de las particiones interiores. Aunque en la mitad de los casos (IdiPAZ, i+12, IRYCIS, IISBiodonostia, IISA ) las divisiones se han realizado con sistemas constructivos tradicionales a base de fábricas de albañilería o tabiques de cartón-yeso y un revestimiento continuo, se observa que en la mayoría de los institutos construidos recientemente han optado por una solución a base de tabiques modulares prefabricados que llevan incorporado el revestimiento de acabado. 
En este último caso, la solución mayoritariamente adoptada es la realización de los tabiques a base de paneles sándwich autoportantes, ensamblados entre sí mediante machihembrado y posterior sellado, lo que proporciona una superficie lisa, y cuyo material de acabado es a base de paneles acabados en resina fenólica. Para evitar la acumulación de polvo y facilitar la limpieza, los encuentros con los pavimentos y los techos, así como las esquinas, se resuelven con perfiles sanitarios en formación de media caña. Otra de las soluciones prefabricadas modulares que hemos encontrado es a base de mamparas prefabricadas acabadas en paneles de compacto (IISGM).

En los casos en los que la solución ha sido a base de divisiones tradicionales, los revestimientos que nos encontramos en las salas de alojamiento y experimentación animal son de dos tipos; por una parte, revestimientos a base de láminas de PVC en rollo con juntas termosoldadas y medias cañas integradas en las esquinas; $y$, por la otra, paramentos verticales acabado en pintura epoxi.

Todas las soluciones planteadas son funcionales y con acabados lisos, los cuales proporcionan las exigencias establecidas para este tipo de instalaciones, si bien atendiendo a la durabilidad de los materiales, el acabado a base de pintura epoxi requiere tareas de mantenimiento más frecuentes, y por lo tanto, mayor afección al desarrollo de la actividad investigadora. Por otra parte, teniendo en cuenta el concepto de flexibilidad que requiere el diseño de las instalaciones para poder albergar las futuras necesidades del centro, la solución modular permite afrontar una redistribución de manera más sencilla que las soluciones tradicionales.

En las instalaciones de experimentación de animales pequeños, los pasillos son zonas especialmente propensas a sufrir frecuentes impactos debido al continuo movimiento de carros y jaulas, es por ello que suele ser recomendable proteger tanto las paredes con algún tipo de elemento parachoques como las esquinas con elementos protectores, para garantizar la durabilidad de los materiales. En este sentido, observamos que en algunos casos (i+12, liSGM, IRYCIS, VHIR, IGTP) se han instalado protecciones en los paramentos verticales de los pasillos más concurridos, siendo muy recomendable su instalación para garantizar la integridad de los paramentos. En algunos casos, la protección se sitúa en las parte bajas, mientras que en otros, se ha optado por instalarlos a una altura intermedia del paramento.

\section{Pavimentos}

Los pavimentos deben estar diseñados para soportar el tránsito intenso de los carros y jaulas que circulan por la instalación, por lo que se debe garantizar la planeidad y nivelación del pavimento, así como evitar los umbrales y peldaños. Además, deben ser resistentes a la humedad, no absorbentes, 
continuos o con el menor número de juntas posible, fáciles de reparar y resistentes al impacto y a los efectos adversos del agua caliente y los agentes de limpieza (National Research Council 2011, p. 134).

En el estudio realizado observamos que en la mayoría de los casos (IdiPAZ, i+12, liSGM, IRYCIS, IISA, IGTP, IIS La Fe), el acabado del pavimento se realiza a base de láminas de PVC en rollo con juntas termosoldadas que tienen una prolongación en el paramento vertical mediante la instalación de una curva sanitaria. En el resto de los casos, el material elegido ha sido la resina epoxi, siendo un material que ofrece un pavimento continuo sin juntas, que además, garantiza la planeidad y nivelación del paramento. En todos los casos, la unión del pavimento con los paramentos verticales se realiza mediante la instalación de una curva sanitaria que facilita la correcta limpieza y desinfección de las salas.

Si bien en algunas guías se recomienda la instalación de sumidero en las salas de estabulación de animales pequeños, este criterio no es compartido por todos los responsables del área de experimentación, ya que se considera un posible foco de contaminación de las salas. De esta manera, observamos algún caso (IIS Biodonostia) en el que los sumideros instalados se han sellado para garantizar la asepsia requerida en la investigación.

\section{Techos}

Al igual que ocurre con los pavimentos y revestimientos verticales, los techos deben ser resistentes a la limpieza y desinfecciones frecuentes, aunque no están sujetos a la misma intensidad de limpieza. En general, se recomienda utilizar techos continuos sin juntas y lavables, tanto en las salas de alojamiento de animales como en las de procedimientos (Neil 2003, p.48).

El tipo de techo que habitualmente nos encontramos en las áreas de experimentación (IdiPAZ, i+12, liSGM, IRYCIS, IISBiodonostia, IISA) es un falso techo continuo a base de placa de yeso laminado resistente a la humedad, sellado en todas sus juntas y en los encuentros con la pared, siendo el acabado a base de pintura epoxi y con los registros necesarios para realizar las tareas de mantenimiento de las instalaciones ubicadas en el espacio comprendido entre el techo y el falso techo.

En los casos en los que los tabiques divisorios se han realizado a base de paneles sándwich autoportantes, el falso techo se ha realizado también a base de paneles sándwich (IIS Biocruces, IGTP, IIS La Fe), solución que permite tener un acabado continuo con juntas selladas que garantiza la limpieza necesaria en las salas. Esta solución modular integra las piezas de remate en esquina, lo que permite tener las curvas sanitarias en el encuentro entre el paramento vertical y el techo. 
Como caso excepcional encontramos un caso (VHIR) en el que no se ha diseñado un falso techo que aloje las instalaciones, sino que la solución adoptada ha sido dejar la estructura de hormigón de techo vista con un acabado a base de pintura epoxi, de manera que todas las instalaciones que discurren por la sala quedan vistas. Esta solución, a priori va en contra de los principios de asepsia necesarios en las salas y permite una mayor exposición de los ruidos generados en las instalaciones, al carecer de un elemento aislante como es el falso techo. En cambio, según los responsables del animalario, es una solución muy válida que requiere de un personal de limpieza bien formado, ya que, en caso de producirse alguna avería, tiene la ventaja de que permite una visualización y reparación rápida sin tener que hacer grandes destrozos en la sala. Esta misma solución que parece muy llamativa se ha adoptado también en el PRBB, siendo éste uno de los mayores centros de investigación biomédica del sur de Europa.

\section{Carpintería de puertas}

Por seguridad, las puertas deben abrir hacia el interior de las salas de alojamiento de animales (National Research Council 2011, p. 137). Además, deben ser capaces de soportar el uso frecuente del paso de carros, por lo que se deberían adoptar productos de alta calidad (Neil 2003).

Se observa cómo las puertas de las salas de estabulación de todos los centros son abatibles de apertura manual hacia el interior de las salas. En aras a proporcionar un mantenimiento mínimo a las puertas, en la mayoría de los casos se ha optado por instalar puertas acabadas en resina fenólica, o acabadas en acero inoxidable (I+12, IISA). En el resto de los casos, se ha optado por instalar puertas metálicas lacadas (IdiPAZ, IRYCIS, IIS Biodonostia). Además, en algún caso (IdiPAZ), para garantizar una mayor durabilidad de las puertas, se ha optado por instalar piezas protectoras a base de chapa de acero inxidable en formación de zócalos.

Aparte de las salas de estabulación, las puertas de pasillos y salas de lavado y esterilización son salas de mucho trasiego de carros por lo que interesa que el sistema de aperturas de puerta esté correctamente diseñado para soportar su uso frecuente. Observamos un caso (IGTP), en el que estas puertas de gran uso se han diseñado automatizadas y enrollables, lo cual facilita enormemente la actividad del centro. Aunque entre el resto de los centros visitados solamente hemos encontrado un caso (UCL) en el que también el sistema de apertura de las puertas abatibles se ha automatizado, tanto en la zona de pasillos como en la sala de lavado y esterilización, el responsable de la instalación considera que es un criterio de diseño fundamental para facilitar la operatividad del transporte de carros, garantizar la apertura y el cierre completo de las puertas evitando que queden abiertas por largo periodo de tiempo, así como para garantizar la durabilidad de las mismas. En el resto de los casos, la apertura es manual y en casi todos se han instalado equipos complementarios, tales como, 
muelles cierrapuertas para garantizar el cierre correcto de las puertas, así como felpillos antipolvo en la parte inferior de la hoja de las puertas.

Observamos también que en casi todos los casos las puertas de acceso a las salas de estabulación tienen una ventana de observación que permite tener una visión general de la sala desde el exterior, sin tener que acceder a ella, y por lo tanto mantener la calidad del aire interior de la sala lo más limpia posible. Los sistemas de visión implantados en cada caso varían desde una mirilla, mirilla con tapa de oscurecimiento, mirilla con filtro rojo o mirilla electrónica (Figura 111).
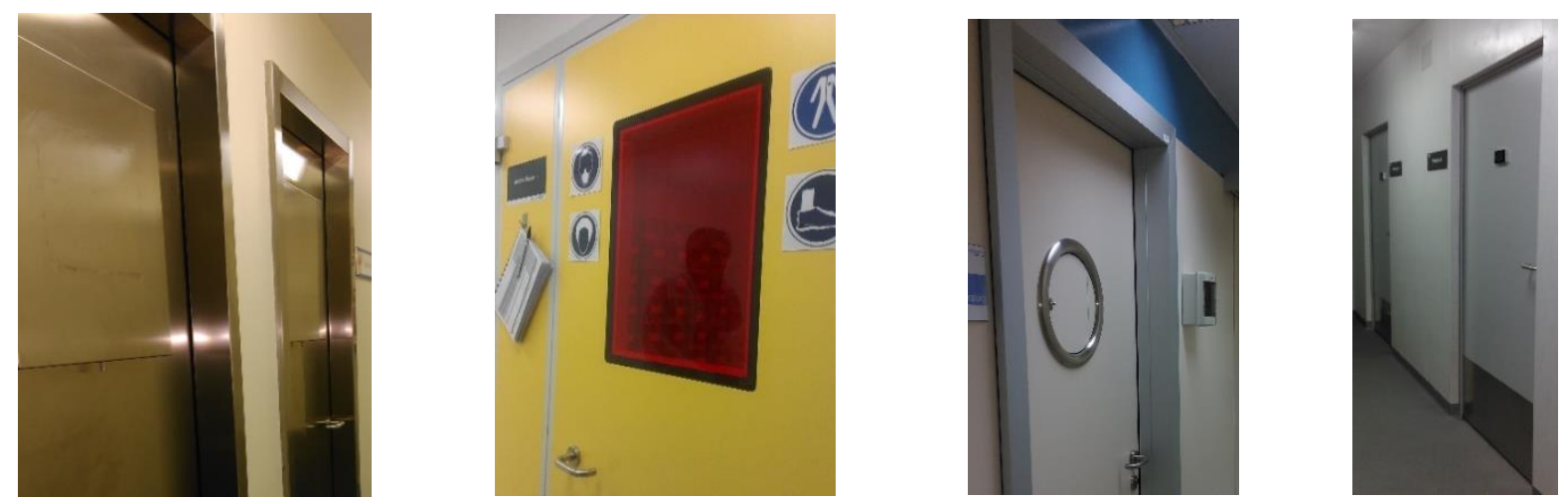

Figura 111. Sistemas de visualización salas de alojamiento animales. Fuente. Elaboración propia.

\section{Iluminación}

En general, las salas de alojamiento de animales se deben diseñar para proporcionar suficiente iluminación, y así garantizar su bienestar, permitir la inspección adecuada de los animales incluidas las jaulas ubicadas en las partes bajas de los bastidores, proporcionar unas condiciones de trabajo seguras para el personal y facilitar las buenas prácticas de limpieza.

En ninguno de los casos las salas de alojamiento de animales disponen de luz natural a través de ventanas exteriores ni interiores, sino que se distribuyen en salas ciegas. Entre las unidades de experimentación en barrera observamos una que tiene luz natural en el pasillo de distribución interior (IGTP); en el resto de los casos, la zona completa se ha distribuido en zonas ciegas.

Los roedores son especialmente sensibles a la iluminación, por lo que el control de la iluminación mediante un sistema de fotoperiodo es fundamental para regular los ciclos circadianos, la estimulación, la sincronización de los reproductivos y porque puede producir lesiones en la retina, sobre todo en animales albinos. Lo habitual son ciclos de luz y oscuridad de 12:12 horas. Teniendo en cuenta que los ratones son más activos por la noche, los los periodos oscuros del día se deberían adaptar a las tareas de trabajo de los investigadores (Laboratoy animals 32 1998, p.246). 
En este sentido, observamos que en todas las áreas de experimentación de animal pequeño existe un control de la iluminación para garantizar el ciclo circadiano. En las instalaciones más básicas este encendido se produce localmente mediante un simple encedido y apagado temporizado, mientras que en los institutos más modernos la iluminación está integrada en el sistema de control general de la instalación, y es muy habitual que dispongan de un sistema de encendido y apagado progresivo que simule el amanecer y atardecer (IIS Biocruces, IISA, VHIR, IGTP). Además, en estas instalaciones existe un potenciómetro que permite regular la intensidad lumínica de las salas para poder adecuarla a las necesidades de la especie que se necesite alojar.

Es muy común que el alumbrado se complemente con la instalación de un encendido manual de luz roja, para poder acceder a las salas en los periodos nocturnos y observar a los animales sin tener que hacer uso del alumbrado normal (i+12, IiSGM, IISBiodonostia, IISBiocruces, IISA, VHIR, IGTP, IIS La Fe).

\section{Ruido y vibraciones}

Los ratones poseen un amplio rango de sensibilidad auditiva y los sonidos altos, incluidos los ultrasonidos, pueden afectarles negativamente durante su desarrrollo y a lo largo de sus vidas. Niveles de ruido elevados pueden ocasionar estrés e interferir en la comunicación con los demás miembros del grupo. Los sistemas de alarma, los teléfonos y los timbres en los animalarios deberían funcionar a frecuencias no audibles para el oído del animal, por debajo de los $500 \mathrm{~Hz}$. Se ha sugerido que un ruido constante de fondo (hilo musical) proporciona beneficios, ya que hace que los animales sean menos asustadizos y más fáciles de manejar, aunque parece que esta afirmación no tiene evidencia científica (Laboratoy animals 32 1998. p.246-247).

Entre los elementos que componen la unidad de experimentación animal y que pueden provocar ruidos y vibraciones se deben considerar, entre otros, ascensores, salas de lavado y esterilización, ciertos cuartos técnicos, pasillos de mucho tránsito, incluso los sistemas de climatización y los equipos de las jaulas ventiladas individualmente. Debido a que estos animales son especialmente sensibles al ruido, es recomendable que las áreas de estabulación de animal pequeño se sitúen aisladas de estas zonas.

Como hemos podido observar, las salas de alojamiento se ubican en todos los casos lejos de ascensores y cuartos técnicos ruidosos, si bien, no siempre se ha conseguido distribuir las salas de estabulación lejos de las salas de lavado, de manera que en varios casos (IdiPAZ, I+12, IiSGM, IRYCIS, IISBiocruces) alguna de las sala,s bien de cuarentena o de estabulación, se sitúan colindantes a esta zona. En el caso del IISBiocruces, los tabiques divisorios entre salas se han aislado con paneles acústicos; por otra parte, en el caso del CIC BiomaGUNE, la sala de estabulación colindante a la sala de lavado se ha tenido que cambiar de ubicación debido a las molestias que el uso de las sala generaba 
a los animales. En el resto de los casos, quizás por el tipo de equipos instalados, por el sistema constructivo divisiorio seleccionado o por su distribución en relación a la sala de estabulación, los usuarios no han detectado incidencias significativas en los animales debido al ruido generado en la instalación.

En las unidades investigadas no se han tomado medidas adicionales, tales como, instalar hilo musical, ni tampoco se han considerado medidas extraordinarias a la hora de definir los equipos que emiten señales acústicas en caso de emergencia, por considerarse casos muy puntuales y excepcionales en los que se hace uso de ellos.

\section{Control temperatura y humedad relativa}

Las salas de alojamiento deben estar diseñadas para garantizar la calidad del aire exigible a la instalación y, por tanto, para asegurar la circulación del aire, para que los niveles de polvo y las concentraciones de gases se mantengan dentro de unos límites que no sean nocivos para los animales alojados. Además, tanto la temperatura como la humedad relativa en los locales de alojamiento deben estar adaptada a las especies y a los grupos de edad de los animales alojados, siendo unos parámetros que deben registrarse diariamente (RD 53/2013 Anexo II).

Como criterio general, el aire en las salas de alojamiento se debe renovar con intervalos frecuentes, y, en condiciones normales, el régimen de ventilación debería ser de 15 a 20 renovaciones de aire por hora. Por otra parte, cada especie animal requiere unas condiciones ambientales específicas; en este sentido, las líneas directrices establecidas para la temperatura ambiental óptima de los roedores en jaulas se establecen en un rango de $20-24^{\circ} \mathrm{C}$, mientras que en el caso de los conejos el rango es de 15 $21^{\circ} \mathrm{C}$. La humedad relativa óptima de los locales de alojamiento se establece en $55 \%+/-10 \%$, debiéndose evitar los índices inferiores al $40 \%$ y superiores al $70 \%$ de humedad relativa durante periodos prolongados (RD 1201/2005 Anexo II).

Observamos que en aras a garantizar la calidad del aire interior de las salas de alojamiento, las unidades de experimentación se han dotado de medios adecuados para asegurar la calidad del aire exigida en cada caso. Se observa también que las instalaciones están diseñadas para garantizar la continuidad del sistema de climatización en caso de corte de suministros eléctricos, a través de grupos electrógenos, si bien no es habitual que el sistema de climatización sea redundante.

Las zonas de barrera se consideran zonas de ambiente controlado, es por ello que resulta recomendable que en el diseño de las instalaciones se consideren conceptos que faciliten y garanticen las exigencias de climatización de estas salas. En este sentido, observamos cómo en todos los casos se 
disponen esclusas colindantes a los accesos, que permiten un control de las diferencias de presión y que permiten asegurar que el flujo de aire circule en la dirección adecuada.

El control de la temperatura y humedad relativa se realiza en todos los centros, si bien la forma varía de unos a otros. En la mayoría de los casos, el sistema de control de los parámetros está centralizado en el sistema de gestión integral del edificio, por lo que el acceso a dicha información no es tan sencilla para los responsables del animalario. En otros casos, este control centralizado se complementa con la instalación de paneles de repetición de los parámetros para la visualización de la temperatura, humedad relativa y la presión junto a las puertas de acceso a las salas de estabulación. En algunos casos en los que esta opción no se ha planteado en la fase de diseño y construcción, los responsables del bienestar animal han utilizado los parámetros que proporcionan los estantes ventilados individualmente, o han instalado equipos de control individual que les ha permitido tener un control visual del estado de las salas e independiente al sistema centralizado. 


\subsubsection{Síntesis del área de experimentación animal pequeño}

El área de experimentación de animal pequeño es una zona específica dentro del centro de experimentación animal destinada a la investigación con animales que por su tamaño se consideran pequeños, como son los roedores (ratones, ratas, hámsteres, cobayas, jerbos), los logomofos (conejos), los animales acuáticos (peces) e insectos (moscas). El presente estudio del área de experimentación de animal pequeño se ha centrado específicamente en la zona destinada a la investigación con roedores y logomorfos, por estar estos últimos habitualmente estabulados junto a los roedores.

Para llevar a cabo este tipo de investigación es necesario el empleo de animales de laboratorio; además, es muy importante escoger la especie animal que mejor se adapte al tipo de estudio que se pretende llevar a cabo. Para ello, hay que tener presente al menos los siguientes aspectos: la enfermedad que se desea estudiar, el tipo, tamaño y facilidad o no para la obtención de las muestras que son necesarias en el estudio y las características anatómicas o fisiológicas de la especie con la que se desea trabajar.

Si bien, tal y como hemos analizado en el área de experimentación de animal grande lo habitual es que los animales grandes estén estabulados de manera convencional, en el caso de los roedores nos encontramos que el tipo de alojamiento a diseñar dependerá del estado sanitario exigible al animal, de manera que nos podemos encontrar con diferentes tipos de estabulación: estabulación convencional, estabulación en barrera y estabulación de contención del riesgo biológico.

La superficie destinada a la experimentación con animal pequeño es muy variable, ya que hay institutos que pueden llegar a triplicar la superficie del centro más pequeño. En la mayoría de los casos vemos que se destina una superficie comprendida entre los 500 y $1.000 \mathrm{~m}^{2}$.

Esta área está diseñada para la experimentación fundamentalmente con roedores y logomorfos, siendo los ratones la especie animal más utilizada en este tipo de investigación. Aunque hemos visto que la experimentación con animales acuáticos se realiza en unos pocos centros, debido a las posibilidades que ofrece la investigación con este tipo de animales y a la facilidad de implantar los locales necesarios para el alojamiento de estos animales en las instalaciones existentes, muchos institutos tienen en mente la posibilidad de ampliar la investigación a este campo.

Todos los institutos tienen una unidad destinada a la experimentación convencional de animal pequeño, siendo muy habitual que también se disponga de un área más reducida para la experimentación en barrera. Por otra parte, la unidad de experimentación de contención del riesgo biológico nivel 2 se realiza prácticamente en la mitad de los institutos, siendo una unidad integrada 
en la unidad convencional, que se configura como una sala de procedimientos con sus condicionantes específicos de diseño, equipamiento y procedimientos de trabajo. En cambio, no es muy habitual encontrarnos con unidades de experimentación de contención del riesgo biológico nivel 3.

En cuanto a la organización en plantas, lo habitual es que el área de experimentación de animal pequeño se distribuya en una única planta con acceso directo desde el exterior. En los casos en los que esta área se ha tenido que dividir en varias plantas, la base del planteamiento general ha sido intentar evitar tener que trasladar los animales de plantas. Por diversas circunstancias, esta premisa no en todos los casos se ha logrado, por lo que este traslado se ha intentado reducir al mínimo número de animales posibles, incluso se han diseñado elementos de comunicación vertical de uso exclusivo para animales.

A pesar de que las necesidades y la actividad a desarrollar en el área de experimentación de animal pequeño son muy diferentes a la del animal grande, no siempre se ha conseguido independizar completamente las dos actividades. Es habitual que los pasillos de distribución, los locales de servicio, incluso en algún caso concreto, las salas de preparación animal sean de uso compartido para ambas actividades, por lo que para el correcto funcionamiento del centro se han establecido una serie de procedimientos específicos de uso y limpieza de las zonas compartidas.

Para conseguir unas instalaciones eficientes también hay que tener muy presentes la correcta definición y ejecución de los sistemas constructivos de la instalación. En este sentido, los materiales de acabado deben ser elegidos para facilitar su limpieza y desinfección en aras a garantizar las condiciones de asepsia necesaria en las instalaciones, así como para garantizar el bienestar animal, para lo cual hay que tener muy presentes los tres focos principales que pueden generar estrés a los animales como son: el ruido, las vibraciones y la iluminación. Por otra parte, se debe tener en cuenta que las salas de alojamiento de animales son instalaciones que deben estar en funcionamiento 24 horas al día, por lo que es fundamental considerar los conceptos básicos de: durabilidad, estabilidad, funcionalidad y mantenimiento.

Según observamos en el estudio realizado, en relación a las particiones interiores, aunque no existe una clara determinación por el sistema elegido, se observa que la mayoría de los institutos construidos recientemente han optado por una solución a base de tabiques modulares prefabricados que llevan incorporado el revestimiento de acabado. Atendiendo a la durabilidad exigida a los materiales de acabado, así como a la flexibilidad que requiere el diseño de este tipo de instalaciones para poder albergar las futuras necesidades del centro, la solución modular permite afrontar una redistribución de manera más sencilla que las soluciones tradicionales. Por otra parte, para proporcionar mayor 
durabilidad a los materiales de acabado de los paramentos verticales, en las zonas especialmente propensas a sufrir frecuentes impactos debido al continuo movimiento de carros y jaulas, como son los pasillos, es muy habitual además de recomendable, la instalación de elemento de protección tipo parachoques.

En el estudio realizado vemos que en la mayoría de los casos el acabado del pavimento se realiza a base de láminas de PVC en rollo con juntas termosoldadas que tienen una prolongación en el paramento vertical mediante la instalación de una curva sanitaria. En el resto de los casos, el material elegido ha sido la resina epoxi. En todos los casos, la unión del pavimento con los paramentos verticales se realiza mediante la instalación de una curva sanitaria que facilita la correcta limpieza y desinfección de las salas.

Al igual que ocurre con los pavimentos y revestimientos verticales, los techos deben ser resistentes a la limpieza y desinfecciones frecuentes, aunque no están sujetos a la misma intensidad de limpieza. El tipo de techo que habitualmente nos encontramos en las áreas de experimentación es un falso techo continuo a base de placa de yeso laminado resistente a la humedad, siendo el acabado a base de pintura epoxi. En los casos en los que los tabiques divisorios se han realizado a base de paneles sándwich autoportantes, el falso techo se ha realizado también a base de paneles de este tipo, solución que permite tener un acabado continuo con juntas selladas que garantiza la limpieza necesaria en las salas. Esta solución modular integra las piezas de remate en esquina, lo que permite tener las curvas sanitarias en el encuentro entre el paramento vertical y el techo.

Como caso excepcional, encontramos un caso en el que no se ha diseñado un falso techo que aloje las instalaciones, sino que la solución planteada ha sido dejar la estructura de techo vista con un acabado a base de pintura epoxi, de manera que todas las instalaciones que discurren por la sala quedan vistas. Esta solución, a priori, va en contra de los principios de asepsia necesarios en las salas y, además, permite una mayor exposición a los ruidos generados en las instalaciones, al carecer de un elemento aislante como es el falso techo. Según los responsables del animalario, es una solución muy válida que requiere de un personal de limpieza bien formado, pero que, en caso de producirse alguna avería, tiene la ventaja de que permite una rápida visualización y reparación sin tener que hacer grandes destrozos en la sala.

Por seguridad, las puertas deben abrir hacia el interior de las salas de alojamiento de animales y deben ser capaces de soportar el uso frecuente del paso de carros. Se observa cómo las puertas de las salas de estabulación de la mayoría de los centros son abatibles de apertura manual hacia el interior de las salas con complementos, tales como, muelles cierrapuertas para garantizar el cierre correcto de las 
puertas, así como felpillos antipolvo en la parte inferior de la hoja de las mismas. Aparte de las salas de estabulación, las salas de lavado y esterilización son salas de mucho trasiego de carros, por lo que interesa que el sistema de aperturas de puerta esté correctamente diseñado para soportar su uso frecuente. El sistema de apertura de puertas automatizado, tanto en la zona de pasillos como en la sala de lavado y esterilización, facilita la operatividad del transporte de carros, garantiza la apertura y el cierre completo de las puertas evitando que queden abiertas por largo periodo de tiempo y aumenta la durabilidad de las mismas.

Vemos que en todos los casos las puertas de acceso a las salas de estabulación tienen una ventana de observación que permite tener una visión general de la sala desde el exterior sin tener que acceder a ella y, por lo tanto, mantener la calidad del aire interior de la sala lo más limpia posible. Los sistemas de visión implantados en cada caso varían desde una mirilla, mirilla con tapa de oscurecimiento, mirilla con filtro rojo o mirilla electrónica.

En general, las salas de alojamiento de animales se deben diseñar para proporcionar suficiente iluminación para garantizar el bienestar de los animales, permitir su inspección adecuada incluidas las jaulas ubicadas en las partes bajas de los bastidores, proporcionar unas condiciones de trabajo seguras para el personal y facilitar las buenas prácticas de limpieza. Además, los roedores son especialmente sensibles a la iluminación, por lo que el control de la iluminación de las salas de estabulación es fundamental para: regular los ciclos circadianos, la estimulación, la sincronización de los reproductivos y porque puede producir lesiones en la retina, sobre todo en animales albinos.

En ninguno de los casos las salas de alojamiento de animales disponen de ventanas exteriores ni interiores, sino que se distribuyen en salas ciegas. En este sentido, observamos que en todas las áreas de experimentación de animal pequeño analizadas existe un control de la iluminación para garantizar el ciclo circadiano, siendo habitual los ciclos 12:12. En las instalaciones más básicas este encendido se produce localmente mediante un simple encendido y apagado temporizado, mientras que en los institutos más modernos, la iluminación está integrada en el sistema de control general de la instalación, y está diseñada tanto para regular la intensidad lumínica de las salas de alojamiento de animales como para simular el amanecer y atardecer en las fases de encendido y apagado.

Los ratones son más activos por la noche, por lo que es habitual que la iluminación de las salas de alojamiento se programe para adaptar los periodos nocturnos de los roedores a las jornadas de trabajo de los investigadores. Por tanto, es muy común que el alumbrado se complemente con la instalación de un encendido manual de luz roja, que permita acceder a las salas en los periodos 
nocturnos y observar a los animales sin perturbarlos, al no tener que hacer uso del alumbrado general de la sala.

Los ratones poseen un amplio rango de sensibilidad auditiva y los sonidos altos pueden afectarles negativamente durante su desarrrollo y a lo largo de sus vidas, ya que pueden ocasionar estrés e interferir en la comunicación con los demás miembros del grupo. Entre las medidas que se han adoptado en los diferentes institutos, para evitar que el ruido y las vibraciones afecte a los roedores se encuentran: ubicar las áreas de estabulación en zonas aisladas de las fuentes que pueden provocar ruido y vibraciones como son la sala de lavado y esterilización, ascensores, cuartos de instalaciones y pasillos concurridos, e implantar soluciones constructivas que permitan una mejora de las condiciones acústicas de las salas de estabulación. Los responsables de los centros no han detectado afecciones significativas en los animales debido al ruido generado en la instalación, por lo que en las unidades investigadas no se han tomado medidas adicionales, tales como, instalar hilo musical, ni tampoco se han considerado medidas extraordinarias a la hora de definir los equipos que emiten señales acústicas en caso de emergencia, por considerarse casos muy puntuales y excepcionales en los que se hace uso de ellos.

Las salas de alojamiento deben estar diseñadas para garantizar la calidad del aire exigible a la instalación y, por tanto, asegurar la circulación del aire, para que los niveles de polvo y las concentraciones de gases se mantengan dentro de unos límites que no sean nocivos para los animales alojados. Además, tanto la temperatura como la humedad relativa en los locales de alojamiento deben estar adaptadas a las especies y a los grupos de edad de los animales alojados, siendo unos parámetros que deben registrarse diariamente.

Observamos también que en aras a garantizar la calidad del aire interior de las salas de alojamiento, las unidades de experimentación se han diseñado para asegurar la calidad del aire exigida en cada caso. Además, para garantizar la continuidad del sistema de climatización en caso de corte de suministros eléctricos, se han instalado grupos electrógenos, si bien no es habitual que el sistema de climatización sea redundante.

El control de la temperatura y humedad se realiza en todos los centros, si bien la forma varía de unos a otros. En la mayoría de los casos, el sistema de control de los parámetros está centralizado en el sistema de gestión integral del edificio, por lo que el acceso a dicha información no es tan sencilla para los responsables de los animalarios. En otros casos, este control centralizado se complementa con la instalación de paneles de repetición de los parámetros para la visualización de la temperatura, humedad relativa y presión diferencial junto a las puertas de acceso a las salas de estabulación. En 
algunos casos en los que esta última opción no se ha planteado en la fase de diseño y construcción, los responsables del bienestar animal han utilizado los estantes autoventilados para obtener la información o bien han instalado equipos de control individual que les ha permitido tener un control visual del estado de las salas e independiente al sistema centralizado. 


\subsubsection{Unidad de experimentación convencional animal pequeño}

Una instalación convencional es aquella que no está diseñada para procedimientos especiales, ya que los animales alojados no requieren mantener un determinado estado sanitario para garantizar el éxito de la investigación y, por lo tanto, no se requiere su aislamiento. A pesar de ello, tiene que estar diseñada para garantizar: el nivel de asepsia necesario, los parámetros ambientales exigidos a cada especie animal, así como los ciclos circadianos de iluminación, no solo para garantizar el bienestar animal, sino también para garantizar la validez de la investigación.

En esta unidad es habitual experimentar con diferentes especies animales, ya que cada especie tiene sus características propias que la hacen especialmente atractiva para un determinado tipo de experimentación. Las especies animales habitualmente utilizadas en este tipo de instalación son el ratón, la rata y el conejo y, aunque en menor medida, también es habitual experimentar con animales como son la cobaya, el jerbo o el hámster.

El estudio de esta unidad se realiza en primer lugar a partir del análisis de los locales que la componen habitualmente; en segundo lugar, tomando como referencia las representaciones gráficas estandarizadas de la unidad de experimentación convencional de animal pequeño se hace una breve descripción de la composición de cada unidad; en tercer lugar, se analizan sus características generales; en cuarto lugar, en base a las recomendaciones establecidas en las diferentes guías publicadas, y a las representaciones gráficas estandarizadas, se estudia la organización del área, así como la configuración de los accesos diseñados; en quinto y último lugar, se hace una síntesis del estudio realizado. 


\subsubsection{Locales que componen la unidad de experimentación convencional animal pequeño}

La unidad de experimentación convencional de animal pequeño lo componen básicamente los locales de alojamiento que son el lugar donde van a vivir normalmente los animales, las salas destinadas a la experimentación y las áreas de servicio necesarias para llevar a cabo la investigación; que deben estar diseñadas para garantizar tanto el cuidado y bienestar animal como las condiciones de trabajo y seguridad del personal. Los principales locales que componen el área de experimentación convencional animal pequeño son los siguientes:
a) Sala de cuarentena y aislamiento
b) Salas de alojamiento
c) Salas de procedimientos
d) Salas de comportamiento
e) Sala de microcirugía
f) Sala necropsias
g) Área imagen
h) Almacenes de servicio
i) Área de lavado y esterilización
j) Vestuarios, aseos y duchas
k) Área administrativa

a) Zona de cuarentena y aislamiento. Esta zona permite el aislamiento de los animales recién llegados al centro hasta que se determine su estado sanitario y se evalúe y minimice el potencial riesgo sanitario para los demás animales, y también para poder alojar por separado los animales enfermos o heridos (RD 53/2013 Anexo II).

b) Salas de alojamiento. Los locales de alojamiento son los locales donde van a vivir normalmente los animales con los que se va a experimentar y que se utilizarán para cría y mantenimiento durante la realización de un procedimiento. Los animales deben estar alojados en locales dedicados para ese propósito y se debe tratar como local de alojamiento cualquier área donde los animales vayan a permanecer durante más de 24 horas (Division of technical resources 2012, p. 2-65). Estas salas deben ser capaces de controlar los parámetros ambientales, tales como, la temperatura, la humedad, la iluminación, el nivel sonoro, incluso los olores, ya que, además de ser críticos para el bienestar de los animales, también es necesario para la validez de la investigación, incluso para el confort del personal.

c) Sala de procedimientos. En general, todos los procedimientos que puedan causar angustia al animal deberían realizarse fuera de la zona de alojamiento de animales en salas específicamente destinadas para ello, ya que pueden transmitir alarma y producir un estrés innecesario al resto de los animales alojados en la sala. 
d) Salas de comportamiento. El área de comportamiento animal es una infraestructura preparada para el análisis comportamental de animales de experimentación. En estas salas, con frecuencia, suele ser necesario mantener a los animales en un ambiente con estricto control sobre los estímulos auditivos, visuales, táctiles y olfativos, de manera que al planificar estas salas, se debe poner especial cuidado para minimizar la transmisión aérea del ruido y la transmisión terrestre de la vibración.

e) Sala de microcirugía. Las instalaciones para la cirugía animal es una unidad básica en los institutos de investigación sanitaria. El grado de complejidad de esta área dependerá de las especies que se van a utilizar, así como de los procedimientos necesarios llevar a cabo. De esta manera, el área de microcirugía destinada a la realización de prácticas quirúrgicas con roedores puede llevarse a cabo en laboratorios específicamente diseñados para tan fin. En general, es recomendable que las instalaciones quirúrgicas estén incorporadas junto a las zonas de estabulación animal, para evitar el traslado de los animales y, así facilitar la supervisión y el cuidado post-operatorio de los animales por parte del personal investigador (Neil 2003, p. 21).

f) Sala necropsias. En un animalario se deben monitorear las causas de la muerte de los animales como parte del sistema de la vigilancia de la salud, ya que esa información post mortem suele ser necesaria para fines científicos, especialmente en el caso de los animales modificados genéticamente. En función del propósito de esta área esta sala puede no ser necesaria, en cuyo caso las tareas de necropsia se pueden llevar a cabo en cabinas de seguridad integradas en el propio área de microcirugía (Neil 2003, p. 29).

g) Área de imagen. El área de diagnóstico por imagen y radiología es una unidad que cada vez tiene más peso específico en los animalarios de investigación. Esta unidad ofrece la posibilidad de realizar estudios de imagen para el aporte de datos objetivos en el estudio de la investigación en salud animal, teniendo aplicación en diferentes disciplinas de investigación biomédica. Cada unidad vendrá definida por el tipo de investigación que se quiera realizar, siendo muy habitual investigar con este tipo de equipos: PET-TAC, SPECT, Resonancia magnética, Bioluminiscencia y NanoPET.

h) Almacenes de servicio. Los locales de servicio son los destinados a almacenar todo el material necesario para el funcionamiento de la instalación, como son los locales para almacenar el alimento, la ropa de cama, los suministros, los equipos, los residuos y los útiles de limpieza entre otros. 
En los almacenes de material limpio habitualmente se guarda el pienso de los animales, así como el material de cama. El alimento que se les suministra a los animales debe estar libre de contaminación y es empaquetado herméticamente después de su esterilización. Con el fin de evitar la contaminación, este alimento debe almacenarse en una sala que sea fácil de desinfectar. En cuanto al material para la formación de la cama de los animales, se puede almacenar en la misma sala, pero no directamente sobre el suelo, sino sobre estantes elevados y separados de las paredes para favorecer la limpieza y vigilancia de los parásitos.

Los materiales de otro tipo, que puedan estar contaminados o suponer un peligro para los animales o el personal, deben almacenarse por separado (RD 53/2013 Anexo II). El espacio de almacenamiento se puede disminuir cuando la entrega de materiales y suministros es confiable y frecuente; sin embargo, debe ser lo suficientemente amplio como para almacenar los productos esenciales para poder garantizar la cría y el cuidado ininterrumpidos de los animales (National Research Council 2011, p. 141).

i) Área de lavado y esterilización. En la zona de lavado y esterilización del área de experimentación animal pequeño se recepcionan todas las jaulas sucias de los animales para lavarlas y prepararlas para poder volver a alojar los animales en ellas. Las actividades habituales suelen ser vaciar las jaulas y biberones, lavarlos y esterilizarlos en caso necesario, preparar las camas y llenar los biberones en el caso de que así sea el suministro de agua. Son salas cuyo dimensionamiento debe ser lo suficientemente grande para que sea posible alojar en ellas los equipos diseñados y poder lavar el número de jaulas previsto cada día.

j) Vestuarios, aseos y duchas. Considerada como zona de frontera situada a la entrada del animalario y destinada a realizar un cambio de ropa para reducir el riesgo de la introducción de agentes nocivos en las zonas de experimentación, así como para facilitar y propiciar la higiene personal de los trabajadores, además de para garantizar las condiciones de seguridad de los trabajadores del centro de experimentación.

k) Zona administrativa. Destinada al desarrollo de los trabajos administrativos para realizar reuniones, así como centro de información para el personal en el que poder incluir libros, revistas, boletines informativos, catálogos, entre otros, incluso para que los trabajadores puedan tomar su descanso. 


\subsubsection{Representaciones gráficas distribución de unidad de experimentación convencional animal}

\section{pequeño}

A partir de los planos en planta estandarizados que se han desarrollado de cada uno de los centros de experimentación animal, y que se encuentran recogidos en las fichas de toma de datos, se ha seleccionado exclusivamente el área destinada a la unidad de experimentación convencional de animal pequeño. Con estas representaciones gráficas se pretende tener una visión específica de su configuración y de las distintas circulaciones diseñadas (Figuras 112-122).

Para facilitar el estudio, en los planos de distribución en planta se ha identificado por código de colores el área funcional y la unidad de experimentación de animal pequeño al que pertenece y por código numérico el tipo de local que es. Por otra parte, con el fin de realizar una lectura sencilla de las circulaciones de la unidad, también se reflejan los flujos de trabajo planteados para el personal que se representa mediante línea continua de color azul; para el suministro de animales, mediante línea continua de color rojo; para el suministro de materiales, con línea continua color verde; incluso para la retirada de residuos, con línea de trazos color verde. Además, también se representa el sentido de los flujos de trabajo mediante las flechas dibujadas junto a cada línea (Figura 98). Junto a cada una de las representaciones gráficas se hace una breve descripción de la configuración de la unidad de experimentación convencional de animal pequeño

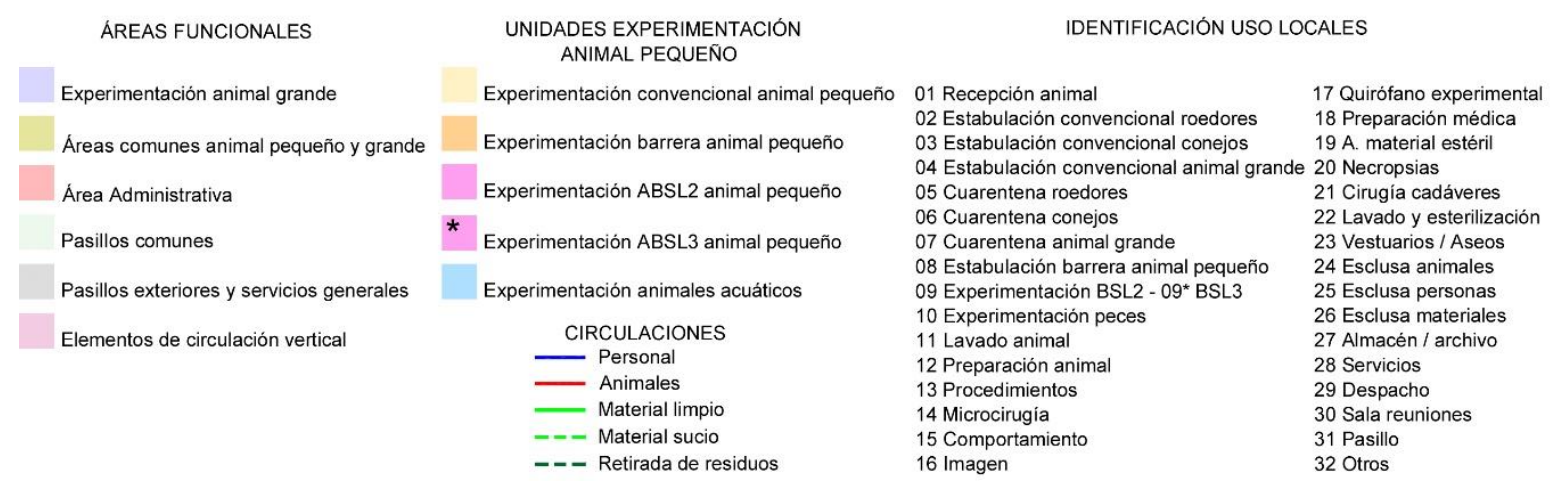

Figura 112. Leyenda unidad experimentación convencional animal pequeño. Fuente. Elaboración propia.

*Esta leyenda se hace extensible a las figuras 113-122. 
La unidad de experimentación convencional de animal pequeño del instituto IdiPAZ (Figura 113) se desarrolla en dos plantas bajo rasante. En la planta sótano -2 se distribuye tanto la zona de cuarentena como el área de estabulación, así como los locales de procedimientos, almacenes, vestuarios de personal, incluso la zona de lavado y esterilización. En la planta sótano -1, en cambio, se distribuye el área de microcirugía, por lo que es necesario el traslado de los animales a través de elementos de comunicación vertical.

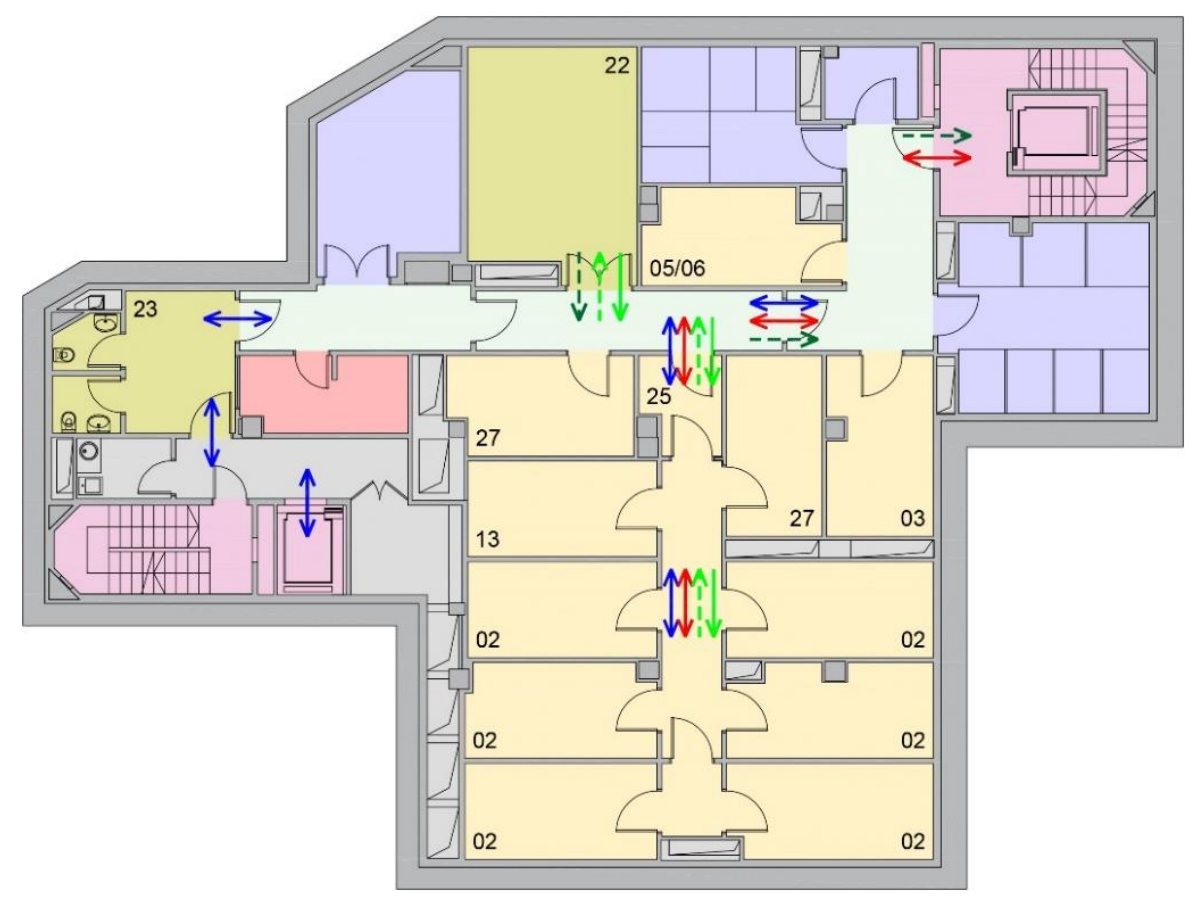

Planta Sótano -2

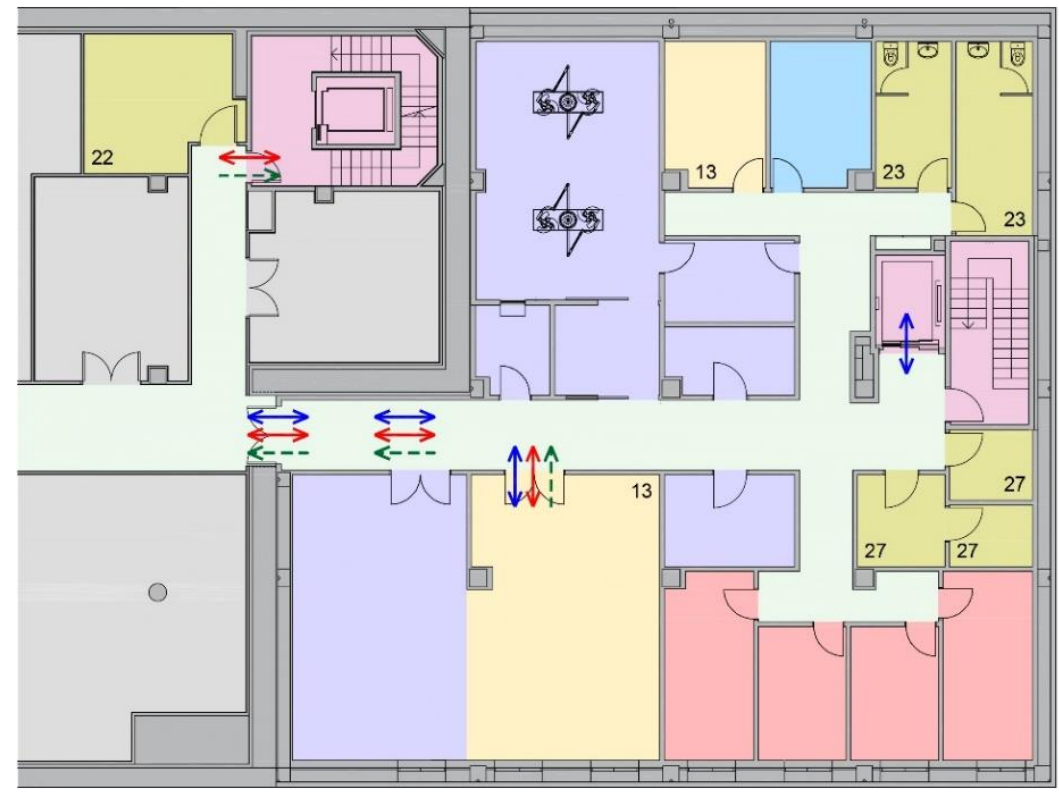

Planta Sótano -1

Figura 113. Unidad experimentación convencional animal pequeño IdiPAZ (S/E).

Fuente. Elaboración propia. 
La unidad de experimentación convencional de animal pequeño del instituto i+12 (Figura 114) se configura en una única planta con acceso directo desde el exterior. La zona de estabulación y experimentación se desarrolla en un núcleo compacto distribuido con doble pasillo en el que se integran tanto los vestuarios, como los locales de servicio y la zona de lavado y esterilización. En cambio, tanto la zona de cuarentena como el área de microcirugía se ubican en una zona periférica, por lo que los animales tienen que ser trasladados a través de pasillos comunes a la zona de experimentación de animal grande.

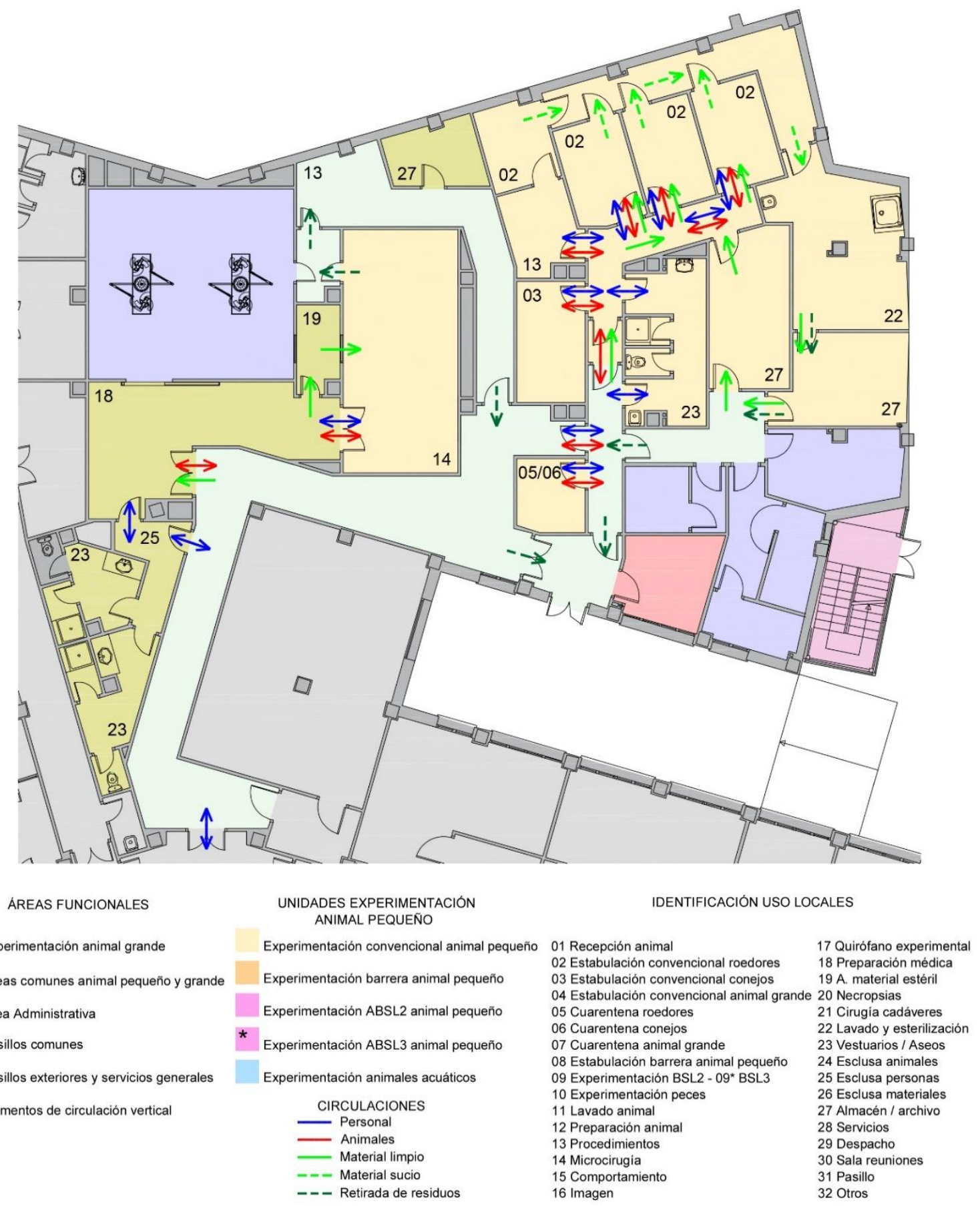

Figura 114. Unidad experimentación convencional animal pequeño i+12 (S/E).

Fuente. Elaboración propia. 
La unidad de experimentación convencional de animal pequeño del instituto liSGM (Figura 115) se distribuye en una única planta. La actividad mayoritaria de esta unidad es el diagnóstico por imagen, de manera que se dispone de dos salas para estabulación convencional de animales integrado en el conjunto del área de estabulación del centro, y una zona destinada a la experimentación en la que los pasillos de circulación son compartidos con el área de experimentación de animal grande.

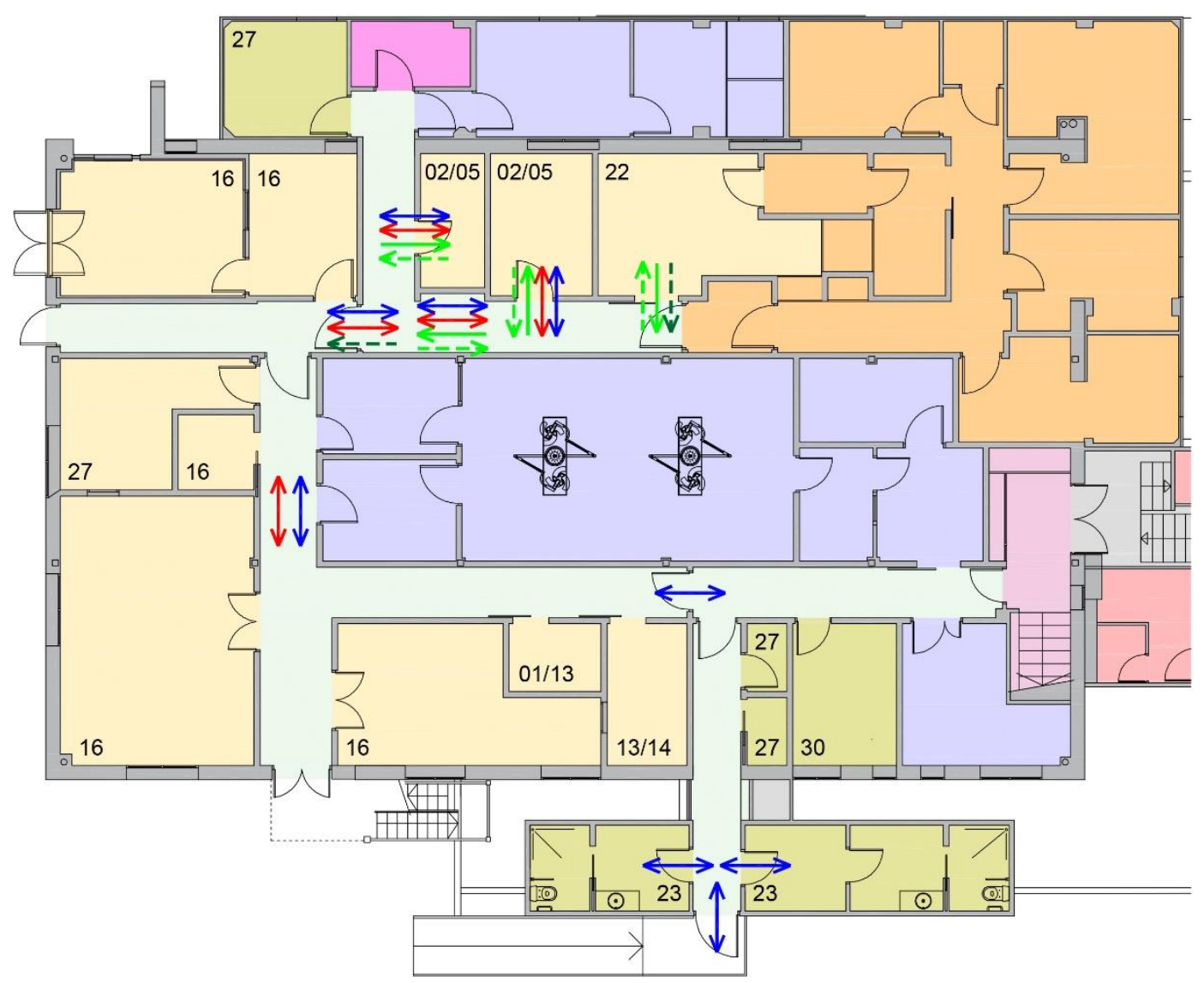

AREAS FUNCIONALES

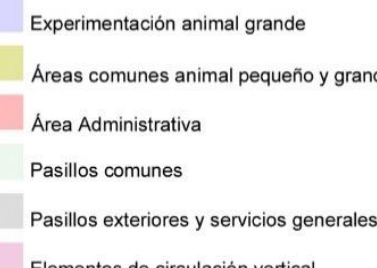

Experimentación animal grande

Áreas comunes animal pequeño y grande

Área Administrativa

illos comunes

Elementos de circulación vertical UNIDADES EXPERIMENTACIÓN
ANIMAL PEQUEÑO

Experimentación convencional animal pequeño 01 Recepción animal

02 Estabulación convencional roedos

03 Estabulación convencional conejos

04 Estabulación conven

05 Cuarentena roedores

06 Cuarentena conejos

07 Cuarentena animal grande

09 Experimentación BSL2 - 09* BSL3

10 Experimentación peces

11 Lavado animal

12 Preparación anima

13 Procedimientos

14 Microcirugia

15 Comportamiento

16 Imagen
17 Quirófano experiment 19 A. material estéril

20 Necropsias

21 Cirugia cadáveres 22 Lavado y esterilización

23 Vestuarios / Aseos

24 Esclusa animales

25 Esclusa personas

26 Esclusa materiales

27 Almacén / archivo

28 Servicios

29 Despacho

30 Sala reuniones

31 Pasillo

Figura 115. Unidad experimentación convencional animal pequeño liSGM (S/E).

Fuente. Elaboración propia. 
La unidad de experimentación convencional de animal pequeño del instituto IRYCIS (Figura 116) se distribuye en una única planta. El área convencional se desarrolla mediante una distribución de doble pasillo en un núcleo en el que se dispone tanto de la zona de estabulación como de experimentación, así como del área de lavado y esterilización. En cambio, en una zona periférica, se distribuyen la zona de cuarentena, así como diversas áreas de experimentación como son el área de microcirugía y sala anecóica. Es en esta zona en la que los pasillos de circulación son compartidos con el animal grande.
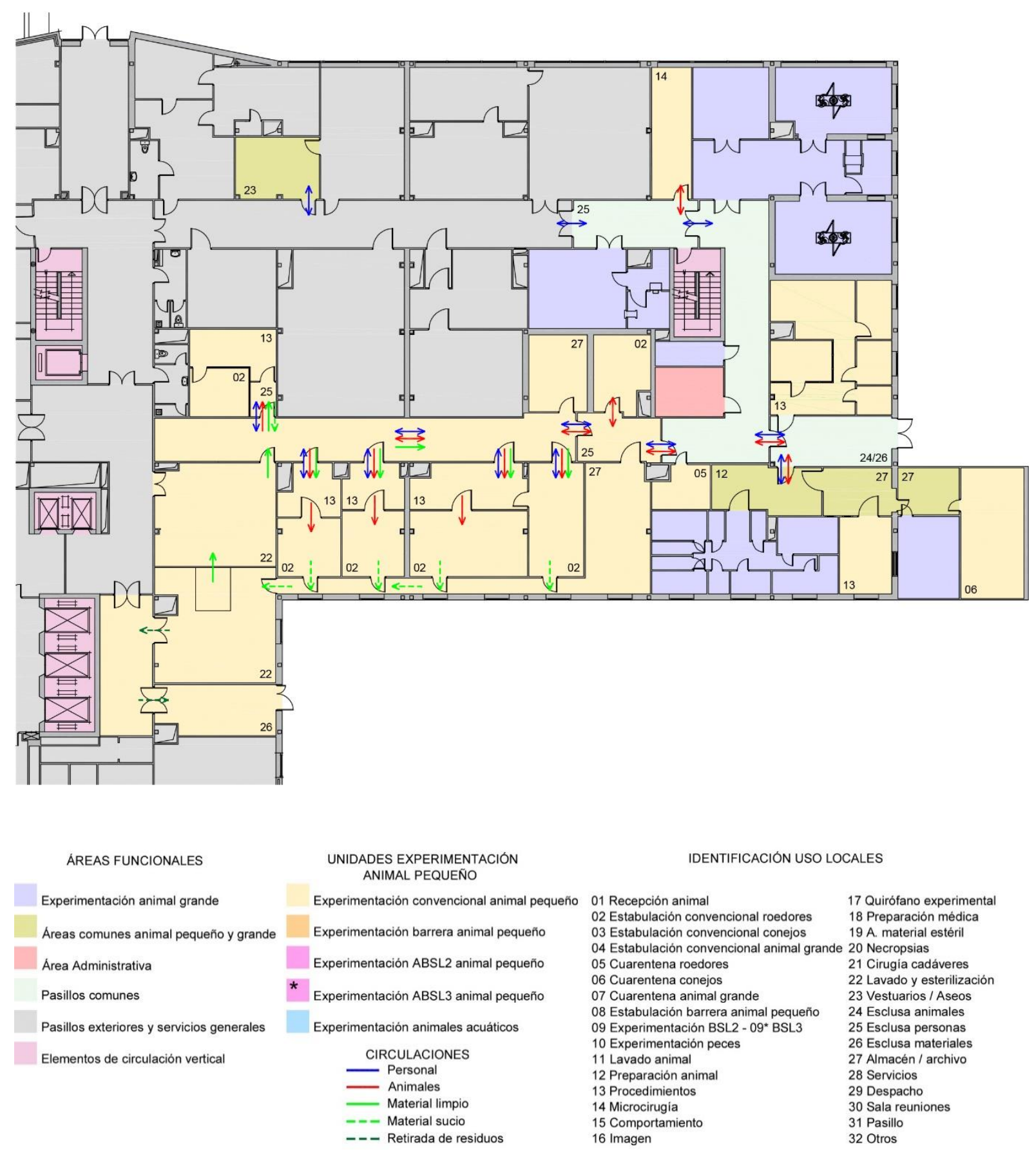

Figura 116. Unidad experimentación convencional animal pequeño IRYCIS (S/E).

Fuente. Elaboración propia. 
La unidad de experimentación convencional de animal pequeño del instituto IISBiodonostia

(Figura117) se desarrolla en una única planta. La zona de estabulación se distribuye en un núcleo compuesto de doble pasillo, uno exterior para el acceso de los animales y otro interior del área de experimentación en el que se integra el área de lavado y esterilización. En cambio, la zona de experimentación dedicada a la microcirugía y comportamiento, se encuentra en una zona exterior, a la que se accede a través de pasillos compartidos con el personal de experimentación de animal grande.

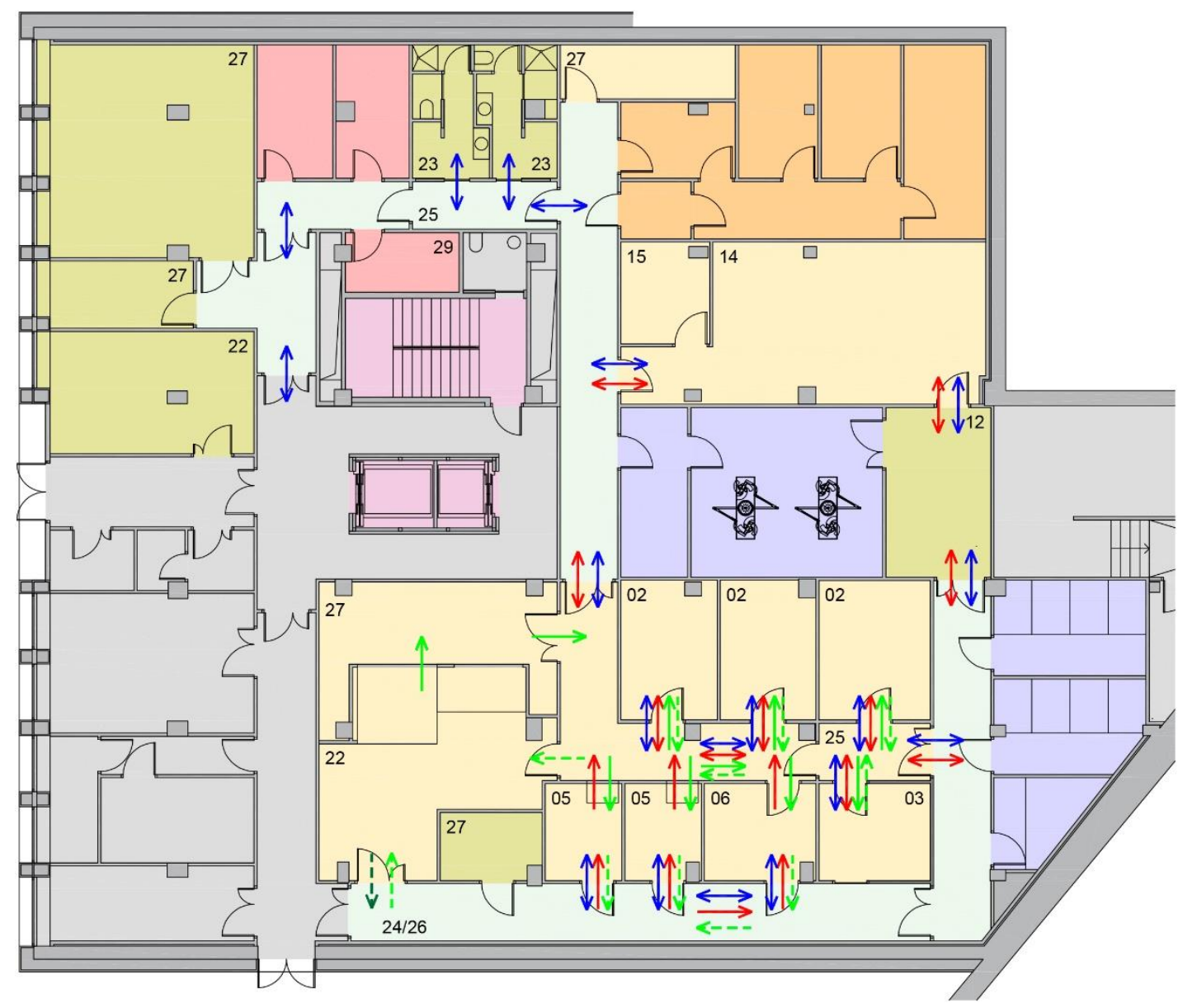

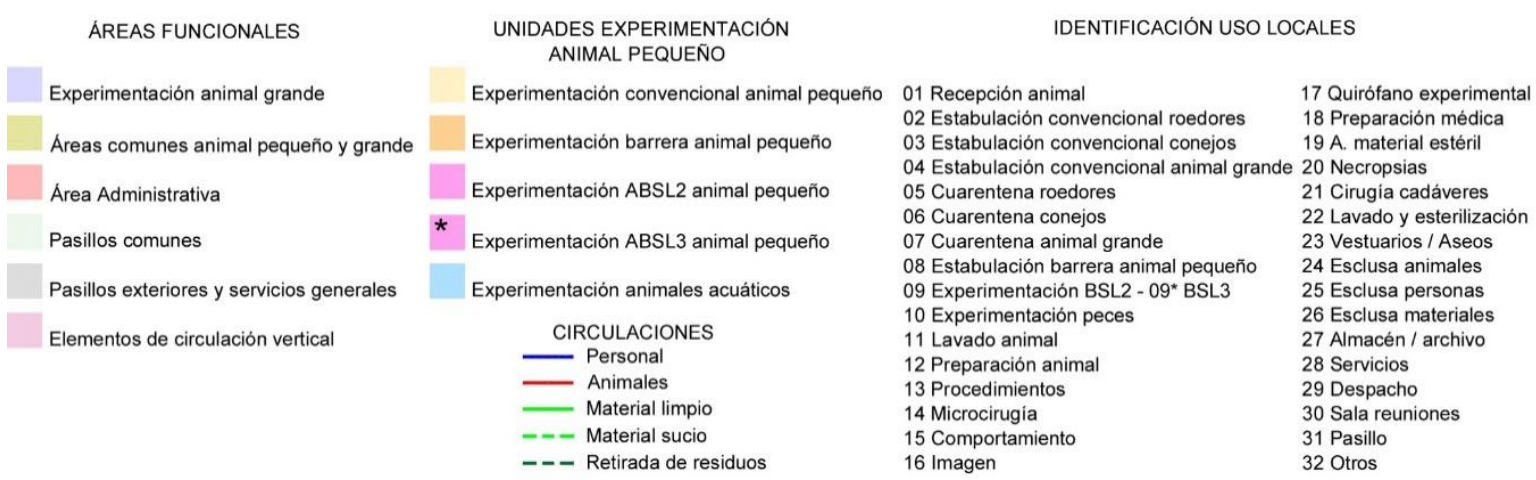

Figura 117. Unida experimentación convencional animal pequeño IIS Biodonostia (S/E).

Fuente. Elaboración propia. 


\section{La unidad de experimentación convencional de animal pequeño del instituto IISBiocruces}

(Figura118) se distribuye en una única planta bajo rasante. Se dispone de un núcleo de vestuarios de acceso directo del personal a la unidad que se desarrolla a través de un único pasillo interior destinado al alojamiento y experimentación con animal convencional, en el que hay un área de procedimientos, microcirugía, y un espacio disponible para un desarrollo futuro de la unidad de imagen. La configuración de pasillo en forma de $U$ planteada permite que los animales y los suministros se introduzcan desde un segundo punto de acceso para a posteriori trasladarlos a la zona de experimentación.

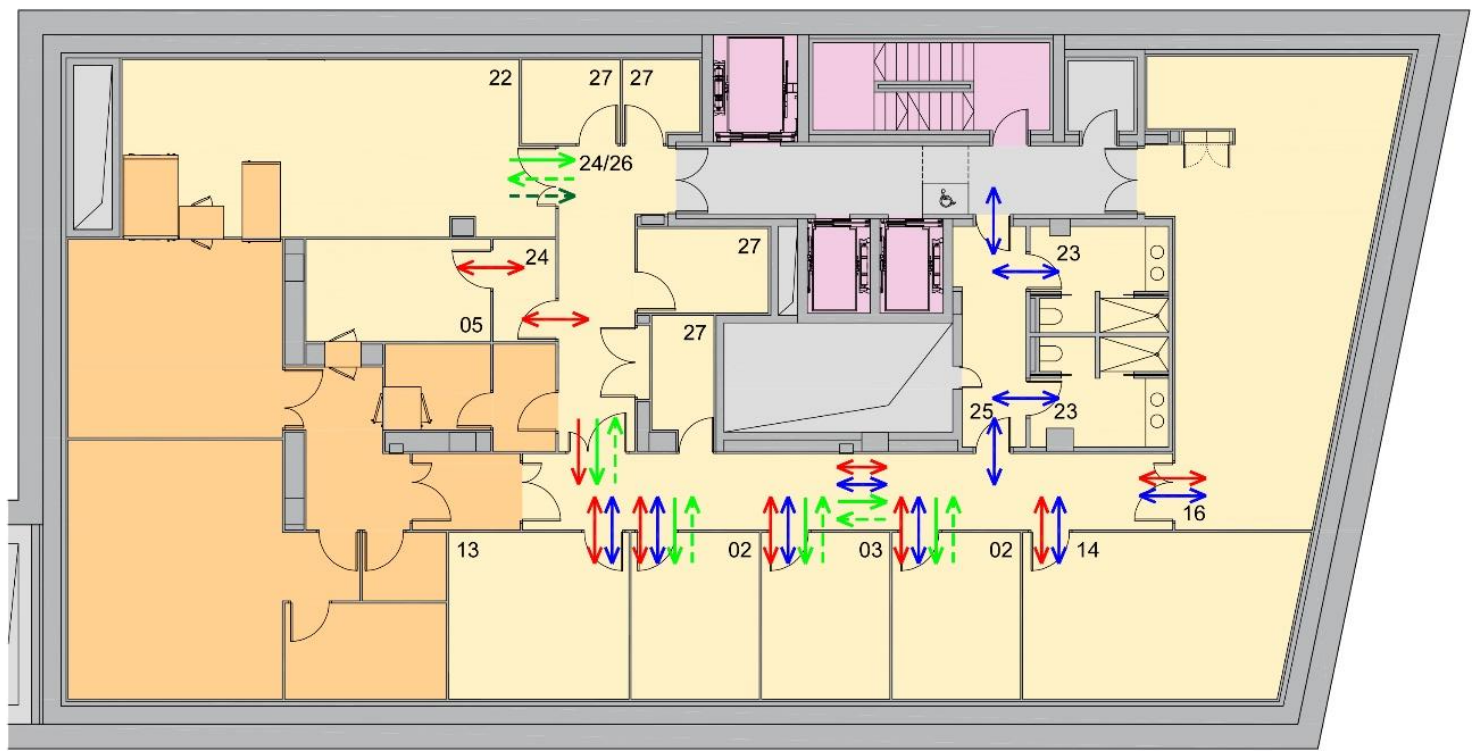

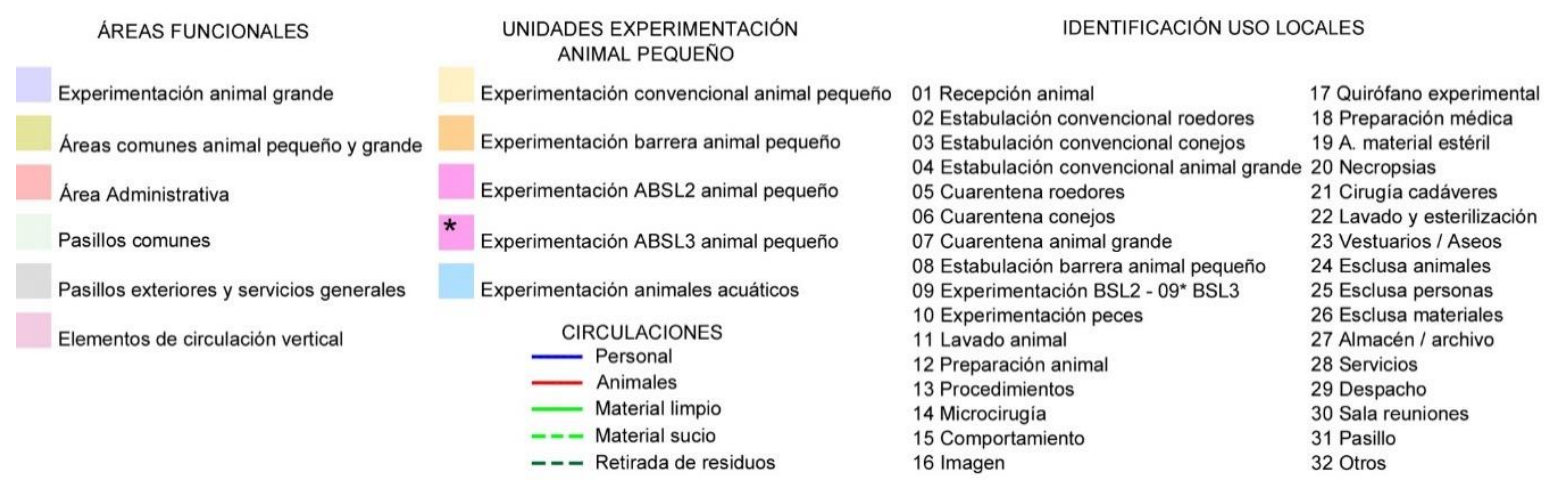

Figura 118. Unidad experimentación convencional animal pequeño IIS Biocruces (S/E).

Fuente. Elaboración propia. 
La unidad de experimentación convencional de animal pequeño del instituto IISA (Figura 119) se distribuye en dos plantas. Por una parte, en la planta semisótano se distribuye el área de microcirugía que se compone también del área de estabulación para roedores y conejos que a su vez está integrado en la zona de estabulación de animal grande. Por la otra, en la planta sótano -1 se desarrolla la zona de experimentación convencional distribuida en forma de espina de pez mediante un pasillo único a través del que se accede tanto a las zonas de estabulación como a las salas de experimentación de procedimientos, área de imagen, microcirugía y comportamiento, a la zona de lavado y esterilización, incluso a las zonas de experimentación ABSL2. Se dispone de una zona de acceso para personal a través de vestuarios de uso exclusivo para esta zona e independizada del acceso de los de animales y suministros.

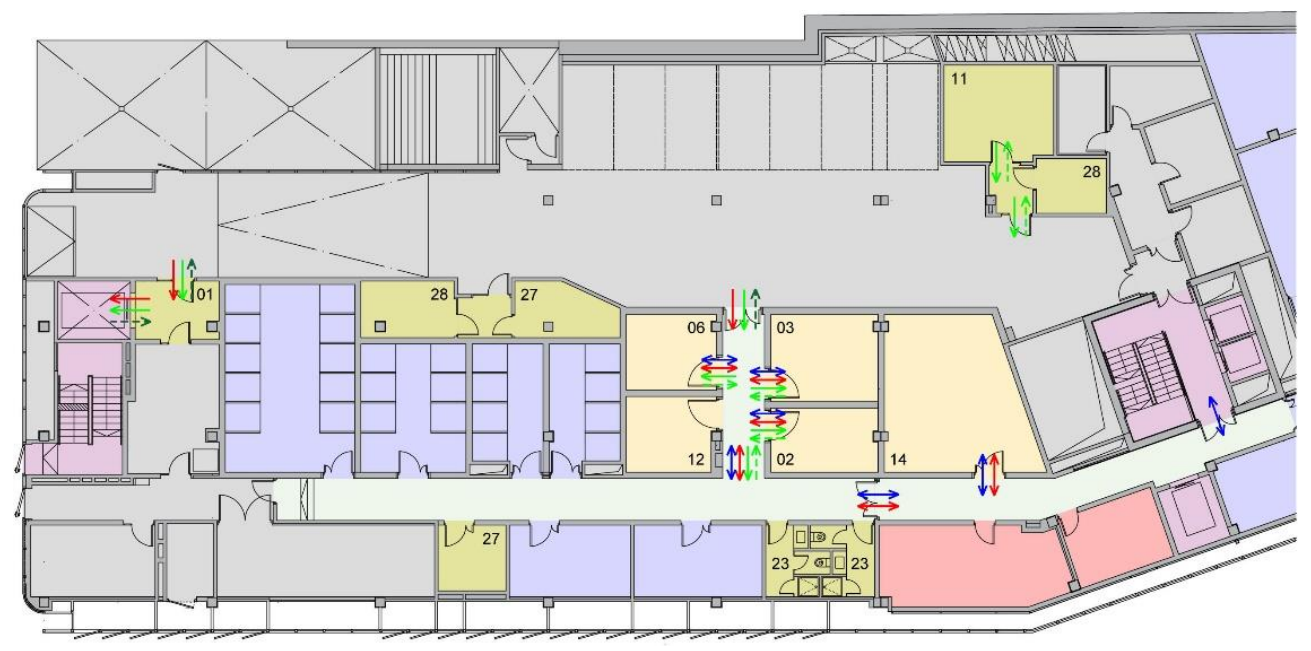

Planta semisótano

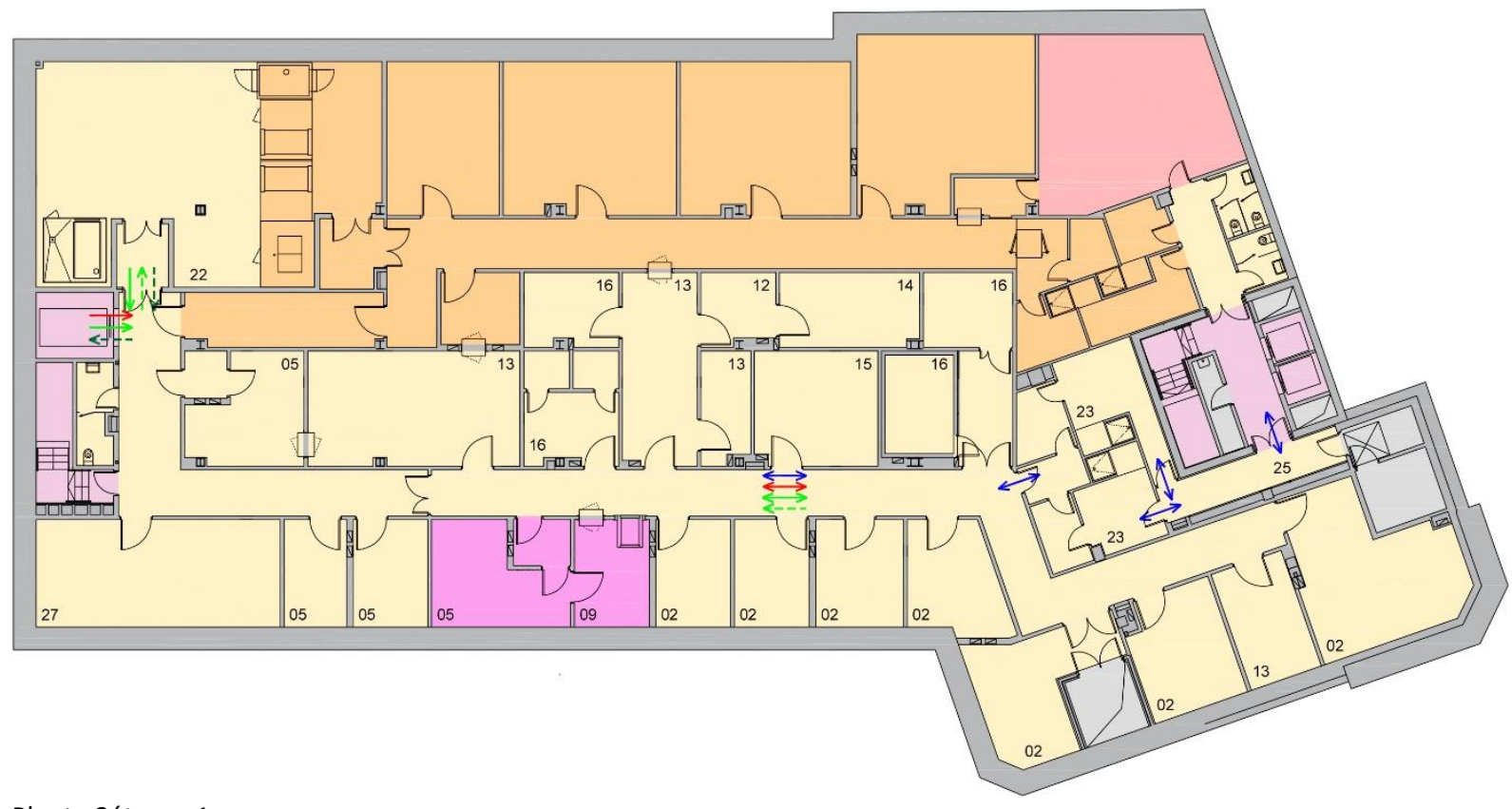

Planta Sótano -1

Figura 119. Unidad de experimentación convencional animal pequeño IISA (S/E).

Fuente. Elaboración propia. 
La unidad de experimentación convencional de animal pequeño del instituto VHIR (Figura 120) se desarrolla en dos plantas bajo rasante. En la planta sótano-1 la distribución se realiza mediante pasillo único y se ubica la zona de cuarentena, la zona de comportamiento, una parte de la unidad de imagen, incluso una zona de experimentación ABSL2. En cambio, en la planta sótano -2 se distribuye mediante una organización de triple pasillo el área de estabulación y procedimientos, el área restante de imagen, otra zona de experimentación ABSL2, incluso la zona de almacenaje de las jaulas desechables.

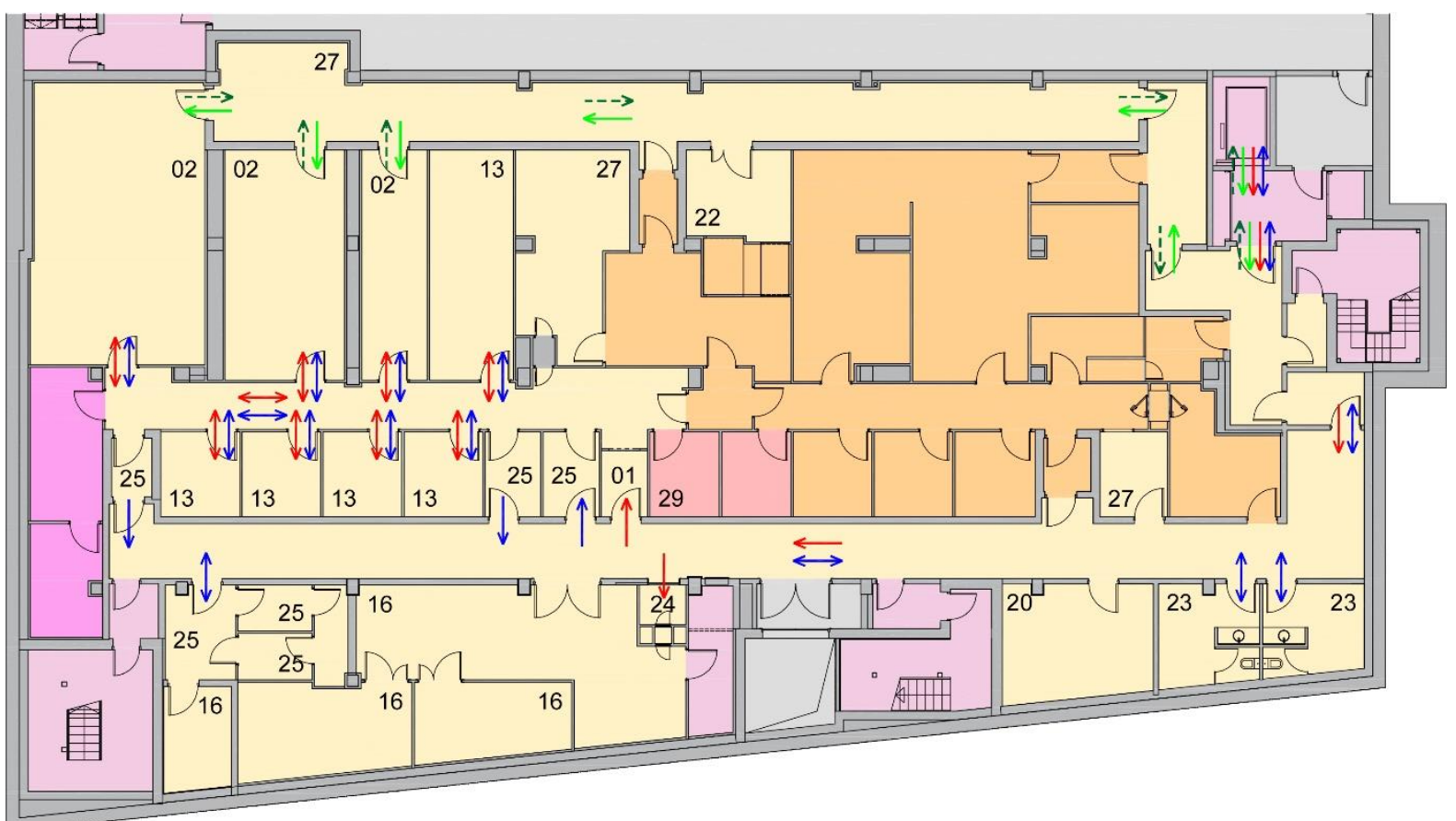

Planta Sótano -2

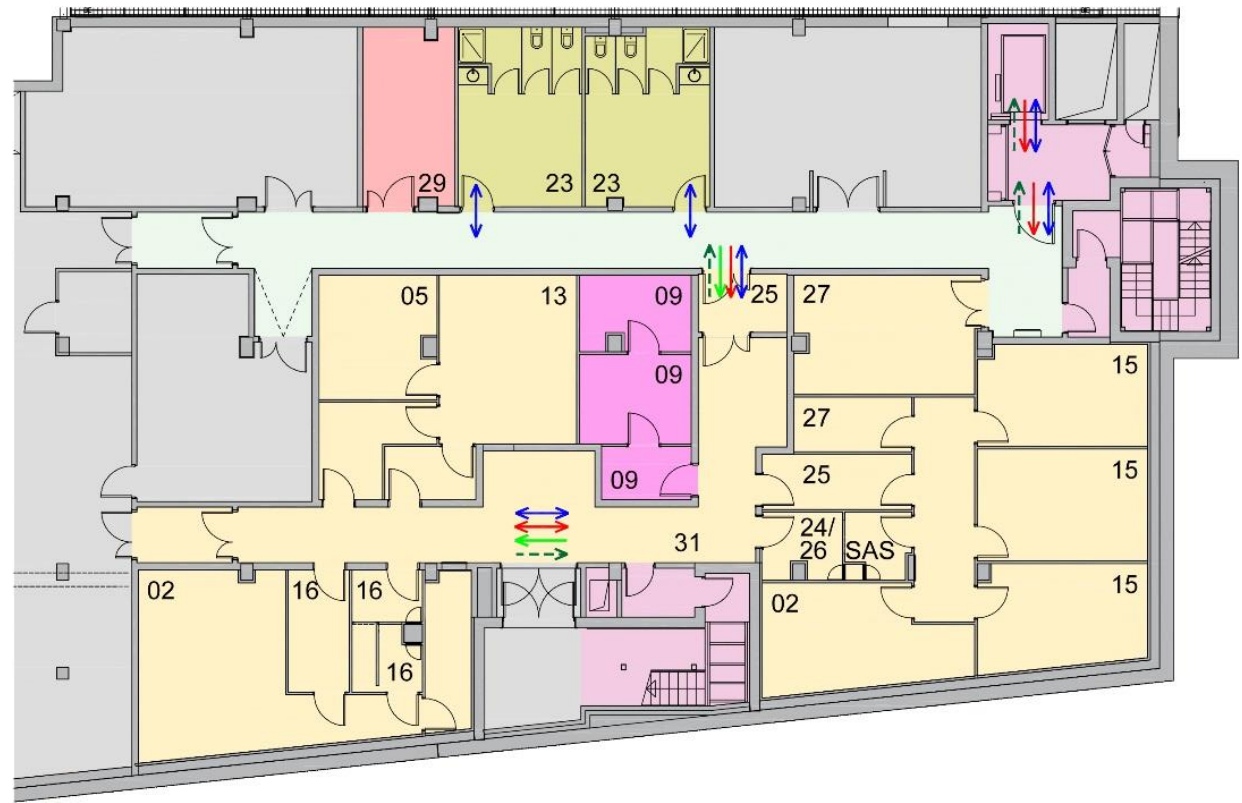

Planta Sótano -1

Figura 120. Unidad experimentación convencional animal pequeño VHIR (S/E).

Fuente. Elaboración propia. 
La unidad de experimentación convencional de animal pequeño del instituto IGTP (Figura 121) se distribuye en una planta semisótano integrada en el conjunto del área de experimentación de animal pequeño, con el que comparte los pasillos de distribución. Está organizada de manera compacta, a través de un único pasillo en forma de "L", lo que permite tener dos accesos diferenciados. En la propia unidad se distribuye tanto la estabulación como las salas de experimentación. En cambio, la sala de lavado y esterilización y los almacenes se sitúan en la planta sótano -1, por lo que existe un desplazamiento vertical de jaulas para su lavado y preparado.
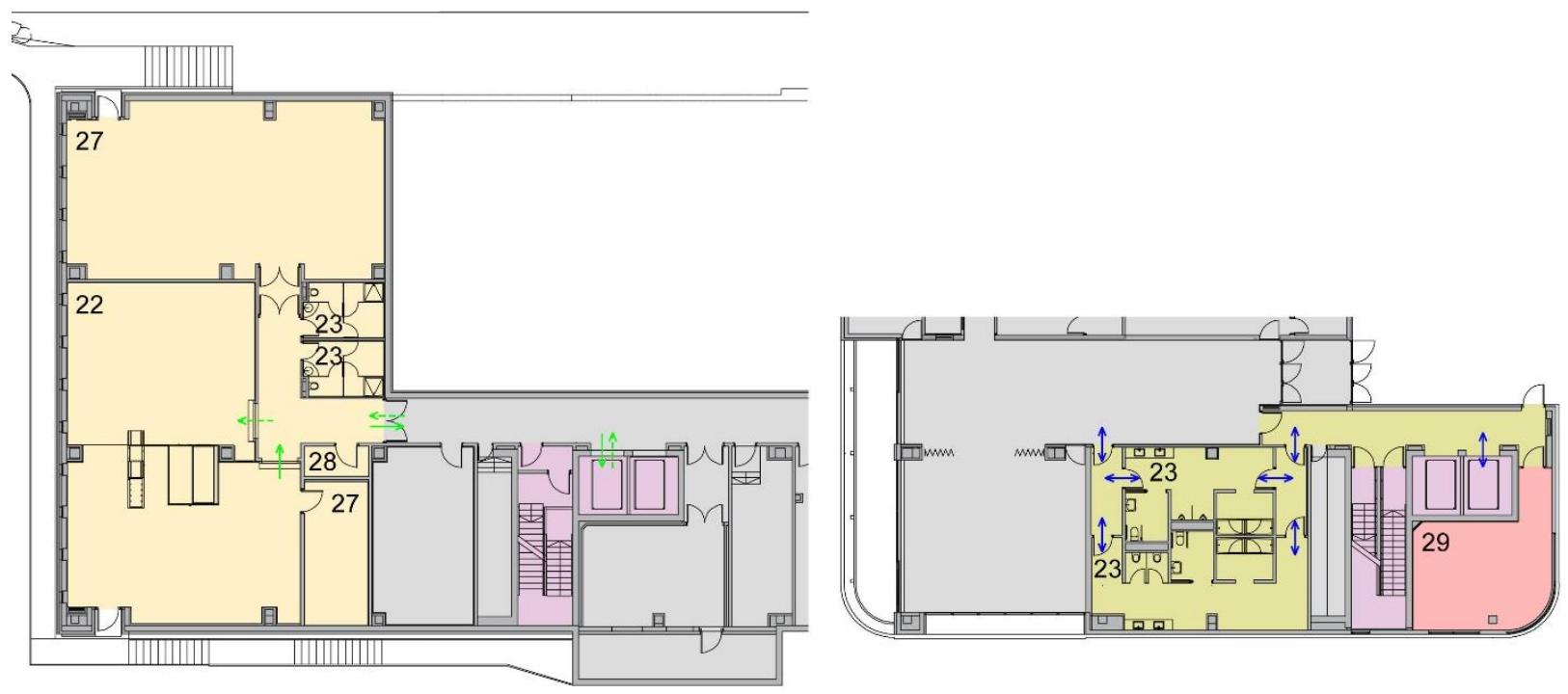

Planta sótano -1
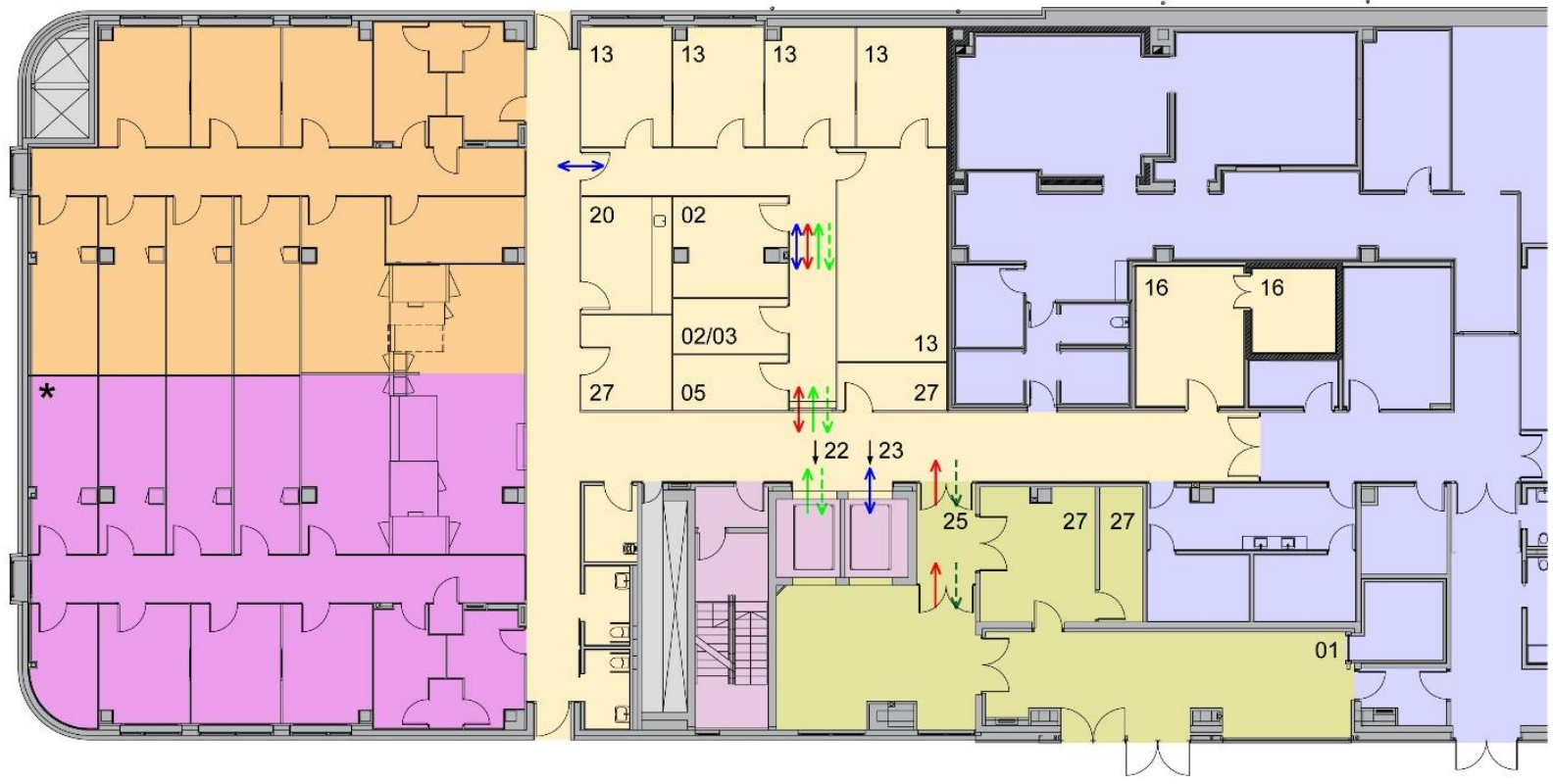

Planta Semisótano

Figura 121. Unidad experimentación convencional animal pequeño IGTP (S/E).

Fuente. Elaboración propia. 
La unidad de experimentación convencional de animal pequeño del instituto IIS La FE (Figura 122) se distribuye en una única planta bajo rasante e integrada en el conjunto del centro de experimentación animal. El sistema de distribución de doble pasillo que disponen las salas de estabulación permite separar la zona de circulación sucia compartida con los animales grandes de otra limpia para uso exclusivo de experimentación con animal pequeño. En esta zona convencional se desarrollan los laboratorios para la realización de procedimientos y microcirugía, así como la zona de experimentación con animales acuáticos.

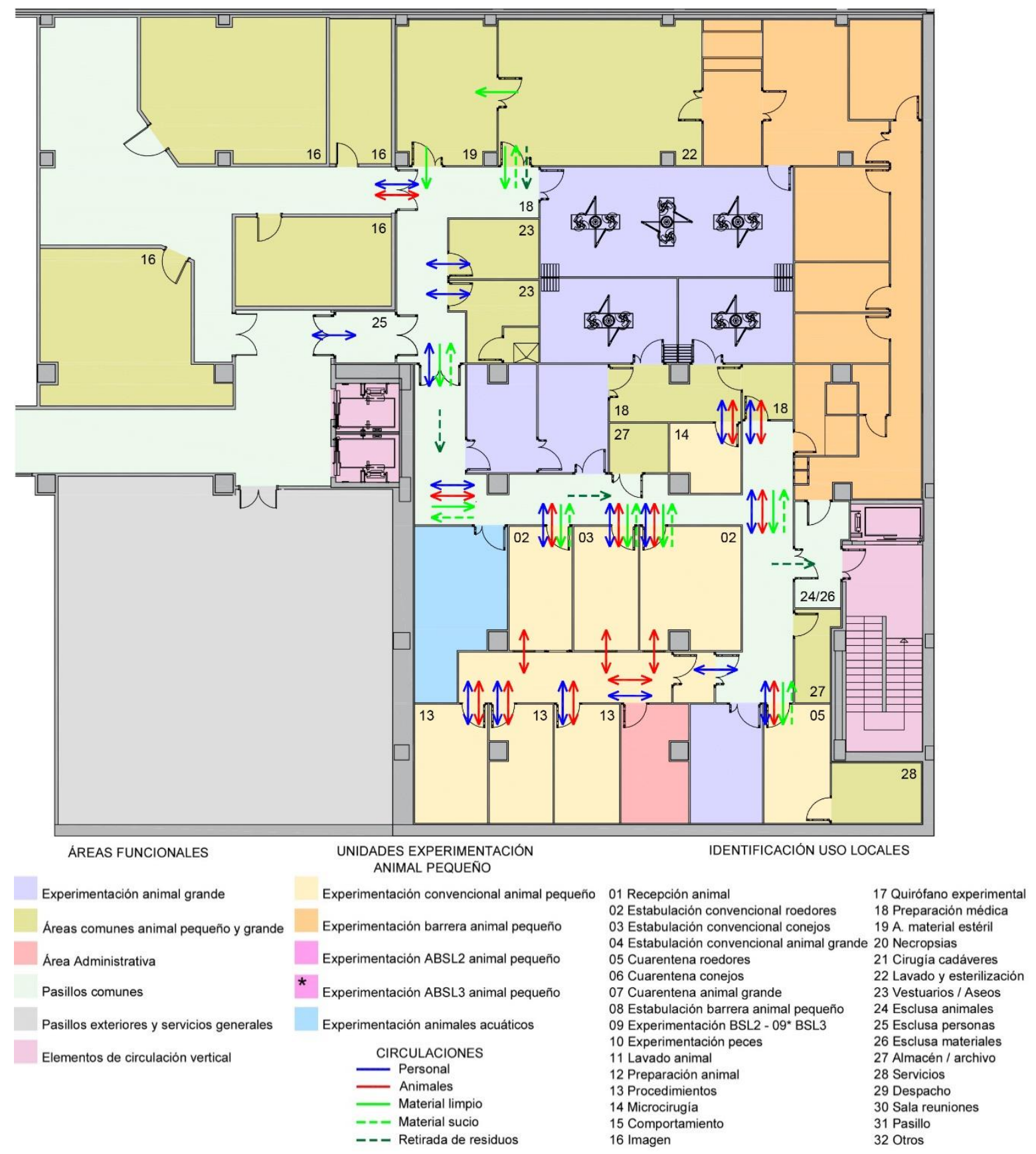

Figura 122. Unidad experimentación convencional animal pequeño IIS La Fe (S/E).

Fuente. Elaboración propia. 


\subsubsection{Características generales de la unidad de experimentación convencional animal pequeño}

El resultado de la investigación sobre las características generales de la unidad de experimentación convencional de animal pequeño se encuentra reflejado tanto en las fichas de la documentación gráfica como en la toma de datos de cada centro.

Para realizar el análisis de dichas características se ha hecho una puesta en común de los resultados obtenidos y, para ello, se ha optado por resumir las más importantes en una tabla (Tabla 14). En ella se listan los parámetros que definen las características generales de la unidad, se establecen cuáles son las características comunes a la mayoría de ellas y se identifica qué institutos cumplen dichas características; además, se determinan las características particulares o específicas, que son aquellas que las cumplen solo unas determinadas unidades de experimentación convencional de animal pequeño, reflejándose así mismo, cuáles son los institutos que las cumplen. El análisis se centra en los siguientes conceptos:

- Las especies animales utilizadas habitualmente en esta área de experimentación, así como los modelos animales usados eventualmente.

- La superficie de alojamiento destinada a la estabulación convencional tanto de roedores como de conejos, así como el número de salas de estabulación incluida las salas de cuarentena.

- El tipo de racks y el tipo de jaulas, así como la elección realizada para proporcionar el agua necesaria a los animales.

- Las salas para experimentación diseñadas y, específicamente, las destinadas a procedimientos, a microcirugía, imagen y comportamiento.

- Sistema de suministro de bebida adoptado para proporcionar a los animales, así como analizar los sistemas diseñados para garantizar el ciclo circadiano de los animales. 
Tabla 14. Características generales unidad experimentación convencional animal pequeño.

\begin{tabular}{|c|c|c|c|c|}
\hline Parámetros & $\begin{array}{l}\text { Características } \\
\text { comunes }\end{array}$ & $\begin{array}{c}\text { Institutos con } \\
\text { características } \\
\text { comunes } \\
\end{array}$ & $\begin{array}{l}\text { Características } \\
\text { específicas }\end{array}$ & $\begin{array}{l}\text { Institutos con } \\
\text { características } \\
\text { específicas }\end{array}$ \\
\hline $\begin{array}{l}\text { Superficie área } \\
\text { experimentación } \\
\text { convencional } \\
\text { animal pequeño }\end{array}$ & $500-1.000 \mathrm{~m}^{2}$ & $\begin{array}{l}\text { IRYCIS, IISBiodonostia, } \\
\text { IISBiocruces, IISLa Fe }\end{array}$ & $\begin{array}{l}<500 \mathrm{~m} 2 \\
>1.000 \mathrm{~m} 2\end{array}$ & $\begin{array}{l}\text { IdiPAZ, i+12, IISGM } \\
\text { IISA, VHIR, IGTP }\end{array}$ \\
\hline $\begin{array}{l}\text { Superficie área } \\
\text { estabulación } \\
\text { convencional } \\
\text { animal pequeño }\end{array}$ & $<100 \mathrm{~m}^{2}$ & $\begin{array}{l}\text { i+12, liSGM, } \\
\text { IISBiodonostia, } \\
\text { IISBiocruces, IGTP, } \\
\text { IISLaFe }\end{array}$ & $\begin{array}{l}100-200 \mathrm{~m}^{2} \\
>200 \mathrm{~m}^{2}\end{array}$ & $\begin{array}{l}\text { IdiPAZ, IRYCIS } \\
\text { VHIR, IISA }\end{array}$ \\
\hline Especies animales & Rata, ratón & $\begin{array}{l}\text { IdiPAZ, i+12, IiSGM, } \\
\text { IRYCIS, IISBiodonostia, } \\
\text { IISBiocruces, IISA, } \\
\text { VHIR, IGTP, IIS La Fe }\end{array}$ & $\begin{array}{l}\text { Conejo } \\
\text { Otros }\end{array}$ & $\begin{array}{l}\text { IdiPAZ, i+12, IRYCIS, } \\
\text { IISBiodonostia, } \\
\text { IISBiocruces, IISA, } \\
\text { VHIR, IGTP, IISLaFe } \\
\text { IdiPAZ, i+12, IRYCIS, } \\
\text { IISBiodonostia }\end{array}$ \\
\hline $\begin{array}{l}\text { № salas de } \\
\text { alojamiento roedores }\end{array}$ & $\leq 5 \cup d$ & $\begin{array}{l}\text { i+12, liSGM, } \\
\text { IISBiodonostia, } \\
\text { IISBiocruces, IGTP, } \\
\text { IISLaFe }\end{array}$ & $>5 \mathrm{Ud}$ & $\begin{array}{l}\text { IdiPAZ, IRYCIS, IISA, } \\
\text { VHIR }\end{array}$ \\
\hline $\begin{array}{l}\text { № salas de } \\
\text { alojamiento conejos }\end{array}$ & $1 \cup d$ & $\begin{array}{l}\text { IdiPAZ, i+12, IRYCIS, } \\
\text { IISBiocruces, IISLaFe }\end{array}$ & $>1 \mathrm{Ud}$ & IISBiodonostia, IISA \\
\hline $\begin{array}{l}\text { Conejos estabulados } \\
\text { con animal pequeño }\end{array}$ & SI & $\begin{array}{l}\text { i+12, IISBiodonostia, } \\
\text { IISBiocruces, IISA, IIS La } \\
\text { Fe }\end{array}$ & NO & IdiPAZ, IRYCIS \\
\hline \multirow{2}{*}{ Tipo de jaula } & Reutilizable & $\begin{array}{l}\text { IdiPAZ, i+12, liSGM, } \\
\text { IRYCIS, IISBiodonostia, } \\
\text { IISBiocruces, IISA, } \\
\text { IGTP, IISLa Fe }\end{array}$ & Desechable & VHIR \\
\hline & $\begin{array}{l}\text { Estática+ } \\
\text { Ventilada individualmente }\end{array}$ & $\begin{array}{l}\text { IdiPAZ, i+12, IRYCIS, } \\
\text { IISBiodonostia, } \\
\text { IISBiocruces, IISA, } \\
\text { IGTP, IISLaFe }\end{array}$ & Ventilada individualmente & IISGM, VHIR \\
\hline $\begin{array}{l}\text { Suministro } \\
\text { de bebida }\end{array}$ & Biberones & $\begin{array}{l}\text { IdiPAZ, i+12, IiSGM, , } \\
\text { IISBiodonostia, } \\
\text { IISBiocruces, VHIR, } \\
\text { IGTP, IISA, IISLa Fe }\end{array}$ & Automático+Biberones & IRYCIS \\
\hline Salas Procedimientos & SI & $\begin{array}{l}\text { IdiPAZ, i+12, IiSGM, } \\
\text { IRYCIS, IISBiodonostia, } \\
\text { IISBiocruces, IISA, } \\
\text { VHIR, IGTP, IISLa Fe }\end{array}$ & & \\
\hline Área Microcirugía & $\mathrm{SI}$ & $\begin{array}{l}\text { IdiPAZ, i+12, IiSGM, } \\
\text { IRYCIS, IISBiodonostia, } \\
\text { IISBiocruces, IISA, } \\
\text { VHIR, IGTP, IISLa Fe }\end{array}$ & & \\
\hline Área Imagen & SI & $\begin{array}{l}\text { liSGM, IRYCIS, } \\
\text { IISBiocruces, IISA, } \\
\text { VHIR, IGTP, IISLa Fe }\end{array}$ & & \\
\hline $\begin{array}{l}\text { Área } \\
\text { Comportamiento }\end{array}$ & SI & $\begin{array}{l}\text { IISBiodonostia, IISA, } \\
\text { VHIR }\end{array}$ & & \\
\hline
\end{tabular}

Fuente. Elaboración propia.

\section{Dimensionamiento área estabulacion convencional}

La superficie destinada a este tipo de experimentación es muy variable, si bien lo habitual es que se sitúe en un rango comprendido entre los 500-1.000 $\mathrm{m}^{2}$. Analizando el dimensionamiento de la superficie global destinada a la estabulación convencional de animal pequeño, observamos también 
gran variedad. Para el cómputo de esta superficie se ha considerado la superficie de estabulación de la zona de cuarentena, la superfice destinada al alojamiento de roedores convencional, así como la superficie destinada al alojamiento de los conejos. Debido a la variedad de los resultados obtenidos, los institutos los hemos agrupado en función de un rango de superficies. De esta manera observamos cómo la mayoría de los centros destinan una superficie inferior a $100 \mathrm{~m}^{2}$ al área de estabulación convencional de animal pequeño (i+12, IiSGM, IISBiodonostia, IISBiocruces, IGTP, IISLaFe). Como casos especiales podemos mencionar el IISA y el VHIR, ya que disponen de una superficie superior a los 200 $\mathrm{m}^{2}$, mientras que en el resto de los institutos el área está comprendida entre los $100-200 \mathrm{~m}^{2}$.

\section{Especies animales}

Los animales para ser utilizados en procedimientos experimentales deben ser criados para tal fin, debiendo proceder de establecimientos registrados y autorizados; si bien se pueden conceder permisos excepcionales científicamente justificados (RD 53/2013). Cada especie animal tiene sus características propias, por lo que el criterio de selección de la especie vendrá determidado por el tipo de experimentación que se quiera llevar a cabo.

Las especies animales habitualmente utilizadas en todos los centros de experimentación convencional de animal pequeño son el ratón y la rata. El ratón es el modelo animal más utilizado en experimentación animal y se selecciona para muchos tipos de estudios porque presenta características muy interesantes debido a la amplia variedad de cepas y modelos de ratones disponibles, su pequeño tamaño, su vida útil relativamente corta y por su corto tiempo de generación (CCAC Mice Subcommittee 2019, p. 6).

Aparte de estos modelos animales, observamos algunos centros (IdiPAZ, i+12, IRYCIS, IISBiodonostia) en los que eventualmente también se utilizan otras especies animales, tales como, la cobaya, el jerbo o el hámster.

Por otra parte, observamos cómo el conejo también es un modelo animal muy utilizado en experimentación animal, ya que se utiliza en la mayoría de los centros estudiados (IdiPAZ, i+12, IRYCIS, IISBiodonostia, IISBiocruces, IISA, VHIR, IISLaFe). Esta especie animal está en una categoría entre los animales pequeños y grandes, ya que se considera animal grande debido a que los requisitos para la cirugía siguen las directrices de animales grandes; sin embargo, como hemos visto en este estudio, en la mayoría de los casos, los conejos se alojan en el área de experimentación convencional de animal pequeño junto a las salas de estabulación de los roedores (i+12, IISBiodonostia, IISBiocruces, IISA, IIS La Fe). 
La distribución de la superficie destinada a la estabulación es muy variable, de manera que nos encontramos desde centros que disponen de únicamente dos salas de estabulación para roedores hasta centros con un total de 11 salas, incluidas las destinadas a la cuarentena de los animales, si bien lo habitual es que los centros dispongan de cinco salas o menos ( $i+12$, liSGM, IISBiodonostia, IISBiocruces, IGTP, IISLaFe). En cambio, para el alojamiento de los conejos lo habitual es que exista un único local o como máximo dos. En los casos en los que existe un único local para estabulación de estos animales, observamos que la zona de cuarentena para roedores es compartida también con los logomorfos.

Se ha decidido no analizar el dimensionamiento de las salas de alojamiento, ya que como veremos más adelante depende de múltiples factores como son el tipo y número de especies animales y el sistema de jaulas de alojamiento, entre otros, conceptos muy variables que habitualmente son determinados por los responsables del centro.

\section{Tipo de jaula}

Las jaulas donde se van a alojar los roedores deben satisfacer las necesidades fisiológicas y etológicas básicas de descanso, de hacinamiento, de exploración, de ocultación, de búsqueda de comida, para roer, de interacción social, de fabricación de nidos, de cavar y de apartarse del grupo. Es importante proporcionar un lecho realizado a base de viruta de madera de pequeño calibre, pedacitos de celulosa y tiras de papel de filtro, para garantizar el bienestar de los animales debido a que satisface varias necesidades de comportamiento y permite al individuo que delimite su propio micro-ambiente. Además, es fundamental proporcionar material de anidamiento porque a los ratones les motiva mucho utilizarlo y hacer nidos, no solo durante la cría, sino también para regular la temperatura y los niveles de luz y porque les permite esconderse y aislarse de los demás miembros del grupo. Por otra parte, se recomienda el suministro de complementos en las jaulas, tales como, particiones, barreras, refugios o cobijos ya que incrementa el abanico de comportamientos, permitiendo que se utilicen distintas áreas para diferentes comportamientos (Laboratory animals 32 1998, p. 233-259).

El dimensionamiento mínimo de las jaulas para cada especie animal viene determindo en el RD53/2013. Como ejemplo hemos tomado las directrices establecidas para los ratones (Figura123). En la figura observamos cómo la dimensión mínima del recinto de las jaulas viene determinado en función del peso corporal y la superficie de suelo mínima asignada a cada animal; y cómo también, se determina la altura mínima del recinto.

La selección del tipo de jaula más adecuada para las necesidades de la experimentación y bienestar animal suele ser una decisión tomada conjuntamente entre los responsables del centro, el personal a 
cargo del cuidado del bienestar animal y los investigadores. En general, los roedores prefieren alojarse en jaulas estáticas y se ha demostrado que en las jaulas ventiladas individualmente sufren estrés por frío y que pueden tener un impacto en la reproducibilidad de los datos de experimentación (CCAC Mice Subcommittee 2019, p. 12).

Cuadro 1.1. Ratonnes

\begin{tabular}{|c|c|c|c|c|}
\hline & $\begin{array}{l}\text { Peso corporal } \\
\text { (g) }\end{array}$ & $\begin{array}{l}\text { Dimensión mínima } \\
\text { del recinto } \\
(\mathrm{cm} 2)\end{array}$ & $\begin{array}{l}\text { Superficie } \\
\text { del suelo } \\
\text { por animal } \\
(\mathrm{cm} 2)\end{array}$ & $\begin{array}{l}\text { Altura } \\
\text { Mínima } \\
\text { del recinto } \\
\text { (cm) }\end{array}$ \\
\hline $\begin{array}{l}\text { En reserva y } \\
\text { durante los } \\
\text { procedimientos }\end{array}$ & $\begin{array}{l}\text { Hasta } 20 . \\
\text { De más de } 20 \text { a } 25 . \\
\text { De más de } 25 \text { a } 30 . \\
\text { Más de } 30 .\end{array}$ & $\begin{array}{l}330 \\
330 \\
330 \\
330 \\
\end{array}$ & $\begin{array}{l}60 \\
70 \\
80 \\
100 \\
\end{array}$ & $\begin{array}{l}12 \\
12 \\
12 \\
12 \\
\end{array}$ \\
\hline Reproducción & & $\begin{array}{l}330 \\
\text { Para una pareja } \\
\text { monógama (no } \\
\text { consanguínea / } \\
\text { consanguínea) o un trío } \\
\text { (consanguíneo). } \\
\text { Por cada hembra } \\
\text { suplementaria y su } \\
\text { camada deben añadirse } \\
\text { otros } 180 \mathrm{~cm} 2 \text {. }\end{array}$ & & 12 \\
\hline $\begin{array}{l}\text { En reserva en } \\
\text { criadores*. }\end{array}$ & & 950 & 40 & 12 \\
\hline $\begin{array}{l}\text { En reserva en } \\
\text { criadores*. }\end{array}$ & & 1.500 & 30 & 12 \\
\hline
\end{tabular}

* Los ratones destetados, y hasta su expedición, y siempre que su peso sea inferior a 20 gramos, y el recinto tenga una superficie mínima de $950 \mathrm{~cm} 2$ pueden mantenerse a una densidad de hasta $40 \mathrm{~cm} 2 /$ animal, o de $30 \mathrm{~cm} 2 /$ animal si la superficie del recinto es de al menos $1500 \mathrm{~cm} 2$. Tampoco podrán mantenerse a estas densidades más elevadas si se produce alguna merma de bienestar, como por ejemplo, mayor agresividad, morbilidad o mortalidad, estereotipias, otras anomalías de comportamiento, pérdida de peso u otras respuestas fisiológicas o conductuales al estrés.

Figura 123. Dimensiones mínimas jaula para ratones.

Fuente. RD 53/2013 Anexo II Sección B.

El tipo de jaula utilizado para los roedores en este tipo de instalaciones no es un criterio unificado. Observamos que los conejos se alojan en todos los casos en jaulas estáticas (Figura 124); en cambio, en el caso del alojamiento de los roedores, si bien hay centros en los que se ha apostado por el empleo de solo jaulas ventiladas individualmente en toda la instalación, tanto en la zona de cuarentena como en todas las salas de alojamiento convencional (IISGM, VHIR), en la mayoría de los centros existe una combinación del uso de las jaulas estáticas y jaulas ventiladas individualmente.

En los casos en los que existe la combinación de jaulas, no existe un único criterio de distribución de las mismas, de manera que podemos encontrar casos (IIS Biodonostia) en el que la sala de cuarentena de roedores dispone de jaulas estáticas, mientras que las salas de alojamiento disponen de jaulas ventiladas individualmente. Justo el caso contrario nos encontramos en el (IIS Biocruces) en el que si bien las salas de alojamiento convencional tienen jaulas estáticas, la sala de cuarentena dispone de jaulas autoventiladas. En el resto de los casos se observa cómo en general se disponen jaulas estáticas, y solo en alguna sala de alojamiento específica se han instalado jaulas ventiladas individualmente. 


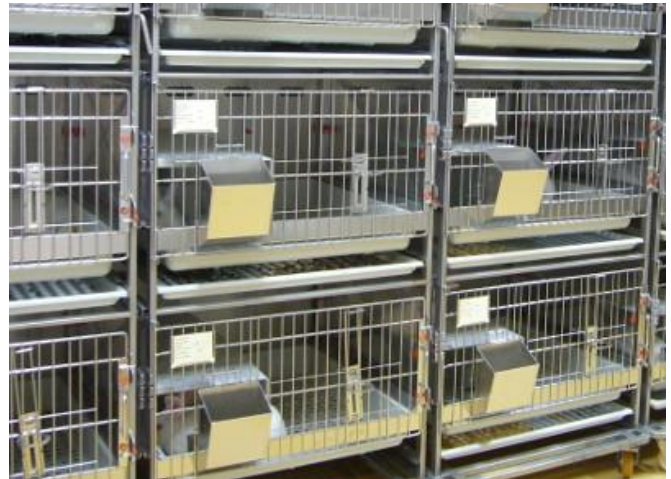

Figura 124. Jaulas estáticas para conejos y roedores. Fuente. Elaboración propia.

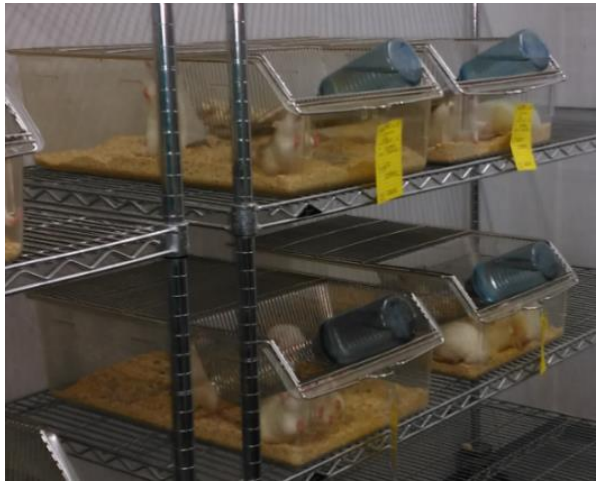

El planteamiento más básico para proporcionar alojamiento en barrera a los roedores es utilizar una sala convencial en la que se utilizan jaulas ventiladas individualmente y cabinas de flujo laminar (Figura125) para el cambio de jaulas que sirven como barrera primaria. La ventaja de las jaulas ventiladas es que generan un microambiente independiente en cada jaula, que permite proteger a los animales de enfermedades, ya que proporcionan una ventilación controlada individualmente filtrando el aire de la sala en la que se alojan, que puede ajustarse a presión negativa o positiva según las necesidades, y que además reducen la exposición humana a alérgenos. De forma adicional, la sala de estabulación donde se alojan se puede diseñar en sobrepresión con respecto al pasillo formando una barrera secundaria. Para que este planteamiento sea eficiente es necesario que el personal esté entrenado en el manejo y uso de este tipo de instalaciones, así como en los procedimientos a seguir para el cambio de jaulas. En los casos que se ha implantado este sistema, los responsables consideran una buena solución, ya que supone un gasto controlado de la instalación.
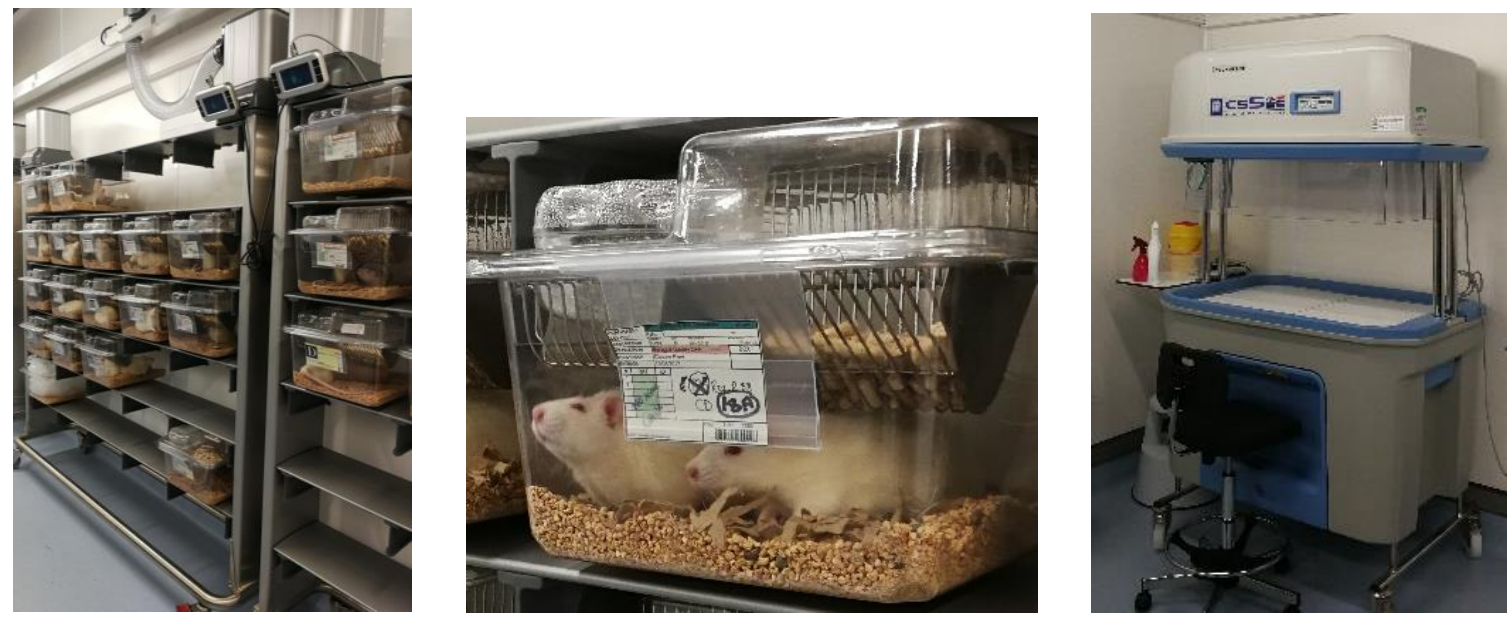

Figura 125. Jaulas ventiladas individualmente, desechables y cabina de cambio. Fuente. Elaboración propia.

Las jaulas deben permitir la observación diaria de los animales con una perturbación mínima. En este sentido, se observa que las jaulas utilizadas en todas las unidades de experimentación convencional 
son de plástico transparente, lo que permite una observación directa de los animales desde el exterior. Además, lo habitual es que las jaulas sean del tipo reutilizable, de manera que una vez vaciadas, lavadas y esterilizadas se vuelvan a utilizar en la instalación. Encontramos un único caso en el que las jaulas son desechables (VHIR), por lo que una vez utilizadas son retiradas del centro y los animales se alojan en unas nuevas. Esta instalación está dimensionada para una capacidad total de 6.000 jaulas, $y$, en estas circunstancias, es una solución muy competitiva a nivel de funcionamiento de centro, ya que supone una menor inversión tanto en equipos de lavado y esterilización, como en su mantenimiento, incluso del personal responsable del lavado de las mismas.

\section{Suministro de alimento y bebida}

Los animales deben tener acceso a alimento y bebida en todo momento, por lo que el suministro debe ser fácilmente accesible para ellos. El alimento normalmente se suministra en los comederos de la jaula; para la bebida, en cambio, se puede suministrar en biberones o de manera automática.

El sistema de suministro de bebida empleado en la mayoría de los institutos es a base de biberones, solución que permite convertir fácilmente una sala cualquiera en una sala de alojamiento, y quizás un mayor control sobre el tipo de agua suministrado; por el contrario, genera una tarea adicional en la preparación de los biberones que el suministro automático no conlleva. Esta misma solución de suministro a base de biberones la encontramos también en los dos grandes centros de experimentación visitados (PRBB, CNIO). Como caso particular observamos un instituto (IRYCIS) en el que hay un planteamiento mixto, pues en algunas salas la bebida se suministra de mantera automática, mientras que en otras se realiza a base de biberones. Esta última solución también la encontramos en otros de los centros visitados (IDIBELL, CIC BioGUNE).

\section{Salas de experimentación}

En general, es recomendable diseñar una sala de procedimientos cada tres o cuatro salas de estabulación de animal pequeño (Division of technical resources 2012, p. 2-60). En todos los centros nos encontramos con salas de procedimientos que sirven para realizar tareas varias, incluso para realizar las necropsias en los casos en los que no existe una zona específica para el desarrollo de esa tarea, y vemos cómo este rango se cumple en todos ellos.

Por otra parte, observamos que el área de microcirugía, destinada a realizar prácticas quirúrgicas con roedores, nos la encontramos en todos los institutos, si bien en la parte de experimentación de animal pequeño del VHIR que estudiamos, esta área específica no se contempla. Una de las áreas que cada vez está adquiriendo mayor importancia en la experimentación con roedores es el área de imagen. En este sentido, el IISBiocruces dispone de un área reservada para la implantación futura de la unidad de 
imagen, mientras que los centros (IISGM, IISA, VHIR, IGTP, IISLa Fe) disponen de infraestructuras destinadas a la experimentación de diagnóstico por imagen. Otra de la áreas de experimentación específica que nos encontramos en los institutos es el área de comportamiento (IISBiodonostia, IISA, VHIR).

En este tipo de instalaciones, lo habitual es que los residuos animales se almacenen en frigoríficos que se ubican en las propias salas de experimentación, o bien en la sala de residuos animal de todo el centro de experimentación. 


\subsubsection{Criterio organizativo de la unidad de experimentación convencional animal pequeño}

Como criterio general, la unidad de experimentación convencional de animal pequeño debe estar diseñada para independizar los accesos del personal responsable al cuidado de los animales y los investigadores, de los animales, suministros y retirada de residuos, además de permitir la circulación desde la zona limpia de la instalación a la sucia para evitar al máximo la contaminación cruzada. En el caso de los roedores, además de tener en cuenta el desplazamiento de los animales desde la zona de alojamiento a la zona de experimentación, también hay que tener en cuenta el tránsito continuo de las jaulas desde la sala de estabulación a la sala de lavado y viceversa.

En este tipo de instalaciones, las zonas limpias corresponden fundamentalmente a los vestuarios de cambio, salas de estabulación, salas de experimentación, sala de lavado limpio y los almacenes de comida y cama. Las zonas sucias corresponderían a la zona de cuarentena, sala de necropsias, sala de lavado sucio y los almacenes de residuos.

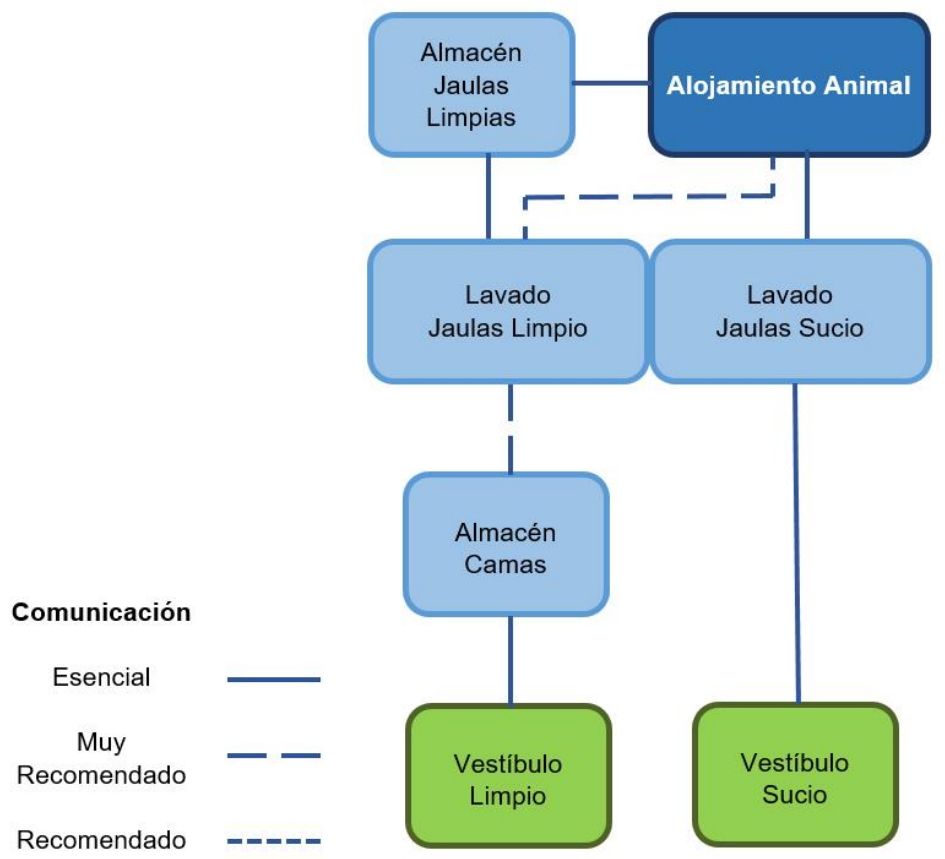

Figura 126. Esquema flujos de trabajo de jaulas de roedores reelaborado.

Fuente. Neil 2003, p. 42.

Para comprender la circulación asociada al movimiento de jaulas se ha tomado como referencia el esquema que se muestra en la guía Guidelines on: laboratory animal facilities-characteristics, design and development (Figura 126). En él observamos los locales que se ven afectados por el flujo de trabajo de las jaulas y en el que se representa con líneas de trazo continuo la comunicación entre los locales que se consideran esenciales, en trazo discontinuo ancho la relación muy recomendada y, por último, en trazo discontinuo estrecho la comunicación recomendada. La sala de alojamiento de animales está directamente comunicada con la zona sucia del área de lavado y con la zona de 
almacenamiento de jaulas limpias, siendo muy recomendable que esté también comunicada con la zona limpia de la sala de lavado. Por otra parte, la zona limpia del área de lavado tiene que tener buena comunicación con el almacén de suministros limpios como el pienso y la ropa de cama.

El resultado de la investigación sobre el criterio organizativo de la unidad de experimentación convencional de animal pequeño se encuentra reflejado tanto en las fichas de la documentación gráfica como en la toma de datos de cada centro.

Para realizar el análisis de dichas características se ha hecho una puesta en común de los resultados obtenidos y, para ello, se ha optado por resumir las más importantes en una tabla (Tabla 15). En ella se listan los parámetros que definen el criterio organizativo del centro, se establecen cuáles son las características comunes a la mayoría de ellos y se identifica qué institutos cumplen dichas características; además, se determinan las características particulares o específicas, que son aquellas que las cumplen solo unos determinados institutos, reflejándose así mismo, los institutos que las cumplen. El análisis se centra en los siguientes conceptos:

- La organización en plantas de la unidad. Identificar los institutos distribuidos en una o varias plantas y, en el caso de que la distribución se haya tenido que realizar en varias, analizar el planteamiento de cada caso.

- El tipo de pasillo de distribución seleccionado: simple o doble; incluso el criterio de flujo de trabajo establecido para cada caso.

- La configuración de las salas de estabulación convencional de animal, asi como los conceptos que condicionan su diseño, tales como el tipo de estanterías que tiene que alojar, así como el equipamiento que se necesite instalar.

- El diseño de las salas de experimentación en base a los criterios de flujo de trabajo diferenciadores implantados en cada caso.

- El concepto de diseño de la sala de lavado y esterilización, el criterio organizativo establecido para separar el material sucio del limpio y del estéril, así como el desarrollo de los flujos de trabajo y los equipos instalados.

- Los locales de servicio necesarios para el desarrollo de la actividad, tales como almacenes de suministros básicos y almacenes de residuos y residuos animales.

- Soluciones adoptadas para garantizar la flexibilidad futura de la instalación. 
Tabla 15. Organización unidad experimentación convencional animal.

\begin{tabular}{|c|c|c|c|c|}
\hline Parámetros & $\begin{array}{l}\text { Características } \\
\text { comunes }\end{array}$ & $\begin{array}{c}\text { Institutos con } \\
\text { características } \\
\text { comunes }\end{array}$ & $\begin{array}{l}\text { Características } \\
\text { específicas }\end{array}$ & $\begin{array}{l}\text { Institutos con } \\
\text { características } \\
\text { específicas } \\
\end{array}$ \\
\hline $\begin{array}{l}\text { № Plantas en las que } \\
\text { se distribuye }\end{array}$ & Una planta & $\begin{array}{l}\text { i+12, liSGM, IRYCIS, } \\
\text { IISBiodonostia, } \\
\text { IISBiocruces, IISLa Fe }\end{array}$ & Varias plantas & $\begin{array}{l}\text { IdiPAZ, IISA, VHIR, } \\
\text { IGTP }\end{array}$ \\
\hline Tipo de planta & A cota " 0 " & $\begin{array}{l}\text { i+12, IiSGM, IRYCIS, } \\
\text { IISBiodonostia }\end{array}$ & $\begin{array}{l}\text { Bajo rasante } \\
\text { Mixta: cota"0"+Bajo } \\
\text { rasante }\end{array}$ & $\begin{array}{l}\text { IdiPAZ, IIS Biocruces, } \\
\text { VHIR } \\
\text { IISA, IGTP }\end{array}$ \\
\hline $\begin{array}{l}\text { Unidad } \\
\text { independiente } \\
\text { animal grande }\end{array}$ & NO & $\begin{array}{l}\text { IdiPAZ, i+12, liSGM, } \\
\text { IRYCIS, IISBiodonostia, } \\
\text { IISA, IISLa Fe }\end{array}$ & SI & $\begin{array}{l}\text { IISBiocruces, VHIR, } \\
\text { IGTP }\end{array}$ \\
\hline Tipo de distribución & Pasillo simple & $\begin{array}{l}\text { IdiPAZ, IiSGM, } \\
\text { IISBiocruces, IGTP, IISA }\end{array}$ & $\begin{array}{l}\text { Pasillo doble } \\
\text { Pasillo triple }\end{array}$ & $\begin{array}{l}\text { i+12, IRYCIS, } \\
\text { IISBiodonostia, IIS La } \\
\text { Fe } \\
\text { VHIR }\end{array}$ \\
\hline $\begin{array}{l}\text { Salas estabulación } \\
\text { colindante a sala } \\
\text { lavado }\end{array}$ & NO & $\begin{array}{l}\text { IISBiodonostia, IISA, VHIR, } \\
\text { IGTP, IISLaFe }\end{array}$ & $\mathrm{SI}$ & $\begin{array}{l}\text { IdiPAZ, I+12, IiSGM, } \\
\text { IRYCIS, IISBiocruces }\end{array}$ \\
\hline Cuarentena con SAS & NO & $\begin{array}{l}\text { IdiPAZ, i+12, liSGM, } \\
\text { IRYCIS, VHIR, IGTP, IISLaFe }\end{array}$ & $\mathrm{SI}$ & $\begin{array}{l}\text { IISBiodonostia, } \\
\text { IISBiocruces, IISA }\end{array}$ \\
\hline $\begin{array}{l}\text { Sala lavado y } \\
\text { esterilización }\end{array}$ & Compartida con barrera & $\begin{array}{l}\text { liSGM, IISBiodonostia, } \\
\text { IISBiocruces, IGTP, IISA, } \\
\text { VHIR, IISLa Fe }\end{array}$ & $\begin{array}{l}\text { Uso exclusivo } \\
\text { convencional }\end{array}$ & IdiPAZ, i+12, IRYCIS \\
\hline
\end{tabular}

Fuente. Elaboración propia.

\section{Organización en plantas}

La mayoría de las unidades de experimentación convencional de animal pequeño se desarrollan en una única planta, si bien existen varios casos (IdiPAZ, IISA, VHIR, IGTP) en los que la distribución se produce en varias plantas. Esta división atiende a la falta de superficie disponible en planta para poder desarrollar el programa completo.

El tipo de división establecido para cada caso es particular. En el caso del IdiPAZ se ha priorizado mantener todos los animales, tanto grandes como pequeños, estabulados en una misma planta, por lo que el área de microcirugía se ha tenido que desarrollar en otra diferente, lo que conlleva tener que desplazar verticalmente los animales desde la zona de estabulación a la zona de microcirugía. En el caso del IISA, también la zona de microcirugía se distribuye en una planta diferente, pero en este caso, en esa misma planta se estabulan los animales pequeños con los que se va a experimentar, con lo que se evita el traslado vertical de los animales.

La instalación de animal pequeño del VHIR también se ha dividido en dos plantas. En este caso se ha optado por estabular los animales, en la medida de lo posible, en la misma planta en la que se va a experimentar con ellos y, en consecuencia, se evita la gran mayoría de los traslados interiores de los animales. Lo que no se ha conseguido es distribuir toda la unidad de imagen en una única planta, por lo que su división ha conllevado la implantación de un elemento de comunicación vertical interno del área para el traslado de los animales. La peculiaridad fundamental de este caso es que al ser las jaulas 
de los animales pequeños desechables, se evita el trasiego de jaulas sucias desde la sala de estabulación a la sala de lavado.

Por último, en el caso del IGTP lo que ocurre es que la división se produce en tres plantas. En una planta de acceso se distribuyen los vestuarios de cambio del personal; en una planta semisótano toda el área de experimentación convencional de animal pequeño excepto los almacenes y la sala de lavado y esterilización que se desarrolla en una planta sótano. Por lo tanto, aunque los animales acceden directamente a la planta de experimentación, existe un movimiento continuo vertical de jaulas desde la zona de estabulación a la zona de lavado y viceversa.

Por otra parte, observamos que la mayoría de las unidades de experimentación convencional de animal pequeño se desarrollan en el conjunto del centro de experimentación animal, compartiendo con animal grande pasillos, locales de servicio, incluso en algún caso, como ya hemos analizado anteriormente, salas de preparación. Entre los casos que podemos decir que esta unidad se desarrolla independientemente se encuentran IISBiocruces, VHIR e IGTP, casos que según analizaremos, se configuran de maneras variadas.

\section{Tipo pasillo de distribución}

Las unidades de experimentación animal deben estar organizadas de manera que la circulación se realice siempre desde las zonas limpias hacia las sucias, y este principio se debe aplicar tanto a las personas como a los materiales y animales. De la misma manera que ocurre con las circulaciones de los quirófanos, históricamente el sistema de distribución mediante doble pasillo ha sido una expresión de organización de este concepto.

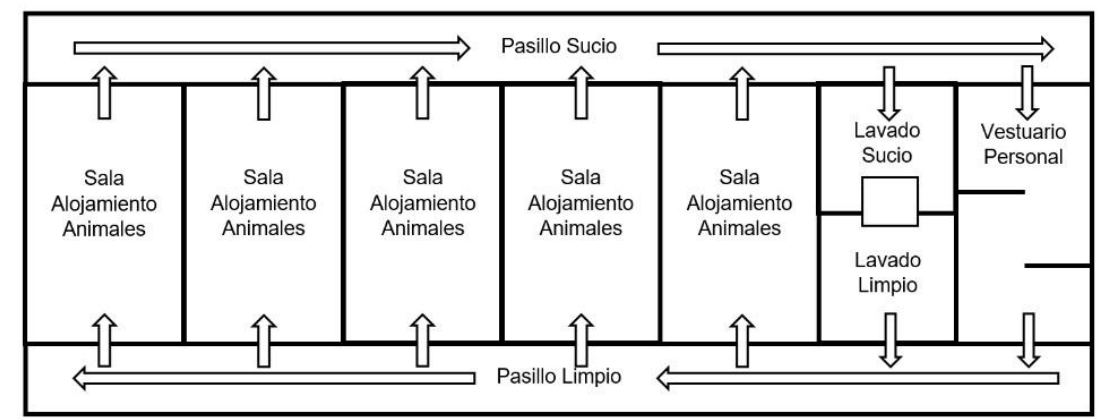

Figura 127. Organización área estabulación con pasillo doble.

Fuente. Neil 2003, p. 45.

El criterio de doble pasillo (Figura 127) está basado en la idea de que a través de un pasillo limpio solo los materiales y equipos limpios y personas pueden ser trasladados a la sala de alojamiento de animales, de manera que al pasillo sucio se accede a través de una segunda puerta ubicada en el extremo opuesto de la sala de alojamiento para la retirada de los residuos. Desde este pasillo sucio se 
traslada todo el material a la zona sucia de lavado para, a continuación, trasladarlo a la zona limpia de la sala de lavado que, a su vez, se comunica con el pasillo limpio. Al pasillo sucio solo se le permite acceder al personal específicamente designado, que no debe acceder a ningún otro lugar de la instalación a no ser que se descontamine y se cambie de ropa; para ello, en el esquema vemos cómo se ha diseñado paralela a la sala de lavado una zona de vestuarios que permite que el personal se pueda descontaminar y cambiar de ropa para poder acceder a la zona limpia. El control de la contaminación es la principal razón para elegir el sistema de doble pasillo, ya que desde el punto de vista de aprovechamiento del espacio no es la solución más adecuada.

Este criterio de organización de espacios a base de doble pasillo, tal y como se refleja en el esquema anterior lo observamos en varios casos de los institutos más antiguos ( $i+12, I R Y C I S)$, incluso en el instituto visitado, pero no incluido en la muestra IDIBELL. En el caso concreto del $i+12$, a pesar de disponer físicamente la distribución de doble pasillo, la realidad es que el uso tal y como se ha expuesto no se desarrolla en el momento de la visita, ya que el personal que trabaja en el animalario es necesario que acabe discurriendo tanto por el denominado pasillo sucio como por el limpio.

En los casos del IIS Biodonosti e IIS La Fe, aunque existe una distribución de doble pasillo, la distribución y, por lo tanto, la organización, se desarrollan de diferente manera a la descrita anteriormente. En el caso de IIS Biodonostia el pasillo sucio está destinado al acceso de los animales al centro, de manera que desde este pasillo se introducen los animales a las salas de cuarentena, y a través de un SAS ubicado en estas salas y que comunica con el pasillo interior se introducen los animales en la unidad. En cambio, en el caso de IIS La Fe, el criterio de pasillo limpio y sucio se organiza desde otro punto de vista. La batería de las salas de alojamiento tienen la posibiblidad de comunicarse con dos pasillos: un pasillo denominado sucio a través del que se introducen los animales y desde el que se trasladan los materiales a la sala de lavado; $y$, un pasillo limpio, desde el que los animales son trasladados a las salas de experimentación.

Como caso especial cabe mencionar el VHIR, que dispone de una configuración de triple pasillo, cada uno con un grado de asepsia diferente, y en el que el primer pasillo exterior sirve para distribuir e introducir los animales en la unidad convencional a través de una zona de recepción animal. El segundo pasillo es interior; está en la propia unidad de experimentación convencional y sirve para trasladar a los animales desde las salas de estabulación a las salas de experimentación que se sitúan enfrentadas. Por último, el tercer pasillo sirve tanto para la retirada de las jaulas sucias de las salas de estabulación, como para introducir a las salas el material limpio. Las salas de estabulación por tanto, tienen dos puertas: una para comunicarlo con el pasillo de experimentación, y otra para comunicarla con el pasillo de suministro de jaulas. 
Sin embargo, se observa que en los animalarios construidos o reformados recientemente se tiende a evitar la duplicidad de pasillos (IdiPAZ, IiSGM, IISBiocruces, IGTP, IISA), debido fundamentalmente a la gran superficie que hay que destinar para su configuración, a que requiere unas estrictas normas de funcionamiento y a que puede llegar a requerir más personal, debido a la limitación de acceso a las áreas que se impone. En estos casos de pasillo único, el flujo del tráfico entre la sala de estabulación y la sala de lavado va en ambos sentidos y, por lo tanto, existe riesgo potencial para la contaminación cruzada al compartir el mismo espacio las jaulas limpias y sucias. Este tipo de sistemas de distribución requiere que se minimice el contacto entre los materiales limpios y sucios, por lo que es fundamental planificar las circulaciones por los pasillos y adoptar el equipamiento necesario para evitar la contaminación (Figura 128). Aunque el sistema de pasillo simple con un sistema de flujo de trabajo unidireccional, en el que el tráfico de las jaulas se produce en un único sentido, permite un mayor control de la asepsia en la instalación, este tipo de distribución no lo hemos visto planteado en ningún instituto.
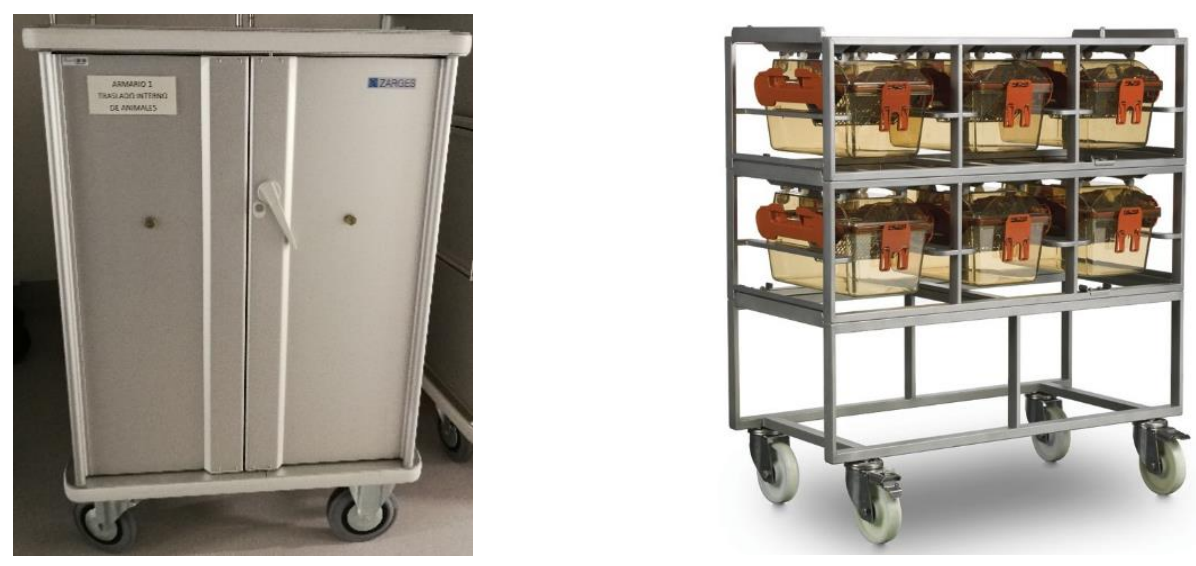

Figura 128. Armario y carro de traslado interno animales. Fuente. Elaboración propia / Techniplast.

\section{Salas de estabulación}

En cuanto a la configuración y dimensionamiento de las salas de estabulación de roedores, observamos que es muy variable. Aparte de estar diseñadas para alojar el tipo y número de animales que se necesiten, así como el carro con las jaulas limpias para hacer el cambio, también influyen en su dimensionamiento otros dos factores como son: por una parte, la decisión de si en el local de alojamiento de animales se van a realizar procedimientos varios; $y$, por otra parte, el tipo de jaulas y estantes que se van a utilizar, ya que en el caso de utilizar jaulas ventiladas individualmente, el dimensionamiento óptimo de la sala está condicionado por la necesidad de disponer de espacio suficiente para instalar una cabina de flujo laminar donde realizar el cambio de jaulas. 

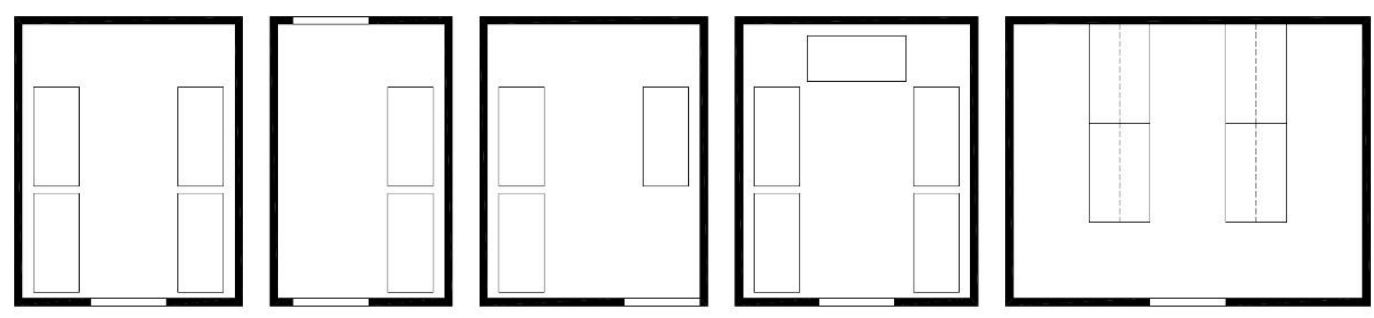

Figura 129. Tipos de configuración salas de alojamiento en función del estante.

Fuente. Elaboración propia.

En este estudio no se hace un análisis pormenorizado del dimensionamiento de las salas de estabulación, sino que nos centramos en el análisis de la configuración de las mismas, ya que atendiendo a la distribución de los estantes en las salas de alojamientos y el criterio de organización seleccionado observamos cinco opciones diferentes de configuracion (Figura 129). Las variables que condicionan la configuración fundamentalmente son: el tipo de estante seleccionado simple o doble y la ubicación del equipo de ventilación en caso de ser del tipo autoventilado (Figura 130), del interes de disponer varias salas de estabulación pequeñas frente a menos salas de estabulación de mayor dimensión y por el criterio sobre la disposición de una o dos puertas en las salas. En el esquema observamos la configuración de cuatro tipos de salas con estantes simples y una con estantes dobles. En las salas con estante simple la tendencia es intentar distribuirlos en la medida de lo posible en todas las paredes perimetrales de la sala, si bien el ubicar la puerta centrada o adosada al tabique lateral acaba condicionando su distribución. En cualquier caso, prever la posibilidad de instalar una cabina de cambio dentro de las sala de estabulación hace que la instalación sea flexible al ofrecer la posibilidad de, en un momento determinado, cambiar las jaulas estáticas a ventiladas individualmente.
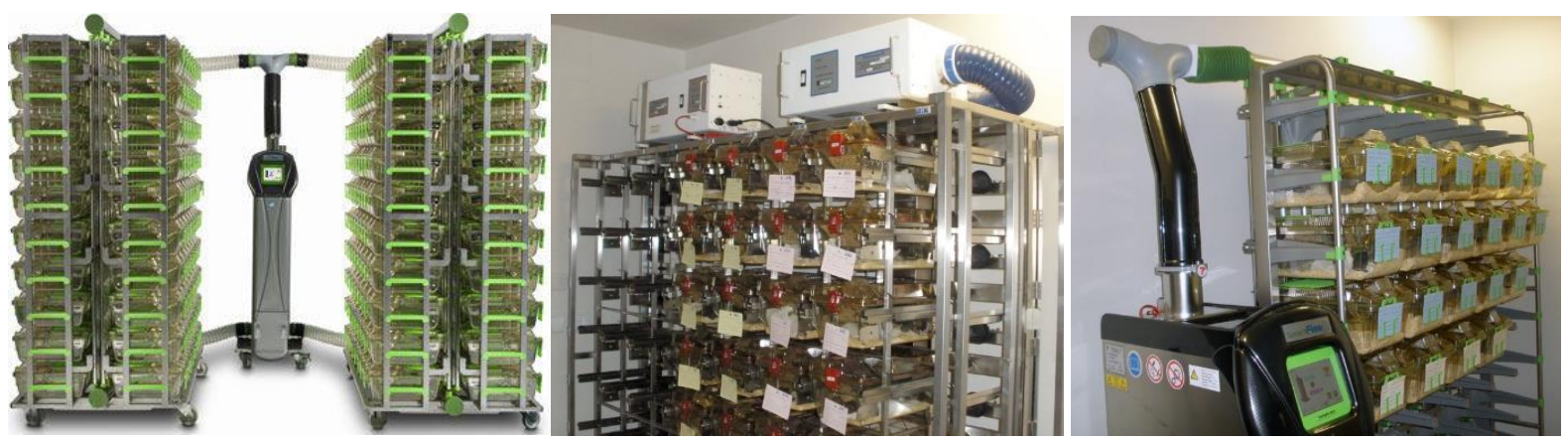

Figura 130. Tipos de configuración de estantes.

Fuente. Techniplast / Elaboración propia.

Por otra parte, observamos cómo las salas de cuarentena están ubicadas en la denominada zona sucia del animalario, en una zona exterior. Aunque es habitual que disponga de una sola puerta de acceso, vemos algunos casos (IISBiodonostia, IISBiocruces, IISA) en los que en la sala de cuarentena se ha 
instalado un SAS pasa materiales para introducir los animales a la denominada zona limpia de la instalación.

En general, todos los procedimientos que puedan causar angustia al animal deberían realizarse fuera de la zona de alojamiento de animales, en salas específicamente destinadas para ello, ya que puede transmitir alarma y producir un estrés innecesario al resto de los animales alojados en la sala. Los procedimientos menores como el suministro de inyecciones o extracción de sangre, sí pueden llevarse a cabo dentro de las salas de alojamiento, incluso en el caso de que los roedores estén alojados en jaulas ventiladas (Neil 2003, p. 18). La realidad es que el traslado de los animales a las salas de procedimientos y su posterior regreso a la sala de alojamiento aumenta el riesgo de contaminación de la instalación con agentes infecciosos. Es por ello que aunque lo habitual es que las salas de alojamiento se destinen únicamente a este fin, en la mayoría de las unidades de experimentación, existe alguna sala de alojamiento en la que también se realizan procedimientos menores. En otros casos observamos como la sala de procedimientos se ha adosado a la sala de estabulación, de manera que los animales son trasladados a través de una puerta que comunica ambas salas (IRYCIS).

\section{Salas experimentación}

Las salas de experimentación habitualmente se distribuyen con una única puerta de acceso. Como caso particular podemos mencionar el IRYCIS, ya comentado anteriormente, en el que al estar ciertas salas de experimentación adosadas a la sala de estabulación, disponen de dos puertas de acceso: una para el personal y otra para los animales.

Por otra parte, destacamos la configuración del área de microcirugía, ya que si bien lo habitual es que se acceda a través de una única puerta, hay varios casos ( $i+12$, IIS Biodonostia) que tienen una organización especial. En el caso del i+12, el área de microcirugía se ha integrado en la unidad quirúrgica de animal grande con el que comparte tanto la zona de preparación médica como el transfer de materiales; además, la sala dispone de dos puertas, una para el acceso del personal y otra para la retirada de residuos. En el caso del IIS Biodonostia, la sala también dispone de dos puertas de acceso y está configurada de tal manera que permite la segregación de circulaciones, de modo que por una acceden el personal y suministro limpio y, por la otra, acceden los animales a la zona de microcirugía previo paso por la zona de preparación animal que es compartida con el animal grande.

\section{Sala lavado y esterilización}

La sala de lavado y esterilización alberga los equipos necesarios para la limpieza y desinfección de las jaulas de los animales, sus accesorios y los biberones. Adicionalmente, puede alojar también la zona 
para la eliminación de la ropa de cama, incluso el equipo necesario para el llenado de ropa de cama y biberones.

El tipo y número de jaulas a utilizar, aparte de afectar al dimensionamiento de las salas de estabulación de animales, también influye determinantemente en el programa de necesidades, en el planteamiento de los equipos necesarios en la sala de lavado y esterilización y, por tanto, en el dimensionamiento global del centro.

Aunque lo habitual es que los centros hagan uso de jaulas reutilizables (IdiPAZ, i+12, IiSGM, IRYCIS, IISBiodonostia, IISBiocruces, IISA, IGTP, IISLa Fe), observamos un caso en el que las jaulas son desechables (VHIR). La elección de un tipo u otro de jaula determinará el tipo de equipamiento necesario en la sala de lavado. Por otra parte, el utilizar jaulas ventiladas individualmente puede conllevar la necesidad de esterilizar las jaulas y sus accesorios y, por lo tanto, condicionar el dimensionamiento necesario de la sala de lavado y esterilización para el desarrollo de la investigación. De esta manera observamos cómo en el caso del VHIR, adquiere gran importancia una sala de almacenaje para las jaulas con una zona para la preparación de la cama y la bebida, mientras que en el caso de jaulas reutilizables se require de una sala donde poder distribuir los equipos necesarios para eliminar la cama sucia, una zona de lavado de carros, jaulas y biberones e incluso una zona de preparación de camas y llenado de biberones.

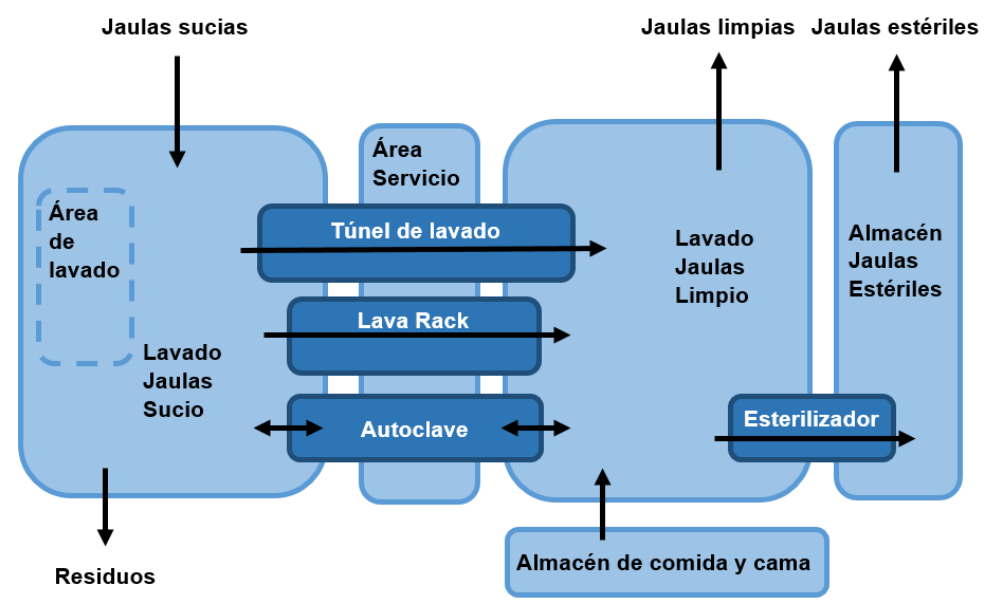

Figura 131. Esquema flujo trabajo sala lavado y esterilización.

Fuente. Division of technical resources 2016, p. 140.

Las salas de lavado, en general, deben estar configuradas para separar las actividades sucias de las limpias. El área sucia debe estar diseñada para recibir las jaulas y los estantes sucios, retirar la ropa de cama, desmontar las jaulas, vaciar los biberones y cargar las lavadoras; mientras que la zona limpia debe estar diseñada para recibir las jaulas y estantes limpios, montar las jaulas, colocar la ropa de 
cama, la comida y llenar los biberones. La zona de separación entre las dos zonas correspondería a los equipos de lavado y desinfección.

Para comprender el funcionamiento de esta zona de lavado y esterilización hemos tomado como referencia el esquema que nos muestra la guia Design requirements manual NIH (Figura 131), que refleja los flujos de trabajo de la sala. En él observamos que las jaulas sucias acceden en unos carros o estantes a la zona sucia del área de lavado para retirar la ropa de cama y separar los residuos de los elementos que es necesario lavarlos para reutilizarlos. Debido al gran movimiento de carros y a su tamaño, el acceso a esta zona es preferible que sea a través de puertas de dos hojas con apertura en el sentido del flujo de trabajo. A continuación, el material reutilizable se introduce en los diferentes equipos para proceder a su lavado y desinfección. Estos equipos de lavado, como son el tunel de lavado, el lava rack y el autoclave, hacen de barrera para comunicar la zona sucia con la denominada limpia. A la zona de lavado limpia llegan los materiales una vez lavados, y está comunicada con el almacén de material limpio que contiene tanto el material de cama como el alimento de los animales, ya que es en esta zona donde se preparan las jaulas limpias. Además, en el caso de que las jaulas preparadas debieran ser esterilizadas, en la zona de lavado limpio se instalaría un esterilizador para acceder a la zona estéril de la instalación.

En el presente estudio observamos cómo este planteamiento de separación física totalmente independiente de la zona sucia, limpia y estéril, tal y como se refleja en el esquema indicado con tres zonas diferenciadas no se produce en ningún caso. Vemos que en los institutos analizados la organización de la sala de lavado y esterilización se plantea desde distintas perspectivas, de manera que podemos diferenciar varias tipologías que vienen determinadas fundamentalmente por el hecho de que en el centro de experimentación de animal pequeño exista una zona de experimentación en barrera o no, por el tipo del material de las jaulas: reutilizable o desechable, y por el criterio de circulación del material establecido.

1. Existe un caso concreto en el que la sala de lavado y esterilización da servicio a la unidad de experimentación convencional y dispone de una única puerta a través de la que se introduce el material sucio en la sala y se retira una vez limpio (IdiPAZ).

2. La sala de lavado y esterilización se organiza con dos áreas diferenciadas y separadas para lo que dispone de varias puertas: una para introducir el material sucio y otra para retirar el material ya limpio y esterilizado, pudiendo estar internamente la sala dividida por los equipos de lavado y esterilización (IRYCIS, IIS Biodonostia, i+12, IGTP). 
3. La sala se organiza con dos áreas diferenciadas y separadas físicamente para dar servicio tanto a la zona convencional como a la zona de barrera. En la zona denominada sucia se introduce el material sucio y se lava. Una vez lavado a través de los equipos de barrera se esteriliza el material para introducirlo directamente a la zona denominada zona estéril para la experimentación en barrera de animal pequeño (IiSGM, IISBiocruces, IISA, IISLa Fe).

En el caso del VHIR, al ser las jaulas desechables, la sala de lavado no tiene gran importacia, y su ubicación y distribución se debe no solo a las necesidades propias de la unidad de experimentación convencional, sino también a la experiementación en barrera.

\section{Equipos de lavado y esterilización}

En el presente trabajo se analiza el tipo de equipos diseñados en la sala de lavado de cada instituto para el desarrollo de la investigación. Es muy importante que estos equipos estén convenientemente ditribuidos, según el flujo de trabajo, para garantizar la calidad del resultado de la limpieza, y, también para facilitar el trabajo del personal, evitando realizar movimientos innecesarios. En este estudio no se realiza un estudio detallado de la distribución de estos equipos en las salas de lavado, por lo que este tema puede ser objeto de desarrollo en trabajos futuros.

Todos los materiales son trasladados constantemente desde la sala de estabulación a la sala de lavado y viceversa para ser lavados y preparados para un nuevo cambio. Los trabajos a llevar a cabo en la sala de lavado corresponden al vaciado de jaulas y biberones, lavado de materiales, preparación de jaulas y llenado de biberones. Adicionalmente, puede ser necesario que los materiales sean esterilizados por dos motivos fundamentalmente: para proporcionar material esteril en determinadas zonas de experimentación o para eliminar el material potencialmente infeccioso que pueden contener los materiales.

De manera genérica, el área sucia estaría equipada con fregadero, estación de descarga de ropa de cama y equipo de eliminación de desechos; y el área limpia con una autoclave, dispensador de ropa de cama, punto de suministro de agua para bebida de animales y equipo de llenado de botellas de agua.

En función del trabajo a realizar dentro de la sala, los equipos a instalar se pueden clasificar en tres tipos: equipos de vaciado, equipos de lavado y esterilización y equipos de llenado. El tipo de equipos instalados en los institutos analizados se han resumido en una tabla (Tabla 16). 


\section{Equipos de vaciado}

Para minimizar la cantidad de suciedad en el equipo de lavado, las botellas de agua y, en particular, la cama de las jaulas deben vaciarse antes de lavarse. En general, de las jaulas se vacía la ropa de cama sucia, posiblemente mezclada con materiales de enriquecimiento desechables y pellets de alimentación; en los biberones, en cambio, generalmente solo quedan restos de agua. Antes de lavar los biberones de agua, se retiran las tapas, de manera que los biberones abiertos se vuelcan para eliminar los líquidos residuales, para después cargarlos en el equipo de lavado con el cuello hacia abajo.

En el estudio realizado vemos cómo en la mayoría de las unidades de experimentación, el vaciado tanto de las jaulas como el de los biberones se realiza de manera manual. En algunos institutos (IIS Biocruces, IISA, IIS La Fe), en los que para faciliar las tareas de vaciado de las jaulas al personal, incluso para reducir el nivel de polvo generado en el volcado de jaulas, se ha instalado un equipo de aspiración de las virutas; ya que la ropa de cama sucia puede plantear varios problemas de salud potenciales como son el peligro de infecciones causadas por la exposición a excrementos de animales, así como el peligro de generar alérgenos (Grupo de trabajo sobre preparación de jaulas 2010, p. 13). La realidad es que los aspiradores de viruta no siempre funcionan correctamente. En algunos casos (IISA, IDIBAPS), al estar estos equipos ubicados en una planta diferente a la del acceso exterior, han presentado problemas en su funcionamiento, por lo que han quedado en desuso.

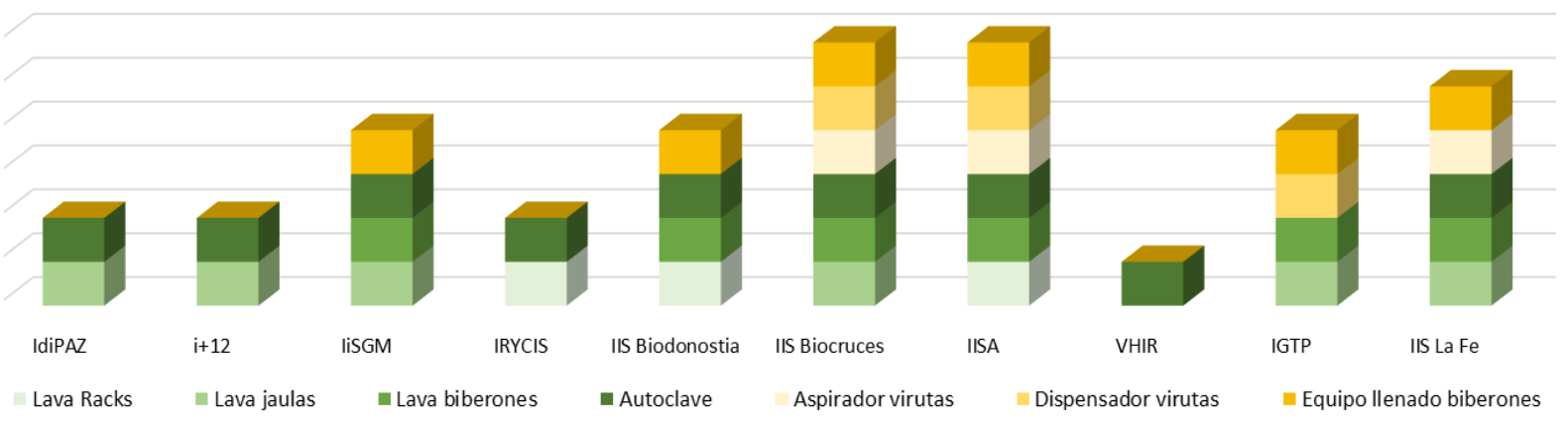

Tabla 16. Equipamiento sala lavado.

Fuente. Elaboración propia.

\section{Equipos de lavado y esterilización}

Los equipos de lavado y esterilización que nos encontramos habitualmente en los animalarios son: equipos para lavado de los racks, lavado de jaulas, lavabiberones, tunel de lavado y autoclave.

En el estudio realizado vemos que no es muy habitual que se diponga del lava rack, siendo un equipo que nos encontramos en unos pocos centros ( IRYCIS, IIS Biodonostia, IISA). En estos casos, este equipo es también utilizado para el lavado de jaulas (Figura 132). En los casos en los que no se dispone de lava racks lo habitual es tener un equipo para el lavado de jaulas (IdiPAZ, I+12, IiSGM, IIS Biocruces, 
IGTP, IIS La Fe). Otro equipo habitualmente utilizado es el lavabiberones (IiSGM, IIS Biodonostia, IIS Biocruces, IISA, IGTP, IIS La Fe), siendo habitual que también realice el procedimiento de llenado de los mismos.

Los autoclaves son los equipos que se utilizan en el caso de que sea necesario esterilizar el material con el que están en contacto los animales para generar un ambiente estéril o en el caso de que la experimentación requiera de un proceso exhaustivo de eliminación de microbios y esporas. El método de esterilización de los autoclaves se basa en el calor húmedo, el cual requiere de temperaturas superiores a las de ebullición, que van desde los $121^{\circ} \mathrm{C}$ a los $134^{\circ} \mathrm{C}$, por lo que estos equipos solo pueden utilizarse para materiales capaces de soportar las altas temperaturas como pueden ser las jaulas y biberones, entre otros. Este equipo es básico en los centros de experimentación animal, de manera que nos lo encontramos en prácticamente todos los institutos.
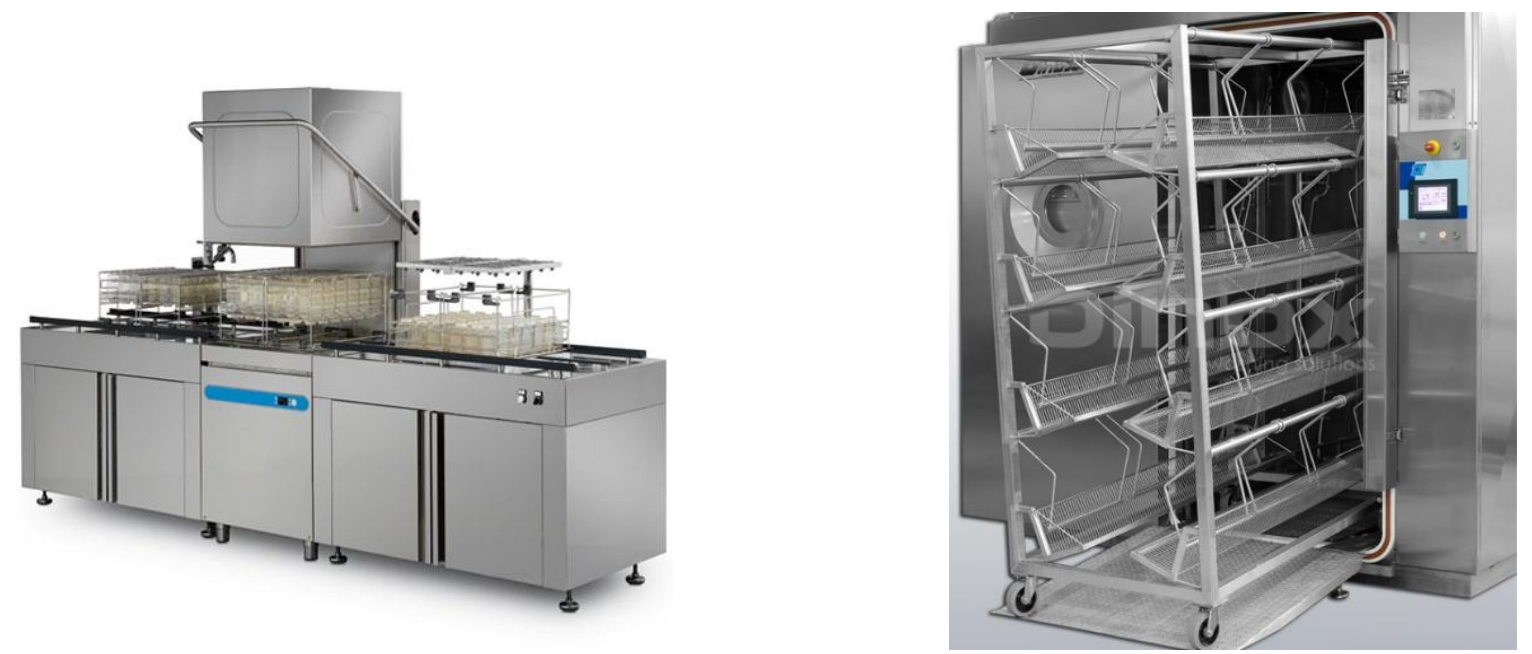

Figura 132. Equipos de lavado: lavabiberones y lavaestantes. Fuente. Dinox.

\section{Equipos de llenado}

Después de la fase de lavado, se vuelven a llenar tanto las bases de la jaula con ropa de cama como los biberones con agua, para ser devueltos a las salas de alojamiento de animales. Cuando se rellenan las jaulas se puede liberar el polvo fino de la ropa de cama limpia, pudiendo provocar alergias, es por ello que en algunos centros (IIS Biocruces, IISA, IGTP) se ha optado por facilitar esta tarea con un equipo dispensador de virutas. Para el caso del llenado de biberones, en cambio, puede ser manual con manguera o automático con el equipo de lavado de biberones.

Aunque no es el caso de los institutos analizados, entre las instalaciones de mayor dimensión visitadas, observamos dos: el PRBB y el CNIO, en los que la sala de lavado se ha diseñado con equipos robóticos (Figura 133). El proceso de robotización contempla un área de clasificación, cintas transportadoras, una estación de descarga de ropa de cama, una manipulación automatizada de jaulas, un tunel de 
lavado, una lavadora de jaula y estante, un esterilizador de vapor, un dispensador de ropa de cama, una estación de llenado de biberones y otros equipos asociados con el sistema robótico.
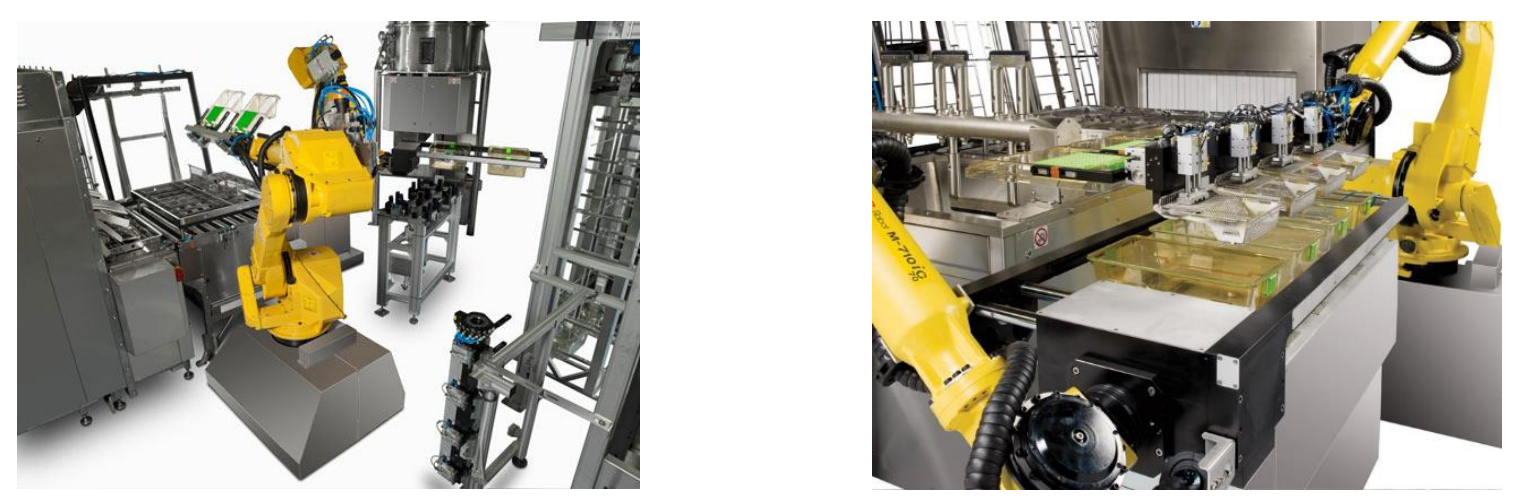

Figura 133. Equipos robotizados para lavado. Fuente. Techniplast.

El dimensionamiento de estas salas va a estar condicionado por el número de jaulas que se deben lavar y/o esterilizar, así como por el tipo y modelo de los equipos que se decidan instalar. Algunos de estos equipos son muy voluminosos y pesados, que además pueden requerir algún sistema especial de recogida de agua o vapor de agua, por lo que tanto el tipo de equipos, su ubicación, como las necesidades de cada uno de ellos se deben conocer desde la fase de diseño. Además, en aras a garantizar una flexibilidad futura en la instalación, se deberían tener en cuenta no solo la necesidad de equipamiento en el momento del diseño, sino también la necesidad de instalar en el futuro el equipamiento complementario necesario para facilitar las tareas de limpieza y esterilización en esta sala. En este sentido, vemos que en los institutos que se desarrollan en plantas bajo rasante se han previsto unos huecos para poder introducir nueva maquinaria diversa (IISBiocruces, IISA, VHIR). 


\subsubsection{Síntesis de la unidad de experimentación convencional animal pequeño}

Como síntesis de lo analizado anteriormente, podemos decir que las instalaciones de experimentación convencional de animal pequeño de los Institutos de Investigación Sanitaria están diseñadas para investigar con las especies más utilizadas: el ratón y la rata. El ratón es el modelo animal más utilizado en experimentación animal y se selecciona para muchos tipos de estudios porque presenta características muy interesantes debido a la amplia variedad de cepas y modelos de ratones disponibles, su pequeño tamaño, su vida útil relativamente corta y por su corto tiempo de generación. Cada especie animal tiene sus características propias que lo hacen idonéo para cada tipo de experimentación concreta. Es por ello que en algunos institutos eventualmente se experimenta con otras especies que también se estabulan en esta zona como son la cobaya, el jerbo o el hamster. Además, el conejo, que es un modelo utilizado en casi todos los institutos, también es habitual que se estabule en esta unidad convencional.

La superficie destinada a este tipo de experimentación es muy variable, si bien lo habitual es que se sitúe en un rango comprendido entre los 500-1.500 m². En relación al área destinada a la estabulación de los animales, teniendo en cuenta tanto las salas de alojamiento como las de cuarentena, normalmente es inferior a $100 \mathrm{~m}^{2}$. Por otra parte, el número de locales destinados al alojamiento convencional también es diverso. Si bien para los conejos suele haber uno o dos locales como mucho, en el caso de los roedores el número de locales disponibles suele ser igual o menor a cinco unidades.

Las jaulas deben permitir la observación diaria de los animales con una perturbación mínima. En este sentido, se observa que las jaulas utilizadas en todas las unidades de experimentación convencional son de plástico transparente, lo que permite una observación directa de los animales desde el exterior. En cuanto al material utilizado para la configuración de las jaulas, aunque prácticamente en todos los casos es reutilizable, observamos un caso en el que debido al dimensionamiento del centro, la elección realizada ha sido del tipo desechable.

En relación al tipo de jaula utilizada en esta zona no hay un criterio unificado. Algunos centros han optado por instalar jaulas ventiladas individualmente en todos los locales de alojamiento, incluso en la zona de cuarentena, aunque lo habitual es que exista una mezcla del tipo convencional y autoventilada. En este último caso no existe un consenso unificado sobre dónde instalar las jaulas ventiladas, ya que en algunos casos están ubicadas en la sala de cuarentena, mientras que en otros en los locales de alojamiento. La ventaja de las jaulas ventiladas es que generan un microambiente independiente en cada jaula que permite proteger a los animales de enfermedades, ya que proporcionan una ventilación controlada individualmente filtrando el aire de la sala en la que se 
alojan, que puede ajustarse a presión negativa o positiva según las necesidades, y que además reducen la exposición humana a alérgenos.

Independientemente del tipo de jaula seleccionado, diseñar las salas de estabulación convencional para poder alojar en un momento determinado jaulas ventiladas individualmente, proporciona la flexibilidad necesaria en este tipo de instalaciones, puesto que las líneas de investigación y, por tanto, los requerimientos de la instalación, son variables con el paso del tiempo.

Las áreas para experimentación que nos encontramos en todas las unidades son salas de procedimientos y de microcirugía, si bien algunos pocos centros destacan por las infraestructuras diseñadas para el diagnóstico por imagen, incluso, por las salas de comportamiento.

Los animales deben tener acceso a alimento y bebida en todo momento, por lo que el suministro debe ser fácilmente accesible para ellos. Aunque en algunos casos se ha realizado un planteamiento mixto, siendo el suministro de agua a base de biberones y de manera automática, el sistema de suministro de bebida empleado en la mayoría de los institutos es a base de biberones. Esta solución permite convertir fácilmente una sala cualquiera en una sala de alojamiento, y quizás un mayor control sobre la calidad del agua suministrada; por el contrario, genera una tarea adicional en la preparación de los biberones que el suministro automático no conlleva.

Atendiendo a la distribución en plantas, vemos que lo habitual es que el área de experimentación de animal pequeño se desarrolle en una única planta con acceso directo desde el exterior. En los casos en los que esta área se ha tenido que dividir en varias plantas, la base del planteamiento general ha sido intentar evitar tener que trasladar los animales de planta. Por diversas circunstancias, esta premisa no en todos los casos se ha logrado, por lo que este traslado se ha intentado reducir al mínimo número de animales posibles, incluso se han diseñado elementos de comunicación vertical de uso exclusivo para animales. Además, en la mayoría de los casos esta unidad se distribuye en el conjunto del centro de experimentación animal compartiendo con el área de experimentación de animal grande pasillos, locales de servicio e incluso alguna sala de preparación.

Las unidades de experimentación animal deben estar organizadas de manera que la circulación se realice siempre desde las zonas limpias hacia las sucias, y este principio se debe aplicar tanto a las personas como a los materiales y a los animales. De la misma manera que ocurre con las circulaciones de los quirófanos, históricamente el sistema de distribución mediante doble pasillo ha sido una expresión de organización de este concepto. 
En estos casos, el criterio de doble pasillo está basado en la idea de que a través de un pasillo limpio solo los materiales y equipos limpios y personas pueden ser trasladados a la sala de alojamiento de animales, de manera que al pasillo sucio se accede a través de una segunda puerta ubicada en el extremo opuesto de la sala de alojamiento para la retirada de las jaulas sucias y los residuos. El control de la contaminación es la principal razón para elegir el sistema de doble pasillo, ya que desde el punto de vista de aprovechamiento del espacio no es la solución más adecuada. Sin embargo, se observa cómo en los animalarios construidos o reformados recientemente se tiende a evitar la duplicidad de pasillos debido fundamentalmente a la gran superficie que hay que destinar para su configuración, a que requiere unas estrictas normas de funcionamiento y a que puede llegar a requerir más personal debido a la limitación de acceso a las áreas que se impone. En estos casos de pasillo único, el flujo del tráfico entre la sala de estabulación y la sala de lavado va en ambos sentidos y, por lo tanto, existe riesgo potencial para la contaminación cruzada al compartir el mismo espacio las jaulas limpias y sucias, por lo que es necesario desde la fase de diseño, considerar los equipos necesarios para minimizar el contacto de los diferentes materiales, así como planificar las circulaciones por los pasillos para evitar que coincidan.

En cuanto a la distribución planteada en función del número de pasillos vemos que aunque la tendencia es organizarlos a través de un pasillo único, podemos distinguir cuatro tipologías de organización:

1. A base de pasillo simple. En este caso el personal, los animales, los suministros y los residuos acceden a un único pasillo a través del cual transitan dentro de la unidad.

2. A base de pasillo doble con segregación de limpio y sucio. En este caso existen dos pasillos de circulación dentro de la propia unidad de experimentación convencional: uno denominado limpio por el que circulan el personal, los animales y los materiales limpios; y, un segundo, por el que circula el material sucio, así como el personal responsable de recogerlo.

3. A base de pasillo doble con segregación de pasillo exterior e interior. En este caso también existen dos pasillos de circulación, pero el área se organiza de diferente manera. Por una parte, existe un pasillo exterior a la unidad que comunica con las salas de cuarentena para el acceso de los animales al centro; $y$, por otra parte, un pasillo interior dentro de la unidad, por el que circulan el personal, los materiales limpios y sucios y a través del cual los animales son trasladados desde las salas de cuarentena a las salas de estabulación, así como a las salas de experimentación.

4. A base de pasillo triple. En este caso la organización se desarrolla a partir de tres pasillos de distribución paralelos entre sí con diferentes grados de asepsia. El primer pasillo exterior sirve 
para introducir los animales a la unidad; el segundo es el pasillo donde se realiza la investigación que sirve para trasladar los animales desde la zona de estabulación a la de experimentación, y por tanto, por el que circulan el personal y los animales; y, el tercer pasillo que sirve para la logística de suministros, tanto para el suministro de materiales limpios como para la retirada de residuos.

En general, todos los procedimientos que puedan causar angustia al animal deberían realizarse fuera de la zona de alojamiento de animales en salas específicamente destinadas para ello, ya que puede transmitir alarma y producir un estrés innecesario al resto de los animales alojados en la sala. Por otra parte, el traslado de los animales a las salas de procedimientos y su posterior regreso a la sala de alojamiento aumenta el riesgo de contaminación de la instalación con agentes infecciosos. Es por ello que aunque lo habitual es que las salas de alojamiento se destinen únicamente a este fin, en la mayoría de las unidades de experimentación existe alguna sala de alojamiento en la que también se realizan procedimientos menores. Como criterio de distribución alternativo a los traslados, en algún caso se ha tomado la decisión de adosar la sala de procedimientos a la sala de estabulación, de manera que los animales son trasladados a través de una puerta que comunica ambas salas, sin tener que discurrir por pasillos comunes.

En cuanto al dimensionamiento y configuración de las salas de estabulación de roedores, observamos que es muy variable, ya que aparte del tipo y número de animales que se quieran alojar en el local, influyen otros dos factores fundamentales: por una parte, la decisión de si en el local de alojamiento de animales se van a realizar procedimientos varios; $y$, por otra parte, el tipo de jaula que se va a utilizar, ya que en el caso de utilizar jaulas ventiladas individualmente el dimensionamiento óptimo de la sala está condicionado por el tipo jaula y la configuración del estante donde se alojan las jaulas, y por la necesidad de disponer de espacio suficiente dentro de la sala para instalar una cabina de flujo laminar para realizar el cambio de jaulas, así como del carro para alojar las jaulas limpias a cambiar. En cualquier caso, prever la posibilidad de instalar una cabina de cambio dentro de las sala de estabulación hace que la instalación sea flexible al ofrecer la posibilidad de, en un momento determinado, cambiar las jaulas estáticas a ventiladas individualmente.

Todos los materiales son trasladados constantemente desde la sala de estabulación a la sala de lavado y viceversa para ser lavados y preparados para un nuevo cambio. Los trabajos a llevar a cabo en la sala de lavado corresponden al vaciado de jaulas y biberones, lavado de materiales, preparación de jaulas y llenado de biberones. Adicionalmente, puede ser necesario que los materiales sean esterilizados por dos motivos fundamentalmente: para proporcionar material estéril en determinadas zonas de experimentación o para eliminar el material potencialmente infeccioso que pueden contener los materiales. 
En relación a los equipos instalados en la sala de lavado y esterilización, vemos que en la mayoría de las unidades de experimentación, el vaciado tanto de las jaulas como el de los biberones se realiza de manera manual, si ben cuando se ha dispuesto de presupuesto suficiente, con el fin de faciliar las tareas de vaciado de las jaulas al personal, incluso para reducir el nivel de polvo generado en su volcado, y por tanto, el peligro de generar alérgenos, se ha instalado un equipo de aspiración de las virutas. Por otra parte, los equipos de lavado y esterilización que nos encontramos habitualmente en estos animalarios son: equipos para lavado de los racks, lavado de jaulas, lavabiberones y autoclave. Después de la fase de lavado, se vuelven a llenar tanto las bases de la jaula con ropa de cama como los biberones con agua, para ser devueltos a las salas de alojamiento de animales. En los casos que se ha tenido disponibilidad económica, se ha instalado un equipo dispensador de virutas para mecanizar la tarea y evitar las posibles alergias de los trabajadores. Para el caso del llenado de biberones, en cambio, lo habitual es que el llenado sea manual con manguera.

El tipo y número de jaulas a utilizar, aparte de influir en el dimensionamiento de las salas de estabulación de animales, también influyen determinantemente en el programa de necesidades y en el planteamiento de la sala de lavado y esterilización y, por tanto, en el dimensionamiento global del centro. Además, es muy importante que estos equipos estén convenientemente ditribuidos, según el flujo de trabajo, para garantizar la calidad del resultado de la limpieza y, también para facilitar el trabajo del personal, evitando realizar movimientos innecesarios.

La organización de la sala de lavado y esterilización vemos que se plantea desde distintas perspectivas de manera que podemos diferenciar varias tipologías que vienen determinadas fundamentalmente por el hecho de que en el centro de experimentación de animal pequeño exista una zona de experimentación en barrera o no, por el tipo del material de las jaulas: reutilizable o desechable; y por el criterio de circulación del material establecido. En el caso de jaulas desechables, la sala de lavado no tiene gran importacia, por lo que este caso no lo incluimos dentro de las tipologías de sala a analizar. Las diferentes tipologías observadas son las siguientes:

1. La sala de lavado y esterilización da servicio únicamente a la unidad de experimentación convencional y dispone de una única puerta a través de la que se introduce el material sucio en la sala y se retira una vez limpio.

2. La sala de lavado y esterilización se organiza con dos áreas diferenciadas y separadas para lo que dispone de varias puertas y está organizada para introducir el material sucio por una; y, por la otra, retirar el material ya limpio y esterilizado, pudiendo estar internamente la sala dividida por los equipos de lavado y esterilización. 
3. La sala se organiza con dos áreas diferenciadas y separadas físicamente para dar servicio tanto a la zona convencional como a la zona de barrera. En la zona denominada sucia se introduce el material sucio y se lava. Una vez lavado, a través de los equipos de barrera, se esteriliza para introducirlo directamente a la zona denominada zona estéril para realizar la experimentación en barrera.

Algunos de estos equipos son muy voluminosos y pesados, que además, pueden requerir algún sistema especial de recogida de agua o vapor de agua, por lo que tanto el tipo de equipos y su ubicación como las necesidades de cada uno de ellos se deben conocer desde la fase de diseño. Además, en aras a garantizar una flexibilidad futura en la instalación, se deberían tener en cuenta no solo los equipos necesarios en el momento del diseño, sino también la necesidad de instalar en el futuro el equipamiento necesario para facilitar las tareas de limpieza y esterilización en esta sala. 


\subsubsection{Unidad de experimentación en barrera animal pequeño}

El alojamiento en barrera para animal pequeño se ha convertido en un estándar para albergar animales de experimentación. Si bien este tipo de instalaciones se han utilizado principalmente para la producción de roedores y para mantener roedores inmunodeprimidos, muchas de las instalaciones nuevas incorporan instalaciones de barrera para albergar ratas y ratones libre de patógenos específicos (SPF), animales especialmente valiosos modificados genéticamente, incluso otras especies animales SPF (National Research Council 2011, p. 145).

En el contexto de las ciencias del animal de laboratorio, el término barrera se refiere a los sistemas de alojamiento de animales diseñados y gestionados para proteger a los animales de infecciones no deseadas por agentes procedentes desde fuera de la barrera. Por lo tanto, las barreras consisten en una combinación de sistemas físicos y criterios de trabajo para que conjuntamente minimicen la transferencia de agentes infecciosos de un lado de la barrera a la otra.

Las barreras relacionadas con el diseño de la instalación se pueden crear a nivel de jaula, de carro, de sala de estabulación, de área de experimentación, a nivel de centro de experimentación, incluso se pueden formar con la combinación de ellas ${ }^{43}$. De esta manera, una instalación en barrera puede ser un área concreta dentro del área de experimentación animal, una planta específica de las diferentes que componen el área de experimentación animal o puede ser la instalación completa del centro de experimentación animal.

En este estudio, al analizar la unidad de experimentación en barrera, nos centramos específicamente en el estudio de las barreras relacionadas con el espacio físico de las denominadas barreras de exclusión, cuyo objetivo principal no es proteger a los trabajadores, sino el de proteger el estado de salud de los animales de laboratorio evitando la entrada de infecciones en la instalación y generando un ambiente lo más estéril posible.

Para garantizar el correcto funcionamiento de este tipo de instalaciones, aparte de una instalación bien planificada, diseñada, construida y mantenida, es necesario que el personal investigador y el personal al cuidado de los animales esté bien formado y entrenado, sea conocedor de los peligros y capaz de dominar las técnicas para controlar la contaminación de la instalación y de los animales.

Entre los diez Institutos de Investigación Sanitaria sometidos a análisis son siete de ellos los que disponen de esta unidad específica de experimentación en barrera, siendo esta instalación destinada a la experimentación con ratas y/o ratones:

\footnotetext{
${ }^{43}$ Ver apartado 6.2.4. Conceptos generales: las barreras
} 
1. IiSGM Instituto de Investigación Sanitaria Gregorio Marañón Madrid

2. IIS Biodonostia Instituto de Investigación Sanitaria Biodonostia Gipuzkoa

3. IIS Biocruces Instituto Ramón y Cajal de Investigación Sanitaria

Bizkaia

4. IISA

IIS Aragón Instituto de Investigación Sanitaria Aragón

Zaragoza

5. VHIR

IR-HUVH Institut de Recerca Hospital Universitari Vall D’hebron

Barcelona

6. IGTP Institut d’investigació en Ciéncies de la Salut Germans Trias I Pujol

Barcelona

7. IIS La Fe Fundación para la Investigación del Hospital Universitario La Fe

Valencia

El análisis de esta unidad se realiza en primer lugar a partir del estudio de los locales que lo componen habitualmente; en segundo lugar, tomando como referencia las representaciones gráficas estandarizadas de la unidad de experimentación en barrera de animal pequeño se hace una breve descripción de la composición de cada una de ellas, para, en tercer lugar, analizar sus características generales; y, por último, en cuarto lugar, se estudia la organización del área, así como la configuración de los accesos diseñados. 


\subsubsection{Locales que componen la unidad de experimentación en barrera}

La mayoría de las instalaciones de barrera para roedores tienen procedimientos de trabajo específicos que impiden que los animales regresen a la barrera una vez que han salido de ella. Esto significa que las barreras, además de tener que estar diseñadas para garantizar la protección de los animales frente a los agentes externos, el cuidado y bienestar animal, así como las condiciones de trabajo y seguridad del personal, tienen que estar diseñadas para alojar los locales, instalaciones, equipos y servicios necesarios para el desarrollo de la investigación sin tener que salir de ella.

La peculiaridad de este tipo de instalaciones es que con el fin de mantener la calidad del aire interior y evitar la entrada de agentes patógenos, es necesario diseñar unos puntos de entrada y salida específicos para las personas, animales, suministros y residuos que son los que van a determinar los pasos fronterizos entre el interior y el exterior de la barrera.

Los principales locales que componen la unidad de experimentación en barrera de animal pequeño son las siguientes:
a) Salas de alojamiento de animales
b) Salas de procedimientos y experimentación
c) Almacenes material limpio
d) Área de lavado y esterilización
e) Sistemas de acceso a barrera

a) Salas de alojamiento de animales. Son los locales donde van a vivir normalmente los animales con los que se va a experimentar. En este caso, se trata de mantener el ambiente interior lo más estéril posible y es por ello que aparte del macro ambiente, que es la sala donde se van a alojar los animales, también se debe tener en cuenta el micro ambiente, que es la jaula con la que está en contacto directo y que contiene todos los recursos que los animales necesitan.

b) Salas de procedimientos. Son las salas destinadas a la realización de aquellos procedimientos que no se recomienda que se realicen en las salas de alojamiento porque puedan causar angustia a los animales o porque no se pueda realizar en ellas. La mayoría de los procedimientos rutinarios con animales, como pesar, dosificar o la recolección de fluidos corporales, entre otros, se realiza generalmente en la cabina de flujo laminar dentro de la propia sala de estabulación de animales. Las salas de experimentación que se encuentran habitualmente en la zona de barrera son las salas de comportamiento, microcirugía y laboratorio transgénico, entre otros.

c) Almacén material limpio. Local de servicio destinado a almacenar dentro de la unidad todo el material estéril necesario para el funcionamiento de la instalación; los carros, las jaulas y la 
comida fundamentalmente. En la zona periférica de la instalación se tiende a ubicar el resto de los locales de servicio necesarios para el funcionamiento de la instalación tales como el de material limpio, equipos, limpieza y residuos generados. Además, debería preverse una zona de almacenaje seguro para los suministros rutinarios de laboratorio, tales como agujas, jeringas, tubos de ensayo, tejidos, cortinas, etc. y de reposición periódica, debido a los requisitos poco prácticos para poder introducir los materiales a la zona de barrera.

d) Área de lavado y esterilización. En la zona de lavado y esterilización se reciben todas las jaulas sucias de los animales para vaciarlas, lavarlas, prepararlas y esterilizarlas para poder volver a alojar los animales en ellas. El mismo proceso siguen los biberones en el caso de que así sea el suministro de agua y el material sea de tipo reutilizable.

e) Sistemas de acceso a barrera. Las instalaciones en barrera se consideran salas de ambiente controlado cuyo objetivo es mantener una calidad de aire determinada evitando que accedan a ella agentes patógenos que puedan afectar al estado sanitario de los animales. Pueden estar diseñadas y gestionadas para diferentes niveles de control microbiológico, lo que se traduce en un grado determinado de exigencia a la hora de plantear cómo entran y salen de la zona de barrera las personas, los animales, los suministros, los equipos y los residuos. Independientemente del nivel exigido, en las instalaciones de barrera es necesario diseñar unos puntos de entrada y salida determinados que son los que van a determinar los pasos fronterizos entre el interior y el exterior de la barrera.

Según analizaremos durante el estudio de estas instalaciones, tanto los accesos para el personal, los materiales y los animales, como la salida de las jaulas sucias y los residuos se pueden desarrollar de diferentes maneras en base a los criterios de asepsia establecidos por el propio centro. 


\subsubsection{Representaciones gráficas de la distribución de la unidad de experimentación en barrera}

A partir de los planos en planta estandarizados que se han desarrollado de cada uno de los centros de experimentación animal y que se encuentran recogidos en las fichas de toma de datos, se ha seleccionado exclusivamente el área destinada a la unidad de experimentación en barrera de animal pequeño. Con estas representaciones gráficas se pretende tener una visión específica de su configuración y de las distintas circulaciones diseñadas (Figuras 134-141).

Para facilitar el estudio, en los planos de distribución en planta se ha identificado por código de colores el área funcional y la unidad de experimentación al que pertenece y por código numérico el tipo de local que es. Con el fin de realizar una lectura sencilla de las circulaciones, se representa; por una parte, mediante líneas de diferentes trazos y colores la dirección; y, por la otra, mediante flechas el sentido hacia donde va dirigida la circulación para el personal, para los animales, los suministros y la retirada de residuos (Figura 134). Junto a cada una de las representaciones gráficas se hace una breve descripción de la configuración de la unidad de experimentación en barrera de animal pequeño.

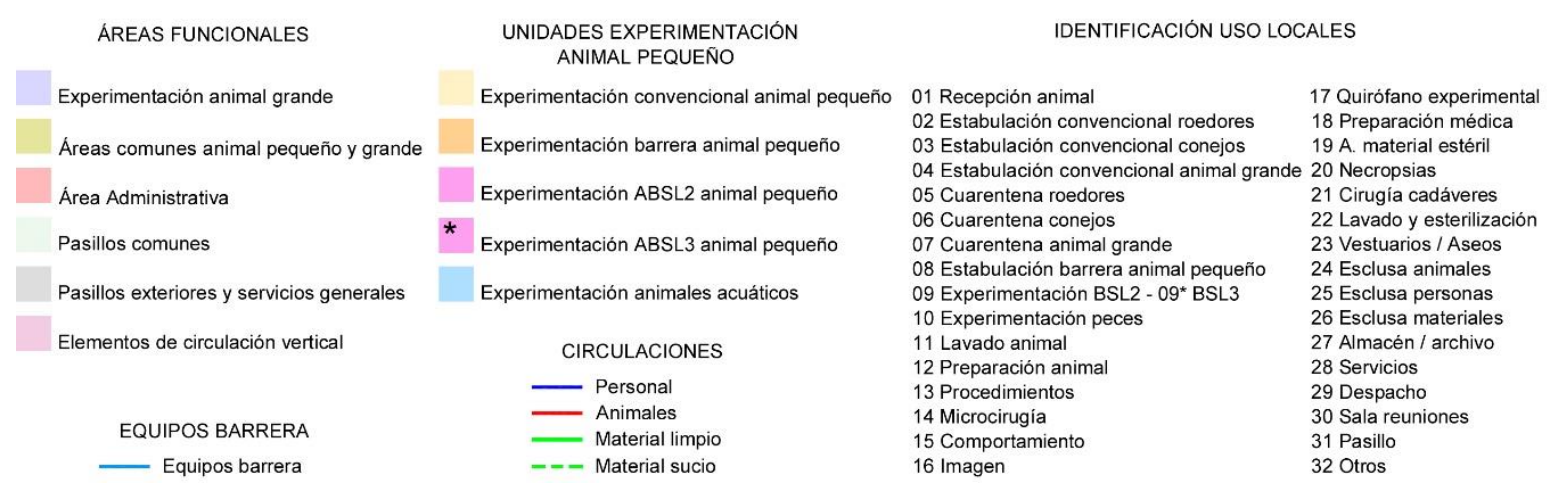

Figura 134. Leyenda unidad experimentación barrera animal pequeño.

Fuente. Elaboración propia.

*Esta leyenda se hace extensible a las figuras 135-141. 
La unidad de experimentación en barrera de animal pequeño del instituto liSGM (Figura 135) se desarrolla en una planta baja en la que comparte locales de servicio, tales como los vestuarios de cambio de personal, los almacenes, la zona de cuarentena y la sala de lavado con el área de experimentación convencional. Las personas acceden a la barrera a través de una esclusa para personas, mientras que los animales y los suministros acceden a través de los equipos ubicados en la sala de lavado. La unidad se compone de dos almacenes de material estéril: dos salas para estabulación para roedores y dos salas para experimentación.

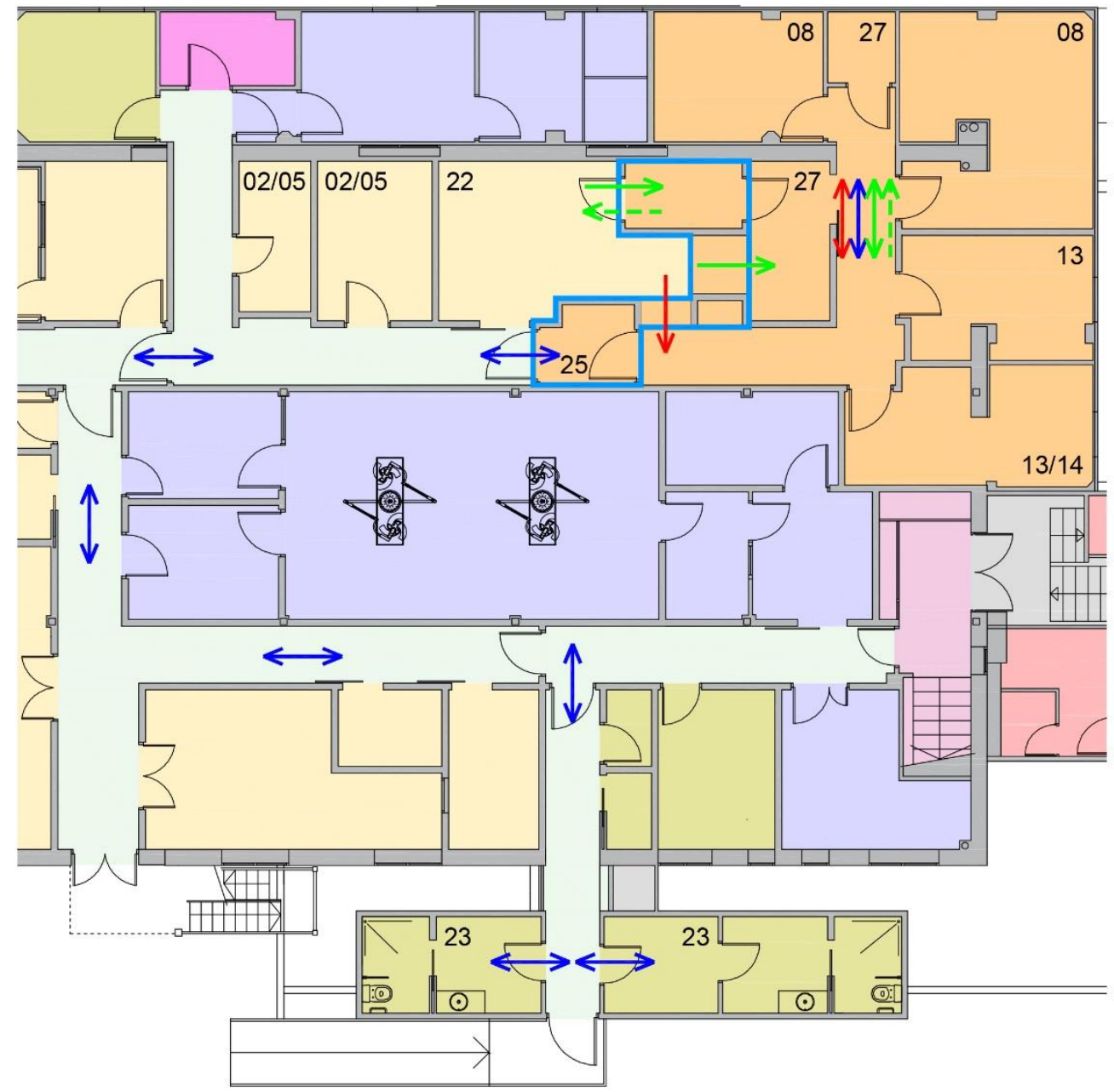

ÁREAS FUNCIONALES

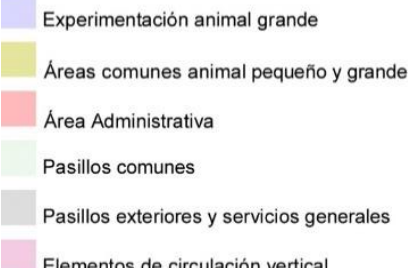

Elementos de circulación vertical

EQUIPOS BARRERA

Equipos barrera
UNIDADES EXPERIMENTACIÓN ANIMAL PEQUEÑO

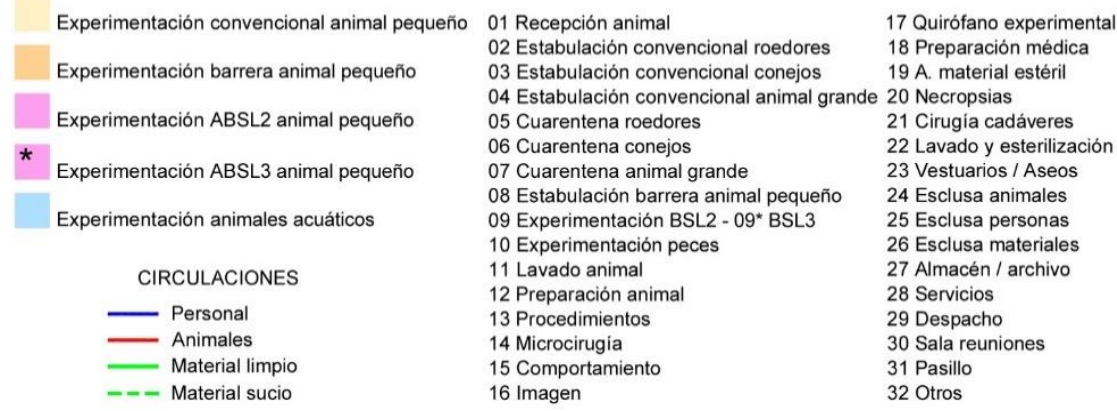

Figura 135. Unidad experimentación barrera animal pequeño liSGM (S/E).

Fuente. Elaboración propia. 


\section{La unidad de experimentación en barrera de animal pequeño del instituto IIS Biodonostia}

(Figura136) se desarrolla en una planta semisótano en la que comparte locales de servicio, tales como los vestuarios de cambio de personal, los almacenes, la zona de cuarentena y la sala de lavado con el área de experimentación convencional. Las personas utilizan la zona de vestuarios general para acceder al animalario, y un SAS de personas para acceder a la zona de barrera. Por otra parte, los animales y los suministros acceden a través del equipo instalado para tal fin con acceso desde el pasillo de distribución general. Internamente, la unidad se compone de tres salas de alojamiento en las que también se realizan pequeños procedimientos.

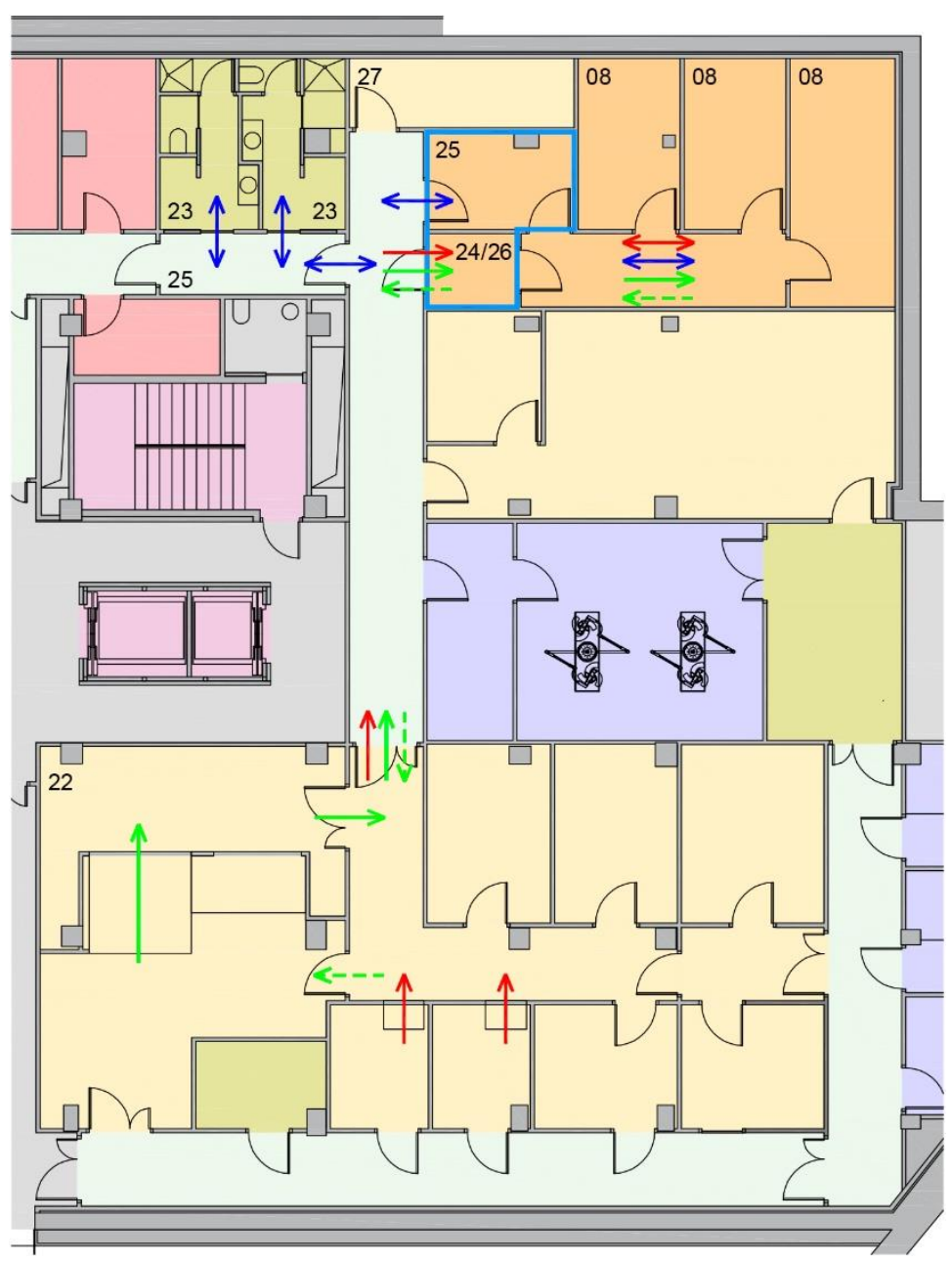

AREAS FUNCIONALES

Experimentación animal grande

Áreas comunes animal pequeño y grande

Area Administrativa

Pasillos comunes

Pasillos exteriores y servicios generales

Elementos de circulación vertical

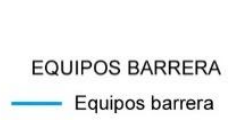

UNIDADES EXPERIMENTACIÓN ANIMAL PEQUEÑO

Experimentación convencional animal peque
Experimentación barrera animal pequeño
Experimentación ABSL2 animal pequeño
* Experimentación ABSL3 animal pequeño
Experimentación animales acuáticos
CIRCULACIONES
- Personal
- Material limpio
-- Material sucio

IDENTIFICACIÓN USO LOCALES

01 Recepción animal

02 Estabulación convencional roedores $\begin{array}{ll}02 \text { Estabulación convencional roedores } & 18 \text { Preparación médica } \\ 03 \text { Estabulación convencional conejos } & 19 \mathrm{~A} \text {. material estéril }\end{array}$ 04 Estabulación convencional animal grande 20 Necropsias 05 Cuarentena roedores 21 Cirugia cadáveres 06 Cuarentena conejos 22 Lavado y esterilización 07 Cuarentena animal grande 23 Vestuarios / Aseos 08 Estabulación barrera animal pequeño 24 Esclusa animales 09 Experimentación BSL2 - 09* BSL3 25 Esclusa personas 10 Experimentación peces 26 Esclusa materiales 11 Lavado animal 27 Almacén/archivo 12 Preparación anim 12. Preparación anim 13 Procedimientos 15 Comportamiento 16 Imagen

28 Servicios

29 Despacho

30 Sala reuniones

31 Pasillo 32 Otros

Figura 136. Unidad experimentación barrera animal pequeño IIS Biodonostia (S/E). Fuente. Elaboración propia. 
La unidad de experimentación en barrera de animal pequeño del instituto IIS Biocruces (Figura137) se desarrolla en una planta sótano -1 integrada con la unidad de experimentación convencional de animal pequeño con la que comparte locales de servicio tales como los vestuarios de cambio de personal, los almacenes, la zona de cuarentena y la sala de lavado. Las personas utilizan la zona de vestuarios general para acceder al animalario, además de un vestuario propio de la unidad de barrera en la que además de cambio de ropa se debe hacer uso de la ducha de aire para acceder a ella. Por otra parte, los animales acceden desde una ventana SAS ubicada en la sala de cuarentena que es compartida con la unidad convencional, mientras que los suministros acceden a través de los equipos de barrera instalados en la sala de lavado y esterilización. La unidad se compone de una sala de alojamiento desde la que se accede a la única sala de experimentación y de dos almacenes para material.

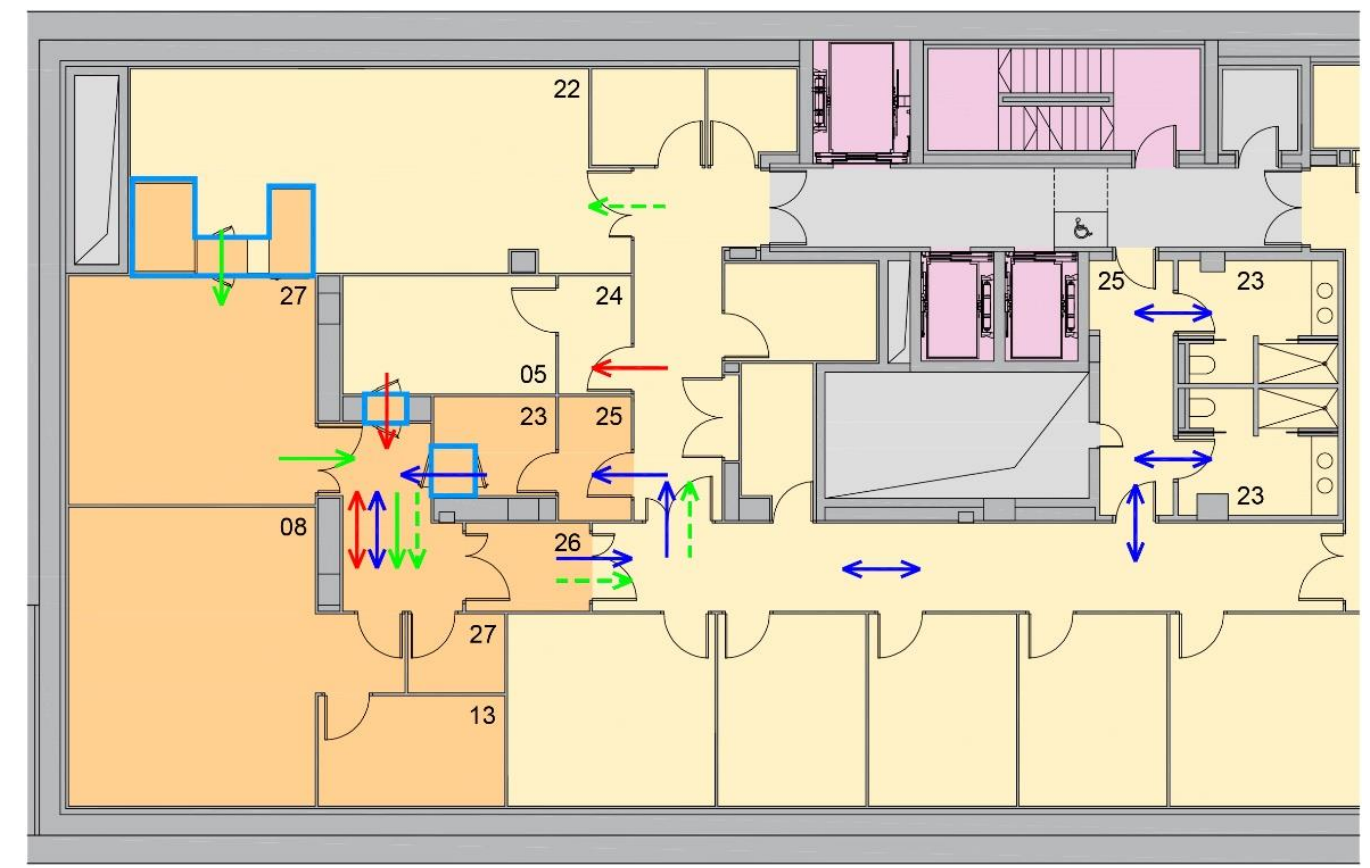

AREAS FUNCIONALES

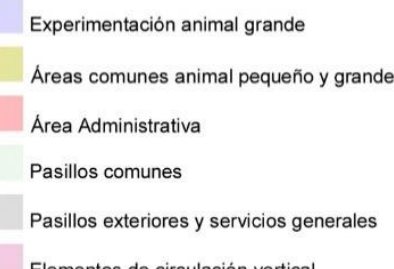

Elementos de circulación vertical

EQUIPOS BARRERA

Equipos barrera
UNIDADES EXPERIMENTACIÓN ANIMAL PEQUEÑO

Experimentación convencional animal pequeño
Experimentación barrera animal pequeño
Experimentación ABSL2 animal pequeño
* Experimentación ABSL3 animal pequeño
Experimentación animales acuáticos
CIRCULACIONES
$\square$ Personal
- Material limpio
--- Material sucio

\section{IDENTIFICACIÓN USO LOCALES}

01 Recepción animal

17 Quirófano experimental

02 Estabulación convencional roedores 18 Preparación médica

03 Estabulación convencional conejos $19 \mathrm{~A}$. material esté

$\begin{array}{ll}04 \text { Estabulación convencional animal grande } 20 \text { Necropsias } \\ 05 \text { Cuarentena roedores } & 21 \text { Cirugia cadáveres }\end{array}$

$\begin{array}{ll}05 \text { Cuarentena roedores } & 21 \text { Cirugia cadáveres } \\ 06 \text { Cuarentena conejos } & 22 \text { Lavado y esterilización }\end{array}$

07 Cuarentena animal grande 23 Vestuarios / Aseos

08 Estabulación barrera animal pequeño 24 Esclusa animales

09 Experimentación BSL2 - 09* BSL3 25 Esclusa personas

10 Experimentación peces 26 Esclusa materiales

11 Lavado animal 27 Almacén / archivo

12 Preparación anima

13 Procedimientos

14 Microcirugia

15 Comportamiento

16 Imagen
28 Servicios

29 Despacho

31 Pasillo
30 Sala reuniones

Figura 137. Unidad experimentación barrera animal pequeño IIS Biocruces (S/E).

Fuente. Elaboración propia. 
La unidad de experimentación en barrera de animal pequeño del instituto IISA (Figura 138) se desarrolla en una planta sótano -1 integrada con la unidad de experimentación convencional de animal pequeño. Dispone de vestuarios propios e independientes para el acceso del personal a la unidad previo paso por una ducha de aire, mientras que los materiales limpios se introducen a través de los equipos de barrera instalados en las sala de lavado y esterilización compartida con la unidad convencional. Los animales, en cambio, se introducen a la zona de barrera a través de una ventana SAS diseñada para ello.

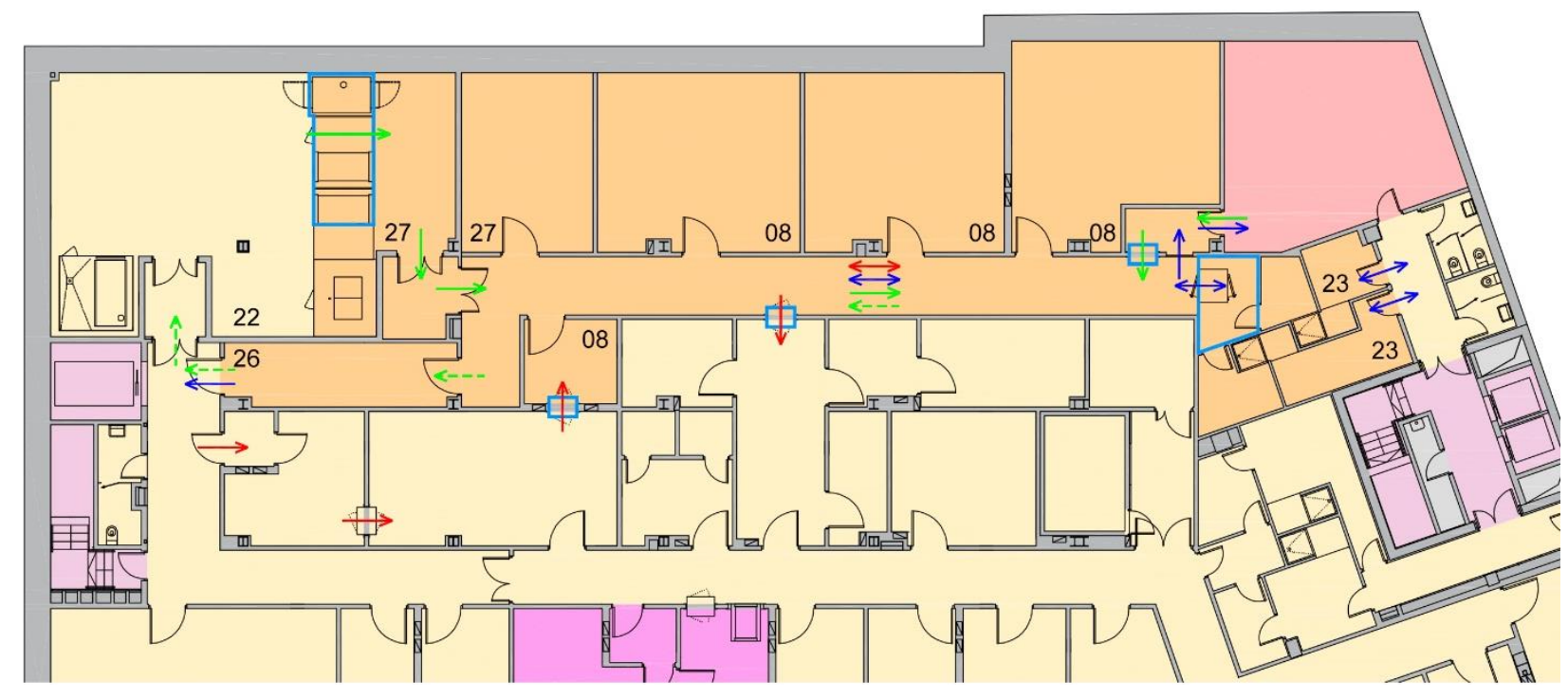

ÁREAS FUNCIONALES

Experimentación animal grande

Áreas comunes animal pequeño y grande

Area Administrativa

Pasillos comunes

Pasillos exteriores y servicios generales

Elementos de circulación vertical

EQUIPOS BARRERA

- Equipos barrera
UNIDADES EXPERIMENTACIÓN ANIMAL PEQUEÑO

Experimentación convencional animal pequeño 01 Recepción animal

Experimentación barrera animal pequeño

Experimentación ABSL2 animal pequeño

Experimentación ABSL3 animal pequeño

Experimentación animales acuáticos

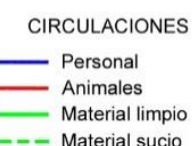

02 Estabulación convencional roedores 03 Estabulación convencional conejos

04 Estabulación convencional animal grande 20 Necropsias

05 Cuarentena roedores 21 Cirugia cadáveres

06 Curenter

07 Cuarentena animal grande

08 Estabulación barrera animal pequeño

09 Experimentación BSL2 - 09* BSL3

10 Experimentación peces

11 Lavado animal

12 Preparación animal

13 Procedimientos

14 Microcirugia

15 Comportamiento

16 Imagen
22 Lavado y esterilización

23 Vestuarios / Aseos

24 Esclusa animales

25 Esclusa personas

26 Esclusa materiales

27 Almacén / archivo

28 Servicios

29 Despacho

30 Sala reuniones

31 Pasillo

Figura 138. Unidad experimentación barrera animal pequeño IISA (S/E).

Fuente. Elaboración propia. 
La unidad de experimentación en barrera de animal pequeño del instituto VHIR (Figura 139) se desarrolla en una planta sótano -2 integrada con la unidad de experimentación convencional de animal pequeño. Aunque se comparte con la unidad convencional servicios generales, la unidad de barrera dispone de circuitos diferenciados para el personal, los animales, el suministro de materiales y la retirada de residuos. El personal accede a través de una ducha de aire previo paso por el vestuario propio. Por otra parte, los animales tienen una zona de recepción animal para introducirlos a través de un SAS y los materiales limpios acceden a través de los equipos de barrera ubicados en la sala de lavado, mientras que los residuos se retiran a través de un vestíbulo propio. Internamente, la unidad se compone de un almacén de material estéril, dos salas de estabulación, tres salas de procedimientos y un despacho.

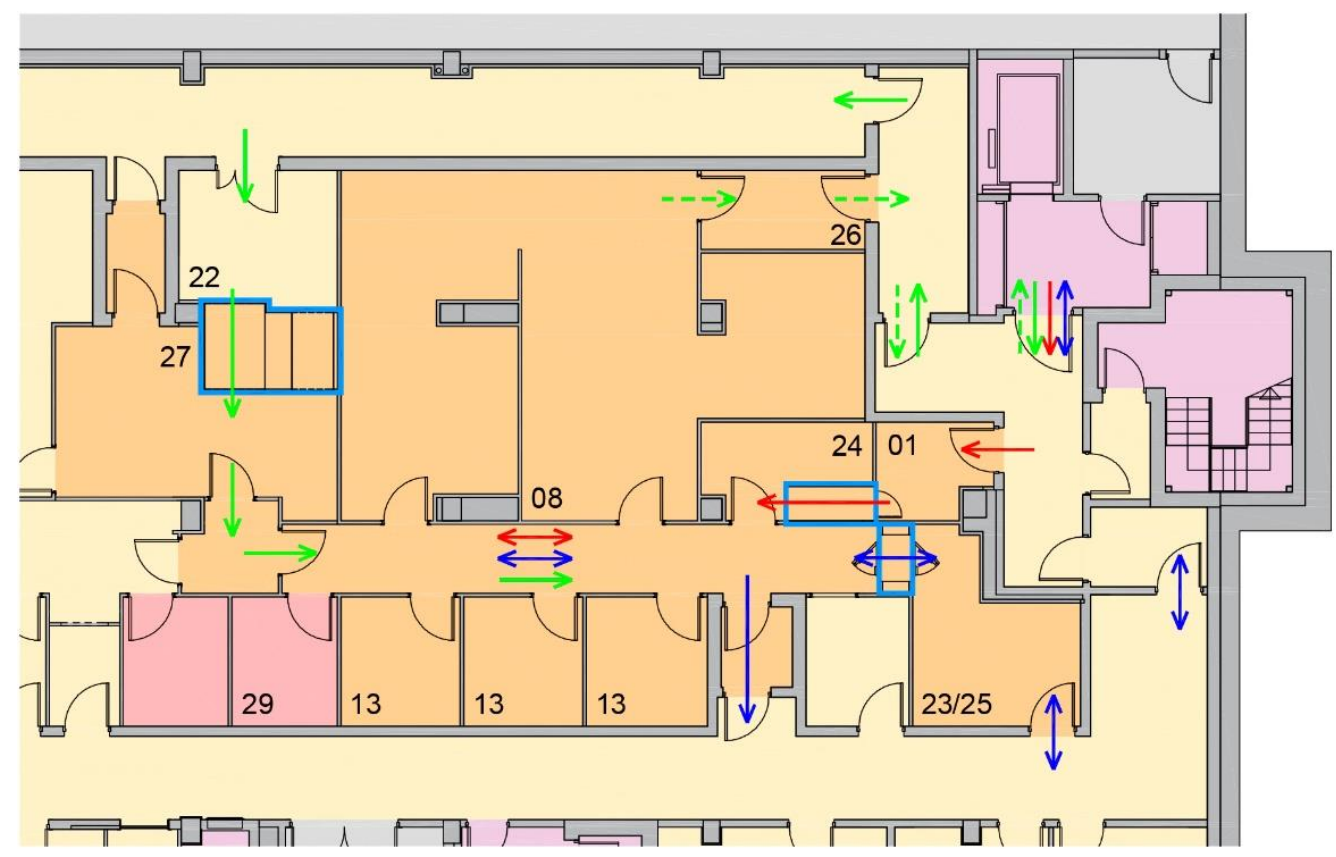

ÁREAS FUNCIONALES

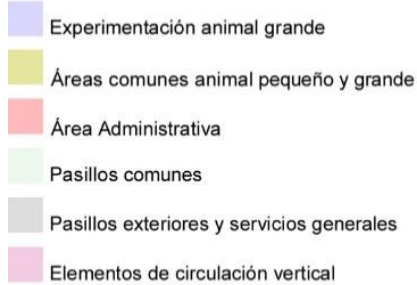

EQUIPOS BARRERA
UNIDADES EXPERIMENTACIÓN ANIMAL PEQUEÑO

Experimentación convencional animal pequeño
Experimentación barrera animal pequeño
Experimentación ABSL2 animal pequeño
* Experimentación ABSL3 animal pequeño
Experimentación animales acuáticos
CIRCULACIONES
- Personal
- Mnimales
-- Material limpio

IDENTIFICACIÓN USO LOCALES

01 Recepción animal 19 A. material estéri 04 Estabulación convencional animal grande 20 Necropsias 05 Cuarentena roedores 21 Cirugia cadáveres 06 Cuarentena conejos 07 Cuarentena animal grande 23 Vestuarios / Aseos 24 Esclusa animales 09 Experimentación BSL2 - 09* BSL3 25 Esclusa personas 10 Experimentación peces 26 Esclusa materiales 11 Lavado animal 12 Preparación animal 13 Procedimientos 14 Microcirugia 15 Comportamiento
16 Imagen 27 Almacén / archivo 28 Servicios 29 Despacho 30 Sala reuniones 31 Pasillo 32 Otros

Figura 139. Unidad experimentación barrera animal pequeño VHIR (S/E).

Fuente. Elaboración propia. 
La unidad de experimentación en barrera de animal pequeño del instituto IGTP (Figura 140) se desarrolla en una planta semisótano integrada con la unidad de experimentación convencional y ABSL3 de animal pequeño. Aunque comparte con la unidad convencional servicios generales, la unidad de barrera dispone de servicios propios para el acceso del personal y los materiales. El personal accede a la unidad a través de un vestuario y SAS para personas. Por otra parte, tanto los materiales como los animales se introducen a través de los equipos de barrera propios ubicados en una sala compartida con los equipos de barrera de la zona de experimentación ABSL3. Internamente, la unidad se compone de cuatro salas de estabulación, cuatro salas de experimentación y un almacén para material.

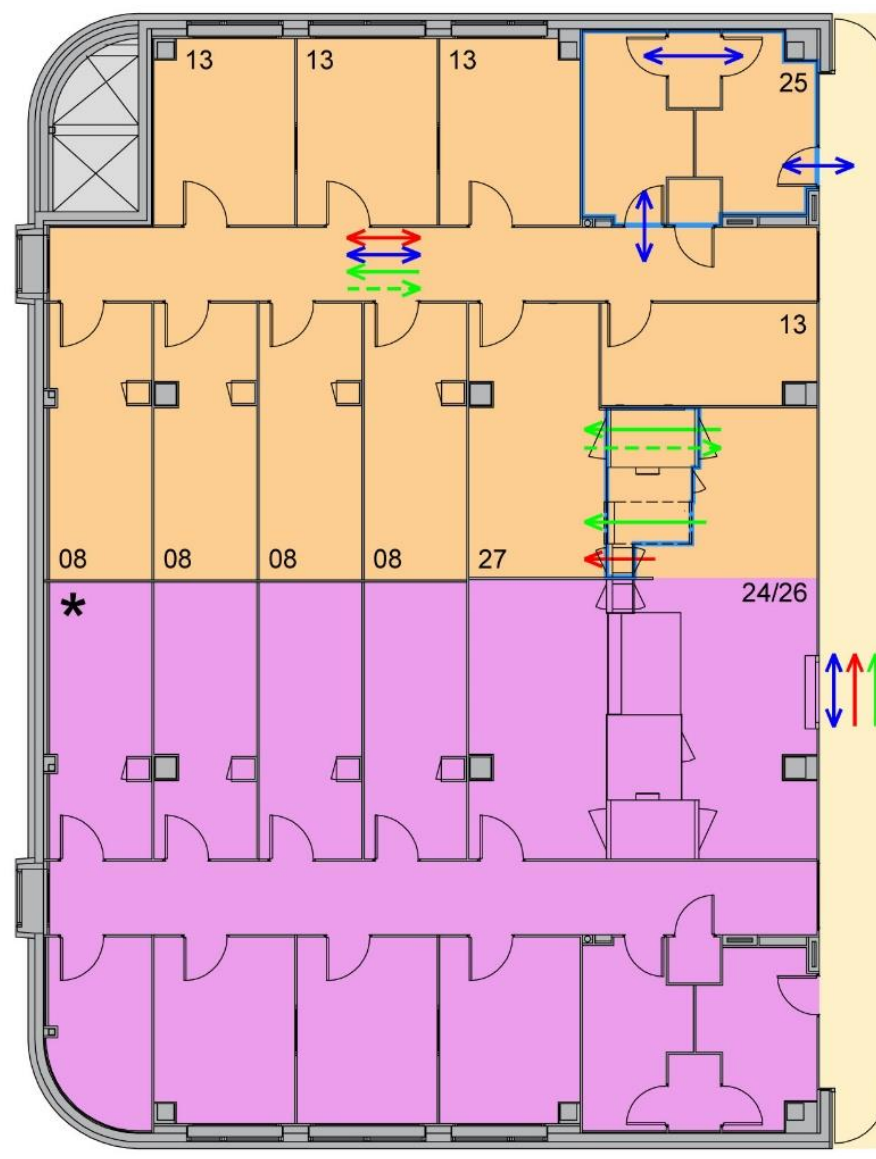

ÁREAS FUNCIONALES

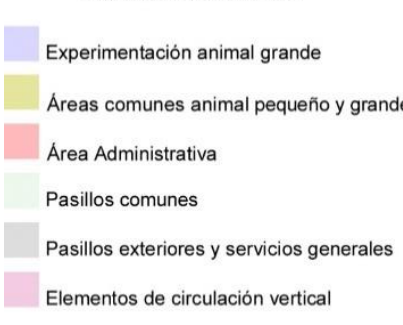

EQUIPOS BARRERA

Equipos barrera
UNIDADES EXPERIMENTACIÓN ANIMAL PEQUEÑO

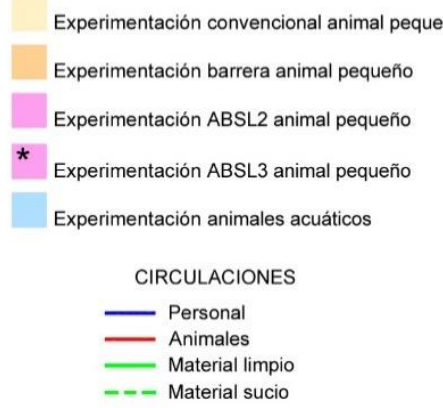

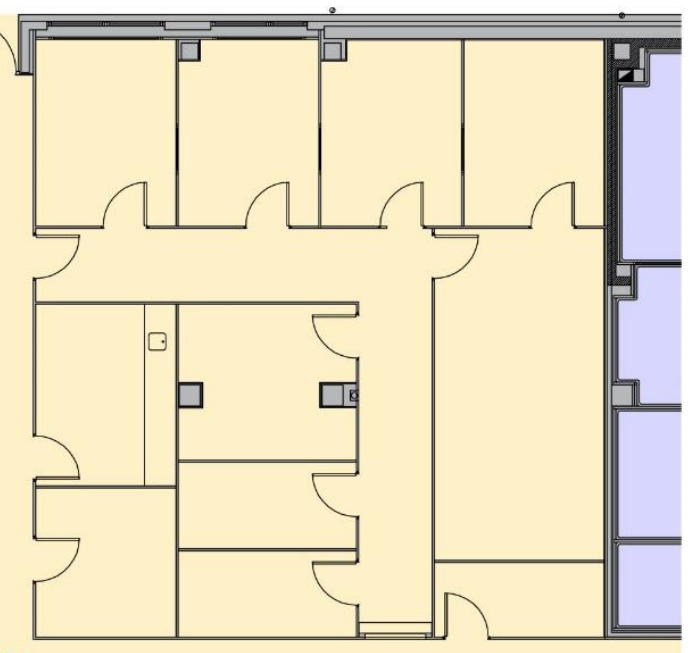

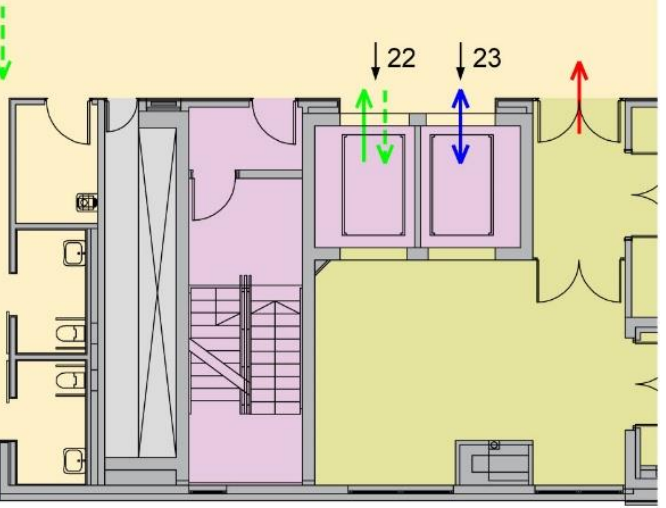

IDENTIFICACIÓN USO LOCALES

01 Recepción animal

02 Estabulación convencional roedores 03 Estabulación convencional conejos Estabulación convencional animal grande 20 Necropsias 05 Cuarentena roedores 21 Cirugia cadáveres 07 Cuarentena animal grande 22 Lavado y esterilización 08 Estabulación barrera animal pequeño 24 Esclusa animales 09 Experimentación BSL2 - 09* BSL3 25 Esclusa personas 10 Experimentación peces 26 Esclusa materiales $\begin{array}{ll}10 \text { Experimentación peces } & 26 \text { Esclusa materiales } \\ 11 \text { Lavado animal } & 27 \text { Almacén / archivo }\end{array}$ 12 Preparación animal 13 Procedimientos 15 Comportamiento 16 Imagen

$$
\begin{aligned}
& 17 \text { Quirófano experimental } \\
& 18 \text { Preparación médica } \\
& 19 \text { A. material estéril } \\
& 20 \text { Necropsias } \\
& 21 \text { Cirugia cadáveres } \\
& 22 \text { Lavado y esterilización } \\
& 23 \text { Vestuarios / Aseos } \\
& 24 \text { Esclusa animales } \\
& 25 \text { Esclusa personas } \\
& 26 \text { Esclusa materiales } \\
& 27 \text { Almacén / archivo } \\
& 28 \text { Servicios } \\
& 29 \text { Despacho } \\
& 30 \text { Sala reuniones } \\
& 31 \text { Pasillo } \\
& 32 \text { Otros }
\end{aligned}
$$

Figura 140. Unidad experimentación barrera animal pequeño IGTP (S/E).

Fuente. Elaboración propia. 
La unidad de experimentación en barrera de animal pequeño del instituto IIS La Fe (Figura 141) se desarrolla en una planta sótano -1 integrada con la unidad de experimentación convencional de animal pequeño con la que comparte locales de servicio, tales como los vestuarios generales de cambio de personal, los almacenes y la sala de lavado. Las personas acceden a la zona de barrera a través de una ducha de aire previo paso por un vestuario propio. Por otra parte, los animales acceden desde un SAS ubicado en el pasillo general, mientras que los suministros acceden a través de los equipos instalados en la sala de lavado y esterilización. La unidad se compone de un almacén para material estéril, dos salas de alojamiento de animales, una sala de cuarentena y dos salas de experimentación.

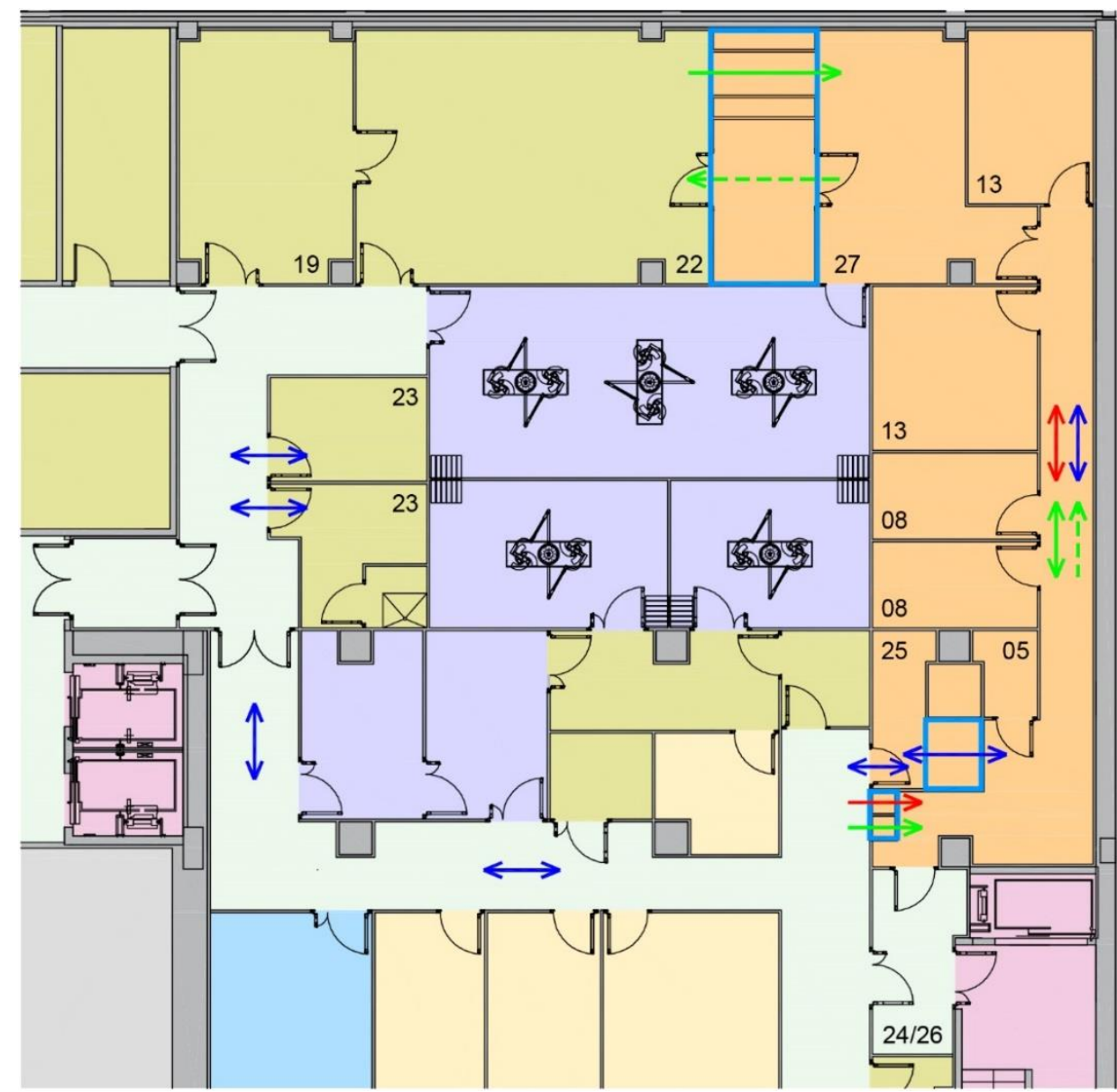

ÁREAS FUNCIONALES

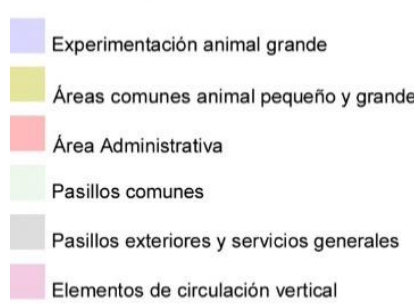

EQUIPOS BARRERA _— Equipos barrera
UNIDADES EXPERIMENTACIÓN ANIMAL PEQUENO

Experimentación convencional animal pequeño 01 Recepción animal

02 Estabulación convencional roedores

03 Estabulación convencional conejos

04 Estabulación conven

06 Cuarentena conejos

07 Cuarentena animal grande

08 Estabulación barrera animal pequeño

09 Experimentación BSL2 - 09* BSL3

10 Experimentación peces

11 Lavado animal

12 Preparación anima

13 Procedimientos

14 Microcirugia

15 Comportamiento

16 Imagen
17 Quirófano experimental 18 Preparación médica 19 A. material estéril 20 Necropsias

21 Cirugia cadáveres 22 Lavado y esterilización 23 Vestuarios / Aseo 24 Esclusa animales 25 Esclusa personas 26 Esclusa materiales 27 Almacén / archivo 28 Servicios 29 Despacho 30 Sala reuniones 31 Pasillo 32 otros

Figura 141. Unidad experimentación barrera animal pequeño IIS La Fe (S/E).

Fuente. Elaboración propia. 


\subsubsection{Características generales de la unidad de experimentación en barrera}

El resultado de la investigación sobre las características generales de la unidad de experimentación en barrera se encuentra reflejado tanto en las fichas de la documentación gráfica como en la toma de datos de cada centro.

Para realizar el análisis de dichas características se ha hecho una puesta en común de los resultados obtenidos y, para ello, se ha optado por resumir las más importantes en una tabla (Tabla 17). En ella se listan los parámetros que definen las características generales de la unidad, se establecen cuáles son las características comunes a la mayoría de ellas y se identifica qué institutos cumplen dichas características; además, se determinan las características que son particulares o específicas, que son aquellas que las cumplen solo unas determinados unidades de experimentación, reflejándose así mismo, cuáles son los institutos que las cumplen. El análisis se centra en los siguientes conceptos:

- La superficie destinada a la experimentación en barrera de animal pequeño, así como la destinada a los locales de alojamiento de los animales.

- Las especies animales utilizadas habitualmente en esta unidad de experimentación.

- El tipo de jaula y estante utilizados, así como la elección realizada para proporcionar el agua necesaria a los animales.

- Los locales de alojamiento y experimentación diseñados para esta área en concreto.

- Los sistemas de acceso y equipos diseñados para el acceso de las personas, los animales y los materiales a la zona de barrera. 
Tabla 17. Características generales unidad experimentación en barrera animal pequeño.

\begin{tabular}{|c|c|c|c|c|}
\hline Parámetros & $\begin{array}{l}\text { Características } \\
\text { comunes }\end{array}$ & $\begin{array}{l}\text { Institutos con } \\
\text { características } \\
\text { comunes }\end{array}$ & $\begin{array}{l}\text { Características } \\
\text { específicas }\end{array}$ & $\begin{array}{l}\text { Institutos con } \\
\text { características } \\
\text { específicas }\end{array}$ \\
\hline $\begin{array}{l}\text { Superficie área } \\
\text { experimentación en } \\
\text { barrera } \\
\text { animal pequeño }\end{array}$ & $<200 \mathrm{~m}^{2}$ & $\begin{array}{l}\text { liSGM, IISBiodonostia, } \\
\text { IISBiocruces, IIS La Fe }\end{array}$ & $>200 \mathrm{~m}^{2}$ & IGTP, IISA, VHIR \\
\hline $\begin{array}{l}\text { Superficie área } \\
\text { estabulación barrera } \\
\text { animal pequeño }\end{array}$ & $<50 \mathrm{~m}^{2}$ & $\begin{array}{l}\text { liSGM, IISBiodonostia, } \\
\text { IISBiocruces, IIS La Fe }\end{array}$ & $>50 \mathrm{~m}^{2}$ & IISA, VHIR, IGTP \\
\hline Especies animales & Rata, ratón & $\begin{array}{l}\text { liSGM, IISBiodonostia, } \\
\text { IISBiocruces, IGTP, IISA, } \\
\text { VHIR, IIS La Fe }\end{array}$ & & \\
\hline $\begin{array}{l}\text { № salas de } \\
\text { alojamiento }\end{array}$ & $\geq 2 \mathrm{Ud}$ & $\begin{array}{l}\text { liSGM, IISBiodonostia, } \\
\text { IGTP, IISA, VHIR, IIS La Fe }\end{array}$ & $1 \mathrm{Ud}$ & IISBiocruces, \\
\hline \multirow{2}{*}{ Tipo de jaula } & Reutilizable & $\begin{array}{l}\text { liSGM, IISBiodonostia, } \\
\text { IISBiocruces, IGTP, IISA, } \\
\text { IIS La Fe }\end{array}$ & Desechable & VHIR \\
\hline & Ventilada individualmente & $\begin{array}{l}\text { liSGM, IISBiodonostia, } \\
\text { IISBiocruces, IGTP, IISA, } \\
\text { VHIR, IIS La Fe }\end{array}$ & & \\
\hline Suministro de bebida & Biberones & $\begin{array}{l}\text { liSGM, IISBiodonostia, } \\
\text { IISBiocruces, IGTP, IISA, } \\
\text { VHIR, IIS La Fe }\end{array}$ & & \\
\hline $\begin{array}{l}\text { Sistema acceso } \\
\text { personas }\end{array}$ & Ducha aire & $\begin{array}{l}\text { IISBiocruces, IISA, VHIR, } \\
\text { IIS La Fe }\end{array}$ & SAS personas & $\begin{array}{l}\text { liSGM, } \\
\text { IISBiodonostia, IGTP }\end{array}$ \\
\hline $\begin{array}{l}\text { Sistema acceso } \\
\text { animales }\end{array}$ & Ventana SAS & $\begin{array}{l}\text { liSGM, IISBiocruces, IGTP, } \\
\text { IISA, VHIR, IIS La Fe }\end{array}$ & & \\
\hline $\begin{array}{l}\text { Sistema acceso } \\
\text { materiales }\end{array}$ & Cabina VPH & $\begin{array}{l}\text { liSGM, IISBiocruces, } \\
\text { IISBiocruces, IGTP, IISA, } \\
\text { VHIR, IIS La Fe }\end{array}$ & Autoclave & $\begin{array}{l}\text { liSGM, IISBiocruces, } \\
\text { IGTP, IISA, VHIR, IIS } \\
\text { La Fe }\end{array}$ \\
\hline
\end{tabular}

Fuente. Elaboración propia.

\section{Dimensionamiento}

En relación a la superficie destinada a este ámbito vemos que es muy variable de manera que si bien algún centro dispone de una superficie inferior a los $100 \mathrm{~m}^{2}$ (IISGM), observamos otro cuya superficie es superior a los $300 \mathrm{~m}^{2}$ (IISA). En el cómputo de la superfice se ha considerado únicamente la superficie de la zona de barrera teniendo en cuenta los diversos equipos para poder acceder a ella. Haciendo un análisis general y agrupandolos por rango de superficie observamos que la mayoría disponen de una superficie inferior a los $200 \mathrm{~m}^{2}$ (IISGM, IISBiodonostia, IISBiocruces, IIS La Fe). Además, dentro de esta superficie, la destinada al alojamiento de los animales suele ser una superficie normalmente inferior a los $50 \mathrm{~m}^{2}$.

\section{Especies animales}

De entre los diez institutos investigados, siete de ellos son los que disponen de una unidad destinada a la investigación en barrera (IiSGM, IISBiodonostia, IISBiocruces, IGTP, IISA, VHIR, IIS La Fe), estando esta unidad diseñada para alojar el ratón, la especie más utilizada en experimentación animal junto con la rata. 
Lo habitual es que a la zona de barrera solo se permita el acceso de animales con un estado sanitario definido SPF, mediante rederivación sanitaria o que dispongan de un certificado sanitario de proveedores autorizados con solvencia contrastadas y altamente especializados en la cría de animales de experimentación. Además, una vez que los animales salen de la zona de barrera, no pueden volver a regresar a ella, siendo habitual que permanezcan en ella hasta la finalización de la experimentación. Los animales alojados en esta zona suelen ser animales de cría, animales genéticamente definidos, modificados genéticamente e inmunodeprimidos.

\section{Tipos de jaulas}

La barrera primaria más común utilizada en la actualidad es a nivel de la jaula. En las instalaciones en barrera analizadas, todas las jaulas instaladas son de tipo autoventiladas. Este tipo de jaulas están especialmente diseñadas para proporcionarles una ventilación controlada individualmente, ya que cuentan con una tapa que se conecta al sistema de ventilación con filtros absolutos HEPA, tanto en la impulsión como en la extracción, pudiendo ajustarse a presión negativa o positiva en función de los requerimientos específicos de la experimentación.

El uso de este tipo de jaulas lleva inevitablemente asociado la necesidad de hacer uso de las cabinas de flujo laminar para el cambio de jaula, siendo su objetivo conseguir la máxima protección de los animales, evitando la exposición y previniendo la contaminación cruzada al sacarlos de la jaula sucia para trasladarlos a la limpia.

Las jaulas deben permitir la observación diaria de los animales con una perturbación mínima. En este sentido, se observa que todas las jaulas utilizadas en la unidad de experimentación en barrera son de plástico transparente, lo que permite una observación directa de los animales desde el exterior. Además, en prácticamente todos los casos la jaula es reutilizable, excepto en el caso del VHIR, en el que las jaulas son desechables.

Las jaulas ventiladas se alojan en unos estantes especialmente diseñados para ello, que dispone del sistema de ventilación con filtración necesaria y que, en la mayoría de los casos, está conducida al sistema de extracción general de la sala, con el fin de mantener la sala en las mejores condiciones higiénicas y de olores posibles. En los casos en los que la extracción no se ha conducido durante la fase de ejecución de la obra, se observa que se ha tenido que acabar de realizar a posteriori (IISBiodonosti). La estantería, además, cuenta con un panel de control que permite registrar la temperatura, la humedad, las renovaciones de aire y el estado de los filtros, entre otros parámetros. 


\section{Locales de alojamiento}

Generalmente, cualquier sala donde los animales puedan permanecer durante más de 24 horas se debería considerar como sala de alojamiento. Aunque lo habitual es que el número de locales de alojamiento sea igual o superior a dos unidades, encontramos una zona de barrera que cuenta con una única sala de estabulación (IIS Biocruces). En muchos casos se ha considerado preferible disponer varias salas de estabulación más pequeñas frente a una única sala más grande. Esta circunstancia permite, ante cualquier problema no previsto en una sala de estabulación, tener una segunda opción de alojamiento. En los casos en los que existen varias salas de estabulación, la tendencia es diseñarlas de diferentes tamaños.

El dimensionamiento de estas salas de estabulación está condicionado; por una parte, por la decisión de si en el local de alojamiento de animales se van a realizar procedimientos varios; $y$, por otra parte, por el tipo y configuración del estante seleccionado para el alojamiento de la jaula ventilada, por el dimensionamiento del equipo que se va a utilizar dentro de la sala para hacer el cambio de jaula para los roedores y por el tipo de carro que se va a utilizar para alojar las jaulas limpias. Para optimizar el dimensionamiento de las salas es necesario conocer el tipo de estante desde la fase de diseño, entre otros motivos, porque los equipos de ventilación pueden tener distintas ubicaciones y cuando se ubican en la parte superior del estante, adquiere una altura superior a la altura estándar de las puertas, siendo necesario su desmontaje para poder introducir y retirar el estante de la sala.

Las necesidades de suministro de los equipos para este tipo de instalaciones incluyen los requerimientos de los racks ventilados: tomas eléctricas, toma de datos, toma de agua en caso de suministro automático, que deben estar distribuidos acorde a su distribución en la sala de estabulación. Aunque hay guías que recomiendan tener disponible un pequeño lavabo con agua fría y caliente dentro de la sala de estabulación, este criterio no es compartido por todos los responsables de los centros visitados, ya que se considera un posible foco de contaminación de la sala que puede aportar más problemas que beneficios.

\section{Salas de experimentación}

En general, se recomienda diseñar una sala de procedimientos cada tres o cuatro salas de estabulación de animal pequeño (Division of technical resources 2012, p. 2-60). En el estudio realizado observamos que este criterio se cumple en todos los casos. Por otra parte, se observa que en algunos casos, las salas de estabulación son también las destinadas a los procedimientos (IIS Biodonostia, IISA). Donde se han diseñado salas específicas de procedimientos, lo habitual es que el número sea igual o superior a dos, si bien nos encontramos un centro en el cual se ha diseñado una única sala (IIS Biocruces). Para 
ofrecer mayor flexibilidad a la instalación, sería conveniente que las salas de procedimientos de las unidades investigadas pudieran convertirse en salas de estabulación animal.

\section{Acceso de personas}

Los requisitos para el acceso de las personas a una barrera varían considerablemente dependiendo de la función de la barrera, la investigación a desarrollar dentro de la barrera y los criterios del responsable del animalario; en definitiva, del nivel de control microbiológico exigible a la instalación. Un alto nivel de barrera puede ser exigible para mantener la reproducción de los animales transgénicos, de manera que los accesos se pueden limitar a unas pocas personas, y pueden tener como requisito de entrada cambiarse de ropa y ducharse. Mientras que un nivel inferior de exigencia de la barrera utilizada para alojar animales en estudio, puede permitir el acceso a más personas, y los requisitos de entrada pueden reducirse a ponerse los equipos de protección individual necesarios sobre ropa de trabajo.

Según el estudio realizado, el criterio adoptado para el acceso del personal a la zona de barrera se produce de dos maneras posibles:

- En la mayoría de los casos, (IISBiocruces, IISA, VHIR, IIS La Fe) existe una ducha de aire para el acceso a la zona de barrera, previo paso por un vesturio para cambio de vestimenta. Las duchas de aire son las esclusas activas que permiten descontaminar al personal antes de acceder a la zona limpia. La persona es chorreada con aire limpio a través de las toberas integradas en la ducha, de manera que las partículas que se desprenden de la persona son aspiradas y filtradas cerca del nivel del suelo (Figura 142).
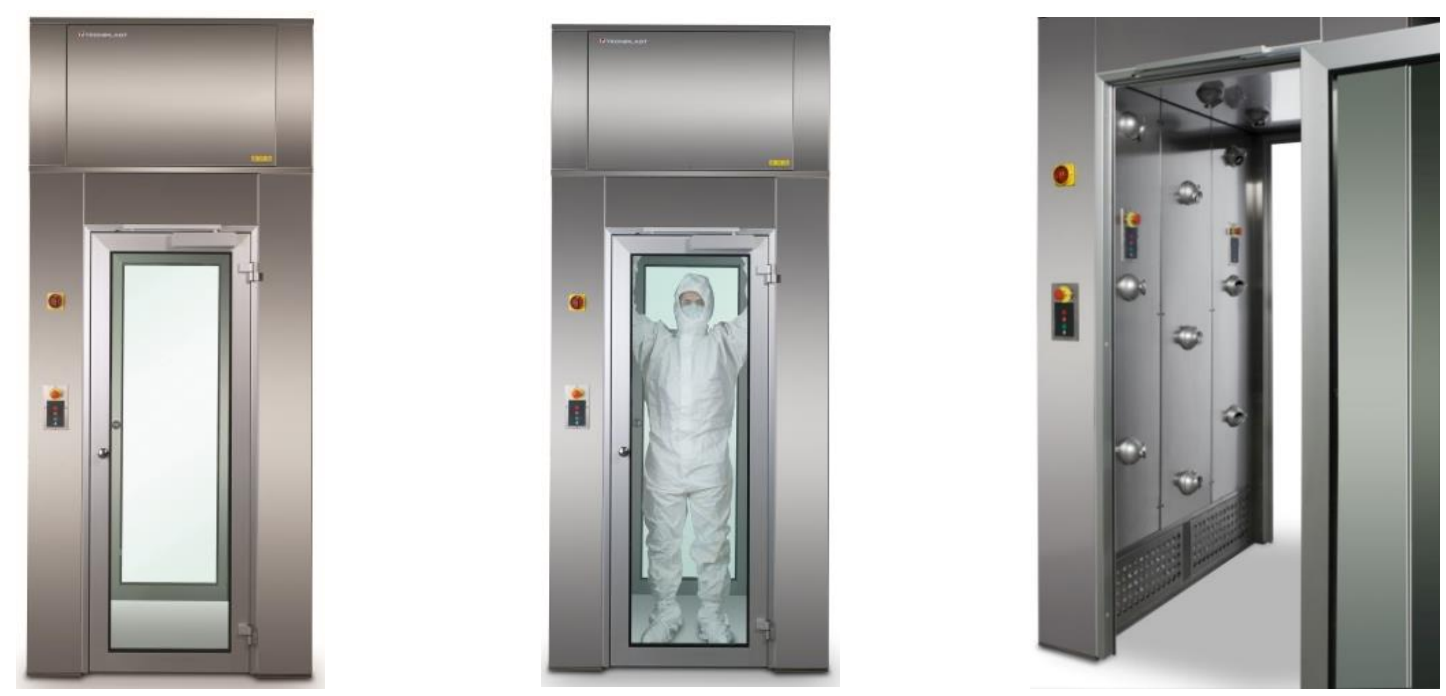

Figura 142. Ducha de aire acceso personal a la zona de barrera. Fuente. Techniplast. 
En este sistema de acceso a la barrera, generalmente, suele ser necesario realizar un cambio de ropa para colocarse un mono de trabajo estéril, que puede ser lavable o desechable. Además, es necesario colocarse los EPIs como son la bata, el gorro para la cabeza, los zapatos, los guantes, e incluso la máscara facial. Para realizar este cambio de ropa es necesario instalar un vestuario de cambio adosado a la ducha. Debido al tamaño de este tipo de instalaciones, lo habitual es que esta zona de vestuarios sea unisex. Observamos un único caso (IISA) en el que se han planteado dos vestuarios independientes para la separación por sexos que confluyen en un punto para el uso común de la ducha de aire. Aunque esta es la solución más común, existen dudas sobre la eficacia y/o rentabilidad de este sistema de acceso (Hessler 2009, c 24, p. 341).

- En el resto de los casos (IiSGM, IISBiodonostia, IGTP) el acceso a la zona de barrera se produce a través de una esclusa de personas en la que se realiza la puesta de los EPIs complementarios necesarios para acceder a la unidad (Figura 143).
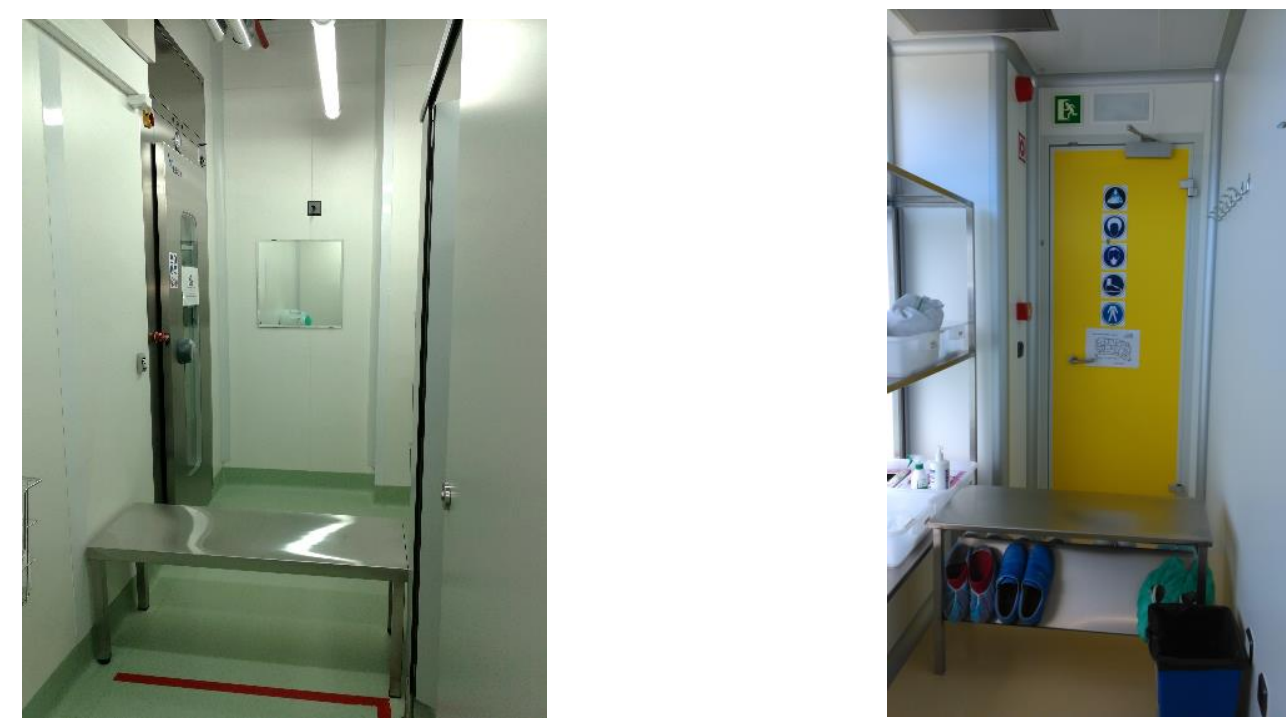

Figura 143. Esclusa acceso personal a la zona de barrera. Fuente. Elaboración propia.

Las esclusas de aire son salas de paso aisladas, diseñadas con su sistema de climatización que permiten controlar tanto la presión diferencial como la temperatura con respecto a las salas colindantes para garantizar que el aire circule en la dirección correcta y, por tanto, la asepsia necesaria en la zona de barrera. Para conseguir su correcto funcionamiento se requiere de un sistema de enclavamiento de puertas que evite que ambas se abran al mismo tiempo. En ellas, el personal se coloca los EPIs necesarios sobre la ropa de trabajo que previamente se ha puesto en los vestuarios generales de acceso al animalario. Es muy común que la zona limpia y la sucia estén identificadas dentro de la esclusa, bien con la colocación transversal de un banco, bien con la colocación de una cinta adhesiva en el pavimento. 


\section{Acceso materiales y suministros básicos}

Como criterio general, todos los materiales que deban ser introducidos a la zona de barrera deben ser previamente esterilizados y excepcionalmente, algunos materiales únicamente se desinfectarán. La esterilización es el proceso, físico o químico, por el cual se elimina cualquier forma de vida microbiana, incluidas las esporas bacterianas. Para reducir la carga bacteriana en una instalación se pueden utilizar los procesos de lavado y/o desinfección; sin embargo, si lo que se quiere es eliminar todos los microorganismos, incluidas las esporas, será obligatorio esterilizar (Ponencia Matachana). El proceso de esterilización es fundamental en las instalaciones en barrera por la necesidad de mantener el ambiente estéril en la zona de experimentación.

Según el estudio realizado, en todas las unidades de experimentación en barrera existen procedimientos específicos para introducir los materiales, pero no es habitual que el material saliente de la zona de barrera se procese de una manera especial.

La gestión de las jaulas constituye una gran parte del volumen de trabajo generado en la barrera. Desde la fase de diseño se deben considerar los procedimientos de trabajo en esta zona, ya que existen diferentes estrategias de trabajo que influyen en las necesidades de la instalación, así como en el tipo de equipamiento (Hessler 2009, c 24, p. 339):

- Lo recomendable es que las jaulas lavadas y preparadas, completas para su uso, con el fondo de jaula, la ropa de cama, la alimentación (opcional), la tapa y la parte superior del filtro, sin botellas de agua, se esterilizen para acceder a la zona de barrera. En este caso, se requiere más capacidad de autoclave y de los carros de transporte, pero esta solución en la que las jaulas se preparan en la sala de lavado es mucho más eficiente, ya que después de esterilizadas, solo se abren dentro de una cabina de flujo laminar y, por tanto, se elimina la posibilidad de contaminación cruzada de las jaulas.

- La capacidad del autoclave se puede aumentar considerablemente si las piezas de la jaula se apilan separadas para esterilizar en autoclave y se preparan a posteriori; sin embargo, esta opción requiere manipular las jaulas antes de que se usen, lo que niega parte de la eficiencia que justifica la instalación de barrera.

- Una estrategia alternativa es esterilizar en el autoclave las partes de la jaula desmontada y luego preparar las jaulas listas para usar en una sala destinada a esta tarea dentro de la zona de barrera antes de trasladarlas a la sala de estabulación. Este sistema de trabajo es aún más eficiente y seguro, en términos de evitar la contaminación cruzada, que montar las jaulas en la sala de animales. 
Lo habitual es que en las unidades de experimentación en barrera las jaulas lavadas y preparadas se autoclaven, y dentro de la zona de barrera se suministre la comida a los animales.

En base al estudio realizado, vemos que los equipos de esterilización y desinfección que se utilizan en la mayoría de las unidades de barrera para introducir los materiales a la zona de barrera son los siguientes:

a) Autoclave de doble puerta. Es el equipo diseñado para esterilizar por calor húmedo o vapor, siendo el procedimiento de esterilización universal y preferente utilizado en las instalaciones de experimentación animal. La esterilización por vapor es de aplicación únicamente a los productos resistentes al calor, ya que los materiales tienen que ser capaces de soportar el vapor a $121^{\circ} \mathrm{C}$ durante al menos 20 minutos.

Como criterio general, todos los equipos y suministros que se pueden esterilizar en autoclave entrarán a la barrera a través de autoclaves de paso de doble puerta, por lo que lo habitual es que las jaulas una vez lavadas, se autoclaven completamente preparadas con la cama y enriquecimiento y la tapa para entrar a la zona de barrera.

Por razones de seguridad, los materiales sólidos se deben tratar de manera diferente a los líquidos, por lo que los biberones llenos de agua se autoclavan en procesos independientes, debido a la demora en la ebullición de los biberones llenos de agua. También los productos porosos como las bolsas de alimentación, las jaulas con ropa de cama y textiles se deben independizar de los no porosos como son las jaulas, los estantes y las botellas de agua vacías.

b) Cabina SAS pasamateriales de doble puerta con desinfección química mediante pulverización de vapor de peróxido de hidrógeno (VPH). Los materiales que son sensibles al calor y que no son esterilizables por vapor, acceden habitualmente a la zona de barrera previa desinfección química por medio de peróxido de hidrógeno, siendo una desinfección superficial cuyo objetivo es inactivar los microorganismos patógenos. Los materiales que habitualmente acceden a la zona de barrera a través de este sistema son: herramientas eléctricas, ordenadores, microscopios y cabinas de cambio de jaulas, entre otros.

c) Ventana SAS pasamateriales con lámparas germicidas UV. Son equipos de pequeño tamaño, tipo 'ventana' que llevan incorporados lámparas germicida ultra violeta, siendo habitual utilizarlos para el ingreso de los animales y, también, para la desinfección de pequeños objetos que tienen que entrar a la zona de barrera. La luz UV tiene una acción germicida de gran alcance, especialmente para partículas en suspensión como las microbacterias. 


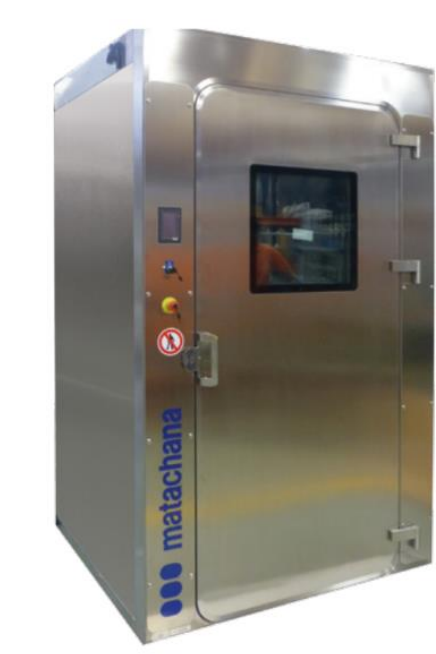

Cabina SAS desinfección química

Figura 144. Equipos de barrera.

Fuente. Matachana

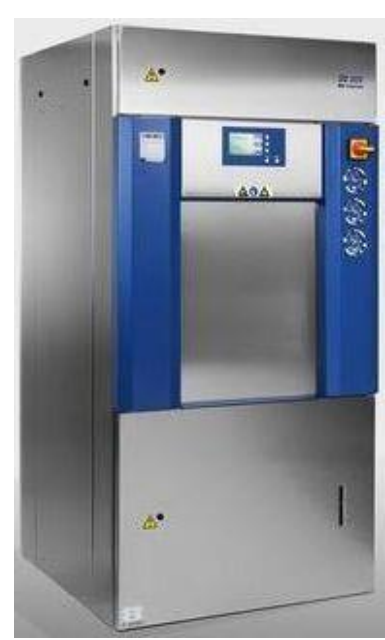

Autoclave

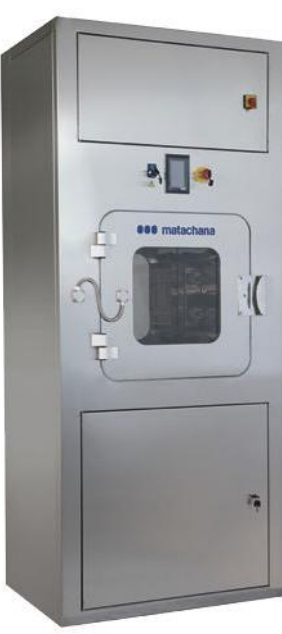

Ventana SAS pasamateriales

Estos equipos, diseñados para mantener la separación entre la zona exterior y la zona de experimentación SPF, forman lo que comúnmente se llama los equipos de barrera (Figura 144). Lo habitual es que en los institutos investigados existan estos tres equipos de barrera. Aunque en todos los casos existe un autoclave para esterilizar los equipos, no en todos los casos existe uno grande de doble puerta en el que poder introducir las jaulas y que a su vez esté comunicado directamente con la zona de barrera. En estos casos (IISGM, IIS Biodonostia), la solución adoptada ha sido instalar una cabina SAS pasamateriales de doble puerta de VPH a través del que poder introducir los estantes.

\section{Sistemas de desinfección de salas}

Para garantizar el ambiente estéril requerido en las unidades de experimentación en barrera, aparte de estar diseñados y construidos para los procedimientos de experimentación, es fundamental realizar las tareas de limpieza y desinfección necesarias acorde al nivel exigido en la instalación. De esta manera, observamos que si bien en algunos centros el objetivo se alcanza con una limpieza y desinfección rutinaria con personal específicamente entrenado para ello, en otros casos, se considera necesario un grado de desinfección superior, por lo que las salas son descontaminadas mediante equipos portátiles con la tecnología de peróxido de hidrógeno vaporizado (IISGM, IIS Biodonostia, IISA, VHIR, IIS La Fe). Este sistema rápido de esterilización a baja temperatura permite la esterilización in situ de superficies y objetos contenidos en salas cerradas, como son las salas de alojamiento de animales, así como pequeños habitáculos cerrados, como son las cabinas de flujo laminar. 


\subsubsection{Criterio organizativo de la unidad de experimentación en barrera}

La zona de experimentación en barrera debe estar diseñada y organizada para garantizar un estado sanitario concreto de los animales. Para ello, por una parte, es necesario que la instalación esté organizada y diseñada para que los sistemas de acceso y salida, así como los flujos de trabajo para las personas, los animales, los materiales y los suministros sean acordes al nivel de exigencia establecido para cada instalación; y, por la otra, que tanto los sistemas constructivos como la instalación de climatización estén diseñados para garantizar la calidad del aire interior exigibles.

A la hora de plantear la organización de esta unidad, aparte de tener en cuenta los conceptos anteriormente mencionados, así como las necesidades establecidas por la investigación que en ella se quiera llevar a cabo, hay que tener en cuenta el trabajo de procesamiento de las jaulas donde van a vivir los animales, ya que constituyen una gran parte del volumen de trabajo generado en la instalación de barrera.

El diseño de las instalaciones se debe complementar con un personal debidamente capacitado en procedimientos que minimicen la entrada de contaminantes, con el equipamiento necesario para garantizar las condiciones de uso de la instalación, y con un protocolo de limpieza y mantenimiento capaz de mantener las condiciones de asepsia necesarias en este tipo de instalaciones.

Para comprender el funcionamiento de esta unidad se ha tomado como referencia el siguiente esquema genérico (Figura 145), en el que se representan los locales que son necesarios para el desarrollo de la actividad, así como los principales flujos de trabajo. De esta manera; en azul se representa la unidad de barrera; en verde los tres puntos de acceso para las personas, los animales y los materiales; y en gris las zonas periféricas a la barrera necesarias para el desarrollo de la investigación como son: la sala de lavado y esterilización y los almacenes de material limpio y sucio. La unidad de barrera identificada en azul comprende todos los locales necesarios para el desarrollo de la actividad como son las salas de alojamiento de animales, las salas de procedimientos y los locales de servicio para el almacenamiento de materiales.

Para realizar el análisis de las diferentes circulaciones, se han identificado los flujos de trabajos dentro de la unidad, de modo que en línea de trazo continua azul se representa al personal, en línea de trazo continua rojo los animales; en línea de trazo continua verde el suministro de materiales y en línea de trazo discontinua verde los residuos. Según se observa en el esquema, existe una zona de acceso específica para el personal, que una vez finalizados los trabajos puede salir de la instalación, en función del diseño y procedimientos establecidos, bien por la zona desde donde ha entrado o bien a través de un vestíbulo de salida general de la unidad compartido con los animales y residuos. Para el acceso de 
los animales, existe un segundo punto de acceso independiente, siendo la salida de los animales a través del vestíbulo de salida general. Para los materiales y suministros se plantea un tercer acceso a través de los equipos de barrera ubicados en la sala de lavado y esterilización. El personal de la barrera recibirá las jaulas limpias para trasladarlas a las salas de estabulación y allí, en las cabinas de flujo laminar, realizar el cambio de jaulas. Las jaulas sucias y residuos generados generalmente son depositados en el vestíbulo de salida por el personal que trabaja en la barrera, para que el personal externo a ella los retire y los traslade a la zona de lavado y esterilización para su posterior reingreso en la barrera.

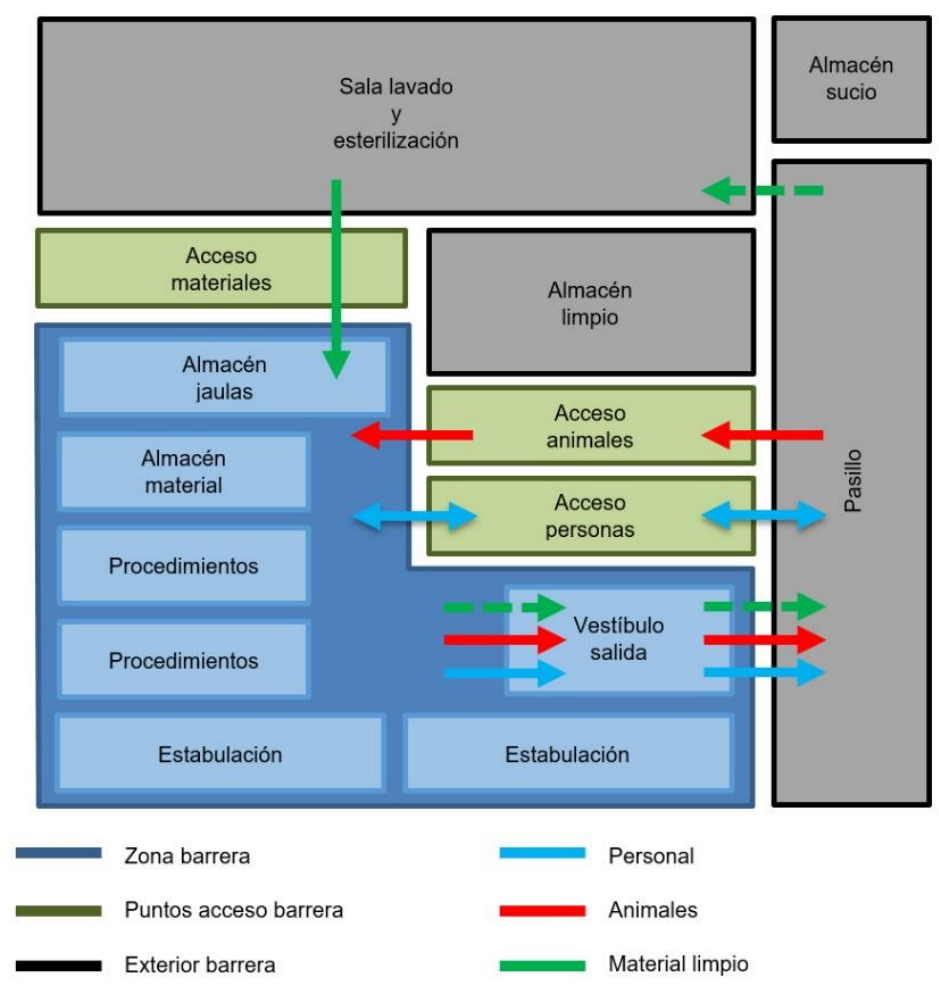

Figura 145. Esquema organización de la instalación en barrera.

Fuente. Elaboración propia.

El resultado de la investigación sobre la organización de la unidad de experimentación en barrera de animal pequeño se encuentra reflejado tanto en las fichas de la documentación gráfica como en la toma de datos de cada centro.

Para realizar el análisis del criterio organizativo y de los flujos de trabajo implantados en la unidad de experimentación en barrera de animal pequeño, se ha hecho una puesta en común de los resultados obtenidos; y, para ello, se ha optado por resumir las más importantes en una tabla (Tabla 18). En ella se listan los parámetros que definen el criterio organizativo de la unidad, se establecen cuáles son las características comunes a la mayoría de ellas y se identifica qué institutos cumplen dichas características; además, se determinan las características particulares y específicas, que son aquellas 
que las cumplen solo unas determinadas unidades, reflejándose así mismo, cuáles son lo institutos que las cumplen. El análisis se centra en los siguientes conceptos:

- La organización en plantas de la unidad. Se trata de identificar las distribuidas en una o varias plantas, así como si está configurada de manera independiente o integrada en el conjunto del área de experimentación de animal pequeño.

- El tipo de pasillo de distribución seleccionado: simple o doble, incluso el criterio de flujo de trabajo establecido para cada caso.

- La organización de los accesos de materiales a la zona de barrera, teniendo en cuenta la ubicación y uso de la zona de lavado y esterilización, incluso la del personal y la de los animales.

- Los criterios de diseño implantados en cada caso en aras a facilitar el mantenimiento de la instalación.

Tabla 18. Organización unidad experimentación animal en barrera.

\begin{tabular}{|c|c|c|c|c|}
\hline Parámetros & $\begin{array}{l}\text { Características } \\
\text { comunes }\end{array}$ & $\begin{array}{l}\text { Institutos con } \\
\text { características } \\
\text { comunes }\end{array}$ & $\begin{array}{l}\text { Características } \\
\text { específicas }\end{array}$ & $\begin{array}{l}\text { Institutos con } \\
\text { características } \\
\text { específicas } \\
\end{array}$ \\
\hline $\begin{array}{l}\text { № plantas en las que } \\
\text { se distribuye }\end{array}$ & 1 Planta & $\begin{array}{l}\text { liSGM, IISBiodonostia, } \\
\text { IISBiocruces, IISA, IIS La Fe }\end{array}$ & Varias plantas & VHIR, IGTP \\
\hline $\begin{array}{l}\text { Unidad } \\
\text { independiente } \\
\text { convencional }\end{array}$ & NO & $\begin{array}{l}\text { liSGM, IISBiodonostia, } \\
\text { IISBiocruces, IISA, VHIR, } \\
\text { IGTP, IIS La Fe }\end{array}$ & & \\
\hline Zonas compartidas & Almacenes y Sala lavado & $\begin{array}{l}\text { liSGM, IISBiodonostia, } \\
\text { IISBiocruces, IISA, VHIR, } \\
\text { IGTP, IIS La Fe }\end{array}$ & Vestuarios generales & $\begin{array}{l}\text { liSGM, } \\
\text { IISBiodonostia, } \\
\text { IISBiocruces, } \\
\text { VHIR, IGTP, } \\
\text { IISLaFe }\end{array}$ \\
\hline $\begin{array}{l}\text { Tipo de distribución } \\
\text { interior }\end{array}$ & Pasillo simple & $\begin{array}{l}\text { liSGM, IISBiodonostia, } \\
\text { IISBiocruces, IISA, VHIR, } \\
\text { IGTP, IIS La Fe }\end{array}$ & & \\
\hline $\begin{array}{l}\text { Área de personal } \\
\text { en la barrera }\end{array}$ & NO & $\begin{array}{l}\text { liSGM, IISBiodonostia, } \\
\text { IISBiocruces, IISA, IGTP, } \\
\text { IISLa Fe }\end{array}$ & Despacho & VHIR \\
\hline Acceso animales & SAS desde otro local & $\begin{array}{l}\text { liSGM, IISBiodonostia, } \\
\text { IISBiocruces, IGTP, IISA, } \\
\text { VHIR, IIS La Fe }\end{array}$ & SAS desde cuarentena & IISBiocruces, IISA \\
\hline $\begin{array}{l}\text { Acceso materiales } \\
\text { desde }\end{array}$ & Sala lavado y esterilización & $\begin{array}{l}\text { liSGM, IISBiocruces, IISA, } \\
\text { VHIR, IIS La Fe }\end{array}$ & Otras & $\begin{array}{l}\text { IISBiodonostia } \\
\text { IGTP }\end{array}$ \\
\hline $\begin{array}{l}\text { Barrera materiales } \\
\text { comunicada con }\end{array}$ & Almacén material limpio & $\begin{array}{l}\text { liSGM, IISBiocruces, IISA, } \\
\text { IGTP, IIS La Fe }\end{array}$ & Pasillo & IISBiodonostia, \\
\hline $\begin{array}{l}\text { Mantenimiento } \\
\text { instalaciones }\end{array}$ & Registros en falso techo & $\begin{array}{l}\text { liSGM, IISBiodonostia, } \\
\text { IISA }\end{array}$ & $\begin{array}{l}\text { Planta Técnica transitable } \\
\text { Instalaciones vistas }\end{array}$ & $\begin{array}{l}\text { IISBiocruces, IGTP, } \\
\text {,IIS La Fe } \\
\text { VHIR }\end{array}$ \\
\hline
\end{tabular}

Fuente. Elaboración propia. 


\section{Distribución en plantas}

Las instalaciones en barrera diseñadas en los institutos investigados representan una parte de la instalación de la experimentación de animal pequeño, de manera que no hemos encontrado ningun instituto en el que la experimentación de animal pequeño se realice integramente en barrera.

Observamos que el desarrollo de la actividad de esta unidad, en la mayoría de los casos se realiza en una única planta, si bien podemos destacar dos casos particulares. Por una parte, en el caso del VHIR, aunque toda la unidad de experimentación en barrera se desarrolla en la planta sótano -2, en la planta superior se distribuye la zona de vestuarios para cambio de vestimenta general del personal, necesario para poder acceder al animalario. Por otra parte, en el caso del IGTP, la distribución se produce en tres plantas, de manera que en la planta de acceso al edificio se encuentran los vestuarios generales para cambio de personal; en la planta semisótano se desarrolla la unidad de experimentación en barrera, incluidas otras areas de experimentación para animal pequeño y en la planta sótano -1 la sala de lavado y esterilización.

La unidad de experimentación en barrera no se configura como una unidad totalmente independiente a la unidad convencional, sino que se integra en el conjunto de la instalación de experimentación de animal pequeño con la que habitualmente comparte las zonas de servicio generales. Observamos que los almacenes de material y la zona de lavado y esterilización son locales de servicio que se comparten en todos los casos, mientras que en el caso de los vestuarios para cambio de personal, si bien lo habitual es que se compartan con el área convencional, observamos un caso (IISA) en el que se han diseñado unos vestuarios para uso exclusivo del personal investigador y al cuidado de los animales de la barrera.

\section{Tipo de distribución pasillo}

Internamente, la unidad de experimentación en barrera se distribuye mediante un pasillo simple en todos los casos, entre otros motivos, para optimizar la superficie disponible; ya que en estos centros, la superficie destinada a la barrera es una parte pequeña de la del animal pequeño.

\section{Flujos de trabajo del personal en la barrera}

Independientemente del nivel exigido en la instalación, es necesario diseñar unos puntos de entrada y salida determinados, que son los que van a determinar los pasos fronterizos entre el interior y el exterior de la barrera. Las características de las zonas de acceso planteadas ya las hemos analizado 
anteriormente ${ }^{44}$. En este caso, analizaremos los flujos de trabajo establecidos para el personal que trabaja en la instalación de barrera.

Dada la cantidad de tiempo que pasan dentro de la barrera, el lugar de trabajo debe diseñarse de cara a crear ambientes lo más agradables posibles, máxime teniendo en cuenta que dependiendo de los requisitos de acceso, entrar y salir de las instalaciones para realizar los descansos puede no ser una opción práctica. En este sentido, hay criterios diferentes a la hora de considerar incluir ciertas áreas de servicio para el personal dentro de la barrera. Entre los institutos analizados, el VHIR es el único que ha considerado diseñar un despacho para el personal del animalario, y en ningún caso se ha planteado incorporar aseos o zonas de descanso. Lo que sí se garantiza en todos los casos es una buena comunicación entre los trabajadores del interior y exterior de la barrera.

Siendo la zona de barrera una zona especialmente sensible de la instalación, marcada por las exigencias de asepsia y de la calidad del aire, es muy habitual que los accesos de personas estén restringidos y controlados. En este sentido, observamos que en la mayoría de los casos existe un sistema de control de accesos a base de tarjeta de proximidad tanto a nivel de centro de experimentación animal como a nivel de acceso a la zona de barrera (IISBiodonostia, IISBiocruces, IISA, VHIR, IGTP, IIS La Fe).

Centrándonos en el diseño del acceso para personas encontramos casuísticas diferentes en función de si los vestuarios de cambio son propios de la unidad y de si el acceso a la zona de barrera es mediante ducha de aire o SAS de personas. A continuación se resumen los diversos planteamientos observados:

1. El acceso de personas a la zona de barrera se configura de manera totalmente independiente a la de la unidad convencional, por lo que se han diseñado dos vestuarios propios e independientes para la separación por sexo que confluyen en una ducha de aire a través de la que se accede a la zona de barrera. (IISA).

2. Existe una zona de vestuarios separada por sexo para acceder al área de experimentación de animal pequeño que es de paso obligatorio tanto para los investigadores de la experimentación convencional como para los de barrera. Una vez dentro, el acceso a la zona de barrera se observa que se ha diseñado de las siguientes maneras diferentes:

${ }^{44}$ Ver apartado 7.3.3.3. 
a) Desde la zona de pasillos generales del área de experimentación animal pequeño se accede a una esclusa de personas, para una vez puestos los EPIs correspondientes, poder acceder a la zona de barrera (IISGM, IIS Biodonostia, IGTP).

b) Desde la zona de pasillos generales del área de experimentación animal pequeño se accede a un vestuario propio de la unidad de barrera que habitualmente suele ser de uso común para ambos sexos y a través del cual se accede a una ducha de aire comunicada con la zona de barrera (IIS Biocruces, VHIR, IIS La Fe).

Centrándonos en el flujo de trabajo establecido para el personal en las diferentes unidades de barrera, observamos que en los casos en los que el acceso del personal se ha planteado mediante una esclusa (IISGM, IIS Biodonostia), la salida del personal se produce a través de esa misma esclusa, de manera que el flujo de trabajo es en ambos sentidos: de entrada y de salida.

En cambio, en los casos en los que se ha diseñado una ducha de aire como sistema de acceso a la barrera (IISBiocruces, IISA, VHIR, IIS La Fe), la salida del personal se puede realizar a través de dos recorridos alternativos: a través de la ducha de aire o a través de la esclusa diseñada para la salida del material sucio de la instalación.

\section{Flujos de trabajo de los materiales en la barrera}

Los animales de la zona de barrera generalmente se alojan en unas jaulas autoventiladas preparadas con el fondo de jaula, ropa de cama, alimentación, tapa superior y filtro y biberón para suministro del agua, en el caso de que sea así el suministro. Estos animales se suelen cambiar de jaula una vez por semana aproximadamente, y estos cambios habitualmente se realizan en cabinas de flujo laminar (cabinas de cambio o cabinas de seguridad biológica) que se situan en las propias salas de estabulación. Las jaulas sucias hay que retirarlas desde la zona de estabulación en unos carros de transporte de jaulas para llevarlas al área sucia de la zona de lavado y esterilización, siendo recomendable que estos carros sean capaces de transportar las jaulas completamente montadas. Una vez lavadas, esterilizadas y preparadas las jaulas se almacenan en el lado limpio del área de lavado, para introducirlas de nuevo, a través de los equipos de acceso para materiales, a la zona de barrera y a través de los pasillos de la instalación volver a trasladarlas a la sala de estabulación para realizar un nuevo cambio de jaula. El tipo de jaula reutilizable o desechable que se vaya a utilizar en la instalación influirá en el dimensionamiento de la sala de lavado y esterilización, pero no evitará la necesidad de establecer el flujo de trabajo para las jaulas y los carros.

Como regla general, se requiere un vestíbulo de salida para las jaulas sucias, los residuos, los cadáveres de animales, que también puede ser utilizado como punto de salida habitual para las personas e 
incluso como salida en caso de emergencia. Este vestíbulo debe ser lo suficientemente grande como para contener un número significativo de jaulas sucias y contenedores de basura porque los artículos serán colocados en el vestíbulo por técnicos que trabajan dentro de la barrera y eliminado por técnicos que trabajan fuera de ella. En una barrera muy pequeña, por consideraciones de espacio puede llegar a utilizarse el mismo vestíbulo de entrada al utilizado para los artículos que no se pueden esterilizar en autoclave (Hessler 2009, c. 24, p. 340). Esta situación nos encontramos en varias instalaciones (IISGM, IIS Biodonostia).

Para el acceso de los diferentes materiales, los carros y las jaulas a la zona de barrera, lo habitual es que los equipos de barrera se distribuyan en las salas de lavado y esterilización compartidas con la zona de experimentación convencional, si bien existen algunos casos en los que los equipos de barrera son para uso exclusivo de la zona barrera y se alojan fuera de la sala de lavado; bien en zona de pasillo (IIS Biodonostia) o bien en una sala específica (IGTP).

Por otra parte, observamos que es muy habitual que los materiales, una vez que acceden a la zona de barrera, se ubiquen en un almacén de material limpio que integra los equipos de barrera (IiSGM, IIS Biocruces, IISA, IGTP, IIS La Fe).

El funcionamiento de la instalación en barrera depende del uso del autoclave, por lo que es necesario tener un plan de contingencia para cuando el autoclave esté fuera de servicio. En este sentido observamos que no es habitual que existan equipos redundantes que garanticen la continuidad del servicio, sino que la opción planteada pasa por tener una zona de almacenamiento de material limpio dentro de la barrera para tener un suministro de repuesto disponible que permita la continuidad de la actividad hasta la reparación del equipo (IISGM, IISBiocruces, IISA, IGTP, IIS La Fe).

Podemos apreciar diferencias en cuanto al sistema de organización implantado. Hay algunos casos en los que el material limpio y sucio tienen el mismo punto de entrada y de salida, de manera que por el pasillo de distribución circulan todo tipo de materiales. En otros casos, el material tiene un recorrido unidireccional, lo que evita que el material limpio y sucio coincidan (IISBiocruces, VHIR), para lo que disponen de puntos de salida del material independientes a los de entrada.

\section{Flujos de trabajo de los animales en la barrera}

Únicamente los animales con un estado de salud definido son aceptados en la barrera, y una vez que salen de ella, se les prohíbe volver a entrar sin volver a realizarles las pruebas necesarias. Los roedores generalmente se entregan en la barrera en un contenedor de envío. Para introducir los animales a la zona de barrera, será necesario su paso a través de un equipo que pueda esterilizar la superficie 
exterior antes de trasladarlos a la sala de cuarentena o estabulación, donde los animales son transferidos a las jaulas dentro de la cabina de cambio.

En base al estudio realizado, observamos que el acceso de los animales habitualmente se produce a través de un equipo ventana SAS que únicamente en algunos casos (IISBiocruces, IISA) se encuentra ubicado en la sala de cuarentena. En otros casos, el equipo SAS puede estar ubicado en zona de pasillos, sala de lavado y esterilización, en salas de procedimientos, incluso a través de una zona específica para recepción animal con esclusa comunicada con pasillo (VHIR). La salida de los animales, bien sea vivos o muertos, habitualmente se realiza a través del mismo vestíbulo de salida utilizado para jaulas sucias.

\section{Accesibilidad para el mantenimiento}

Una de las tareas no asociadas a la experimentación, pero necesaria para el desarrollo de la actividad investigadora es el mantenimiento de las instalaciones. Los principales suministros y componentes que requieren de un mantenimiento periódico deberían situarse en zonas que sean accesibles sin tener que entrar a la zona de barrera, siempre que sea posible. Hay multiples estrategias que facilitan el mantenimiento de las instalaciones y entre ellas, para representar de manera gráfica las distintan opciones, hemos seleccionado la reflejada en el manual Design requeriments manual NIH (Figura 146). En ella se observan planteamientos diversos a adoptar en función de lo crítico que sea para el desarrollo de la actividad investigadora realizar las tareas de mantenimiento en el interior de las salas. Por una parte, está el diseño de una planta técnica sobre el animalario, que puede ser transitable o no; la distribución de pasillos de servicio, la implantación de galerias de servicios colindantes a las instalaciones críticas, así como el registro de instalaciones a través de una galería de servicios inferior. Algunas de estas soluciones permiten un acceso casi completo para realizar el mantenimiento de las instalaciones, mientras que otras pueden limitar el acceso a las zonas menos críticas de la instalación, como pueden ser los pasillos.

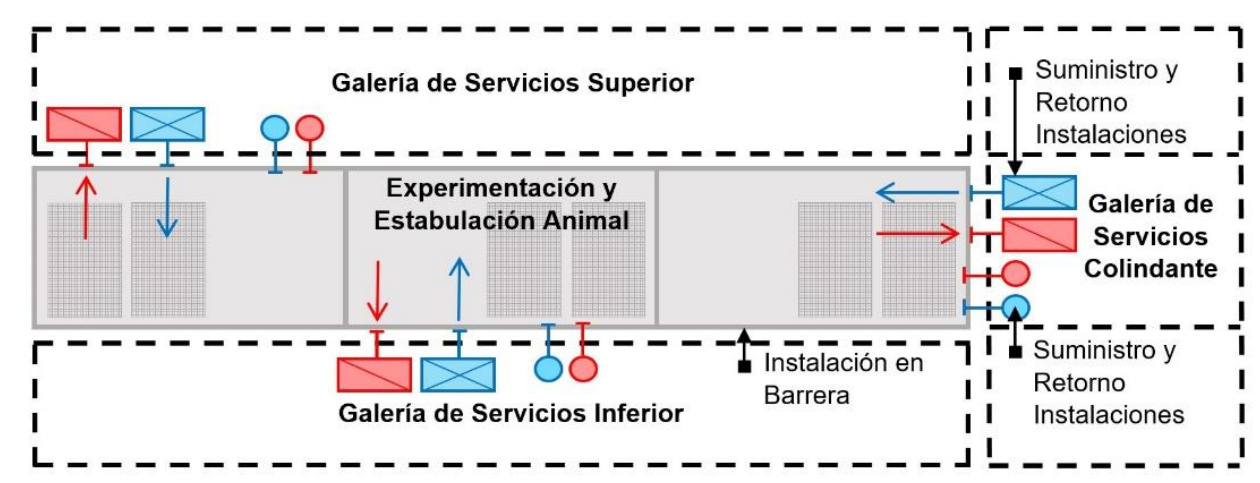

Figura 146. Esquema estrategias de distribución de servicios.

Fuente. Division of technical resources 2016, p. 138. 
En los centros visitados hemos observado que la estrategia implantada para el mantenimiento de las instalaciones varía adoptándose los siguientes tres criterios de diseño (Figura 147):

- Institutos en los que las tareas de mantenimiento se realizan a través de galerías de servicio verticales y registros previstos en el falso techos para tal fin (IiSGM, IISBiodonostia, IISA, IIS La Fe). Además, estos registros se tienden a ubicar en zonas exteriores a la barrera o bien en los pasillos interiores de distribución.

- En otros casos, se ha diseñado una planta técnica transitable(IIS Biocruces, IGTP), lo que permite realizar las tareas de mantenimiento a través de esta planta transitable superior sin tener que acceder a las instalaciones del animalario.

- En otros casos, se ha optado por dejar todas las instalaciones vistas, de tal manera que cualquier fallo en la instalación permite acceder fácilmente a ella y, por lo tanto, repararlo causando las mínimas incidencias posibles (VHIR). Esta última opción que llama la atención debido a que requiere de unas tareas de limpieza y desinfección más exigentes y laboriosas con respecto a las solución del falso techo continuo, también lo hemos visto en las instalaciones del PRBB.
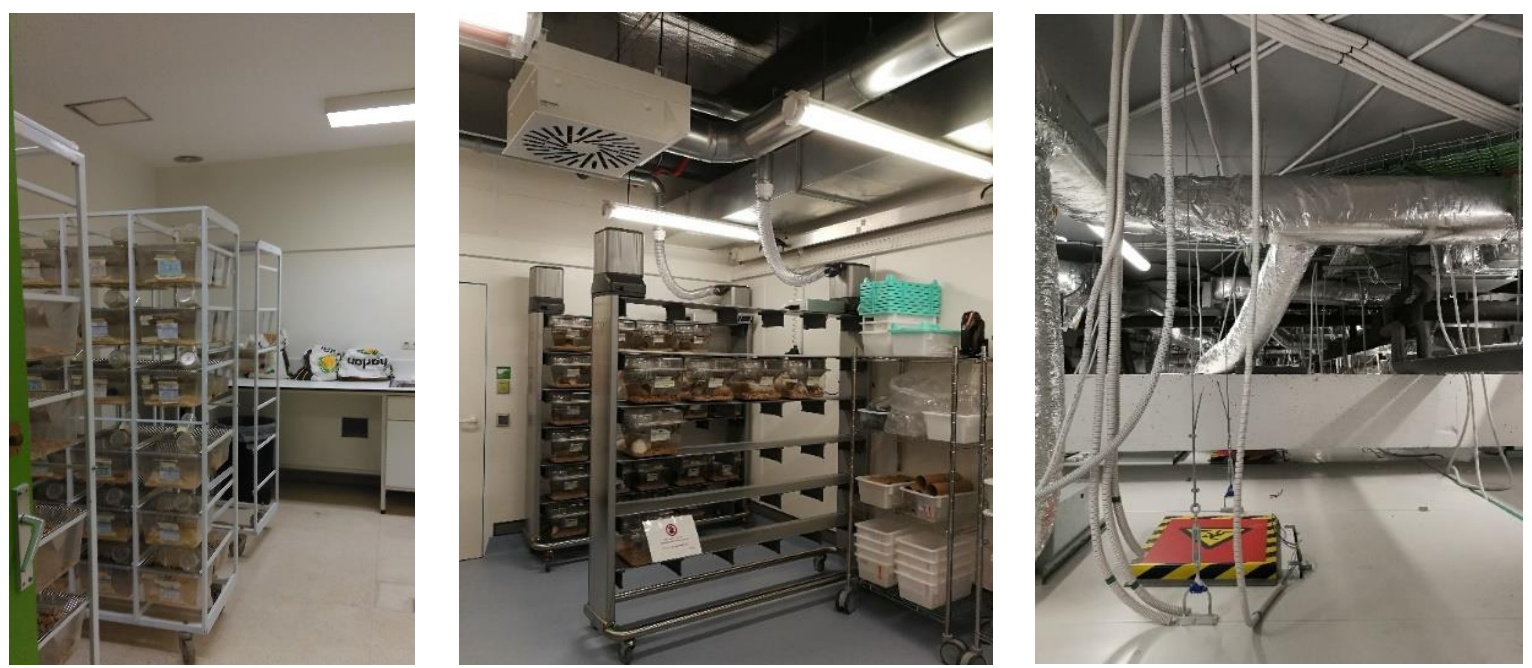

Figura 147. Instalaciones con registros en falso techo, instalaciones vistas y planta técnica transitable. Fuente. Elaboración propia.

Para adoptar una solución u otra es fundamental tener en cuenta los condicionantes de la investigación que se quiere llevar a cabo, así como la vida util de la instalación. Aunque la mayoría de los usuarios consideran que la mejor opción para garantizar el correcto mantenimiento de la instalación era la de disponer de una planta técnica transitable, para así reducir al máximo las entradas a la zona de barrera. En el caso de no poder adoptar esta solución, había discrepancias sobre las diferentes alternativas que hemos analizado. Algunos usuarios consideran una mejor opción el tener todas las instalaciones vistas, ya que además de pemitir realizar y verificar la limpieza de todas las 
superficies, también permite detectar las fugas de las instalaciones fácilmente y, por lo tanto, su reparación sin tener que afectar en gran medida al funcionamiento de la instalación; otros consideran que la mejor manera de garantizar la asepsia en la instalación es a través del diseño de un falso techo continuo con el mínimo número de juntas posible, solución que además ayuda a mitigar los ruidos que las instalaciones pudieran generar. 


\subsubsection{Síntesis de la unidad de experimentación en barrera animal pequeño}

En el contexto de las ciencias del animal de laboratorio, el término barrera se refiere a los sistemas de alojamiento de animales diseñados y gestionados para proteger a los animales de infecciones no deseadas por agentes procedentes desde fuera de la barrera. Por lo tanto, las barreras consisten en una combinación de sistemas físicos y criterios de trabajo para que conjuntamente minimicen la transferencia de agentes infecciosos de un lado de la barrera al otro.

El alojamiento en barrera para animal pequeño se ha convertido en un estándar para albergar animales de experimentación, siendo muy común que en los Institutos de Investigación Sanitaria se desarrolle una unidad de experimentación en barrera. De hecho, siete de los diez institutos analizados disponen de esta unidad, que está diseñada para investigar con las especies más utilizadas en experimentación: la rata y el ratón. Los animales que habitualmente se alojan en estas instalaciones son animales de cría, genéticamente definidos o modificados e inmunideprimidos, entre otros. Además, la procedencia y el estado sanitario de los animales que pueden acceder a la zona de barrera está limitado y controlado.

La superficie destinada a este ámbito de experimentación es muy variable. La mayoría de los centros destinan a esta unidad una superficie inferior a los $200 \mathrm{~m}^{2}$, siendo la superficie destinada a los locales de alojamiento de animales inferior a $50 \mathrm{~m}^{2}$.

Las instalaciones en barrera diseñadas en estos institutos representan una parte de la instalación destinada a la investigación de animal pequeño, siendo lo habitual que la unidad en barrera se distribuya en una única planta distribuida mediante pasillo simple e integrada en el conjunto de la instalación de experimentación convencional de animal pequeño con la que comparte zonas de servicios generales, tales como vestuarios de cambio para personal, almacenes de materiales, incluso la zona de lavado y esterilización.

La barrera primaria más común utilizada es a nivel de jaula y en todos los casos las jaulas utilizadas son de tipo ventiladas individualmente, lo que garantiza el control ambiental de las jaulas y permite invertir la presión del aire en las mismas en función de la experimentación que se necesite llevar a cabo. El material utilizado en las jaulas es transparente de tipo reutilizable, si bien observamos un caso en el que debido al dimensionamiento del centro se ha optado por las jaulas desecahables.

Lo habitual es que el número de las salas de alojamiento de animales sea igual o superior a dos unidades, solución que permite, ante cualquier circunstancia no prevista en una sala, tener una segunda opción de estabulación. En lo relacionado con las salas de procedimientos, aunque existen 
institutos en los que los procedimientos se realizan dentro de las salas de estabulación, en la mayoría de los casos se disponen salas específicas para la realización de procedimientos varios.

La mayoría de las instalaciones de barrera para roedores tienen procedimientos de trabajo específicos que impiden que los animales regresen a la barrera una vez que han salido de ella. Esto significa que las barreras, además de tener que estar diseñadas para garantizar la protección de los animales frente a los agentes externos, el cuidado y bienestar animal, así como las condiciones de trabajo y seguridad del personal, tienen que estar diseñadas para alojar los locales, instalaciones, equipos y servicios necesarios para el desarrollo de la investigación sin tener que salir de ella.

La peculiaridad de este tipo de instalaciones es que, con el fin de mantener la calidad del aire interior y evitar la entrada de agentes patógenos, es necesario diseñar unos puntos de entrada y salida específicos para las personas, los animales, los suministros y los residuos, que son los que van a determinar los pasos fronterizos entre el interior y el exterior de la barrera.

Los requisitos para el acceso de las personas a una barrera varían considerablemente dependiendo de la función de la barrera, la investigación a desarrollar dentro de la barrera y los criterios establecidos por los responsables del animalario; en definitiva, dependen del nivel de control microbiológico exigible a la instalación. Un alto nivel de barrera puede ser exigible para mantener la reproducción de los animales transgénicos, de manera que los accesos se pueden limitar a unas pocas personas y pueden tener como requisito de entrada ducharse y cambiarse de ropa. Mientras que un nivel inferior de exigencia de la barrera utilizada para alojar animales en estudio, puede permitir el acceso a más personas, y los requisitos de entrada pueden reducirse a ponerse los equipos de protección individual necesarios sobre la ropa de trabajo.

Observamos que el criterio adoptado para el acceso del personal a la zona de barrera se produce de dos maneras posibles. Aunque en la mayoría de los casos existe una ducha de aire para el acceso a la zona de barrera, previo paso por un vestuario para cambio de vestimenta, en el resto de los casos, el acceso a la zona de barrera se produce a través de una esclusa de personas en la que se realiza la puesta de los EPIs complementarios necesarios para acceder a la unidad. En los casos que el acceso del personal se ha diseñado mediante una esclusa, la salida del personal se produce a través de esa misma esclusa, de manera que el flujo de trabajo es en ambos sentidos, tanto para la entrada como para la salida. En cambio, en los casos en los que se ha diseñado una ducha de aire como sistema de acceso a la barrera la salida del personal se puede realizar a través de dos recorridos alternativos: a través de la ducha de aire o a través de la esclusa diseñada para la salida del material sucio de la instalación. 
Como criterio general, todos los materiales que deban ser introducidos a la zona de barrera deben ser previamente esterilizados y, excepcionalmente, algunos materiales únicamente se desinfectarán. El proceso de esterilización para el acceso de los materiales es fundamental en las instalaciones en barrera, por la necesidad de mantener el ambiente estéril en la zona de experimentación; en cambio, no es habitual que el material saliente de la zona de barrera se procese de una manera específica.

Los equipos diseñados para mantener la separación entre la zona exterior y la zona de experimentación SPF forman lo que comúnmente se llama los equipos de barrera. Lo habitual es que en los institutos investigados existan tres equipos de acceso a la zona de barrera para introducir los materiales: autoclave, cabina pasamateriales de VPH y ventana SAS pasamateriales con lámparas germicidas UV. Aunque en todos los casos existe un autoclave para esterilizar los equipos, no en todos los casos existe uno grande de doble puerta en el que poder introducir las jaulas y que a su vez esté comunicado directamente con la zona de barrera. En estos casos, la solución adoptada ha sido instalar una cabina SAS pasamateriales de doble puerta de VPH a través del que poder introducir los estantes y que conecta directamente con el interior de la zona de barrera. Lo habitual es que la salida de las jaulas sucias, los residuos y los cadáveres de animales se produzca a través de un vestíbulo de salida que suele ser utilizado también como punto de salida habitual para las personas y como salida en caso de emergencia.

El acceso de los animales habitualmente se produce a través de un equipo SAS. Únicamente los animales con un estado de salud definido son aceptados en la barrera, y una vez que salen de ella se les prohíbe volver a entrar sin volver a realizarles las pruebas necesarias. La salida de los animales, bien sean vivos o muertos, habitualmente se realiza a través del mismo vestíbulo de salida utilizado para jaulas sucias.

Para garantizar el ambiente estéril requerido en las unidades de experimentación en barrera, por una parte, en necesario que estén diseñadas y construidas para los procedimientos de experimentación y cuidado de los animales; y, por la otra, es fundamental realizar las tareas de limpieza y desinfección acorde al nivel exigido en la instalación. Si bien en algunos centros el objetivo se alcanza con una limpieza y desinfección rutinaria con personal específicamente entrenado para ello, en la mayoría de los casos, se considera necesario un grado de desinfección superior, por lo que las salas son descontaminadas mediante equipos portátiles con la tecnología de peróxido de hidrógeno vaporizado.

En cuanto a las estrategias adoptadas para facilitar el mantenimiento de la instalación, si bien la mayoría de los usuarios consideran que la disposición de una planta técnica transitable para realizar las tareas de mantenimiento sería la mejor opción, no en todos los casos ha sido posible, por lo que como alternativa a la clásica solución de falso techo continuo con registros practicables, en instituto se ha planteado la solución de dejar todas las instalaciones vistas. 


\section{CONCLUSIONES}

El objetivo principal de la tesis ha sido realizar un estudio pormenorizado sobre la organización y diseño de los centros de experimentación animal de los Institutos de Investigación Sanitaria Acreditados. Una vez que se ha desarrollado el trabajo de investigación se tiene información suficiente sobre el diseño, las características principales, la implantación, el criterio organizativo, las distribuciones en planta, así como el equipamiento necesario a tener en cuenta desde la fase de diseño. Por tanto, con este trabajo se han conseguido los objetivos inicialmente planteados.

Los resultados del trabajo de investigación son la base de la que se parte para elaborar las conclusiones. Las conclusiones son afirmaciones relativas al resultado del análisis de los datos obtenidos; $y$, se han planteado desde una visión objetiva de dichos resultados, para explicarlos e interpretarlos, ya que, por sí mismos, lo que hacen es informar de forma concisa lo estudiado en relación a los centros de experimentación animal. Con ellas se proporciona una visión estructurada de dichos resultados, aportando el conocimiento adquirido en un trabajo tan complejo como este; y, así mismo, se aporta una valiosa información sobre los criterios de diseño y organización de unas infraestructuras muy costosas, que requieren de una inversión pública considerable, pero a su vez necesaria para mejorar y garantizar la salud y calidad de vida de la población. A pesar de que las conclusiones parciales se han avanzado en el apartado denominado síntesis correspondiente a cada unidad sometida a estudio, para un mejor entendimiento, las conclusiones globales se han estructurado de la siguiente manera:

Conclusiones generales: se describen las aportaciones generales de la investigación realizada, teniendo en cuenta los antecedentes y la bibliografía existente.

Conclusiones particulares: se explican de forma objetiva y estructurada los resultados del desarrollo del trabajo de investigación, tanto del centro de experimentación animal como de las dos áreas de experimentación que lo componen: el animal grande y pequeño.

Conclusiones finales: tomando como base las conclusiones particulares, se exponen los resultados finales del estudio de la organización y diseño de los centros de experimentación animal de los Institutos de Investigación Sanitaria. 


\subsection{Conclusiones generales}

Este estudio constituye el primer compendio sobre la organización y diseño de los centros de experimentación animal de los Institutos de Investigación Sanitaria Acreditados. En este trabajo se recogen conceptos sobre las áreas, las unidades y los locales principales que componen este tipo de centros, los condicionantes de organización, los criterios establecidos, así como las distribuciones planteadas en cada caso. Tras una búsqueda exhaustiva, no se han encontrado tesis relacionadas con el diseño y construcción de los centros de experimentación animal. La información localizada donde se cita o se abordan aspectos relacionados con este tema se ha centrado en publicaciones tales como manuales, guías, artículos de revista, actas de congresos y referencias en páginas web. Estos documentos proporcionan recomendaciones para la planificación y diseño con respecto a códigos, regulaciones, especificaciones técnicas y equipos. En este trabajo se analiza cómo se han aplicado dichas recomendaciones en los centros de experimentación animal; por tanto, este compendio supone una importante aportación al estudio de este tipo de centros.

Como resultado de este trabajo se ha obtenido un breve inventario sobre la organización y distribución de los centros de experimentación de los Institutos de Investigación Sanitaria analizados. El inventario está formado por las fichas que conforman la toma de datos y proporcionan una información detallada sobre cada centro, en las que quedan identificados los siguientes conceptos: la presentación del instituto, las características principales sobre los centros de experimentación, la documentación gráfica estandarizada, así como la encuesta de opinión anónima. Estas fichas constituyen un elemento realmente valioso para el estudio, ya que permiten identificar y extraer de cada centro la información más relevante necesaria para llevar a cabo, no solo este trabajo, sino también futuras investigaciones centradas en los centros de experimentación animal. Por tanto, permite realizar un estudio individual de las soluciones adoptadas en cada centro; y además, proporciona una herramienta adecuada para posteriormente relacionar los datos de los diferentes centros analizados.

En este trabajo de investigación se ha diseñado una metodología que constituye un modelo que puede resultar útil para futuros trabajos dirigidos al estudio del diseño y organización de otros centros de experimentación animal. Se ha basado en estudiar los centros, visitarlos y conocer la opinión de los usuarios sobre sus propias instalaciones, para a través de representaciones gráficas estandarizadas comprender la organización planteada en cada caso; y a través de las tablas tipo hacer una puesta en común de los principales parámetros que definen cada centro y de este modo afrontar el análisis de los diferentes diseños realizados. 


\subsection{Conclusiones particulares}

\subsubsection{Conclusiones de la organización y diseño del centro de experimentación animal}

\section{Implantación del centro en el conjunto de la edificación}

A la hora de afrontar el planteamiento global de la organización de un nuevo edificio destinado a la investigación sanitaria, lo habitual es que la plataforma del centro de experimentación animal sea una de las consideradas críticas en cuanto a exigencias de calidad de aire, y que, por lo tanto, la decisión sobre su implantación influya en el resto de la organización del instituto. El diseño de la instalación en un nuevo edificio permite tener la oportunidad para organizar adecuadamente el centro, pero la realidad es que, en la mitad de los casos los centros se han tenido que distribuir en edificaciones existentes.

Lo habitual es que se destine una superficie comprendida entre los 750 y $1.500 \mathrm{~m}^{2}$ distribuida en un mismo edificio, y aunque lo deseable sería poder desarrollar todo el centro de experimentación animal en una misma planta con el fin de evitar el traslado interior vertical tanto de los animales como de los responsables al cuidado de ellos, la realidad es que no en todos los casos se ha conseguido.

\section{Accesos exteriores y circulación interior}

Estos centros habitualmente están situados en una planta con acceso directo desde el exterior para minimizar el traslado vertical de animales por el interior del edificio, $y$, por consiguiente, molestias de ruidos y olores al resto de usuarios del instituto.

En todos los casos se han planteado varios accesos al edificio para poder diferenciar las circulaciones de las personas de los animales, suministros y residuos. Además, esta política de segregación es la que se ha mantenido en casi todos los casos para plantear y distribuir los núcleos de comunicación vertical de acceso y distribución interior del centro.

Aunque la situación ideal sería disponer unos elementos independientes y propios del centro de experimentación para el transporte de animales, material limpio y retirada de residuos, en especial cuando la distribución del centro requiera el traslado vertical interior de los animales desde la zona de estabulación al área de experimentación, la realidad es que normalmente solo se dispone de un único montacargas para el traslado de los animales, suministros y residuos, de manera que no se realiza ningún tipo de segregación del material limpio del sucio; y, además, su uso suele ser compartido con otras plataformas de experimentación del instituto. En cambio, el personal habitualmente utiliza otros elevadores independientes y destinados únicamente para uso del personal, tanto del animalario como del resto de plataformas del instituto. 


\section{Diversas tipologías de organización del centro de experimentación}

Teniendo en cuenta el análisis de la organización realizada, en base al número de edificios y número de plantas en los que se ha distribuido el centro, así como al tipo de división realizado, entre los centros analizados, se pueden establecer seis tipologías de organización:

1. La experimentación animal se desarrolla en varios edificios.

2. El centro se ha distribuido en un único edificio y en una misma planta.

3. El centro se distribuye en dos plantas de manera que la división se realiza distribuyendo en una planta toda el área de estabulación de animal grande y pequeño, y en otra diferente el área de experimentación de animal grande y pequeño.

4. El centro se distribuye en dos plantas, de manera que la división se realiza distribuyendo en una planta el área de estabulación y experimentación de animal grande, y en otra diferente, el área de estabulación y experimentación de animal pequeño.

5. El centro se distribuye en dos plantas de manera que la división se realiza distribuyendo en una planta todo el área de experimentación quirúrgica, tanto la microcirugía como la cirugía con animales grandes, incluso la zona de estabulación de los animales tanto pequeños como grandes; y en otra planta diferente, el área de experimentación de animal pequeño.

6. El centro se distribuye en tres plantas: en una primera planta se distribuye la zona de vestuarios y cambio de personal; en una segunda planta se desarrolla el área de estabulación y experimentación de animal tanto grande como pequeño; $y$, en una tercera planta se distribuyen las áreas de servicio tales como el área de lavado y esterilización y la zona logística de almacenes.

En el presente estudio hemos visto que el análisis de las necesidades específicas del centro de experimentación animal, junto con las necesidades globales del resto de plataformas que conforman el instituto de investigación, incluso la afección de las líneas de investigación consideradas prioritarias, han determinado la ubicación del centro de experimentación animal en el conjunto edificatorio, aunque no siempre ha tenido el beneplácito de los usuarios finales o del propio equipo responsable del diseño. Además, el resultado final de la variedad de las tipologías de organización de los centros se ve afectado también principalmente debido a ciertos factores impuestos que pueden variar en función de si se trata de un edificio existente o de nueva construcción y que fundamentalmente tienen relación, entre otros, con conceptos tales como la disponibilidad de suelo, orografía del terreno, circunstancias urbanísticas, afecciones del entorno, incluso con la asignación presupuestaria disponible. 


\subsubsection{Conclusiones del área de experimentación animal grande}

\section{Actividades del área de experimentación de animal grande}

La investigación principal realizada en el área de experimentación de animal grande es la cirugía experimental, bien para realizar las intervenciones quirúrgicas necesarias en el desarrollo de procedimientos experimentales, o bien para la realización de prácticas en aras a adquirir la destreza necesaria en cualquiera de las especialidades quirúrgicas y médico-quirúrgicas, así como en técnicas anestésicas o laparoscópicas, entre otras. Es por ello que todos los institutos tienen quirófanos experimentales. Otra de las unidades de experimentación que nos hemos encontrado es el área de diagnóstico por imagen, adquiriendo gran importancia en unos determinados institutos.

\section{Diversidad de tipologías de organización del área de experimentación de animal grande}

En el presente estudio se observa cómo la organización del área de experimentación animal grande, a pesar de tener objetivos de investigación comunes, se puede organizar de múltiples maneras bajo criterios de organización y circulación variados, haciendo que cada instituto tenga unas características particulares y propias.

En la mayoría de los casos, esta área de experimentación se distribuye en una única planta con acceso directo desde el exterior, por lo que, aunque no en todos los casos se ha conseguido, no es habitual hacer uso de elementos de comunicación vertical para el desarrollo de la investigación. Además, es muy habitual que el área de experimentación de animal grande se encuentre integrado con el de animal pequeño en el conjunto del centro de experimentación animal. Atendiendo a todas estas variantes, las diferentes tipologías de organización de esta área son las siguientes:

1. El área de experimentación de animal grande se desarrolla como una unidad funcional específica, compacta e independiente.

2. Se crea una unidad funcional específica de cirugía experimental que comprende toda la actividad quirúrgica del centro, tanto para experimentación con animal grande como pequeño.

3. El área de experimentación de animal grande se desarrolla integrado con el conjunto de la experimentación de animal pequeño.

En base al estudio realizado, el análisis de las premisas generales del área de experimentación de animal grande, junto con las necesidades del área de experimentación de animal pequeño, incluso las globales del resto de plataformas del Instituto de Investigación Sanitaria, son las que acaban determinando la ubicación del área de experimentación de animal grande dentro del conjunto edificatorio; por lo tanto, se convierte en el punto de partida para el desarrollo de la propia área. 


\subsubsection{Conclusiones de la unidad de estabulación animal grande}

\section{Especies animales estabuladas en esta unidad}

La unidad de estabulación de animal grande se tiende a diseñarla para poder alojar de manera convencional la especie animal más utilizada hoy en día en cirugía experimental: el cerdo y el cerdo en miniatura o minipig. En menor medida, también se experimenta con modelos animales como la oveja y la cabra; y si bien hace años la experimentación con perros y gatos era habitual, hoy en día la experimentación con ellos apenas se realiza. En el caso concreto de los perros se limita prácticamente a su experimentación con cadáveres. En el presente estudio observamos cómo los conejos habitualmente se estabulan en el área de experimentación de animal pequeño, si bien encontramos algunos casos reducidos en los que se estabulan junto con el animal grande.

\section{Dimensionamiento del área de estabulación}

La investigación mayoritaria realizada con animal grande es la cirugía experimental, actividad totalmente programada, siendo en la mayoría de los casos animales terminales. Teniendo en cuenta este criterio y que la mayoría de los institutos se ubican en el recinto hospitalario, el dimensionamiento de las salas de estabulación se tiende a realizarlo para que la estancia de los animales en el centro sea la menor posible, lo que permite tener un área de estabulación reducida a cambio de un servicio de suministro de animales más frecuente. De esta manera, la mayoría de las áreas de estabulación disponen de dos salas de alojamiento, una de las cuáles se usa de cuarentena.

\section{Implantación del área de estabulación}

El área de estabulación de animal grande se tiende a ubicarlo en una planta con acceso directo desde el exterior con el fin de evitar traslados verticales interiores de los animales, y de esta manera minimizar las afecciones de estos animales en el resto del instituto. Además, lo habitual es que existan dos accesos diferentes al área de estabulación que permita segregar los accesos de los animales, los suministros y la retirada de residuos de la del personal del centro.

\section{Tipos de estabulación}

Teniendo en cuenta las afecciones que el uso de la instalación puede tener en otras áreas del centro, fundamentalmente por la posibilidad que existe de provocar inundación debido a la gran cantidad de agua necesaria para su limpieza y desinfección, se observa que la tendencia es que las jaulas de estabulación se diseñen sobre foso, solución que permite crear un vaso estanco con la pendiente necesaria para poder limpiar adecuadamente los residuos generados. Además, se tiende a diseñarlos con elementos prefabricados modulares, lo que proporciona la flexibilidad que requieren este tipo de instalaciones al poder alojar especies animales diferentes, y poder así adaptarse no solo a las necesidades actuales de la investigación, sino también a los posibles requerimientos futuros. 


\subsubsection{Conclusiones de la unidad quirúrgica experimental}

\section{Modelo animal más utilizado}

En los Institutos de Investigación Sanitaria Acreditados existe un área quirúrgica para experimentación con animal grande, bien para realizar las intervenciones quirúrgicas necesarias en el desarrollo de procedimientos experimentales, o bien para la realización de prácticas y adquirir la destreza necesaria en cualquiera de las especialidades quirúrgicas y medico quirúrgicas, así como en técnicas anestésicas o laparoscópicas, entre otras.

Para la realización de dichas prácticas quirúrgicas lo habitual es que se diseñen quirófanos experimentales, siendo el modelo animal más habitual utilizado el cerdo o cerdo en miniatura. Además, se observa cómo en algunos casos, para complementar las prácticas quirúrgicas se ha planteado una sala de experimentación con cadáveres.

\section{Implantación del área quirúrgica}

Observamos cómo el criterio utilizado para la implantación del área quirúrgica en el conjunto edificatorio es diferente al establecido en el ámbito hospitalario. Lo habitual es que los quirófanos se distribuyan en plantas con acceso directo desde el exterior, bien en plantas bajas o plantas semisótanos, ya que en general, lo que se prioriza en estos casos es la cercanía al área de estabulación de animal grande. El suministro de los animales grandes al centro es constante y estos animales, que son bastante ruidosos y pueden ocasionar problemas de olores, hay que trasladarlos hasta la zona de estabulación. Es por ello que con el fin de evitar molestias al resto de los usuarios del instituto, la zona de estabulación de animales grandes se sitúe en una planta con acceso directo al exterior y lo más cercano a este acceso.

Las instalaciones para experimentación con animal grande y pequeño tienen requerimientos de bases muy diferentes debido fundamentalmente al tipo de investigación que se realiza, a las condiciones de asepsia y de bioseguridad exigibles, incluso a las exigencias de los propios animales de experimentación. Es por ello que, aunque lo ideal sería poder diseñar un área de cirugía experimental totalmente independiente al área de experimentación de animal pequeño, la realidad es que es muy común que ambas áreas compartan servicios comunes.

\section{Composición del área quirúrgica experimental}

En cuanto al número de quirófanos que componen el área quirúrgica, aunque es muy variable, lo habitual es que sea igual o superior a dos. Con el fin de optimizar la superficie disponible en el centro, habitualmente son diseñados para instalar dos mesas de operaciones. En los casos en los que el dimensionamiento de la sala lo ha permitido, con el paso del tiempo incluso se ha complementado la 
instalación con alguna mesa quirúrgica más. Además, la implantación de tabiques móviles como elementos divisorios entre quirófanos ofrece mayor versatilidad al uso de las salas, llegando a conseguir ampliar considerablemente el número de mesas quirúrgicas disponibles.

\section{Diseñados según el criterio de los quirófanos asistenciales}

Atendiendo a las características del diseño constructivo de los quirófanos, observamos cómo la tendencia de las áreas quirúrgicas experimentales es diseñarlos como si fueran quirófanos asistenciales con los locales de servicio necesarios, así como con los materiales de acabado similares a los que nos encontramos en el ámbito hospitalario, siguiendo las directrices generales de facilidad de asepsia y con el equipamiento correspondiente tales como: lámparas cenitales, torre de cirugía y anestesia, paneles técnicos y equipos de video para retransmisión quirúrgica entre otros.

El uso de estas áreas quirúrgicas es una actividad totalmente programada en la que la circulación de los animales está protocolizada, si bien existe una diferencia importante a tener en cuenta entre los quirófanos de experimentación animal y los quirófanos en los que se prestan servicios de salud, ya que, si bien en los quirófanos de hospitales es fundamental garantizar la protección del paciente contra los agentes nocivos, en el caso de la experimentación animal este aspecto no es tan crítico, ya que lo habitual es que los animales sean terminales, o bien que interese ver la evolución durante un determinado periodo de tiempo sin tener que estabularlos en el propio instituto durante un periodo largo de tiempo, por lo que las exigencias de la calidad de aire pueden ser más permisivas.

Los quirófanos se consideran salas de ambiente controlado por lo que es recomendable que en su diseño se consideren conceptos que garanticen el control requerido en estas salas. Ubicar la sala de preparación médica, la sala de preparación animal, así como el almacén de material estéril, incluso la salida de residuos, colindante a los quirófanos, realiza la función de esclusa, lo que permite tener un control de las diferencias de presión entre salas, asegurando que el flujo de aire circule en la dirección adecuada, y, por lo tanto, evita la contaminación de agentes patógenos en la sala de operaciones. Así mismo, el grado de asepsia en la instalación mejora con la implantación de los vestuarios colindantes y con acceso directo al área quirúrgica o a la zona de preparación médica.

\section{Opciones de configuración del área quirúrgica experimental}

Según el estudio realizado, la configuración del área de cirugía experimental se puede organizar de diferentes maneras en función del criterio de distribución de pasillos seleccionado, de manera que podemos establecer tres tipologías diferentes de organización.

1. Distribución con pasillo único en el que tanto el personal investigador, el suministro de material limpio, los animales incluso los residuos acceden o salen del quirófano por el mismo pasillo. 
2. Distribución con pasillo doble en el que se separara el acceso del personal investigador y suministro del material limpio al quirófano del de animales y los residuos.

3. Distribución con pasillo doble en el que el personal investigador, el suministro de material estéril y los animales son segregados de los residuos.

La implantación de un tipo u otro de diseño afecta directamente a la organización del personal y la disciplina de trabajo, por lo que en su decisión está habitualmente implicado tanto el equipo de diseño como los responsables del área de experimentación. Si bien la tipología de distribución con pasillo único es la solución más adecuada desde el punto de vista de aprovechamiento de la edificabilidad y optimización de recursos, esta opción en la que se produce el cruce de los investigadores con los animales y del material limpio y sucio, requiere por parte de los profesionales del cumplimiento estricto de los procedimientos de trabajo establecidos en aras a garantizar las condiciones asépticas necesarias en el quirófano. Es por ello que la tendencia es realizar una distribución de manera que exista una segregación de circulaciones a la entrada del quirófano que permite independizar la circulación limpia de la sucia, considerando la limpia la destinada al personal investigador y suministro de material estéril, y la sucia la destinada a la circulación animal y retirada de residuos.

La mezcla de factores tales como el número de quirófanos, el número de mesas quirúrgicas en cada sala de operaciones, la ubicación de los locales de servicio con respecto al quirófano, así como el tipo configuración de pasillo seleccionado hacen que la organización de esta área no siga un patrón específico, resultando una distribución particular en cada caso.

Estas soluciones de organización y distribución tan variadas son el resultado obtenido de la combinación; por una parte, de las líneas de investigación establecidas por los responsables del área de experimentación animal; por otra parte, de las limitaciones impuestas por el conjunto edificatorio para la implantación del área quirúrgica; y, por último, de unos criterios de organización diferentes propuestos por los propios diseñadores.

La explosión tecnológica de los últimos años en el desarrollo de equipamiento médico cada vez más eficiente obliga a los profesionales médicos a adquirir la destreza necesaria para su aplicación posterior en el ámbito hospitalario en aras a mejorar la calidad de vida de la población. Lo que este estudio aporta es una visión de las diferentes soluciones adoptadas en el diseño de las áreas quirúrgicas experimentales en las que los profesionales médicos desarrollarán sus habilidades. Su estudio permitirá enfocar los futuros quirófanos experimentales con una visión amplia una vez conocidas las fortalezas y debilidades de cada solución adoptada. 


\subsubsection{Conclusiones del área de experimentación animal pequeño}

\section{Modelos animales de experimentación utilizados}

El área de experimentación de animal pequeño es una zona específica dentro del centro de experimentación animal destinada a la investigación con los animales que por su tamaño se consideran pequeños como son los roedores (ratones, ratas, hámsteres, cobayas, jerbos), los logomorfos (conejos), los animales acuáticos (peces) y los insectos (moscas).

El presente estudio del área de experimentación de animal pequeño se ha centrado específicamente en la zona destinada a la investigación con roedores y logomorfos, por estar estos últimos habitualmente estabulados junto a los roedores.

Así mismo, hemos podido comprobar que, aunque la experimentación con animales acuáticos se realiza en unos pocos centros, muchos de ellos tenían en mente la posibilidad de ampliar la investigación a este campo debido a las posibilidades que ofrece y a la facilidad de implantar los locales necesarios para su alojamiento en las instalaciones existentes.

\section{Características principales del área de experimentación}

La superficie destinada a la experimentación con animal pequeño es muy variable, ya que hay institutos que pueden llegar a triplicar la superficie del centro más pequeño. En la mayoría de los casos vemos que se destina una superficie comprendida entre los 500 y $1.000 \mathrm{~m}^{2}$

Si bien, tal y como hemos analizado en el área de experimentación de animal grande, lo habitual es que esos animales estén estabulados de forma convencional, en el caso de los roedores nos encontramos que el tipo de alojamiento a diseñar dependerá del estado sanitario exigible al animal, de manera que nos podemos encontrar con diferentes tipos de estabulación: estabulación convencional, estabulación en barrera y estabulación de contención del riesgo biológico.

Todos los institutos tienen una unidad destinada a la experimentación convencional de animal pequeño, siendo muy habitual que también dispongan de un área más reducida para la experimentación en barrera. Por otra parte, la unidad de experimentación de contención del riesgo biológico nivel 2 se realiza prácticamente en la mitad de los institutos, siendo una unidad integrada en la unidad convencional, que se configura como una sala de procedimientos con sus condicionantes específicos de diseño, equipamiento y procedimientos de trabajo. En cambio, no es muy habitual y solo encontramos un caso que dispone de una unidad de experimentación de contención del riesgo biológico nivel 3. 


\section{Organización del área}

En cuanto a la organización en plantas, observamos cómo lo habitual es que el área de experimentación de animal pequeño se distribuya en una única planta con acceso directo desde el exterior. En los casos en los que esta área se ha tenido que dividir en varias plantas, la base del planteamiento general ha sido intentar evitar tener que trasladar los animales de planta. Por diversas circunstancias, esta premisa no en todos los casos se ha logrado, por lo que este traslado se ha intentado reducir al mínimo número de animales posibles, incluso se han diseñado elementos de comunicación vertical de uso exclusivo para animales.

A pesar de que las necesidades y la actividad a desarrollar en el área de experimentación de animal pequeño son muy diferentes a la del animal grande, no siempre se ha conseguido independizar completamente las dos actividades. Es habitual que los pasillos de distribución, los locales de servicio, incluso en algún caso concreto las salas de preparación animal sean de uso compartido para ambas actividades, por lo que para el correcto funcionamiento del centro se han establecido una serie de procedimientos específicos de uso y limpieza de las zonas compartidas.

\section{Diseño constructivo del área}

En este estudio se hace un análisis somero sobre el diseño constructivo relacionado exclusivamente con la arquitectura interior de las salas de experimentación. En el diseño de este tipo de instalaciones hay que tener muy presente que los materiales de acabado deben ser elegidos para facilitar su limpieza y desinfección en aras a garantizar las condiciones de asepsia necesaria en las instalaciones; además, las salas de alojamiento de animales son instalaciones que están en funcionamiento 24 horas al día, por lo que es fundamental considerar los conceptos básicos de durabilidad, estabilidad, funcionalidad y mantenimiento. Por otra parte, para garantizar el bienestar animal, aparte de garantizar las condiciones ambientales exigibles a cada especie animal, es necesario tener presentes los tres focos principales que pueden generar estrés a los animales como son: el ruido, las vibraciones y la iluminación.

En relación a las particiones interiores, se observa cómo la mayoría de los institutos construidos recientemente han optado por una solución a base de tabiques modulares prefabricados que llevan incorporado el revestimiento de acabado. Estas soluciones modulares permiten afrontar una redistribución del área de una manera más sencilla que las soluciones tradicionales, ya que aportan la flexibilidad que requiere el diseño de este tipo de instalaciones para albergar futuras necesidades.

Los pavimentos están diseñados para soportar el tránsito intenso de los carros y jaulas que circulan por la instalación. En todos los casos se ha optado por pavimentos continuos, bien a base de láminas 
de PVC en rollo con juntas termosoldadas, bien a base de resina epoxi; y la unión del pavimento con los paramentos verticales se ha resuelto mediante la instalación de una curva sanitaria que facilita la correcta limpieza y desinfección de las salas.

Al igual que ocurre con los pavimentos y revestimientos verticales, los techos deben ser resistentes a la limpieza y desinfecciones frecuentes, aunque no están sujetos a la misma intensidad de limpieza. La solución implantada en estos casos está relacionada con la estrategia planteada para el mantenimiento de las instalaciones. En los casos en los que se ha considerado crítico acceder a las salas para realizar el mantenimiento de las instalaciones, la solución adoptada ha sido diseñar una planta técnica transitable mediante paneles autoportantes, mientras que en los casos en los que esta solución no ha sido posible, se ha optado por la solución a base de falsos techos continuos con puntos de acceso practicables ubicados preferentemente en las zonas no críticas de la instalación. Observamos un caso en el que se ha optado por la solución de dejar las instalaciones vistas, obteniendo un resultado satisfactorio por parte de los usuarios.

Las puertas son elementos que adquieren gran importancia en este tipo de instalaciones, ya que deben ser capaces de soportar el uso frecuente del paso de carros. En la mayoría de los centros son abatibles de apertura manual con complementos tales como muelles cierrapuertas, felpillos antipolvo y ventanas de observación que permite tener una visión general de la sala sin tener que acceder a ella, y, por lo tanto, mantener la calidad del aire interior de la sala lo más limpia posible. Los centros que han instalado puertas automatizadas consideran que es una inversión fundamental, ya que facilita la operatividad del transporte de carros y garantiza la apertura y el cierre completo de las puertas evitando que queden abiertas por largo periodo de tiempo, así como por la durabilidad de las mismas.

Las salas de alojamiento de animales están diseñadas para proporcionar la iluminación necesaria para garantizar el bienestar de los animales, para permitir su inspección adecuada, proporcionar unas condiciones de trabajo seguras para el personal y permitir las buenas prácticas de limpieza. Los roedores son especialmente sensibles a la iluminación, por lo que el control de la iluminación de las salas de estabulación es fundamental para: regular los ciclos circadianos, la estimulación, sincronización de los reproductivos y porque puede producir lesiones en la retina, sobre todo en animales albinos. En todas las áreas de experimentación de animal pequeño existe un control de la iluminación para garantizar el ciclo circadiano, siendo habitual los ciclos 12:12. En las instalaciones más básicas este encendido se produce localmente mediante un simple encendido y apagado temporizado, mientras que en los institutos más modernos la iluminación está integrada en el sistema de control general de la instalación, y está diseñada tanto para regular la intensidad lumínica de las 
salas de alojamiento de animales, como para simular el amanecer y atardecer en las fases de encendido y apagado de la iluminación.

Los ratones son más activos por la noche, por lo que es habitual que la iluminación de las salas de alojamiento se programe para adaptar los periodos nocturnos de los roedores a las jornadas de trabajo de los investigadores. En consecuencia, es muy común que el alumbrado se complemente con la instalación de un encendido manual de luz roja, que permita acceder a las salas en los periodos nocturnos y observar a los animales sin perturbarlos, al no tener que hacer uso del alumbrado general de la sala.

Las salas de alojamiento están diseñadas para garantizar la calidad del aire exigible a la instalación, y, por tanto, asegurar la circulación del aire, para que los niveles de polvo y las concentraciones de gases se mantengan dentro de unos límites que no sean nocivos para los animales alojados, en función de las especies. Siendo unos parámetros que deben registrarse diariamente, el control de la temperatura y humedad se realiza en todos los centros, si bien, la forma varía de unos a otros. En la mayoría de los casos, el sistema de control de los parámetros está centralizado en el sistema de gestión integral del edificio, por lo que el acceso a dicha información no es tán sencilla para los responsables de los animalarios. En otros casos, este control centralizado se complementa con la instalación de paneles de repetición de los parámetros para la visualización de la temperatura, humedad y presión junto a las puertas de acceso a las salas de estabulación, solución muy bien valorada y fundamental para los responsables del animalario. En algunos casos en los que esta opción no se ha planteado en la fase de diseño y construcción, los responsables del bienestar animal, han instalado equipos de control individual que les ha permitido tener un control visual del estado de las salas e independiente al sistema centralizado. Además, para garantizar la continuidad del sistema de climatización en caso de corte de suministros eléctricos, se han instalados grupos electrógenos, si bien no es habitual que el sistema de climatización sea redundante.

El análisis de la organización y diseño del área de experimentación animal pequeño ha permitido analizar las diferentes unidades que lo componen, las zonas de investigación que se potencian en cada centro, su organización y diseño, así como las características comunes y las diferencias entre ellas. En relación a los criterios del diseño constructivo se observa cómo en general, se han establecido medidas para ofrecer flexibilidad, durabilidad y para facilitar la limpieza y desinfección, en aras a garantizar las condiciones de asepsia necesaria en cada área, así como para garantizar el bienestar animal. En cuanto a las posibles soluciones para garantizar el mantenimiento de las instalaciones, la solución preferente pasaría por diseñar una planta técnica transitable, con el fin de evitar tener que acceder a la instalación, fundamentalmente para la experimentación en barrera. Se ha observado una solución alternativa que plantea dejar las instalaciones vistas, y aunque en principio choca con los conceptos básicos de asepsia requeridos en este tipo de instalaciones, esta solución tiene una opinión positiva de los usuarios sobre su conveniencia. 


\subsubsection{Conclusiones de la unidad de experimentación convencional animal pequeño}

\section{Modelos animales utilizados}

Una instalación convencional es aquella que no está diseñada para procedimientos especiales, ya que los animales alojados no requieren mantener un determinado estado de salud para garantizar el éxito de la investigación, y, por lo tanto, no se requiere su aislamiento.

La unidad de experimentación convencional de animal pequeño está diseñada para investigar con las siguientes especies más utilizadas: el ratón y la rata. Aunque en menor medida, también son utilizados la cobaya, el jerbo o el hamster. Además, el conejo, que es un modelo utilizado en casi todos los institutos, también es habitual que se estabule en esta unidad convencional. El ratón es el modelo animal más utilizado en experimentación animal y se selecciona para muchos tipos de estudios porque presenta características muy interesantes debido a la amplia variedad de cepas y modelos de ratones disponibles, su pequeño tamaño, su vida útil relativamente corta y por su corto tiempo de generación.

\section{Características de la unidad de experimentación convencional}

La superficie destinada a este tipo de experimentación es muy variable, si bien lo habitual es que se sitúe en un rango comprendido entre los 500-1.000 $\mathrm{m}^{2}$. Las áreas para experimentación que nos encontramos en todas las unidades son salas de procedimientos y de microcirugía, si bien algunos pocos centros destacan por las infraestructuras diseñadas para el diagnóstico por imagen, incluso por las salas de comportamiento.

\section{Diseño de las salas de estabulación}

Observamos que el dimensionamiento y configuración de las salas de estabulación de roedores es muy variable. Habitulamente, la superficie destinada a la estabulación de los animales teniendo en cuenta tanto las salas de alojamiento como las de cuarentena suele ser inferior a $100 \mathrm{~m}^{2}$. Si bien para los conejos se suelen diseñar uno o dos locales como mucho, en el caso de los roedores el número de locales disponibles suelen ser igual o menor a cinco unidades.

En el diseño de las salas de estabulación, aparte del tipo y número de animales que se quieran alojar en el local, influyen otros dos factores fundamentales: por una parte, la decisión de si en el local de alojamiento de animales se van a realizar procedimientos varios; $y$, por otra parte, el tipo de jaula que se va a utilizar, ya que en el caso de utilizar jaulas ventiladas individualmente el dimensionamiento óptimo de la sala está condicionado por el tipo jaula y la configuración del estante donde se alojan las jaulas, y por la necesidad de disponer de espacio suficiente dentro de la sala para instalar una cabina de flujo laminar para realizar el cambio de jaulas. 
En general, todos los procedimientos que puedan causar angustia al animal deberían realizarse fuera de la zona de alojamiento de animales en salas específicamente destinadas para ello, ya que puede transmitir alarma y producir un estrés innecesario al resto de los animales alojados en la sala. Por otra parte, el traslado de los animales a las salas de procedimientos y su posterior regreso a la sala de alojamiento aumenta el riesgo de contaminación de la instalación con agentes infecciosos. Es por ello que aunque lo habitual es que las salas de alojamiento se destinen únicamente a este fin, en la mayoría de las unidades de experimentación, existe alguna sala de alojamiento en la que también se realizan procedimientos menores. Como criterio de distribución alternativo a los traslados, en algún caso se ha tomado la decisión de adosar la sala de procedimientos a la sala de estabulación de manera que los animales son trasladados a través de una puerta que comunica ambas salas, sin tener que discurrir por pasillos comunes.

Las jaulas deben permitir la observación diaria de los animales con una perturbación mínima. En este sentido, se observa que las jaulas utilizadas en todas las unidades de experimentación convencional son de plástico transparente, lo que permite una observación directa de los animales desde el exterior. En cuanto al material utilizado para la configuración de las jaulas, aunque prácticamente en todos los casos son reutilizables, observamos un caso en el que debido al dimensionamiento del centro, la elección realizada ha sido del tipo desechable.

En relación al tipo de jaula utilizada en esta zona no hay un criterio unificado. Algunos centros han optado por instalar jaulas ventiladas individualmente en todos los locales de alojamiento, incluso en la zona de cuarentena, aunque lo habitual es que exista una mezcla del tipo convencional y autoventilada. En este ultimo caso no existe un consenso unificado de dónde instalar las jaulas ventiladas, ya que en algunos casos están ubicadas en la sala de cuarentena, mientras que en otros en los locales de alojamientos.

Independientemente del criterio de jaula seleccionado, puesto que las líneas de investigación y por tanto, los requerimientos de la instalación son variables con el paso del tiempo, diseñar las salas de estabulación convencional para poder alojar en un momento determinado jaulas ventiladas individualmente proporciona la flexibilidad necesaria en este tipo de instalaciones.

\section{Criterios organizativos unidad experimentación convencional}

Atendiendo a la distribución en plantas, observamos cómo lo habitual es que el área de experimentación de animal pequeño se desarrolle en una única planta con acceso directo desde el exterior. En los casos en los que esta área se ha tenido que dividir en varias plantas, la base del planteamiento general ha sido intentar evitar tener que trasladar de planta los animales. Por diversas 
circunstancias, esta premisa no en todos los casos se ha logrado, por lo que este traslado se ha intentado reducir al mínimo número de animales posibles, incluso se han diseñado elementos de comunicación vertical de uso exclusivo para animales.

Estas unidades de experimentación están organizadas de manera que la circulación se realiza siempre desde las zonas limpias hacia las sucias. De la misma manera que ocurre con las circulaciones de los quirófanos, históricamente el sistema de distribución mediante doble pasillo ha sido una expresión de organización de este concepto. El estudio nos muestra cómo en los animalarios construidos o reformados recientemente se tiende a evitar la duplicidad de pasillos debido fundamentalmente a la gran superficie que hay que destinar para su configuración, a que requiere unas estrictas normas de funcionamiento y a que puede llegar a requerir más personal debido a la limitación de acceso a las áreas que se impone; por el contrario, requiere considerar los equipos necesarios para minimizar el contacto de los diferentes materiales, así como una planificación exhaustiva de las circulaciones por los pasillos para evitar que coincidan.

Aunque la tendencia es organizar la unidad a través de un pasillo único, el estudio nos ha mostrado cuatro tipologías de organización:

1. Pasillo simple. En este caso el personal, los animales, los suministros y los residuos acceden a un único pasillo a través del cuál transitan dentro de la unidad.

2. Pasillo doble con segregación de limpio y sucio. En este caso existen dos pasillos de circulación dentro de la propia unidad de experimentación convencional: uno denominado limpio, por el que circulan el personal, los animales y los materiales limpios; y, un segundo, por el que circula el material sucio, así como el personal responsable de recogerlo.

3. Pasillo doble con segregación de pasillo exterior e interior. En este caso también existen dos pasillos de circulación, pero el área se organiza de diferente manera. Por una parte, existe un pasillo exterior a la unidad que comunica con las salas de cuarentena para el acceso de los animales al centro; y, por otra parte, un pasillo interior dentro de la unidad, por el que circulan el personal, los materiales limpios y sucios y a través del cual los animales son trasladados desde las salas de cuarentena a las salas de estabulación, así como a las salas de experimentación.

4. Pasillo triple. En este caso la organización se desarrolla a partir de tres pasillos de distribución paralelos entre sí, con diferentes grados de asepsia. El primer pasillo exterior sirve para introducir los animales a la unidad; el segundo es el pasillo donde se realiza la investigación que sirve para trasladar los animales desde la zona de estabulación a la de experimentación, y por tanto, por el 
que circulan el personal y los animales; y, el tercer pasillo sirve para la logística de suministros, tanto para el suministro de materiales limpios como para la retirada de residuos.

\section{Diseño y organización de la sala de lavado y esterilización}

Los trabajos a llevar a cabo en la sala de lavado corresponden al vaciado de jaulas y biberones, lavado de materiales, preparación de jaulas y llenado de biberones. Adicionalmente, puede ser necesario que los materiales sean esterilizados por dos motivos fundamentalmente: para proporcionar material estéril en determinadas zonas de experimentación o para eliminar el material potencialmente infeccioso que pueden contener los materiales.

En el estudio hemos observado que, aunque en algunos casos estas tareas se hacen de manera manual, en los casos que se ha tenido presupuesto suficiente se han instalado equipos que automatizan estas tareas tales como: equipos para lavado de los racks, lavado de jaulas, lavabiberones, así como aspirador y dispensador de virutas. Es por ello que en aras a garantizar una flexibilidad futura en la instalación, es importante desde la fase de diseño tener en cuenta no solo los equipos necesarios en el momento del diseño, sino también el posible futuro equipamiento.

Vemos que la organización de la sala de lavado y esterilización se plantea desde distintas perspectivas, determinadas fundamentalmente por el hecho de que en el centro de experimentación de animal pequeño exista una zona de experimentación en barrera o no, por el tipo del material de las jaulas reutilizable o desechable utilizado; y por el criterio de circulación del material establecido. Además, es muy importante que estos equipos estén convenientemente ditribuidos, según el flujo de trabajo, para garantizar la calidad del resultado de la limpieza, y, también para facilitar el trabajo del personal, evitando realizar movimientos innecesarios. Las diferentes tipologías observadas son las siguientes:

1. La sala de lavado y esterilización da servicio únicamente a la unidad de experimentación convencional y dispone de una única puerta a través de la que se introduce el material sucio y se retira una vez limpio.

2. La sala de lavado y esterilización se organiza en dos áreas diferenciadas y separadas para lo que dispone de varias puertas y está organizada para introducir el material sucio por una y retirar el material ya limpio y esterilizado por la otra, pudiendo estar internamente la sala dividida por los equipos de lavado y esterilización.

3. La sala se organiza en dos áreas diferenciadas y separadas físicamente para dar servicio tanto a la zona convencional como a la zona de barrera. En la zona denominada sucia se introduce el 
material sucio y se lava. Una vez lavado, a través de los equipos de barrera, se esteriliza para introducirlo directamente a la zona denominada de experimentación en barrera.

Los resultados de este estudio han mostrado que el área de experimentación convencional de animal pequeño puede variar en cuanto al dimensionamiento de un centro a otro, así como en el tipo de equipamiento implantado debido, entre otros motivos, a la asignación presupuestaria disponible. A pesar de ello, tanto las especies animales como las áreas de experimentación son comunes en la mayoría de los centros. Aunque puede haber diferencias en el planteamiento del tipo de jaula de alojamiento seleccionado, teniendo en cuenta la flexibilidad exigible a este tipo de instalaciones, es recomendable diseñar las salas de estabulación para poder alojar jaulas ventiladas individualmente, así como las cabinas de cambio necesarias. En cuanto a la organización en planta, a pesar de que hemos observado diferentes alternativas de distribución, los centros construidos o reformados recientemente tienden a diseñarse mediante un único pasillo de distribución, motivado fundamentalmente porque requiere menor superficie para su configuración y procedimientos de trabajo del personal menos exigentes. 


\subsubsection{Conclusiones de la unidad de experimentación en barrera animal pequeño}

\section{La importacia de la instalación en barrera}

El alojamiento en barrera para animal pequeño se ha convertido en un estándar para albergar animales de experimentación, siendo muy común que en los Institutos de Investigación Sanitaria se desarrolle la unidad de experimentación en barrera. De hecho, siete de los diez institutos analizados disponen de esta unidad que está diseñada para investigar con las especies más utilizadas en experimentación: la rata y el ratón.

Los animales que habitualmente se alojan en estas instalaciones son animales de cría, genéticamente definidos o modificados e inmunodeprimidos, entre otros. Además, la procedencia y el estado sanitario de los animales que pueden acceder a la zona de barrera está muy limitado y controlado, siendo lo habitual que los animales que salgan de ella no puedan regresar.

\section{Dimensionamiento de la unidad}

La superficie destinada a este ámbito de experimentación es muy variable. Observamos cómo la mayoría de los centros destinan a esta unidad una superficie inferior a los $200 \mathrm{~m}^{2}$, siendo la superficie destinada a los locales de alojamiento de animales inferior a $50 \mathrm{~m}^{2}$.

\section{Organización de la instalación en barrera}

En el contexto de las ciencias del animal de laboratorio, el término barrera se refiere a los sistemas de alojamiento de animales diseñados y gestionados para proteger a los animales de infecciones no deseadas por agentes procedentes desde fuera de la barrera. Por lo tanto, las barreras consisten en una combinación de sistemas físicos y criterios de trabajo para que conjuntamente minimicen la transferencia de agentes infecciosos de un lado de la barrera a la otra.

Las instalaciones en barrera diseñados en estos institutos representan una parte de la instalación destinada a la investigación de animal pequeño, siendo lo habitual que se distribuya en una única planta mediante pasillo simple de distribución. Con el objetivo de optimizar la superficie disponible, así como los recursos de equipamiento y personal, es muy común que se integre en el conjunto de la instalación de experimentación de animal pequeño y que ambas unidades compartan los locales de servicio tales como son la sala de lavado y esterilización, almacenes y vestuarios.

La mayoría de las instalaciones de barrera para roedores tienen procedimientos de trabajo específicos que impiden que los animales regresen a la barrera una vez que han salido de ella. Esto significa que, además de estar diseñadas para garantizar la protección de los animales frente a los agentes externos, el cuidado y bienestar animal, así como las condiciones de trabajo y seguridad del personal, están 
diseñadas para alojar los locales, instalaciones, equipos y servicios necesarios para el desarrollo de la investigación sin tener que salir de ella.

La barrera primaria más común utilizada es a nivel de jaula y en todos los casos las jaulas utilizadas son de tipo ventiladas individualmente, lo que garantiza el control ambiental de las jaulas y permite invertir la presión del aire en las mismas en función de la experimentación que se necesite llevar a cabo.

Lo habitual es que el número de las salas de alojamiento de animales sea igual o superior a dos unidades, solución que permite ante cualquier circunstancia no prevista en una sala, tener una segunda opción de estabulación. En lo relacionado con las salas de procedimientos, aunque existen institutos en los que los procedimientos se realizan dentro de las salas de estabulación, en la mayoría de los casos se disponen salas específicas para la realización de procedimientos varios.

\section{Sistemas de acceso a la zona de barrera}

La peculiaridad de este tipo de instalaciones es que con el fin de mantener la calidad del aire interior y evitar la entrada de agentes patógenos, es necesario diseñar unos puntos de entrada y salida específicos para las personas, animales, suministros y residuos que son los que van a determinar los pasos fronterizos entre el interior y el exterior de la barrera.

Los requisitos para el acceso de las personas a una barrera varían considerablemente dependiendo de la función de la barrera, la investigación a desarrollar dentro de la barrera y los criterios establecidos por los responsables del animalario; en definitiva, del nivel de control microbiológico exigible a la instalación.

Observamos cómo el criterio adoptado para el acceso del personal a la zona de barrera se produce de dos maneras posibles; aunque en la mayoría de los casos existe una ducha de aire para el acceso a la zona de barrera previo paso por un vestuario para cambio de vestimenta, en el resto de los casos, el acceso a la zona de barrera se produce a través de una esclusa de personas en la que se realiza la puesta de los EPIs complementarios necesarios para acceder a la unidad.

Como criterio general, todos los materiales que deban ser introducidos a la zona de barrera deben ser previamente esterilizados y, excepcionalmente, algunos materiales únicamente se desinfectarán. EI proceso de esterilización para el acceso de los materiales es fundamental en las instalaciones en barrera, por la necesidad de mantener el ambiente estéril en la zona de experimentación; en cambio, no es habitual que el material saliente de la zona de barrera se procese de una manera específica. 
Los equipos, diseñados para mantener la separación entre la zona exterior y la zona de experimentación en barrera, forman lo que comúnmente se llama equipos de barrera. Lo habitual es que en los institutos investigados existan tres equipos de acceso para introducir los materiales: autoclave, cabina pasamateriales de VPH y ventana SAS pasamateriales con lámparas germicidas UV. Aunque en todos los casos existe un autoclave para esterilizar los equipos, no en todos los casos existe un autoclave grande de doble puerta en el que poder introducir las jaulas y que a su vez esté comunicado directamente con la zona de barrera. En estos casos, la solución adoptada ha sido instalar una cabina SAS pasamateriales de doble puerta de VPH a través del que poder introducir los estantes que conecta directamente con el interior de la zona de barrera.

El acceso de los animales habitualmente se produce a través de un equipo SAS. Únicamente los animales con un estado de salud definido son aceptados en la barrera, y una vez que salen de ella se les prohíbe volver a entrar sin volver a realizarles las pruebas necesarias.

\section{Diversas soluciones para facilitar el mantenimiento de la instalación}

En cuanto a las estrategias adoptadas para facilitar el mantenimiento de la instalación, aunque la mayoría de los usuarios consideran que la disposición de una planta técnica transitable para realizar las tareas de mantenimiento sería la mejor opción, no en todos los caso ha sido posible, por lo que como alternativa a la clásica solución de falso techo continuo con registros practicables, en algún instituto se ha planteado la solución de dejar todas las instalaciones vistas, con un resultado satisfactorio.

La mezcla de factores tales como los sistemas de barrera diseñados para el acceso de personas, materiales y animales, así como la ubicación de la sala de lavado y esterilización hacen que la organización de esta unidad no siga un patrón específico, resultando prácticamente una distribución particular para cada caso. 


\subsection{Conclusiones finales}

La investigación biomédica vivió a nivel nacional cambios importantes organizativos y de funcionamiento a partir del Real Decreto sobre acreditación de los Institutos de Investigación Sanitaria. De esta manera, en el año 2009 se acreditan los primeros institutos: IDIBAPS, Vall d'Hebrón, Bellvitge, Germans Trias i Pujol y el Instituto de Biomedicina de Sevilla. Con el paso de los años, el número de acreditaciones ha ido aumentando, y a fecha de febrero de 2020 están acreditados treinta y un institutos, los cuales se encuentran distribuidos por todo el territorio nacional.

\section{Evolución del diseño adaptado a las nuevas técnicas de experimentación}

El diseño de los centros de experimentación animal que ofrecen servicios de apoyo en los institutos de investigación sanitaria han ido evolucionando con el paso del tiempo, ya que han tenido que adecuarse a los diversos cambios sufridos en el ámbito de la investigación, como son: los cambios en la actitud ética de la experimentación, las condiciones genético-sanitarias y ambientales exigibles, la evolución en las técnicas de uso, los modelos animales utilizados, así como al tipo de experimentación a llevar a cabo. Además, la explosión tecnológica de los últimos años en el desarrollo de equipamiento médico cada vez más eficiente obliga a los profesionales médicos a adquirir la destreza necesaria para su aplicación posterior en el ámbito hospitalario, en aras a mejorar la calidad de vida de la población.

\section{Diversidad de modelos organizativos}

La normativa de aplicación para el diseño de este tipo de centros es muy generalista, lo que propicia que la organización de los centros de experimentación animal se pueda realizar de múltiples maneras, bajo criterios de planificación y circulación variados, haciendo que cada instituto tenga unas características particulares y propias a pesar de que tengan objetivos de investigación comunes.

Intentar crear un modelo de diseño estandarizado en relación a los centros de experimentación animal para su aplicación en los Institutos de Investigación Sanitaria, que desarrolle todo lo analizado anteriormente, sería un trabajo arduo y complejo, por no decir que imposible.

Como se ha visto, la tipología es muy variada debido principalmente a que han sido diseñados en función de las líneas y proyectos de investigación prioritarios de cada centro, por ciertos factores impuestos de partida, así como por los criterios organizativos propuestos por los proyectistas. Estos factores impuestos pueden variar en función de si se trata de un centro ubicado en un edificio existente o de nueva construcción y fundamentalmente tienen relación, entre otros, con conceptos tales como la disponibilidad de suelo, orografía del terreno, circunstancias urbanísticas, afecciones al entorno, incluso con la asignación presupuestaria disponible. Además, no existe un consenso 
generalizado sobre la idoneidad entre diferentes tipologías. Por lo tanto, no hay conceptos invariables a los que agarrarse para a partir de ellos elaborar una propuesta de modelo estandarizada.

\section{Incorporación progresiva de las nuevas tecnologías constructivas al diseño de los centros}

Los sistemas constructivos implantados han evolucionado según los avances tecnológicos producidos en este campo. En este sentido, si bien en los centros de experimentación animal más antiguos se han adoptado los modelos constructivos tradicionales realizados in situ que aportan una solución rígida, poco flexible y con largos periodos de implantación, en los centros más modernos se han ido sustituyendo por elementos prefabricados modulares que aportan la flexibilidad que exigen este tipo de instalaciones, debido fundamentalmente a los cambios que habitualmente es necesario llevar a cabo a lo largo del periodo de vida útil de sus instalaciones.

\section{Alto grado de satisfacción de los usuarios respecto al centro de experimentación}

El éxito del planteamiento del diseño de una instalación de este tipo parte de la base de un plan funcional amplio y detallado, y que, a su vez, sea válido para el conjunto de la comunidad científica, misión que corresponde habitualmente a los profesionales del ámbito de la biomedicina, siendo en esta transmisión donde se encuentra la base del resultado final de la actuación en cuestión.

La percepción que tienen los usuarios de los centros sobre sus instalaciones es, en general, muy satisfactoria ya que, a pesar de disponer de unas infraestructuras mejorables, han conseguido organizar el centro de manera que los resultados de la investigación y docencia sean de excelencia. Aunque en algunos aspectos particulares, los planteamientos realizados no han sido los considerados más idóneos, y, por tanto, no siempre han tenido el beneplácito de los usuarios finales o del propio equipo responsable del diseño, no ha habido otra opción que adoptarlos. En estos casos en los que el diseño constructivo no ha sido el óptimo, se han implantado unos procedimientos de trabajo específicos que han garantizado la asepsia requerida en cada una de las áreas, y, por tanto, el correcto funcionamiento del centro.

Lo que este trabajo de investigación aporta es una visión de la variedad de soluciones adoptadas en el diseño de los centros de experimentación animal, con las diferentes áreas y unidades que lo componen. Se considera una herramienta complementaria a las guías existentes y fundamental para afrontar el diseño y construcción de nuevos centros de investigación de este tipo. Su estudio y análisis probablemente permita a los diseñadores en el ámbito de la arquitectura e ingeniería enfocar el proyecto de una nueva instalación con una visión más amplia y a su vez más selectiva, una vez conocidas las fortalezas y debilidades de cada solución analizada en este trabajo, teniendo presente el objetivo final de este tipo de instalaciones: intentar planificar, diseñar y construir lo mejor en a facilitar un funcionamiento eficiente, económico y seguro. 


\section{FUTURAS LÍNEAS DE INVESTIGACIÓN}

Con las recomendaciones de las futuras líneas de investigación se pretende establecer unas directrices para dar continuidad al trabajo realizado, bien completando el estudio iniciado en el ámbito de los centros de experimentación animal con el estudio de los centros y temas que no se han abordado en esta investigación, o bien ampliando el campo de estudio a los centros de experimentación animal de aplicación en otros ámbitos diferentes al hospitalario.

El trabajo aquí expuesto pretende ser de aplicación en los centros de experimentación animal del ámbito hospitalario, de manera que pueda servir de utilidad en el diseño de futuros centros. La investigación, inevitablemente, se ha tenido que acotar por lo que puede completarse con el estudio de las siguientes líneas de investigación que han quedado fuera del alcance del estudio:

- La investigación se ha limitado al estudio de los centros de experimentación animal de diez institutos acreditados. Sería interesante completar la investigación con el análisis de las soluciones adoptadas en el resto de los Institutos de Investigación Sanitaria Acreditados, o incluso con otros institutos en proceso de acreditación, para poder efectuar estudios comparados entre ellos, y así definir con mucha mayor amplitud las características de la organización y diseño de este tipo de centros de experimentación animal.

- El estudio se ha acotado a las unidades de experimentación convencional y en barrera, por lo que podría complementarse con el estudio de la organización y diseño pormenorizado de las unidades de contención del riesgo biológico nivel 2 y 3, así como de las unidades de experimentación con animales acuáticos. Estas especies animales son cada vez más utilizadas en experimentación biomédica, por lo que el estudio de su diseño, características constructivas y parámetros de las instalaciones aportarían gran valor.

- En el trabajo realizado se han expuesto las diferentes unidades de investigación que nos encontramos habitualmente en la experimentación animal. Se ha analizado su implantación y organización en el conjunto del centro de experimentación animal, pero no se ha podido realizar un estudio detallado de todas y cada una de ellas. La investigación se podría completar con el estudio de la organización interna, equipos e instalaciones de las unidades que han quedado fuera del alcance del estudio como pueden ser el área de imagen, microcirugía, comportamiento y necropsias, entre otros.

- Estudio específico y comparativo sobre los sistemas constructivos, materiales de acabado, así como del cumplimiento de los parámetros de calidad exigibles a los mismos en base a la normativa 
vigente, a las exigencias de uso y mantenimiento, a la consecución de procesos de certificación, así como al aseguramiento de los parámetros tanto funcionales como ambientales y de bienestar animal.

- Profundizar en el análisis de las instalaciones diseñadas para el funcionamiento de los centros de experimentación animal. En la presente investigación se han analizado someramente las necesidades de las instalaciones sin hacer un estudio detallado de los parámetros de diseño de cada una de ellas, ni tampoco el diseño y características de los equipos implantados en cada caso. La investigación se podría complementar con el estudio pormenorizado de las instalaciones que son necesarias implantar para poder garantizar el funcionamiento de los centros las veinticuatro horas al día, los trescientos sesenta y cinco días del año.

- Estudio del diseño de este tipo de instalaciones desde la perspectiva para afrontar situaciones de emergencia y alarma tales como situaciones prolongadas de corte de suministro eléctrico, inundaciones, accidentes que afecten a la movilidad de los trabajadores, incluso evacuación en caso de incendio, entre otros. A partir de la identificación y clasificación de las posibles emergencias en este tipo de centros y dependiendo del tipo de riesgo, de la gravedad del mismo, de la ocupación de la instalación y de los medios humanos disponibles para hacer frente a la emergencia, se puede afrontar el estudio de los procedimientos de actuación, así como los mecanismos y equipos de intervención necesarios para afrontar la situación de alarma.

- Estudio del coste económico de este tipo de instalaciones teniendo en cuenta el tipo de diseño, las características constructivas y los materiales de acabado seleccionados, así como la repercusión de cada uno de ellos en el coste de mantenimiento de las mismas. Este tipo de instalaciones requieren de una inversión enconómica inicial considerable, y, además, deben estar en funcionamiento veinticuatro horas al día. Es por ello que a la hora definir cada uno de los parámetros de diseño se debería considerar no solo la inversión económica inicial si no también los costes de mantenimiento generados por el tipo de elección realizada y asociados al periodo de vida útil de la instalación.

- Desarrollo del estudio enfocado hacia la mejora del diseño de este tipo de centros. Tomando como referencia las encuestas de opinión realizadas a los usuarios de los diferentes centros de experiementación animal, y con el fín de poner mucho más en valor la información recopilada, sería interesante continuar la investigación mediante la aplicación de alguno de los diferentes modelos de gestión de la calidad existentes como puede ser el QFD (Quality Function Deployment) también llamado La casa de la calidad. La finalidad sería crear nuevos diseños que se adapten a 
las necesidades y gustos de los usuarios. Se trataría, básicamente, de realizar un estudio para tener una visión objetiva de qué es lo que buscan los usuarios, identificando cuales son las características prioritarias y aquellas que no lo son, así como los aspectos que serían necesarios mejorar, con el objetivo de transformar las demandas del usuario en calidad de diseño.

La experimentación animal tiene ámbitos de aplicación diferentes al hospitalario y a la investigación biomédica, por lo que la investigación podría ampliarse tanto a los centros de experimentación animal de entornos diferentes al hospitalario, pero dedicados a la investigación biomédica, como a los centros de experimentación animal de aplicación en otros sectores distintos. De esta manera, las nuevas vías de investigación podrían ser las siguientes:

- Sería de gran interés ampliar la investigación a los centros de experimentación animal destinados a ámbitos de aplicación diferentes al hospitalario, para comprobar si la información obtenida en este estudio es extrapolable al resto de ámbitos y determinar las unidades de investigación diferentes que se planteen.

- Estudido y análisis los centros de experimentación animal en el sector de la industria farmacéutica, probablemente marcados por conceptos diferenciales.

- Estudio y análisis de los centros de experimentación animal de grandes instalaciones y laboratorios de bioseguridad como son los ABSL3.

- Estudio y análisis de los centros de experimentación animal destinados a la cría y producción de animales de determinado estado sanitario o transgénicos, para el suministro y distribución a los centros de investigación. 


\section{BIBLIOGRAFÍA}

\subsection{Libros, manuales y guías}

Acosta-Gnass, S.I.; Andrade, V. de. 2008. Manual de esterilización para centros de salud. Washington, DC: Organización paramericana de salud. ISBN: 9789275329269.

Albarracín, A. y otros. 2015. Libro blanco de la actividad y gestión del bloque quirúrgico en España. Madrid: Antares consulting.

Benavides, F.J. y Guénet, J.L. 2003. Manual de genética de roedores de laboratorio. Madrid: Universidad de Alcalá. ISBN: 9788481385847.

Boada, M; Colom, A. y Castelló, N. 2011. La experimentación animal. Trabajo de la asignatura de Deontología Veterinaria. Universidad Autónoma de Barcelona. Barcelona. [consulta: 10-02-2020]. Disponible en: https://ddd.uab.cat/record/80084

Boixareu, P. y otros. 2012. Guia de buenas practicas para la seguridad y la sostenibilidad del area quirúrgica. Barcelona: Departament de Salut Generalitat de Catalunya.

Cabo, J.; Sánchez-Caro, J.; Herreros, J. M. y otros. 2010. Gestión sanitaria integral: pública y privada. Madrid: Centro de Estudios Financieros. ISBN: 978-84-454-1631-0. [Consulta 10-02-2020]. Disponible en: https://www.gestion-sanitaria.com/gestion-sanitaria-integral-publica-privada.html

Castro, F.; San José, J.F.; Villafruela, J.M. y Guijarro, A. 2011. Manual de diseño de la climatización y ventilación de quirófanos y habitaciones en centros hospitalarios de castilla y león. Valladolid: Malta Digital. ISBN 9788461445889.

CCAC Mice Subcommittee. 2019. CCAC guidelines: Mice. Ottawa: Canadian Council on Animal Care. ISBN: 978-0-919087-77-4.

CCAC Subcommittee on husbandry. 2017. CCAC guidelines: Husbandry of animals in science. Otawa: Canadian Council on Animal care. ISBN: 9780919087651.

CCPA Consejo Canadiense de protección de animales. 1998. Manual sobre el cuidado y uso de animales de experimentación, 2aㅡ ed. Canada: CCPA Consejo Canadiense de protección de animales. ISBN: 0919087310.

Comisión de Normas Sanitarias de la OIE. 2019. Utilización de animales en la investigación y educación. Código sanitario para los animales terrestres. 28th ed.: OIE. ISBN 978-92-95108-90-5. 
Declaración de Helsinki de la Asociación Médica Mundial. 1964. Principios éticos para las investigaciones médicas en seres humanos. Helsinki.

División de desarrollo de sistemas y servicios de salud. 2002. Cabinas de seguridad biológica: Uso, desinfección y mantenimiento. Washington, DC: Organización panamericana de salud. ISBN: 9275 324166.

Division of technical resources. 2012. NIH Design requirements manual. The national institutes of health.

Division of technical resources. 2016. NIH Design requirements manual. Rev 1.4. The national institutes of health. [Consulta: 10-02-2020]. Disponible en: https://www.orf.od.nih.gov/TechnicalResources/Pages/DesignRequirementsManual2016.aspx

España. Academia europea de ciencias y arte. 2011. Libro Blanco sobre el Sistema Sanitario Español. Madrid: Academia Europea de ciencias y arte. ISBN: 978-84-614-6612-2.

España. Ministerio de Sanidad y Política Social. 2009. Bloque quirúrgico estándares y recomendaciones. Madrid: Ministerio de Sanidad y Política Social Centro de publicaciones.

España. Ministerios de sanidad y consumo. 1996. Guía Práctica para el diseño y mantenimiento de la climatización en quirófanos. Madrid: Instituto Nacional de la Salud. ISBN: 8435102211.

España.Ministerio de defensa. 2013. Manual de procedimientos en medicina y cirugía experimental. Ministerio de defensa. ISBN: 9788497818773.

Felasa. 2007. EUROGUIDE: On the Accommodation and Care of Animals Used for Experimental and Other Scientific Purposes. United Kingdom: Royal Society of Medicine Press. ISBN: 9781853157516.

Fox, J. G. Fox y otros. 2007. The mouse in biomedical research.2nd ed. San Diego: Elveisser. ISBN 10: 0123694582.

Fuentes F.M., Mendoza R.A., Rosales A.L. y Cisneros R.A. 2008. Guia de manejo y cuidado de animales de laboratorio: Ratón. Lima: Ministerio de salud - Instituto Nacional de Salud.ISBN 9789972857690.

Giráldez, A. 2008. Breve historia de la experimentación animal. Madrid: Instituto de España. Real Academia Nacional de farmacia. ISBN: 978-84-934430-8-5. 
Grupo de buenas prácticas de laboratorio (BPL). 2014. Programa de cumplimiento de las buenas prácticas de laboratorio. Ministerio de sanidad, servicios sociales e igualdad, Agencia española de medicamentos y productos sanitarios.

Grupo de trabajo Sociedad Andaluza de Medicina Preventiva y Salud Pública. 2016. Recomendaciones para la monitorización de la calidad microbiologica del aire (bioseguridad ambiental) en zonas hospitalarias de riesgo. Vol 2. SAMPSP.

Grupo de Trabajo. 1999. Recomendaciones para la minimización de los riesgos microbiológicos asociados a las infraestructuras hospitalarias de Osakidetza/Servicio Vasco de Salud. Coordinación de Programas de Salud Pública Dirección de Asistencia Sanitaria Osakidetza. Departamento de Sanidad Gobierno Vasco. ISBN: 9788489342958.

Health Canada. 2004. Laboratory Biosafety Guidelines. 3a ed. Ottawa: Minister of Health. ISBN 0-66237722-2.

Hernandez, R; Fernández, C; y Baptista, P. 2014. Metodología de la investigación. 6 ed: Mexico: Mc Graw Hill. ISBN: 9781456223960.

Hessler, J.R. 1991. Handbook of facilities planning. Vol. 2. Laboratory animal facilities. New York: Theodorus Ruys. ISBN-13: 978-0442234263.

Hessler, J.R. y Lehner, N.D.M. 2009. Planning and designing research animal facilitie. $1^{\text {st }}$ ed: San Diego: Elsevier. ISBN: 978-0-12-369517-8.

Instituto Nacional de Seguridad e Higiene en el Trabajo. 2014. Guía técnica para la evaluación y prevención de riesgos relacionados con la exposición de agentes biológicos. Madrid: Instituto Nacional de Seguridad e Higiene en el Trabajo (INSHT).

Mani, P. y Langevin, P. 2006. Veterinary containment facilities: design \& construction handbook. International Veterinary Biosafety Working group.

Martínez, M. L. 2014. Guía de buenas prácticas para la circulación en el bloque quirúrgico, Madrid: Instituto Nacional de Gestión Sanitaria.ISBN: 9788435104227.

Mc Glone J. y otros. 2010. Guide for the care and use of agricultural animals in research and teaching. $3^{\text {rd }}$ ed. Champaign: Federation of animal science societies. ISBN: 978-1-884706-11-0.

McAnulty, P.A. et al 2012. The minipig in biomedical research. CRC Press. ISBN -13: 978143981119 1. 
Míguez, M.P., Largo, J.D. y Pérez, M. 2016. Perspectiva de la experimentación animal en ciencias biomédicas. Cáceres: Colección manuales UEX-101 Universidad de Extremadura. ISBN: 97884608 46161.

España. Ministerio de agricultura, pesca y alimentación. 2018. Informe sobre usos de animales en experimentación y otros fines científicos incluyendo la docencia.

España. Ministerio de economía, industria y competititvidad. 2017. Plan Estatal de Investigación Científica, Técnica y de Innovación 2017-2020. [Consulta 02-02-2020] Disponible en: http://www.ciencia.gob.es/portal/site/MICINN/menuitem.7eeac5cd345b4f34f09dfd1001432ea0/?v gnextoid=83b192b9036c2210VgnVCM1000001d04140aRCRD

National Academies of Sciences, Engineering, and Medicine. 2015. Design, Implementations, monitoring and sharing of performance standars for laboratory animal use: summary of a workshop. Washington, DC: The National academy press. ISBN: 9780309379243.

National Research Council. 2011. Guide for the Care and Use of Laboratory Animals. 8th ed. Washington, DC: The National Academy Press. ISBN: 978-0-309-15401-7.

Neil, D. y Mckay, D. 2003. Guidelines on: laboratory animal facilities - characteristics, design and development. Canada: CCAC Canadian Council on animal care. ISBN: 0919087418.

NHS Estates. 1991. Health Building Note 26. Operating department. London: HMSO. ISBN 011 3213859

NHS Estates. 2004. Health Buliding Note 26. Facilities for surgical procedures: Vol. 1. London: The Stationery Office. ISBN 0113224958.

Organización mundial de la salud. 2003. Prevención de las infecciones nosocomiales: Guía práctica. 2nd ed. Organización mundial de la salud.

Organización Mundial de la Salud. 2005. Manual de bioseguridad en el laboratorio. 3rd. ed, Ginebra: Ediciones de la OMS. ISBN 9243546503.

Organización Mundial de la Salud. 2013. Manual de bioseguridad en el laboratorio de tuberculosis. Ginebra: Ediciones de la OMS. ISBN: 9789241504638.

Perez, C.C. 2014. Algunas preguntas y pocas respuestas sobre el uso de animales en experimentación biomédica y el papel del veterinario. Leon: Academia de ciencias veterinaria de Castilla y león. ISBN: 978-84-9773-683-1. 
Quito. Ministerio de salud pública. 2013. Guia de acabados interiores para hospitales GAlH. Quito: Organización Panamericana de Salud. ISBN: 978-9942-07-455-3.

Russel, W.M.S. y Burch, R.L. 1959. The principles of humane animal experimental techniques, London: Methuen.

Sánchez, O.D. y Bernal, I. 2019. Interés público en la innovación biomédica. Creative commons. DOI 10.5281/zenodo.2545338.

Sanchez-Caro, J. y Abellán F. 2007. Investigación biomédica en España: aspectos bioéticos, jurídicos y científicos. Granada: Comares. ISBN: 9788498363067.

The National Commission for the Protection of Human Subjects of Biomedical and Behavioral. 1979. The Belmont Report: Ethical Principles and Guidelines for the Protectionof Human Subjects of Research. Washington, DC: Department of Health, Education, and Welfare.

Tribunal internacional de Nüremberg. 1947. Código de Nüremberg. Nüremberg.

U.S. Department of Health and Human Services. 2009. CDC Biosafety in Microbiology and Biomedical Laboratories. 5th ed. Bethesda, MD: National Institute of Health.

United States Department of Agriculture. 2017. Animal Welfare Act and Animal Welfare Regulations. Washington, D.C.: The Animal and Plant Health Inspection Service. [Consulta 10-02-2020]. Disponible en $\quad: \quad$ https://www.govinfo.gov/content/pkg/USCODE-2015-title7/html/USCODE-2015-title7chap54.htm.

Working group for cage processing AK KAB. 2013. Cage processing in animal facilities properly done.

Zúñiga, J.M.; Tur, J.A. y Orellana, J.M. 2008. Ciencia y tecnología del animal de laboratorio. Alcalá de Henares: Universidad de Alcalá. ISBN: 9788481387834.

\subsection{Artículos, revistas y congresos}

Abad, X. 2010. Bioseguridad y biocontención: reflexiones. Actualidad SEM, 49: 20-26.

Alestrom, P.; D’Angelo, L.; Midtlyng, P.J.; Schorderet, D.F. y otros. 2019. Zebrafish: Housing and husbandry recommendations. Laboratory Animals, 0: 1-12.

Barrasa, J.L.; Martínez, N. y Martínez, J. 2009. El impacto de la luz, ruido, limpieza de las cubetas y transporte interno sobre el bienestar y estrés de las ratas de laboratorio. Edición en español de Laboratory Animals, 43: 311-327. 
Blanes, S.; Souza, R.; Chammas, R. and Poli-de-Figueiredo, L.F. 2010. The fundamentals of experiments with animals - applications in experimental surgery. Revista Associación Médica Brasil, 56(1): 103111.

Bujalance, F.; Hurtado, R.; Ocaña. A.; Romero, L. y Ayala, N. y otros. 2019. Diseño de un laboratorio modular de biocontención de nivel p-2. Documento presentado en el XV Congreso Nacional de la Sociedad Española para las Ciencias del Animal de Laboratorio. Sevilla 6-7-8 noviembre de 2019. ID: 96.

Cámara, J.A.; Andrés, E.; Sánchez, S. y Mulero, F. 2014. Aplicación de la imagen molecular preclínica en biomedicina. Radioprotección, 79: 44-60. Disponible en: www.sepr.es

Campos, A. 2014. Institutos de Investigación Sanitaria. Diez años de historia. Actualidad Médica, 99 $(791): 5$

Carrasco, M. 2007. El futuro de la investigación en el Sistema Nacional de Salud. Revista de Administración Sanitaria Siglo XXI, Vol 5. 2: 237-257.

Castelhano-Carlos, M.J. and Baumans, V. 2009. The impact of light, noise, cage cleaning and in-house transport on welfare and stress of laboratory rats. Laboratory Animals, 43: 311-327.

Cruceta, G. 2017. Novedades normativas europeas en climatización y calidad de aire en quirófanos. Proyecto de Norma EN 16244-2. Documento presentado en el 350 Congreso Nacional de Ingeniería Hospitalaria. Las Palmas de Gran Canaria, 25-27 de octubre de 2017. http://congresodeingenieriahospitalaria.com/laspalmasdegrancanaria2017/wpcontent/uploads/2017/11/Novedades-Normativas-Europeas-en-climatizaci\%C3\%B3n-y-calidad-deaire-en-quir\%C3\%B3fanos.-Proyecto-de-No.pdf

FELASA Working Group on Accreditation of Diagnostic laboratories 1999. FELASA guidance paper for the accreditation of laboratory animal diagnostic laboratories. Laboratory Animals, 33 S1:19-38.

Fernández, J.M. y Mosquera, L. 2006. Unidad de investigación de animalario (1/2) Hospitla doce de octubre. Documento presentado en el XXIV Seminario de Ingeniería Hospitalaria. Congreso Nacional. Valencia, 25-26 y 27 de octubre de 2006.

Font, D.; Gomis, R.; Trilla, A.; Bigorra, J.; Piqué, J.M. y Roldés, J. 2008. Organización y modelo de funcionamiento de las estructuras de investigación biomédica. Situación y retos de futuro. Medicina clínica, 103(3): 510-516. 
Gomis, R. 2009. Centros de investigación y hospitales. SEBBM, 159:8-10.

Grupo de trabajo del FELASA sobre la salud de los animales. 1996. Recomendaciones de FELASA para los Controles de Sanidad en las Unidades Experimentales de Ratones, Ratas, Hámsters, Gerbos, Cobayas y Conejos. Laboratory Animals, 30: 193-208.

Guillen, J. 2012. FELASA Guidelines and Recommendations, Javier Guillen. Journal of the American Association for Laboratory Animal Science, Vol 51, 3: 311-321.

Hauschildt, A. 2016. Tecnologías de esterilización a baja temperatura de Matachana. Magazine Matachana, 3: 4.

Hernández, S. 2006. El modelo animal en las investigaciones biomédicas. Biomedicina, 2(3): 252-256.

Howard, B.; van Herck, H.; Guillen, J.; Bacon, B.; Joffe, R. and Ritskes-Hoitinga, M. 2004. Report of the FELASA Working Group on evaluation of quality systems for animal units. Laboratory Animals, 38: $103-118$.

Informe de la reunión de trabajo sobre refinamiento de roedores. 1998. Refinamiento de la estabulación de roedores: El ratón. Laboratory Animals, 32: 233-259.

Informe del grupo de trabajo sobre transporte establecido por la sociedad para la Ciencia del animal de laboratorio (LASA). 2005. Guía para el transporte de animales de laboratorio. Edición en español de Laboratory Animals, 39: 1-39.

Jiménez, J.L. 2012. Criterios de diseño de equipos de transferencia tipo esclusa para materiales y personas. Industria farmaceutica, 170: 40-47.

Klaunberg, B.A. and Davis, J.A. 2008. Considerations for Laboratory Animal Imaging Center Design and Setup. ILAR Journal Vol 49, 1: 4-16.

Kobayashi, E.; Hishikawa, S.; Teratani, T and Lefor, A.T. 2012. The pig as a model for translational research: overview of porcine animal models at Jichi Medical University. Transplantation Research, 1(1): 8.

Kollmus, H.; Post, R.; Brielmeier, M.; Fernández, J. et al. 2012. Structural and functional conepts in current mouse phenotyping and archivinf faclilities. Journal of the American Association for Laboratory Animal Science, 51 (4): 418-435. 
Lunney, J.K. 2007. Advances in Swine Biomedical Model Genomics. International Journal of Biological Sciences, 3(3): 179-184.

Manso, G. 2012. Aplicaciones de la resonancia magnética en pequeños animales. Documento presentado en XI Congreso de especialidades veterinarias. Córdova 24-25 marzo de 2012. Disponible en:https://www.researchgate.net/publication/259872751_APLICACIONES_DE_LA_RESONANCIA_MA GNETICA_EN_PEQUENOS_ANIMALES

España. Ministerio de economía, industria y competititvidad. 2013. Estrategia Española de Ciencia y Tecnología y de Innovación 2013-2020. [Consulta 02-02-2020] Disponible en: http://www.ciencia.gob.es/portal/site/MICINN/menuitem.26172fcf4eb029fa6ec7da6901432ea0/?v gnextoid=1387571a3db06610VgnVCM1000001d04140aRCRD

Natividad, C. 2014. Organización, políticas e instrumentos de investigación biomédica. Madrid: Escuela Nacional de Sanidad. Consultado febrero 2020. Tema 15.2. Disponible en: http://62.204.194.45/fez/eserv/bibliuned:500981/n15.2 Investigación Biomédica.pdf

Newcomer, C.E. 2012. The Evolution and Adoption of Standards Used by AAALAC. Journal of the American Association for Laboratory Animal Science, 51(3): 293-297.

Nistal, C.; Barrasa, J.L.; Palacio, J. 2011. Guía para definir e implementar protocolos para la evaluación del bienestar de los animales de laboratorio: décimo primer informe del grupo de trabajo sobre refinamiento AAWF/FRAME/RSPCA/UFAW (Revisión de la traducción del artículo original al español). Edición en español de Laboratory Animals, 45: 1-13.

Olmedo, C.; Buño, I.; Plá, R.; Lomba, I.; Bardinet, T. y Bañares, R. 2015. La gestión de un Instituto de Investigación Sanitaria: hacia la investigación de excelencia a través de la mejora continua. Gaceta Sanitaria. 29(6):458-460. http://dx.doi.org/10.1016/j.gaceta.2015.06.003

P. alter, V.N. y Grantcharov T.P. 2010. Simulation in surgical education. CMAJ, 182(11): 1191-1196.

Pastor Pérez, P. 2016. Módulo 2-3 Diseño de quirófanos: especificaciones y parámetros. Curso de especialización Norma Europea EN 16244- 2 Climatización y calidad de aire en quirófanos. Segla.

Pons, J.M.V. y Adam, P. 2018. La investigación biomédica en la encrucijada y vías de salida. Medicina Clínica, 151 (3): 109-110.

Rincon D.E.; Fernández, P. y Reséndez-Pérez, D. 2009. De la genética de la mosca a la salud humana. Ciencia UANL, Vol XII, 1. 
Rodriguez Yunta, E. 2007. Ética de la investigación en modelos animales de enfermedades humanas. Acta bioethica, 13 (1).

Romeo, C.M. 2009. Ley de Investigación Biomédica: un nuevo y completo mapa para la investigación científica en biomedicina. Medicina Clínica, 132(16):633-637.

Romero, A. 2015. Investigación biomédica responsable. Sanidad Militar, 71 (4).

Rozkot M., Václavková E., Bělková J. 2015. Minipigs as laboratory animals - review. Research in pig breeding, 9:10-14.

Ruiz, M. y Rodriguez, M.A. 2017. Transferencia de materiales en salas limpias: SAS y Esclusas. Farmespaña Industrial, octubre 17: 42-49.

Shepherd, M. 2012. Special Issue: Regulatory Updates in Animal Research. Journal of the American Association for Laboratory Animal Science: JAALAS, 51(3) :292.

Sherry E. Vaughan. 2012. Review of the Third Edition of the Guide for the Care and Use of Agricultural Animals in Research and Teaching. Journal of the American Association for Laboratory Animal Science, 51(3): 298-300.

Smith, A.J.; Clutton, R.E.; Lilley, E.; Hansen, K.E.A. and Brattelid, T. 2018. PREPARE: guidelines for planning animal research and testing. Laboratory Animals, 52(2): 135-141.

Stout, D.B.; Chatziioannou, A.F.; Lawson, T.P.; Silverman, R.W.; Gambhir, S.S. y Phelps, M.E. 2005. Small Animal Imaging Center Design: The Facility at the UCLA Crump Institute for Molecular Imaging. Molecular imaging and biology, 7(6):393-402.

Stricker-Krongrad, A.; Shoemake, C.R. and Bouchard, G.F. 2016. The Miniature Swine as a Model in Experimental and Translational Medicine. Toxicologic Pathology, 44(4): 612-623.

Swindle, M.M.; Makin, A.; Herron, A.J.: Clubb, F.J. Jr and Frazier, K.S. 2012. Swine as Models in Biomedical Research and Toxicology Testing. Veterinary Pathology, 49(2): 344-56.

Turner, P.V. and Wayne, R. B. 2020. Responsible Science and Research Animal Use. ILAR Journal. Vol. 60, 1: 1-4.

Usera, F. y Perez, J. 2014. Nuevas normas para la gestión del riesgo en laboratorios. AENOR Bioseguridad, 296: 42-45. 
Van der Meer, E.; Van Loo, P.L. and Baumans, V. 2004. Short-term effects of a disturbed light-dark cycle and environmental enrichment on aggression and stress-related parameters in male mice. Laboratory Animals, 38(4): 376-383.

Vaquero de la Hoz, M.T.; Fariñas M. y Vaquero, J.L. 2011. Biodescontaminación ambiental con peróxido de hidrógeno vaporizado en el ámbito quirúrgico. Revista Española de investigaciones quirúrgicas, 4: 218-224.

Vargas-Vargas, R.A. 2017. Pez cebra (Danio Rerio) y anestesia. Un modelo animal alternativo para la realizar investigación biomédica básica. Anestesia en México, 29 (1): 86-96.

Vega, A.M. 2005. Tecnología VHP para la esterilización ambiental. 2005. El autoclave, Revista Española de esterilización, 1: 14-20.

Vega, A.M. 2009. Vapor de peróxido de hidrógeno. La tecnología definitiva en la esterilización a baja temperatura. El autoclave. Revista Española de esterilización, 2: 30-36.

Vodika, P.; Smetana, K. Jr.; Dvoránková, B.; Emerick, T.; Xu, Y.Z.; Ourednik, V. and Motlík, J. 2005. The Miniature Pig as an Animal Model in Biomedical Research. Annals New York Academy of Sciences, 1049: 161-171.

Wenke, C.; Pospiech, J.; Reutter, T.; Truyen, U. and Speck, S. 2017. Efficiency of different air filter types for pig facilities at laboratory scale. PLOS ONE 12(10): e0186558. Disponible en: ttps://journals.plos.org/plosone/article?id=10.1371/journal.pone.0186558.

\subsection{Tesis doctorales}

Orellana, J.M. 2007. Revisión del convenio Europeo ETS 123 del consejo de Europa: Impacto de su aplicación sobre los animalarios Españoles. Tesis doctoral. Universidad Complutense de Madrid. Departamento Fisiología. Madrid.

\subsection{Normativa}

AENOR. 1998. Biotecnología, Laboratorios de investigación, desarrollo y análisis. Niveles de contención de los laboratorios de microbiología, zonas de riesgo, instalaciones y requisitos de seguridad. UNE EN 12128: 1998. Madrid: AENOR.

AENOR. 2014. Competencia del profesional en bioseguridad. UNE-CWA 16335:2014. Madrid: AENOR.

AENOR. 2019. Diseño de instalaciones de nivel 3 de contención biológica (NCB3). UNE 171400-1:2019. Madrid: AENOR. 
AENOR. 2020. Filtros absolutos (EPA, HEPA y ULPA). Parte 1: Clasificación, principios generales del ensayo y marcado. UNE-EN 1822-1:2020. Madrid: AENOR.

AENOR. 2017. Filtros de aire utilizados en ventilación general. Parte 1: Especificaciones técnicas, requisitos y clasificación según eficiencia basado en la materia particulada (PM). (ISO 16890-1:2016). UNE-EN ISO 16890-1:2017. Madrid: AENOR.

AENOR. 2014. Gestión del riesgo biológico en el laboratorio. Guía para la aplicación del CWA 15793:2008. UNE-CWA 16393:2014. Madrid: AENOR.

AENOR. 2013. Gestión del riesgo biológico en el laboratorio. UNE-CWA 15793:2013. Madrid: AENOR. AENOR.2005. Instalaciones de acondicionamiento de aire en hospitales. UNE 100713:2005. Madrid: AENOR.

AENOR. 2014. Instalaciones de acondicionamiento de aire en hospitales. UNE 100713:2005. Madrid: AENOR.

AENOR. 2016. Salas limpias y locales anexos controlados. Parte 1: Clasificación de la limpieza del aire mediante la concentración de partículas (ISO 14644-1:2015). UNE-EN ISO 14644-1:2016. Madrid: AENOR.

AENOR. 2012. Validación y cualificación de salas de ambiente controlado en hospitales. UNE 171340: 2012. Madrid: AENOR.

Andalucía. Decreto 142/2002, de 7 de mayo, por el que se crea y regula el Registro de establecimientos de cría, suministradores y usuarios de animales de experimentación y otros fines científicos. Boletín oficial de la Junta de Andalucía, de 11 de mayo de 2002, núm. 55.

Andalucía. Decreto 199/2005, de 20 de septiembre, por el que se modifica el Decreto 142/2002. Boletín oficial de la Junta de Andalucía, de 27 de septiembre de 2005, núm. 189.

Andalucía. Ley 11/2003, de 24 de noviembre, de Protección de los Animales. Boletín Oficial del Estado, 19 de diciembre de 2003, núm. 303, pp. 45194 - 45203.

Aragón. Decreto 239/2008, de 16 de diciembre, del Gobierno de Aragón, por el que se establecen las normas de homologación de los cursos de formación y las de acreditación de las entidades de formación, de los cuidadores y manipuladores de animales, de los adiestradores de los animales de compañía y de los animales potencialmente peligrosos. Boletín Oficial de Aragón, de 24 de diciembre de 2008, núm. 218, pp. 26733-26750. 
Aragón. Ley 11/2003, de 19 de marzo, de protección animal, de la Comunidad Autónoma de Aragón. Boletín Oficial del Estado, 22 de abril de 2003, núm. 96, pp. 15406-15425.

Aragón. Orden de 20 de abril de 2006, del Departamento de Agricultura y Alimentación, por la que se convoca el proceso de homologación para el ejercicio profesional en los centros de experimentación animal y otros fines científicos. Boletín Oficial de Aragón, de 3 de mayo de 2006, núm. 49, pp. 58865890.

Cantabria. Orden de 2 de febrero de 1989, de la Consejería de Ganadería, Agricultura y Pesca, sobre protección de los animales utilizados para experimentación y otros fines científicos. Boletín oficial de Cantabria de 20 de febrero de 1989, núm. 36.

Cataluña. Decreto 164/98, de 8 de julio, que modifica el Decreto 214/1997 de 30 de julio de 1997. Diario Oficial de la Generalitad de Cataluña, de 14 de julio de 1998, núm. 164.

Cataluña. Decreto 214/1997, de 30 de julio, por el que se regula la utilización de animales para experimentación y para otras finalidades científicas. Diario Oficial de la Generalitad de Cataluña, de 7 de agosto de 1997, núm. 214.

Cataluña. Decreto 286/1997, de 31 de octubre, de modificación del Decreto 214/1997, de 30 de julio, por el que se regula la utilización de animales para experimentación y para otras finalidades científicas. Diario Oficial de la Generalitad de Cataluña, de 4 de noviembre de 1997, núm. 2518.

Cataluña. Ley 22/2003, de 4 de julio, de protección de los animales (DOGC 3929, de 16.7.2003, BOE de 8 de agosto). Artículo 24 prohíbe la instalación, en todo el territorio de Cataluña, de granjas, centros de cría o centros de suministro de primates que tengan como objeto su reproducción o comercialización para experimentación animal. Boletín Oficial del Estado, de 8 de agosto de 2003, núm. 189., pp. 30724-30738.

Cataluña. Ley 5/1995, de 21 de junio, sobre Protección de los Animales utilizados para experimentación y otras finalidades científicas. Boletín Oficial del Estado, de 10 de agosto de 1995, núm. 190.

Comunidad de Madrid. Orden de 4 de agosto de 1989 del Consejero de Agricultura y cooperación por la que se dan normas sobre protección de los animales utilizados para experimentación y otros fines científicos. Boletín Oficial de la comunidad de Madrid, de 24 de agosto de 1989. 
Comunidad Valenciana. Decreto 13/2007, de 26 de enero, del Consell, sobre protección de los animales utilizados para experimentación y otros fines científicos. Diario Oficial de la Comunidad Valenciana de 30 de enerode 2007, núm. 5439.

Consejo de Europa. Convenio europeo sobre protección de los animales vertebrados utilizados con fines experimentales y otros fines científicos ETS 123 (número 123 del consejo de europa), hecho en estrasburgo el 18 de marzo de 1986. Boletín Oficial del Estado de 25 de octubre de 1990, núm. 256. España. Ley 13/1986, de 14 de abril, de Fomento y Coordinación General de la Investigación Científica y Técnica. Boletín Oficial del Estado, 18 de abril de 1986, núm. 93, pp. 13767-13771.

España. Ley 14/2007, de 3 de julio de Investigación Biomédica. Boletín Oficial del Estado, 4 de julio de 2007, núm. 93, pp. 28826-28848.

España. Ley 14/2011, de 1 de junio de la Ciencia, la Tecnología y la Innovación. Boletín Oficial del Estado, 2 de junio de 2011, núm. 131, pp. 54387-54455.

España. Ley 16/2003, de 28 de mayo de cohesión y calidad del Sistema Nacional de Salud. Boletín Oficial del Estado, 29 de mayo de 2003, núm. 128, pp. 20567-20588.

España. Ley 32/2007, de 7 de noviembre, para el cuidado de animales, en su explotación, transporte, experimentación y sacrificio. Boletín Oficial del Estado, 8 de noviembre de 2007, núm. 268, pp. 4591445920.

España. Ley 6/2013, de 11 de junio, de modificación de la Ley 32/2007, de 7 de noviembre, para el cuidado de los animales, en su explotación, transporte, experimentación y sacrificio. Boletín Oficial del Estado, 12 de junio de 2013, núm. 140, pp. 44289-44292.

España. Ley Orgánica 3/2018, de 5 de diciembre, de Protección de Datos Personales y garantía de los derechos digitales. Boletín Oficial del Estado, 6 de diciembre de 2018, núm. 296, pp. 119788-119857.

España. Orden ECC/566/2015, de 20 de marzo, por la que se establecen los requisitos de capacitación que debe cumplir el personal que maneje animales criados o suministrados con fines de experimentación y otros fines científicos, incluyendo la docencia. Boletín Oficial del Estado, 1 de abril de 2015, núm. 78, pp. 27940-27973.

España. Real Decreto 1027/2007, de 20 de julio, por el que se aprueba el Reglamento de Instalaciones Térmicas en los Edificios. Boletín Oficial del Estado, 29 de agosto de 2007, núm. 207, pp. 35931 a 35984. 
España. Real Decreto 1386/2018, de 19 de noviembre, por el que se modifica el Real Decreto 53/2013, de 1 de febrero, por el que se establecen las normas básicas aplicables para la protección de los animales utilizados en experimentación y otros fines científicos, incluyendo la docencia. Boletín Oficial del Estado, 20 de noviembre de 2018, núm. 280, pp. 112804-112806.

España. Real Decreto 223/1988, de 14 de marzo, sobre protección de los animales utilizados para experimentación y otros fines científicos. Boletín Oficial del Estado, 18 de marzo de 1988, núm. 67, pp. 8509-8512.

España. Real Decreto 279/2016, de 24 de junio, sobre acreditación de institutos de investigación biomédica o sanitaria. Boletín Oficial del Estado, 5 de julio de 2016, núm. 161, pp. 47272-47283.

España. Real Decreto 339/2004 de 27 de febrero, sobre acreditación de institutos de investigación sanitaria. Boletín Oficial del Estado, 13 de marzo de 2004, núm. 63, pp. 11409-11412.

España. Real Decreto 339/2004, de 27 de febrero, sobre acreditación de institutos de investigación sanitaria. Boletín Oficial del Estado, 13 de marzo de 2004, núm. 63, pp. 11409-11412.

España. Real Decreto 479/2004, de 26 de marzo, por el que se establece y regula el Registro General de Explotaciones Ganaderas. Boletín Oficial del Estado, 13 de abril de 2004, núm. 89, pp. 14978-14983.

España. Real Decreto 53/2013, de 1 de febrero, por el que se establecen las normas básicas aplicables para la protección de los animales utilizados en experimentación y otros fines científicos, incluyendo la docencia. Boletín Oficial del Estado, 8 de febrero de 2013, núm. 34, pp. 11370-11421.

España. Real Decreto 664/1997, de 12 de mayo, sobre la protección de los trabajadores contra los riesgos relacionados con la exposición a agentes biológicos durante el trabajo. Boletín Oficial del Estado, 24 de mayo de 1977, núm. 124, pp. 16100-16111.

España.Real Decrecto 1201/2005, de 10 de octubre, sobre protección de los animales utilizados para experimentación y otros fines científicos. Boletín Oficial del Estado, 21 de octubre de 2005, núm. 252, pp. 34367-34391.

Galicia. Decreto 296/2008, de 30 de diciembre, de protección de los animales utilizados para experimentación y otros fines científicos, incluida la docencia, y por el que se crea el Registro de los centros de cría, de suministradores y usuarios y la Comisión Gallega de Bienestar de los Animales de Experimentación. Diario Oficial de Galicia, de 16 de enero de 2009, núm 11. 
Navarra. Orden Foral de 5 de agosto de 1991, del Consejero de Agricultura, Ganadería y Montes, sobre protección de los animales utilizados en experimentación y fines científicos en la C.F de Navarra. Boletín Ofical de Navarra de 23 de agosto de 1991, núm. 105.

NTP 859 Ventilación general en hospitales. Instituto Nacional de Seguridad e Higiene en el Trabajo (INSHT)entilación general en hospitales. Grosell, M. y Farrás, A. Nota técnica de prevención 2010. Madrid: Instituto Nacional de Seguridad e Higiene en el Trabajo, 2010.

País Vasco. Orden de 25 de junio de 1991, del Consejero de Agricultura y Pesca, por la que se dictan normas sobre protección de los animales utilizados para la experimentación y otros fines científicos. Boletín Oficial del País Vasco, de 4 de julio de 1997, núm. 1991136.

UE EN 16244-2 Climatización y calidad de aire en quirófanos

Unión Europea. Directiva 2010/63/UE del Parlamento Europeo y del Consejo de 22 de septiembre de 2010 relativa a la protección de los animales utilizados para fines científicos. Diario Oficial de la Unión Eurpoea de 20 de octubre de 2010, L 276, pp. 33-79.

Unión Europea. Directiva 86/609/CEE del Consejo de 24 de noviembre de 1986 relativa a la aproximación de las disposiciones legales, reglamentarias y administrativas de los Estados Miembros respecto a la protección de los animales utilizados para experimentación y otros fines científicos. Diario Oficial de la Unión Europea de 24 de noviembre de 1986, L 358, pp. 1-28.

\subsection{Sitios Web}

AAALAC. Association for Assessment and Accreditation of Laboratory Animal Care International, 2020. [consulta 10-02-2020]. Disponible en: https://www.aaalac.org/accreditationprogram/directory/directory-of-accredited-organizations-search-

result/?nocache=1\#home_acc_dir_search

IIS Biodonosti. Instituto de investigación sanitaria Biodonostia, 2020. [consulta 10-02-2020]. Disponible en: http://www.biodonostia.org

IGTP. Instituto de investigación sanitaria Germans Trias y Pujol, 2020. [consulta 10-02-2020]. Disponible en: http://www.germanstrias.org/es-index/

IDIBELL. Instituto investigación sanitaria Bellvitge, 2020. [consulta 10-02-2020]. Disponible en: http://www.idibell.cat/es 
IdiPAZ. Instituto investigación sanitaria La Paz, 2020. [consulta 10-02-2020]. Disponible en: http://www.idipaz.es

IISA. Instituto investigación sanitaria Aragón, 2020. [consulta 10-02-2020]. Disponible en: http://www.iisaragon.es/instituto/informacion-iisa/

liSGM. Instituto investigación sanitaria Gregorio Marañon, 2020. [consulta 10-02-2020]. Disponible en: http://www.iisgm.com

IRYCIS. Instituto investigación sanitaria Ramón y Cajal, 2020. [consulta 10-02-2020]. Disponible en: http://www.irycis.org/

ISCIII. Instituto de salud carlos tercero, 2020. [consulta 10-02-2020]. Disponible en: http://www.isciii.es/ISCIII/es/contenidos/fd-investigacion/fd-institutos-investigacionsanitaria/listado-de-iis-acreditados.shtml

VHIR. Instituto de Investigación Sanitaria Vall d'Hebron, 2020. [consulta 10-02-2020]. Disponible en: http://www.vhir.org/portal1/

Hospitecnia [consulta 10-02-2020]. Disponible en: https://hospitecnia.com/documentacion/articulos/

ICLAS. International Council for laboratory animals science, 2020. [consulta 10-02-2020]. Disponible en: https://iclas.org/

1+12. Instituto investigación sanitaria 12 de octubre. [consulta 10-02-2020]. Disponible en: https://imas12.es/

Laboratory animals. Publicación periódica. [consulta 10-02-2020]. Disponible en: https://journals.sagepub.com/loi/lana

SECAL. Sociedad Española para las Ciencias del Animal de Laboratori. [consulta 10-02-2020]. Disponible en: https://secal.es/

IIS Biocruces. Instituto investigación sanitaria Biocruces. [consulta 10-02-2020]. Disponible en: https://www.biocrucesbizkaia.org/web/biocruces/inicio

CIC Biogune. Centro investigación cooperativa en biociencias. [consulta 10-02-2020]. Disponible en: https://www.cicbiogune.es/ 
CIC Biomagune. Centro investigación cooperativa en biomateriales. [consulta 10-02-2020]. Disponible en: https://www.cicbiomagune.es/

Idibpas. [consulta 10-02-2020]. Disponible en: https://www.clinicbarcelona.org/idibaps

IIS La Fe. Instituto investigación sanitaria La Fe. [consulta 10-02-2020]. Disponible en: https://www.iislafe.es/es/

IMIM. Instituto investigación sanitaria Hospital del Mar. [consulta 10-02-2020]. Disponible en: https://www.imim.cat/es_index.html

Ministerio de agricultura, pesca y alimentación. [consulta 10-02-2020]. Disponible en: https://www.mapa.gob.es/va/ganaderia/temas/produccion-y-mercados-

ganaderos/bienestanimal/animales-de-laboratorio/

Matachana. Empresa suministradora equipamiento. [consulta 10-02-2020]. Disponible en: https://www.matachana.com/es/

Metal plastic. Empresa suministradora equipamiento. [consulta 10-02-2020]. Disponible en: https://www.metall-plastic.com/en/isolator-rabs/flexible-film-isolators

News to use. Publicación periódica on line. consulta [10-02-2020]. Disponible en: https://www.orf.od.nih.gov/TechnicalResources/Pages/DRM_News_to_Use.aspx

PRBB. El Parque de Investigación Biomédica de Barcelona. Consulta [10-02-2020]. Disponible en: https://www.prbb.org/es/serveis

Tecbhiplast. Empresa suministradora equipamiento. Consulta [10-02-2020]. Disponible en: https://www.tecniplast.it/en/product/air-shower.html

Telstar. Empresa suministradora equipamiento. Consulta [10-02-2020]. Disponible en: https://www.telstar.com/es/equipos-para-laboratorios-del-sector-de-las-ciencias-de-la-vida-y-parahospitales/cabinas-de-seguridad-biologica/ 


\section{LISTAS DE FICHAS, FIGURAS Y TABLAS}

Todas las fichas, figuras y tablas identificadas como propias son de la autora Aitziber Goikoetxea Ibarrondo; en el resto de los casos, junto a cada figura o tabla se ha identificado su autor o procedencia.

\subsection{Lista de fichas}

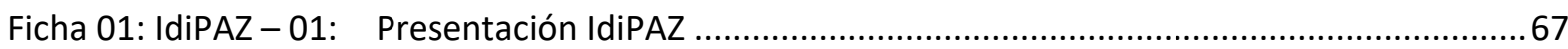

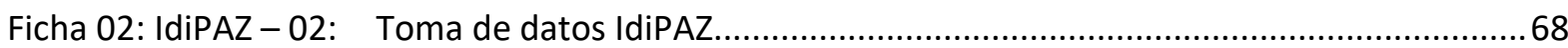

Ficha 03: IdiPAZ - 03: Documentación gráfica I IdiPAZ …................................................................. 71

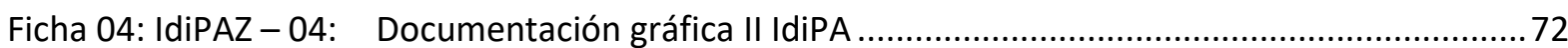

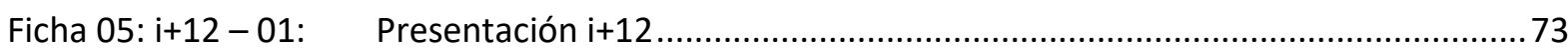

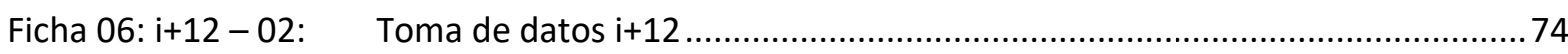

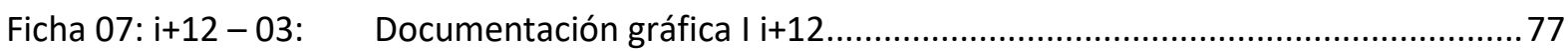

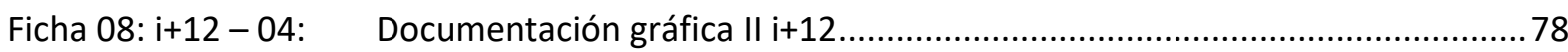

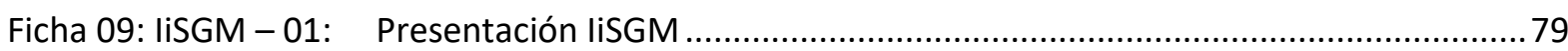

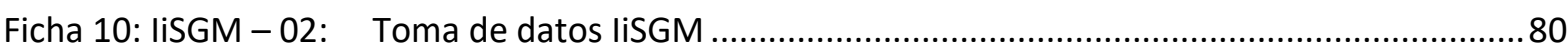

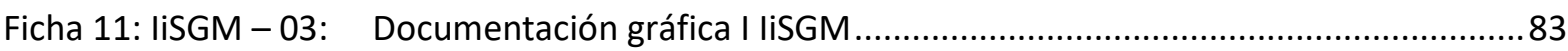

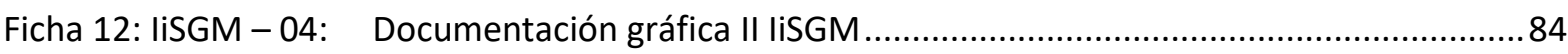

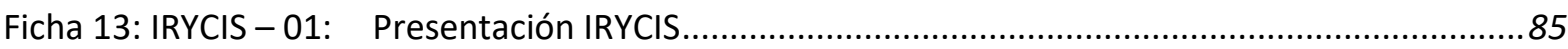

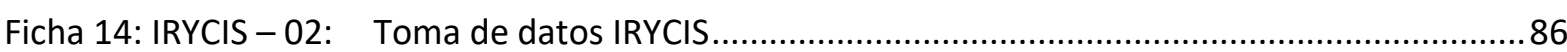

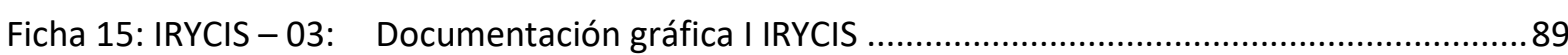

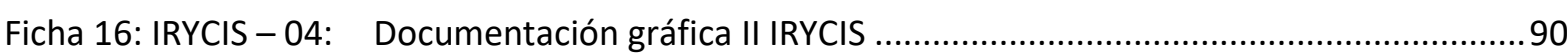

Ficha 17: IIS Biodonostia - 01: Presentación IIS Biodonostia ...............................................................91

Ficha 18: IIS Biodonostia - 02: Toma de datos IIS Biodonostia ........................................................ 92

Ficha 19: IIS Biodonostia - 03: Documentación gráfica I IIS Biodonostia ............................................95

Ficha 20: IIS Biodonostia - 04: Documentación gráfica II IIS Biodonostia .............................................96

Ficha 21: IIS Biocruces - 01: Presentación IIS Biocruces ................................................................97

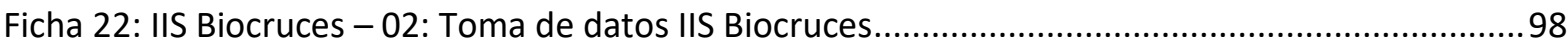

Ficha 23: IIS Biocruces - 03: Documentación gráfica I IIS Biocruces ................................................. 101

Ficha 24: IIS Biocruces - 04: Documentación gráfica II IIS Biocruces ................................................ 102

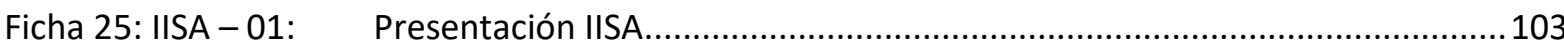

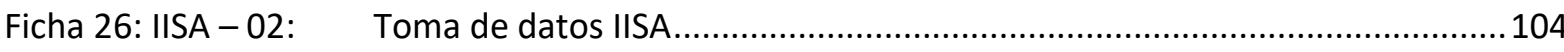

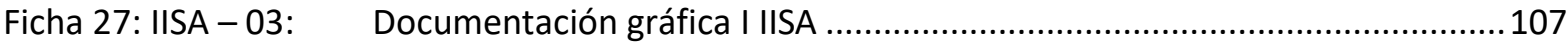

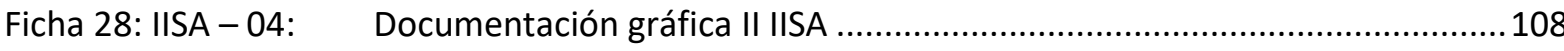

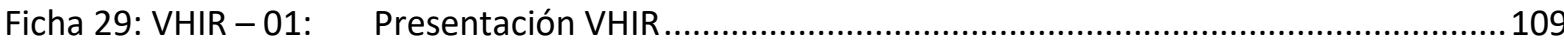




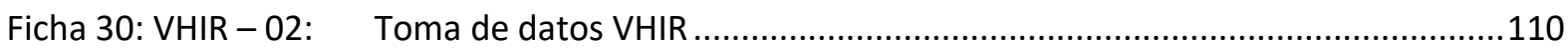

Ficha 31: VHIR - 03: Documentación gráfica I VHIR ..............................................................113

Ficha 32: VHIR - 04: Documentación gráfica II VHIR ...............................................................114

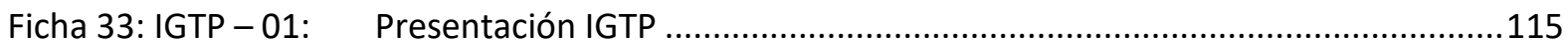

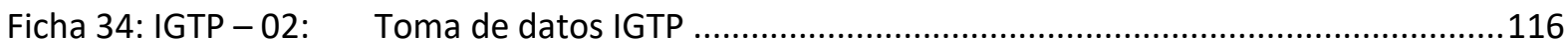

Ficha 35: IGTP - 03: Documentación gráfica I IGTP ...................................................................119

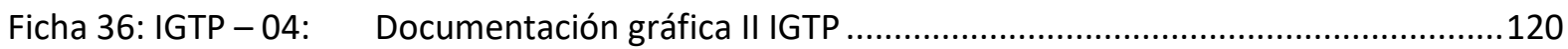

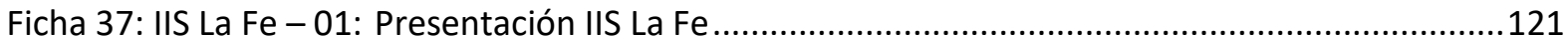

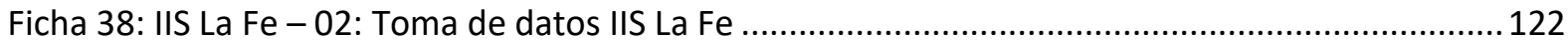

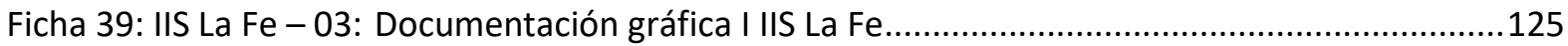

Ficha 40: IIS La Fe - 04: Documentación gráfica II IIS La Fe...............................................................126

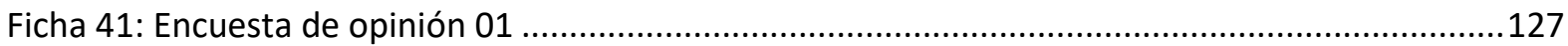

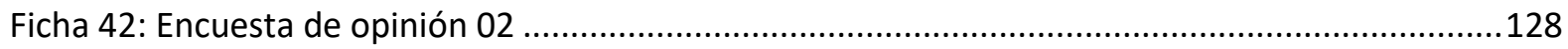

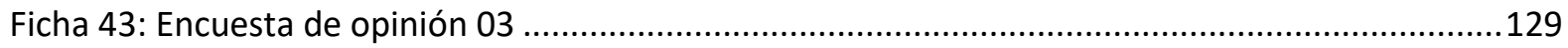

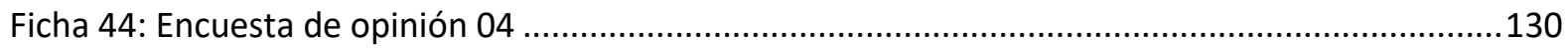

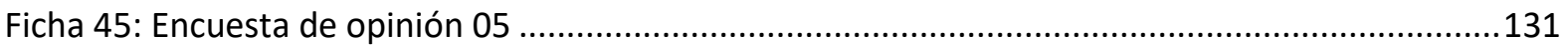

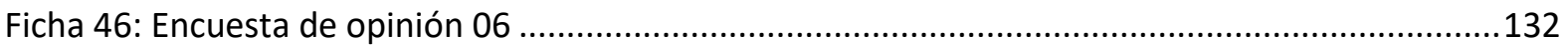

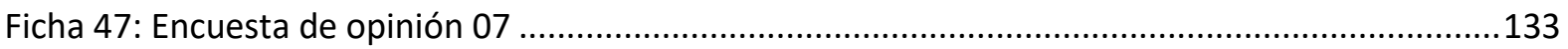

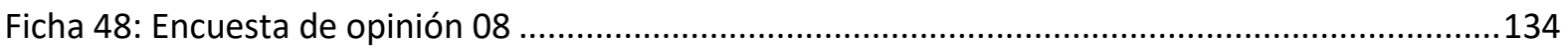

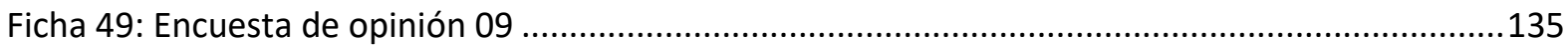

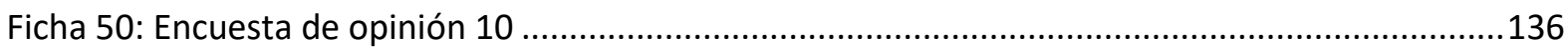




\subsection{Lista de figuras}

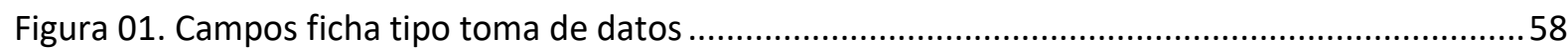

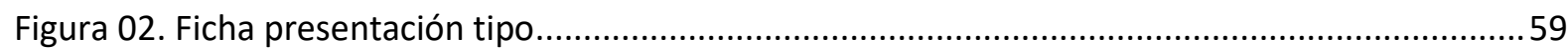

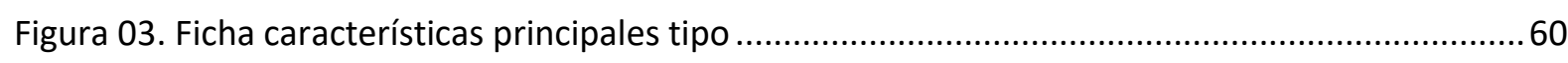

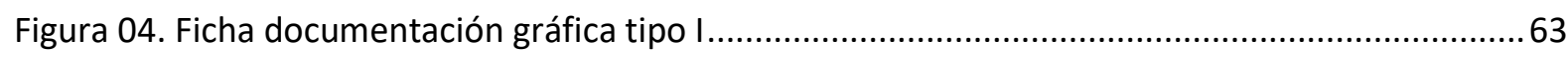

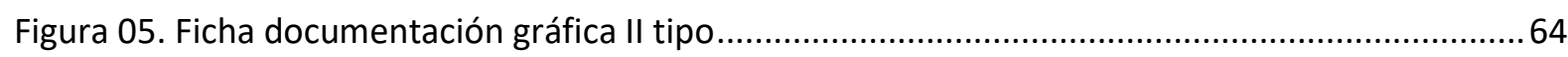

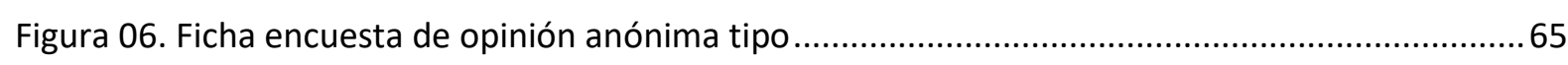

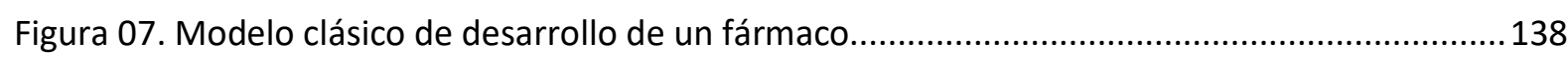

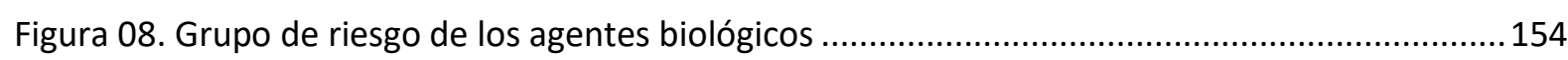

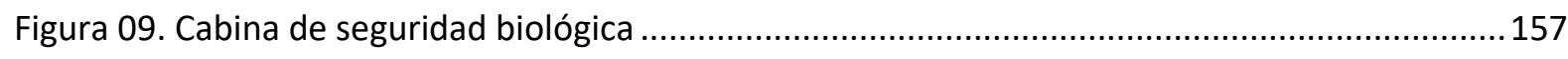

Figura 10. Sistema de alojamiento de jaulas autoventilada en racks para roedores ........................ 158

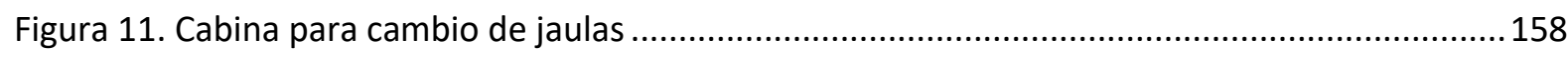

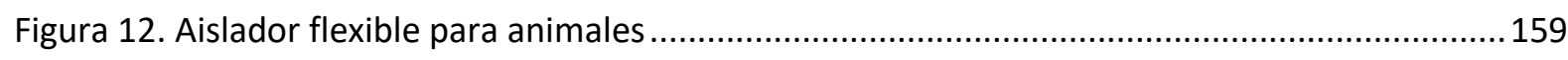

Figura 13. Esquema estructural de los centros de experimentación animal .................................... 162

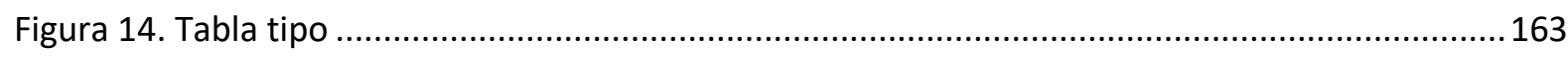

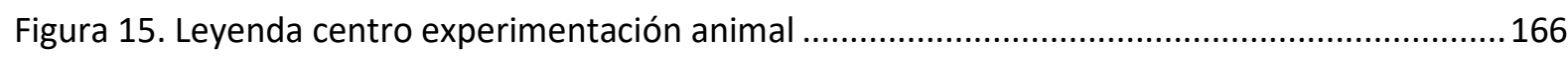

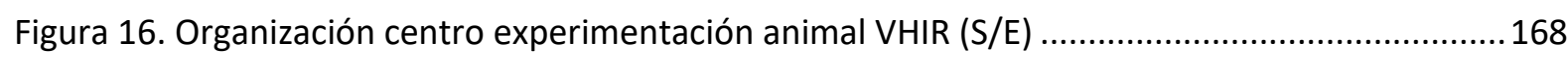

Figura 17. Organización centro experimentación animal i+12 (S/E) .............................................. 169

Figura 18. Organización centro experimentación animal IiSGM (S/E) ........................................... 170

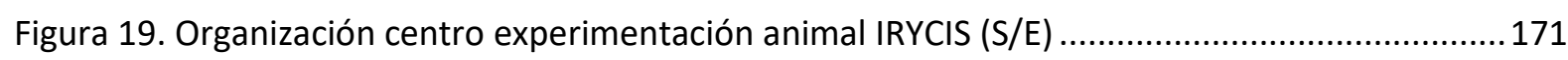

Figura 20. Organización centro experimentación animal IIS Biodonostia (S/E) ................................172

Figura 21. Organización centro experimentación animal IIS La Fe (S/E) ......................................... 173

Figura 22. Organización centro experimentación animal IGTP (S/E) .............................................. 174

Figura 23. Organización centro experimentación animal IdiPAZ (S/E) .......................................... 175

Figura 24. Organización centro experimentación animal IISBiocruces (S/E) .................................... 176

Figura 25. Organización centro experimentación animal IISA (S/E) …........................................... 177

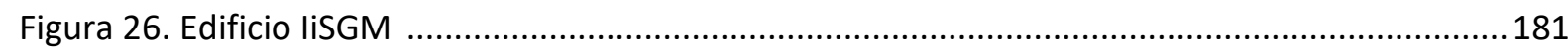

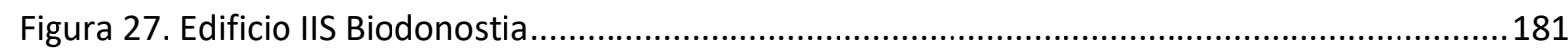

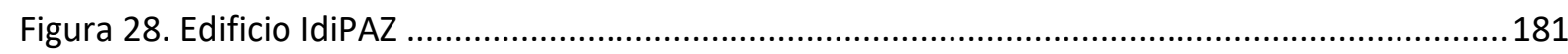

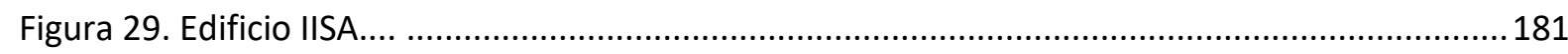

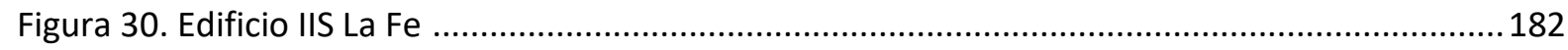

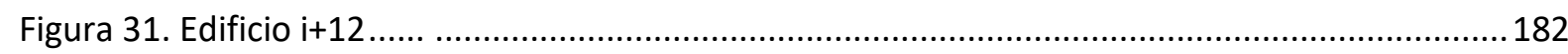

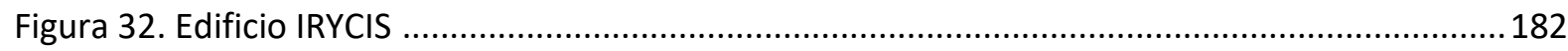

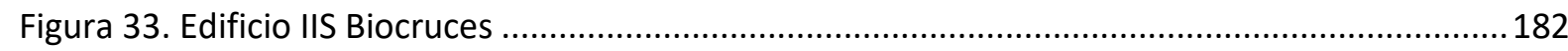

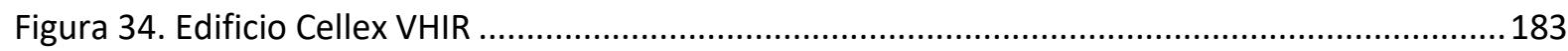




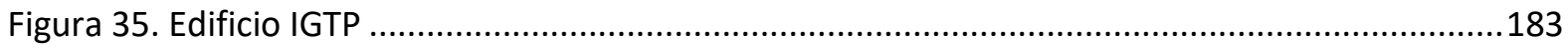

Figura 36. Esquema organización centros de experimentación animal ........................................186

Figura 37. Diagrama de flujos del área de experimentación animal ...........................................203

Figura 38. Esquema de relaciones de la unidad de estabulación de animal grande ........................204

Figura 39. Esquema organizativo área experimentación animal ...............................................206

Figura 40. Esquema de relaciones de la unidad quirúrgica ......................................................206

Figura 41. Leyenda área experimentación animal grande .................................................208

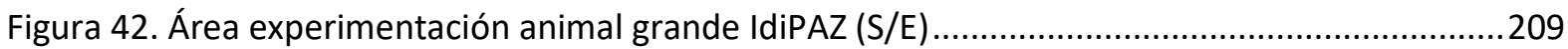

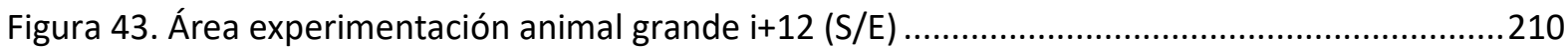

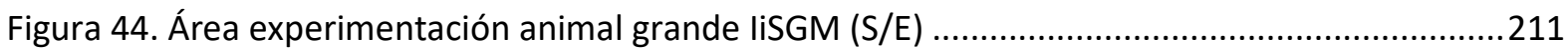

Figura 45. Área experimentación animal grande IRYCIS (S/E) ..............................................212

Figura 46. Área experimentación animal grande IIS Biodonostia (S/E) ....................................213

Figura 47. Área experimentación animal grande IIS Biocruces (S/E) ......................................214

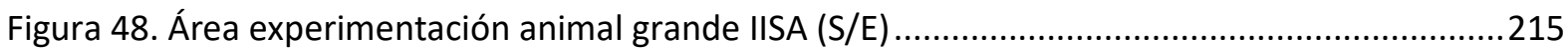

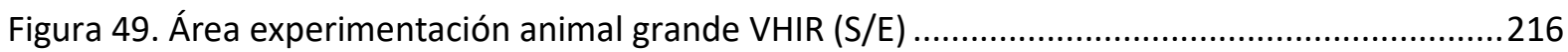

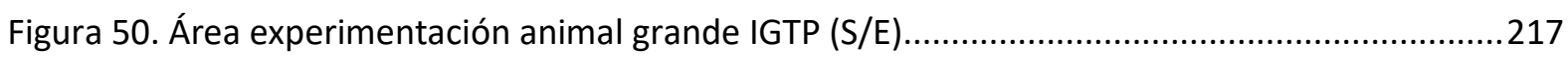

Figura 51. Área experimentación animal grande IIS La Fe (S/E) ............................................218

Figura 52. Leyenda unidad estabulación animal grande ......................................................228

Figura 53. Unidad estabulación animal grande IdiPAZ (S/E) ................................................229

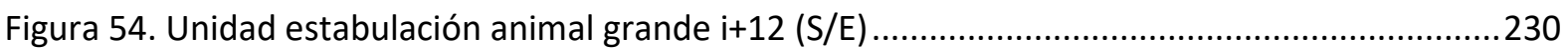

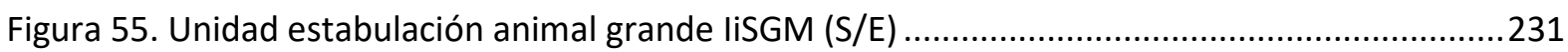

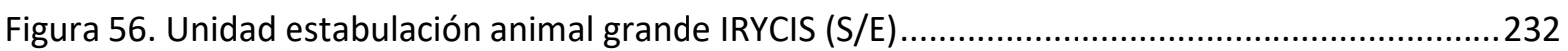

Figura 57. Unidad estabulación animal grande IIS Biodonostia (S/E) ......................................233

Figura 58. Unidad estabulación animal grande IIS Biocruces (S/E) ...........................................234

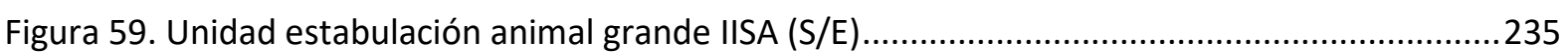

Figura 60. Unidad estabulación animal grande VHIR (S/E) ...............................................236

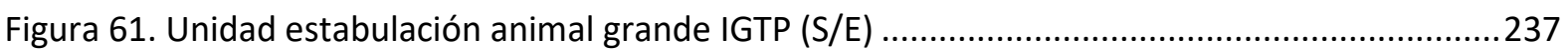

Figura 62. Unidad estabulación animal grande IIS La Fe (S/E) .............................................238

Figura 63. Dimensionamiento de corrales para animales grandes...............................................242

Figura 64. Esquema flujos de trabajo zona estabulación animal grande .....................................244

Figura 65. Compartimentación tradicional estabulación animal grande. .....................................249

Figura 66. Compartimentación modular estabulación animal grande ........................................250

Figura 67. Sistemas de estabulación sobre pavimento animal grande ......................................251

Figura 68. Deterioro revestimiento en estabulación animal grande .........................................251

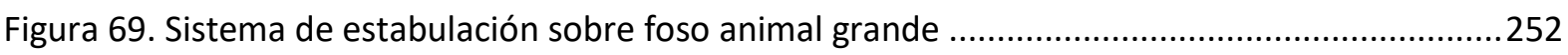




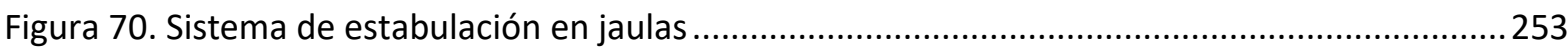

Figura 71. Box recuperación postanestésica con gases medicinales y placas calefactadas ................253

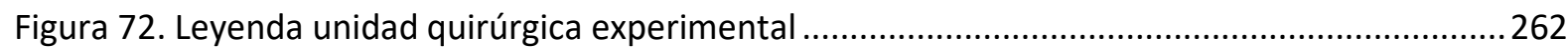

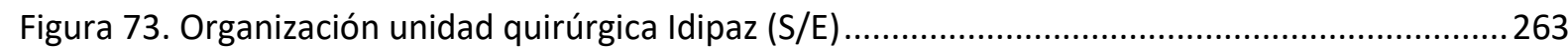

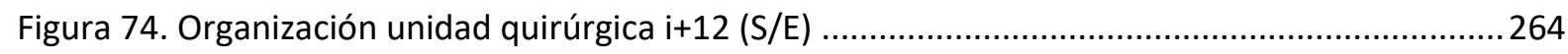

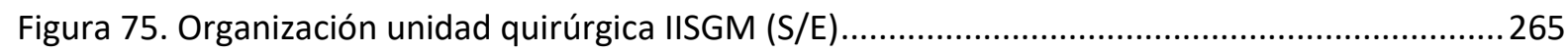

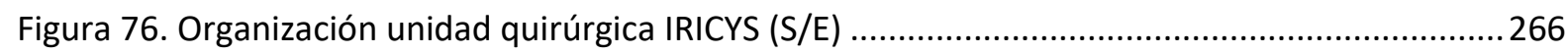

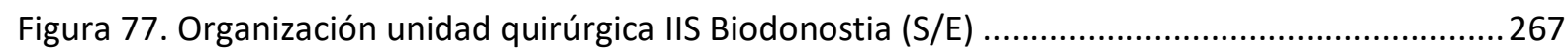

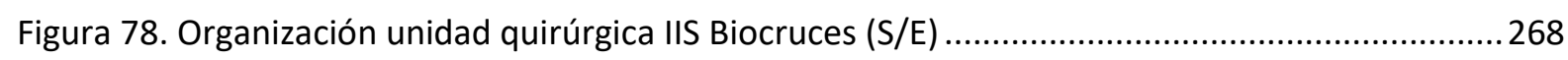

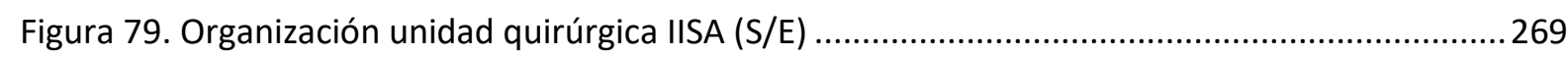

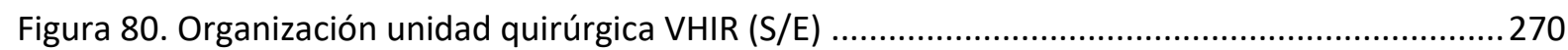

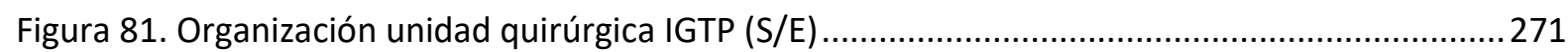

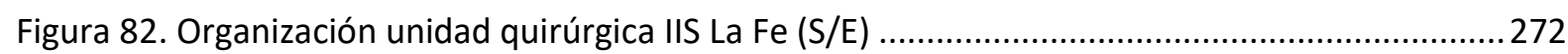

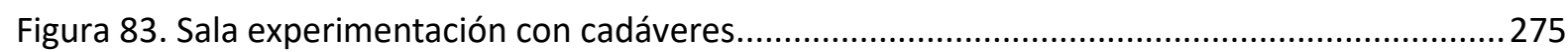

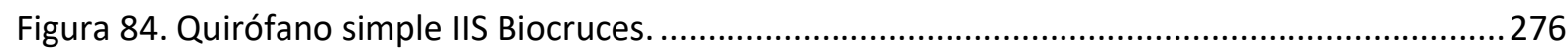

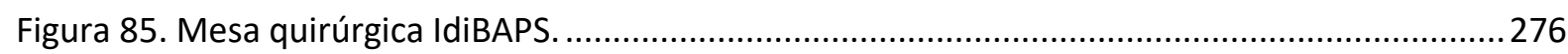

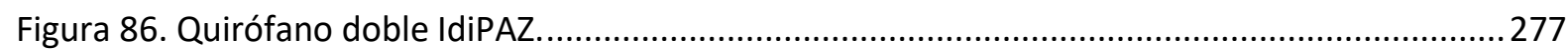

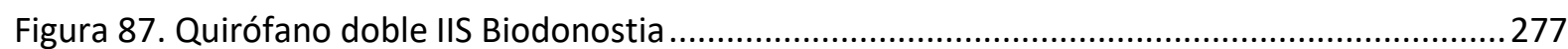

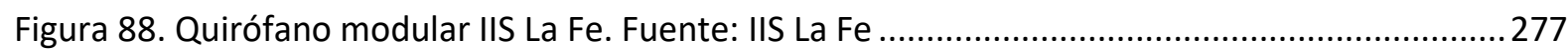

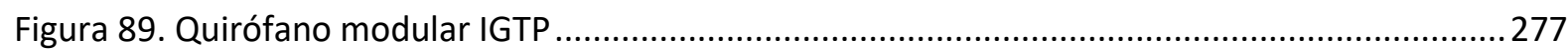

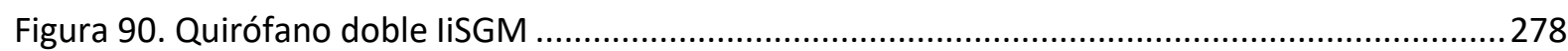

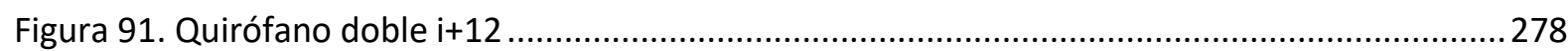

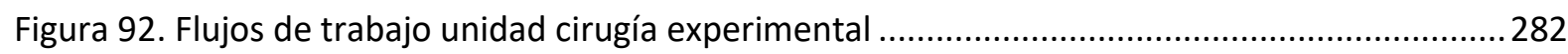

Figura 93. Esquema organización básica circulaciones en función del grado de asepsia necesaria .. 283

Figura 94. Relación entre quirófano y las políticas de segregación de circulaciones..........................284

Figura 95. Niveles de contención de los animalarios: procedimientos y equipo de seguridad...........299

Figura 96. Diagrama de flujos del área de experimentación convencional animal pequeño .............301

Figura 97. Esquema organización área experimentación convencional y barrera animal pequeño.. 302

Figura 98. Esquema organización funcional experimentación en barrera y convencional ..................304

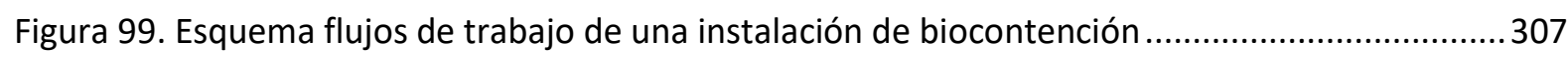

Figura 100. Leyenda área experimentación animal pequeño ……………………......................... 309

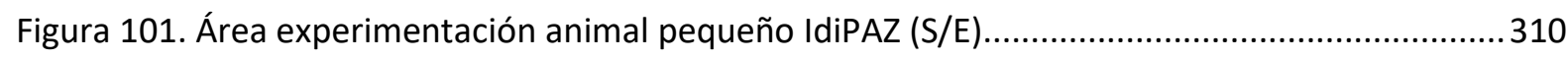

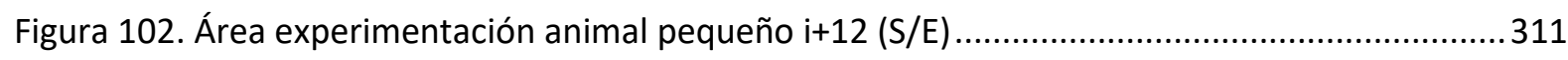

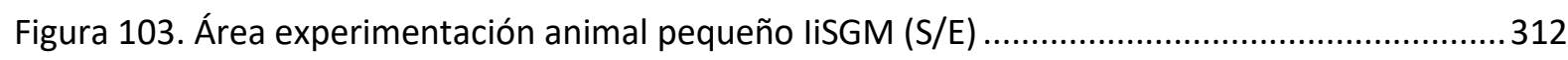

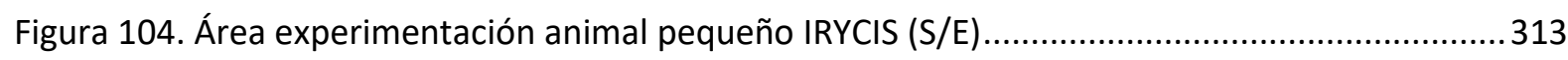


Figura 105. Área experimentación animal pequeño IIS Biodonostia (S/E) .......................................314

Figura 106. Área experimentación animal pequeño IIS Biocruces (S/E) .......................................315

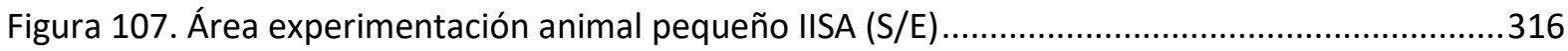

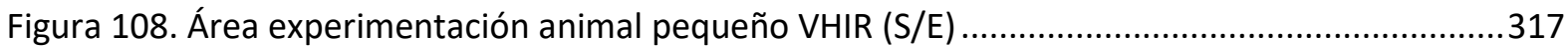

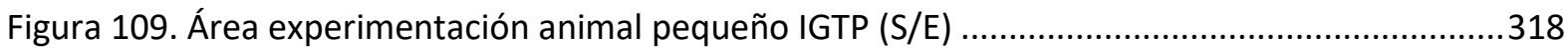

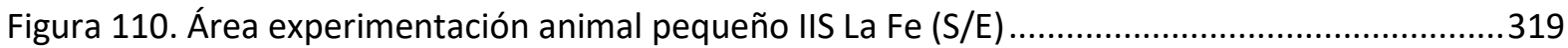

Figura 111. Sistemas de visualización salas de alojamiento animales..............................................330

Figura 112. Leyenda unidad experimentación convencional animal pequeño................................345

Figura 113. Unidad experimentación convencional animal pequeño IdiPAZ (S/E) ..........................346

Figura 114. Unidad experimentación convencional animal pequeño i+12 (S/E) .............................347

Figura 115. Unidad experimentación convencional animal pequeño liSGM (S/E) ..........................348

Figura 116. Unidad experimentación convencional animal pequeño IRYCIS (S/E)...........................349

Figura 117. Unida experimentación convencional animal pequeño IIS Biodonostia (S/E).................350

Figura 118. Unidad experimentación convencional animal pequeño IIS Biocruces (S/E) ..................351

Figura 119. Unidad de experimentación convencional animal pequeño IISA (S/E) ..........................352

Figura 120. Unidad experimentación convencional animal pequeño VHIR (S/E) .............................353

Figura 121. Unidad experimentación convencional animal pequeño IGTP (S/E) ............................354

Figura 122. Unidad experimentación convencional animal pequeño IIS La Fe (S/E).......................355

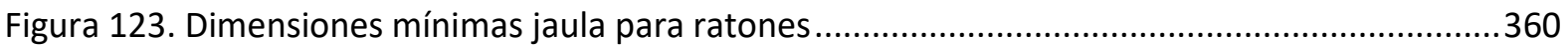

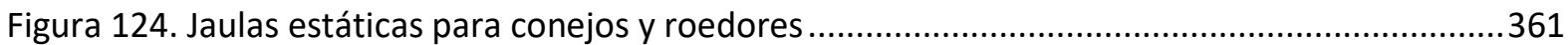

Figura 125. Jaulas ventiladas individualmente, deshechables y cabina de cambio ...........................361

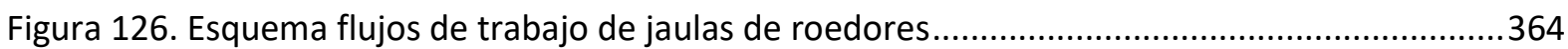

Figura 127. Organización área estabulación con pasillo doble...........................................................367

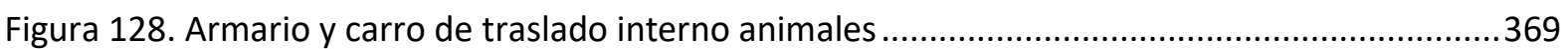

Figura 129. Tipos de configuración salas de alojamiento en función del estante..............................370

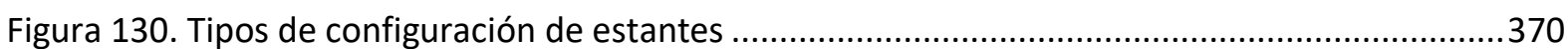

Figura 131. Esquema flujo trabajo sala lavado y esterilización ........................................................372

Figura 132. Equipos de lavado: lavabiberones y lavaestantes.......................................................376

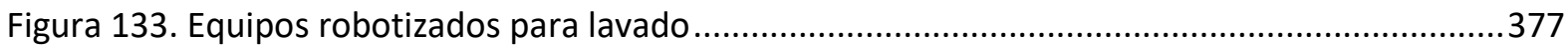

Figura 134. Leyenda unidad experimentación barrera animal pequeño .........................................389

Figura 135. Unidad experimentación barrera animal pequeño liSGM (S/E) ..................................390

Figura 136. Unidad experimentación barrera animal pequeño IIS Biodonostia (S/E) .......................391

Figura 137. Unidad experimentación barrera animal pequeño IIS Biocruces (S/E)..........................392

Figura 138. Unidad experimentación barrera animal pequeño IISA (S/E) .........................................393

Figura 139. Unidad experimentación barrera animal pequeño VHIR (S/E) ......................................394 


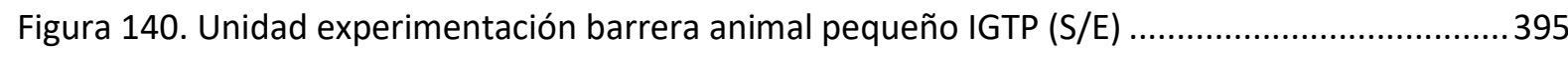

Figura 141. Unidad experimentación barrera animal pequeño IIS La Fe (S/E) ..................................396

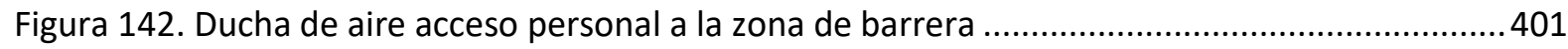

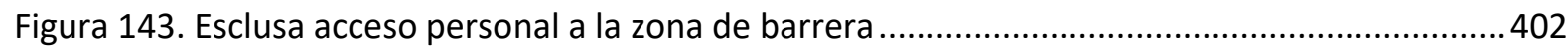

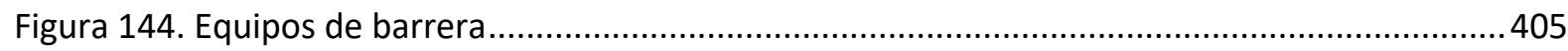

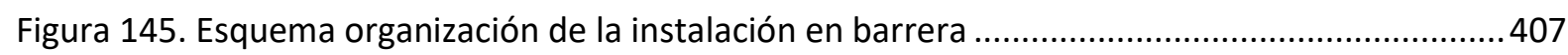

Figura 146. Esquema estrategias de distribución de servicios ...................................................... 413

Figura 147. Instalaciones con registros en falso techo, instalaciones vistas y planta técnica transitable.......414 


\subsection{Lista de tablas}

Tabla 01. Características generales del centro de experimentación animal ..................................179

Tabla 02. Organización centro de experimentación animal..........................................................189

Tabla 03. Organización área de experimentación animal grande...................................................220

Tabla 04. Características generales unidad estabulación animal grande..........................................240

Tabla 05. Identificación de salas y boxes de estabulación en área alojamiento animal grande........242

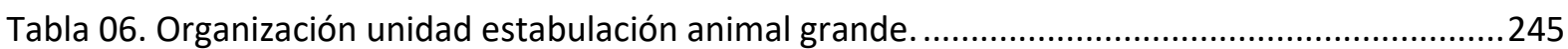

Tabla 07. Sistemas constructivos de estabulación animal grande. …...............................................248

Tabla 08. Características generales unidad de cirugía experimental. .............................................274

Tabla 09. Número de quirófanos y mesas área quirúrgica experimental.........................................276

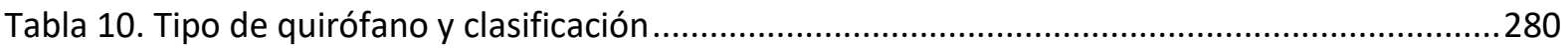

Tabla 11. Organización unidad quirúrgica experimental animal grande.........................................286

Tabla 12. Características generales área de experimentación animal pequeño...............................321

Tabla 13. Características constructivas área experimentación animal pequeño. ..............................326

Tabla 14. Características generales unidad experimentación convencional animal pequeño...........357

Tabla 15. Organización unidad experimentación convencional animal. ............................................366

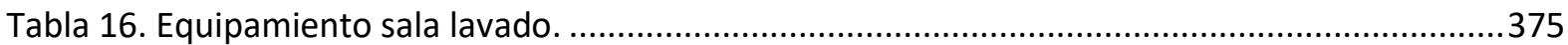

Tabla 17. Características generales unidad experimentación en barrera animal pequeño. ...............398

Tabla 18. Organización unidad experimentación animal en barrera. ................................................408 


\section{SIGLAS, ACRÓNIMOS Y GLOSARIO}

\subsection{Siglas y acrónimos}

AAALAC: Association for Assessment and Accreditation of Laboratory Animal Care International ABSA: Asociación Americana de Seguridad Biológica

ABSL: Animal biosafety level; nivel de bioseguridad animal

AEBIOS: Asociación Española de Bioseguridad

AENOR: Asociación Española de Normalización y Certificación

AES: Acción estratégica en salud

BPL: Buenas prácticas de laboratorio

BSL: Biosafety level; nivel de bioseguridad

CCAC: Canadian Council on Animal Care

CEEA: Comité ético de experimentación animal

CEN: Comité Europeo de Normalización

CIC Biogune: Centro de Investigación Cooperativa en Biociencias

CIC Biomagune: Centro de Investigación Cooperativa en Biomateriales

CNIO: Centro Nacional de Investigaciones Oncológicas

CSB: Cabina de seguridad biológica

CSIC: Consejo Superior de Investigaciones Científicas

CWA: CEN Work Agreement

DRM: Design Requeriments Manual

EBSA: Asociación Europea de Seguridad Biológica

ENAC: Entidad Nacional de Acreditación

EPI: Equipo de protección individual

FELASA: Federation of European Laboratory Animal Science

GF: Germen free

HEPA: High efficiency particulate air

i+12: Instituto de Investigación Hospital 12 de Octubre

I+D+i: Investigación, desarrollo e innovación

IBIMA: Instituto de Investigación Biomédica de Málaga

IBIS: Instituto de Biomedicina de Sevilla

ibs.GRANADA: Instituto de Investigación Biosanitaria de Granada

IBSAL: Instituto de Investigación Biómedica de Salamaca

ICLAS: Internaional Council for Laboratory Animal Science

IDIBAPS: Institut d'investigaciones Biomédicas August Pi Y Sunyer 
IDIBELL: Institut d'investigació Biomédica de Bellvitge

IdiPAZ: Instituto de Investigación Sanitaria Hospital La Paz

IDIPHIM IIS: Instituto de Investigación Sanitaria Puerta de Hierro

idis: Instituto de Investigación Sanitaria de Santiago de Compostela

IdISBa: Instituto de Investigación Sanitaria Islas Baleares

IDISNA: Instituto de Investigación Sanitaria de Navarra

IdISSC: Instituto de Investigación Sanitaria del Hospital Clínico San Carlos

idival: Instituto de Investigación Marqués de Valdecilla

IGTP: Institut d'investigació en Ciéncies de la Salut Germans Trias I Pujol

IIB SANT PAU: Instituto de Investigación Biomédico Sant Pau

IIS Aragón: Instituto de Investigación Sanitaria Aragón

IIS BIOCRUCES: Biocruces Health Research Institute

IIS BIODONOSTIA: Instituto de Investigación Sanitaria Biodonostia

IIS La Fe: Fundación para la Investigación del Hospital Universitario La Fe

IIS: Instituto de Investigación Sanitaria

IISFJD: Instituto de Investigación Sanitaria Fundación Jiménez Díaz

liSGM: Instituto de Investigación Sanitaria Gregorio Marañón

IIS-PRINCESA: II Sanitaria Hospital Universitario de La Princesa

IMIB: Instituto Murciano de Investigación Biosanitaria Virgen de La Arrixaca

IMIBIC: Instituto Maimónides de Investigación Biomédica de Córdoba

IMIM: Instituto Hospital del Mar de Investigaciones Biomédicas

INCLIVA: Instituto de Investigación Sanitaria Fundación para la Investigación Del Hospital Clínico de Valencia

INIBIC: Instituto de Investigación Biomédica A Coruña

IRB LÉRIDA: Instituto de Investigación Biomédica de Lérida

IR-HUVH: Institut de Recerca Hospital Universitari Vall D'hebron

IRICYS: Instituto Ramón y Cajal de Investigación Sanitaria

ISCIII: Instituto de Salud Carlos III

ISO: International Organization for Standardization

JAALAS: Journal of the American Association for Laboratory Animal Science

NBSA: Nivel de bioseguridad de las instalaciones para los animales

NCB: Nivel de contención biológica

NCB3: Nivel de contención biológica 3

NIH: National Institute of Health

NTP: Nota técnica de prevención 
OMS: Organización Mundial de la Salud

PET: Tomografía por emisión de positrones

PRBB: Parque de Investigaciones Biomédicas de Barcelona

PVC: Policloruro de vinilo

RMI: Resonancia magnética de imagen

SAS: Security airlock system

SECAL: Sociedad Española para las ciencias del animal de laboratorio

SEDISA: Sociedad Española de Directivos de la Salud

SNS: Sistema Nacional de Salud

SPECT: Tomografía computarizada por emisión de un fotón

SPF: Specific pathogens free; libre de patógenos específicos

TAC: Tomografía axial computarizada

TC: Tomografía computarizada

UCL: University College London

UNE: Una Norma Española

UV: Ultra violeta

VHIR: Instituto de Investigación Sanitaria Vall d'Hebron 


\subsection{Glosario}

Agente biológico: Se incluyen dentro de la definición de agentes biológicos a los microorganismos, con inclusión de los genéticamente modificados, a los cultivos celulares y a los endoparásitos humanos, susceptibles de originar cualquier tipo de infección, alergia o toxicidad.

Análisis de daños-beneficios: Designa el balance entre los probables efectos nocivos (daños) en los animales y los beneficios potenciales obtenidos de la investigación propuesta.

Angustia: Designa el estado de un animal que no ha podido adaptarse a los factores de estrés y que manifiesta respuestas anormales, fisiológicas o comportamentales. Puede ser aguda o crónica y convertirse en patológica.

Animal clonado: Designa la copia genética de otro animal, vivo o muerto, creado por transferencia nuclear de células somáticas o por otra tecnología reproductiva.

Animal de laboratorio: Designa un animal destinado para utilizarse en la investigación. En la mayoría de los casos, esos animales han sido criados para tener una determinada condición fisiológica, metabólica, genética o libre de patógenos.

Animal: Cualquier ser vivo vertebrado no humano, incluidas las crías de vida propia o las formas de cría en reproducción, excluidas las formas fetales o embrionarias.

Animalario: Edificio donde se tiene los animales destinados a experimentos de laboratorio.

Animales de cría: Los animales especialmente criados para su utilización en los procedimientos en establecimientos aprobados o registrados por la autoridad competente.

Animales de experimentación: Los animales utilizados o destinados a ser utilizados en los procedimientos.

Área quirúrgica: Conjunto de locales e instalaciones especialmente acondicionados y equipados, selectivamente aislados del resto del hospital, que constituyen una unidad física y funcionalmente diferenciada, cuya finalidad es ofrecer un lugar idóneo para tratar quirúrgicamente al enfermo.

Barrera: En el contexto del diseño de los animalarios consiste en una combinación de sistemas físicos y criterios de trabajo para que conjuntamente minimicen la transferencia de agentes de las enfermedades animales o humanas de un lado de la barrera a la otra.

Bienestar animal: Designa el estado físico y mental de un animal en relación con las condiciones en las que vive y muere. 
Biocontención: Designa los sistemas y procedimientos diseñados para evitar la liberación accidental de material biológico, incluyendo los alérgenos.

Bioexclusión: Designa las medidas establecidas para prevenir una transferencia no intencional de organismos adventicios que puede acarrear la consiguiente infección de los animales y, por lo tanto, afectar su sanidad, con lo que serían inutilizables para toda investigación.

Bioprotección: La bioprotección o protección biológica (biosecurity) se refiere a las medidas de protección de la institución y del personal destinadas a reducir el riesgo de pérdida, robo, uso incorrecto, desviaciones o liberación intencional de patógenos o toxinas.

Bioseguridad: La bioseguridad o seguridad biológica (biosafety) es el término utilizado para referirse a los principios, técnicas y prácticas aplicadas con el fin de evitar la exposición no intencional a patógenos y toxinas, o su liberación accidental, es decir, con el establecimiento y ejecución de procedimientos para minimizar el riesgo en el uso, manipulación y propagación de microorganismos patógenos. Designa el proceso continuo de evaluación y gestión del riesgo destinado a minimizar o eliminar las infecciones microbiológicas causadas por organismos adventicios que pueden provocar enfermedades clínicas en humanos o animales o impedir que los animales sean aptos para la investigación biomédica.

Bloque quirúrgico: Desde el punto de vista estructural, se define como el espacio en el que se agrupan todos los quirófanos, con los equipamientos y características necesarios para llevar a cabo todos los procedimientos quirúrgicos previstos. El bloque quirúrgico comprende los locales donde se desarrolla el proceso asistencial del procedimiento quirúrgico: los quirófanos, la unidad de recuperación postanestésica o reanimación y los locales de soporte que precisa.

Cabina de cambio: Es un equipo aislador destinado para el cambio de jaulas en las mejores condiciones, garantizando así la línea de manejo de los animales y minimizando el riesgo de contaminación.

Compartimento: Designa una subpoblación animal mantenida en una o varias explotaciones, separada de otras poblaciones susceptibles por un sistema común de gestión de la bioseguridad y con un estatus zoosanitario particular respecto de una o más infecciones o infestaciones contra las que se aplican las medidas de vigilancia, bioseguridad y control necesarias con fines de comercio internacional o prevención y control de enfermedad en un país o zona.

Condicionamiento comportamental: Designa la asociación que hace un animal entre una respuesta particular (tal como presionar una barra) y un refuerzo particular que puede ser positivo (un alimento 
de recompensa, por ejemplo) o negativo (por ejemplo, una descarga eléctrica suave). Como resultado de esta asociación, puede modificarse un comportamiento específico del animal (aumento o disminución de su frecuencia o intensidad, por ejemplo).

Contención: Designa una zona infectada definida dentro de una zona previamente libre que incluye todos los casos confirmados o sospechosos que están epidemiológicamente vinculados, y en la que se aplican medidas de control de desplazamientos, de bioseguridad y sanitarias para impedir la propagación y erradicar la infección o infestación.

Convencional: En el contexto del diseño de los animalarios es aquella instalación que no tiene que estar diseñada para procedimientos de trabajo específicos.

Cuarentena: Designa un local o un establecimiento bajo control de la autoridad veterinaria, en el que se mantiene a los animales aislados, sin ningún contacto directo ni indirecto con otros animales, para garantizar que no se produzca la transmisión de determinados agentes patógenos fuera del local o establecimiento mientras los animales son sometidos a observación durante un período de tiempo determinado y, si es preciso, a pruebas de diagnóstico o a tratamientos.

Cuidador de animales: Designa una persona que conoce el comportamiento y las necesidades de los animales y que, gracias a su experiencia, profesionalidad y buena disposición para atenderles, logra manejarlos con eficacia y preservar su bienestar.

Desinfección: Designa la aplicación, después de una limpieza completa, de procedimientos destinados a destruir los agentes infecciosos o parasitarios responsables de enfermedades animales, incluidas las zoonosis; se aplica a los locales, vehículos y objetos diversos que puedan haber sido directa o indirectamente contaminados.

Dolor: Designa una experiencia sensorial y emocional desagradable, asociada con daños, posibles o reales, en los tejidos. Puede desencadenar reacciones de defensa, evasión o angustia aprendidas y modificar los rasgos de comportamiento de ciertas especies, incluyendo el comportamiento social.

Enriquecimiento ambiental: Consiste en proporcionar al animal una serie de estímulos (por ejemplo juguetes o accesorios para las jaulas, dándole oportunidades de hurgar y alojarlo con otros de su misma especie) que pongan a prueba sus sentidos y su intelecto para que desarrolle sus habilidades y comportamientos similares a los que tendría en su estado natural. 
Esclusa: Espacio cerrado con 2 o más puertas, interpuesto entre 2 o más salas, por ejemplo, de distinto nivel de limpieza, con el fin de controlar la circulación de aire entre dichas salas cuando se pasa a las mismas. Las esclusas se diseñan para su uso por personas o por objetos"

Estabulación: Designa las jaulas o compartimentos, corrales y demás recintos de espera utilizados para alojar a los animales y dispensarles los cuidados necesarios (agua, forraje, descanso, etc.) antes de desplazarlos o utilizarlos para determinados fines, incluido el sacrificio.

Estabulario: Recinto acondicionado para albergar los animales de experimentación.

Eutanasia: Designa el acto de inducir la muerte usando un método que ocasione una pérdida rápida e irreversible de la conciencia, con un mínimo de dolor y angustia para el animal.

Evaluación del riesgo: Designa la evaluación de la probabilidad y las consecuencias biológicas y económicas de la entrada, radicación y propagación de un peligro.

Evaluación ética: Designa la consideración de la validez de la investigación o la justificación de emplear animales. Deberán detallarse: una evaluación y comparación de los daños potenciales para los animales y los posibles beneficios derivados de su empleo y el equilibrio entre ambos (véase, a continuación, análisis de daños y beneficios); y reflexiones sobre el protocolo experimental, la implementación de las $3 \mathrm{R}$, la cría y el cuidado animal y otros aspectos relacionados como la formación del personal. Los juicios éticos están influenciados por la opinión pública.

Infección nosocomial o intrahospitalaria: Se define como una infección contraída en el hospital por un paciente internado por una razón distinta de esa infección.

Infección: Designa la introducción y el desarrollo o la multiplicación de un agente patógeno en el cuerpo de una persona o de un animal.

Jaula: Receptáculo fijo o móvil cerrado por paredes sólidas y al menos por un lado, con barrotes o tela metálica en su caso, redes, donde se alojan o transportan uno o más animales.

Laboratorio: Designa una institución debidamente equipada y dotada de personal técnico competente que trabaja bajo el control de un especialista en métodos de diagnóstico veterinario, el cual es responsable de la validez de los resultados.

Locales de alojamiento: Locales donde se aloja normalmente a los animales, bien para cría y mantenimiento, bien durante la realización de un procedimiento. 
Logomorfo: Orden de mamíferos de pequeño tamaño y aspecto similar a los roedores, de los que se diferencian por presentar dos pares de incisivos de crecimiento continuo dispuestos uno delante del otro. Entre otros animales, el conejo y la liebre pertenecen a los logomorfos.

Peligro: Designa la presencia de un agente biológico, químico o físico en un animal o en un producto de origen animal, o estado de un animal o de un producto de origen animal que puede provocar efectos adversos en la sanidad.

Procedimiento: La utilización, tanto invasiva como no invasiva, de un animal con fines experimentales u otros fines científicos, cuyos resultados sean predecibles o impredecibles, o con fines educativos siempre que dicha utilización pueda causarle al animal un nivel de dolor, sufrimiento, angustia o daño duradero equivalente o superior al causado por la introducción de una aguja conforme a las buenas prácticas veterinarias.

Producción animal: La producción animal se define como el conjunto de técnicas y normas que, aplicadas a la unidad de producción ganadera, consigue la optimización económica de sus rendimientos asegurando su sanidad y bienestar. Estos principios se aplican también en el manejo de los animales de experimentación.

Proyecto de investigación (a veces denominado protocolo): Designa la descripción escrita de un estudio, una experimentación, un programa de investigación o de cualquier otra actividad que exponga los objetivos, caracterice la utilización de los animales y aborde las consideraciones éticas.

Punto final humanitario: Designa el momento en el que se evita, se reduce o se pone fin al dolor y/o la angustia del animal experimental por medio de acciones tales como: administrar un tratamiento para aliviar el dolor y/o la angustia, terminar un procedimiento doloroso, retirar al animal del estudio o sacrificar un animal de modo compasivo.

Rack o estante ventilado: Se define como el equipo aislador eficiente con inyección individual y directa del aire para alojar ratones, ratas contando para ello con un nivel de protección micro ambiental esto es insuflando aire con pre filtro y filtro absoluto (HEPA) mientras que la expulsión es con otro filtro de retención.

Reducción: Estrategia encaminada a utilizar el mínimo número de animales necesario para alcanzar el objetivo propuesto en el procedimiento.

Reemplazo: Utilización de técnicas alternativas que puedan aportar el mismo nivel de información que el obtenido en procedimientos con animales y que no impliquen la utilización de estos. 
Refinamiento: Incluye la mayoría de aquellos procedimientos que afectan a la vida del animal de experimentación y permiten aliviar o reducir el posible dolor o malestar.

Roedor: Orden de mamíferos caracterizados por poseer un único par de dientes incisivos de gran tamaño, de crecimiento continuo; son generalmente de pequeña envergadura, con el cuerpo cubierto de pelo y vegetarianos. Entre otros animales, la rata, ratón, cobaya pertenecen a los roedores.

SAS: Sterilized air system. Son esclusas para el paso de productos o materiales entre distintas salas para mantener la presión y temperatura con la posibilidad de esterilización del producto.

Sufrimiento: Designa un estado no deseado y desagradable, resultado del impacto sobre un animal de una gran variedad de estímulos nocivos y/o de la ausencia de estímulos positivos importantes. Se opone a la noción de bienestar animal.

Suministrador: Cualquier persona, distinta del criador, que adquiera o mantenga animales con el fin de que éstos se utilicen en procedimientos o de que sus tejidos $u$ órganos se utilicen con fines científicos, y suministre dichos animales con alguno de estos fines, con o sin ánimo de lucro.

Usuario: Cualquier persona que utilice animales en procedimientos, con o sin ánimo de lucro.

Veterinario: Designa una persona con la debida formación registrada o autorizada por el organismo veterinario estatutario de un país para ejercer la medicina o la ciencia veterinaria en dicho país. 
